\title{
The patient's own bone marrow-derived stromal cells
}

Citation for published version (APA):

de Munter, H. (2021). The patient's own bone marrow-derived stromal cells: disease modifiers in (neuro)degenerative disorders. [Doctoral Thesis, Maastricht University]. ProefschriftMaken. https://doi.org/10.26481/dis.20210409jm

Document status and date:

Published: 01/01/2021

DOI:

10.26481/dis.20210409jm

Document Version:

Publisher's PDF, also known as Version of record

\section{Please check the document version of this publication:}

- A submitted manuscript is the version of the article upon submission and before peer-review. There can be important differences between the submitted version and the official published version of record.

People interested in the research are advised to contact the author for the final version of the publication, or visit the DOI to the publisher's website.

- The final author version and the galley proof are versions of the publication after peer review.

- The final published version features the final layout of the paper including the volume, issue and page numbers.

Link to publication

\footnotetext{
General rights rights.

- You may freely distribute the URL identifying the publication in the public portal. please follow below link for the End User Agreement:

www.umlib.nl/taverne-license

Take down policy

If you believe that this document breaches copyright please contact us at:

repository@maastrichtuniversity.nl

providing details and we will investigate your claim.
}

Copyright and moral rights for the publications made accessible in the public portal are retained by the authors and/or other copyright owners and it is a condition of accessing publications that users recognise and abide by the legal requirements associated with these

- Users may download and print one copy of any publication from the public portal for the purpose of private study or research.

- You may not further distribute the material or use it for any profit-making activity or commercial gain

If the publication is distributed under the terms of Article $25 \mathrm{fa}$ of the Dutch Copyright Act, indicated by the "Taverne" license above, 


\section{THE PATIENT'S OWN BONE MARROW-DERIVED STROMAL CELLS: DISEASE MODIFIERS IN (NEURO)DEGENERATIVE DISORDERS}

Johannes P.J.M. de Munter 

The patient's own bone marrow-derived stromal cells: disease modifiers in (neuro)degenerative disorders

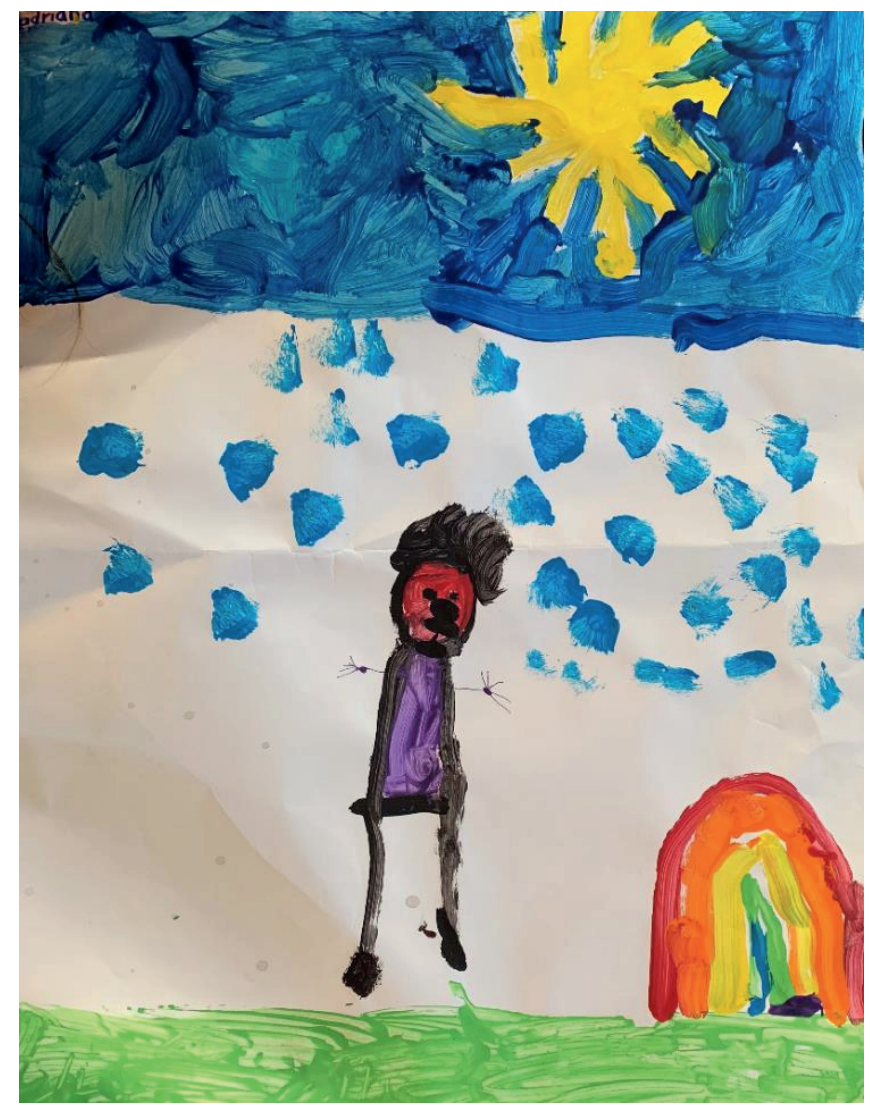

After rain comes sunshine 
(C) J.P.J.M. de Munter, Geleen, The Netherlands, 2021

All rights are reserved.

No part of this publication may be reproduced or transmitted in any form or by any means, electronic or mechanical, including photocopy, recording or any information storage or retrieval system, without permission in writing from the copyright owner.

ISBN: $\quad 9789090344706$

Printed by: ProefschriftMaken

Layout by: Johannes de Munter

Cover design by: Sasja Verhoog 


\section{The patient's own bone marrow-derived stromal cells: disease modifiers in (neuro)degenerative disorders}

Proefschrift ter verkrijging van de graad van doctor in de Geneeskunde aan de Rijksuniversiteit Maastricht, op gezag van de Rector Magnificus Prof. dr. Rianne Letschert, volgens besluit van het College van Dekanen in het openbaar te verdedigen op 9 april 2021 om 16.00 uur.

door

Johannes P.J.M. de Munter

\section{Promotoren:}

Prof. dr. Boris W. Kramer

Prof. dr. Erik Ch. Wolters

\section{Co-promotoren:}

Dr. Tatyana Strekalova

Prof. dr. Jörg Mey

\section{Beoordelingscommissie:}

Prof. dr. Luc J.L. Zimmermann (voorzitter)

Prof. dr. David Linden

Prof. dr. Daniel Clive Anthony

Prof. dr. Harry Steinbusch

Prof. dr. Thorsten Orlikowsky 


\section{Table of contents}

Table of contents

Chapter 1

$\begin{array}{lr}\text { General introduction } & 9 \\ \text { Abstract } & 9 \\ \text { Neurodegeneration } & 10 \\ \text { Interventions in neurodegeneration } & 15 \\ \text { Stem cells } & 15 \\ \text { Aims and outlines of this book } & 19\end{array}$

Chapter 2

Cell based therapy in Neurology: the search for the best cells

Introduction chapter 2

2.1. Autologous stem cells in neurology: is there a future?

Abstract 22

Introduction 22

Stem cells 22

Autologous adult stem cells 24

Clinical application of autologous adult stem cells in neurological disorders 30

2.2. Autologous adult stem cells in ischemic and traumatic CNS disorders 31

Abstract 31 Introduction 31

Stem cells 32

Preclinical studies 32

Clinical studies 35

Discussion 39

2.3. Cell based therapy in Parkinsonism 41

Abstract Introduction 41

Adult stem cells (ASC) 41

Preclinical experience with ASC in motor parkinsonism 42

Clinical experience with ASC in motor, parkinsonism 43

Discussion 47

Conclusions 48 50

2.4. Stem cell grafting in parkinsonism - Why, how, and when 51 
Abstract

Parkinson's Disease and parkinsonism ___ 51

Stem cells

How to interpret the effects in animal models of parkinsonism?

Conclusions_ 56

Chapter 3 _ 57

Bone marrow-derived stem cells in acute vascular ischemia ___ 57

Introduction chapter 3

3.1. Efficacy of Different Doses of Human Autologous Adult Bone Marrow Stem Cell Transplantation on Angiogenesis in an Immune Deficient Rat Model with Hind

Limb Ischemia. _ 58

Introduction

Methods 59

Cell Preparation 60

Statistical Analysis 61

Results _61 63

Discussion_ 63

Conclusion — 64

Chapter 4 _ 65

Bone marrow-derived stem cells in acute neurodegenerative processes ___ 65

Introduction chapter $4 \_65$

4.1. Standardized human bone marrow-derived stem cells infusion improves survival and recovery in a rat model of spinal cord injury ___ 66

Abstract 66

Introduction 66

Methods 68

Results

Discussion _ 83

Conclusion — 87

4.2. Treatment of rats with spinal cord injury using human bone-marrow-derived stromal cells prepared by negative selection

Abstract — 88

Background _ 88

Methods 90

Results__ 95

Discussion_ 105

Supplementary__ 110 


\section{Chapter 5}

Bone marrow-derived stem cells in chronic neuro-degenerative processes 111 Introduction chapter 5

5.1. Neuro-Cells therapy improves motor outcomes and suppresses inflammation during experimental syndrome of amyotrophic lateral sclerosis in mice 113

Abstract

Introduction

Material and methods

Results

Discussion

Conclusions

Supplementary

5.2. Molecular and behavioral abnormalities in the FUS-tg mice mimic frontotemporal lobar degeneration: effects of old and new anti-inflammatory therapies

Abstract

Introduction 138

Methodology

Results and Discussion

Conclusions 144

Supporting information 144

Chapter 6

Discussion

Introduction chapter 6

6.1. Why do anti-inflammatory signals of bone marrow-derived stromal cells improve neuro-degenerative conditions where anti-inflammatory drugs fail?

Abstract

Introduction

Anti-inflammatory drug-Interventions in neurodegeneration 165

BM-Derived Stromal Cell-Interventions in neurodegeneration 166

Mode-of-action of BM-Derived Stromal Cells 167

Conclusion

\section{Chapter 7}

Conclusions and Summary

Introduction chapter 7

7.1. Bone marrow-derived stem cells: from bench to bedside 
7.2. Summary: the patient's own bone marrow-derived stromal cells as disease modifier in (neuro)degenerative disorders

7.3. Samenvatting: patiënt's eigen beenmerg stamcellen om (neuro)degeneratieve aandoeningen aan te pakken 184

Literature 185

Acknowledgment 214

Curriculum Vitae 215 


\title{
Chapter 1
}

\section{General introduction}

\begin{abstract}
Neurodegenerative disorders are responsible for the sickness and impaired quality of life of nearly one-fifth of the world population and, in part, are responsible for the enormous growth in health care costs in the last decade. In these disorders, new therapeutic approaches are thus an unmet need. Stem cells have unique characteristics and are a potential solution to help treating patients with neurodegenerative disorders. This first chapter will give a short introduction of the process of neurodegeneration, most common neurodegenerative disorders, and the immune-modulative role of stem cells in these diseases. Inflammation is highlighted because of its important role in the pathophysiology of these diseases. Stem cells are no static drugs but can adapt easily to local stimuli. To illustrate this in more detail, the hypothesis of stem cells as decision-making cells is introduced. Finally, the outline of this book is described with the main questions, which this book will address in detail.
\end{abstract}




\section{Neurodegeneration}

Neurodegeneration is the progressive loss of structure or function of neurons, including their death. Neurodegeneration can be found in many different levels of the neuronal circuitry, ranging from molecular to systemic level. As research progresses, many similarities appear that relate these processes to one another on a sub-cellular level. Discovering these similarities offers hope for adequate therapeutic interventions that could ameliorate many, at first glance unrelated, diseases. Neurodegenerative diseases are acute or chronic disorders of the central nervous system, the brain and/or spinal cord, caused by a trauma (such as spinal cord injury and traumatic brain injury), ischemia, or a mixture of genetic and environmental factors (sometimes leading to genotypes with various phenotypes such as in typical dopaminergic deficiencies (Parkinson disease -PD) or motor neuron disease (amyotrophic lateral sclerosis -ALS), now recognized to be a multisystem disorder. The processes leading to the loss of neural tissue are described as neurodegeneration.

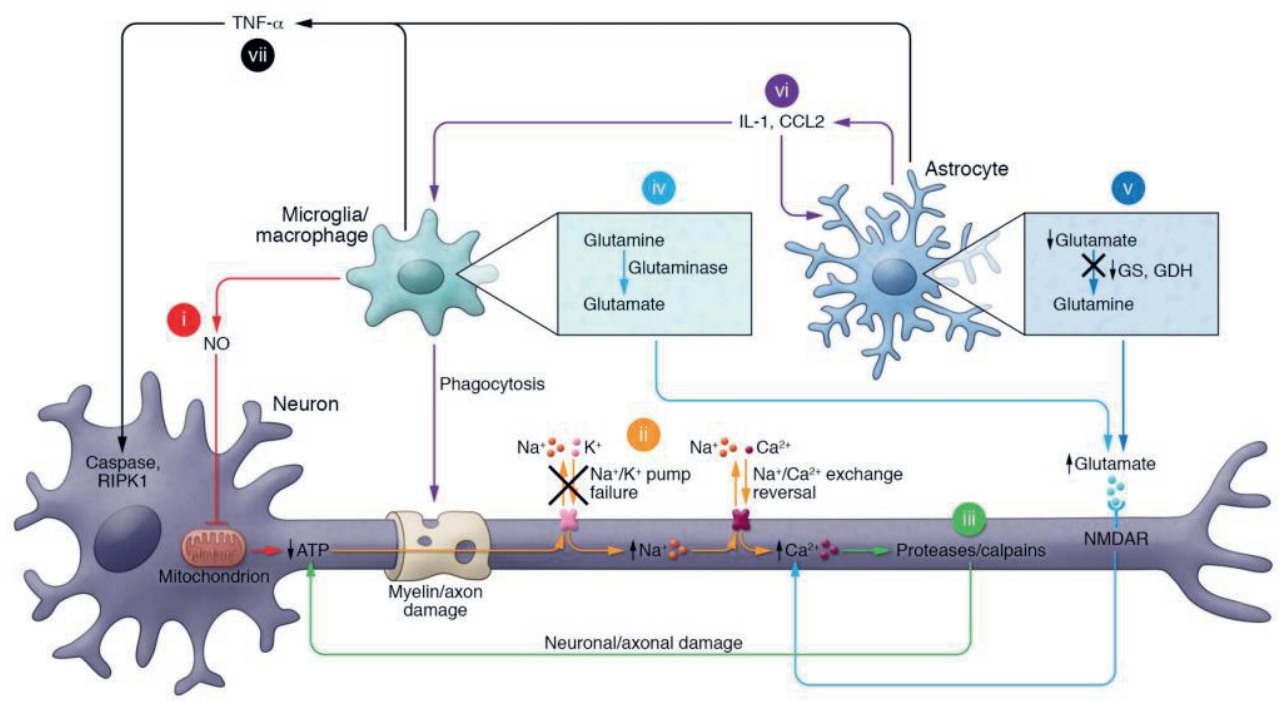

Figure 1.Secondary degeneration of the axon and neuronal cell body is a multi-pathway mediated process as described by Chitnis and Weiner (Chitnis and Weiner 2017) (with permission of the authors and the Journal). The following mechanisms are involved: (i) Nitric oxide (NO) produced by macrophages. (ii) Reductions in neuronal ATP production which may lead to failure of the Na+/K+ pump. (iii) activation of degradative enzymes, including proteases, phospholipases, and calpains. (iv) production of glutamate by microglia and macrophages. (v) Impaired glutamate uptake and degradation of astrocytes, accompanied by a downregulated expression of glutamine synthase (GS) and glutamate dehydrogenase (GDH), perpetuates increased extracellular glutamate levels. (vi) Astrocytes produce CCL2 and cytokines that further activate microglia and macrophages. In turn, microglia and macrophages consume damaged myelin sheaths and axons. (vii) Secondary neuronal cell body degradation can occur by apoptotic or necroptotic mechanisms, triggered in part by immune molecules (e.g., TNF- $\alpha$, TRAIL) that are produced by microglia/macrophages or astrocytes.

The variety of these processes share a final common pathophysiology: an underlying specific etiology-induced necrotic process, boosted through a secondary inflammatory process (Figure 1) due to both innate and adaptive immune responses (Chitnis and Weiner 2017).

In acute neurodegenerative disorders (such as traumatic spinal cord injury, traumatic brain injury and/or vascular infarcts of the central nervous system) this activation is caused by primary insultinduced necrosis, whereas in chronic disorders (such as Parkinson disease and/or amyotrophic 
lateral sclerosis) ongoing activation is elicited by a genetic and/or environmental-driven abnormal accumulation of misfolded proteins, mitochondrial dysfunction, oxidative stress and/or inflammation. These processes reinforce each other (Lin and Beal 2006, Ganguly, Chakrabarti et al. 2017). In many neurodegenerative diseases, damage to the associations of the endoplasmic reticulum (ER) with the mitochondria has been described (Stoica, Paillusson et al. 2016). This damage is linked to activation of glycogen synthase kinase $3 \beta$ with a reduction of ATP and consequent cell death. Targeting GSK3 signaling, therefore, might be regarded a potential therapy of neurodegenerative diseases (Duda, Wisniewski et al. 2018). Reduced ERmitochondria associations, for instance, are evidenced in transgenic mouse studies with mutations at the FUS (fused-in-sarcoma) and TDP-43 (transactive response DNA binding protein $43 \mathrm{kDa}$ ), both inducing a combination of ALS and frontotemporal lobe degeneration (FTLD)-like syndromes. Pathological TDP-43 aggregates are the major component of ubiquitin-positive cytoplasmic inclusions found in the brains of patients with ALS and FTLD. These aggregates, though, are also evidenced in patients suffering Alzheimer's disease, Parkinson's disease and other synucleinopathies (Stoica, Paillusson et al. 2016). In these disorders, the induced mitochondriopathy results in reduced ATP levels with necrosis (Figure 1).These necrotic processes and necrotic cells are responsible for the expression/activation of inflammasomes (proteins of the immune system responsible for the activation of inflammation), which evoke an activation of monocytes, microglia and astrocytes (Lewis, Manning et al. 2012, Orsini, Oliveira et al. 2015). Activated microglia, astrocytes, and T-helper cells secrete pro-inflammatory chemokines and cytokines and widen the fenestrations in the blood-brain-barrier, enabling free passage of these activated monocytes. Activated microglia, astrocytes and infiltrated T-helper cells thus regulate cell death and eliminate associated waste materials within the central nervous system.

Microglia play a surveillance role in the homeostasis of the central nervous tissue as can be visualized by Figure 2 (Subramaniam and Federoff 2017). The type, location and connections of the necrotic cell populations are leading in the variable clinical expression of these neurodegenerative processes. The cerebrospinal fluid (CSF) circulating around the damaged neural tissue carries the released cytokines, and the presence of M1-activated macrophages (Figure 3), which can pass the opened tight junctions of the blood-brain-barrier, turns CSF toxic for neighboring cells (Stamatovic, Keep et al. 2008, Chao, He et al. 2009, Podjaski, Alvarez et al. 2015). Both innate and adaptive immune responses are involved in the progression of neurodegenerative disorders and can promote either neuroprotection or neurotoxicity depending on disease stage, evidencing a dual role of inflammation (Zhao, Beers et al. 2013). Microglia (M), astrocytes (A) and T-helper cells (Th) thus appear to have central roles in the pathogenesis of neurodegenerative processes. When being activated in response to various insults, these cells differentiate into a pro-inflammatory (M1, A1 and Th1) phenotype (Frankola, Greig et al. 2011, Hagar, Powell et al. 2013). Once the inciting event has been adequately dealt with, a lower production of pro-inflammatory cytokines might be responsible for polarization of these cells, switching from a pro-inflammatory M1/A1/Th1 (IRM) to an anti-inflammatory M2/A2/Th2 (ARM) 'alternative' phenotype resolution (a kind of yin and yang) (Kim and Hematti 2009, Shechter, Miller et al. 2013). However, when the pathogenic stimulus cannot be adequately cleared, chronic inflammation develops with persistent IRM activity that can cause continuous propagative damage to local tissues. 


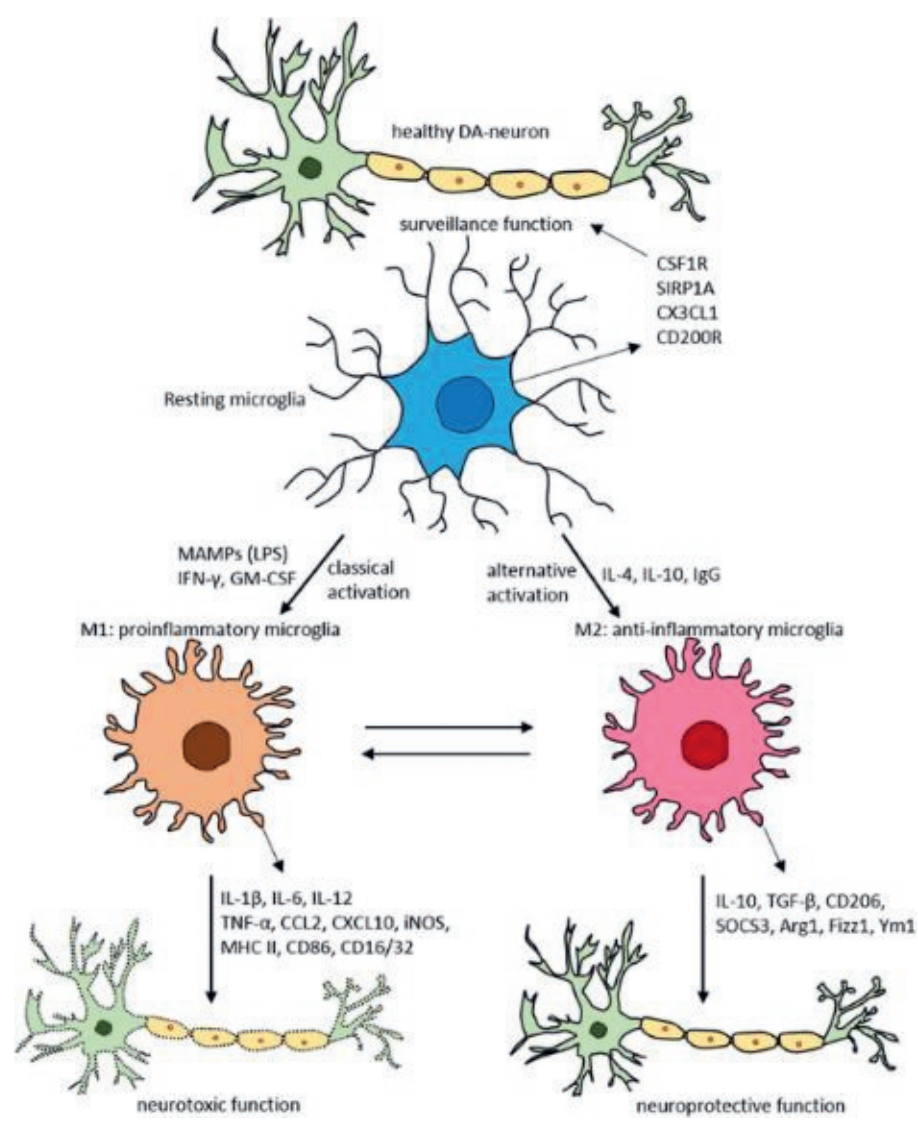

Figure 2. Schematic of microglial polarization states and function. In normal physiological conditions microglia acquire the surveillance phenotype to maintain all CNS cell types including neurons. To maintain this surveillance state, microglia secrete several factors including colony stimulating factor 1 receptor (CSF1R), signal regulatory protein CD172 (SIRP1A), chemokine CX3CL1 and CD200R. Upon classical activation when triggered by LPS, IFN- $\gamma$, or GM-CSF microglia develop into interferon response microglia (IRM) (M1 pro-inflammatory microglia) leading to neurotoxicity by secreting several pro-inflammatory substances (for detailed list, see Table 1). When activated alternatively by IL-1, IgG, or IL-10, they become activated response microglia (ARM) (M2 anti-inflammatory microglia) prompting neuroprotection through secretion of variety of substances (for detailed list, see Table 1). Arg1, arginase 1; CCL, chemokine (C-C motif) ligand; CD, cluster of differentiation; CSF1R, colony stimulating factor 1 receptor; CXCL, chemokine (C-X-C motif) ligand; Fizz1, found in inflammatory zone; IL, interleukin; GM-CSF, granulocyte-macrophage colony-stimulating factor; IFN- $\gamma$, interferon- $\gamma$; iNOS, inducible nitric oxide synthase; LPS, lipopolysaccharide; MAMPs, microbe-associated molecular patterns; MHC-II, major histocompatibility complex II; SIRP1A, signal regulatory protein CD172; SOCS3, suppressor of cytokine signaling-3; TNF- $\alpha$, tumor necrosis factor- $\alpha$; Ym1, chitinase-like protein (Subramaniam and Federoff 2017)(with permission of the authors and the Journal).

The IRM phenotypes show increased expression of pro-inflammatory cytokines, nitric oxide species, TNF- $\alpha$, and the interleukins IL-1 $\beta$ and IL- 6 inclusive, thus increasing the production of cytotoxic reactive oxygen species (ROS). ARM microglia secrete anti-inflammatory cytokines which annihilate pro-inflammatory tendencies, as well as neurotrophic factors such as glial cell line-derived neurotrophic factor (GDDF), brain-derived neurotrophic factor (BDNF), and insulinlike growth factor-1 (IGF1) (Khalid, Ampie et al. 2017). Macrophages (microglia) react to injury and degeneration with immune-phenotypic and morphological changes. they proliferate, form 
dense clusters around the cell bodies of injured neurons and produce a pro-inflammation signal by the expression and secretion of various cytotoxic factors, pro-inflammatory signalling molecules, and immune molecules, TNF- $\alpha$ and other inflammatory cytokines inclusive. An uncontrolled macrophages response secondary to sustained CNS damage can put neuronal survival at risk due to excessive inflammation. A neuroinflammatory response is considered key among the etiological factors of the major aged-related neurodegenerative diseases of the central nervous tissue, and microglial cells are the key players in these neurodegenerative lesions (Eggen, Raj et al. 2013, Li, Tan et al. 2013, Ramirez, de Hoz et al. 2017). Thus, neurodegeneration is facilitated by both, the continued production of cytotoxic by-products of a pro-inflammatory response and the lack of neurotrophic growth factors.

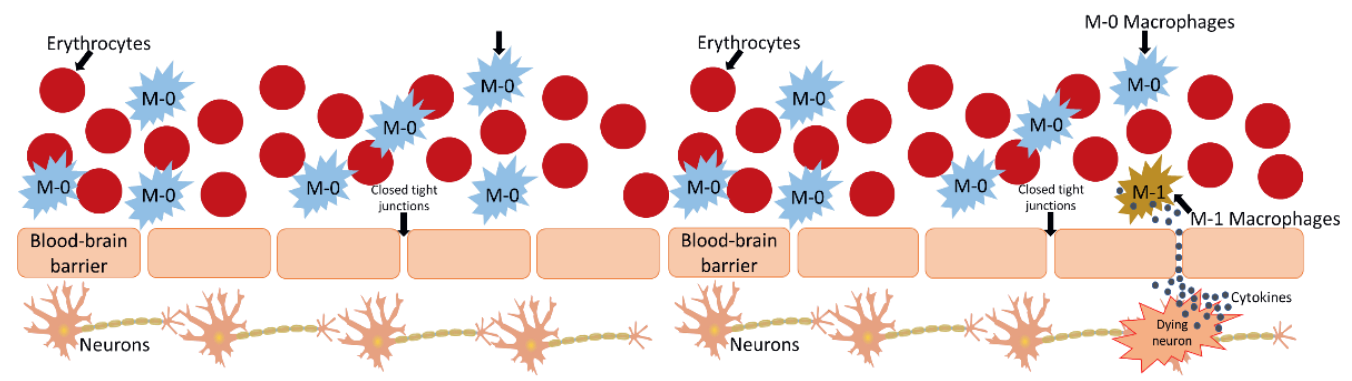

Figure 3a. Normal situation

Figure 3b. Dying neuron

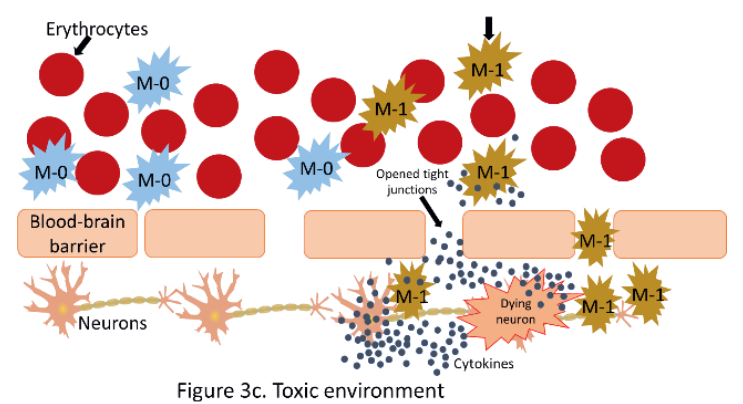

Figure 3.In a normal situation the tight junctions of the blood-brain barrier are closed and the macrophages are circulating in the blood stream in a non-activated stage (fig 3a). After an insult of the CNS, neurons get damaged and rupture with the release of all kind of proinflammatory proteins (cytokines), which can freely pass the blood-brain-barrier because of their very small dimensions (fig $3 b$ ). Those cytokines open the tight junctions of the blood-brain barrier and in parallel activate the macrophages to a pro-inflammatory IRMI (M-1) phenotype. Thus activated macrophages can pass the opened tight junctions of the blood-brain-barrier and together with the circulating cytokines they are responsible for the clean-up of damaged and dying cells and create a hostile toxic environment (fig $3 c$ ).

So, in chronic neurodegenerative processes cell debris and damaged cells are cleaned-up by the activated IRM (M1/A1/Th1) phenotypes. This cleaning-up process triggers further cell death (Hooten, Beers et al. 2015). In most neurodegenerative disorders, especially in the more chronic disorders, there is a vicious circle: cell death evokes inflammasomes that initiate a cleaning-up process by IRMs (M1/A1/Th1 phenotypes), leading to progressive cell death, which in turn evokes more inflammasomes To stop this vicious circle and to stop the expression of inflammasomes, therefore, is an unmet need (Voet, Srinivasan et al. 2019). 
As mentioned before, neurodegenerative disorders might be caused by acute, recurrent or chronic traumatic, toxic and/or ischemic insults of the central nervous system (CNS). Typical chronic progressive neurodegenerative disorders, though, are mainly the consequence of genetic or combined genetic and environmental factors, which is the case in dementia, parkinsonisms, and amyotrophic lateral sclerosis. Unfortunately, there is no effective therapy available for most of these disorders. The financial and psychosocial impact of these diseases on the community are high. Nearly $20 \%$ of the global population suffers from a neurodegenerative disease (Erkkinen, Kim et al. 2018). As the majority of the neurodegenerative diseases is correlated with aging, the percentage will be even more than $20 \%$ when looking at age groups above 65 years of age. The compiled Table 1 presents the incidence, prevalence and life expectancy of the main neurodegenerative diseases. This table illustrates clearly the health burden for the individual patient but also the economic burden for an aging community.

\section{Table 1.}

Incidence, prevalence and life expectancy of the neurodegenerative diseases

\begin{tabular}{|c|c|c|c|}
\hline Disease/disorder & Incidence & Prevalence & Life expectancy \\
\hline Spinal cord injury & $\begin{array}{l}\text { 34/1,000,000 person-years } \\
\text { (Singh, Tetreault et al. 2014, } \\
\text { Kumar, Lim et al. 2018) }\end{array}$ & $\begin{array}{l}2.27-5.26 / 10.000 \\
\text { inhabitants } \\
\text { (Furlan, Sakakibara et al. } \\
\text { 2013). }\end{array}$ & $\begin{array}{l}\text { 23.96-26.17 years (Krause, } \\
\text { Saunders et al. 2012, Chamberlain, } \\
\text { Meier et al. 2015, Savic, DeVivo et } \\
\text { al. 2017) }\end{array}$ \\
\hline $\begin{array}{l}\text { Traumatic Brain } \\
\text { Injury }\end{array}$ & $\begin{array}{l}\text { 235/100,000 person-years } \\
\text { (Tagliaferri, Compagnone et al. } \\
\text { 2006) }\end{array}$ & $\begin{array}{l}\text { 155/10,000 inhabitants } \\
\text { (Tagliaferri, Compagnone } \\
\text { et al. 2006) }\end{array}$ & \\
\hline Ischemic Stroke & $\begin{array}{l}\text { 95-290/100,000 person-years } \\
\text { (Feigin, Lawes et al. 2003, } \\
\text { Bejot, Bailly et al. 2016) }\end{array}$ & $\begin{array}{l}\text { 199/10,000 inhabitants } \\
\text { (Feigin, Lawes et al. 2003, } \\
\text { Giang, Mandalenakis et al. } \\
\text { 2017) }\end{array}$ & \\
\hline $\begin{array}{l}\text { Parkinsons } \\
\text { Disease }\end{array}$ & $\begin{array}{l}\text { 8-27.8/100,000 person-years } \\
\text { (de Lau and Breteler 2006, } \\
\text { Park, Kim et al. 2019) }\end{array}$ & & $\begin{array}{l}10 \text { years after confirmation } \\
\text { Parkinson's disease (de Lau and } \\
\text { Breteler 2006, Park, Kim et al. 2019) }\end{array}$ \\
\hline $\begin{array}{l}\text { Amyotrophic } \\
\text { Lateral Sclerosis }\end{array}$ & $\begin{array}{l}\text { 0.6-3.8/100,000 person-years } \\
\text { (Mehta, Kaye et al. 2018, } \\
\text { Gowland, Opie-Martin et al. } \\
\text { 2019) }\end{array}$ & $\begin{array}{l}\text { 4.1-9/100,000 inhabitants } \\
\text { (Mehta, Kaye et al. 2018, } \\
\text { Nelson, Topol et al. 2018, } \\
\text { Gowland, Opie-Martin et } \\
\text { al. 2019, Longinetti and } \\
\text { Fang 2019) }\end{array}$ & $\begin{array}{l}30 \text { months from first symptoms } \\
\text { (Logroscino, Traynor et al. 2010, } \\
\text { Rooney, Byrne et al. 2013) }\end{array}$ \\
\hline $\begin{array}{l}\text { Frontotemporal } \\
\text { lobar( dementia) } \\
\text { degeneration } \\
\text { (FTLD) }\end{array}$ & $\begin{array}{l}\text { incidence is } 2.7-4.1 / 100,000 \\
\text { inhabitants (Onyike, Diehl- } \\
\text { Schmid. 2013) }\end{array}$ & $\begin{array}{l}\text { Prevalence is estimated at } \\
\text { 15-22/100,000 inhabitants } \\
\text { (Onyike, Diehl-Schmid. } \\
\text { 2013) }\end{array}$ & $\begin{array}{l}\text { Life expectancy is poor ( } 3-14 \text { years) } \\
\text { and comparable to ALS (Onyike, } \\
\text { Diehl-Schmid. 2013) }\end{array}$ \\
\hline
\end{tabular}




\section{Interventions in neurodegeneration}

As stated in the sections above, there is Increasing evidence to suggest that inflammation is particularly involved in the pathogenesis of neurodegenerative diseases, and that even if inflammation is not a primary causative process, its presence may contribute to the continued neuronal loss. This suggestion is quite robust as pro-survival signaling mechanisms from neurotrophic factors are effective in attenuating neuronal death in many in vitro and in vivo models of neurodegeneration. Individual anti-inflammatory agents, such as steroidal and nonsteroidal anti-inflammatory drugs (N)SAIDs) do not break/resolve the neuro-inflammation. Unfortunately, all larger preclinical and clinical phase $\mathrm{II} / \mathrm{II}$ trials in acute and chronic neurodegenerative disorders with (N)SAIDs (non-steroidal and steroidal anti-inflammatory drugs), compounds that target inflammatory mechanisms and associated cascades (including thalidomide, selective cyclooxygenase-2 inhibitors such as Celecoxib, cyclophosphamide, cyclosporine, caspase-reducing drugs, and various neurotrophic factors) so far did only bring equivocal and/or worse outcomes (Gilgun-Sherki, Melamed et al. 2006, Hernan, Logroscino et al. 2006, Gordon, Moore et al. 2007, McGeer and McGeer 2007, Schwartz and Ziv 2008, Calvo, Moglia et al. 2010, Schwartz and Shechter 2010, Bracken 2012, Rosado, Lavor et al. 2014, Ling, Murdoch et al. 2016, Collins and Bowser 2017, Fehlings, Wilson et al. 2017, Ulndreaj, Badner et al. 2017). Maybe wrong timing of administration, nonselective inhibition of cyclooxygenase(COX)-2 inhibitors or Rho-associated protein kinases, sub-optimal dose in target site, or limited penetration to the brain through the blood-brain barrier here may have played a role in the failed approaches (Lossinsky and Shivers 2004, Stamatovic, Keep et al. 2008, Gabathuler 2010). Differences between rodent models and humans aside, perhaps the most confounding factor might be that the point(s) of action might be downstream of the pathophysiological process and retrospective in terms of neuronal death induction. Neuroprotection via pro-survival signaling also might not adequately annihilate the continuing pathological insult or might be too late to reverse the demise of compromised neurons and neighboring cells (Tang 2017). Although interventions with anti-inflammatory drugs in experimental neuro-degenerative animal studies have not resulted in successful clinical trials, a more recent approach to treat such disorders in both experimental animals and humans with implanting bone marrow-derived stromal cells (bm-SC), however, seems very promising. Such transplants supposedly modulate the immune system in both acute (spinal cord injuries) (Tsai, Liou et al. 2018, Cofano, Boido et al. 2019, Jin, Medress et al. 2019, Shao, Tu et al. 2019), as well as chronic (amyotrophic lateral sclerosis) (Deda, Inci et al. 2009, Mazzini, Vescovi et al. 2016, Schroeder, Kepler et al. 2016, Ciervo, Ning et al. 2017, Gashmardi, Hosseini et al. 2017, Sykova, Rychmach et al. 2017, Cizkova, Cubinkova et al. 2018, Garbuzova-Davis, Haller et al. 2018, Oh, Noh et al. 2018, Gugliandolo, Bramanti et al. 2019), neurodegenerative disorders in both experimental animals and patients.

\section{Stem cells}

Recently, cell-based therapies, and especially stem cells, emerged as a promising strategy to modulate the immune system in these patients. Stem cells are undifferentiated cells that can divide to produce some offspring cells that continue as stem cells, and some cells that are destined to differentiate (become specialized) in all kind of target cells. The hall marks of stem 
cells thus are proliferation and differentiation. Stem cells are needed to develop, assemble and repair bodily structures. Without these cells one cannot survive (Hemmat, Lieberman et al. 2010). Stem cells can be harvested out of adipose tissue (Vilalta, Degano et al. 2008), bone marrow (Jager, Hernigou et al. 2010), olfactory mucosa (Murrell, Wetzig et al. 2008), umbilical cord blood (Dalous, Larghero et al. 2012) and embryonic tissue (Hentze, Graichen et al. 2007), as well as special niches in organs (Gao, Enikolopov et al. 2008, Paspala, Balaji et al. 2009). Another way of acquiring stem cells is to reprogram adult somatic cells back into pluripotent stem cells, induced pluripotent stem cells (iPSCs). To reach quantitative numbers of stem cells, expanding procedures might be used. The exact mechanisms of action of stem cells remain to be elucidated. Furthermore, stem cells have the capability of switching on/off processes of cells, and can act selective or act situational and adapt to local circumstances (Fischbach, Bluestone et al. 2013). They act fundamentally different compared to small molecules such as neurotransmitters and biologics such as antibodies, growth factors and or cytokines. Cell-based products can adapt to the environment, can target more precise and can influence their environment to help creating a more controlled environment. Stem cells are able to modulate immune processes by modulating T- and B-cell activity, and are able to secrete or stimulate other cells to secrete paracrine factors with the goal to maintain tissue homeostasis (de Munter and Wolters 2013, Harting, Srivastava et al. 2018, Ruppert, Nguyen et al. 2018). The action of classical drugs/biologics is in contrast determined by their dose at the moment of administration. The pharmacokinetics are determined by the elimination time of the drug and tissue penetration of the drug. The pharmacokinetics are highly important to avoid side effects (Benet, Bowman et al. 2019, Farkouh, Riedl et al. 2019).

\section{Table 2.}

Cell-based therapeutics compared to small molecules/biologics (Fischbach, Bluestone et al. 2013)

\begin{tabular}{lll}
\hline Comparisons & Small molecules and biologics & Stem cells \\
\hline Selectivity & Molecular recognition & Complex sensing and response systems
\end{tabular}

Distribution

Dose Controlled at time of administration

Therapeutic niche

\author{
Cell decision-making: \\ - Proliferation/Activation/ \\ death \\ - Closed-loop autoregulation
}

Conditions that require precise dynamic control

These interventions have also off-target effects, meaning that they are also penetrating in and acting on non-target cells creating those side effects. Cells are able to adapt and make their own interpretations and act accordingly. They can stay in a non-active phase (OFF-phase) and when certain signal proteins reach a threshold level, can activate themselves (ON phase). The question 
'How many cell are needed for a certain effect' is difficult to answer, because cells act dynamically and can activate existing cells to secrete paracrine factors (Kinnaird, Stabile et al. 2004) or assist in coping with the original insult (Fischbach, Bluestone et al. 2013). Table 2 compares the characteristics of today's therapeutic arsenal, cells inclusive (Fischbach, Bluestone et al. 2013) in more detail. Bone marrow can be a source of stem cells and is easily accessible for collection of hematopoietic (HSCs) and mesenchymal (MSCs) stem cells (Jager, Hernigou et al. 2010). Hematopoietic stem cells (HSCs) mainly replenish all adult hemato-poietic lineages throughout lifetime, and mesenchymal stem cells (MSCs) play crucial roles in maintaining tissue homeostasis during physiological turnovers and injuries by their trans-differentiation into tissuespecific cell types and their anti-inflammatory and regenerative/apocrine actions. MSCs and HSCs can promote regeneration; figure 4 illustrates the multitasking capabilities of the cells related to neural repair (Wagenaar, Nijboer et al. 2017).

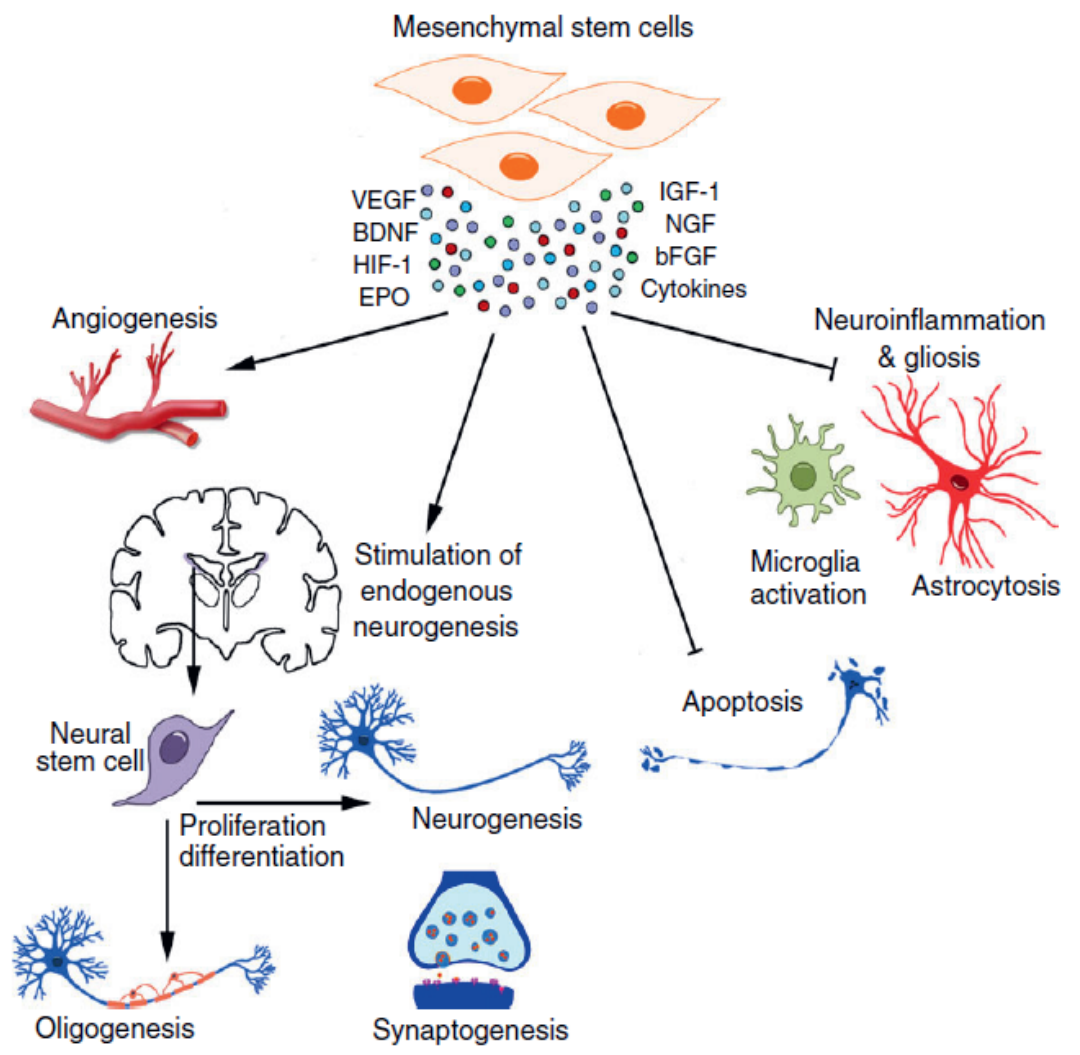

Figure 4. Potential mechanisms for mesenchymal stem cells to induce repair of brain injury, including of angiogenesis, stimulation of neurogenesis, reduction of apoptosis, neuroinflammation, and gliosis. These pathways are mediated by the secretome of MSCs, which consists of growth factors such as vascular endothelial growth factor (VEGF), brain-derived neurotrophic factor (BDNF), hypoxia-inducible factor 1 (HIF-1), erythropoietin (EPO), insulin-like growth factor 1 (IGF-1), nerve growth factor (NGF), basic fibroblast growth factor (bFGF) and anti-inflammatory cytokines. Modified from Wagenaar et al. (Wagenaar, Nijboer et al. 2017)(with permission of author and Journal) 
Stem cells are big cells and cannot pass an intact blood-brain barrier and/or cortico-spinal fluidbrain barrier (Stamatovic, Keep et al. 2008, Jackson, Golding et al. 2010). Their communication with other cells takes probably place by communicators, signalling proteins, extracellular vesicles that can freely pass the blood-brain barriers. Communicators are soluble factors such as cytokines (including chemokines, interferons, interleukins, lymphokines, and tumour necrosis factor) and small vesicles containing dedicated proteins (extracellular vesicles). Extracellular vesicles (EVs) are small, membrane-bound nanoparticles that can be released from most, if not all cells, and that can carry functionally active cargo (proteins, nucleic acids, lipids). The active molecules in this cargo showed to modify the recipient cells physiology to react in a paracrine and endocrine manner (Dostert, Mesure et al. 2017, Cizkova, Cubinkova et al. 2018, Harting, Srivastava et al. 2018, Kim, Oh et al. 2018, Wang, Pei et al. 2018, Beers and Appel 2019). Figure 5 illustrates a cell with EVs, showing also their dimensions (Shahjin, Chand et al. 2019).

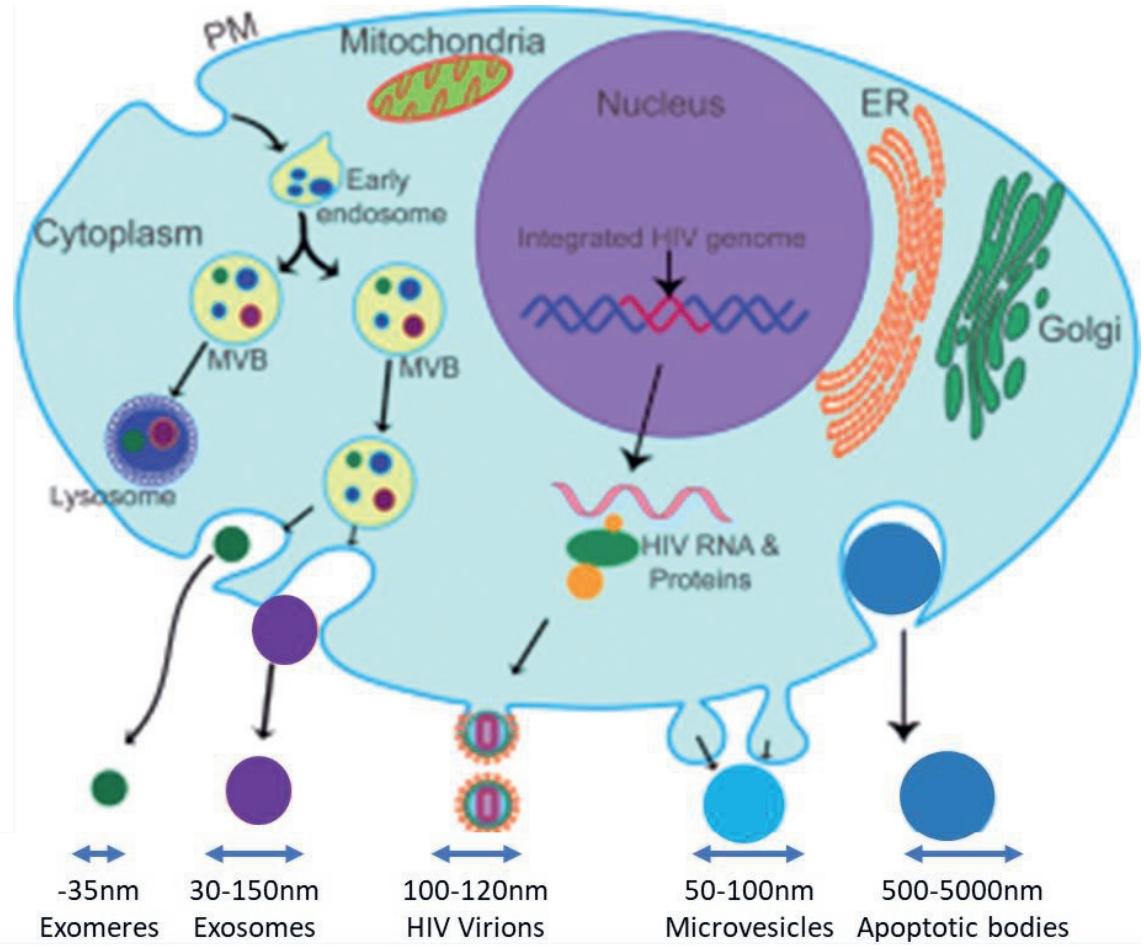

Figure 5. Schematic representation of the biogenesis of extravesicular vesicles subpopulations and HIV, with size ranges. ER: endoplasmic reticulum; PM: plasma membrane; MVB: multivesicular bodies (Shahjin, Chand et al. 2019)(with permission of author and Journal)

Another paracrine factor of stem cells relevant to mention in this chapter is VEGF (vascular endothelial growth factor) (Friedrich, Walenta et al. 2006, Wragg, Mellad et al. 2008, Zisa, Shabbir et al. 2009, Cobellis, Maione et al. 2010), a pro-angiogenetic growth factor. VEGF is seen as a secreted protein of stem cells able to promote vascular growth in ischemic tissue. This is 
relevant for diseases with an acute vascular occlusion such as critical limb ischemia, myocardial infarction and ischemic stroke.

In summary, stem cells are very promising as a new therapeutic concept to combat neurodegeneration but there are questions, which are relevant to be answered before going into translation with a stem cell preparation:

- Which patients can be universally treated with stem cells as a disease modifier in diseases in which secondary inflammatory processes play a major role in the neurodegenerative process?

- Which stem cells are best suited to be applied as an intervention?

- Which is the best route of administration when dealing with neurodegenerative diseases?

- Which is the best dose?

- Which is the best time in respect to the disease process to administer the stem cells?

Based on a comprehensive evaluation of literature, and based on own experiences, nonmanipulated bone marrow-derived MSCs and HSCs are selected as a concept therapy to be applied in the treatment of neuro-degenerative diseases such as spinal cord injury, amyotrophic lateral sclerosis and frontotemporal lobe degeneration inclusive. Translational, this preparation is called Neuro-Cells. Neuro- being the target area and -Cells the content of fresh living cells. Conceptually, this preparation acts like a multi-tasker, taking decisions pending the environment, and secreting repair/immune-modulating substances such as paracrine factors and/or extracellular vesicular vesicles.

\section{Aims and outlines of this book}

The aim of this thesis is to identify a standardized stem cell product that can be used to treat secondary inflammation in neurodegenerative diseases to improve the clinical outcome.

In Chapter 2, the harvesting and manufacturing of the various human stromal/stem cell preparations, as well as their characterization, capabilities, functions, and their clinical application in human neurodegenerative conditions are comprehensively reviewed. Here, the effects of world-wide interventions with human stem cell preparations in animal models of acute (traumatic and/or vascular-induced) and chronic (parkinsonism, multiple sclerosis, amyotrophic lateral sclerosis) neurodegenerative disorders as well as in patients suffering these disorders are also extensively reviewed.

Chapter 3 deals with the angiogenetic capabilities of a human bone marrow-derived stem cell preparation in a preclinical model of ischemic limb.

In Chapter 4, the clinical effects of an intrathecal transplantation with negatively selected MSCs and HSCs (Neuro-Cells) in rats suffering an acute traumatic balloon compression- as well as weight-induced spinal cord injury resulting in a paraplegia will be discussed. 
In Chapter 5, the effects of intrathecal interventions with Neuro-Cells in transgenic FUS (1-358) and SOD-1-induced amyotrophic lateral sclerosis (ALS)-like mice as well as in FUS (1-358)-induced frontotemporal lobar degeneration (FTLD)-like mice will be discussed in detail. Here, the beauty of the experiments was the head-to-head comparison with anti-inflammatory drugs.

Finally, in Chapter 6, we discussed the question why anti-inflammatory signals of bone marrowderived stem cells improve neurodegenerative conditions where anti-inflammatory drugs fail. We concluded that in preclinical trials, a transplantation with human stem cells might be seen as a disease modifier, acting on the secondary inflammatory mechanisms. So, as of now, we have cleared the way to test this hypothesis in human trials, as we realize that we not only need more human clinical data to substantiate this conclusion, but also better biomarkers for monitoring (neuro)-inflammation.

Chapter 7 elaborates on the concept of the decision-making stem cells, which detox the hostile cerebrospinal fluid, after displaying the preclinical results. The whole process from the first laboratory tests to the proof of concept in the animal experiments allowing to test our hypothesis in a clinical trial in patients suffering neurodegenerative disorders, will be addressed. Chapter 7.2 provides the reader with a summary of the presented studies looking at the effects of Neuro-Cells in acute and chronic neurodegenerative disorders. 


\section{Chapter 2}

\section{Cell based therapy in Neurology: the search for the best cells}

\section{Introduction chapter 2}

Chapter 2 provides a general introduction of stem cells and their use as an intervention to treat traumatic, vascular and neurodegenerative insults of the central nervous system. This chapter comprises four separate review articles in which the first one (2.1) highlights the various different sources of stem cells and the choice to work with autologous non-manipulated stem cells. Especially, the autologous stem cells and their benefits are discussed reflecting the state of the art in literature.

The second article (2.2) presents an overview of the different preclinical and clinical studies performed with autologous stem cells in acute neurodegenerative disorders such as traumatic spinal cord injury, traumatic brain injury and ischemic stroke will be highlighted. The third article (2.3.) give a detailed overview of the literature on stem cell transplantations in the treatment of parkinsonistic animal models and patients suffering a chronic neuro-degenerative process (parkinsonism). The last, fourth article (2.4.) focuses on more practical issues in stem cell transplantation the best choice of cells and the best timing and route of administration.

Both in acute and chronic neurodegenerative disorders, dying neural tissue provoke inflammatory cascades. Indeed, secondary inflammation plays a role in these processes, and stem cells are suggested to suppress and/or slow down ongoing inflammation, thereby saving neural tissue and postponing symptomatology. 


\title{
2.1. Autologous stem cells in neurology: is there a future?
}

\author{
de Munter JPJM, Wolters ECh (2013) J Neural Transm 120:65-73.
}

\begin{abstract}
Stem cells seem very promising in the treatment of degenerative neurological diseases for which there are currently no or limited therapeutic strategies. However, their clinical application meets many regulatory hurdles. This article gives an overview of stem cells, their potential healing capacities as well as their identified and potential risks, such as tumour formation, unwanted immune responses and the transmission of adventitious agents. As there is no clinical experience with embryonic and induced pluripotent stem cells (as the result of their unacceptable risk on tumour formation), most attention will be paid to fresh autologous adult stem cells (ASCS). To evaluate eventual clinical benefits, preclinical studies are essential, though their value is limited as in these studies, various types of stem cells, with different histories of procurement and culturing, a reapplied in various concentrations by various routes of administration. On top of that, in most animal studies allogenic human, thus non autologous, stem cells are applied, which might mask the real effects. More reliable, though small-sized, clinical trials with autologous ASCs did show satisfying clinical benefits in regenerative medicine, without major health concerns. One should wonder, though, why it is so hard to get compelling evidence for the healing and renewing capacities of these stem cells when these cells indeed are really essential for tissue repair during life.

Why so many hurdles have to be taken before health authorities such as the European Medicine Agency (EMA) and/or the Food and Drug Administration (FDA) approve stem cells in the treatment of (especially no-option) patients.
\end{abstract}

\section{Introduction}

There is worldwide consensus about stem cells, playing a vital role in tissue repair and plasticity, and all of us realize that without these cells, life is not possible (Schofield 1983).

Over the last 10 years, however, the eventual application of these stem cells as well as their regulatory framework (Astori, Soncin et al. 2010) in therapeutic strategies for all kind of end stage (neurological) diseases in humans (Zietlow, Lane et al. 2008) has been subject to critical discussion. As of yet, these discussions did not lead to a consensus regarding the clinical application of stem cells in such disorders. To better understand this discussion, and to elucidate these hurdles, we will discuss the various moieties of stem cells, especially those of the autologous adult stem cells (ASCs).

\section{Stem cells}

Stem cells are expressed and can be harvested from embryonic tissue, from umbilical cord blood and from adult tissue such as peripheral blood, bone marrow, liver and fat tissue. They are not specialized in any specific cell type as yet, though share the ability to on the one hand reproduce themselves indefinitely and on the other hand to differentiate themselves into any specialized cell type (Hemmat, Lieberman et al. 2010). Indeed, their specific strength is defined by their 
capacity to differentiate into various cell types. This ability for self-renewal makes them particularly interesting for expanding.

During the first four blastomere cleavage phases, embryonic stem cells are the most capable stem cells, as they are totipotent, meaning that these cells are able not only to differentiate themselves into virtually all cell types needed to constitute a human body (so, cell types within all germ layers: endoderm, mesoderm and ectoderm) but also into extra-embryonic cells (umbilical cord tissue).

After the fourth cleavage phase, the embryonic cells lose their totipotency and become pluripotent stem cells. Those cells are now only able to differentiate themselves into the three essential lineages, but not into extra-embryonic cells. Later on, during development, these cells will become multipotent stem cells: initially, they still can differentiate into two of these specific lineages, but in due time they even become unipotent cells, cells which may differentiate only in cell types limited to one germ layer.

Finally, when the end stage cell line is formed, differentiation into other cell types is not possible anymore and the cells are called nullipotent, although, under certain conditions, they still will be able to renew themselves.

Table 1 presents an overview of the different groups of stem cells with the main characteristics.

\section{Table 1}

The potential stem cells for treatment of neurodegenerative diseases with their main characteristics

\begin{tabular}{|c|c|c|c|c|c|}
\hline Type & Source of harvest & $\begin{array}{l}\text { Ability to } \\
\text { differentiate }\end{array}$ & Tumor risk & Immunogenicity & $\begin{array}{l}\text { Ability to } \\
\text { expand }\end{array}$ \\
\hline $\begin{array}{l}\text { Embryonic } \\
\text { stem cells }\end{array}$ & $\begin{array}{l}\text { Derived from an embryo in } \\
\text { the first four blastomere } \\
\text { cleavage phases }\end{array}$ & Totipotent & High & High & High (indefinitely) \\
\hline $\begin{array}{l}\text { Embryonic } \\
\text { stem cells }\end{array}$ & $\begin{array}{l}\text { Derived from an embryo } \\
\text { after the fourth blastomere } \\
\text { cleavage phase }\end{array}$ & Pluripotent & Medium/high & High & High (indefinitely) \\
\hline $\begin{array}{l}\text { Umbilical } \\
\text { cord stem } \\
\text { cells }\end{array}$ & $\begin{array}{l}\text { Derived from the umbilical } \\
\text { cord at birth }\end{array}$ & Pluripotent & Medium/high & $\begin{array}{l}\text { High (except for child or } \\
\text { parents) }\end{array}$ & Medium \\
\hline $\begin{array}{l}\text { Allogenic } \\
\text { adult stem } \\
\text { cells }\end{array}$ & $\begin{array}{l}\text { Derived from already } \\
\text { specialized human tissue }\end{array}$ & Pluripotent & Low & $\begin{array}{l}\text { High/medium (depends } \\
\text { on genetic match) }\end{array}$ & Limited \\
\hline $\begin{array}{l}\text { Autologous } \\
\text { adult stem } \\
\text { cells }\end{array}$ & $\begin{array}{l}\text { Derived from already } \\
\text { specialized human tissue }\end{array}$ & Pluripotent & Low & $\begin{array}{l}\text { Low (same donor and } \\
\text { receiver) }\end{array}$ & Limited \\
\hline $\begin{array}{l}\text { Neural stem } \\
\text { cells }\end{array}$ & $\begin{array}{l}\text { Derived out of the } \\
\text { periventricular sub- } \\
\text { ependymal layer and } \\
\text { subgranular zone of the } \\
\text { dentate gyrus }\end{array}$ & Multipotent & Low & $\begin{array}{l}\text { Low (same donor and } \\
\text { receiver) }\end{array}$ & Limited \\
\hline $\begin{array}{l}\text { Induced } \\
\text { pluripotent } \\
\text { stem cells }\end{array}$ & $\begin{array}{l}\text { Derived from already } \\
\text { specialized human tissue but } \\
\text { reprogrammed back to } \\
\text { embryonic like stem cells }\end{array}$ & Pluripotent & Medium/high & $\begin{array}{l}\text { Low (same donor and } \\
\text { receiver) }\end{array}$ & Medium \\
\hline
\end{tabular}


The application of cells, able to differentiate themselves into highly differentiated cell types, of course, seems very attractive in the treatment of neurodegenerative diseases, where clinical symptoms express the progressive loss of functional cells, to combat the lack of effective therapies. However, not all stem cells seem to be good candidates for human application. As the most powerful stem cells, the totipotent cells, deriving from living embryos before the fifth blastomere cleavage phase (Hemmat, Lieberman et al. 2010), have the significant disadvantage to enable tumor formation (Lee, Tang et al. 2009), not to mention the ethical aspects of using embryos to harvest stem cells (Andersson 2011). Another problem is that those embryonic cells (from non-autologous donors) might be rejected after clinical application and, therefore, need to be combined with immune response inhibitors when applied. The use of pluripotent cord blood-derived stem cells seems more attractive, and harvesting them could play a role in the preventive storage of genetically matched cell lines for future treatment of degenerative diseases limited to the child and or the parents (Riordan, Chan et al. 2007). As we know now, long-term storage of these stem cells with additives such as dimethyl sulfoxide (DSMO) does not change the viability of the stem cells, even after a freezing period of nearly 18 years (Veeraputhiran, Theus et al. 2010). These cells are also considered free of eventual tumor genesis and do not need any immune suppressive therapy to prevent rejection after reapplication in the donor. Autologous ASCs, mainly mesenchymal and hematopoietic stem cells, though, are considered to be most promising, as they do not bear the risk of tumor genesis and are easily harvested out of the iliac crest of the patients. So, these cells do have the same genetic base as the patient, and might be applied without immune suppressive medication to prevent graft rejection (Barzilay, Levy et al. 2006). On top of that, recent studies with these multipotent stem cells produced firm evidence that they might even differentiate into cell types of all lineages (Junker, Sommar et al. 2010), suggesting pluripotency. As a matter of fact, ASCs can also be reprogrammed to a pluripotent state, by enforcing the expression of embryonic transcription factors (Stadtfeld and Hochedlinger 2010), in that way combining the strength of embryonic stem cells and the absence of the need to prevent for an immune response. However, one should realize that in any case of manipulative and/or expanding procedure (which is the case in induced pluripotent stem cells), there is a high risk of aneuploidy (unequal number of chromosomes), which limits the differentiation capacity and increases the tumorigenicity (Mayshar, Ben-David et al. 2010). Neural stem cells are situated in the periventricular subependymal layer and subgranular zone of the dentate gyrus and are multipotent. Neural stem cells can differentiate into glial cells, astrocytes and oligodendrocytes. These cells are difficult to harvest, though, and limited in number (Andres, Choi et al. 2008). We will discuss the state of art considering the harvesting and preparation as well as characterization of autologous ASCs, focusing on mesenchymal (MSCs) and hematopoietic stem cells (HSCs).

\section{Autologous adult stem cells}

\section{Harvesting and preparing adult stem cells}

As the bone marrow is one of the major sources of autologous ASCs, harvesting those cells might be readily and safely performed by bone marrow biopsy (Siddiq, Pamphilon et al. 2009). Usually, the bone marrow aspirate is then filtered and processed by gradient centrifugation. In the centrifugate, the buffy coat (the layer between the plasma and the red blood cells with the 
highest yield of the stem cells with the best therapeutic potential, such as HSCs and MSCs) is then isolated for further processing, for instance with cell separators to select and concentrate stem cells in a closed system, allowing point-of-care treatment (Scerpa, Daniele et al. 2011). Nevertheless, the number of these cells in a centrifuged bone marrow aspirate is rather low, the percentage of MSCs usually not exceeding $1 \%$ of HSCs and $0.01 \%$ of the total number of mononuclear cells (Pittenger, Mackay et al. 1999). Extrapolated from animal studies, a dose between 1.0 and $3.0 \times 10^{7}$ BMMCs (containing 1.0-3.0 x 105 HSCs) per kilogram body weight is considered to be adequate in the treatment of human neurological diseases including ischemic brain injury (Yang, Strong et al. 2011).

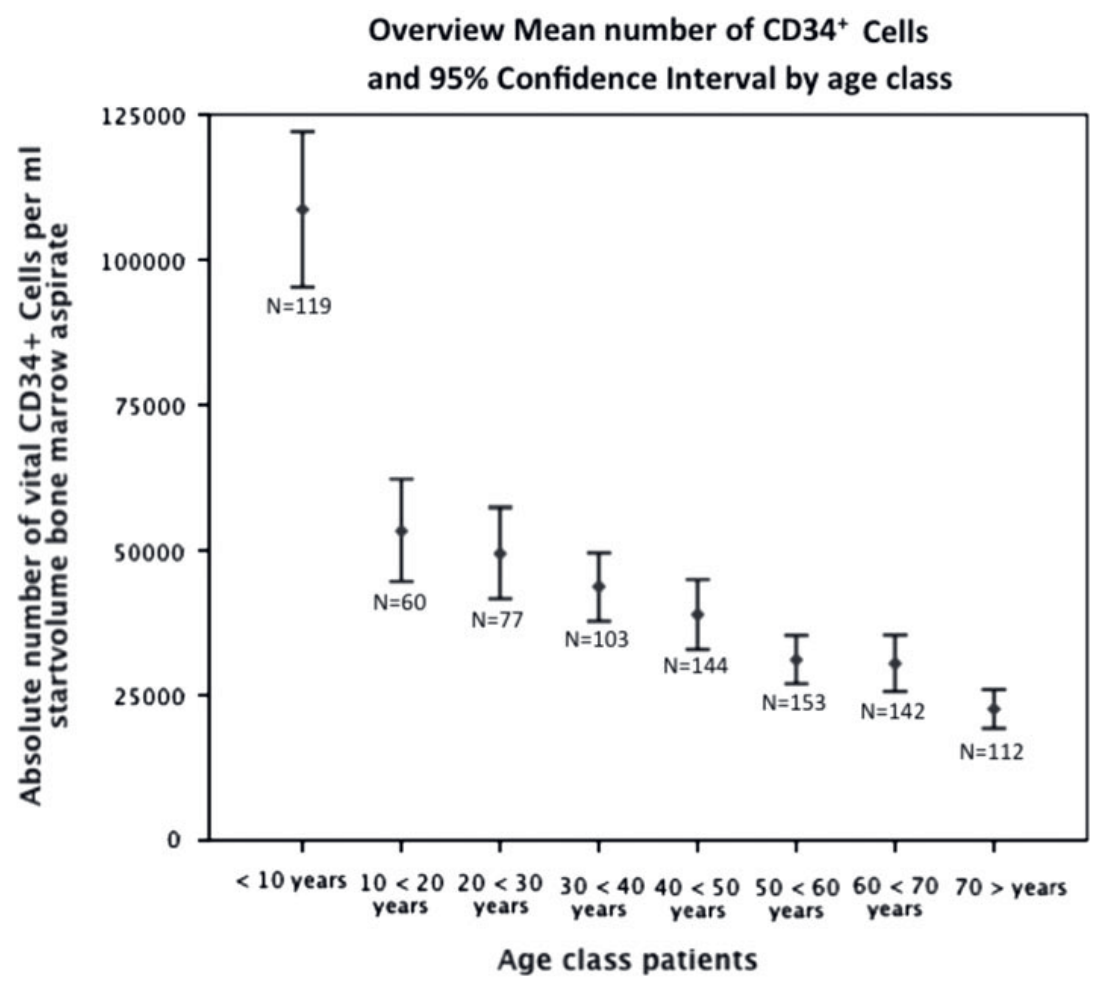

Figure 1 Overview mean number of $\mathrm{CD}_{3} 4^{+}$cells and 95\% confidence interval by age class (own data)

Figure 1 gives an overview of the mean number of $\mathrm{CD} 34^{+}$cells (mainly $\mathrm{HSCs}$ ) calculated per ml bone marrow aspirate per age class (own data).

So, $150-200 \mathrm{ml}$ bone marrow aspirate (containing about 5-10 x 106 $\mathrm{HSCs}$ ) is needed to prepare an adequate dose of stem cells for clinical interventions. 


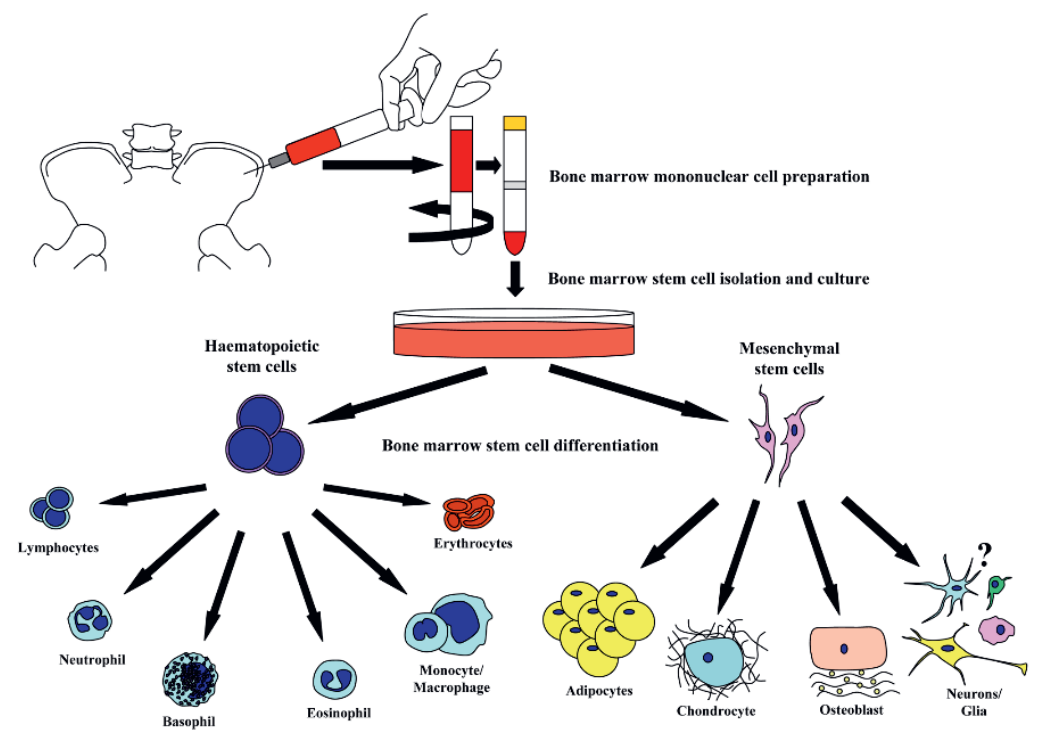

Figure 2 Overview of the trans-differentiation of adult stem cells (Wright et al. 2010 with permission)

Figure 2 gives an overview of the trans-differentiation of ASCs (Wright, El Masri et al. 2010). Both MSCs and HSCs are not only able to transdifferentiate into more specialized cells though, they also secrete all kind of proteins/factors, which are important in making the injured neighborhood more accessible for local repair mechanisms (Gnecchi, Zhang et al. 2008).

\section{Characterization of adult stem cells}

To characterize MSCs, the Tissue Stem Cell Committee of the International Society for Cellular Therapy defined a minimal set of criteria (Dominici, Le Blanc et al. 2006):

a) MSCs must be plastic-adherent when maintained in standard culture conditions.

b) MSCs must express the surface molecules CD105, CD73 and CD90, and lack expression of CD45, CD34, CD14 or CD11b, CD79a or CD19 and HLA-DR surface molecules.

c) Finally, in vitro, MSCs must be able to differentiate into osteoblasts, adipocytes and chondroblasts.

HSCs are defined by expression of the surfer molecule $\mathrm{CD}_{3} 4^{+}$, enabling to mark them in accordance with the guidelines defined by the International Society of Hematotherapy and Graft Engineering (ISHAGE) by flowcytometry with the glycosylated transmembrane protein CD34 (Keeney, Chin-Yee et al. 1998).

\section{Homing}

There is firm proof that ASCs, and especially MSCs, are capable to move towards injured or damaged(cardiac and/or nervous) tissue, a process called homing (Pittenger and Martin 2004). Here, stromal cell-derived factor 1 (SDF-1) presumably plays an important role as a chemotactic factor, attracting MSCs towards an injured site (Wragg, Mellad et al. 2008). Homing into neural 
tissue, though, is limited by the blood-brain barrier, which prevents stem cells to penetrate into brain tissue (Stamatovic, Keep et al. 2008).Even in case of a defect blood-brain barrier (for instance caused by an inflammatory process), there is a limited passage from intravenously administrated stem cells through this barrier. In such case, out of 50,000 stem cells administered intravenously, only 4,000 (8\%) could be traced in the region of the lesion within the central nervous system (Jackson, Golding et al. 2010).

\section{Cell differentiation}

As an organism matures, stem cells are usually downregulated and only express an epigenetic profile in which they lose their pluripotency. Both in vitro and in vivo studies, however, showed that ASCs under certain conditions are still able to differentiate into neural cells. So, MSCs were efficiently transduced into functional neuronal cells producing action potentials, by transfection of the notch intracellular domain (NICD) in the presence of basic fibroblast growth factor (bFGF), ciliary neurotrophic factor (CNTF) and forskolin (FSK) (Dezawa, Kanno et al. 2004). Under influence of a combination of Edaravone (a free radical scavenger), epidermal growth factor (EGF) and bFGF, human MSCs also did differentiate into functional neurons (Zeng, Wang et al. 2011). In vivo, axonal growth with functional recovery is reported in Sprague-Dawley rats with a right subtotal cervical hemisection, treated with cultivated MSCs, but not in the placebo gelfoam-treated animals (Neuhuber, Timothy Himes et al. 2005). Also, in a rodent stroke model, transplantation with both human MSCs and human MSC-derived neural cells induced recovery of neurological function without cell fusion (Xu, Miki et al. 2010).

In vitro experiments suggested that the intrathecal administration of stem cells directly into the cerebrospinal fluid might speed up the development of neural like cells (Ye, Zeng et al. 2011).

\section{Expanding capabilities}

As mentioned before, stem cells are able to reproduce themselves indefinitely, making these cells particularly interesting for culturing. Especially embryonic cells can be cultured indefinitely for many years. ASCs can also be expanded in culture, but the number of successful passages is rather limited. This limited replicative capacity is known as the "Hayflick limit", presumably the result of chromosomal telomere shortening after each cell division. There is a significant difference in maximal life span of bone marrow-derived stem cells of young donors (41 population doublings) compared to elderly donors (24 population doublings) (Stenderup, Justesen et al. 2003). Reproducibility, though, is only one aspect of expanding activities. Another aspect is the differentiation into different target cells. Aging has a negative effect on the plasticity of autologous ASCs, thereby limiting their application in the treatment of age-related diseases (Asumda and Chase 2011). Also, chronic diseases such as diabetes (Dimmeler and Leri 2008), Amyotrophic lateral sclerosis (Cho, Noh et al. 2010), or renal failure are known to reduce the angiogenic potency of stem cells, thereby further limiting the use of autologous stem cells to treat chronic diseases (Li, Kubo et al. 2010).

\section{Immune modulation}

By secreting various immune regulatory factors, stem cells, and especially MSCs, may influence the immune response. Pending their production and secretion of interferon- $\gamma$ (IFN- $\nu$ ), by 
modulating inflammation, MSCs might both enhance (low concentration of IFN- $\gamma$ ) and inhibit (high concentration IFN- $\gamma$ ) immune responses (Chan, Tang et al. 2006). Moreover, MSCs also influence the functioning of B-Cells, T-Cells and NK (natural killer)-cells (Aggarwal and Pittenger 2005). Although it is assumed that MSCs in contact with T-cells influence the Stat5-

phosphorylation by producing nitric oxide, thereby inhibiting T-cell proliferation (and T-cell mediated destruction of human stem cells in the same way as macrophages)(Sato, Ozaki et al. 2007), the underlying mechanism is still not fully elucidated.

\section{Trophic factors and growth factors}

Pending specific environmental circumstances, stem cells may act like a "cameleon", by producing and secreting a variety of trophic factors promoting neuroplasticity (neuroprotection and neuro-restoration) and/or differentiating into specialized cells. In acute (ischemic or inflammatory) conditions, the release of MSCs and HSCs primarily stimulates neuroprotection by the up-regulation of interleukin pathways (Li, Kubo et al. 2010) or the production of neuroprotective trophic factors, such as granulocyte macrophage colony stimulating factor (GMCSF), which prevent for apoptosis (Huang, Kim et al. 2009). In more chronic conditions, though, the same cells mainly promote axonal outgrowth, re-myelination and neo-angiogenesis.

For instance, in experimental chronic spinal cord lesions, both MSC (in rat) and HSC (in mice) transplants stimulate the production of an array of neurotrophic factors by astrocytes, promoting the myelinating activity of oligodendrocytes, thus contributing to their functional recovery (Koshizuka, Okada et al. 2004). In stable environmental conditions, stem cells thus rather stimulate neuro-restoration (Wright, El Masri et al. 2010). Indeed, bone marrow-derived stem cells are capable of producing (direct or indirect) chemotrophins relevant for neurorestoration, including brain-derived neurotrophic factor (BDNF), nerve growth factor (NGF), vascular endothelial growth factor (VEGF), transforming growth factor- $\beta$ (TGF- $\beta$ ), insulin-like growth factor 1 (IGF1), brain natriuretic peptide (BNP), neurotrophin 3 (NT-3), and stem cell factor 1 (SCF1) (Crigler, Robey et al. 2006). Illustrating the direct relationship between axonal growth and the secretion of these neurotrophic factors, the growth of axons promoted by neural progenitor cells was significantly suppressed when BDNF, NT-3 and NGF were neutralized (Kamei, Tanaka et al. 2007). The stem cell-derived production and secretion of chemotrophins, thus, might explain the regeneration and functional restoration as shown in experimental animal spinal cord injury (Shi, Kazui et al. 2007) and stroke models (Taguchi, Soma et al. 2004). The effect of neuroprotection initiated by MSCs is also illustrated in Table 2 presenting an overview of preclinical studies concerning multiple sclerosis (Zappia, Casazza et al. 2005, Zhang, Li et al. 2005, Gerdoni, Gallo et al. 2007, Kassis, Grigoriadis et al. 2008), Parkinson's disease (Bouchez, Sensebe et al. 2008, Levy, Bahat-Stroomza et al. 2008) and Amyotrophic Lateral Sclerosis (Zhang, Zhou et al. 2009, Forostyak, Jendelova et al. 2011).

In a dog model with spinal cord injury, both autologous and allogenic MSCs were administered intrathecally by lumbar puncture, and the outcome was compared with placebo-treated dogs. Stem cell-treated dogs did significantly better as placebo-treated dogs, and, interestingly, the effects in dogs treated with autologous cells were significantly better as in those treated with allogenic cells (Jung, Ha et al. 2009). 


\section{Table 2}

Placebo-controlled animal studies with allogenic expanded bone marrow-derived stem cells

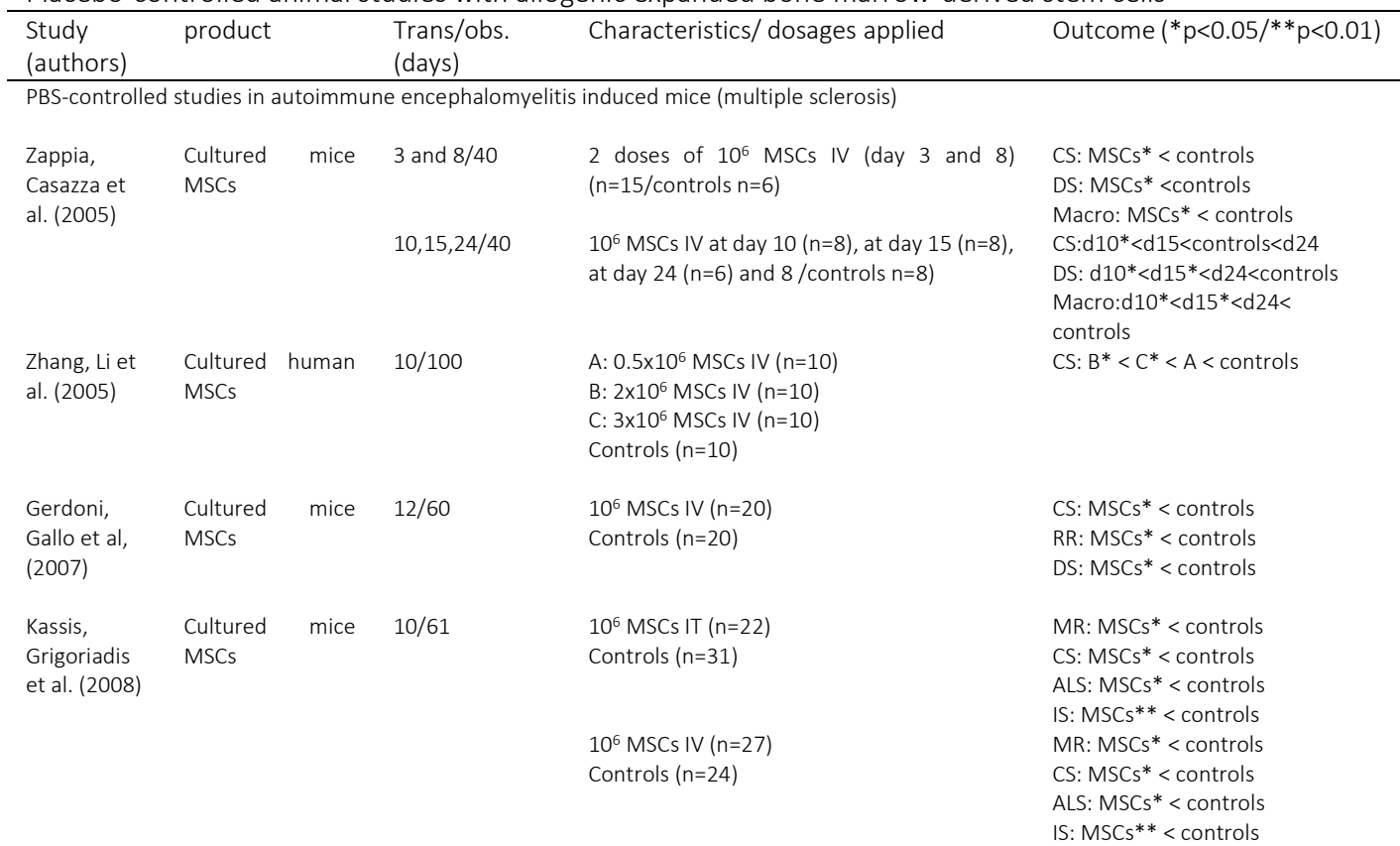

PBS-controlled studies in 6-OHDA lesioned parkinsonistic rats (Parkinson's disease)

\begin{tabular}{|c|c|c|c|c|}
\hline $\begin{array}{l}\text { Bouchez, } \\
\text { Sensebe et } \\
\text { al. (2008) }\end{array}$ & $\begin{array}{l}\text { Cultured rat } \\
\text { MSCs }\end{array}$ & $14 / 35$ & $\begin{array}{l}0.18 \times 10^{6} \text { MSCs IP }(n=7) \\
\text { Controls }(n=7)\end{array}$ & RB: MSCs* < controls \\
\hline $\begin{array}{l}\text { Levy, Bahat- } \\
\text { Stroomza et } \\
\text { al. (2008) }\end{array}$ & $\begin{array}{l}\text { Cultured } \\
\text { human MSCs }\end{array}$ & $35 / 125$ & $\begin{array}{l}\text { A: } 0.5 \times 10^{6} \text { hMSCs IP }(n=7) \\
\text { B: } 0.5 \times 10^{6} \text { hhMSCs IP }(n=7) \\
\text { Controls }(n=7)\end{array}$ & RB: $\mathrm{B}^{*}<\mathrm{A}<$ controls \\
\hline \multicolumn{5}{|c|}{ PBS-controlled studies in SOD-1 expressing rodents (amyotrophic lateral sclerosis) } \\
\hline $\begin{array}{l}\text { Zhang, Zhou } \\
\text { et al. (2009) }\end{array}$ & $\begin{array}{l}\text { Cultured } \\
\text { human MSCs }\end{array}$ & $\begin{array}{l}56 / \text { variable } \\
\text { survival }\end{array}$ & $\begin{array}{l}0.5 \times 10^{6} \text { hMSCS IT }(n=22) \\
\text { Controls }(n=21) \\
\left.3 \text { doses of } 0.5 \times 10^{6} \text { hMSCs IT (day } 56,70 \text { and } 94\right) \\
(n=21) \\
\text { Controls }(n=20)\end{array}$ & $\begin{array}{l}\text { MOD: MSCs = controls } \\
\text { MS: MSCs = controls } \\
\text { MNC: MSCs > controls } \\
\text { MOD: MSCs* > controls } \\
\text { MS: MSCs** > controls } \\
\text { MNC: } M S C s^{* *}>\text { controls }\end{array}$ \\
\hline $\begin{array}{l}\text { Forostyak, } \\
\text { Jendelova } \\
\text { et al. (2011) }\end{array}$ & $\begin{array}{l}\text { Cultured rat } \\
\text { MSCs }\end{array}$ & $\begin{array}{l}\text { 112/variable } \\
\text { survival }\end{array}$ & $\begin{array}{l}0.1 \times 10^{6} \text { MSCs IT }+2 \times 10^{6} \text { MSCs IV }(n=9) \\
\text { Controls }(n=8)\end{array}$ & $\begin{array}{l}\text { MS: MSCs* > controls } \\
\text { MF: MSCs* > controls } \\
\text { MNC: } \text { MSCs* }^{*} \text { controls }\end{array}$ \\
\hline
\end{tabular}

ALS axonal loss score, CS clinical score, DS demyelination score, hMSC human mesenchymal stem cell, IP intraparenchymal, IS infiltration score, IT intrathecal, IV intravenous, Macro macrophages cells $/ \mathrm{mm}^{2}$, MS mean survival days, MF motor function, MSCs mesenchymal stem cells, MNC motor neuron counts, MOD mean onset disease in days, $n h M S C$ neural human mesenchymal stem cells, PBS phosphate buffered saline, $R B$ rotational behavior, $R R$ relapse rate, SOD-1 superoxide dismutase 1, 6-OHDA 6-hydroxydopamine.

\section{Safety}

As of yet, the clinical application of autologous ASCs, for instance in leukemia patients, has been found to be relatively safe (Holowiecki 2008). In allogenic embryonic, umbilical cord or ASCs, 
though, there is the problem of immunogenicity, which has to be addressed by the concomitant application of immune suppressive drugs to prevent rejection after application. Mainly due to their increased tumor risk, the application of allogenic embryonic as well as induced pluriform stem cells seems not advantageous (Lee, Tang et al. 2009).

\section{Clinical application of autologous adult stem cells in neurological disorders}

Autologous bone marrow-derived ASCs are easy to harvest and to concentrate (with cell separators) in a closed system for point of care treatment and are considered relatively safe. As the development of ASCs is reported multifactorial, being especially age- and diseasedependent, as a rule, the application of fresh autologous bone marrow-derived cells in otherwise healthy younger patients seems the most promising (Li, Zhu et al. 2010, Asumda and Chase 2011). As of yet, there is only consensus about the human clinical application of autologous ASCs in leukemia. However, compelling evidence of effective therapeutic application of these cells in both humans and experimental animals, suffering clinical end stages of ischemic limbs (Van Tongeren, Hamming et al. 2008) and/or myocardial infarctions (Assmus, Rolf et al. 2010), will expand clinical indications for human application in the next future.

It is attractive, though, to also consider the application of autologous ASCs in the treatment of a limited number of neurological conditions such as traumatic spinal cord and/or brain injuries, with no therapeutic options at all (Sekhon and Fehlings 2001), as these conditions often occur in younger patients, without chronic diseases limiting the plasticity of autologous stem cells, with a dramatically impaired life expectancy (Wyndaele and Wyndaele 2006). So far, the application of stem cells in experimental animal models with lesions of the central nervous system, although very encouraging (Samdani, Paul et al. 2009), did not establish convincing evidence for clinical effectivity. Those experiments are hampered though by both, the intravasal, and not intrathecal, application of stem cells, and the use of allogenic, human, and thus not autologous, ASCs.

Indeed, most experimental animals do not allow for intrathecal application of stem cells, although in lesions of the central nervous system, it is considered essential to apply these cells in the most adequate (neuronal) environment, as close as possible to the lesion. In such conditions, the intrathecal administration of these cells directly into the cerebrospinal fluid is supposed to speed up cell differentiation as well as the secretion of relevant neurotrophic factors. Earlier experiments in spinal cord injured dogs, treated with both autologous and allogenic ASCs, also confirmed the superiority of the application of autologous to allogenic stem cells. Unfortunately, however, most animals do not allow to function as both donor and recipient of (their own) ASCs. Considering that the proof of concept of the therapeutic effects of autologous ASCs in spinal cord and brain injured experimental animals has their limitations (Courtine, Bunge et al. 2007); in our opinion, the time is right to start carefully developed doubleblind studies in patients suffering no-therapeutic-option spinal cord and/or brain injuries, with autologous ASCs in the context of good defined clinical trials. The intrathecal administration of autologous stem cells by lumbar puncture in humans is considered a safe and minimal invasive procedure (Bakshi, Barshinger et al. 2006), and in 297 patients with spinal cord injury treated with intrathecal application of autologous stem cells, no side effects were reported (Kumar, Kumar et al. 2009). 


\title{
2.2. Autologous adult stem cells in ischemic and traumatic CNS disorders
}

de Munter JPJM, Wolters ECh (2013) J Neural Transm 120:91-102

\begin{abstract}
Ischemic and traumatic insults of the central nervous system both result in definite chronic disability, only to some extent responsive to rehabilitation. Recently, the application of autologous stem cells (fresh bone marrow-derived mononuclear cells including mesenchymal and hematopoietic stem cells) was suggested to provide a strategy to further improve neurological recovery in these disorders. During the acute phase, stem cells act mainly by neuroprotection with prevention of apoptosis, whereas during the chronic situation they provide neuro-restoration by trans-differentiation and/or the secretion of neurotrophic factors. To reach these goals, in the acute phase, stem cells (10 million mononuclear cells per kg body weight) might be best applied intravenously, as during the first 7 days after the lesion, the blood-brain barrier permits passage of cells from the blood into the brain or the spinal cord. In the more chronic situation, though, those cells might be applied best intrathecally by lumbar puncture. Based on the reported results so far, it seems justified to develop well designed clinical doubleblind trials in chronic spinal cord injury and ischemic stroke patients, as efficacy and safety concerns might not be answered by preclinical studies.
\end{abstract}

\section{Introduction}

Ischemic and traumatic insults of the central nervous system (CNS) both result in definite chronic disability with an impaired life expectancy (Strauss, Devivo et al. 2006)only to some extent responsive to rehabilitation in order to limit disability and to prevent complications.

Worldwide, age standardized prevalence for stroke in people aged 65 years or more ranges from 46 to 73/1,000 (Feigin, Lawes et al. 2003), and prevalence for spinal cord injury is estimated at 22-36.5/100,000 (Knutsdottir 1993, Hagen, Eide et al. 2010). Up to date, the management in stroke patients is based on intra-arterial thrombolysis with a minimal 'stroke to needle' time to limit ischemic necrosis (Novakovic, Toth et al. 2009), rehabilitation and prevention of reinfarction of the brain (Broussalis, Killer et al. 2011).

The management of patients with a spinal cord injury focuses on rehabilitation to secure as much as possible functions of the upper and lower extremities and to prevent complications including bowel and bladder dysfunctions, venous thrombosis, pathological autonomic reflexes and decubitus (Gupta, Bathen et al. 2010). Of course, in both conditions, also psychological help is needed to improve coping and reduce suicide (Hagen, Lie et al. 2010). As of yet, for both conditions, the transplantation of stem cells is suggested to be very promising (Park, Eve et al. 2010), as those cells are able to influence the direct environment of damaged neural cells by secreting trophic factors (Caplan and Dennis 2006), as well as to penetrate glial scar tissue (Huang, Kim et al. 2009), transdifferentiate into functional neurons (Zeng, Wang et al. 2011) and promote synaptic connections (Bareyre 2008). Bone marrow hosts heterogeneous populations of hematopoietic and non-hematopoietic stem cells suggested to constitute thus a source of 
repair mechanisms, probably by promoting neuroplasticity (Kucia, Reca et al. 2005). In this article, the results of preclinical and clinical trials applying fresh, not expanded, adult stem cells in spinal cord injury and ischemic stroke will be reviewed and discussed to motivate new, adequate clinical trials in patients suffering these debilitating conditions.

\section{Stem cells}

Adult stem cells (ASC), especially hematopoietic (HSCs) and mesenchymal stem cells (MSCs), are pluripotent cells located throughout the body, mainly in the bone marrow (Junker, Sommar et al. 2010). Those cells are able to secrete all kind of factors, which influence the direct environment of injured cells (Gnecchi, Zhang et al. 2008). For instance, in ischemic conditions, both MSCs and HSCs thus may stimulate neovascularization and increase oxygenation (Zhang, Zhang et al. 2008). As these cells also have the possibility of transdifferentiating into specific (neuronal) cells, in theory they are also able to replace damaged neural tissues (Zeng, Wang et al. 2011). These specific properties suggested the use of ASC in the treatment of otherwise notreatment-option conditions such as spinal cord or brain injury and ischemic stroke (Zietlow, Lane et al. 2008). The therapeutic application of autologous, minimally manipulated stem cells was not only found helpful in the treatment of chronic conditions, but also offered significant benefits in the acute phase of these conditions (Leistner, Fischer-Rasokat et al. 2011). Autologous adult stem cells are easy to harvest from the iliac crest of a patient. After collection, gradient centrifugation is used to separate the buffy coat layer, which contains the highest concentration of HSCs and MSCs. The thus conceived product is suitable for intravascular/intravenous reapplication into the patient. As a rule, this minimally manipulative procedure is used for hematopoietic reconstitution in case of total eradication of the bone marrow in the treatment of leukemia.

\section{Preclinical studies}

\section{Traumatic spinal cord injury}

As seen in Table 1, only in one out of five reported studies (Inoue, Honmou et al. 2003), autologous bone marrow-derived mononuclear cells (BMMNs) were used to investigate the clinical effects of MSCs and HSCs in animal models with a standardized spinal cord compression injury. Spinal cord compression, in these studies, was induced by weight drop (Basso, Beattie et al. 1996) or balloon compression (Vanicky, Urdzikova et al. 2001). In the other studies, allogenic BMMNs were applied. However, in a comparative study with allogenic and autologous MSCs in a dog spinal cord injury model, the best clinical outcome was observed with autologous cells (Jung, Ha et al. 2009). So, we cannot rule out that the results with allogenic cells are hampered by the eventual negative effects of immune suppression and/or by the fact that the donor cells have a different genetic origin. Nevertheless, but for one study (Carvalho, Vialle et al. 2008), presumably due to the very traumatic procedure of administration of these cells and the short term (10 days) of follow-up, significant neurological recovery was established in the four other reported studies with both autologous and allogenic HSCs and/or MSCs as compared to placebo, irrespective of the method of application (intravenous, intrathecal and/or intraparenchymal). Neurological functions were measured by the standardized Basso Beattie Bresnahan Score 
(Basso, Beattie et al. 1995) or the hindlimb motor scores. Although in one study, 5 weeks after transplantation, immunohistochemistry did reveal surviving HSCs in the spinal cord tissue, expressing specific markers for oligodendrocytes, astrocytes and neural precursors (Koshizuka, Okada et al. 2004), as of yet, the presence of stem cell derived functional neurons has not been established (Urdzikova, Jendelova et al. 2006). In the animal groups, MSC and/or HSC transplants significantly increased the volume of the intact white matter, but not for the animal groups treated with granulocyte colony stimulating factor (G-CSF). G-CSF, also known as colony stimulating factor 3 (CSF-3) and commercially available as recombinant human G-CSF (Thomas, Liu et al. 2002), stimulates the production and release of granulocytes and stem cells by the bone marrow. In the animal study, G-CSF was used to prevent neural cell apoptosis (Pitzer, Klussmann et al. 2010). It is questionable if observed neurological recoveries in these studies share the same mechanisms of action. In an acute rat model, in which stem cells were applied within $24 \mathrm{~h}$ after the lesion (Yoshihara, Ohta et al. 2007), a significant higher level of hepatocyte growth factor (HGF), a significant lower level of tumor necrotic factor- $\alpha$ (TNF- $\alpha$ ), a significant lower number of TUNEL-positive cells and a significant higher density of nerve fibers as compared to controls were established, suggesting a neuroprotective effect with prevention of apoptosis. In other studies, in which stem cells were applied 7 days after the lesion, neuro-restoration might have played a major role. As in most of the studies, stem cells were applied in a rather acute situation, and we cannot rule out that eventual lesions of the blood-brain(cord) barrier influenced the reported outcome in intravenously applied cells. However, a substantial part of thus applied cells will be trapped in the lungs and the liver and might not reach the arteries supplying the spinal cord (Fischer, Harting et al. 2009). Looking at the different routes of administration used in the presented animal models, intrathecal administration into the cerebrospinal fluid seems the most favorable way of application, especially in the more chronic cases ([7 days) where the bloodbrain(cord) barrier supposedly is functioning normal again.

\section{Table 1}

Placebo-controlled animal studies with autologous/allogenic fresh bone marrow-derived cells

\begin{tabular}{|c|c|c|c|c|c|}
\hline $\begin{array}{l}\text { Study } \\
\text { (references) }\end{array}$ & Product & $\begin{array}{l}\text { Trans/ } \\
\text { obs (d) }\end{array}$ & SCl study model & $\begin{array}{l}\text { Characteristics/ } \\
\text { dosages applied }\end{array}$ & Outcome $\left({ }^{*} p<0.05\right)$ \\
\hline \multicolumn{6}{|c|}{ Traumatic spinal cord injury models } \\
\hline \multirow[t]{2}{*}{$\begin{array}{l}\text { Female Wistar rats } \\
\text { (inoue, Honmou et } \\
\text { al. 2003) }\end{array}$} & $\begin{array}{l}\text { BMMN: MSC- } \\
\text { HSC autolog }\end{array}$ & $3 / 21$ & Demyelinating L1 & $\begin{array}{l}\text { IV: } 1 \mathrm{ml} \text { medium } \\
1 \times 10^{4} / 1 \times 10^{5} / 1 \times 10^{6} \\
/ 1 \times 10^{7} \text { BMMN cells }\end{array}$ & $\begin{array}{l}\text { Remyelination* with IV doses } \\
>1 \times 10^{6} \text { BMMN's }\end{array}$ \\
\hline & & & & $\begin{array}{l}\text { IP: } 1 \mu \text { medium } 1 \times 10^{2} / 1 \times 10^{3} / \\
1 \times 10^{4} / 1 \times 10^{5} \text { BMMN cells }\end{array}$ & $\begin{array}{l}\text { Remyelination* with IP doses } \\
>1 \times 10^{4} \text { BMMN's }\end{array}$ \\
\hline $\begin{array}{l}\text { Adult female } \\
\text { C57BI/6J mice } \\
\text { (Koshizuka. 2004) }\end{array}$ & $\begin{array}{l}\text { BMMN: HSC } \\
\text { allogenic }\end{array}$ & $7 / 42$ & $\begin{array}{l}\text { Compression T7-8 } \\
(20 \mathrm{~g} / 5 \mathrm{~min})\end{array}$ & IP: $3 \times 10^{4} \mathrm{HSCS}$ & $\begin{array}{l}\text { Hind limb score: } 4.2^{*} \\
\text { (C: } 2.9) \text { / expression neural lineage } \\
\text { cells }\end{array}$ \\
\hline $\begin{array}{l}\text { Male Wistar rats } \\
\text { (Urdzikova, et al. } \\
2006\end{array}$ & $\begin{array}{l}\text { BMMN: MSC- } \\
\text { HSC exp.MSC } \\
\text { G-CSF allogenic }\end{array}$ & $7 / 35$ & $\begin{array}{l}\text { Compression T10 } \\
\text { (balloon } / 5 \mathrm{~min} \text { ) }\end{array}$ & $\begin{array}{l}\text { IV: } 2 \times 10^{6} \text { expand.MSC } \\
\text { IV: } 2 \times 10^{6} \text { BMMN cells } \\
\text { SC: } 5 \text { days G-CSF }\end{array}$ & $\begin{array}{l}\text { BBB score } 10-12 * \text { (C: 7-9) } \\
\text { BBB score 10-12* (C: 7-9) } \\
\text { BBB score 10-12* (C: 7-9) }\end{array}$ \\
\hline $\begin{array}{l}\text { Male Wistar rats } \\
\text { (Yoshihara, Ohta }\end{array}$ & $\begin{array}{l}\text { BMMN: MSC- } \\
\text { HSC allogenic }\end{array}$ & $1 / 35$ & $\begin{array}{l}\text { Compression T8-9 } \\
(10 \mathrm{~g} / 12.5 \mathrm{~mm})\end{array}$ & $\begin{array}{l}\text { Intraventricular }\left(4^{\text {th }}\right): 5 \times 10^{6} \\
\text { BMMN cells }\end{array}$ & $\begin{array}{l}\left.\text { BBB score } 15.5^{*} \text { (C: } 10\right) \\
\text { Reduction* of cavity at site injury }\end{array}$ \\
\hline
\end{tabular}


Table 1 continued

\begin{tabular}{|c|c|c|c|c|c|}
\hline $\begin{array}{l}\text { Study } \\
\text { (references) }\end{array}$ & Product & $\begin{array}{l}\text { Trans/ } \\
\text { obs (d) }\end{array}$ & $\mathrm{SCl}$ study model & $\begin{array}{l}\text { Characteristics/ } \\
\text { dosages applied }\end{array}$ & Outcome $\left({ }^{*} p<0.05\right)$ \\
\hline \multicolumn{6}{|c|}{ Traumatic spinal cord injury models } \\
\hline $\begin{array}{l}\text { Male Wistar rats } \\
\text { (Carvalho, Vialle et } \\
\text { al. 2007) }\end{array}$ & $\begin{array}{l}\text { BMMN: } \\
\text { MSC-HSC } \\
\text { allogenic }\end{array}$ & $14 / 24$ & $\begin{array}{l}\text { Compression T9-10 } \\
(10 \mathrm{~g} / 12.5 \mathrm{~mm})\end{array}$ & IP): $5 \times 10^{5}$ BMMN cells & Increased BBB score 7\% (C: 4.5\%) \\
\hline \multicolumn{6}{|c|}{ Ischemic brain injury models } \\
\hline $\begin{array}{l}\text { Long Evans rats } \\
\text { (Brenneman et al. } \\
\text { 2010) }\end{array}$ & $\begin{array}{l}\text { BMMN: } \\
\text { MSC-HSC } \\
\text { autolog }\end{array}$ & $24 \mathrm{~h} / 30$ & $\begin{array}{l}180 \text { min occlusion } \\
\text { MCA+CCA }\end{array}$ & $\begin{array}{l}3 \text { months old rats } \mathrm{CA}: 1 \times 10^{7} \\
\text { BMMN cells }\end{array}$ & $\begin{array}{l}\text { Cylinder test asymmetry } 2 \% * \text { (C: } \\
48 \%) \\
\text { Corner } 50 \pm 6 \% \text { (C: } 90 \pm 5 \%) \\
\text { Reduced infarct volumes* }\end{array}$ \\
\hline $\begin{array}{l}\text { Male Sprague- } \\
\text { Dawley rats } \\
\text { (lihoshi, Honmou } \\
\text { et al. 2004) }\end{array}$ & $\begin{array}{l}\text { BMMN: } \\
\text { MSC-HSC } \\
\text { autolog }\end{array}$ & $3-72 h / 14$ & $\begin{array}{l}45 \text { min occlusion } \\
\text { MCA }\end{array}$ & $\begin{array}{l}\text { IV: } 1 \times 10^{7} \text { BMMN cells } \\
\text { at } 3 \mathrm{~h} \\
\text { At } 6 \mathrm{~h} \\
\text { At } 12 \mathrm{~h} \\
\text { At } 24 \mathrm{~h} \\
\text { At } 72 \mathrm{~h}\end{array}$ & $\begin{array}{l}\left.\text { Minimal (C: } 258 \pm 55 \mathrm{~mm}^{3}\right) \\
40 \pm 28 \mathrm{~mm}^{3}\left(\mathrm{C}: 258 \pm 55 \mathrm{~mm}^{3}\right) \\
80 \pm 25 \mathrm{~mm}^{3}\left(\mathrm{C}: 258 \pm 55 \mathrm{~mm}^{3}\right) \\
140 \pm 18 \mathrm{~mm}^{3}\left(\mathrm{C}: 258 \pm 55 \mathrm{~mm}^{3}\right) \\
180 \pm 22 \mathrm{~mm}^{3}\left(\mathrm{C}: 258 \pm 55 \mathrm{~mm}^{3}\right) \\
\text { All: improved morris water maze* } \\
\text { All: improved treadmill tests* }\end{array}$ \\
\hline $\begin{array}{l}\text { Male Albino } \\
\text { Wistar rats } \\
\text { (Giraldi-Guimaraes } \\
\text { et al. 2009) }\end{array}$ & $\begin{array}{l}\text { BMMN: } \\
\text { MSC-HSC } \\
\text { allogenic }\end{array}$ & $24 \mathrm{~h} / 28 \mathrm{of}$ & $\begin{array}{l}\text { Thermo-coagulation } \\
\text { of blood vessels of } \\
\text { the sensorimotor } \\
\text { cortex }\end{array}$ & IV: $3 \times 10^{7}$ BMMN cells & $\begin{array}{l}\text { Cylinder test asymmetry } 8 \% * \text { (C: } \\
42 \% \text { ) } \\
\text { Reduced number of degenerating } \\
\text { neurons* }\end{array}$ \\
\hline $\begin{array}{l}\text { Male Sprague- } \\
\text { Dawley rats (Shyu, } \\
\text { Lin et al. 2006) }\end{array}$ & $\begin{array}{l}\text { PBMN: HSC } \\
\text { autolog }\end{array}$ & $168 \mathrm{~h} / 35$ & $\begin{array}{l}\text { Occlusion of the } \\
\text { right MCA + bilateral } \\
\text { CCA }\end{array}$ & IV: $2 \times 10^{5} \mathrm{HSCS}$ & $\begin{array}{l}\text { Reduction body asymmetry* } \\
\text { Improved grip strength } 1.63^{*} \\
\text { (C:0.61)/Increased penumbric } \\
\text { neovascularization* } \\
\text { Increased expression trophic } \\
\text { factors*: (SDF-1, BDNF, GDNF, } \\
\text { NGF,and VEGF) }\end{array}$ \\
\hline $\begin{array}{l}\text { Male Sprague- } \\
\text { Dawley rats } \\
\text { (Kamiya, Ueda et } \\
\text { al. 2008) }\end{array}$ & $\begin{array}{l}\text { BMMN: } \\
\text { MSC-HSC } \\
\text { autolog }\end{array}$ & $1.5 \mathrm{~h} / 7$ & $\begin{array}{l}90 \text { min occlusion of } \\
\text { the left CCA, ECA } \\
\text { and ICA }\end{array}$ & $\begin{array}{l}\text { CA: } 1 \times 10^{7} \text { BMMN cells } \\
\text { IV: } 1 \times 10^{7} \text { BMMN cells }\end{array}$ & $\begin{array}{l}\text { Reduced infarct volumes } 70.7 \mathrm{~mm}^{3 *} \\
\left(\mathrm{C}: 140.6 \mathrm{~mm}^{3}\right) \\
\text { Improved Rotarod test* } \\
\text { Reduced infarct volumes } \\
\left.119.0 \mathrm{~mm}^{3 *} \text { (C: } 140.6 \mathrm{~mm}^{3}\right)\end{array}$ \\
\hline \multirow[t]{4}{*}{$\begin{array}{l}\text { Long Evans rats } \\
\text { (Yang, Strong et al. } \\
\text { 2011) }\end{array}$} & $\begin{array}{l}\text { BMMN: } \\
\text { MSC-HSC } \\
\text { autolog }\end{array}$ & $24 \mathrm{~h} / 28$ & $\begin{array}{l}180 \text { min occlusion } \\
\mathrm{MCA}+\mathrm{CCA}\end{array}$ & IV: $3.5 \times 10^{5}$ BMMN cells & $\begin{array}{l}\text { Cyl: } 30 \% \text { (C: } 38 \%) \\
\text { Corner: } 72 \% \text { (C: } 80 \%) \\
\text { No reduced infarct volume }\end{array}$ \\
\hline & & & & IV: $3.5 \times 10^{6}$ BMMN cells & $\begin{array}{l}\text { Cyl: } 18 \% *(C: 38 \%) \\
\text { Corner: } 62 \% *(\text { C: } 80 \%) \\
\text { Reduced infarct volume* }\end{array}$ \\
\hline & & & & IV: $10.5 \times 10^{6}$ BMMN cells & $\begin{array}{l}\text { Cyl: } 15 \% *(C: 38 \%) \\
\text { Corner: } 60 \% *(C: 80 \%) \\
\text { Reduced infarct volume* }\end{array}$ \\
\hline & & $24-168 / 28$ & $\begin{array}{l}180 \text { min occlusion } \\
M C A+C C A\end{array}$ & $\begin{array}{l}\text { IV: } 3.5 \times 10^{6} \text { BMMN cells } 24 \mathrm{~h} \\
\text { IV: } 3.5 \times 10^{6} \text { BMMN cells } 168 \mathrm{~h}\end{array}$ & $\begin{array}{l}\text { Cyl: 12\%* (C: 29\%) } \\
\text { Corner: 62\%* (C: 78\%) } \\
\text { Cyl: 31\% (C: 34\%) } \\
\text { Corner: } 76 \% \text { (C: } 78 \%)\end{array}$ \\
\hline
\end{tabular}

$B B B$ Basso,Beattie and Bresnahan Score, BDNF brain-derived neurotrophic factor, BMMN bone marrow-derived mononuclear, $C A$ carotid artery, $C C A$ common carotid artery, CSF cerebrospinal fluid, Cyl cylinder test asymmetry, ECA external carotid artery, G-CSF granulocyte colony stimulating factor, GDNF glial cell linederived neurotrophic factor, HSC hematopoietic stem cells, ICA internal carotid artery, IV intravenously, IP intra-parenchymal, MCA middle cerebral artery, MSC mesenchymal stem cells, NGF nerve growth factor, Obs observation, $P B M N$ peripheral blood-derived mononuclear cells, SC subcutaneous, SCI spinal cord injury, SDF-1 stromal cell-derived factor 1, Trans transplantation, VEGF vascular endothelial growth factor. 


\section{Ischemic brain injury}

Table 1 gives an overview of animal studies with minimally manipulated autologous and/or allogenic stem cells in the treatment of ischemic brain injury, both in the acute and chronic phase. In all studies, except for one (Giraldi-Guimaraes, Rezende-Lima et al. 2009), autologous bone marrow and/or peripheral blood (Shyu, Lin et al. 2006) mononuclear cells were applied in a standardized reperfusion injury model (Aronowski, Strong et al. 1997). Within 7 days after the lesion, these cells were applied intravenously or intra-arterially into the artery supplying the lesioned side of the brain. Neurological outcome was screened with a battery of sensorimotor tests, sensitive to cortical damage, such as the cylinder test asymmetry, the asymmetry-corner test (Schallert, Fleming et al. 2000) and/or the treadmill and Morris water maze tests (Yonemori, Yamada et al. 1996).

The observation period was limited to 28 days after transplantation of the cells. All reported studies established (mostly) significant neurological improvements as compared to placebotreated animals. Best improvements were reached in the more acute models, probably by neuroprotection, as insinuated by the significant reduction of the necrotic brain area (lihoshi, Honmou et al. 2004), whereas less impressive improvements were established in the more chronic models, most probably by neuro-restoration with neovascularization, as evidenced by the increased vascular density in the penumbric area (Shyu, Lin et al. 2006).

In the acute phase, the direct application of cells in the arteries supplying the affected side of the brain seems superior to the intravenous route of application (Kamiya, Ueda et al. 2008). In this way, more cells reach the brain by escaping the lung and liver trap (Fischer, Harting et al. 2009). As in spinal cord lesions, in ischemic brain injuries for good results [107 BMMN cells per $\mathrm{kg}$ body weight had to be applied intravascularly (Yang, Strong et al. 2011). As a rule, the sooner stem cells were applied after the ischemic lesion, the better was the neurological outcome, and when applied 7 days after the lesion, in one study, no significant improvement in neurological outcome could be reached at all (Yang, Strong et al. 2011). In our opinion, both intravenous application and a short observation time may hamper results. Although immediately after the stroke there will be an increased permeability of the blood-brain barrier, permitting passive penetration of all kind of cells and trophic factors (Stamatovic, Keep et al. 2008), the actual passage of stem cells is still limited (Jackson, Golding et al. 2010). So, in the acute stage, intraarterial application of stem cells, and in the more chronic stage, the intrathecal administration of stem cells into the cerebrospinal fluid, flushing the brain, might give better results (Orito, Harada et al. 2010). In chronic stages of stroke, neovascularization seems not to play a major role anymore.

\section{Clinical studies}

\section{Traumatic spinal cord injury}

To translate preclinical results into clinical strategies, clinical trials are needed. Table 2a presents the results of eight rather small, open label clinical trials in patients with an acute or chronic spinal cord injury, treated with not expanded BMMN cells. As a rule, fresh autologous stem cells were applied; in one study (Deda, Inci et al. 2008), cells were frozen for a short period to enable transport. Yoon et al. (Yoon, Shim et al. 2007) also used granulocyte-macrophage stimulating factor (GM-CSF), supposedly providing long term protection of neural cells, inhibition of glial scar 
formation and stimulation of axonal regeneration by expression of brain-derived neurotrophic factor (BDNF) (Bouhy, Malgrange et al. 2006, Hayashi, Ohta et al. 2009). All studies established an increase in ASIA motor and sensory scores and there were no serious adverse events reported, related to the administration of mononuclear cells.

In the studies with acute spinal cord injuries, the cells were applied directly into the parenchyma and/or intravenously/intravascularly (Park, Shim et al. 2005, Sykova, Homola et al. 2006, Yoon, Shim et al. 2007, Geffner, Santacruz et al. 2008). In a more chronic situation, it seems more beneficial, however, to apply the cells directly intra-parenchymally (Chernykh, Stupak et al. 2007) or intrathecally (Kumar, Kumar et al. 2009, Kishk, Gabr et al. 2010) to pass through the bloodbrain(cord) barrier. A mild increase of neuropathic pain (in 4/12 patients) was reported in a small study with chronic ([8 weeks post injury) spinal cord injured patients (Yoon, Shim et al. 2007). This could not be reproduced though in a bigger cohort in a more chronic condition ([3 years post injury) where only 15 out of 297 patients noticed such increase (Kumar, Kumar et al. 2009). Three of the studies were performed with historical or matched controls: one study on acute spinal cord injuries (Yoon, Shim et al. 2007) and two on chronic spinal cord injuries, lasting for at least 3 years (Chernykh, Stupak et al. 2007, Kishk, Gabr et al. 2010). One of those studies in the chronic situation did establish significant clinical improvements expressed as an increase in mean ASIA motor and/or sensory score of about 9 and 12 points, respectively (Chernykh, Stupak et al. 2007). In this study, stem cells were applied both intra-parenchymally and intravenously. In the other study, there was a small though not clinically relevant increase in the mean motor and sensory ASIA scores, 1 year after intrathecal application of stem cells by lumbar puncture, although $27.9 \%$ (12 out of 43 ) of the patients with a complete ASIA-A spinal cord lesion at baseline in that period changed into an incomplete spinal cord injury (11 patients into ASIA-B and 1 patient into ASIA-C) compared to only $10 \%$ in the controls (Kishk, Gabr et al. 2010). In literature, only $5.6 \%$ (31 out of 571) of patients with a complete spinal cord injury at 1 year changed at year 5 to an incomplete lesion without any intervention, rehabilitation not included (Kirshblum, Millis et al. 2004). In summary, the few small clinical trials so far seem to be promising by showing the feasibility of the application of mononuclear cells in the treatment of both acute and chronic spinal cord injured patients.

\section{Table 2a}

Human studies with fresh bone marrow-derived cells for neurological indications

\begin{tabular}{|c|c|c|c|c|}
\hline References & Product & Study & Treatment & Outcome $\left({ }^{*} p<0.05\right)$ \\
\hline \multicolumn{5}{|c|}{ Traumatic spinal cord injury } \\
\hline $\begin{array}{l}\text { Park, Shim } \\
\text { et al. (2005) }\end{array}$ & $\begin{array}{l}\text { BMMN MSC- } \\
\text { HSC autolog + } \\
\text { GM-CSF }\end{array}$ & $\begin{array}{l}\text { Open label study in } \\
\text { acute SCI AIS-A; } \\
\text { follow-up 6-18 } \\
\text { months }\end{array}$ & $\begin{array}{l}\text { Acute } \mathrm{SCl}(\mathrm{N}=6) \\
\text { IP: } 1.9 \times 10^{8} \mathrm{BMMN} \text { cells } \\
\text { SC: GM-CSF for } 5 \text { days for } 5 \\
\text { months }\end{array}$ & $\begin{array}{l}6 / 6 \text { improved }>5 \text { points in motor and } \\
\text { sensory ASIA scores } 4 / 6 \text { improved from AIS } \\
\text { A to } C 1 / 6 \text { improved from AIS A to B, no } \\
\text { serious adverse events }\end{array}$ \\
\hline \multirow[t]{2}{*}{$\begin{array}{l}\text { Sykova, Homola } \\
\text { et al. (2006) }\end{array}$} & $\begin{array}{l}\text { BMMN MSC- } \\
\text { HSC autolog }\end{array}$ & $\begin{array}{l}\text { Open label study in } \\
\text { acute (10-30 days post } \\
\text { injury) SCl; follow-up } 1 \\
\text { year }\end{array}$ & $\begin{array}{l}\text { IA: } 4 \text { patients received } \\
104.0 \pm 55.3 \times 10^{8} \text { BMMN cells } \\
\left(\mathrm{CD}^{+} 4^{+}: 89.7 \pm 70.7 \times 10^{6}\right)\end{array}$ & $\begin{array}{l}\text { 4/4 improved in motor and sensory scores; } \\
1 / 4 \text { changed from AIS B to D } \\
1 / 4 \text { from AIS A to } B \text {. }\end{array}$ \\
\hline & & & $\begin{array}{l}\text { IV: } 3 \text { patients received } \\
104.0 \pm 55.3 \times 10^{8} \text { BMMN cells } \\
\left(C D 34^{+}: 89.7 \pm 70.7 \times 10^{6}\right)\end{array}$ & $1 / 3$ improved in motor and sensory scores \\
\hline
\end{tabular}


Table 2a

continued

\begin{tabular}{|c|c|c|c|c|}
\hline References & Product & Study & Treatment & Outcome $\left({ }^{*} p<0.05\right)$ \\
\hline & & $\begin{array}{l}\text { Open label study in } \\
\text { chronic (2-17 } \\
\text { months post injury) } \\
\text { SCl; follow-up } 1 \text { year }\end{array}$ & $\begin{array}{l}\text { IA: } 2 \text { patients received } \\
104.0 \pm 55.3 \times 10^{8} \mathrm{BMMN} \text { cells } \\
\left(\mathrm{CD} 34^{+}: 89.7 \pm 70.7 \times 10^{6}\right) \\
\text { IV: } 10 \text { patients received } \\
104.0 \pm 55.3 \times 10^{8} \mathrm{BMMN} \text { cells } \\
\left(\mathrm{CD} 34^{+}: 89.7 \pm 70.7 \times 10^{6}\right)\end{array}$ & $\begin{array}{l}\text { 1/2 IA improved } 14 \text { points in ASIA motor } \\
\text { score } \\
\text { No improvements }\end{array}$ \\
\hline $\begin{array}{l}\text { Yoon, Shim } \\
\text { et al. (2007) }\end{array}$ & $\begin{array}{l}\text { BMMN MSC-HSC } \\
\text { autolog + GM- } \\
\text { CSF }\end{array}$ & $\begin{array}{l}\text { Open label study in } \\
\text { acute }(<2 \text { wks), sub- } \\
\text { acute }(2-8 \text { wks) and } \\
\text { chronic ( }>8 \text { wks) } \\
\text { AIS-A SCI with } \\
\text { matched controls; } \\
\text { follow-up }<10.4 \\
\text { months }\end{array}$ & $\begin{array}{l}\text { Subacute ( } \mathrm{N}=6) \\
\text { IP: } 1.9 \times 10^{8} \text { cells }+\mathrm{SC}: 5 \text { days } \\
\text { monthly GM-CSF for } 5 \text { months } \\
\text { Chronic SCI }(\mathrm{N}=12) \\
\text { IP: } 1.9 \times 10^{8} \text { cells }+\mathrm{SC}: 5 \text { days } \\
\text { monthly GM-CSF for } 5 \text { months } \\
\text { Controls }(\mathrm{N}=13)\end{array}$ & $\begin{array}{l}2 / 6 \text { changed from AIS } A \text { to } B / C \\
2 / 6 \text { reported neuropathic pain } \\
0 / 12 \text { changed from AIS } A \text { to } B / C \\
4 / 12 \text { reported neuropathic pain } \\
1 / 13 \text { changed from AIS } A \text { to } B / C \\
1 / 13 \text { reported neuropathic pain }\end{array}$ \\
\hline $\begin{array}{l}\text { Chernykh, } \\
\text { Stupak } \\
\text { et al. (2007) }\end{array}$ & $\begin{array}{l}\text { BMMN MSC-HSC } \\
\text { autolog }\end{array}$ & $\begin{array}{l}\text { Open label case } \\
\text { control study in } \\
\text { chronic ( } 36.4 \pm 7.9 \\
\text { months post injury) } \\
\text { cervical SCl; Follow- } \\
\text { up: } 9.4 \pm 4.6 \text { months }\end{array}$ & $\begin{array}{l}\text { Chronic } \mathrm{SCl}(\mathrm{N}=12) \\
\mathrm{IV}+\mathrm{CC} \text { : mean } 10.9 \times 10^{6} \text { cells } / \mathrm{ml}+ \\
\text { meningomyeloradiculysis }\end{array}$ & $\begin{array}{l}\text { ASIA mSc: } 22.2 \pm 3.5 \text { to } 31.0 \pm 3.2^{*} \text { ASIA } \\
\text { sSc: } 44.3 \pm 5.0 \text { to } 58.3 \pm 7.2^{*} \\
\text { Ashworth: } 3 \pm 0.12 \text { to } 2.37 \pm 0.16^{*} \\
\text { Change Bartel Scale: } 14.1 \pm 2.6^{*} \\
\text { ASIA mSc: } 19.6 \pm 0.84 \text { to } 21.7 \pm 0.8 \\
\text { ASIA sSc: } 53.0 \pm 7.0 \text { to } 58.3 \pm 7.2 \\
\text { Ashworth: } 3.1 \pm 0.12 \text { to } 2.60 \pm 0.18 \\
\text { Change Bartel Scale: } 5.60 \pm 0.63\end{array}$ \\
\hline $\begin{array}{l}\text { Deda, Inci } \\
\text { et al. (2008) }\end{array}$ & $\begin{array}{l}\text { BMMN MSC- } \\
\text { HSC autolog } \\
\text { (frozen) }\end{array}$ & $\begin{array}{l}\text { Open label study in } \\
\text { chronic (mean } 5.2 \\
\text { years) SCI AIS-A; } \\
\text { follow-up } 12 \\
\text { months }\end{array}$ & $\begin{array}{l}\text { Chronic } \mathrm{SCl}(\mathrm{N}=9) \\
\mathrm{IV}(1.5 \mathrm{ml}), \mathrm{S}(1.5 \mathrm{ml}) \text {, storage } \\
\text { foam }(3 \mathrm{ml}) \text { and IP }(0.1 \mathrm{ml})-35(21- \\
67) \times 10^{6} \mathrm{BMMN} \text { cells }\end{array}$ & $\begin{array}{l}7 / 9 \text { changed from AIS-A to AIS-C } \\
2 / 9 \text { changed from AIS-A to AIS-B } \\
9 / 9 \text { improved sensory functions } \\
\text { no adverse events reported. }\end{array}$ \\
\hline $\begin{array}{l}\text { Geffner, } \\
\text { Santacruz } \\
\text { et al. (2008) }\end{array}$ & $\begin{array}{l}\text { BMMN MSC- } \\
\text { HSC autolog }\end{array}$ & $\begin{array}{l}\text { Open label study in } \\
\text { acute (5-210 days } \\
\text { post injury) SCl; } \\
\text { follow-up } 24 \\
\text { months }\end{array}$ & $\begin{array}{l}\text { Acute } \mathrm{SCl}(\mathrm{N}=4) \\
\mathrm{IP}+\mathrm{IT}+\mathrm{IV}: 1.2 \times 10^{6} \mathrm{CD} 34^{+} / \mathrm{kg} \text { body } \\
\text { weight in } 80 \mathrm{ml} \text { suspension } \\
\text { Chronic } \mathrm{SCl}(\mathrm{N}=4) \\
\mathrm{IP}+\mathrm{IT}+\mathrm{IV}: 1.2 \times 10^{6} \mathrm{CD} 34^{+} / \mathrm{kg} \text { body } \\
\text { weight in } 80 \mathrm{ml} \text { suspension }\end{array}$ & $\begin{array}{l}1 / 4 \text { changed from AIS-A to AIS-C } \\
1 / 4 \text { changed from AIS-C to AIS-D } \\
1 / 4 \text { changed from AIS-A to AIS-C }\end{array}$ \\
\hline $\begin{array}{l}\text { Kumar, Kumar } \\
\text { et al. (2009) }\end{array}$ & $\begin{array}{l}\text { BMMN MSC-HSC } \\
\text { autolog }\end{array}$ & $\begin{array}{l}\text { Open label study in } \\
\text { chronic (mean } 2.61 \\
\text { years) } \mathrm{SCl} \text { with } \\
\text { retrospective } \\
\text { cohorts; follow-up } \\
21 \text { months }\end{array}$ & $\begin{array}{l}\text { Chronic SCI ( } \mathrm{N}=297) \\
\mathrm{IT}: \pm 3.77 \times 10^{8} \mathrm{BMMN} \text { cells (SD } \\
2.33 \times 10^{8} \text { ) of which } 3.98 \times 10^{6} \\
\left.\mathrm{CD} 34^{+} \text {cells (SD } 3.17 \times 10^{6}\right)\end{array}$ & $\begin{array}{l}97 / 297 \text { reported improvements in } \\
\text { sensory and motor scales; } 15 / 297 \\
\text { reported neuropathic pain; No adverse } \\
\text { events reported; Improvements } \\
\text { correlated to the number of CD34+ cells. }\end{array}$ \\
\hline $\begin{array}{l}\text { Kishk, Gabr } \\
\text { et al. (2010) }\end{array}$ & $\begin{array}{l}\text { BMMN MSC-HSC } \\
\text { autolog }\end{array}$ & $\begin{array}{l}\text { Open label study in } \\
\text { chronic (mean } \\
3.6 \pm 2.5 \text { years post } \\
\text { injury); Follow-up: } 1 \\
\text { year }\end{array}$ & $\begin{array}{l}\text { Chronic } \mathrm{SCl}(\mathrm{N}=43) \\
\text { IT: } 5-10 \times 10^{6} \mathrm{BMMN} \text { cells in monthly } \\
\text { intervals for } 6 \text { months + } \\
\text { rehabilitation }\end{array}$ & $\begin{array}{l}11 / 43 \text { changed from AIS A to B } \\
1 / 43 \text { changed from AIS-A to C } \\
\text { ASIA mSC from } 48.7 \pm 9.1 \text { to } 49.3 \pm 9.2 \\
\text { Improved bladder \& bowel functions } \\
1 \text { serious adverse event reported }\end{array}$ \\
\hline
\end{tabular}

Controls ( $\mathrm{N}=20$ ) only rehabilitation $\quad 2 / 20$ changed from AIS-A to AIS-B

BMMN bone marrow-derived mononuclear, CC cystic cavity, GCS Glasgow coma Scale, GM-CSF granulocyte macrophage colony stimulating factor, HSC hematopoietic stem cells, IA intra-arterial, IP intra-parenchymal, IT intra-thecal, IV intravenously, MCA middle cerebral artery, mSC ASIA motor score, MSC mesenchymal stem cells, NIHSS National Institutes of Health Stroke Scale, SA subarachnoid space, SC subcutaneous, SCI spinal cord injury, SA standard deviation, sSc ASIA sensory score. 
Table $2 b$

Human studies with fresh bone marrow-derived cells for neurological indications

\begin{tabular}{|c|c|c|c|c|}
\hline References & Product & Study & Treatment & Outcome $\left({ }^{*} p<0.05\right)$ \\
\hline \multicolumn{5}{|c|}{ Ischemic/traumatic brain injury } \\
\hline $\begin{array}{l}\text { Friedrich, } \\
\text { Martins } \\
\text { et al. (2012) }\end{array}$ & $\begin{array}{l}\text { BMMN MSC- } \\
\text { HSC autolog }\end{array}$ & $\begin{array}{l}\text { Open label study in } \\
\text { acute }(<7 \text { days }) \\
\text { mild/severe MCA } \\
\text { ischemic stroke; follow- } \\
\text { up } 6 \text { months }\end{array}$ & $\begin{array}{l}\text { Acute stroke }(\mathrm{N}=20) \\
\text { IA (affected } \mathrm{MCA}): 22.1(5.1-60) \times 10^{7} \\
\text { BMMN cells } / 15 \mathrm{ml}\end{array}$ & $\begin{array}{l}\text { Decrease* in median (mean) NIHSS: } 15.5 \\
\text { (17.05) at day } 0 \text { to } 7.5 \text { (9.9) at day } 180 . \\
\text { No reduction in infarct volume } \\
2 \text { deaths not related to the treatment } \\
\text { No serious adverse events reported }\end{array}$ \\
\hline $\begin{array}{l}\text { Savitz, Misra, } \\
\text { et al. (2011) }\end{array}$ & $\begin{array}{l}\text { BMMN MSC- } \\
\text { HSC autolog }\end{array}$ & $\begin{array}{l}\text { Open label study in acute } \\
\text { MCA ischemic stroke; } \\
\text { follow-up } 6 \text { months }\end{array}$ & $\begin{array}{l}\text { Acute stroke }(\mathrm{N}=10) \\
\text { IV: } 7-10 \times 10^{6} \mathrm{BMMN} \text { cells (with } 1.2- \\
4.3 \times 10^{5} \mathrm{CD} 34^{+} \text {cells } / \mathrm{kg} \text { body weight in } \\
30 \text { minutes) }\end{array}$ & $\begin{array}{l}\text { Decrease* in median NIHSS: } 13 \text { at day } 0 \text { to } \\
3 \text { at day } 180 \text {. } \\
10 / 10 \text { decreased } 1 \text { point in the modified } \\
\text { Ranking Scale } \\
7 / 10 \text { reached Barthel Index } \geq 90 \\
\text { No serious adverse events reported }\end{array}$ \\
\hline $\begin{array}{l}\text { Barbosa da } \\
\text { Fonseca et al. } \\
\text { (2010); } \\
\text { Battistella et al. } \\
\text { (2011) }\end{array}$ & $\begin{array}{l}\text { BMMN MSC- } \\
\text { HSC autolog } \\
\text { (Tc-99m } \\
\text { labelled) }\end{array}$ & $\begin{array}{l}\text { Open label study in } \\
\text { chronic ( } 59-82 \text { days) MCA } \\
\text { ischemic stroke; follow- } \\
\text { up } 6 \text { months }\end{array}$ & $\begin{array}{l}\text { Chronic stroke }(\mathrm{N}=6) \\
\text { IA (affected MCA): } 2.2 \times 10^{8}(1- \\
\left.5 \times 10^{8}\right) \text { BMMN cells in } 10 \mathrm{ml} \text { during } \\
10 \text { minutes. Cells labelled with } \\
\text { Technetium-99m }\end{array}$ & $\begin{array}{l}\text { Decrease* in mean) NIHSS: } 7.5 \text { at day } 0 \text { to } \\
5.8 \text { at day } 180 \text {. } \\
\text { No reported adverse events } \\
\text { Mean radioactive uptake cells as ratio of } \\
\text { brain/body } 1.68 \pm 1.71 \% \text { (range } 0.5-5.1 \% \text { ) }\end{array}$ \\
\hline
\end{tabular}

Traumatic brain Injury

\begin{tabular}{|c|c|c|c|c|}
\hline $\begin{array}{l}\text { Cox, } \\
\text { Baumgartner } \\
\text { et al. } \\
\text { (2011) }\end{array}$ & $\begin{array}{l}\text { BMMN MSC- } \\
\text { HSC autolog }\end{array}$ & $\begin{array}{l}\text { Open label study in } \\
\text { children with an acute } \\
\text { (<48 hours) severe (GCS } \\
5-8) \text { traumatic brain } \\
\text { injury; Follow-up } 6 \\
\text { months }\end{array}$ & $\begin{array}{l}\text { Acute traumatic brain injury }(\mathrm{N}=10) \\
\text { IV: } 6 \times 10^{6} \mathrm{BMMN} \text { cells } / \mathrm{kg} \text { body } \\
\text { weight }\end{array}$ & $\begin{array}{l}\text { Mean Glasgow Outcome Score expanded } \\
\text { for children changed from } 17.5 \pm 9.1 \text { to } \\
7.9 \pm 8.1^{*} \\
\text { No negative effects on hemodynamics } \\
\text { No death and no reported adverse events }\end{array}$ \\
\hline
\end{tabular}

BMMN bone marrow-derived mononuclear, CC cystic cavity, GCS Glasgow coma Scale, GM-CSF granulocyte macrophage colony stimulating factor, HSC hematopoietic stem cells, IA intra-arterial, IP intra-parenchymal, IT intra-thecal, IV intravenously, MCA middle cerebral artery, MSC mesenchymal stem cells, NIHSS National Institutes of Health Stroke Scale, SA subarachnoid space, SC subcutaneous, SCI spinal cord injury, SA standard deviation.

\section{Traumatic brain injury}

Table $2 \mathrm{~b}$ shows the results of an open label study with fresh BMMN cells in children with an acute $(<8 \mathrm{~h}$ ), severe (Glasgow Coma Score 5-8) traumatic brain injury. The authors reported a significant improvement in the mean Glasgow Outcome Score Expanded for Children (GOSEC) from 17.5 to 7.9 points after 6 months. None of the children died, and no serious adverse events were mentioned. The bone marrow collection in the acute phase of the brain injury did not cause hemodynamic disturbances and was well tolerated (Cox, Baumgartner et al. 2011)).

\section{Ischemic brain injury}

Table $2 \mathrm{~b}$ also represents the results of three open label clinical studies with application of fresh $B M M N$ cells in the treatment of ischemic brain injury. During those studies, without controls, no serious adverse events were reported. Clinical meaningful improvements were established in the National Institute of Health Stroke Scale (NIHSS) and the modified Rankin Scale (Kasner 2006). Mononuclear cells were administered intravenously (Savitz, Misra et al. 2011) or, in order to trespass the pulmonary trap, intra-arterially (Barbosa da Fonseca, Gutfilen et al. 2010, Battistella, de Freitas et al. 2011, Friedrich, Martins et al. 2011). In the acute setting (Friedrich, Martins et al. 2011, Savitz, Misra et al. 2011), after the application of stem cells within 7 days after the onset 
of the stroke, mean NIHSS decreased dramatically ([7 points). Compared to the normal behavior of an ischemic stroke involving the middle cerebral artery, this is a major reduction in neurological outcome (Adams, Davis et al. 1999). The change in outcome of six patients suffering a chronic ischemic condition after treatment with labeled mononuclear cells, though still clinically relevant, was more modest (Barbosa da Fonseca, Gutfilen et al. 2010, Battistella, de Freitas et al. 2011). A possible explanation here might be that in the chronic condition the restored blood-brain barrier only allows a small uptake of mononuclear cells in the brain, and/or that the poor validity of the NIHSS Score, when not measured in the first week after the onset of the stroke, only allows questionable results (Bruno, Saha et al. 2006).

\section{Discussion}

BMMN cells include mesenchymal and hematopoietic stem cells and all kind of leucocytes. HSCs constitute about $1 \%$ and MSCs about $0.01 \%$ of the total number of mononuclear cells (Pittenger and Martin 2004). Extrapolated from animal studies, for the intravenous or intraarterial treatment of acute spinal cord and/or brain lesions, $>107$ BMMN cells/kg body weight (Yang, Strong et al. 2011) is considered adequate. In humans, as a rule, at least 150-180 ml bone marrow aspirate (with a mean of about 50,000 CD34+ cells (HSC's)/ml) (de Munter and Wolters 2013), providing about 107 BMMN cells/kg body weight, might be collected without causing hemodynamic disturbances (Savitz, Misra et al. 2011).

From a translational perspective, we may thus conclude that it is possible to harvest enough BMMN cells to treat acute CNS lesions by intravascular administration. In our opinion, intravascular administration of stem cells is not adequate in the treatment of chronic conditions, as an (again) intact blood-brain(cord) barrier may prevent those cells from reaching the damaged tissue and to establish repair. Applying these cells intrathecally by lumbar puncture might offer a better alternative in these patients, as this (minimally invasive) procedure bypasses the blood-brain barrier (Bakshi, Hunter et al. 2004).

As a rule, acute stroke is followed by a spontaneous mobilization of peripheral blood mononuclear CD34+ cells (containing mainly HSCs), resulting in a doubling of these cells (Dunac, Frelin et al. 2007). This doubling of CD34+ cells, especially in younger patients, comes with some recovery of stroke-related neurological deficits. Intra-person variations in this mobilization might partly explain the differences in recovery of patients. As of yet, we do not know for sure if such a burst of CD34+ cells also follows acute traumatic lesions of the central nervous system, such as spinal cord or brain injuries.

From a translational perspective, though, we suggest that the artificial administration of stem cells might (further) improve recovery after acute lesions of the nervous system, and that this effect is more pronounced in the early stage of the disease.

In the acute phase of traumatic CNS injuries, the mechanism of action of stem cells consists of neuroprotection, preventing apoptosis and thus conserving jeopardized neural cells (Wright, El Masri et al. 2010). 
In more chronic conditions, neuro-restoration seems more obvious. The eventual role of transdifferentiation of MSCs and/or HSCs into fully functioning neurons is still unclear. Applying stem cells directly into the cerebrospinal fluid promotes the expression of neural lineage cells (Zeng, Wang et al. 2011). Human studies on the clinical effects of exclusively intrathecally applied stem cells in chronic spinal cord injuries suggested clinically more meaningful recovery in motor and sensory scores as compared to the other studies in the same chronic condition, in which stem cells were applied intravascularly (Kumar, Kumar et al. 2009, Kishk, Gabr et al. 2010).

As of now, the abundance of proof of clinical improvements in traumatic and ischemic clinical and preclinical CNS lesions such as spinal cord injury and ischemic stroke, after stem cell intervention, in our opinion qualifies for the development of adequately designed clinical trials in spinal cord injury and stroke, applying BMMN cells by lumbar puncture. 


\title{
2.3. Cell based therapy in Parkinsonism
}

\author{
de Munter JPJM, Lee C, Wolters ECh (2013) Translat. Neurodegeneration 2:13
}

\begin{abstract}
Parkinson's disease (PD) is a synucleinopathy-induced chronic progressive neurodegenerative disorder, worldwide affecting about 5 million humans. As of yet, actual therapies are symptomatic, and neuro-protective strategies are an unmet need. Due to their capability to transdifferentiate, to immune modulate and to increase neuroplasticity by producing neurotrophic factors, adult stem cells (ASC) might fill this gap. Preclinical research in 6hydroxydopamine (6-OHDA) and/or 1-methyl-4-phenyl-1,2,3,6-tetrahydropyridine (MPTP) lesioned animals established persistent improvements of motor behaviour after ASC-treatment. Histological/histochemical measurements in these animals evidenced an intracerebral applied ASC-induced increase of Tyrosine Hydroxylase-positive $\left(\mathrm{TH}^{+}\right)$cells with increased striatal dopamine levels, suggesting cell rescue. Likewise, clinical experience with subventricular applied ASCs in PD patients, although limited, is encouraging, evidencing neuro-rescue especially during the early phase of the disease. In multiple system atrophy (MSA) or progressive supranuclear palsy (PSP) patients, though, only marginal reduced progression of natural progression could be established after subventricular or intra-vasal ASC implantations.
\end{abstract}

\section{Introduction}

Parkinson's disease (PD) is the most common chronic progressive neurodegenerative disorder after Alzheimer's disease (Wirdefeldt, Adami et al. 2011), world-wide affecting nearly 5 million people aged 50 years or more, and expected to double over the next 20 years (Dorsey, Constantinescu et al. 2007). It comes with a twofold higher mortality rate, mainly due to pneumonia, shortening life expectancy with nearly 10 years (Driver, Kurth et al. 2008, DiemZangerl, Seppi et al. 2010). The result of the $\alpha$-synucleinopathic degeneration of the nervous system, starting in the peripheral nervous system and lower brainstem and progressively extending over the upper brainstem and neocortex, symptomatology in PD comprises dysfunctions of the whole nervous system. It may start with a range of non-motor symptoms such as disorders of the autonomic nervous system, olfaction, sleep, mood and subtle cognitive deterioration, before a degeneration of the dopamine producing cells in the upper brainstem (nigral substance) may manifest with motor parkinsonism, the clinical hallmark of this disease, and way before involvement of the neocortex induces dementia (Wolters, Van Laar et al. 2010). PD is mainly recognized when first symptoms of motor parkinsonism (hypokinesia, bradykinesia, rigidity, tremor and the loss of postural reflexes) develop as the result of the loss of the majority of the dopaminergic neurons of the pars compacta of the Substantia Nigra with a striatal dopaminergic depletion of over $80 \%$ (Marsden 1996). As of yet, treatment in PD is based on the pulsatile (oral) or continuous (subcutaneous, intrajejunal) suppletion of the striatal dopamine deficiency with dopamine agonists and/or the dopamine precursor levodopa, mostly in combination with a peripheral dopa decarboxylase inhibitor and/or in combination with inhibitors of mono-amine oxidase B (MAO-B) and/or catechol-O-methyl transferase (COMT), in 
order to restore striatal dopaminergic denervation (Fox, Katzenschlager et al. 2011). Actual therapy only symptomatically affects motor parkinsonism, though. Therapies affecting nonmotor symptomatology, and above all protective or restorative treatments are unmet needs in PD. In order to reach these needs, recently, experiments with cell based therapies to rescue or replace dopamine-secreting cells, or with cells able to secrete paracrine factors modulating brain tissue repair were initiated (Fillmore, Holloway et al. 2005, Hall, Li et al. 2007, Parish and Arenas 2007, Laguna Goya, Tyers et al. 2008, Meyer, Maisel et al. 2010). In this review, these experimental stem cell based therapeutic strategies will be discussed. As the application of embryonic stem cells and induced pluripotent stem cells comes with an unacceptable risk of tumor induction (Fujikawa, Oh et al. 2005, Hentze, Graichen et al. 2007, Lee, Tang et al. 2009, Ben-David, Benvenisty et al. 2010), this review will only cover experiments dealing with expanded, whether or not genetically modified, autologous or allogenic bone marrow-derived and/or neural progenitor stem cells.

\section{Adult stem cells (ASC)}

Adult stem cells comprise mesenchymal stem cells (MSCs), hematopoietic stem cells (HSCs) and ectodermal stem cells (ESCs). The majority of the cited preclinical and clinical studies use expanded and/or induced mesenchymal stem cells. Re-implanted adult autologous stem cells, easily harvested out of the iliac crest and whether or not expanded, as a rule, will migrate towards diseased tissue, a phenomenon called homing (Sadan, Bahat-Stromza et al. 2009, de Munter and Wolters 2013). Those stem cells have the potency to modulate immune responses (Aggarwal and Pittenger 2005, Zappia, Casazza et al. 2005) and to both transdifferentiate into target cells in order to replace damaged cells (Tropel, Platet et al. 2006, Barzilay, Kan et al. 2008, Ye, Zeng et al. 2011, Zeng, Wang et al. 2011), and secrete paracrine (trophic) factors relevant for cell protection and cell repair by the inhibition of apoptotic pathways (Gnecchi, Zhang et al. 2008, $\mathrm{Xu}$, Chen et al. 2008, Jager, Hernigou et al. 2010). So, even before differentiation (Tondreau, Lagneaux et al. 2004, Croft and Przyborski 2009), mesenchymal stem cells, might express brainderived neurotrophic factor (BNDF), glial cell-derived neurotrophic factor (GDNF) and stromalderived factor (SDF-1 $\alpha$ ). BDNF is shown to have a neuroprotective effect on cultured rodent neurons via the $\mathrm{Pl}_{3}$ kinase/Akt pathway by inhibiting neural death initiated by trophic factor withdrawal or by the exposure to nitric oxide (Wilkins, Kemp et al. 2009). GDNF provides neural protection against proteasome inhibitor-induced dopamine neuron degeneration (Du, Li et al. 2008), although its biological effect on the clearance of mature formed $\alpha$-synuclein aggregation could not be observed, probably due to its short duration of administration (Du, Li et al. 2008). SDF-1 $\alpha$, in low doses, promotes dopamine release from 6-OHDA-exposed PC12 cells (cell line derived from a pheochromocytoma), presumably by preservation and enhanced survival of these cells, as these phenomena are blocked by administration of anti-SDF-1 $\alpha$ antibodies (Wang, Yasuhara et al. 2010). A high concentration of SDF-1 $\alpha$, however, rather enhances apoptosis (Geeraerts, Deiva et al. 2006). SDF-1 $\alpha$ acts through CXCR4 (chemokine receptor type 4) resulting in a down regulation of caspase-3 and an activation of the PI3/Akt pathway (Shyu, Lin et al. 2008). SDF- $1 \alpha$ also enhances the survival of neural progenitor cells through the receptors CXCR7 and CXCR4 by up regulation of the ERK1/2 (Mitogen-Activated Protein kinase 3) endocytotic signaling pathway (Zhu, Xu et al. 2012). 
The route of administration (intra-vasal, intraparenchymal) during the re-implantation of the stem cells seems to have a major impact on the specific trans-differentiation and/or secretion patterns of them, as the actual environment influences the further developments of these cells. However, by inducing stem cells before re-implantation it is also possible to induce these developments already in vitro. Indeed, by exposing these cells to trophic factors, including epidermal growth factor (EGF) and basic fibroblast growth factor (bFGF) (Delcroix, Curtis et al. 2010), by transducing them with a viral vector, and/or by binding them to pharmacologically active microcarriers, containing trophic factors such as NT-3 (Neurotrophin-3) (Delcroix, Garbayo et al. 2011), it is possible to further differentiate the stem cells, prior to the re-administration to the target organs (Bjorklund, Kirik et al. 2000, Blits, Kitay et al. 2005). So, in vitro, adult stem cells may be predisposed to differentiate into dopamine producing cells (Barzilay, Kan et al. 2008, Chen, He et al. 2009), thus offering a potential alternative for dopamine substitution therapies, or into cells secreting neuroprotective and/or neurorestorative trophic factors, thus protecting for dopaminergic cell death respectively stimulating neuro-restoration (Kim, Park et al. 2009). Due to the lung trap (Fischer, Harting et al. 2009) and the blood-brain-barrier (Stamatovic, Keep et al. 2008, Jackson, Golding et al. 2010), intravasal application of stem cells for disorders of the central nervous system is suggested less effective as compared to intracerebral administration (Zhang, Zhou et al. 2009, Ye, Zeng et al. 2011).

\section{Preclinical experience with ASC in motor parkinsonism}

In experimental animals, motor parkinsonism (but not PD) might be induced by intra-nigral 6hydroxydopamine (6-OHDA) as well as by subcutaneous carbobenzoxy-leuleu-leucinal (MG-132) and/or subcutaneous or intravasal 1-methyl-4-phenyl-1,2,3,6-tetrahydropyridine (MPTP) (Duty and Jenner 2011, Garea-Rodriguez, Schlumbohm et al. 2012). MPTP models have the advantage that the lesions are induced through a less invasive (subcutaneous or intravasal) route of administration as compared with the stereotactic surgical approach when applying 6-OHDA. To optimally investigate neural protection, the non-human primate MPTP model seems to be preferred (Duty and Jenner 2011). Tables 1 and 2 present the results of preclinical interventions using cell-based strategies in the 6-OHDA, MPTP and the proteasome inhibitor MG-132 animal models. In all the presented animal studies immune suppression was used to prevent rejection of the cells. However, the use of immune suppression may influence not only the behavior of the Stem Cells (Guo, Zeng et al. 2007) but also the severity of the lesions in animal models (Palladini, Caronti et al. 1996, Ibarra, Correa et al. 2003). As might be appreciated, in the studies reviewed in Tables 1 and 2, the following stem cells were used:

- Expanded bone marrow-derived mesenchymal cells (of the mesodermal lineage) of rat (Bouchez, Sensebe et al. 2008, Park, Lee et al. 2008, Wang, Yasuhara et al. 2010, Danielyan, Schafer et al. 2011, Delcroix, Garbayo et al. 2011), mouse (Chao, He et al. 2009) or human origin (Levy, Bahat-Stroomza et al. 2008, Sadan, Bahat-Stromza et al. 2009, Blandini, Cova et al. 2010, Cova, Armentero et al. 2010);

- Expanded and enriched, or epigenetically induced bone marrow-derived mesenchymal stem cells (Bouchez, Sensebe et al. 2008, Levy, Bahat-Stroomza et al. 2008, Sadan, Bahat-Stromza et al. 2009, Delcroix, Garbayo et al. 2011), enabling functional development before actual transplantation; 
- Expanded neural stem cells of the ectodermal lineage, derived from the subventricular zone of the rat (Zhu, Ma et al. 2009) or from a cultivated fetal human cell line (Bjugstad, Teng et al. 2008, Ramos-Moreno, Castillo et al. 2012).

But for three studies with intravenous (Chao, He et al. 2009, Wang, Yasuhara et al. 2010) and/or intranasal (Danielyan, Schafer et al. 2011) application, all stem cells are applied intranigral and/or intra-striatal. Outcome measures comprised motor behavior (rotational behavior) as well as histological/ histochemical measures. The main findings on the rotational motor behavior showed a significant reduction of turns/minute. But for 4/7 studies (Bouchez, Sensebe et al. 2008, Blandini, Cova et al. 2010, Wang, Yasuhara et al. 2010, Danielyan, Schafer et al. 2011), in all studies with expanded MSCs (Courtine, Bunge et al. 2007, Blandini, Cova et al. 2010, Danielyan, Schafer et al. 2011), as well in all studies with expanded and enriched or epigenetically induced MSCs (Bouchez, Sensebe et al. 2008, Levy, Bahat-Stroomza et al. 2008, Sadan, BahatStromza et al. 2009, Delcroix, Garbayo et al. 2011), and expanded neural stem cells (Zhu, Ma et al. 2009, Ramos-Moreno, Castillo et al. 2012), this reduction was established.

\section{Table 1}

Placebo-controlled stem cell applications in rodent animal models of parkinsonism

\begin{tabular}{|c|c|c|c|c|}
\hline \multicolumn{5}{|c|}{ Striatal 6-OHDA lesioned rats } \\
\hline $\begin{array}{l}\text { Authors } \\
\text { (Sprague- } \\
\text { Dawley rats) }\end{array}$ & $\begin{array}{l}\text { Product expanded } \\
\text { allogenic ASCs } \\
\text { cyclosporin A }\end{array}$ & $\begin{array}{l}\text { Applic/ } \\
\text { observ time }\end{array}$ & $\begin{array}{l}\text { Characteristics/ } \\
\text { Dosages/ } \\
\text { application }\end{array}$ & $\begin{array}{l}\text { Outcome } \\
{ }^{*} p<0.05 * * p<0.01 \\
* * * p<0.001\end{array}$ \\
\hline $\begin{array}{l}\text { Bouchez, Sensebe } \\
\text { et al. } \\
\text { Female rats }\end{array}$ & $\begin{array}{l}\text { rMSCs } \\
\text { riMSCs }\end{array}$ & $14 / 35$ days & $\begin{array}{l}\text { 1. No intervention } \\
(n=6) \\
\text { 2.Intrastriatal saline } \\
(n=7) \\
\text { 3. Intrastriatal } 1.8 \times 10^{5} \\
\text { rMSCs }(n=7) \\
\text { 4. Intrastriatal } 1.8 \times 10^{5} \\
\text { riMSCs }(n=7)\end{array}$ & $\begin{array}{l}\text { - Rotational behaviour (turns/min) } \\
\text { 1.No-intervention group: } 23.8 \pm 2.1 \\
\text { 2.Control saline treated group: } 25.1 \pm 1.7 \\
\text { 3.rMSC-treated group: } 14.1 \pm 3.3^{*} \\
\text { 4.Enriched riMSC-treated group: } 10.8 \pm 1.7^{*} \\
\text { TH-positive neurons } \\
\text { 1.No-intervention group: } \\
24.2 \pm 6.7 \% \\
\text { 4.Enriched riMSC-treated } \\
\text { group: } 52.5 \pm 8.2 \% *\end{array}$ \\
\hline $\begin{array}{l}\text { Wang, Yasuhara } \\
\text { et al. } \\
\text { Female rats }\end{array}$ & $\begin{array}{l}\text { Fibroblasts } \\
\text { rMSCs }\end{array}$ & $2 \mathrm{hr} / 28$ days & $\begin{array}{l}\text { 1. Intravenous saline } \\
\quad(n=7) \\
\text { 2. Intravenous } 10^{7} \\
\text { fibroblasts }(n=6) \\
\text { 3. Intravenous } 10^{7} \\
\text { rMSCs }(n=6)\end{array}$ & $\begin{array}{l}\text { - Amphetamine induced Rotational behaviour } \\
\text { 1.Control saline treated } \\
\text { group: } 8.5 \pm 3.5 \\
\text { 2.Fibroblast-treated group: } 8.2 .1 \pm 3.3 \\
\text { 3.rMSC-treated group: } 1.2 \pm 0.7 \text { turns/min* } \\
\text { Cylinder test } \\
\text { 1.Control saline treated } \\
\text { group: } 64.7 \pm 17.3 \% \\
\text { 2.Fibroblast-treated group: } 60.2 .1 \pm 16.1 \% \\
\text { 3.rMSC-treated group: } 29.3 \pm 13.7 \% * \\
\text { - Preservation of } \mathrm{TH}^{+} \text {cells: } \\
3^{*}>2>1 \text {. }\end{array}$ \\
\hline $\begin{array}{l}\text { Danielyan, Schafer } \\
\text { et al. } \\
\text { Female rats }\end{array}$ & $\begin{array}{l}\text { rMSCs (EGFP } \\
\text { labeled) }\end{array}$ & 7.9/110-136 days & $\begin{array}{l}\text { 1. Intranasal saline } \\
\text { day } 7 \text { and } 9(n=7) \\
\text { 2.Intranasal } 5 \times 10^{5} \text { MSC } \\
\text { day } 7 \text { and } 9(n=9) \\
\text { 3.Intranasal saline } \\
\text { day } 7 \text { and } 9(n=10) \\
\text { 4.Intranasal } 5 \times 10^{5} \text { MSC } \\
\text { day } 7 \text { and } 9(n=12)\end{array}$ & $\begin{array}{l}\text { - Stepping ratio (contralateral/ipsilateral): } \\
2 \mathrm{MSC}(0.7)^{* *}>1 \text { saline }(0.1) \\
\text { - } \text { Amphetamine-induced rotational behaviour: } \\
4 \mathrm{MSC}^{*}<3 \text { saline group } \\
\text { - Histology } 4 \mathrm{MSC} 24 \% \mathrm{MSC} \text { survived in CNS } \\
\text { for at least } 4.5 \text { months. } \\
\text { - } \quad \mathrm{H}^{+} \text {survival } 2^{*}>1 \text { and } 4^{*}>3 \\
\text { - Inflammatory cytokines } 2^{*}<1 \text { and } 4^{*}<3\end{array}$ \\
\hline
\end{tabular}


Table 1 continued

\begin{tabular}{|c|c|c|c|c|}
\hline $\begin{array}{l}\text { Authors } \\
\text { (Sprague- } \\
\text { Dawley rats) }\end{array}$ & $\begin{array}{l}\text { Product expanded } \\
\text { allogenic ASCs } \\
\text { cyclosporin A }\end{array}$ & $\begin{array}{l}\text { Applic/ } \\
\text { observ time }\end{array}$ & $\begin{array}{l}\text { Characteristics/ } \\
\text { Dosages/ } \\
\text { application }\end{array}$ & $\begin{array}{l}\text { Outcome } \\
{ }^{*} \mathrm{p}<0.05 * * \mathrm{p}<0.01 \\
* * * \mathrm{p}<0.001\end{array}$ \\
\hline $\begin{array}{l}\text { Blandini, Cova } \\
\text { et al. } \\
\text { Male rats }\end{array}$ & hMSCs & $5 / 28$ days & $\begin{array}{l}\text { 1.Intrastriatal saline } \\
(n=9) \\
\text { 2.Intrastriatal } 1 \times 10^{5} \\
\text { hMSCs }(n=8)\end{array}$ & $\begin{array}{l}\text { - Apomorphine-induced Rotational behaviour: } \\
\text { 1.No effect } \\
\text { 2.Reduced rotational behaviour* } \\
\text { - Apoptosis decreased in hMSCs treated group } \\
(2<1)\end{array}$ \\
\hline $\begin{array}{l}\text { Cova, Armentero } \\
\text { et al. } \\
\text { Male rats }\end{array}$ & hMSCs & $5 / 28$ days & $\begin{array}{l}\text { SHAM unilateral lesion } \\
\text { 1.Intrastriatal saline } \\
\text { 2.Intrastriatal } 3.2 \times 10^{4} \\
\text { hMSCs }(n=6-10) \\
\text { 3.Intrastriatal } 1.8 \times 10^{5} \\
\text { hMSCs ( } n=6-10) \\
\text { 6-OHDA unilateral lesion } \\
\text { 1.Intrastriatal saline } \\
\text { 2.Intrastriatal 3.2 } \times 10^{4} \\
\text { hMSCs ( } n=6-10) \\
\text { 3.Intrastriatal } 1.8 \times 10^{5} \\
\text { hMSCs }(n=6-10)\end{array}$ & $\begin{array}{l}\text { - Dose-dependent neuro-rescue effects } \\
\text { (hMSCs vs saline) in unilateral 6-OHDA } \\
\text { lesioned, but not SHAM lesioned rats with: } \\
\text { a).Reduction }{ }^{* * *} \text { ongoing toxin-induced } \\
\text { degeneration of dopaminergic terminals } \\
\text { b).Enhanced neuro-genesis }{ }^{* / * *} \text { (neural } \\
\text { progenitor cells) in the periventricular zone } \\
\text { c).Persistent release of specific cytokines }\end{array}$ \\
\hline $\begin{array}{l}\text { Delcroix, Garbayo } \\
\text { et al. } \\
\text { Female rats }\end{array}$ & $\begin{array}{l}\text { rMSCs } \\
\text { riMSCs+P } \\
\text { riMSCs+P+NT3 }\end{array}$ & $14 / 64$ days & $\begin{array}{l}\text { 1.Intrastriatal saline } \\
(n=6) \\
\text { 2.Intrastriatal } 1.5 \times 10^{5} \\
\text { rMSCs }(n=6) \\
\text { 3.Intrastriatal } 1.5 \times 10^{5} \\
\text { riMSCs+P }(n=6) \\
\text { 4.Intrastriatal } 1.5 \times 10^{5} \\
\text { riMSCs+P+NT3(n=6) }\end{array}$ & $\begin{array}{l}\text { - Rotational behaviour (turns/min): } \\
\text { 1.saline group } 18.5 \\
\text { 2.rMSCs group } 17.5 \\
\text { 3.riMSCs+P group } 8.5^{*} \\
\text { 4.riMSCs+P+NT3 group 3.0* } \\
\text { - Preservation of } \mathrm{TH}^{+} \text {cells: } \\
4^{*}>3>2>1\end{array}$ \\
\hline $\begin{array}{l}\text { Levy, Bahat- } \\
\text { Stroomza et al. }\end{array}$ & $\begin{array}{l}\text { hMSCs } \\
\text { hiMSCs (neural } \\
\text { phenotype) }\end{array}$ & $35 / 125$ days & $\begin{array}{l}\text { 1.Intrastriatal saline } \\
(\mathrm{n}=7) \\
\text { 2. Intrastriatal } 5 \times 10^{5} \\
\text { hMSCs }(\mathrm{n}=7) \\
\text { 3.Intrastriatal } 5 \times 10^{5} \\
\text { neural hiMSCs }(\mathrm{n}=7)\end{array}$ & $\begin{array}{l}\text { - Rotational behaviour (turns/min/post-lesional } \\
\text { 100\%): } \\
\text { 1.saline group: } 88 \% \\
\text { 2.hMSCs group: } 90 \% \\
\text { 3.hiMSCs+P group: } 42 \% *\end{array}$ \\
\hline $\begin{array}{l}\text { Sadan, Bahat- } \\
\text { Stroomza et al. }\end{array}$ & $\begin{array}{l}\text { hMSCs } \\
\text { hiMSCs } \\
\text { (BDNF/GDNF) }\end{array}$ & 1h/42 days & $\begin{array}{l}\text { 1.Intrastriatal saline } \\
(\mathrm{n}=10) \\
\text { 2.Intrastriatal } 1.5 \times 10^{5}\end{array}$ & $\begin{array}{l}\text { D-Amphetamine-induced Rotational } \\
\text { behaviour increase: } \\
\text { 1.Saline grp } 4.74 \pm 1.07\end{array}$ \\
\hline Male rats & & & 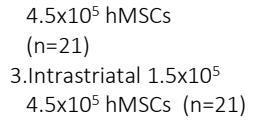 & $\begin{array}{l}\text { 2.hMSCs grp } 2.86 \pm 0.54 \\
\text { 3.hiMSCs grp } 2.16 \pm 0.37^{*} \\
\text { - } \mathrm{TH}^{+} \text {cells (treated vs untreated site: } \\
\mathrm{hMSCs}(2)>\text { and } \operatorname{hiMSCs}(3)^{*}>\end{array}$ \\
\hline Zhu, Ma et al. & rNSCs & $35 / 155$ days & $\begin{array}{l}\text { 1.No intervention } \\
(n=13)\end{array}$ & $\begin{array}{l}\text { - Rotational behaviour } \\
\text { 1.No intervention group } 233.9 \pm 70.43\end{array}$ \\
\hline Male rats & & & $\begin{array}{l}\text { 2.Intranigral } 5 \times 10^{4} \\
\text { rNSCs }(n=20) \\
\text { 3. Intrastriatal } 5 \times 10^{4} \\
\text { rNSCs }(n=5)\end{array}$ & 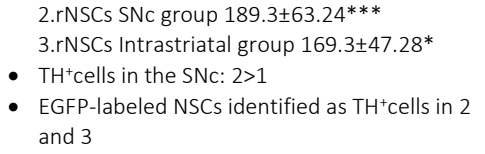 \\
\hline $\begin{array}{l}\text { Ramos-Moreno, } \\
\text { Castillo et al. } \\
\text { Female rats }\end{array}$ & $\begin{array}{l}\text { hNSCS } \\
\text { hiNSCS } \\
\text { (expressing } B C l-X_{L} \text { ) }\end{array}$ & $45 / 165$ days & $\begin{array}{l}\text { 1.Intrastriatal saline } \\
(n=15) \\
\text { 2.Intrastriatal } 3 \times 10^{5} \\
\text { hNSCs }(n=17) \\
\text { 3.Intrastriatal } 3 \times 10^{5} \\
\text { hiNSCs Bcl- } X_{L} \\
\text { expression }(n=21)\end{array}$ & $\begin{array}{l}\text { - D-amphetamine-induced rotational } \\
\text { behaviour: } \\
\text { 1.saline grp } 18 \text { turns/m / 2.hNSCs grp } 17 \\
\text { turns/m / 3.hiNSCs grp } 3 \text { turns/m*** } \\
\text { - Apomorphine-induced rotational behaviour: } \\
\text { 1.saline grp } 6.5 \text { turns/m / } 2 . \text { hNSCs grp } 2 \\
\text { turns/m** / 3.hiNSCs grp } 2.5 \text { turns/m** } \\
\text { - Paw mobility test: } 3^{* *}>2^{*}>1\end{array}$ \\
\hline
\end{tabular}

Abbreviations: 6-OHDA 6-hydroxydopamine, ASCs Adult stem cells, MSCs Mesenchymal stem cells, NSCs Neural stem cells, $h$ human, $r$ rat, $l$ induced or transduced, EGFP Enhanced Green Fluorescent Protein, BDNF Brain-Derived Neurotrophic Factor, GDNF Glial cell Derived Neurotrophic Factor, $m$ minute, NT-3 Neurotrophine-3, $P$ Pharmacologically active microcarriers, $B C l-X L_{L}$ anti-apoptotic granulocyte-colony stimulating factor enhancing the expression of key genes (involved in dopaminergic patterning, differentiation and maturation), SNc Substantia Nigra pars compacta, $\mathrm{TH}^{+} \mathrm{Trosine} H \mathrm{H} d \mathrm{droxylase} I m m u n o r e a c t i v e ~ p o s i t i v e$ cells. 
The administration of expanded, not-induced stem cells in these studies varied widely in relation to the onset of the toxin-induced motor parkinsonism. Stem cells were applied within 2 hours (Sadan, Bahat-Stromza et al. 2009, Wang, Yasuhara et al. 2010), within 5 to 14 days (Blandini, Cova et al. 2010, Cova, Armentero et al. 2010), or 30 days after the lesion (Bjugstad, Teng et al. 2008, Levy, Bahat-Stroomza et al. 2008, Chao, He et al. 2009, Zhu, Ma et al. 2009, RamosMoreno, Castillo et al. 2012). Overlooking the effects in these studies on rotational behavior, the period in between application and lesioning seems to influence the clinical outcome: the earlier the application, the better the resulting clinical effects. Remarkably, after intra-vasal administration of ASCs, whether applied in the acute phase (Wang, Yasuhara et al. 2010)or 3 weeks after lesioning (Wang, Yasuhara et al. 2010), only a few ASCs (about 2\%) could be detected in the nigral substance, the majority was trapped in the lungs. Nevertheless, also in these experiments, a significant beneficial effect on motor behavior could be established (Wang, Yasuhara et al. 2010). Here, it seems relevant to mention that after intrastriatal (intracaudate) application in the non-human primate MPTP model, $1 \%$ of the implanted stem cells could be identified at the injection site, whereas over $80 \%$ was found to be migrated to and along the impaired nigrostriatal pathways (Bjugstad, Teng et al. 2008). As for the histological /histochemical findings, after intracerebral stem cell application, in all experiments, more striatal TH-positive neurons were seen in the treated as compared to the non-treated, control lesioned animals, suggesting ASC-induced increased neuronal plasticity (neurorescue) with increased modulation of cell survival (and an increased striatal dopamine level), enhanced neurogenesis (progenitor cells in the subventricular zone), and a decreased modulation of inflammation, gliosis and death-signaling (Bouchez, Sensebe et al. 2008, Park, Lee et al. 2008, Sadan, Bahat-Stromza et al. 2009, Zhu, Ma et al. 2009, Cova, Armentero et al. 2010, Park, Bang et al. 2011). The same preservation of TH-positive cells was also observed after intravenous (Wang, Yasuhara et al. 2010) and intranasal MSC application (Danielyan, Schafer et al. 2011).

\section{Table 2}

Placebo-controlled stem cell applications in animal models of parkinsonism

\begin{tabular}{|c|c|c|c|c|}
\hline \multicolumn{5}{|c|}{ Striatal MPTP and subcutaneous proteasome inhibitor (MG-132) lesioned animals } \\
\hline $\begin{array}{l}\text { Authors } \\
\text { animals }\end{array}$ & $\begin{array}{l}\text { Product exp. } \\
\text { allogenic ASCs } \\
\text { cyclosporin A }\end{array}$ & $\begin{array}{l}\text { Applic/ } \\
\text { observ time }\end{array}$ & $\begin{array}{l}\text { Characteristics/ } \\
\text { Dosages/ } \\
\text { application }\end{array}$ & $\begin{array}{l}\text { Outcome } \\
{ }_{*} p<0.05 * * p<0.01 \\
* * * p<0.001\end{array}$ \\
\hline $\begin{array}{l}\text { Chao, He et al. } \\
\text { Male C57BL/6 } \\
\text { mice }\end{array}$ & mMSCs & $\begin{array}{l}\text { Directly after last } \\
\text { MPTP injection/1 } \\
\text { month }\end{array}$ & $\begin{array}{l}\text { 1.Intraperitoneal } \\
\text { saline }(n=24) \\
\text { 2. Intraperitoneal } \\
\text { MPTP+IV saline } \\
(n=24) \\
\text { 3.Intraperitoneal } \\
\text { MPTP+IV } 10^{5} \\
\text { mMSCs }(n=24)\end{array}$ & $\begin{array}{l}\text { - } \mathrm{SN} \mathrm{TH} \mathrm{TH}^{+} \text {cells: } 3^{* *}>2 \\
\text { - } \mathrm{SN} \text { microglial cells: } 3^{*}<2 \\
\text { - } \text { Phagocytosis and Complement inhibition: } 3^{*}<2\end{array}$ \\
\hline $\begin{array}{l}\text { Park, Bang } \\
\text { et al. } \\
\text { Male C57BL/6 } \\
\text { mice }\end{array}$ & hiMSCs & $\begin{array}{l}1 \text { day after last } \\
\text { MPTP and 3-NP } \\
\text { injections/ } 28 \text { days }\end{array}$ & $\begin{array}{l}\text { 1.Intraperitoneal } \\
\text { saline }(n=10) \\
\text { 2. Intraperitoneal } \\
\text { MPTP+3-NP( } n=8) \\
\text { 3. Intraperitoneal } \\
\text { MPTP+3-NP and IV } \\
10^{6} \text { hiMSCs in } 200 \mu \mathrm{Il} \\
(n=8)\end{array}$ & $\begin{array}{l}\text { - Group } 2 \text { and 3: } 48 \% \text { loss of nigral cells } \\
\text { - Group } 3 \text { compared to group 2: } \\
\text { a. } 2 \% \text { of hiMSCs in SN and } 4 \% \text { in the Striatum } \\
\text { b.Motor behaviour improved }{ }^{*} \text { during } 10 \text { days } \\
\text { - c.Increased modulation of cell survival }{ }^{*} \text { and } \\
\text { decreased modulation of death-signaling }{ }^{* *} \\
\text { pathways, with } 20 \% \text { cell survival }{ }^{* *} \\
\text { d.Decreased modulation of inflammation }{ }^{* *} \text { and } \\
\text { gliosis }^{* * *}, \text { with a marked decrease of activated } \\
\text { microglia**and astrocytes }^{* * *}\end{array}$ \\
\hline
\end{tabular}


Table 2

continued

\begin{tabular}{|c|c|c|c|c|}
\hline \multicolumn{5}{|c|}{ Striatal MPTP and subcutaneous proteasome inhibitor (MG-132) lesioned animals } \\
\hline $\begin{array}{l}\text { Authors } \\
\text { (Sprague- } \\
\text { Dawley rats) }\end{array}$ & $\begin{array}{l}\text { Product } \\
\text { expanded } \\
\text { allogenic ASCs } \\
\text { cyclosporin A }\end{array}$ & $\begin{array}{l}\text { Applic/ } \\
\text { observ time }\end{array}$ & $\begin{array}{l}\text { Characteristics/ } \\
\text { Dosages/ } \\
\text { application }\end{array}$ & $\begin{array}{l}\text { Outcome } \\
{ }^{*} p<0.05 * * p<0.01 \\
* * * p<0.001\end{array}$ \\
\hline $\begin{array}{l}\text { Bjugstad, Teng et } \\
\text { al. } \\
\text { African green } \\
\text { monkeys }\end{array}$ & hiNSCs & $\begin{array}{l}4 \text { and/or } 6 \\
\text { months after } \\
\text { last MPTP inj/4 } \\
(n=3) \text { and } 7 \\
(n=4) \text { months }\end{array}$ & $\begin{array}{l}\text { Bilateral intrastriatal and } \\
\text { unilateral intranigral } \\
\text { implantation of each } 10^{6} \\
\text { hiNSCs }\end{array}$ & $\begin{array}{l}\text { - }>80 \% \text { of hiNSCs immigrated along the impaired } \\
\text { nigrostriatal pathway } \\
\text { - }<1 \% \text { of } 2 \times 10^{6} \text { hiNSCs implanted within the } \\
\text { caudate nucleus (intrastriatal) was identified at } \\
\text { this site }\end{array}$ \\
\hline $\begin{array}{l}\text { Park, Lee } \\
\text { et al. } \\
\text { Male rats }\end{array}$ & hMSCs & $\begin{array}{l}21 \text { days/ } \\
3,4,6,7,10 \\
\text { weeks }\end{array}$ & $\begin{array}{l}\text { 1.MG-132 lesioned } \\
\text { rats } \\
\text { 2.MG-132 lesioned } \\
\text { rats treated during } 3 \\
\text { weeks with weekly } \\
\text { intravasal applied } \\
10^{6} \mathrm{hMSCs}\end{array}$ & $\begin{array}{l}\text { - } 1.7 \% \text { hMSCs detected in the nigral substance } \\
\text { - Survival of nigral and striatal } \mathrm{TH}^{=} \text {cells after } \\
\text { hMSCs } \\
\text { - Increased striatal dopamine level* after hMSCs } \\
\text { - Reduction* in microglia activation after hMSCs }\end{array}$ \\
\hline
\end{tabular}

Abbreviations: ASCs Adult stem cells, IV intravenous, MPTP 1-methyl-4-phenyl-1,2,3,6-tetrahydropyridine, MSCs Mesenchymal stem cells, NSCs Neural stem cells, $h$ human, $m$ mouse, $I$ induced or transduced, MG-132 carbobenzoxy-Leu-Leu-leucinal, a proteasome inhibitor, $S N$ substantia Nigra, $T H^{+}$Tyrosine Hydroxylase.

\section{Clinical experience with ASC in motor, parkinsonism}

As of yet, only three studies were reported, dealing with the effects of, intracerebral or intravasal applied, allogenic or autologous adult stem cells in patients suffering motor parkinsonism in PD, multiple system atrophy (MSA) or progressive supranuclear palsy (PSP) (Lee, Kim et al. 2008, Venkataramana, Kumar et al. 2010, Venkataramana, Pal et al. 2012).

The results are summarized in Table 3. In most but not all PD patients, the subventricular application of both, allogenic and autologous bone marrow-derived mesenchymal stem cells did improve clinical scores of motor behavior, as expressed in a significant decrease of UPDRS scores in ON and OFF conditions. Interestingly, these effects did appear faster and more outspoken the earlier these interventions were applied, mimicking the results in preclinical experiments. Magnetic Resonance tractography of degenerated dopaminergic projections did show significant improvements in those patients.

In MSA and PSP patients, compared to placebo treated patients, in some patients, a temporary improvement (Bjugstad, Teng et al. 2008) or reduced deterioration in motor and cognitive functions (Bjugstad, Teng et al. 2008) witnessed a reduction in natural progressive deterioration with subventricular or intravasal ASC implantations. This reduced disease progression in these patients was also found reflected in MRI (Magnetic Resonance Imaging)- and FDG PET (fluorodeoxyglucose positron emission tomography)- imaging, showing less atrophy and less decreased glucose metabolism in cortex and cerebellum. 


\section{Table 3}

Open label and placebo-controlled stem cell applications in clinical parkinsonism

\begin{tabular}{|c|c|c|c|c|}
\hline $\begin{array}{l}\text { Authors } \\
\text { patients }\end{array}$ & Product & $\begin{array}{l}\text { Observ. } \\
\text { time } \\
\text { (months) }\end{array}$ & $\begin{array}{l}\text { Characteristics/ } \\
\text { Dosages/Application }\end{array}$ & Outcome $\left({ }^{*} p<0.05 /{ }^{* *} p<0.01\right)$ \\
\hline $\begin{array}{l}\text { Venkataramana } \\
\text { Pal et al. } \\
\text { PD patients } \\
\text { MSA patients } \\
\text { PSP patients } \\
\text { Open label }\end{array}$ & $\begin{array}{l}\text { Allogenic } \\
\text { MSCs }\end{array}$ & $3,6,12$ & $\begin{array}{l}\text { 1.PD patients with bilat. } \\
\text { subventr. application of } \\
2 \times 10^{6} \mathrm{MSCs} / \mathrm{kg} \text { weight } \\
\text { in } 2 \mathrm{ml}(\mathrm{n}=8) \\
\text { 2.MSA+PSP patients with } \\
\text { bilat.subventr.application of } 2 \times 10^{6} \\
\mathrm{MSCs} / \mathrm{kg} \text { weight } \\
\text { in } 2 \mathrm{ml}(\mathrm{n}=4)\end{array}$ & $\begin{array}{l}\text { UPDRS in ON/OFF: } \\
\text { a. In PD: permanently improved*compared with baseline } \\
\text { during both ON ( } 18 \%: 51.2 \text { vs } 62.3 \text { ) and OFF ( } 31.2 \%: 59.5 \\
\text { vs } 86.5) \text {. Effect stronger in PD with disease duration < } 5 \text { yrs } \\
\text { (ON } 45.5 \% \text { OFF } 56.7 \% \text { ) as compared to PD with a duration } \\
\text { > } 10 y \text { rs (ON 6.3\% OFF } 12.4 \%) \\
\text { b. Some MSA/PSP temporarily improved. The effect was not } \\
\text { correlated with disease severity and duration. MR } \\
\text { tractography: } \\
\text {-PD patients,after implantation, did show a } \\
\text { trend of steadily improvement in tracto- } \\
\text { graphical images in genu and peduncles } \\
\text {-MSA/PSP showed further reduction of } \\
\text { tractographical images after implantation. }\end{array}$ \\
\hline $\begin{array}{l}\text { Venkataramana } \\
\text { Kumar et al. } \\
\text { PD patients } \\
\text { Open label }\end{array}$ & $\begin{array}{l}\text { Autolog } \\
\text { MSCs }\end{array}$ & $10-36$ & $\begin{array}{l}\text { PD patients }(n=7) \text { with an UPDRS } \\
\text { ON/OFF score } 50.6 / 65.0 \text { and a } \\
\text { mean disease duration of } 14.7 \mathrm{yr} \\
\text { treated with } 10^{6} \mathrm{MSC} / \mathrm{kg} \\
\text { bodyweight in the subventricular } \\
\text { zone }\end{array}$ & $\begin{array}{l}\text { UPDRS in ON/OFF: } \\
\text { a. In } 3 / 7 \text { patients there was a stable improvement of } \\
\text { ON/OFF scores of } 38 \% \text { respect. } 22.9 \% \text { with unchanged } \\
\text { anti-parkinsonian medication } \\
\text { b. In } 3 / 7 \text { patients after treatment, only marginal clinical } \\
\text { effects were observed } \\
\text { c. Anti-parkinsonian medication significantly reduced in } 2 \\
\text { patients }\end{array}$ \\
\hline $\begin{array}{l}\text { Lee, Kim et al. } \\
\text { MSA patients } \\
\text { Placebo }\end{array}$ & $\begin{array}{l}\text { Autolog } \\
\text { MSCs }\end{array}$ & $\begin{array}{l}1,2,3,4,5,6 \\
8,10,12\end{array}$ & $\begin{array}{l}\text { Patients with cognitive intact MSA- } \\
\text { C (with UMSARS scores between } \\
30 \text { to } 50) \\
\text { 1.IV or IA Placebo }(n=17)\end{array}$ & $\begin{array}{l}\text { UMSARS score: } \\
\text { a. MSCs-treated patients showed a reduced* increase of } \\
\text { UMSARS score compared to placebo treated patients } \\
\text { b. Intra-arterial (IA) application of MSCs was complicated } \\
\text { with some MRI-detectable ischemic lesions }\end{array}$ \\
\hline & & & 2.MSCs $\left(4 \times 10^{6}\right)$ IV or IA $(n=14)$ & $\begin{array}{l}\text { The cognitive functions significantly* worsened in placebo } \\
\text { but not in MSCs-treated patients } \\
\text { MRI and FDG PET showed significantly* increased gray } \\
\text { cerebral cortical areas respect. more decreased cortical and } \\
\text { cerebellar glucose metabolism in placebo-treated, as } \\
\text { compared to MSCs-treated patients }\end{array}$ \\
\hline
\end{tabular}

Abbreviations: MSCS Mesenchymal stem cells, MSA Multiple system atrophy, MSA-C Multiple system atrophy, cerebellar type, PSP Progressive supranuclear palsy, MRI Magnetic resonance imaging, UMSARS unified MSA rating scale, FDG PET fluorodeoxyglucose positron emission tomography.

\section{Discussion}

PD is a chronic progressive, diffuse $\alpha$-synucleinopathic disease of the central nervous system in which (symptomatic) therapeutic strategies aim to compensate for the striatal dopamine deficiency in order to mainly decrease motor symptomatology. As of yet, protective/repairing therapeutic strategies in PD are an unmet need. Generally speaking, stem cells, and specifically adult stem cells, pending their environment after re-implantation or pending their in-vitro induction, are supposed to not only differentiate into functional (neuronal) cells, including dopamine producing neurons, but to also easily expand and thus to deliver enough cells for transplantation. Although differentiation and proliferation of bone marrow-derived stem cells 
are jeopardized by aging and chronic diseases including diabetes (Dimmeler and Leri 2008), renal failure (Li, Kubo et al. 2010) and ALS (Amyotrophic lateral sclerosis) (Koh, Baik et al. 2012), in PD patients, up to the 15th passage, ASCs are fully comparable to those of healthy age-matched individuals regarding phenotype, morphology and capacity to multi-differentiate (Zhang, Wang et al. 2008), and are also able to inhibit T-lymphocyte proliferation induced by mitogens. Next to the multi-differentiated proliferative capacity, adult stem cells, and especially expanded and induced ASC's, may secrete an array of trophic factors. As a matter of fact they may specialize to express mainly such factors by induction in vitro through exposure to trophic factors (including epidermal growth factor EGF and basic fibroblast growth factor bFGF), by transduction with a viral vector and/or by binding these ASCs to pharmacologically active microcarriers, containing trophic factors such as NT-3 prior to the application.

When adding epidermal growth factor (EGF) and basic fibroblast growth factor (bFGF) to serumfree medium, in order to expand and induce human ASCs, the secretion of neurotrophic factors such as BDNF (normally neglectable) will increase to $125 \pm 12$ pg/day/106 ASCs (Somoza, Juri et al. 2010). Thus, induced ASCs will function as a vehicle for adequate delivery of neurotrophic factors (BDNF and GDNF) when transplanted in the central nervous system (Sadan, BahatStromza et al. 2009, Somoza, Juri et al. 2010). It is suggested that ASC-produced neurotrophic factors such as GDNF and BDNF enhance neuro-protection with an increased modulation of cell survival and a decreased modulation of inflammation, gliosis and death signaling.

These trophic factors thus stimulate neurorescue by better protection of $\alpha$-synucleinopathic jeopardized neurons, including DA producing neurons. This effect was also reported in a MPTP animal model in which allogenic neural stem cells were applied unilateral (Ourednik, Ourednik et al. 2002). The jeopardized DA producing neurons were rescued and this effect was also observed in the opposite side of the SN in which no stem cells were applied (Ourednik, Ourednik et al. 2002). So, in PD patients, autologous ASCs, and especially expanded and/or induced ASCs, due to their capacity to increase neuroplasticity, theoretically not only offer an increased neuroprotection, but also an increased neuro-repair in PD patients resulting in a slowing down of natural progression in this debilitating disease. In preclinical studies, the stimulated secretion of GDNF and BDNF by ASCs is found to result in a higher number of striatal TH-positive neurons in the rat lesioned striatum as compared to placebo-treated rats, accompanied with a higher striatal dopamine level and decreased rotational behavior (Blandini, Cova et al. 2010, Somoza, Juri et al. 2010). Other ASC produced trophic factors, such as basic fibroblast growth factor bFGF and epidermal growth factor EGF, seem to be more relevant for neurorestoration (synthesis of extracellular matrix). In rodents, the intranigral application of (adenovirus mediated) glial cell line derived neurotrophic factor (GDNF), one week before the ipsilateral nigral 6-OHDA lesioning, did rescue $70 \%$ of the nigral $\mathrm{TH}$-positive cells as compared to $30 \%$ in the not-pretreated, lesioned (control) animals, resulting in a significantly reduced rotational behavior: $5.4 \pm 15.2$ turns/15minutes versus $40.8 \pm 25$ turns/15-minutes $(p<0.05$ ) (Chen, Liu et al. 2003). Note however that each intracerebral needle-induced manipulation per se might initiate the secretion of the same neurotrophic factors and/or cytokines mimicking a clinical effect, which may confound the results of a placebo treatment (Perry, Bell et al. 1995, McCluskey, Campbell et al. 2008).

In the preclinical studies, reviewed above, two studies were performed in which ASCs were locally applied within 2 hours after the application of a 6-OHDA unilateral lesion in rodents (Sadan, Bahat-Stromza et al. 2009, Wang, Yasuhara et al. 2010). Both studies, reported a 
significant improvement in rotational behavior and in survival of TH positive neurons within 4-6 weeks. In the studies applying ASCs, and especially expanded noninduced ASCs, later on, in a more chronic phase of a lesion, no significant reduction in rotational behavior could be established (Croft and Przyborski 2009). In translation, the clinical effects of implantation of expanded MSCs in PD patients might profit their application in an early phase of their disease. Indeed, in PD patients, the clinical effects of stem cell application seem to relate with disease duration (Bjugstad, Teng et al. 2008).

Finally, as ASCs are large cells, unable to cross the blood-brain barrier (Stamatovic, Keep et al. 2008), intracerebral application seems to be superior to intravasal application, as only 1-2\% of thus applied cells will reach the central nervous system (Park, Lee et al. 2008).

Intranasal administration of MSCs, however, might offer an alternative, as this way of application in unilateral 6-OHDA-lesioned rodents did result in both, a significantly improved motor behavior and a significant decrease in inflammatory cytokines (suggesting a strong cell protective effect by inhibiting inflammation cascades) with $24 \%$ of the cells surviving for at least 4.5 month in the central nervous system (Danielyan, Schafer et al. 2011).

\section{Conclusions}

- $\quad$ ASCs are capable of migration to the lesioned cells/organs throughout the body, a phenomenon, which is called homing.

- $\quad$ ASCs are easily to harvest out of the iliac crest. Their number might be increased by expanding them, and their functions might be developed prior to re-application by inducing them. Unlike ASCs in patients with other chronic diseases, in PD patients those cells are not impaired.

- $\quad$ Expanded and/or induced ASCs may stabilize motor (and non-motor) parkinsonism in patients suffering PD and may be also Parkinson-plus syndromes, by increasing neural plasticity rather than by differentiating into neurons. Early in the disease, ASCs will promote neuro-rescue/neuroprotection by increasing immune modulation and reducing inflammation), especially when expanded (undifferentiated) ASCs are administered. Later in the disease, they mainly will promote neuro-restoration, especially when induced (differentiated) ASCs are given.

- $\quad$ Neurotrophic factors such as BDNF and GDNF (mainly interfering with destructive pathways) play a major role in neuroprotection, whereas other growth factors such as EGF and bFGF (promoting synthesis of extracellular matrix) are more important in neurorepair. The best time to start with ASCs administration is in the very early phase of Parkinson's disease. 


\title{
2.4. Stem cell grafting in parkinsonism - Why, how, and when
}

\author{
de Munter JPJM,Melamed E,Wolters ECh (2013)Parkinsonism Relat Disord 20.S1:67-70
}

\begin{abstract}
Parkinson's disease is a devastating, progressive neurodegenerative disorder that affects the central and peripheral nervous systems. Although recent advancements have led to a better understanding of the disorder, there is currently no long-term disease-modifying strategy. Recently, preclinical data have identified the significant effects of pluripotent stem cell grafting in 6-OHDA and MPTP animal models of motor parkinsonism; there have also been some clinical data in patients with motor parkinsonism.

Pluripotent stem cells can nestle in affected organs and can differentiate into a variety of cells, including neural (dopamine producing) cells. Depending on the environment into which they are grafted, these stem cells can also influence immune responses by regulating the activity of Bcells, T-cells, and NK-cells. Pluripotent stem cells can also produce chemotrophins, including BDNF (brain-derived neurotrophic factor), GDNF (glial-derived neurotrophic factor), NGF (nerve growth factor), TGF-b (transforming growth factor-b), IGF-1 (insulin-like growth factor 1), NT-3 (neurotrophin 3), and SCF-1 (stem cell factor 1). Influencing these trophic factors can influence plasticity. This article explores the potential of pluripotent stem cells in the treatment of PD. We will explore the utilization of pluripotent stem cells in the immune-modulation of B-cells, T-cells and NK-cells, the trans-differentiation of pluripotent stems cells into DA-cells, and the secretion of trophic factors and its relation to plasticity. We will also cover how best to conduct a clinical trial, which stem cells can be safely used in patients, what are the methods of induction before application, and how to re-apply stem cells in patients by intravasal, intrathecal or intracerebral methods. Finally, we will describe how to objectively record the clinical results.
\end{abstract}

\section{Parkinson's Disease and parkinsonism}

Parkinson's disease (PD) is the most common chronic progressive neurodegenerative movement disorder, and it affects at least 5 million people aged 50 years or older worldwide. This number is expected to double over the next 20 years. Individuals with PD are also more likely to have a shortened life span because PD has a twofold higher mortality rate compared to individuals of the same age without PD mainly due to pneumonia, which shortens the average life expectancy by 10 years. The clinical hallmark of idiopathic PD is a complex of bradykinesia, hypokinesia, rigidity, and the loss of postural reflexes. These clinical manifestations are also found in other forms of parkinsonism, including genetic, iatrogenic, and toxic parkinsonism. However, they can also be seen in multiple system atrophy (MSA) and progressive supranuclear palsy (PSP). PD was historically considered an abiotrophic disorder that exclusively affected the dopaminergic motor neurons, and clinically expressed motor dysfunction as the result of striatal dopaminergic denervation. However, the current understanding is that PD is the result of a varied pathology that may affect nearly every part of the nervous system. Numerous genes that have been identified in familial parkinsonism have provided significant clues into both the genetic and environmental risks. The neurodegeneration that is seen in PD is characterized by asynucleinopathy; it starts in the peripheral nervous system and lower brainstem, and it 
progressively extends through the upper brainstem and neocortex. Therefore some patients may first present with a range of non-motor symptoms, including disturbances of the autonomic nervous system affecting olfaction, sleep and mood, and subtle cognitive deterioration. Recent research also suggests that more aggressive neurodegeneration and cellular dysfunction, which occur in the substantia nigra, may precede the formation of Lewy pathology (Milber, Noorigian et al. 2012), indicating that Lewy pathology-associated neurodegeneration may not be the primary pathologic phenomenon occurring in Parkinson's disease. Although not yet complete, this greater understanding of the mechanisms underlying the neuronal dysfunction of PD has resulted in new therapies, such as antioxidant administration to reduce oxidative stress, trophic factor administration to promote neuronal survival, and anti-inflammatory medications to counteract any inflammatory attack. PD is clinically diagnosed the onset of motor symptoms that develop as the result of the striatal dopaminergic denervation caused by degeneration of the dopaminergic neurons in the pars compacta of the substantia nigra. Treatment of PD is based on the conservative pulsatile (oral) or continuous (transdermal, subcutaneous, and/or intrajejunal) supplementation of the striatal dopamine deficiency with dopaminomimetics to restore striatal dopaminergic denervation. Therapy affects only symptomatic motor parkinsonism and PD-related non-motor symptomatology. However, protective and restorative treatments are still unmet needs. Recently, experiments with cell-based therapies have been initiated to rescue or replace dopaminergic cells with stem cells through trans-differentiation, immunomodulation, and stimulation of neural plasticity with stem cell-secreted paracrine factors (Meyer, Maisel et al. 2010).

\section{Stem cells}

\section{Which stem cells to apply?}

Umbilical cord-derived and bone marrow-derived stem cells may qualify for grafting in humans as efficiently as embryonic stem cells; however, only autologous stem cells (ASCs) qualify as treatment options in PD (de Munter and Wolters 2013). ASCs are harvested easily, they are safe, and they can differentiate into neural cells under certain conditions. The ASCs in PD, unlike those in other chronic diseases such as diabetes mellitus, are fully functional and comparable with the healthy cells in quantity, quality, plasticity, and immune response (Zhang, Wang et al. 2008). From a clinical translational perspective, there are no impassible regulatory hurdles associated with non-manipulated autologous stem cells. Mesenchymal stem cells (MSCs) and the more common hematopoietic stem cells (HSCs) also seem to be effective (Cabanes, Bonilla et al. 2007) in the treatment of PD. Both cell types can be expanded and stored for a long period of time by using cryopreservation. This does not affect plasticity (Veeraputhiran, Theus et al. 2010).

\section{Harvesting}

Harvesting ASCs is easy and can be safely performed through bone marrow biopsy. Usually, bone marrow aspirate is filtered after extraction and processed by gradient centrifugation. The number of ASCs in centrifuged bone marrow aspirate is low. Additionally, the percentage of MSCs usually does not exceed $1 \%$ of the level of HSCs, and this is $0.01 \%$ of the total number of mononuclear cells.

However, adequate doses for intravascular application in human neurological ischemic disorders should contain at least $1.0-3.0 \times 10^{7}$ bone marrow-derived mononuclear cells (with $1.0-3.0 \times 10^{5}$ 
HSCs and 1.0-3.0 $\times 10^{3}$ MSCs) per kilogram body weight (Yang, Strong et al. 2011). In summary, bone marrow aspirate contains sufficient quantities of ASCs to apply to the patient. In vitro expansion with cryopreservation is not needed in the case of a once-only autologous treatment.

\section{Expansion}

Today, both MSCs and HSCs can be cultured and expanded to achieve sufficient numbers of cells for frequent autologous re-applications or allogenic applications by using small volumes of bone marrow aspirate. Although expansion is a common practice in regenerative medicine, expanding in vitro ASCs is still an object of major concern because of the limited replicative capacity, which is known as the "Hayflick limit". This limit is presumably the result of chromosomal telomere shortening after each cell division in bone marrow-derived and adipose tissue-derived stem cells (Ferreira, Irioda et al. 2012). Additionally in early cell passages, aneuploidies were the most common findings, reflecting the uncertainties about the safety of ASCs cultivation. The age of the donor also limits the expansion of ASCs (Stenderup, Justesen et al. 2003). In summary, there are still major concerns regarding the long-term effect of expanded cells in vivo. However, the risk of inducing malignancies cannot be ruled out.

\section{Preservation}

Cryopreservation is also an option to optimally exploit adult stem cells. Cryopreservation with dimethyl sulfoxide (DMSO) prevents degeneration of the adult stem cells and enables safe storage for decades (Veeraputhiran, Theus et al. 2010). However, DMSO is toxic, but it is necessary to prevent the formation of ice crystals within the frozen cells. With the use of the appropriate protocols, DMSO can be washed out safely, thereby reducing the adverse effects accompanying transplantation of frozen bone marrow-derived stem cells. In summary, preservation could be a safe option to store ASCs for future use to avoid repeated bone marrow punctures over time. Preservation can also help avoid the use of aged and less effective stem cells.

\section{Immunosuppressive drugs}

The main advantage of using autologous ASCs is the fact that there is no need to suppress the immune system to enable the cells to perform their tasks. Immunosuppression is necessary with embryonic stem cells, umbilical cord-derived stem cells, and allogenic stem cells. Immunosuppressive drugs can have a negative impact on the survival, differentiation, and plasticity of allogenic ASCs, and should be avoided if possible (Guo, Zeng et al. 2007).

\section{Induction}

There are protocols available to induce stem cells into a desirable genetic expression profile prior to administration (Somoza, Juri et al. 2010). However, this reprogramming is not without risk, and it complicates the availability from a regulatory perspective. The main risk is the increased chance for tumor formation; thus, the application of induced pluriform stem cells does not seem advantageous (Lee, Tang et al. 2009). There is a similar risk with embryonic stem cells. Both embryonic and induced stem cells may not be optimal for treating PD. 


\section{How to apply stem cells?}

Stem cells may be administered for the treatment of central nervous system (CNS) disorders in four ways: intracerebrally, intrathecally/ intraventricularly, intranasally, or intravascularly. Intracerebral application of stem cells involves applying stem cells directly to the injured or disease-affected tissue. Intrathecal/intraventricular application of stem cells involves applying stem cells directly into the cerebral spinal fluid. Intranasal application of stem cells involves applying stem cells into the brain via the olfactory epithelium and fila olfactoria. Finally, intravascular application involves applying stem cells into the blood vessels. Adult stem cells, and especially MSCs, are capable of migration toward injured or damaged tissue by a process called homing. Stromal cell derived factor 1 (SDF-1) presumably acts as a chemotactic factor, attracting MSCs towards an injured site (Wragg, Mellad et al. 2008). However, treating diseases of the CNS may require directed application because the blood-brain barrier may hamper CNS penetration of the stem cells. One of the major challenges to the use of stem cells may be ensuring that the highest number of stem cells reaches the lesion (de Munter, Lee et al. 2013).

\section{Intravascular/Intravenous administration}

For the intravascular administration of stem cells to be successful, the stem cells must be able to cross the liver and lung capillary networks and the blood-brain barrier (BBB) and eventually reach the brain. In normal situations, cells are not able to pass through the BBB; however, there is evidence that the BBB becomes leaky in the case of acute lesions and inflammations of CNS tissues (Engelhardt and Sorokin 2009). The intra-arterial route is more beneficial than the intravenous route because the stem cells do not need to cross the liver and lung capillary networks. Only $2 \%$ of intravascular applied stem cells were reported to penetrate into the substantia nigra (Wang, Yasuhara et al. 2010).

\section{Intranasal/intrathecal administration}

Intranasal administration and intrathecal administration of stem cells are more effective because the blood-brain barrier and the capillary networks of the lung and liver can be avoided. Intranasal administration may allow CNS penetration through the olfactory epithelium and the fila olfactoria. Intrathecal application will also bypass the blood-cerebrospinal fluid (CSF) barrier which, compared to the BBB, is easier for stem cells to cross (Redzic 2011). In CSF, stem cells are also forced to express a neural lineage direction (Ye, Zeng et al. 2011). Trophic factors can also pass through CNS without any problems. When in contact with CSF, stem cells produce neuroprotective factors such as BDNF and GDNF; however, when the cells are in contact with serum they mainly produce endothelial growth factors (Kinnaird, Stabile et al. 2004).

\section{Intracerebral administration}

Finally, stem cells may also be applied directly into the cerebral nigrostriatal regions through stereotactic brain surgery. Ipsilateral grafted stem cells and/or paracrine factors produced by those cells will also reach the contralateral nigrostriatal regions (Ourednik, Ourednik et al. 2002).

\section{When to apply stem cells?}

A recent comprehensive meta-analysis (de Munter, Lee et al. 2013) illustrated the beneficial effects of stem cell application in 10 published preclinical studies with ASCs that were expanded, 
but not induced in three different models of parkinsonism (6-OHDA, MPTP and MG-132 induced lesioning). ASCs were applied intravascularly or directly into the nigral striatum. The time of application related to the onset of the lesion, and this varied from 0 to 30 days after lesioning. Five out of 6 studies in which the ASCs were applied within 14 days after lesioning reported significant improvements both in rotational behavior and the preservation of $\mathrm{TH}^{+}$cells when compared to the vehicle groups. Three out of 4 studies in which the ASCs were applied 14 days or more after the lesioning also reported significant, but less impressive improvements in rotational behavior and/or in the preservation of $\mathrm{TH}+$ cells compared to the vehicle groups. Behavioral effects in the early-treated animals (40-80\%) exceeded those in the later-treated animals (2-43\%). These findings suggest that early intervention with stem cells induces more clinical effects compared to later interventions. Currently, only a few studies in patients with parkinsonism treated with ASCs have been published. Clinical results reported from intracerebral (Venkataramana, Kumar et al. 2010, Venkataramana, Pal et al. 2012) or intravascular (Lee, Lee et al. 2012) application of autologous (Venkataramana, Kumar et al. 2010, Lee, Lee et al. 2012) or allogenic stem cells without immune suppression (Venkataramana, Pal et al. 2012), in PD (Venkataramana, Kumar et al. 2010, Venkataramana, Pal et al. 2012) and/or MSA patients (Lee, Lee et al. 2012) did not draw any conclusions, but the improvements that were described were encouraging, if modest. It is likely that the effects were modest because stem cells were applied in late, advanced parkinsonism.

\section{How to interpret the effects in animal models of parkinsonism?}

The reported significant effects, especially after early grafting, in animal models and in humans with parkinsonism (although the results from end-stage MSA patients are still controversial) might be reached by trans-differentiation of the applied stem cells and by immunomodulation of these cells; they can also be reached by stimulation of neural plasticity by stem cell-secreted paracrine factors that modulate brain tissue repair (Meyer, Maisel et al. 2010).

\section{Trans-differentiation}

It is not likely that intravascular grafted stem cells pass the BBB. Less than $2 \%$ of these stem cells were found to penetrate the CNS in an acutely injured brain (Wang, Yasuhara et al. 2010). After intracerebral grafting, these numbers may be significantly higher. In vitro, ASCs are capable of transdifferentiating into dopamine-producing neurons (Tatard, D'Ippolito et al. 2007). However, it is not known if the phenotype of the reproduced neurons is similar to the originally lost DA producing cells. It is also still unknown if trans-differentiation is possible in living animal models or in humans. Grafted cells in PD patients are vulnerable for transmissible degradation, and therefore those cells might not bring definite stable improvements (Olanow and Brundin 2013).

\section{Immunomodulation}

Epidemiological studies indicate that anti-inflammatory medication use in PD patients provides some protection, which supports the concept that microglial activation is an important component of disease progression. While the evidence supports a role for the innate activation of microglia by a-synuclein, more recent work has revealed a role for their up-regulation through the adaptive immune system. It is also supported by the presence of $\mathrm{CD} 8^{+}$and $\mathrm{CD} 4^{+} \mathrm{T}$-cells in post-mortem PD brain tissue (Brochard, Combadiere et al. 2009). 


\section{Neurotrophic factors}

Neurotrophic factors promote neuroplasticity with cell protection and cell repair (Zhou and Shine 2003). Preclinical animal studies reported beneficial effects in behavior and in surviving $\mathrm{TH}^{+}$cells after ASC grafting.

Increased GDNF and BDNF levels seem to be responsible for these effects (Somoza, Juri et al. 2010). In one study, GDNF was measured and found to be significantly higher in the ASC-treated group compared to the placebo-treated group; this suggests a direct relationship between improved clinical outcome, more preserved $\mathrm{TH}^{+}$cells, and the increased expression of GDNF (Blandini, Cova et al. 2010). In another preclinical study with epigenetically induced ASCs, the stimulated secretion of GNDF and BNDF resulted in a higher number of surviving striatal $\mathrm{TH}^{+}$ neurons in the lesioned rat striatum compared to placebo-treated rats. This was accompanied by a higher striatal dopamine level and a decreased rotational behavior, illustrating the suggested paracrine effect of ASCs (Somoza, Juri et al. 2010). Spared $\mathrm{TH}^{+}$cells contralateral to the applied intranigral ASCs argue for a paracrine mechanism (Blandini, Cova et al. 2010).

Finally, the intranigral application of GDNF in rodents one week prior to ipsilateral nigral 6-OHDA lesioning rescued $70 \%$ of the nigral $\mathrm{TH}^{+}$cells compared to a loss of $70 \%$ of these cells in the nonpretreated, lesion-control animals. This resulted in a significantly reduced rotational behavior (Chen, Liu et al. 2003). In vitro, the genetic expression profile can be programmed to boost BDNF/GDNF production following cultivation of stem cells in enriched medium (Somoza, Juri et al. 2010). Although the stimulation of neurotrophic factor production in vitro and in vivo seems promising, so far all translational clinical trials with these factors in PD patients were disappointing. The trials were prematurely terminated due to adverse events and a lack of significant improvement, potentially due to an adenovirus-induced immune response (Dass, Olanow et al. 2006).

\section{Conclusions}

There is an unmet need in parkinsonism for protective and restorative therapies. Hopefully, adult stem cells will inhibit disease progression by secreting neurotrophic factors and by stimulating neuroplasticity. Even if they are successful, age and concomitant diseases, including diabetes or renal failure, may influence the quality of the adult stem cells, thereby limiting their use. Further research is essential to further develop this promising field of cell-based therapies.

\section{In summary:}

- ASCs (both HSCs and MSCs) are the optimal cells to graft because both are safe and promote neuroplasticity, but unlike induced pluripotent stem cells and embryonic stem cells they do not induce the development of malignancies.

- The observed clinical effects are induced rather by the production of neurotrophic factors than by trans-differentiation.

- Intranasal and intrathecal administration seems to be the best route of administration.

- Expanding MSCs and HSCs is possible but might induce chromosomal aberrations.

- Cryopreservation of stem cells is safe and cell banking may be a good strategy for overcoming the effects of aging and chronic diseases, such as renal failure and diabetes.

- Translated from preclinical studies, the strongest clinical effect is reached when applying the cells in a very early stage of the disease. 


\section{Chapter 3}

\section{Bone marrow-derived stem cells in acute vascular ischemia}

\section{Introduction chapter 3}

Chapter 3 is based on the first experiments with a transplantation of a fresh bone marrowderived human stem cell preparation, based on a buffy-coat procedure, in animals with an hindlimb ischemia. This buffy-coat procedure is based on centrifugation.

As erythrocytes, lymphocytes, stem cells and plasma with platelets have different weights, they will be separated in different layers using centrifugation. The white layer contains lymphocytes and stem cells, the red layer contains erythrocytes, and the lucent layer consists of plasm and proteins. In the animals with the induced vascular occlusion, only the white layer containing mesenchymal and hematopoietic stem cells (both having angiogenetic potentials) is injected intra-arterial and intra-muscular.

The purpose of this experiment was to test the effect of these stem cells on micro-angiogenesis in rats with an acute occlusion of a main limb artery, and to compare this effect with those in animals with an identical occlusion without any intervention. 


\subsection{Efficacy of Different Doses of Human Autologous Adult Bone Marrow Stem Cell Transplantation on Angiogenesis in an Immune Deficient Rat Model with Hind Limb Ischemia.}

Beugels J, De Munter JPJM, Van der Hulst R, Kramer BW, Wolters ECh (2019); J Stem

Cell Res Dev Ther S1002 dx.doi.org/10.24966/SRDT-2060/S1002

Background: Stem cell transplantation has been implied to facilitate angiogenesis by direct paracrine effects on signaling pathways. There are many different sources, types, dosages and routes of administration of stem cells under investigation. In this study we tested the concomitant intramuscular and intravenous administration of human mesenchymal and hematopoietic stem cells from bone marrow aspirates in three different dosages in order to establish an optimal dose for angiogenesis. For this purpose a nude T cell deficient rat model with hind limb ischemia was used as a model for angiogenesis which did not warrant immunosuppressive drugs.

Methods and Results: Seven days after a surgical occlusion of the A. iliaca externa in the right hind limb, a baseline Digital Subtraction Angiography (DSA) was performed, and animals were intra arterially and intramuscularly injected with low, medium or high concentrations of human mesenchymal stem cells or with a saline $0.9 \%$ solution (vehicle). At day 35 , DSA was repeated, and the images of both registrations were compared between the different concentration groups and the vehicle group. DSA clearly demonstrated the presence of occlusions, resulting in moderate to severe ischemia 7 days after ligation. Comparing Mean Gray Values at day 35 DSA versus day 7 DSA, the difference did show a natural decrease in the Vehicle-treated group, whereas low- and medium human mesenchymal stem cell doses established a significant increase. High dose had a tendency to decreased values resulting in muscle damage and further occlusions. A dose response could not be detected.

Conclusion: This study showed that the centrifuged human bone marrow suspension containing low and medium concentrations of mesenchymal and hematopoietic stem cells significantly improved the hind limb ischemia as compared to vehicle-treated group in T-cell deficient rats, and that this effect is almost lost with higher doses, may be due to hyper viscosity.

\section{Introduction}

Angiogenesis is essential for the function of most organs. The angiogenesis after organ injury or transplantation is key to the survival, regeneration and functioning of the affected organ. Stem cell trans-plantation was established to induce promotion of repair of ischemic tissue partially through angiogenesis which has been shown in models of hind limb ischemia for example (Tateishi-Yuyama, Matsubara et al. 2002). Stem cell therapies differ with respect to the origin of the cells, cell numbers and route of application (Fadini, Agostini et al. 2010, Scheubel, Holtz et al. 2010, Klepanec, Mistrik et al. 2012, Wang, Li et al. 2014). Studies were for example performed with unfractionated bone marrow cells, endothelial progenitor cells and/or peripheral blood mononuclear cells which make comparison very difficult (Fadini, Agostini et al. 2010). In addition, the different cell types have different properties and functions. A recent meta-analysis could not 
identify an approach that is clinically established neither with respect to cell type, dose route of application (Fadini, Agostini et al. 2010, Abdul Wahid, Ismail et al. 2018). Mesenchymal stem cells offer a unique combination of anti-inflammatory and regenerative effects whereas endothelial stem cells may directly promote angiogenesis (Ponemone, Gupta et al. 2017). In animals with subacute ligated femoral arteries, neo-angiogenesis with restoration of the blood flow to the ischemic limb was reported to develop after injection of different kinds of stem cells (Schatteman, Hanlon et al. 2000, Hirata, Li et al. 2003, Pesce, Orlandi et al. 2003, Kinnaird, Stabile et al. 2004, Kinnaird, Stabile et al. 2004, Urbich and Dimmeler 2004, Lian, Zhang et al. 2010, Lawall, Bramlage et al. 2011). These findings are considered to be the effect of both cell presence and the paracrine secretion of growth factors and cytokines. The role of the various cell types of the transplants (mesenchymal cells, hematopoietic cells, etc.), however, remains unclear, although after transplantation, both the number of circulating endothelial progenitor cells increases (Takahashi, Kalka et al. 1999, Shintani, Murohara et al. 2001). Some cells of the transplant were found to be incorporated into newly formed collaterals in ischemic areas (Asahara, Masuda et al. 1999, Takahashi, Kalka et al. 1999). However, the intra-arterial versus the intramuscular route was found to be equivalent which raises questions about the mechanisms since no direct initial contact of the transplanted cells with the injured tissue was apparently necessary (Klepanec, Mistrik et al. 2012, Abdul Wahid, Ismail et al. 2018). Although a systemic effect may be suspected, there was however a dose dependency in response (Klepanec, Mistrik et al. 2012).

We asked in this study whether we can determine an optimal dose for the administration of unfractionated human bone marrow derived cells, containing a mixture of mesenchymal, hematopoietic stem cells and angiotrophic factors after centrifugation, in an immunodeficient animal model in order to promote angiogenesis after hind limb ischemia. We combined intraarterial with intramuscular administration of human cells to test for enhanced revascularization after 35 days in a dose dependent manner.

\section{Methods}

The animal experiments were executed after animal approval was obtained. We chose an immunodeficient animal model which does not mandate the concomitant administration of immunosuppressive drugs in order to avoid confounding. After clinical examination, 35 female animals were anesthetized and the right $A$. iliaca externa was proximally occluded to establish a right hind limb ischemia. Rats were anesthetized with isoflurane, and the right hind limb was shaved with an electric clipper, and disinfect-ed with ethanol. The animals then were subcutaneously injected with tramadol $2 \mathrm{mg} / \mathrm{kg}$ Body Weight (BW) for analgesia. After an incision in the right hind limb, the A. iliaca externa was exposed and proximally occluded with Vycril 5-0. Subcutaneous tissue was then sutured with Vycril 3-0 and the skin was closed with Michel clamps. After the occlusion, the animals were kept one week in their cages for recovery before digital subtraction angiography. Seven days after the occlusion, the animals were again anesthetized with isoflurane and then the ventral region of the neck was clipped and disinfected with ethanol. The animals received Tramadol $2 \mathrm{mg} / \mathrm{kg}$ BW subcutaneously for analgesia. First, a conventional X-Ray was performed to document the anatomic locations for further analysis. Secondly, the Arteria Carotis Communis Sinistra (ACCS - left common carotid artery) was 
prepared and a catheter (1270.02 Umbilical Catheter, Vygon, 2,5 French $30 \mathrm{~cm}$ ) was inserted into the ACCS and guided into the aorta, with the catheter tip ending directly in front of the bifurcation of the A. iliaca interna. Finally, a Digital Subtraction Angiography (DSA) was performed with a GE OEC 7700 X-ray device and using 0.3 to $0.5 \mathrm{ml}$ of Ultravist ${ }^{\circledR}$ in a fast bolus to visualize the vessels of the rats. The complete DSA procedures were repeated at day 35 after the occlusion with the difference that the catheters were then inserted directly in the abdominal aorta. The DSA device (GE, OEC 7700) settings were 2 images per second at 1,1-1,2 mA and 52$54 \mathrm{mV}$. The analysis of the angiography was performed using Image ${ }^{\circledR}$ software.

\section{Cell Preparation}

Six healthy volunteers were recruited for iliac crest-bone marrow collection, after giving written informed consents. Bone marrow samples were processed under Good Manufacturing Practice (GMP) conditions by centrifugation according to standard operating protocols to obtain the buffy coat (internal product name ASCT01). The samples were analysed to assess the total number of viable $\mathrm{CD}_{34}{ }^{+}$cells. Within 48 hours after the bone marrow procurement, the samples were administered to the rats. During the whole procedure, bone marrow cells were kept between 28 degrees Celsius, which ensured a cellular viability greater than $95 \%$ (data not shown). Directly before administration to the rats, bone marrow cell suspensions were care-fully resuspended and adjusted with sodium chloride $0.9 \%$ (vehicle) solution to the needed concentrations. Table 1 gives for each group the mean number of administrated viable $\mathrm{CD}_{3} 4^{+}$cells per kg. Study drugs (bone marrow cell suspension and vehicle) were injected both intra-arterial (through the DSA catheter over a period of $10 \mathrm{~min}$ ) and intramuscular through syringes, warmed in the water bath at $37^{\circ} \mathrm{C}$ prior to injection. The ratio of cells injected intraarterially and intra-muscularly was 2:1. Cell concentrations for intra-arterial injections are given in table 1.

Table 1

Overview mean number of $\mathrm{CD} 34^{+}$Cells per treatment group.

\begin{tabular}{llc}
\hline Concentration group & $\begin{array}{l}\text { Mean number of viable CD34+Cells } \\
\text { administered intra-arterially (I.A.) and } \\
\text { intra-muscularly (I.M.) per animal }\end{array}$ & Total number of rats \\
\hline Low Concentration & I.A.: 327,600 CD34+Cells $/ \mathrm{kg}$ \\
I.M.: $163,800 \mathrm{CD} 34^{+}$Cells $/ \mathrm{kg}$ & 7 \\
Medium Concentration & I.A.: $688,800 \mathrm{CD} 34^{+}$Cells $/ \mathrm{kg}$ \\
I.M.: $344,400 \mathrm{CD} 34^{+}$Cells $/ \mathrm{kg}$ & 6 \\
High Concentration & I.A.: $1,308,000 \mathrm{CD} 34^{+}$Cells $/ \mathrm{kg}$ \\
& I.M.: $654,800 \mathrm{CD} 34^{+}$Cells $/ \mathrm{kg}$ \\
\hline
\end{tabular}

The primary outcome of this study was the change in the vascular density of the blood vessels as an indicator of angiogenesis in the ischemic limbs after treatment with various doses of bone marrow cells versus treatment with the vehicle. Therefore, Regions of Interest (ROI) were set by conventional X-ray from the head of the femur to the distal end of the fibula of both the vascular occluded right and the intact left hind limbs of the individual rats. In these regions, the Mean Gray Value (MGV) was visualized in the digital images taken during the subtraction angiography 
(DSA) at day 7 and day 35 (MGV-7 and MGV-35). MGV was calculated using the pixel calculator of the Image ${ }^{\circledR}$ Software.

The effect of the unilateral ligation of the (right) iliac artery was studied by comparing MGV-7 of both legs. Then, the effect of the vehicle on vascularization in the right hind limb after ligation was studied by comparing Vehicle MGV-7 and MGV-35 calculations in the right hind limb. The effect of bone marrow cells on the vascularization in the ischemic legs was studied by comparing their MGV-7 and MGV-35 calculations in the ligated right hind limbs with the vehicle MGVs.

\section{Statistical Analysis}

The changes in MGV for the different bone marrow cells treated groups were tested to the changes in the MGV for the Vehicle group using Analysis of Variance (ANOVA).The individual changes between the MGV at day 35 and day 7 for every group were tested within the group using a pair wise T-test. At last, the positive changes in the MGV ratio's for the occluded legs are grouped as 1 . No changes or negative changes are grouped as 0 . With a Chi-square nonparametric test the bone marrow treated group was compared with the Vehicle group and tested for significance. Statistical significance was assumed with $p<0.05$ levels.

\section{Results}

The surgery was successfully performed in all animals. There was no difference in body weight between the different treatment groups and the vehicle group before the surgery (data not shown).In the treatment group treated with the high bone marrow cell dose, two animals died during the application of this dose, and another one had to be sacrificed during follow-up. During the follow-up of the treated animals, all remaining animals showed an uncomplicated and expected body weight development (data not shown). During the study the limb temperatures were measured. The temperature of the limb was stable over time (data not shown). The MGV7 and MGV-35 for both vascular occluded right and in-tact left legs were calculated for each animal. There was a significant decrease in MGV-7 in the occluded right legs as compared with the intact left legs in MGV-7 (Figure 1a), which showed about $40 \%$ loss of calculated vascular density as compared to the left MGV. During the follow-up, vehicle-treated animals showed significant progression up to roughly $60 \%$ of the MGV at day 35 (Figure 1 b) which is in line with results in immunocompetent animal models (Kinnaird, Stabile et al. 2004)

At day 35, a significant increase of vascular density was found in all other bone marrow cells treated groups compared to the vehicle treated group (Figure 1b) except in the high dose group. To set these changes into proportion to each other, figure 1c presents the percentages of change in MGV at day 35 for the occluded leg for the different ASCT01 and vehicle treated groups. Low and medium dose of unfractionated bone marrow cells improved mean gray values significantly which high dose treatment did not. The proportional improvement was highest in the low dose bone marrow cells group. We then asked the question whether there was a correlation between the number of CD34+ cells and the MGV improvement. 


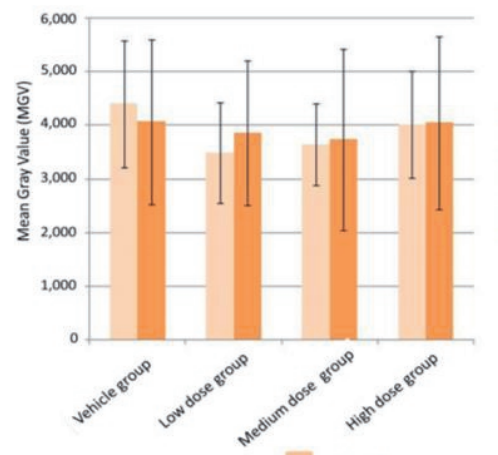

1a

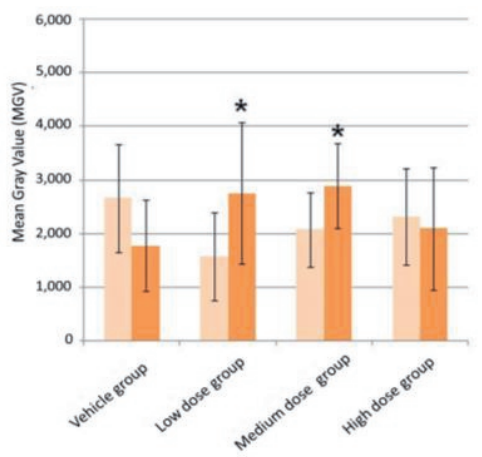

$1 \mathrm{~b}$

At day 35

* Significance compared to vehicle group with ANOVA

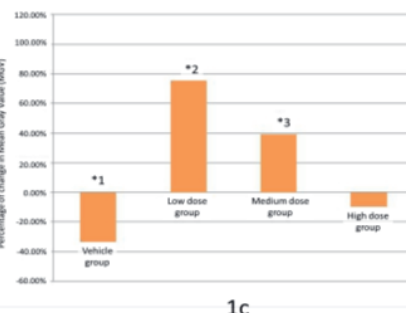

Figure 1. Overview MGV-7 and MGV-35 values in the ischemic right hind leg (left) and in the intact left hind leg. (1a): MGV in intact left leg for Vehicle, low dose, medium dose and high dose group. (1b): MGV in occluded right leg for vehicle, low dose, medium dose and high dose group. Significance compared to MGV-7 with ANOVA marked with ${ }^{*} p<0.01$. (1c): Percentage of change between the MGV at day 7 and 35 for the occluded leg and the different groups. $\left({ }^{*} 1\right)$ Deterioration of the limb ischemia in vehicle treated animals (Pair wise T-Test $\left.p=0.003\right)$; $\left({ }^{*} 2\right)$ Difference after low dose cell therapy to the vehicle treated group (ANOVA $p<0.001$ ); ( $\left.{ }^{*} 3\right)$ Difference after medium dose cell therapy to the vehicle treated group (AOVA $p<0.01$ ). No improvement after high dose therapy.

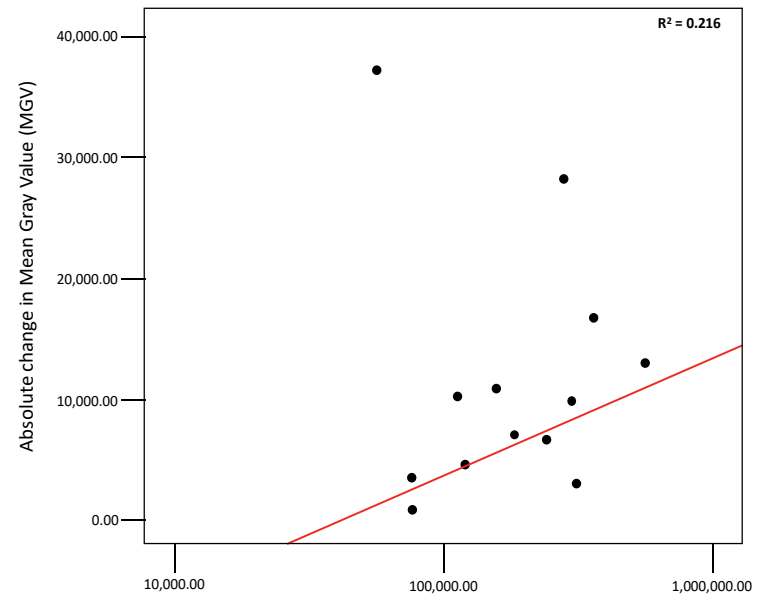

Absolute number of administered $\mathrm{CD}_{3} 4^{+}$Cells on a log-scale

Figure 2. The dose-response graph describes the relationship between the total number of $\mathrm{CD}_{34} 4^{+}$cells in low and medium dose ASCTO1 and the improvement on day 35 in Mean Gray Value (MGV). The values are weighted by dividing the expected value by the measured value for each point. The $R^{2}$ is 0.216 , which means that no correlation between the total CD $34^{+}$and the Mean Gray Value was found. 
Figure 2 represents the dose response curve which showed no clear correlation between the absolute number of $\mathrm{CD}_{3} 4^{+}$cells administered intra-arterially and intramuscularly and the absolute change in MGV at day 35 compared with day 7. The concomitant application of cells intraarterially and intramuscularly into the affected limb was done to optimize the revascularisation. Angiographical data, as obtained during this study, illustrated that the newly formed vessels were still very small. A representative study is shown in figure 3 .
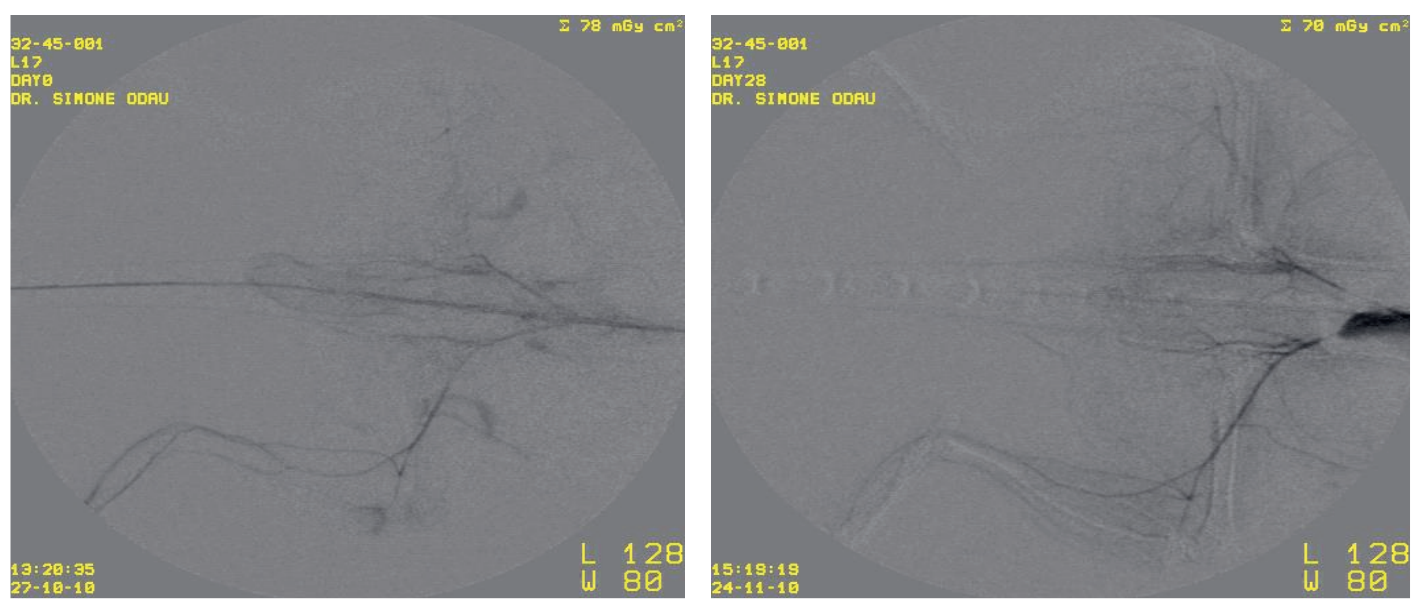

Figure 3. Example of a set of angiographic images of a with human bone marrow cells (ASCTO1) treated T cell deficient rat. The left image is taken at day 7 (before treatment) and the right image is taken at day 35 after the treatment with low dose of human bone marrow cells. Despite concomitant application of cells intramuscularly and intravenously, the newly formed vessels are very small

\section{Discussion}

We used for our study a T cell deficient rat model in order to avoid confounding effects of immunosuppressive drugs. The critical limb ischemia did deteriorate in the vehicle group, which is in line with the natural course of the disease. In order to promote the effects of the unfractionated bone marrow preparation we tested the combined intra-arterial/intramuscular treatment with human bone marrow-de-rived stem cells in the ischemic leg, at day 35 in a dose dependent manner. We found no dose dependency but a profound clinical improvement after the lower and medium cell concentrations with a significant increase of vascular density, if compared with the reduced vascular density at day 7 . This significant repair of vascular density, though, was not seen in the animals treated with higher bone marrow cell concentrations. Treating the ligated legs with these high doses, on the contrary, had a non-significant tendency to further loss of vascular density as compared to the MGV-7 situation was established.

We tested in 5 animals the highest possible cell concentration of bone marrow cells which resulted in the death of 2 out of 5 rats during administration of this preparation. Although in general, bone marrow cell treatment was well tolerated in the low and medium dose groups, in the higher dose groups there were some difficulties with the intra-arterial administration, due to the high viscosity of the solutions, probably resulting in physical obstruction in these vessels despite the rather long infusion period.

Angiographical data illustrated that the newly perfused vessels were still very small (Figure 3). This could indicate that our intra-arterial and intramuscular approach did not generate an 
expedition of the underlying angiogenesis. The process of angiogenesis is starting up slowly, making the clinical improvements initially difficult to detect. Therefore, a longer follow up period after treatment would probably result in more and longer blood vessels formation and diameter in the treatment groups. This is most likely not possible in the placebo group due to the natural deterioration of the hind limb occlusion.

Our approach of intra-arterial plus intramuscular administration was very different from currently clinically tested intramuscular or intra-arterial approaches (Ponemone, Gupta et al. 2017, Abdul Wahid, Ismail et al. 2018). We chose the combined approach to bring the cells to the circulation and allow access from the endothelial side for cell to cell interaction and secretion of paracrine factors (Kinnaird, Stabile et al. 2004, Sahoo, Klychko et al. 2011). In addition, the allogenic cells have a short half-life irrespective of the immunosuppression of the animals (Schiattarella, Perrino et al. 2014). The chosen xenograft model, in which T-cell deficient rats were treated with human bone marrow stem cells without any further immune suppression, is useful in order to avoid the confounding effects of immunosuppression (Amann, Luedemann et al. 2009). It has the advantages, such as better animal treatment conditions, and better mimicking the human clinical situation when compared with studies were immune suppressive drugs were used.

It would be interesting to also assess the effect of individual treatments (intra-arterial and intramuscular administration) to clarify the contribution of each route of stem cells administration. Since clinical trials have shown equipoise between the two administration routes, we did not include these groups in order to reduce the number of experimental animals.

We faced serious limitation due to the high viscosity which makes this approach less promising (Fadini, Agostini et al. 2010). Our study has additional limitations with respect to the time period of follow up and the mode of administration.

The approach to test cell-based or cell-derived preparations in T-cell deficient rats is however possible and allows the assessment of cell-based or cell-derived preparations without additional drugs administration since the quest for the best cell preparation is still ongoing (Schiattarella, Perrino et al. 2014). The different properties of the cell mixture of bone marrow versus mesenchymal stromal cells offer opportunities in particular with respect to immunomodulation and/or regeneration (Aurora and Olson 2014). Despite the evolving evidence for clinical effectiveness of autologous bone marrow derived treatment (Ponemone, Gupta et al. 2017), the preparation of bone marrow and the selection of subgroups of cells from bone marrow warrants further studies (Fadini, Agostini et al. 2010).

\section{Conclusion}

This study reports that $\mathrm{T}$ cell deficient rats can be used as a model for angiogenesis after critical limb ischemia. We used the immunosuppressed animals to test centrifuged human bone marrow suspension containing mesenchymal and hematopoietic stem cells which significantly improved hind limb perfusion in T cell deficient rats. This study did show that the centrifuged human bone marrow suspension containing low and medium doses of bone marrow cells significantly improved the hind limb ischemia as compared to vehicle-treated group in T-cell deficient rats, and that this effect was lost with higher doses, most likely due to hyper viscosity. 


\section{Chapter 4}

\section{Bone marrow-derived stem cells in acute neurodegenerative processes}

\section{Introduction chapter 4}

Chapter 4 focus on two experiments performed with a minimal manipulated stem cell preparation derived from human bone marrow in acute preclinical models for a traumatic neurodegenerative disorder. As animal models for traumatic brain injury are quite complex, we chose for models displaying traumatic spinal cord injuries ( $\mathrm{SCl}$ ). The stem cell preparation was manufactured under good manufacturing practice (GMP). After permission of the ethic committee of Maastricht university medical center $\left(\mathrm{MUMC}^{+}\right)$and the university Maastricht, bone marrow collection was performed in healthy volunteers. Conform the results of the preclinical studies (chapter 2), in these experiments, we avoided any co-medication with immune suppressive medication, as this medication might present a major confounder masking the results of neuroprotection and induces also a negative effect on the plasticity/viability of stem cells. The first part of this chapter (4.1.) presents the experiments in T-cell deficient rats with a balloon compressed spinal cord injury, the second part (4.2.) the experiments in normal immune competent rats with a drop-weight-induced spinal lesion. Results were compared with those found in placebo-treated as well as (mimicking human $\mathrm{SCl}$ treatment) in methylprednisolonetreated $\mathrm{SCl}$-rats. These experiments were designed for the confirmation of the hypothesized decrease of the spinal cord lesion-induced secondary inflammation. Special attention was given to apply fresh stem cell preparations in a very limited time window, within 24 hours after the animal lesioning (Figure 1).

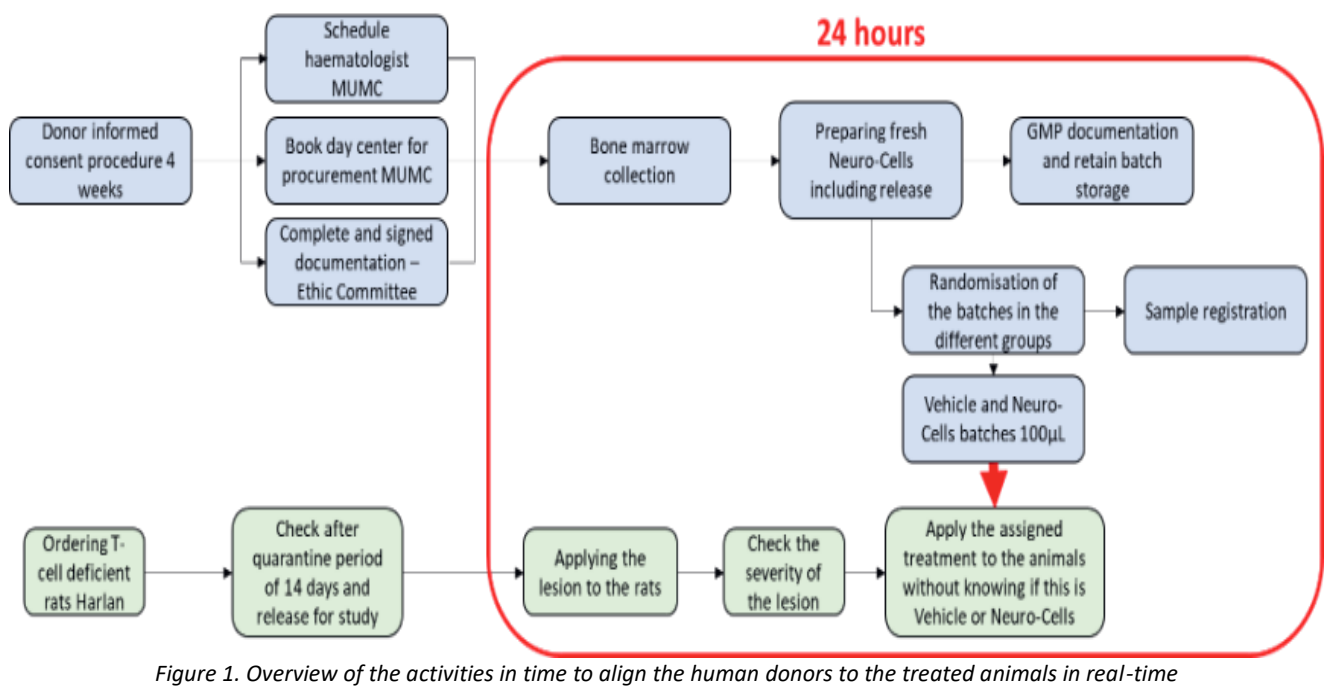




\title{
4.1. Standardized human bone marrow-derived stem cells infusion improves survival and recovery in a rat model of spinal cord injury
}

De Munter JP, Beugels J, De Munter S, Janssen L, Cillero-Pastor B, Moskvin O, Brook G, Pavlov D, Strekalova T, Kramer BW, Wolters ECh (2019) J Neurol Sci 402:16-29.

\begin{abstract}
Spinal cord injury (SCl) is an incurable disorder with an unmet need of an effective treatment. Recently, autologous human bone marrow-derived stem cells have shown to promote functional improvement, due to their anti-inflammatory and regenerative/apocrine properties. In this study, the primary objective was to test whether a single intrathecal injection with a $100 \mu \mathrm{L}$ suspension of 400,000 fresh human bone marrow-derived $C D 34^{+}$and an equal number of CD105 stem cells (Neuro-Cells(NC)), one day after balloon-compression of the spinal cord, improves motor function and reduces secondary damage in immune-deficient rats. During the first 5 weeks after this intervention, NC significantly improved locomotor recovery and induced less injury-associated adverse events compared to vehicle-treated rats. Histological analysis showed that NC reduced astrogliosis, and apoptosis early after administration (day4), but not at a later stage (day56) after $\mathrm{SCl}$. Proteomic studies (at day56) pointed to the release of paracrine factors and identified proteins involved in regenerative processes. As stem cells seem to reach their effects in acute lesions by mainly suppressing (secondary) inflammation, it is thus realistic to expect a lower magnitude of their eventual beneficial effect in T-cell deficient rats, a fact reinforcing the robustness of Neuro-Cells efficacy. Taken together, this study indicates that an intrathecal instillation of Neuro-Cells holds great promise as a neuro-regenerative intervention in a clinical setting with acute $\mathrm{SCl}$ patients.
\end{abstract}

\section{Introduction}

The prevalence of spinal cord injury $(\mathrm{SCl})$ worldwide is estimated at 2.5 million cases and the financial burden per case is calculated to be between 200,000 and 260,000 Euros/year (DeVivo 1997). Pending severity of the injury, SCls may cause an (in)complete loss of sensory, motor, and vegetative functions under the level of the spinal cord involved: in legs (paraplegia) or in arms and in legs (tetraplegia). Traditionally, in $60 \%$ of the cases, traumatic spinal cord injury is caused by falls and by motor vehicle accidents (Norenberg, Smith et al. 2004), but recently more and more combat-wounded soldiers are affected (Schoenfeld, Laughlin et al. 2013). Due to the lack of disease-modifying interventions, life expectancy in SCI patients is impaired (Strauss, Devivo et al. 2006) and the quality of their lives is poor (McKinley, Meade et al. 2004, Gupta, Bathen et al. 2010). As a small functional improvement in $\mathrm{SCl}$ patients might come with a major increase in quality of life and daily independency, recently, much attention is given to control and reduce collateral damage of neural tissue by inhibiting the posttraumatic inflammatory cascades (Donnelly and Popovich 2008, Alexander and Popovich 2009, Silva, Sousa et al. 2014, Lawrence 2018). Less than $10 \%$ of functional long-tract connections is needed to enable locomotion (Blight 1983). Although this level of connectivity often remains after the injury, axons might become 
non-functional because of collateral damage resulting in neuro-degeneration at a later stage (Bunge, Puckett et al. 1993). Therefore, prevention of secondary damage in the acute phase of spinal cord injury is of utmost importance, which offers the opportunity of functional improvement by disease-modifying interventions (McDonald and Sadowsky 2002, Silva, Sousa et al. 2014). Until the recent past, steroids were applied for this purpose (Bracken 2002), although widespread use has stopped due to limited effects and severe adverse effects (Suberviola, Gonzalez-Castro et al. 2008, Botelho, Daniel et al. 2009).

In $\mathrm{SCl}$, a therapeutic intervention combining both anti-inflammatory and regenerative properties is an unmet need. Hypothetically, stem cells may be such an intervention, as one of the characteristics of adult stem cells (both hematopoietic and mesenchymal stem cells) is the ability to both inhibit inflammation and to mediate regeneration by increasing neuroplasticity in neurodegenerative processes (Schwarting, Litwak et al. 2008, Antonic, Sena et al. 2013, Akyurekli, Le et al. 2015, Chen, Jia et al. 2015, Neirinckx, Agirman et al. 2015, Assinck, Duncan et al. 2017, Nejati-Koshki, Mortazavi et al. 2017, Lawrence 2018, Jin, Medress et al. 2019).

Recent studies suggested that not only the site of the lesion, but also the timing of the administration of stem cells after the lesion are crucial for their beneficial effects in the context of the evolving post-traumatic inflammatory response (Donnelly and Popovich 2008, Wragg, Mellad et al. 2008, Alexander and Popovich 2009, de Munter and Wolters 2013, Wagey 2014, Assinck, Duncan et al. 2017, Nejati-Koshki, Mortazavi et al. 2017, Jin, Medress et al. 2019). Dose and number of cells administrated appear to be of less importance (Caplan 2017).

The objective of this study was to investigate whether a single intrathecal administration with 'Neuro-Cells' (a not substantial manipulated low immunogenic, fresh human bone marrowderived stem cell preparation, depleted of erythrocytes and the majority of the lymphocytes according to the manufacturing standard operating procedures of Neuroplast BV) provided a better survival and functional recovery in T-cell deficient rats after spinal cord injury. In this study, a moderate grade $\mathrm{SCl}$ was applied in rats by a moderate balloon compression of a spinal thoracic (Th 9) segment. Unfortunately, treatment of these animals with autologous stem cells or with a low-immunogenic rat stem cell preparation (following the manufacturing procedure of Neuro-Cells) is not realistic due to the limited volume of rat bone marrow, and the invasiveness of the cell collection procedure itself in rats.

Thus, T-cell deficient rats were selected to avoid both rejection of human stem cells and the use of immune suppressive drugs. Immune suppressive drugs are considered major confounders as they not only interfere with stem cells but also offer a cell protective effect to local neurons (Palladini, Caronti et al. 1996, Ibarra, Correa et al. 2003, Diaz-Ruiz, Vergara et al. 2004, Guo, Zeng et al. 2007). They can substantially influence the outcome in experimental studies after the effects of stem cell interventions in favour of the vehicle treated animals. Therefore, these drugs dampen neuro-inflammation following acute spinal cord injury and thus final damage, with consequent less sensorimotor and neurovegetative symptoms (Potas, Zheng et al. 2006). In comparison to normal, immune competent rats, the higher liability to infections may also have a significant effect on survival of the experimental animals (Potas, Zheng et al. 2006).

We hypothesized that infusion with Neuro-Cells $24 \mathrm{~h}$ after $\mathrm{SCl}$ will improve locomotor recovery by reducing secondary damage. Functional behavioral recovery was monitored weekly using the Basso, Beattie, Bresnahan (BBB) open field test (Basso, Beattie et al. 1995). Histological studies were performed 4- and 56-days post-surgery to determine the number of apoptotic cells, 
reactive astrocytes, and microglia infiltration in both vehicle and Neuro-Cells-treated animals. Moreover, we used mass-spectrometry technology to screen for and identify peptides in each site relative to the spinal lesion (rostral, lesion, caudal) obtained in vivo. We hypothesized that Neuro-Cells changes the composition of local peptides by down regulation of pro-inflammatory proteins as compared to the vehicle treated animals. This effect is expected to be the strongest in the lesion site as compared to the rostral and caudal sites.

\section{Methods}

\section{Animals and experimental design}

Adult male T-cell deficient A-thymic RH-Foxn1rnu (260-310g) purchased from Harlan (Harlan laboratories, The Netherlands) were housed in pairs during the acclimatization period, for postoperative care and throughout the rest of the experiments. Rats were maintained in an isolated part of the animal facility apart from immune competent animals and under standard housing conditions (12h light/dark cycle, lights on at 8:00a.m., humidity $40-60 \%$, temperature $22 \pm 1^{\circ} \mathrm{C}$ ) with ad libitum access to food and water. The Animal Care and Use Committee of the University of Maastricht reviewed and approved all animal surgeries, procedures, and post-operational care (permit number DEC2013-013). Laboratory personnel managed animals following the National Institute of Health Guide for the Care and Use of Laboratory Animals. A total number of 62 rats underwent surgical procedures for inclusion in this study (Fig.1).

\section{Transplantation}

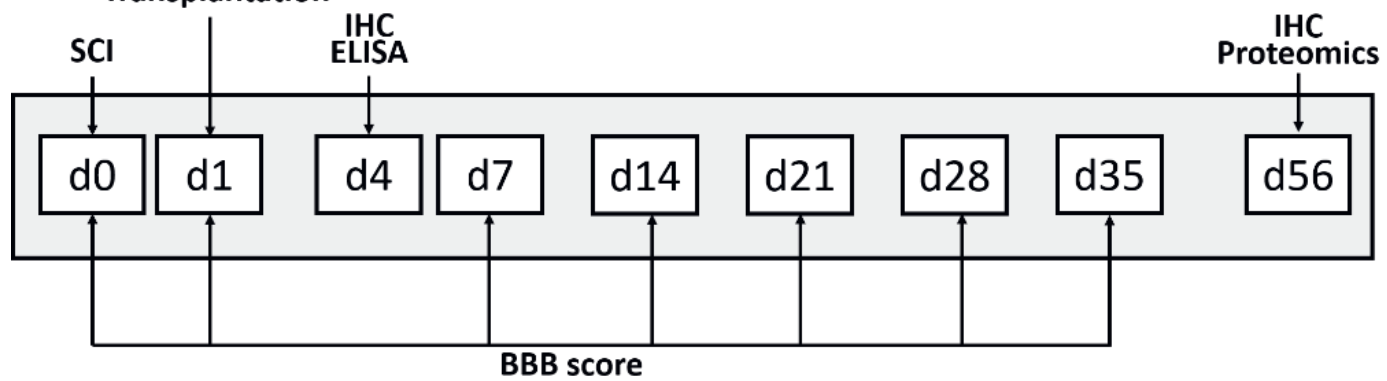

Figure 1. Experimental design. At day $0(\mathrm{dO})$, spinal cord injury (SCI) or a sham lesion was induced in T-cell deficient rats. Rats were injected intrathecal with vehicle or Neuro-Cells, caudal to the lesion at day 1. Immunohistochemistry (IHC) was performed at day 4 and day 56 after administration. Proteomic studies were performed at day 56. Throughout the study, Basso-Beattie-Bresnahan (BBB) measurements for assessing locomotor behaviour (Basso, Beattie et al. 1995) were performed on a weekly base.

\section{Spinal cord balloon compression}

After a subcutaneous injection of buprenorphine $(0.05 \mathrm{mg} / \mathrm{kg})$, animals were anaesthetized (3$4 \%$ Isoflurane) and maintained (1.5-2.5\% Isoflurane, Sigma-Aldrich) in anaesthesia with a stable body temperature of $37^{\circ} \mathrm{C}$. Having removed the spinal processes T10-T11 after a 2-cm midline incision at T10-L1, a small hole (1.5mm diameter) was drilled in the vertebral arch T10, using a surgical microscope (Vanicky, Urdzikova et al. 2001). After opening the periosteal membrane in order to allow direct visualization of the spinal cord with intact dura mater, a groove was drilled in the midline on the dorsal surface of the vertebral T11 lamina. Then, an epidural inserted 
French Fogarty catheter (Baxter Healthcare Corporation, Irvine, CA) filled with saline and connected to an airtight $50 \mu \mathrm{L}$ Hamilton syringe type 1705 , cranially for $1 \mathrm{~cm}$, was guided through this groove, thus positioning the center of the balloon at T8-T9. In case of SCl-lesioning, but not in sham-lesioning, the balloon was then rapidly inflated with $15 \mu \mathrm{L}$ saline and held in situ during 5 min before deflating and removal of the catheter, closing the wound and terminating anaesthesia. Post-operative care included subcutaneous application of buprenorphine $0.05 \mathrm{mg} / \mathrm{kg}$ during 4 days to relief the pain.

\section{Neuro-Cells}

Neuro-Cells (NC) is the working name (patent WO2015/059300A1) of a fresh, standardized human bone marrow derived stem cells containing product, that is produced under good manufacturing practices (GMPs) without expansion and/or labelling (or other major manipulation) of the stem cells. Neuro-Cells comprises of hematopoietic stem cells and their progenitors (HSCs), mesenchymal stem cells and their progenitors (MSCs) and other mononuclear cells. Four healthy male volunteer donors were recruited with informed consent for collection of $50-75 \mathrm{~mL}$ bone marrow from their iliac crest under local anaesthesia, following standard operating procedures. Neuro-Cells was depleted from erythrocytes by Ficoll (GE Healthcare, Chicago, III.) density gradient centrifugation (at $400 \mathrm{~g}$, at room temperature) and the number of lymphocytes was substantially reduced (Table1) by positive selection between 95 and $97 \%$ and resuspending the remaining cells in Ringer lactate.

MSCs and HSCs were characterized by flow cytometry (Miltenyi, Germany). The group of MSCs was identified by being positive for CD73, or CD90, or CD105 and negative for CD34 and CD45 and CD14 (Dominici, Le Blanc et al. 2006).

Table 1

Characterization of cell population in Neuro-Cells

\begin{tabular}{ll}
\hline Cell population in Neuro-Cells & $\begin{array}{l}\text { Mean absolute number of cells } \\
\text { injected in each animal (in } 100 \mu \mathrm{L})\end{array}$ \\
\hline Total nucleated cells & $1.2 \times 10^{7}$ \\
HSC: total CD34 cells & $4.0 \times 10^{5}$ \\
MSC: CD271+ cells & $7.8 \times 10^{4} \pm 2.6 \times 10^{4}$ \\
MSC: CD133+ cells & $1.5 \times 10^{4} \pm 0.5 \times 10^{4}$ \\
MSC: CD90 cells & $3.7 \times 10^{3} \pm 1.3 \times 10^{3}$ \\
MSC: CD105+ cells & $3.5 \times 10^{5} \pm 2.0 \times 10^{5}$ \\
MSC: CD73 cells & $4.5 \times 10^{3} \pm 2.1 \times 10^{3}$ \\
\hline
\end{tabular}

HSCs were positive for CD34, and CD38. Every Neuro-Cells batch fulfilled the GMP release criteria of at least 4 million HSCs and an equal number of MSCs suspended in 10mL Ringer-lactate for intrathecal application.

As for the intra-donor variation, the intrathecal treatment of the $\mathrm{SCl}$-rats was calibrated to $4.0 \times 105 \mathrm{CD}^{+} 4^{+}$cells in vials of $100 \mu \mathrm{L}$. However, due to the fresh nature of the cells and the calibration based on the number of $\mathrm{CD}_{3} 4^{+}$cells, the individual number of MSCs will differ per used donor. Table 1 gives an overview of the number of cells applied to the individual rats. 


\section{Intrathecal infusion}

At day 1 post-surgery, we subcutaneously injected the rats with $0.05 \mathrm{mg} / \mathrm{kg}$ buprenorphine (AST Farma B.V., The Netherlands) and further anaesthetized them with isoflurane (induction phase with $3-4 \%$ isoflurane and maintenance phase with $1.5-2.5 \%$ isoflurane), keeping the rats' body temperature at $37^{\circ} \mathrm{C}$ using heating pads.

The wound of the first operation was reopened in order to visualize the dura. Then the dura was punctured and, after collection of a drop of cerebrospinal fluid (CSF), a syringe, either filled with Neuro-Cells or vehicle (Veh.;Ringer lactate), was connected and emptied, caudally of the lesion, through a microliter pump over a time period of $5 \mathrm{~min}$. We infused SCl-treated rats with $100 \mu \mathrm{L}$ Neuro-Cells or $100 \mu \mathrm{L}$ vehicle.

Post-operative treatment and care were identical to those after the lesioning. Local pressure at the puncture hole and applying some drops of the animal's blood on the puncture hole prevented for CSF leakage.

\section{Post-operative care}

Animals' wellbeing, general health condition, urodynamic and body weights were assessed twice per day until day 35 . The bladder was emptied manually twice a day until the rats were able to spontaneously empty their bladder again, usually within 14 days after the lesion. During the period of manual bladder emptying, the urine was routinely checked for bacteria growth using a urine dipstick.

\section{Functional evaluation}

Rats were assessed for locomotor behavior with the Basso-Beattie Bresnahan (BBB) open field test (Basso, Beattie et al. 1995). Locomotor recovery was tested pre-SCI (baseline) and at days 1 , 7, 14, 21, 28 and 35 post-lesion. At post-surgery day 1, SCl-lesioned rats had to display a flaccid paraplegia (BBB score 0) before the application of Neuro-Cells or vehicle. Based on the established natural recovery, $\mathrm{SCl}-$ lesioned animals were also excluded when scoring was below 4 (protracted recovery) and/or above 8 (partial lesion) at day 7 (Vanicky, Urdzikova et al. 2001). The exclusion parameters of animals were established before the execution of the experiment. Open field locomotor function was assessed by two independent researchers, evaluating video tapes not aware of the treatment.

\section{Immunohistochemical analyses}

At days 4 and 56, four rats out of the NC- and Veh.-treated SCl animals and three out of the NCand Veh.-treated Sham animals were anaesthetized with isoflurane (induction phase with 3-4\% isoflurane and maintenance phase with $1.5-2.5 \%$ isoflurane) and sacrificed by transcardial perfusion with Ringer lactate (Baxter, pH 7.4). The spinal cord tissue of the entire affected area was positioned into cryomolds in a longitudinal orientation and embedded in optimal cutting temperature compound (OCT, VWR, The Netherlands; for rats sacrificed 4 days post $\mathrm{SCl}$ ) or porcine gelatin (10\%, Sigma Aldrich; for rats sacrificed 56 days post SCI). Subsequently, the spinal cord tissue was snap frozen in liquid nitrogen and stored at $-80^{\circ} \mathrm{C}$ until further processing.

To assess the presence of human-derived transplanted cells, as well as astrogliosis, inflammation and apoptosis of the infused cells, serial longitudinal cryosections of the spinal cord $(10 \mu \mathrm{m})$ were 
cut through the areas of interest: the rostral part of the lesion (RO), the center of the lesion (CE), and the caudal part of the lesion (CA), using a cryostat (Leica Biosystems), and then stored at -20 ${ }^{\circ} \mathrm{C}$ until further processing.

To identify human stem cells transplanted into the rat spinal cord at day 4 after infusion caudally to the lesion, antibodies directed against human mitochondrial (MAB1273C3, 1:100, clone 1131, Millipore) were used. To study the early- and late-effects of Neuro-Cells in inflammation, astrogliosis and apoptosis, sections were incubated overnight at $4{ }^{\circ} \mathrm{C}$ with the following primary antibodies: rabbit anti-CD68 (Abcam, 1:500, ab125212), rabbit anti-GFAP (Abcam; 1:500, ab7260), and rabbit anti-cleaved caspase-3 (Cell signalling, 1:500, [Asp175]1331311 9661). Sections were washed with $1 \times$ PBS and incubated with secondary antibodies [(donkey anti-rabbit Alexa 488 (Invitrogen, 1:100) or donkey anti-mouse Alexa 488 (Invitrogen, 1:100))] in 0,1\% blocking buffer for $1 \mathrm{~h}$ at room temperature. Cell nuclei were stained for 10 min with 4',6diamidino-2-phenylindole (DAPI, Thermofisher).

For quantitation, two sections per rat were visualized with a confocal microscope (DSU, Olympus ${ }^{\circledR}$ BX51W1; 20x objective) and Stereolnvestigator software (MicroBrightField, Williston, VT) and ImageJ programs (NIH, Bethesda, MD) were used for analysis. Image J was used to calculate the area of each anatomical region (rostral, lesion and caudal) and integrated mean density. The corrected total cell fluorescence (CTCF) of $\mathrm{GFAP}^{+}$and $\mathrm{CD}^{+} 8^{+}$was calculated as integrated density - (area of selected region $x$ mean fluorescent intensity of background reading).

For the CA and RO sites of the lesion, fluorescence intensity was measured at the outer surface of the spinal cord and at the middle part of the section 2 points at each part of the lesion (Appendix S1, Fig. 1). For the CE part, fluorescence intensity was measured at the border of the center lesion. The average values of fluorescence intensities from 2 images were used as the reference for comparisons within each group. Serum of the rats sacrificed at day 4 was taken for ELISA testing to determine the concentration of interleukins and compare the concentrations of the vehicle and Neuro-Cells treated $\mathrm{SCl}$-lesioned animals with the sham lesioned animals. To study the concentrations of IL-1 $\beta, I L-6$ and TNF $\alpha$ in a blood plasma, rat enzyme-linked immunosorbent assay (ELISA) was performed using Rat Interleukin 1 beta (Rt IL-1 $\beta$ ) ELISA kit (ThermoFisher Scientific, Waltham, MA, USA), IL-6 Rat ELISA Kit (ThermoFisher Scientific, Waltham, MA, USA) and TNF $\alpha$ (Rt TNF $\alpha$ ) Rat ELISA Kit (ThermoFisher Scientific, Waltham, MA, USA) according to the manufacturer's instructions. The microwell absorbance was measured at $450 \mathrm{~nm}$ with Promega microplate reader for all cytokines (Promega, Madison, WI, USA).

\section{Statistical analysis}

Analyses were performed using statistical package SPSS 17.0 for Windows XP. Data were normally distributed as determined by Shapiro-Wilk tests for normality and we therefore performed parametrical statistical analyses on datasets. We performed a two-way ANOVA (with 'group' as the predicting factor and 'lesion site' as the moderating factor) to assess the data obtained from the histology study. If a group effect, level on spinal cord effect or an interaction effect (group $x$ lesion site) was significant a post hoc Fishers Least Significant Difference (LSD) test was performed, after determining equality of variances using Levene's test (which was the case unless stated otherwise). 
Repeated measures ANOVA was used to analyse the BBB score and the bladder recovery function over the different days with within-subjects factor "testing day", and "group" as fixed betweensubject factors. Huynh-Feldt correction was used to correct for violations of sphericity. Rat survival as a function of treatment was determined as Kaplan-Meier estimates, and differences in the survival curves were evaluated with this method. There were no censored data. A p value $\leq .05$ was considered significant. Data are presented as mean with standard error of the mean (SEM).

\section{Proteomics}

\section{Materials}

For proteomic studies in NC-treated and Veh-treated rats, sacrificed at day 56, ammonium bicarbonate, dithiothreitol, iodoacetamide and trifluoroacetic acid (ULC grade) were purchased from Sigma-Aldrich, urea from GE Healthcare, the enzyme mix trypsin/lysC (mass spec grade) from Promega, and water, acetonitrile, formic acid, all ULC grade, from Biosolve.

\section{Sample preparation}

Gelatin was removed from the spinal cords by 3 washes in warm $\left(30-35^{\circ} \mathrm{C}\right) 50 \mathrm{mM}$ Ammonium bicarbonate $(A B C)$. After washing, $5 \mathrm{M}$ Urea in $50 \mathrm{mM} \mathrm{ABC}$ was added to the spinal cord tissues. Tissue disruption and lysis was performed by three freeze-thaw cycles using a warm water bath and liquid nitrogen. During $45 \mathrm{~min}$, the lysate then was reduced with $20 \mathrm{mM}$ Dithiothreitol (DTT) before being alkylated with $40 \mathrm{mM}$ lodoacetamide (IAM) for another $45 \mathrm{~min}$ in the darkness. The alkylation was terminated by $20 \mathrm{mM}$ DTT to consume any excess IAM.

Digestion was performed with a mixture of LysC and Trypsin, which was added at a ratio of 1:25 (enzyme to protein). After two hours of digestion at $37^{\circ} \mathrm{C}$ in a water bath, the lysate was diluted with $50 \mathrm{mM} A B C$ to $1 \mathrm{M}$ Urea and further digested at $37{ }^{\circ} \mathrm{C}$ overnight. The digestion was terminated by addition of formic acid (FA) to a total of $1 \%$. Biognosys iRT's were added to each peptide sample according to manufacturer's instructions (required for the DIA analysis using Spectronaut X software, Biognosys Inc., Beverly, MA, USA).

\section{Liquid chromatography - Mass spectrometry}

Peptide separation was performed on a Thermo Scientific (Dionex) Ultimate 3000 Rapid Separation UHPLC system equipped with an Acclaim PepMap C18 analytical column $(2 \mu \mathrm{m}, 100$ $\AA, 75 \mu \mathrm{m} \times 150 \mathrm{~mm}$ ). Peptide samples were first desalted on an online installed C18 trapping column. Desalted peptides were then separated on the analytical column with a 90 min linear gradient from $5 \%$ to $35 \%$ Acetonitrile (ACN) with $0.1 \% \mathrm{FA}$ at $300 \mathrm{~nL} / \mathrm{min}$ flow rate.

The UHPLC system was coupled to a Q Exactive HF mass spectrometer (ThermoScientific). DDA settings were as follows. Full MS scan between 375 and $1500 \mathrm{~m} / \mathrm{z}$ at resolution of 120,000 followed by MS/MS scans of the top 15 most intense ions at a resolution of 15,000. The HRM DIA (data-independent acquisition) method consisted of a survey full MS scan at 120,000 resolution at $350-1650 \mathrm{~m} / \mathrm{z}$. Then 58 DIA windows were acquired at 30,000 resolution (S2, Table $1)$. 


\section{Data analyses}

For protein identification the DDA spectra were analysed with Proteome Discoverer (PD) version 2.1.1.21. Within the PD software, the search engine Sequest was used with the SwissProt Human (Homo sapiens (TaxID=9606) (v2016-11-30)) and Rat (Rattus norvegicus (TaxID=10,116)) (v201611-30) databases and the Biognosys iRT peptide sequences (supplied by Biognosys). The database search was performed with the following settings: enzyme was trypsin, a maximum of 2 missed cleavages, minimum peptide length of 6 , precursor mass tolerance of $10 \mathrm{ppm}$, fragment mass tolerance of $0.02 \mathrm{Da}$, dynamic modifications of methionine oxidation and protein $\mathrm{N}$ terminus acetylation, static modification of cysteine carbamidomethylation. The DDA measurements were used to create a spectral library using spectral library generation in Spectronaut 9 (Bruderer, Bernhardt et al. 2015) (Biognosys). Only identifications with FDR of maximum $1 \%$ at peptide and protein level were taken into account for spectral library generation. For protein quantitation, the DIA data were analysed with Spectronaut 9, with the manufacturer's recommended default settings.

\section{Differential abundance testing}

Within each site of the lesion (RO, CE, CA), differential protein abundance between Neuro-Cellsand vehicle-treated conditions was tested using Spectonaut's built-in algorithm. Abundance data for proteins found differentially abundant with q-value below 0.05 was submitted to downstream functional analysis.

\section{Representations of biological functionality}

The following complementary knowledge-based classifications of protein functionality were used in combination, to create biological interpretation of the detected lists of differentially abundant proteins: i) Gene Ontology (including Biological Process and Cellular Component branches of the hierarchy) were adopted from GSEA website of Broad Institute (Subramanian, Tamayo et al. 2005) ii) regulons, generated by collecting the known transcription-target relationships from HTRIdb (Bovolenta, Acencio et al. 2012) and CellNet (Cahan, Li et al. 2014) and iii) Reactome pathways (Fabregat, Sidiropoulos et al. 2016). For all the functionality representations, members of the gene ID-based categories were remapped to protein IDs with Bioconductor's biomaRt package (Durinck, Spellman et al. 2009). The sets of protein IDs were restricted to proteins actually detected in the experiment (at any lesion site and condition).

\section{Protein set enrichment analysis}

Functionality enrichment tests with lists of responsive proteins (Subramanian, Tamayo et al. 2005) in context of the 3 functionality representations described above, were performed with goseq package (Young, Wakefield et al. 2010) using Wallenius approximation and correction for protein length. Statistical significance of the enrichment tests was estimated with 100,000 data permutations.

\section{Protein-sharing networks}

To identify response patterns at a general level rather than individual functional categories, we generated protein-sharing networks. For this purpose, we collected respective category-protein 
relationships (e.g. Reactome pathways) and restricted them to proteins that were called responsive to Neuro-Cells in at least one of the three sites. Subsequently, for each pair of the categories (network nodes), the number of shared proteins was recorded and used to map to the width of the edge connecting those two nodes. The analysis was performed with a combination of R programming language (R core team, 2014) and Cytoscape network analysis platform (Shannon, Markiel et al. 2003) version 3.6.1.

\section{Results}

\section{Animals}

During the quarantine period, 66 rats were randomized into two groups: group $1(\mathrm{~N}=49)$ for $\mathrm{SCl}-$ lesioning, and group $2(\mathrm{~N}=17)$ for sham-lesioning. Before this lesioning, though, one animal belonging to group 2 was lost because of intercurrent health problems, and during the $\mathrm{SCl}$ lesioning another one (out of group 1), because of anaesthesia related death. The 48 surviving $\mathrm{SCl}$-lesioned animals in group 1 were further randomized in 24 rats for treatment with NeuroCells (SCl-NC animals) and 24 rats for treatment with the vehicle (SCl-Veh animals). The 16surviving sham-lesioned rats were randomized into 7 animals for a treatment with Neuro-Cells (Sham-NC animals) and 9 animals for the intervention with the vehicle (Sham-Veh animals).

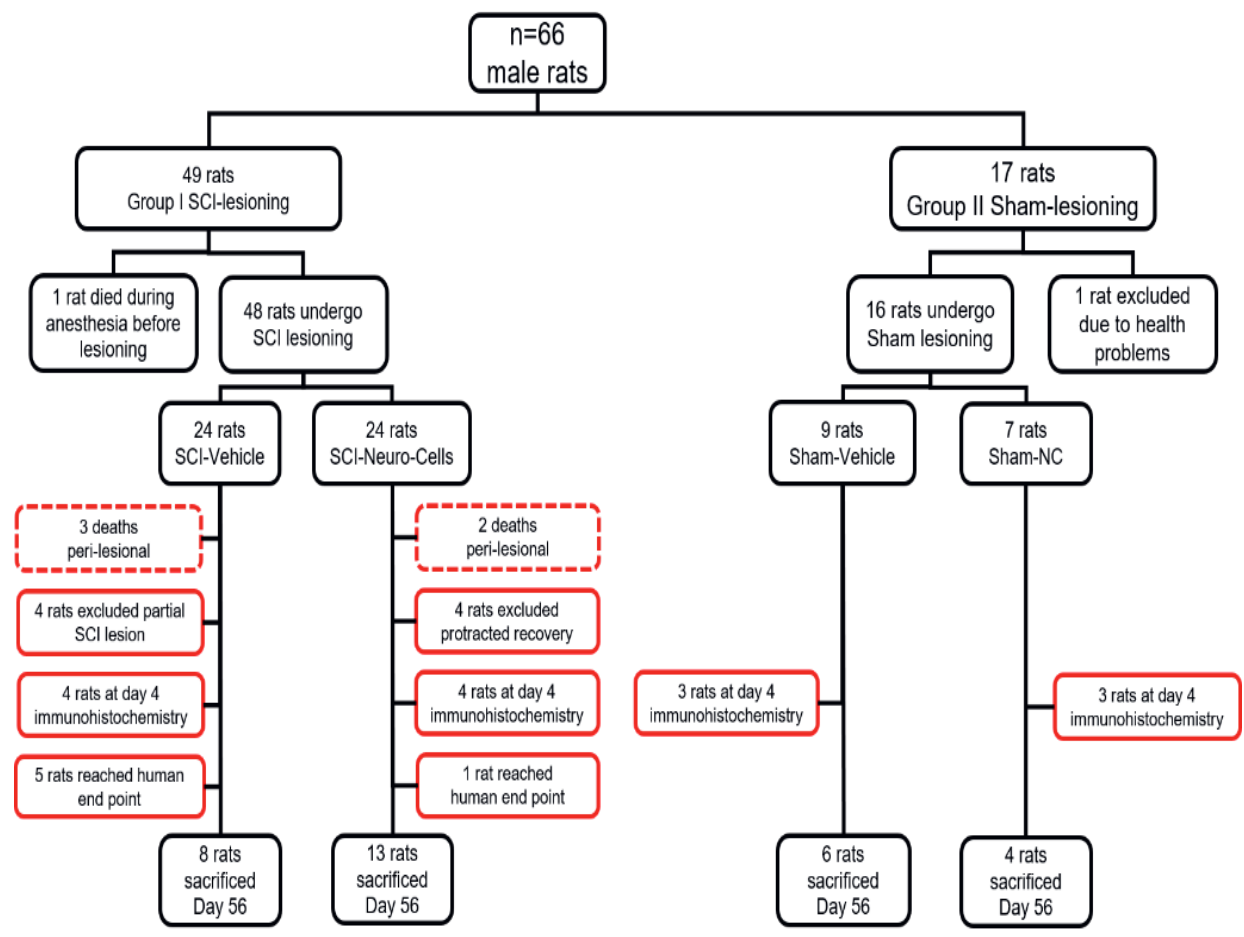

Figure 2 Flowchart with the number of rats used in this study. Red squares represent animals excluded from the study as described in the text. 
All SCl-lesioned animals had a BBB score of 0 points before the application of their treatment. Day 4 of the study, $4 \mathrm{SCl}-\mathrm{NC}$ and $4 \mathrm{SCl}-\mathrm{Veh}$ as well as 3 Sham-NC and $3 \mathrm{Sham}-\mathrm{Veh}$. animals were sacrificed for immunohistochemistry. Within the first week after the $\mathrm{SCl}$-lesioning, 13 animals had to be excluded from the experimental design: $2 \mathrm{SCl}-\mathrm{NC}$ animals (due to direct perilesional surgical complications and shock) and $3 \mathrm{SCl}-V e h$ animals (due to direct post-lesional convulsions, shock, and artificial-induced bladder rupture). Conform the protocol, another $4 \mathrm{SCl}-\mathrm{NC}$ rats had to be excluded because of a BBB-score at day $7<4$ (probably because of a histological confirmed increase of the $\mathrm{SCl}$-lesion due to the intrathecal injection of the viscous Neuro-Cells preparation), and $4 \mathrm{SCl}$-Veh rats because of a BBB-score $>8$ (probably because of an impartial $\mathrm{SCl}$ lesion). During the study, $1 \mathrm{SCl}-\mathrm{NC}$ rat and $5 \mathrm{SCl}-V e h$ animals reached a humane endpoint due to $\mathrm{SCl}$ surgery-induced complications. The 9 Sham-Veh and 7 Sham-NC treated animals, during the study, did not suffer any surgery-related complication, nor did they reach any humane endpoint. So, in the end $13 \mathrm{SCl}-\mathrm{NC}, 8 \mathrm{SCl}-\mathrm{Veh}, 6 \mathrm{Sham}-\mathrm{Veh}$, and 4 Sham-NC treated rats completed the study and were sacrificed at day 56. An overview of the study is displayed in Fig. 2.

\section{Survival}

There were no mortalities in the 16 sham-lesioned animals. In the $\mathrm{SCl}$-lesioned animals, apart from the 5 peri-lesional direct $\mathrm{SCl}$-surgery related deaths, during the 56 days following lesioning, 5 out of 13 Vehicle-treated animals reached a humane endpoint, due to development of ascites ( $n=3$; day4, day5, day6), kidney failure ( $n=1 ;$ day18) and severe body weight loss ( $n=1 ;$ day38). In Neuro-Cells treated rats only 1 out of 14 animals reached a humane endpoint at day 10 postsurgery, due to severe body weight loss (Fig. 2). The $\mathrm{SCl}$-lesioned rats treated with Neuro-Cells appear to survive longer, as group differences reached significance $(p \leq 0.05)$. A plot of the survival function is shown in Fig. 3.

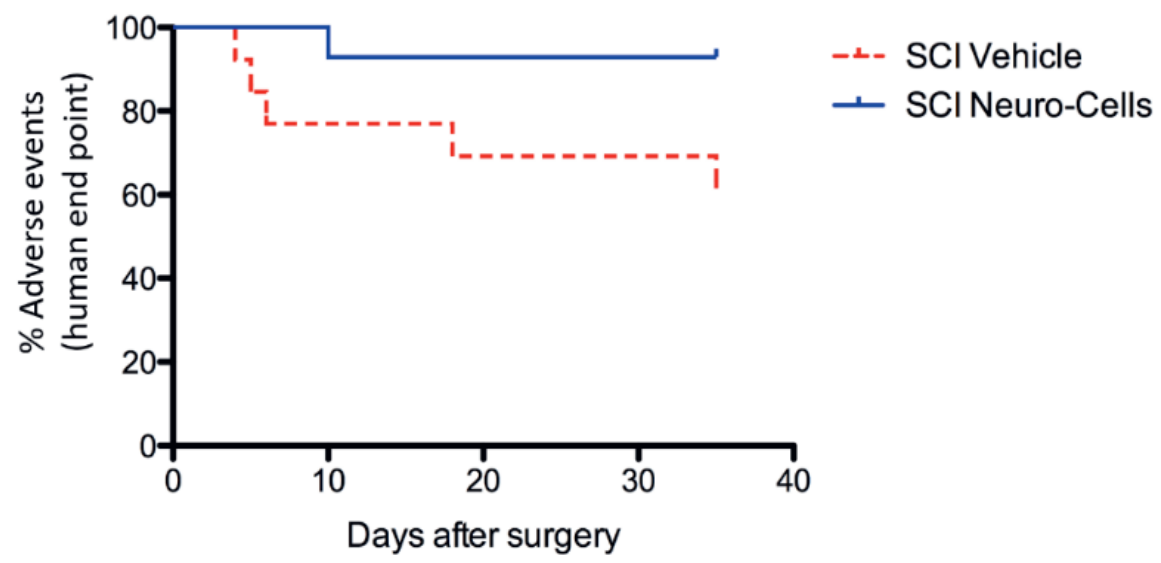

Figure 3 Kaplan-Meier estimates of postoperative survival (adverse events reaching human end point) stratified by treatment with either vehicle or Neuro-Cells. Rats of the SCl-Neuro-Cells group survive longer ( $p \leq 0.05$ ). 


\section{Adverse events, general health conditions, body weight and urodynamic functions}

There were no serious health problems in the 16 sham-lesioned animals. During the 56 days following lesioning, 5 out of 13 vehicle treated animals reached serious adverse events (SAEs) with a humane endpoint, due to development of ascites ( $n=3$; day4, day5, day6), kidney failure $(n=1 ;$ day 18$)$ and severe body weight loss ( $n=1 ;$ day 38$)$. In Neuro-Cells treated rats only 1 out of 14 animals reached such SAE at day 10 post-surgery, due to severe body weight loss (Fig. 2). The $\mathrm{SCl}-$ lesioned rats treated with Neuro-Cells appear to suffer significant less SAEs $(p \leq 0.05)$. A plot of the survival function is shown in Fig. 3.

Apart from these SAEs, surviving animals, suffered a higher incidence in the NC-treated group $(p=0.12)$ of a temporary cystitis, favourably reacting to a treatment with Baycal. All surviving animals, after a modest loss of body weight during the first week after surgery, did gain body weight during the following weeks of the study period. Animals that underwent spinal cord injury and that were treated with Neuro-Cells did not differ in body weight compared to vehicle-treated group at day 1 and day 35 post-surgery (S5, Table 4). Sham-lesioned animals, whether treated with Neuro-Cells or Vehicle, did not suffer any adverse event, loss of body weight, or any loss of urodynamic functions. Regarding the $\mathrm{SCl}$-related loss of urodynamic functions, after surgery, all animals needed assistance with bladder voiding. Measuring manually expelled urine, NCtreatment did not affect the recovery of bladder control throughout a 14 days observation period (repeated measurement ANOVA, $\mathrm{p}=0.916$ ) as compared to the Vehicle-treated animals.

\section{BBB Score}

On day 1, the sham-lesioned groups received almost normal BBB scores, whereas both the $\mathrm{SCl}$ treated groups scored the lowest possible (0 points), demonstrating the validity of this rat model of SCl. The scores increased in both SCl-vehicle and SCl-Neuro-Cells groups over time (repeated measure ANOVA, $F(6,114)=2.72, \quad p<0.032)$. However, by 14 days and 35 days post-surgery, there was a statistically significant difference in BBB scores between the Neuro-Cells- and vehicle-treated rats $(p<0.01 ; p<0.008$ respectively; Fig. 4$)$. These results indicated that NeuroCells induced functional improvement after $\mathrm{SCl}$ in rats.

\section{ELISA-serum}

The concentration of serum interleukin- $1 \beta, 6$ and TNF- $\alpha$ were measured by ELISA. Fig. 5 compared the mean differences between the vehicle respectively Neuro-Cells treated SCllesioned animals with the vehicle and Neuro-Cells treated sham lesioned animals.

\section{Immunohistochemistry}

The survival of human transplanted stem cells was evaluated 3 days post-implantation of NeuroCells. Human positive cells were found partially attached to the spinal cord surface, which were identified by human mitochondrial epitopes (Fig. 6B and C). 


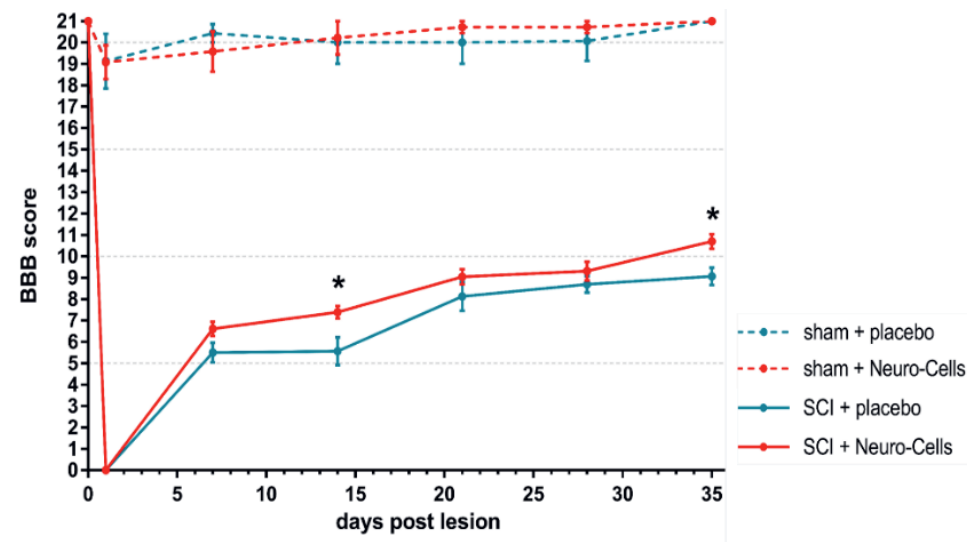

Figure 4 Effects of Neuro-Cells and vehicle (placebo) on locomotor function in rats after SCl-surgery and sham SCl-surgery. The first BBB evaluation took place at day 0 , before surgery. At that time, no statistically significant differences in BBB scores were found between NC and Veh treated $\mathrm{SCl}$-rats, whereas the BBB scores in the sham-operated rats during the whole study were different from SCl-operated rats $(p<0.001)$. During the whole study, BBB scores in NC-treated SCl-rats were higher as those in Veh-treated SCI-rats, differences reaching significance at day 14 and $35\left({ }^{*} p<0.01\right)$.
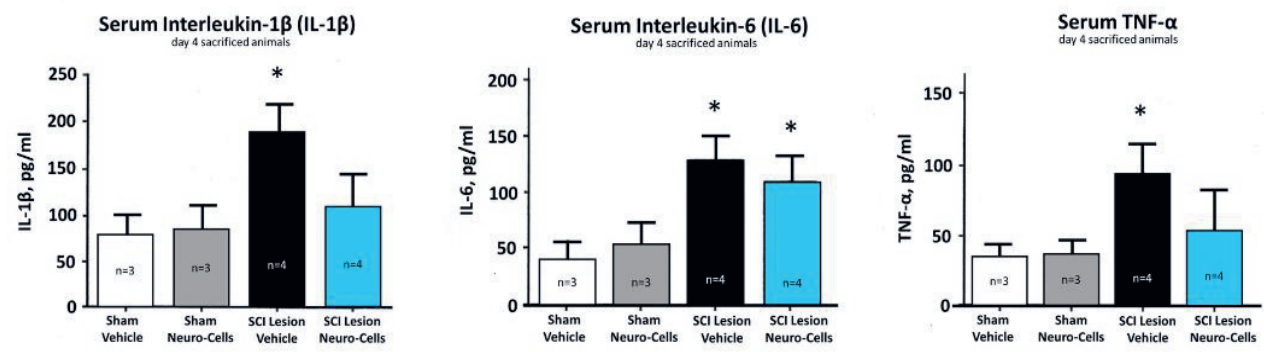

Figure 5 Differences in serum concentration between the Veh.- and NC-treated SCI-lesioned and sham-lesioned animals at day 4. At that time, there was a significant increase of serum Interleukin-16 and serum TNF- $\alpha$ in the Veh.-treated SCI-lesioned animals compared to the Veh.- and NC-treated sham-lesioned animals, but not for the NC-treated groups $\left({ }^{*} p<0.05\right)$. The serum Interleukin- 6 was lower in the NCtreated SCI-lesioned animals as compared to the Veh.-treated SCI-lesioned animals but both were significantly higher as compared to their sham-lesioned counterpart.
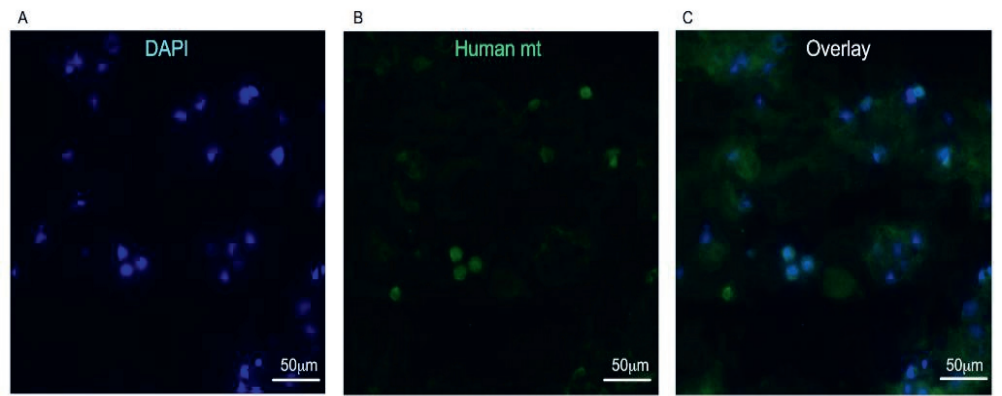

Figure 6 Presence of human cells at CA (and less in CE) in NC-treated SCl rats detected by human mitochondrial epitopes, displayed in representative images at CA, 3 days after the treatment. A) DAPI, B) Human $\mathrm{mt}, \mathrm{C}$ ) Overlay. Scale bars represent $50 \mu \mathrm{m}$. 


\section{Early effects (day 4) on post-injury cellular responses}

Monocytes and macrophages are key players of the inflammatory modulation and of the resolution of inflammation after SCl (Shechter, London et al. 2009, London, Cohen et al. 2013). In comparison to sham lesioned, vehicle or NC-treated animals, we observed a significant effect at the $\mathrm{SCl}$-induced lesion site $(\mathrm{F}(1,42)=56.02, \mathrm{p}<0.001)$ in $\mathrm{CD}^{+} 8^{+}$expression at day 4 , with an increase at the central part of the lesion. Post hoc analysis showed that the $\mathrm{CD}^{2} 8^{+}$expression was significantly increased $(p<0.008)$ at the CA in the Neuro-Cells-treated rats compared to vehicle-treated rats (Fig. 7B). No differences were found in the $\mathrm{CD}^{\circ} 8^{+}$expression at the RO between the two treated groups (Fig. 7B). SCl-induced astrogliosis is an important process in glial scar tissue formation, as reactive astrocytes increase their expression of GFAP. In order to assess astrogliosis in $\mathrm{SCl}$ rats (vehicle vs. Neuro-Cells) 4 days post-injury, we examined the GFAP expression at the RO, CE and CA site of the lesion, in relation to those in the sham lesioned, vehicle or NC-treated animals (Figs. 6C and 7D). Analysis showed a significant main effect of the SCl-induced lesion site in GFAP expression $(F(1,42)=29.05, p<0.001)$ with an increase in GFAP expression at the central part of the lesion. There was also a significant main effect of the group ( $F(1,42)=4.61, p<0.038)$, as Neuro-Cells treated rats had an overall lower number of GFAP+ expression as compared to the vehicle-treated group of rats. Post hoc analysis revealed a significant decrease in $\mathrm{GFAP}^{+}$expression at the CE in the Neuro-Cells-treated rats $(p<0.042$; Fig. 7D) when compared to vehicle-treated rats.

No differences were found in the $\mathrm{GFAP}^{+}$expression between the Neuro-Cells and vehicle-treated groups at the RO or the CA site of the lesion (Fig. 7D). Components of the caspase-3 apoptotic pathway are activated after traumatic $\mathrm{SCl}$ in rats and occur early in neurons at the injury site and hours to days later in oligodendroglia adjacent to and distant from the injury site (Springer, Azbill et al. 1999, Soini, Kahlos et al. 2005).

To examine the effects of vehicle and Neuro-Cells on apoptotic cell death after $\mathrm{SCl}$, we quantified the expression of cleaved caspase- $3^{+}$at day 4 post-injury in relation to those in sham-lesioned, vehicle or NC-treated rats (Fig. 7E and F). We found a significant effect in the SCl-lesion site ( $\mathrm{F}(1$, $42)=9.30, p<0.001)$, namely an increased number of cleaved caspase $-3^{+}$cells at the lesion site and a significant main group effect $(F(1,42)=6.13, p<0.017)$.

Interestingly, a significant interaction effect $(F(1,42)=4.45, p<0.018)$ was observed, suggesting that the pattern of cleaved caspase- $3^{+}$expression differs along the sites of the lesion depending on the group (vehicle versus Neuro-Cells). Post hoc analysis revealed a significant decrease in cleaved caspase- $3^{+}$cells in rats treated with Neuro-Cells at the CA ( $p<0.003$; Fig. 7E and F) and at the CE $(p<0.012)$, suggesting a decreased apoptosis in both segments. The number of cleaved caspase- $3^{+}$cells did not differ between Neuro-Cells and vehicle-treated rats at the RO site of the lesion (Fig. TE and F).

\section{Late effects (day 56) on cellular responses}

At day 56 , we found a significant effect of the SCl-lesion site $(F(1,40)=54.72, p<0.001)$ with a significant increase in $\mathrm{CD}^{+} 8^{+}$expression at the $\mathrm{CE}$ site but no significant differences were observed between Neuro-Cells- and vehicle-treated rats at the RO, CE and CA sites (Fig. 8A and $B)$. A significant main effect of the lesion site $(F(1,41)=6.56, p<0.003)$ with an increase in $G F A P^{+}$ expression was also found at the CE site (Fig. 8C). Post hoc analysis revealed no differences in 
$\mathrm{GFAP}^{+}$expression between Neuro-Cells- and vehicle-treated rats at any site of the lesion (Fig. $8 D)$. A significant main effect of the lesion site $(F(1,42)=8.67, p<0.001)$ was found in the number of cleaved caspase- $3^{+}$cells but post hoc comparisons between Neuro-Cells and vehicle-treated rats did not reach significance, suggesting that the number of cells that are undergoing apoptosis was not different between both groups 56 days post-injury (Fig. 8E and F).
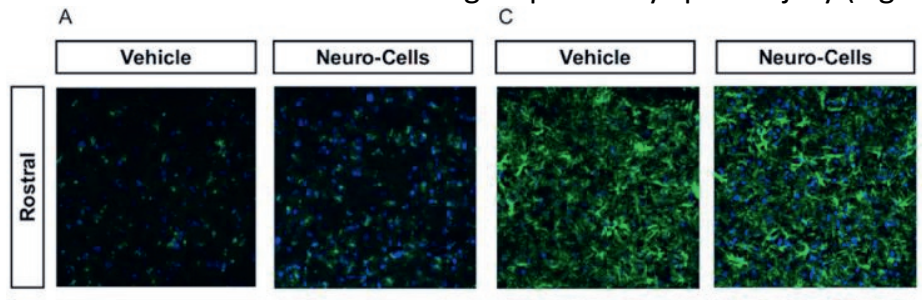

$\mathrm{E}$
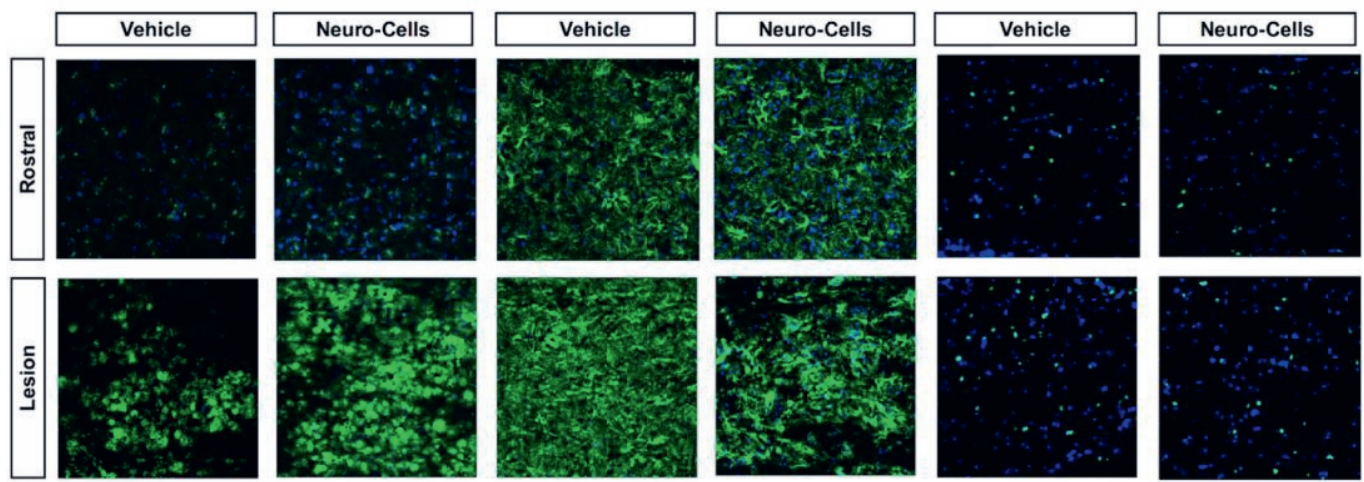

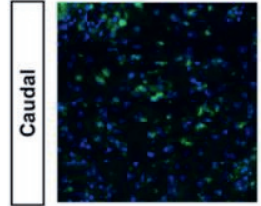

B

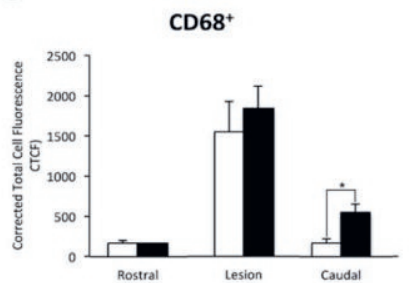

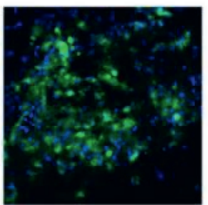

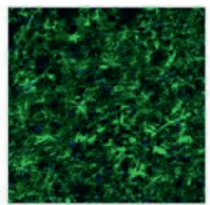

D

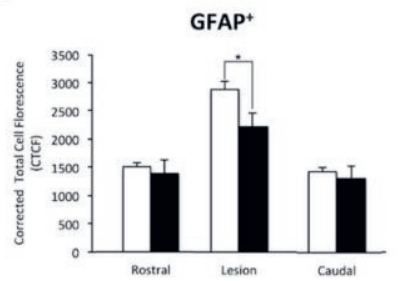

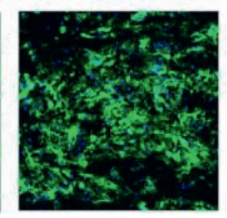
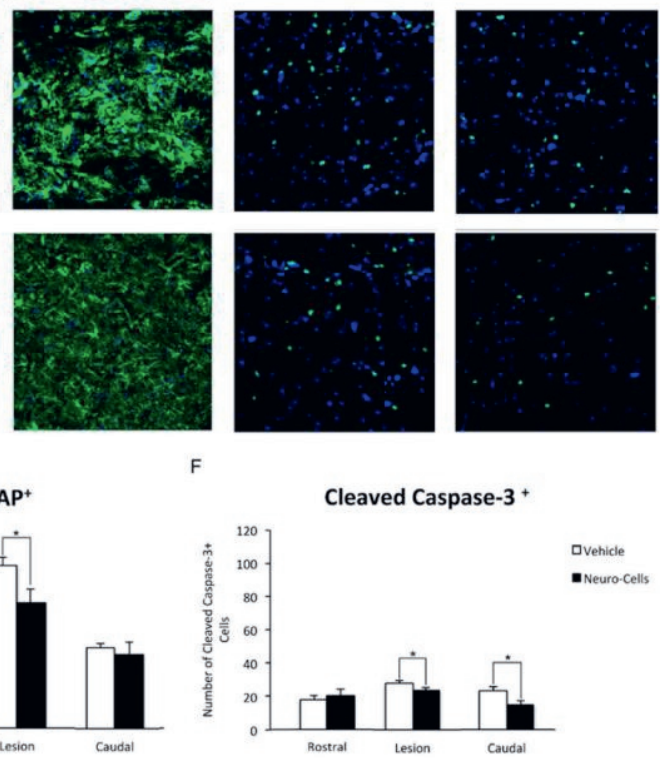

Figure $7 \mathrm{CD}_{68}{ }^{+}, \mathrm{GFAP}+$ and cleaved caspase $-3^{+}$cells in Veh.- and NC-treated rats across the RO, CE and CA sites (Lesion=CE) relative to the lesion at day 4 postinjury. Panels show representative examples of fluorescent labeling of CD68+ $(A), G F A P^{+}(C)$ and caspase- $3^{+}$cells $(E)$. For the caspase- $3^{+}$cells we quantify the total number of positive cells (E). Magnification bar represents $50 \mu m$. The effects of NC in CD68 ${ }^{+}$ $G F A P^{+}$and caspase $-3^{+}$at the RO, CE and CA sites are shown $(B, D, F)$. The data are expressed as mean $\pm S E M$. $n=7-8$ sections per animal in each group. *: significant, $p \leq 0.05$.

\section{Proteomic studies}

\section{Differential protein expression}

We quantified 573 protein abundances in $\mathrm{SCl}$ rats that were injected with Neuro-Cells and in $\mathrm{SCl}$ rats that were injected with vehicle at day 56 after administration. For this purpose, we used tissues from the three different anatomical sites of the lesion: i) rostral (RO), ii) center (CE), and iii) caudal (CA). We compared the functional analyses of the differentially abundant proteins with alternative functional classifications to assess the biological functionality relevant to the NeuroCells effects (see Methods). 
The most relevant representations appeared to be Regulons, Gene Ontology Cellular Component and Reactome pathways taken in a gene-sharing network context.

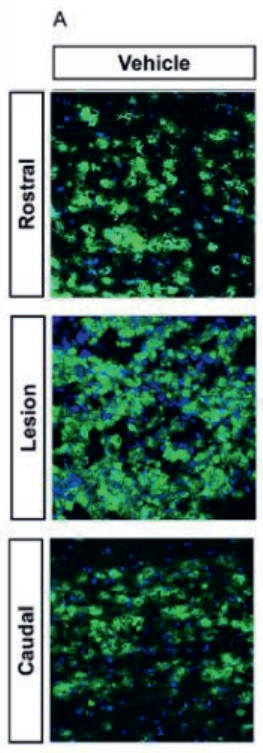

B

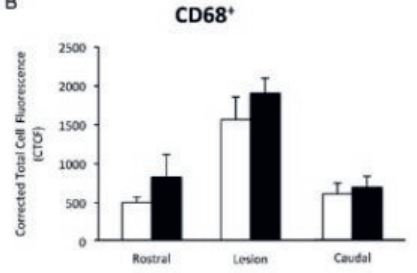

C
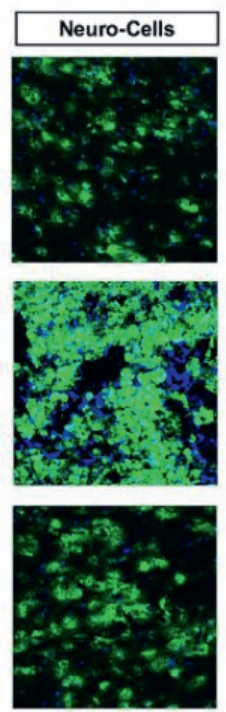

D
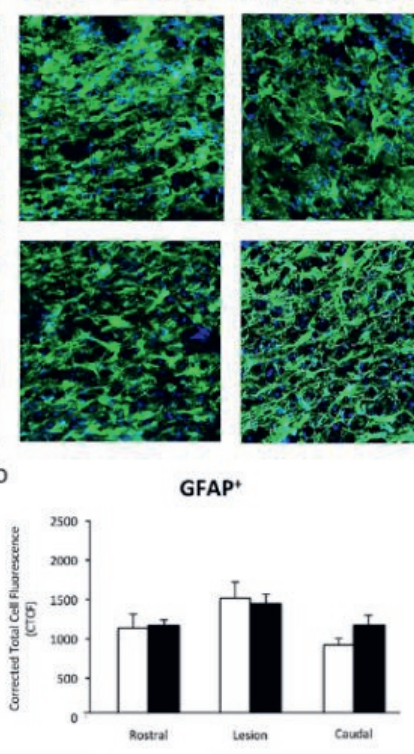

$\mathrm{E}$
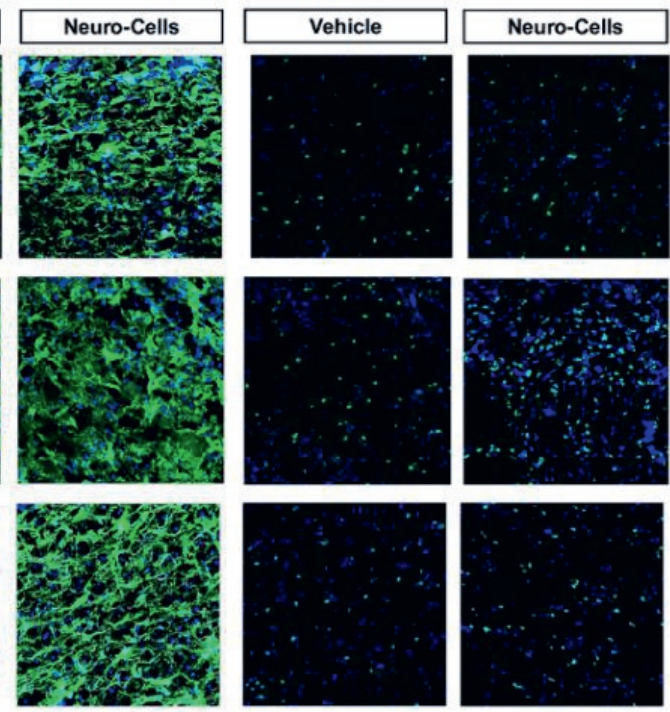

Cleaved Caspase-3+

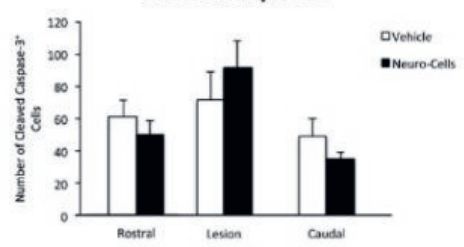

Figure $8 \mathrm{CD}^{\circ} 8^{+}, \mathrm{GFAP}^{+}$and cleaved caspase- $3^{+}$cells in Veh.- and NC-treated rats across the RO, CE and CA sites (Lesion=CE) relative to the lesion at day 56 postinjury. Panels show representative examples of fluorescent labeling of CD68 $8^{+}(A), G F A P^{+}(C)$ and caspase- $3^{+}$cells (E). For the caspase- $3^{+}$cells we quantify the total number of positive cells (E). Magnification bar represents $50 \mu \mathrm{m}$. The effects of NC in CD68 ${ }^{+}$ $G F A P^{+}$and caspase $-3^{+}$at the RO, CE and CA sites are shown $(B, D, F)$. The Data are expressed as mean \pm SEM. $n=7-8$ sections per animal in each group. *: significant, $p<0.05$.

\section{Network of the functional responses: Reactome pathways}

Analysis of the sets of proteins that significantly changed their abundance in response to NeuroCells (with q-value below 0.05) in context of Reactome pathways, and limiting the search to pathways affected in either direction with $p<0.001$, revealed 17 responsive pathways at $R O, 33$ at CE and 17 at CA. The total number of pathways that responded in any direction at any of the 3 levels of the lesion was 60 .

In order to reveal more general functional patterns that transcend categories of individual pathways, we constructed a protein-sharing urine network. Out of 60 responsive pathways, 55 ( 92\%) shared the underlying responsive proteins with at least one another pathway. 
Overall, all the 55 pathways were found in 3 densely connected clusters and 2 outlier clusters of 2-3 pathways (Fig. 9). While those clusters were identified on the basis of connectivity only, irrespective to the sign of response of their members to Neuro-Cells, subsequent visualization of the directions of the effect of Neuro-Cells on expression of the 55 pathways at every level of the lesion revealed that the highly connected clusters also showed a trend to consistent sign of response at a particular level, despite the much less consistent responses at pathway (and especially - individual protein) levels between the site of the lesion.

Hence, by generalizing the considered biological entity from protein to pathway and then to network of pathways, we found a progressively more consistent response to Neuro-Cells-treated rats at the different levels.

In particular, the first cluster from the left was enriched in glycosylation, extracellular matrix, scavenger receptors, keratan and collagen metabolism related proteins. This cluster showed a clear trend to be impaired at the RO and CE sites, and to be upregulated at the CA site, although this last trend was no longer present after multiple testing correction.

The second cluster, in the middle of the network, was enriched in generally defined functional pattern of ion movements across membrane (including such categories as cardiac construction, ion homeostasis, ion transport, reduction of cytosolic Ca2+ levels, ion transport-by-typeATPases) and semaphorins.

This middle cluster had a trend to be upregulated by Neuro-Cells at all the 3 sites of the lesion. The right smallest cluster of 10 pathways was not connected in as dense manner as the major 2 clusters, and the response pattern of the pathways comprising it, was more site dependent. Interestingly, "metabolism of carbohydrates" operated as a link between the two highly connected clusters with opposite trend of response to Neuro-Cells. "Extracellular matrix organization" also provided some protein-sharing links between the two clusters.

Insights on the upstream transcriptional regulatory events from proteomics

Besides functional summarization of the observed protein-level changes, we also leveraged the known transcription factor - target gene relationships to gain preliminary insights on the possible upstream gene regulatory events mediating the observed responses to Neuro-Cells. While transcriptome data is required to draw this level of conclusions more directly and accurately and post-transcriptional and post-translational events alter the gene expression-based signatures. We used backward projection of the en masse protein level changes, in order to map them to known sets of transcription factor targets to identify the responsible upstream transcriptional regulators.

With this approach, 33 regulons were identified to be upregulated in Neuro-Cells injected rats compared to vehicle-treated $\mathrm{SCl}$ rats at the $\mathrm{CE}, 17$ regulons at the $\mathrm{RO}$ and 21 regulons at the $\mathrm{CA}$ respectively ( $S 3$, Table 2 ). When we examined the functions of the candidate regulons of the 3 areas, we found that the regulons identified at the CA and CE level had an identical reported function. In those regions 13 upregulated regulons involved in differentiation could be identified, though none at RO. These CA and CE situated regulons play a role in spinal cord motor neuron differentiation (LMO4), neuron differentiation (NLX2-2, RUNX2), astrocyte differentiation (NKX2-2, PAX6) and oligodendrocyte differentiation (OLIG1, OLIG2, SOX10). GOCC analysis revealed that in the actin cytoskeleton and actin filament the regulons identified at the CE were 
mainly located in the plasma membrane, whereas the regulons identified at the CA and at the $\mathrm{RO}$ were in the mitochondrial membrane (Table 3, S4).

A

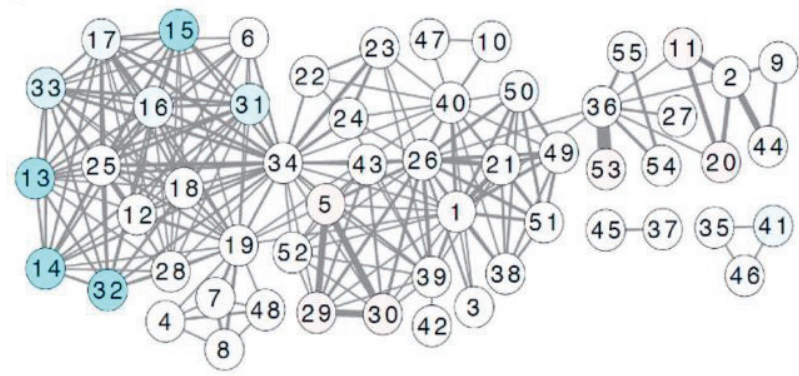

B

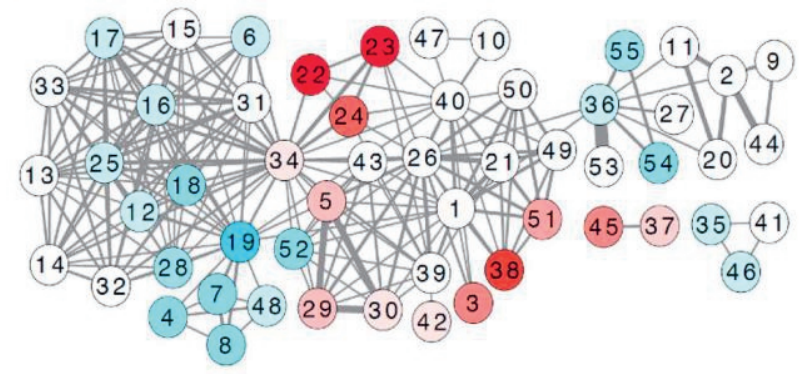

C

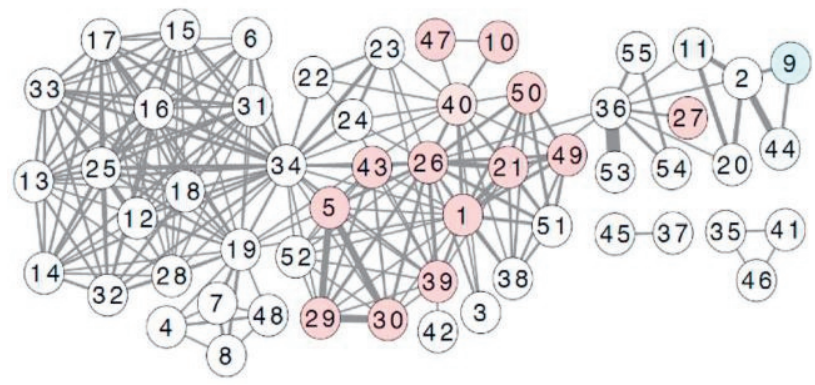

D

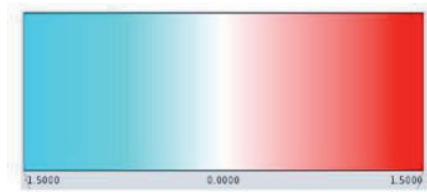

Figure 9. Protein-sharing network of the 55 responsive Reactome pathways that share proteins assigned to them. Significance of the pathway enrichment among proteins overexpressed with Neuro-Cells is mapped to red color, while pathway enrichment among lower expressed proteins is mapped to blue color. A, Rostral part of the lesion; $B$ Central part of the lesion; $C$, Caudal part of the lesion; $D$, Color map showing the range of $-\log 10$ (FDR) values. Numerical pathway IDs: 1, Platelet activation, signaling and aggregation; 2, Respiratory electron transport, ATP synthesis by chemiosmotic coupling, and heat production by uncoupling proteins; 3, Advanced glycosylation end product receptor signaling; 4, Binding and Uptake of Ligands by Scavenger Receptors; 5,Cardiac conduction; 6 , Chondroitin sulfate/dermatan sulfate metabolism; 7 Collagen biosynthesis and modifying enzymes; 8 Collagen formation; 9, Complex I biogenesis; 10, COPII (Coat Protein 2) Mediated Vesicle Transport; 11. Cristae formation; 12, CS/DS degradation; 13, Defective B4GALT1 causes B4GALT1-CDG (CDG-2d), 14, Defective CHST6 causes MCDC1; 15, Defective ST3GAL3 causes MCT12 and EIEE15; 16, Diseases associated with glycosaminoglycan metabolism; 17, Diseases of glycosylation; 18, ECM proteoglycans; 19, Extracellular matrix organization; 20, Formation of ATP by chemiosmotic coupling; 21, G alpha (12/13) signaling events; 22, Gluconeogenesis; 23, Glucose metabolism; 24, Glycolysis; 25, Glycosaminoglycan metabolism; 26, Hemostasis; 27, HUR (ELAVL1) binds and stabilizes MRNA; 28, Integrin cell surface interactions; 29 , Ion homeostasis; 30 , Ion transport by P-type ATPases; 31, Keratan sulfate/keratin metabolism; 32, Keratan sulfate biosynthesis; 33, Keratan sulfate degradation; 34, Metabolism of carbohydrates; 35, Metabolism of fatsoluble vitamins; 36, Metabolism of RNA; 37, Metallothioneins bind metals; 38 , Netrin-1 signaling; 39, Neurotransmitter receptors and postsynaptic signal transmission; 40, Neutrophil degranulation; 41, RA biosynthesis pathway; 42 , Recycling pathway of L1 R-HSA-437239; 43, Reduction of cytosolic Ca++ levels; 44, Respiratory electron transport; 45, Response to metal ions; 46, Retinoid metabolism and transport; 47, Retrograde transport at the TransGolgi-Network; 48, Scavenging by Class A Receptors; 49, Sema4D in semaphorin signaling; 50, Sema4D induced cell migration and growth-cone collapse; 51, Semaphorin interactions; 52, Smooth Muscle Contraction; 53, SRP-dependent cotranslational protein targeting to membrane; 54, Transport of Mature mRNA derived from an Intron-Containing Transcript; 55, Transport of Mature Transcript to Cytoplasm. 


\section{Discussion}

A large body of literature provides evidence for the beneficial effects of cell-based therapies in patients with $\mathrm{SCl}$ (Tetzlaff, Okon et al. 2011). Many studies have investigated the effects of stem cells as a potential treatment for $\mathrm{SCl}$, however most of the studies failed to demonstrate safety and substantial functional improvement, after the use of manipulated stem cells (Yoon, Shim et al. 2007). Manipulation of stem cells before administration leads to proliferation and/or to differentiation in a disease-free signalling environment that is not relevant to the initial aim of the transplantation. Without exposure to signalling proteins in the direct disease environment, active labelling and/or expanding will change the phenotype and function of the stem cells and will bring these cells into the next stage of differentiation in which they are able to expand and/or to exert only basic functions. The latter, however, is key to the working mechanism in neurodegenerative disorders (Caplan 2017). mesenchymal stem cells (MSCs) and hematopoietic stem cells (HSCs) are not able to pass the blood-brain and central nervous system (CNS)-CSF barrier and after intrathecal application float in the CSF (Stamatovic, Keep et al. 2008, Jackson, Golding et al. 2010, Wood, O'Loughlin et al. 2011). However, signalling proteins are able to freely trespass these barriers and thus interact with these cells (Yanez-Mo, Siljander et al. 2015, Bavisotti, Scalia et al. 2019). We have developed therefore a standardized bone marrow fraction of not- or marginally manipulated MSCs and HSCs (Neuro-Cells), which can be intrathecally injected into the disease environment. By depleting the erythrocytes and the majority of the lymphocytes of the original bone marrow-derived stem cell preparation, Neuro-Cells is suitable to be injected straight into the cerebrospinal fluid without eliciting an inflammatory reaction (rejection) (Lossinsky and Shivers 2004, Assmus, Tonn et al. 2010). The advantage of Neuro-Cells over similar products is the fact that the HSCs and MSCs are not labelled or expanded, but are kept in their original state until intrathecally administered, allowing the exposure to the disease specific signalling environment and thus activating the release of paracrine factors by the stem cells to better control the neuron hostile environment (Kinnaird, Stabile et al. 2004, Gnecchi, Zhang et al. 2008, Hsiao, Asgari et al. 2012, Dostert, Mesure et al. 2017). Both bone-marrow- and adipose-tissue-derived stem cells seem to improve motor dysfunction, though the exact mechanisms remain unclear. In this study, the human bone-marrow derived stem cells (NeuroCells) offer the advantage that they were not labelled nor expanded when infused directly into the cerebrospinal fluid in SCl-treated rats, they interact with the disease specific signalling environment (Ren, Han et al. 2014, Zhang, Li et al. 2014, Rani, Ryan et al. 2015, Zhang, Yeo et al. 2016, Harting, Srivastava et al. 2018, Ruppert, Nguyen et al. 2018). We speculate that the beneficial effects of Neuro-Cells during the first days after its intervention in acute $\mathrm{SCl}$ might be induced by its anti-inflammatory properties, as evidenced by histological findings and differences in serum interleukin concentrations at day 4 of the study. 56 Days after this intervention, histological analysis did not reveal any signs of anti-inflammatory properties anymore, though proteomics then provided enough insights in regulons and pathways to suggest that the improvement in locomotor activity at that time was rather associated with neurogenesis and axonal regeneration. Further research, though, is needed to indeed get proof of stem cellexerted dedicated apocrine effects (maybe through extracellular vesicles), induced by the specific pathological environment. Several studies have shown that the therapeutic activity of MSCs is mainly mediated by MSC-secreted factors, suggesting the possible involvement of 
extracellular vesicles (EVs) as important players mediating the therapeutic effects of cells being used as therapeutics (such as MSCs and endothelial cells) via regenerative and anti-inflammatory modes of action (Rani, Ryan et al. 2015, Zhang, Yeo et al. 2016, Harting, Srivastava et al. 2018, Ruppert, Nguyen et al. 2018). For instance, MSC-EVs were found to exert immune-suppressive effects, by enforcing $\mathrm{M} 2$ macrophage polarization and stimulating T-cell induction (Zhang, Li et al. 2014).

\section{Early-onset effects of Neuro-Cells in SCl}

Treatment with Neuro-Cells $24 \mathrm{~h}$ after surgery did not induce serious side effects or mortality in $\mathrm{SCl}$-lesioned and sham-lesioned rats. Apart from a higher incidence of a temporary Baycalresponsive cystitis in the NC-treated animals $(P<0.12)$, their 'well-being', body weight, and bladder control recovery during the entire study was comparable to that in Vehicle-treated rats (S5, Table 2, and S6, Fig. 3). Importantly, not only SCl-related survival (serious adverse events leading to human end points) reached significance, NC-treated animals also reached (significant) better BBB scores. Considering the histological analyses, rats treated with Neuro-Cells initially showed a significant reduction in $\mathrm{GFAP}^{+}$expression at $\mathrm{CE}$, indicative for a lower number of reactive astrocytes. These glial cells are, among others, one of the key players in scar tissue formation following an insult to the spinal cord. Previously, it has been suggested that the improved motor function is associated with a reduction in astrogliosis (Ren, Han et al. 2014). This question, though, is beyond the scope of the current study. Furthermore, we showed that an early intervention with Neuro-Cells significantly increased the $\mathrm{CD}^{+} 8^{+}$cells, caudal of the lesion, 5 days after the acute injury. Several studies testing cell-based therapies in SCl have reported a decrease in inflammation, however it must be noted that different markers have been used to assess inflammation in $\mathrm{SCl}$ rats. In our study, we used CD68, which is frequently used as a marker for microglia and peripheral-derived macrophages, two cell types that are morphologically indistinguishable from each other. The primary role of microglia/macrophages is to remove tissue and cellular debris, thereby enabling the resolution of inflammation and tissue repair (London, Cohen et al. 2013). Since blood-derived macrophages enter the site of injury after approximately 3 days, we speculate that our results mainly reflect the activation, and possibly the proliferation of resident microglia at the lesion and caudal site of the lesion following $\mathrm{SCl}$ and the rapid injection of viscous Neuro-Cells (Popovich and Hickey 2001). The residual presence of human macrophages in Neuro-Cells may be another factor explaining the increased $\mathrm{CD} 68^{+}$cells caudal to the lesion site in the rats treated with the xenotransplant. The anti-CD68 antibody used for immunostaining was specific for rat as well as for human proteins, thus possibly reflecting an immune reaction to the xenotransplant. It has also been reported that subpopulations of HSCs and MSCs do express CD68, which could explain the increased expression of $\mathrm{CD}^{+} 8^{+}$we observed caudal to the lesion and the lesion itself. Over time, due to migration and differentiation, the number of the $\mathrm{CD}_{68}^{+}$cells will eventually increase at all levels.

Interestingly, we found significantly less apoptotic cells in the same anatomical regions (central and caudal part of the $\mathrm{SCl}$-induced lesion) in the Neuro-Cells-treated $\mathrm{SCl}$ rats compared to the vehicle-treated rats. We found that 4 days after infusion with Neuro-Cells, rats in those parts of the lesion had significantly less caspase $-3^{+}$cells. The latter is in line with a recent study indicating that transplantation of bone-marrow stem cells in $\mathrm{SCl}$ mice downregulated the caspase- $3^{+}$cells 
after SCl (Gashmardi, Hosseini et al. 2017). Importantly, cells that stained positive for the human mitochondria antibody were detected at CA and only few at CE in NC-treated rats, 4 days after administration (Fig. 6). These results may suggest that Neuro-Cells migrated from the intrathecal space to the lesion and are able to integrate into the spinal cord tissue. Since only a few positive cells were detected at the lesion, these data also may suggest that the majority of the NeuroCells remained in the intrathecal space. Urdzikova et al. studying the immunomodulatory effects of human-derived MSCs administered in immune-competent rats with $\mathrm{SCl}$ have reported similar observations (Urdzikova, Ruzicka et al. 2014).

\section{Late-onset effects of Neuro-Cells in SCI}

Neuro-Cells continued to improve motor recovery during the 35 days post-injury observation. No effects though were found in $\mathrm{GFAP}^{+}, \mathrm{CD} 8^{+}$cells as well as the number of cleaved caspase- $3^{+}$ cells in Neuro-Cells-treated as compared to vehicle-treated T-cell deficient SCI rats at any site of the lesion, at 56 days after administration. We speculate that the recovery has already happened during the study period resulting in no detectable difference in GFAP and CD68 positive cells. Moreover, it appears that Neuro-Cells-treated SCl rats had a higher number of cleaved caspase$3^{+}$cells at the lesion 57 days postinjury, which may be explained by a recently demonstrated role of caspase-3 in mediating the differentiation of HSCs (Fujita, Crane et al. 2008, Janzen, Fleming et al. 2008). Since Neuro-Cells also contains HSCs, we speculate that HSCs pass on their immunomodulatory effect to resident cells. However, it must be noted that small changes in long tracts can result in a significant improvement of locomotor functions and are not always related to the extent of the lesion (Blight 1983). The regulation of spinal cord injury is possibly a function of complex pathway interactions of cellular and biochemical reactions to trauma-induced primary and secondary inflammatory processes and a dense scar formation. Protein expression profiling in $\mathrm{SCl}$ rats injected with Neuro-Cells 56 days after treatment clearly demonstrated a distinct spatial localization at the rostral and caudal sites of the lesion, which is in agreement with literature (Cizkova, Le Marrec-Croq et al. 2014, Devaux, Cizkova et al. 2016). Our clustering analysis revealed upregulated regulons at the lesion that are involved in positive regulation of differentiation (e.g. astrocyte differentiation, neuron differentiation). Our analysis took into account the spatial distribution of proteins between Neuro-Cells- and vehicle-treated rats. To a certain extent, the same pattern was observed at CA but not at RO. Among the regulons that are significantly upregulated at CA are the LMO4, which is involved in ATP signalling that promotes neuron survival after hypoxia (Chen, Schock et al. 2007), and Olig1 and Olig2, which are linked to the development and maturation of oligodendrocytes (Lu, Sun et al. 2002, Cheng, Wang et al. 2007). Both for CA and CE, NKX2.2, a regulon that has a critically important role in the differentiation of adult oligodendrocyte progenitor cells (OPCs) into remyelinating oligodendrocytes was significantly upregulated (Fancy, Zhao et al. 2004). Moreover, upregulation of HIF1A in the lesion itself is linked to regeneration of lost or damaged tissue in mammals that have a repair response (Zhang, Strehin et al. 2015). Interestingly, in CE and CA, regulons of human origin could be identified (e.g. UBE2L3, ANXA7, ENO1, MYH11, HNRNPA0, TPD52), regulons which role is still obscure, thus providing a novel protein list through which NC might exert its recovery effects. 
This result may support previous evidence, suggesting that MSCs rapidly pass on their effect to resident cells, which may substantially mediate the NC-induced immunomodulatory and regenerative effects (Eggenhofer, Luk et al. 2014).

$\mathrm{SCl}$ regulation might be the result of complex cellular and biochemical pathway interactions during primary and secondary inflammatory processes and scar formation. In the context of reactome pathways, we found a cluster enriched in glycosylation, keratan and collagen metabolism related proteins that appeared to be downregulated at the caudal site of the lesion and at the lesion but upregulated at the rostral site of the lesion. It has been reported, that increased $\mathrm{N}$-glycosylation correlates in vivo with increased astrogliosis (Nourse, Prieto et al. 2014).

Down regulation of glycosylation in Neuro-Cells treated rats may be responsible for the reduced astrogliosis we observed at all sites of the lesion. Interestingly, inhibition of collagen matrix formation in spinal cord lesions have also been associated with axonal regeneration and motor function recovery (Klapka and Muller 2006).

An upregulation in ion movements across membrane (for instance the lon transport by Ptype_ATPases) and semaphorins was identified at all three sites of the lesion. P-type ATPases is a protein family that plays an important role in the ATP-dependent flipping of phospholipids across the cell membranes, a biological process that is vital in vesicle trafficking. Semaphorins are expressed in the adult nervous system and have been implicated in controlling axon guidance (Tran, Kolodkin et al. 2007, Pasterkamp and Giger 2009, Yoshida 2012). However, contrary to netrins, the role of semaphorins in regeneration has not been studied extensively.

At the lesion, Netrin-1 and L1CAM related proteins are found to be significantly upregulated. In a rat model of nerve injury, Ke et al. have shown that overexpression of Netrin-1 in bonemarrow-derived MSCs improves functional recovery (Ke, Li et al. 2015).

The LICAM immunoglobulin family has been involved in the promotion of regenerative axon sprouting and functional improvement after CNS injury as well as neuronal migration and synapse formation (Maness and Schachner 2007, Li, Wu et al. 2008, Barry, Gu et al. 2010). The significant upregulation of platelet activation observed at the rostral site of the lesion has previously shown to be associated with inflammation, angiogenesis, and tissue regeneration. Platelets-derived microparticles were found to trigger endogenous stem cell repair mechanisms after middle cerebral artery occlusion in rats (Shan, Li et al. 2013).

Our proteomic analysis revealed both a signal of plasma-membrane and extracellular space restructuring processes at the lesion and unfolded another two ion transport gene sets at all three sites of the lesion (S7, Table 5), suggesting a paracrine effect of Neuro-Cells in $\mathrm{SCl}$ rats.

Several studies have shown that the therapeutic activity of MSCs is mainly mediated by MSCsecreted factors, suggesting the possible involvement of extracellular vesicles (EVs) as important players mediating the therapeutic effects of cells being used as therapeutics (such as MSCs and endothelial cells) via anti-inflammatory and apocrine modes of action (Zhang, Li et al. 2014, Rani, Ryan et al. 2015, Dostert, Mesure et al. 2017, Harting, Srivastava et al. 2018)). For instance, MSCEVs were found to exert immune-suppressive effects, by enforcing M2 macrophage polarization and stimulating T-cell induction (Ruppert, Nguyen et al. 2018). Extracellular vesicles (EVs), which include micro-vesicles, play an important role in intercellular communication both under physiological as well as pathophysiological conditions (Dignat-George and Boulanger 2011, 
Raposo and Stoorvogel 2013). EVs are carriers of active molecules regulating in a paracrine or endocrine manner the recipient cells (Thery 2011, Yanez-Mo, Siljander et al. 2015).

Taken together, in this particular experimental setting, Neuro-Cells did induce a beneficial effect over Vehicle in the treatment of acute balloon compression-induced immune-deficient SCl-rats, significantly reducing $\mathrm{SCl}$-related mortality and improving locomotor recovery. The advantage of applying low-immunogenic stem cells into T-cell derived immune-deficient rats is the prevention for rejection of the graft and/or host-versus-graft disease, without the co-application of immunosuppressive drugs, which may interfere with stem cell activities (Palladini, Caronti et al. 1996, Ibarra, Correa et al. 2003). Therefore, the significant acceleration of the natural, spontaneous recovery after $\mathrm{SCl}$-lesioning in these rats, as shown in this research project, indeed, might be interpreted as a main effect of the stem cell transplant.

The disadvantage in those immune-deficient rats, though, is that due to the reduced secondary posttraumatic inflammation in these animals, final balloon compression-induced damage with consequent sensorimotor and neuro-vegetative symptoms is significantly less when compared to immune-competent rats.

As stem cells are supposed to reach their effects in acute lesions by suppressing (secondary) inflammation, it is thus realistic to expect a lower magnitude of their eventual beneficial effect in SCl-lesioned T-cell deficient rats. Another disadvantage is that those animals, indeed, especially after an intervention with inflammation-reducing stem cells, are more prone to infections (Potas, Zheng et al. 2006). Most probably, this trend $(p<0.12)$ to a higher frequency of bladder infections in our NC-treated SCl-lesioned rats (as compared to the placebo-treated rats) might be explained in this way.

\section{Conclusion}

Our study provided the first proof of concept that Neuro-Cells improved the survival and accelerated natural motor recovery after $\mathrm{SCl}$. The effects of Neuro-Cells on pathological processes related to acute $\mathrm{SCl}$ are multiple. We speculate that an intrathecal injection of NeuroCells in spinal cord-injured rats, after some days, improved motor function initially, but not later on, in combination with a decrease of interleukins concentrations confirmed by histological established reduction of astrogliosis and apoptosis.

The continued motor recovery may suggest that Neuro-Cells exert their effects on a dual role: 1 ) at an early stage via their anti-inflammatory properties and 2) resulting at a later stage in a modulation of the injury environment. Overall, by targeting multiple mechanistic pathways, the infused Neuro-Cells may induce or pass on certain aspects of their regenerative properties, providing plausible biological mechanisms involved in the regenerative process. Therefore, this treatment holds great promise as a neuro-regenerative treatment including functional recovery in a clinical setting with (sub)acute $\mathrm{SCl}$ patients. 


\title{
4.2. Treatment of rats with spinal cord injury using human bone- marrow-derived stromal cells prepared by negative selection
}

Romero-Ramírez L, Wu S, de Munter J, Wolters ECh, Kramer BW, Mey J (2020); J Biomed Sci 27:35 https://doi.org/10.1186/s12929-020-00629-y

\begin{abstract}
Background: Spinal cord injury $(\mathrm{SCl})$ is a highly debilitating pathology without curative treatment. One of the most promising disease modifying strategies consists in the implantation of stem cells to reduce inflammation and promote neural regeneration. In the present study we tested a new human bone marrow-derived stromal cell preparation (bmSC) as a therapy of $\mathrm{SCl}$.

Methods: Spinal cord contusion injury was induced in adult male rats at thoracic level T9/T10 using the Infinite Horizon impactor. One hour after lesion the animals were treated with a suboccipital injection of human bmSC into the cisterna magna. No immune suppression was used. One dose of bmSC consisted, on average, of 2.3 million non-manipulated cells in $100 \mu \mathrm{L}$ suspension, which was processed out of fresh human bone marrow from the iliac crest of healthy volunteers. Treatment efficacy was compared with intraperitoneal injections of methylprednisolone (MP) or saline. The recovery of motor functions was assessed during a surveillance period of nine weeks. Adverse events as well as general health, weight and urodynamic functions were monitored daily. After this time, the animals were perfused, and the spinal cord tissue was investigated histologically.

Results: Rats treated with bmSC did not reject the human implants and showed no sign of sickness behavior or neuropathic pain. Compared to MP treatment, animals displayed better recovery of their $\mathrm{SCl}$-induced motor deficits. There were no significant differences in the recovery of bladder control between groups. Histological analysis at ten weeks after $\mathrm{SCl}$ revealed no differences in tissue sparing and astrogliosis, however, bmSC treatment was accompanied with reduced axonal degeneration in the dorsal ascending fiber tracts, lower lba1immunoreactivity (IR) close to the lesion site and reduced apoptosis in the ventral grey matter. Neuroinflammation, as evidenced by CD68-IR, was significantly reduced in the MP-treated group.

Conclusions: Human bmSC, which were prepared by negative selection without expansion in culture, have neuroprotective properties after $\mathrm{SCl}$. Given the effect size on motor function, implantation in the acute phase was not sufficient to induce spinal cord repair. Due to their immune modulatory properties, allogeneic implants of bmSC can be used in combinatorial therapies of $\mathrm{SCl}$.
\end{abstract}

\section{Background}

In spinal cord injury ( $\mathrm{SCl}$ ) cellular degeneration and the disruption of connections between the brain and the body cause paralysis and the loss of sensory and autonomic functions. Worldwide, the incidence of $\mathrm{SCl}$ ranges from 13 to 163 per million people per year, depending on the country 
(Kang, Ding et al. 2018). Over two thirds are due to trauma (falls, traffic and sport-related accidents, gun shots) and the rest to non-traumatic SCl (spinal stenosis, tumours, vascular ischemia). In addition to the devastating loss of quality of life to the patients, $\mathrm{SCl}$ causes a large economic burden on their families and society. Although rehabilitation therapy has continuously improved since the 1950s, there is no curative treatment of SCl (Gupta, Bathen et al. 2010, Kang, Ding et al. 2018). Spinal cord injury triggers local and systemic secondary mechanisms resulting in a chronic inflammatory state, which is mainly responsible for extensive cell death (Donnelly and Popovich 2008). These mechanisms are addressed with one available pharmacological treatment, namely the application of a high dose of methylprednisolone (MP) within the first hours after the injury. Following three independent clinical trials in the 1980s and 1990s (National Acute SCI Studies; (Bracken, Shepard et al. 1998)) MP became a standard intervention (Falavigna, Quadros et al. 2018). However, subsequent clinical experience showed that it is often ineffective and causes severe side effects such as higher incidence of sepsis, gastrointestinal haemorrhage or pulmonary embolism (Hugenholtz, Cass et al. 2002). Thus, new therapies of SCl are highly desired. A promising strategy to cure neurodegenerative pathologies is based on the application of stem cells (Tetzlaff, Okon et al. 2011, Shende and Subedi 2017, Tsintou, Dalamagkas et al. 2020). Such attempts where at first directed at cell replacement (Whittemore 1999), and with neural stem cells this continues to be an objective (Lu, Wang et al. 2012). With non-neuronal stem cells, on the other hand, the main rationale consists in modulating the inflammatory response (Tetzlaff, Okon et al. 2011, de Munter, Beugels et al. 2019). Paracrine factors and extracellular vesicles that are released from mesenchymal stem cells (MSC) are expected to prevent secondary degeneration and to support regenerative remodeling after $\mathrm{SCl}$ (Zhang, Chopp et al. 2015, Shende and Subedi 2017, Romanelli, Bieler et al. 2019). An easily accessible source of this type of cells is the bone marrow, which contains hematopoietic and mesenchymal stem cells. Different from induced pluripotent stem cells (Nagoshi, Tsuji et al. 2019), bone marrow-derived stromal cells (bmSC) pose no risk of tumor formation. We have developed a novel procedure to prepare fresh human bmSC with low immunogenicity (Neuroplast BV, patent WO2015/059300A1). This preparation is based on the depletion of erythrocytes and lymphocytes from bone marrow extracts without substantial manipulation or cultivation of the isolated cells. The objective of the present study was to assess the safety and therapeutic benefits of acute intrathecal injection of the novel bmSC preparation in SCl-lesioned rats and to compare it with acute intraperitoneal injection of MP. So far, one study has been published with these bmSC as a treatment of SCl (de Munter, Beugels et al. 2019). In these experiments, cell suspensions were injected into the spinal cord of immune compromised rats after a balloon compression injury. This treatment was associated with an improvement in the recovery of motor function at two and five weeks after $\mathrm{SCl}$ but not at one, three and four weeks. While serum levels of IL-1 $\beta$ and TNF- $\alpha$ were reduced, treatment had no consistent effect on neuro-inflammation in the spinal cord. Based on the outcome, the present investigation has implemented the following design:

1) We have tested the bmSC in immune competent animals. Previously, T-cell deficient rats were used in order to avoid a possible immunological rejection to the human implants. Since one expected mechanism of action consists in the suppression of inflammation, the use of immune competent rats was considered necessary. 
2) As suggested by the EMA, stem cell treatment was compared with MP. Despite its limited efficacy, MP is still the only FDA-approved pharmacological treatment of SCI (Bracken, Shepard et al. 1998, Falavigna, Quadros et al. 2018), and any new intervention should therefore be compared with this standard.

3) A different $\mathrm{SCl}$ model was chosen. While the balloon compression used before is a validated model to investigate physiological consequences of $\mathrm{SCl}$, a much larger number of human $\mathrm{SCl}$ cases (about half of all; (Shende and Subedi 2017)) are represented by the contusion injury model.

4) Rats were monitored up to nine weeks after $\mathrm{SCl}$ to assess the long-term effects of implanted bmSC, which may be observed in the chronic stage.

5) Additional outcome measures in the present study included tests of motor function (Rotarod), autonomic function (bladder control), neuropathic pain (tactile allodynia) and a more extensive histological assessment including axonal degeneration and macrophage activation.

\section{Methods}

\section{Experimental Animals}

The ethics committee for Animal Care of the Hospital Nacional de Parapléjicos reviewed experimental protocol, surgical procedures and post-operational care (163CEEA/2017), which were subsequently approved by the Consejería de Agricultura y Ganadería de Castilla-la Mancha (ref. 210498, following EU directive 2010/63/EU). During the acclimatization period, six to eight week old male Wistar rats (Rattus norwegicus; mean weight $304 \mathrm{~g}+/-14 \mathrm{~g}$, raised in the animal facility of the hospital), were kept in pairs under standard housing conditions (12 hrs light/dark cycle, humidity $40-60 \%$, temperature $22^{\circ} \mathrm{C}$ ) with ad libitum access to food and water. Following surgery, animals were kept in separate cages. A total of 26 animals entered the study (Fig. 1).

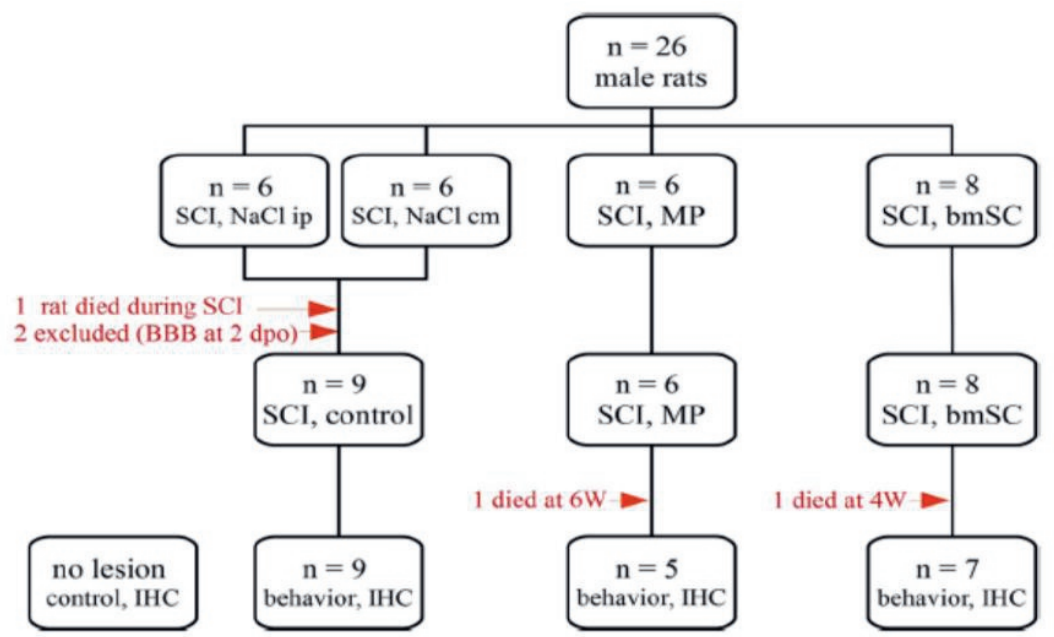

Figure 1. Experimental plan and treatment groups. Animals that received spinal cord contusion injury were pseudo-randomly assigned to four groups. Rats with intraperitoneal and intrathecal (cisterna magna) saline injections were planned to be evaluated as one control group unless behavioral evaluation showed statistical differences between them. One animal was lost due to bleeding during spinal cord surgery, two animals had to be excluded from the study because open field evaluation revealed an incomplete lesion (BBB at 2 dpo) and two rats died during the observation period. In the histological evaluation, treatment groups were also compared to tissue samples of non-injured animals. 
In an exploratory experiment to determine the least invasive way of implanting the stem cells (intrathecal injection in the spinals cord vs. cisterna magna), additional 10 rats had been operated and their motor recovery was followed over a period of 3 weeks.

\section{Spinal cord contusion injury}

To induce anaesthesia the rats were exposed to $5 \%$ isoflurane/95\% oxygen in a plexiglass chamber. During surgery, anaesthetic was reduced to $2,5 \%$ isoflurane/oxygen breathed via an inhalation mask of a vaporizer (flow rate $0.4 \mathrm{~L} / \mathrm{min}$; Medical Supplies and Services). Fifteen minutes before surgery, rats were weighed and received the analgesic buprenorfine $0,05 \mathrm{mg} / \mathrm{kg}$ (Buprex $0.03 \mathrm{mg} / \mathrm{mL}$ ). After induction of anaesthesia, the fur on the back was shaved. The animals were then taped to the operating table, their body temperature being maintained on a heat pad with a rectal thermometer probe. Corneal dehydration was prevented with ophthalmic ointment (Lubrithal). Surgery was performed with the help of an operating microscope (Leica). After skin incision and dissection of the muscle layers covering the vertebrae, serrate muscles were spread with a retractor (Reda 19621-07), and the spinal cord was exposed by laminectomy of vertebrae T9-T11 without damaging the dura mater (small rongeur FST 16021-14, scalpel with round blade, two round forceps mid-size, one forceps with teeth, sterilized cotton-tips, gelatin sponge). To suspend the spinal cord for applying the contusion injury, the dorsal spinal processes T7 and T12 were fixed with the clamps of the impactor device (Infinite Horizon, IH). The impactor rod was positioned centrally at T9/T10 over the spinal cord mid- line, and the contusion was applied, using a force of $2 \mathrm{~N}$, calibrated before every experiment, and zero dwell time. We checked the procedure visually (hematoma) and by monitoring the $\mathrm{IH}$ displacement/time and force/time plots. In two cases, where the impactor rod hit a bone, the laminectomy was extended and the contusion injury repeated. Following this procedure, the rats were released from the IH clamps. The wound was covered with subcutaneous fat tissue from the same animal. Overlying muscles were re-apposed and sutured, and the skin was closed with a non-interrupted intradermal suture (resorbable thread 4.0) and disinfected with iodine. Animals were then disconnected from anaesthesia and received $2 \times 2.5 \mathrm{~mL}$ isotonic saline s.c. and antibiotic treatment marbofloxacin $5 \mathrm{mg} / \mathrm{kg}$ (Marbocyl $10 \mathrm{mg} / \mathrm{mL}$, s.c.).

\section{Postoperative treatment and care}

Following surgery, rats were housed individually to prevent biting at skin sutures. Throughout the study, we performed daily overall health assessments, including inspection of the animal's well-being, body weight, urodynamic assessments and routine checks to detect urinary tract infections. For the first three days animals received two daily s.c. injections of buprenorfine 0.05 $\mathrm{mg} / \mathrm{kg}$ for pain relief. Subcutaneous injections of $5 \mathrm{mg} / \mathrm{kg}$ marbofloxacin were given at the day of surgery, at two- and four-days post operation (dpo). Postsurgical care also included food pellets soaked in water and a water bottle with longer tube. The bladders were checked twice daily and voided manually until the rats were urinating spontaneously. The volume of retained urine was recorded. In case of urinary infection, the animals were treated with marbofloxacin 5 $\mathrm{mg} / \mathrm{kg}$ s.c. every $48 \mathrm{hrs}$ until the urine was clear and without blood. Euthanasia at the end of the study was induced by i.p. injection of $100 \mathrm{mg} / \mathrm{kg}$ of sodium pentobarbital (Dolethal). 


\section{Experimental groups}

Animals were pseudo-randomly assigned to four experimental groups, which all received the same $\mathrm{SCl}$ but differed in the treatment procedure (Fig. 1). Group 1 received five $\mathrm{NaCl}$ i.p. injections, the first immediately after $\mathrm{SCl}$ and subsequently every $8 \mathrm{~h}$; group 2 received one 100 $\mu \mathrm{L} \mathrm{NaCl}$ injection into the cisterna magna at 1-2 $\mathrm{h}$ after SCl; group 3 was treated with five MP injections i.p., one after $\mathrm{SCl}$ and subsequently every $8 \mathrm{~h}$; group 4 was treated with one $100 \mu \mathrm{L}$ bmSC injection into the cisterna magna at 1-2 $\mathrm{h}$ after $\mathrm{SCl}$. Rats were assigned random identifiers, which were written with permanent marker on their tails. During the following 9 weeks of behavioral evaluation, care takers and investigators were blinded regarding the experimental condition of the individual animals. To keep the number of experimental animals low, the control groups ( $\mathrm{NaCl}$ i.p. and per cisterna magna) were planned to be joined in one statistical group unless significant differences were found in the behavioral tests.

\section{Preparation of bmSC}

Bone marrow-derived cells for $\mathrm{SCl}$ treatment were prepared at the Neuroplast facility, Geleen, Netherlands, under GMP conditions. The cells were not expanded by cultivation (Neuro-Cells, patent W02015/059300A1). Recruitment of volunteers for bone marrow collection, procedures and documentation were approved by the ethics committee of Maastricht University Medical Center (METC 13-2-032). From two donors (BM31, BM33) $50 \mathrm{~mL}$ bone marrow was collected. Clotting was prevented by EDTA adjuvants. The fresh bone marrow was immediately processed, using automated Ficoll density gradient centrifugation to remove the erythrocytes and reactive proteins. Subsequently, B-cells $\left(\mathrm{CD} 2 \mathrm{O}^{+}\right)$, T-cells $\left(\mathrm{CD}^{+}\right)$, monocytes $\left(\mathrm{CD}^{2} 4^{+}\right)$and natural killer cells $\left(\mathrm{CD} 56^{+}\right)$were removed using antibody-based cell sorting with magnetic beads (negative selection; CliniMacs Plus, Miltenyi Biotec $\mathrm{GmbH}$ ). The viability and cell type composition of each batch was analysed with flow cytometry (CD34, CD271, CD90, CD105, CD73). For the present study, cells were cryoprotected with DMSO, frozen in liquid nitrogen, shipped on dry ice to Toledo, Spain, and then stored in liquid nitrogen until use. Cell viability was again determined after thawing, i.e. immediately before application in vivo (cytometry, propidium iodide exclusion). On average, cisterna magna injections contained $2.3+/-0.5 \times 10^{6}$ viable cells.

\section{Intrathecal infusion of bmSC, injections of MP or vehicle}

For cisterna magna injections of bmSC or saline, $1.5 \mathrm{~h}$ after $\mathrm{SCl}$, animals were re-anesthetized with ketamine $50 \mathrm{mg} / \mathrm{kg}$ (Ketolar $50 \mathrm{mg} / \mathrm{mL}$. i.p.) combined with xylacine $5 \mathrm{mg} / \mathrm{kg}$ (Sedaxylan 20 $\mathrm{mg} / \mathrm{mL}$, i.p.) and one i.p. injection of atropine $0.04 \mathrm{mg} / \mathrm{kg}$. The head and neck of anesthetized rats were shaved, and the animals were positioned in a stereotactic frame (Kopf) with the neck flexed to $70^{\circ}$ at the atlanto-occipital joint. Ophthalmic ointment was applied, and the skin was superficially disinfected with $70 \%$ ethanol. Simultaneously, the bmSC were prepared for injection: For the treatment of two rats, one batch containing $1 \mathrm{~mL}$ of frozen cell suspension was thawed in a $37^{\circ} \mathrm{C}$ water bath, spun down, washed with saline, centrifuged and resuspended in $210 \mu \mathrm{L}$ saline. From this, $10 \mu \mathrm{L}$ was removed for cytometric counting of cell numbers and determination of cell viability. The remaining $200 \mu \mathrm{L}$ cell suspension was kept on ice until the rats were ready for receiving the injections. The setup for slow injection into the cisterna magna 
consisted of an electric syringe pump and a sterile $1 \mathrm{~mL}$ plastic syringe connected to a Fogarty arterial embolectomy catheter $0.67 \mathrm{~mm}$, fixed to the stereotactic device. A steel canula $23 \mathrm{G}$ $0.6 \mathrm{~mm}$ was used to penetrate the atlantooccipital membrane before inserting the catheter. When the anesthetized rat was in place, the atlantooccipital membrane was accessed by midline anterior-posterior incisions of skin and muscles, which were separated and fixed laterally. Syringe and catheter, previously flushed with sterile saline, were loaded with cell suspension (bmSC treatment) or saline (vehicle treatment) and placed in the holder of the microliter pump. Under microscopic control, the membrane was then punctured and access to the cisterna magna confirmed by observing the appearance of clear cerebrospinal fluid. The catheter was inserted and its content slowly infused $(100 \mu \mathrm{L} / 3 \mathrm{~min}$ ) before retracting the catheter. Finally, the muscle and skin were sutured, wiped with Betadine, and the animal was placed in its cage, receiving postoperative care as described for $\mathrm{SCl}$. Rats belonging to the MP group received in total five i.p. injections of $30 \mathrm{mg} / \mathrm{kg} \mathrm{MP}$, given at $1 \mathrm{~h}$ after $\mathrm{SCl}$ and subsequently one every $8 \mathrm{~h}$. Lyophilized MP was reconstituted to $20 \mathrm{mg} / \mathrm{mL}$ just prior to injection and kept at $4{ }^{\circ} \mathrm{C}$ for the remaining applications. Rats belonging to the second control group were treated with the same volume of saline, $150 \mu \mathrm{L} / 100 \mathrm{~g}$, injected i.p. at the same times.

\section{Evaluation of locomotor functions in the open field}

Recovery of limb movements was evaluated using the Basso/Beattie/Bresnahan (BBB) locomotor function test (Basso, Beattie et al. 1995) for five minutes/rat in an open field. The BBB scale ranges from 0 (no hind limb movement) to 21 (normal movements, coordinated gait with parallel paw placement). Scores from 0-7 indicate the return of isolated movements in the three joints (hip, knee and ankle). Scores from 8 to 13 indicate the return of paw placement and coordinated movements with the forelimbs. Scores from 14 to 21 show the return of toe clearance during stepping, predominant paw position, trunk stability, and tail position. Motor scores were measured pre-SCl (baseline), at $2 \mathrm{dpo}, 4 \mathrm{dpo}$, and once per week for the next nine weeks after lesioning. At the beginning, we established a criterion of $\mathrm{BBB}<2$ at $2 \mathrm{dpo}$ for inclusion in the study because a higher score was considered to indicate incomplete $\mathrm{SCl}$. Scoring was performed by two independent investigators who were blinded with respect to the treatment of the individual animal. Following independent assessment, both investigators discussed their reasons and independently awarded their score.

\section{Rotarod locomotor function test}

The Rotarod test (Mann and Chesselet 2015), which required the rats to maintain their body on a rotating rod, was performed according the instruction manual of the manufacturer (Ugo Basile $\mathrm{SRL}$, Gemonio, Italy). In four training sessions of 5 minutes each, which were administered two and one days before $\mathrm{SCl}$ surgery, all rats learned this task at a constant speed of $5 \mathrm{rpm}$ of the rotating rod. Since balancing on the rotating bar cannot be performed by a rat with completely paralyzed hind legs, the first testing was performed at $4 \mathrm{dpo}$, subsequently at $7 \mathrm{dpo}$ and then once per week. In the test runs, the rotation speed was accelerated from $5 \mathrm{rpm}$ to $15 \mathrm{rpm}$ over a period of 3 minutes. Readout in this assay was the time that the rats were able to stay on the rotating rod before falling off (mean of two repetitions, separated by a break of $\geq 15 \mathrm{~min}$ ). Data obtained from rats that refused to hold on to the bar were included in the evaluation because 
we lacked an independent criterion to distinguish between voluntary refusal and inability to perform the task.

\section{Von Frey test of mechanical allodynia/hyperalgesia}

Before $\mathrm{SCl}$ and at the end of the 9-week observation period, tactile allodynia/hyperalgesia was tested manually using a kit of von Frey filaments with a range of different diameters. For this, rats were placed individually in small cages with a wire mesh bottom. To deliver a constant force, a filament with specific diameter was pressed perpendicularly to the plantar surface of the hind paw until it buckled and held for 2-5 s. A response was considered positive when the animal exhibited any nocifensive behaviour such as brisk withdrawal or licking of the paw (Deuis, Dvorakova et al. 2017). Both hind paws were stimulated from below, and the paw withdrawal threshold determined using the simplified up-down method (Bonin, Bories et al. 2014).

\section{Tissue preparation and histological staining}

Ten weeks after $\mathrm{SCl}$ the rats were sacrificed with an overdose of sodium pentobarbital followed by transcardial perfusion with phosphate buffered saline (PBS) and $4 \%$ paraformaldehyde/PBS. Spinal cords were prepared, post-fixed for $1 \mathrm{~h}$, then transferred to PBS and stored at $4{ }^{\circ} \mathrm{C}$. For histological processing, $18 \mathrm{~mm}$ long spinal cord segments that included the lesion site were dissected, dehydrated, embedded in paraffin and cut in $3 \mu \mathrm{m}$ transverse sections using a Leica RM2265 microtome.

Sections separated by $250 \mu \mathrm{m}$ were mounted on polylysinecoated glass slides (Superfrost Plus) and stored at $4{ }^{\circ} \mathrm{C}$. To assess the extension of the lesion, the complete series of spinal cord sections of all rats were rehydrated, stained with hematoxylin/eosin (H\&E), dehydrated again and cover slipped with Histomount (Merck).

\section{Immunohistochemistry}

Prior to immunohistochemical staining, rehydrated sections were incubated for $30 \mathrm{~min}$ at $90{ }^{\circ} \mathrm{C}$ (water bath) in $10 \mathrm{mM}$ Na citrate/0.05\% Tween 20, pH 6.0, for antigen retrieval. Standard procedure included blocking $1 \mathrm{~h}$ at RT with $5 \%$ normal goat serum/0.05\% Tween 20 in Trisbuffered saline (TBS-T), incubation with primary antibodies for $12 \mathrm{~h}$ at $4{ }^{\circ} \mathrm{C}$ in a humidified chamber and $2 \mathrm{~h}$ incubation with fluorescence-labeled secondary antibodies at RT. Nuclei were stained with $10 \mu \mathrm{g} / \mathrm{mL}$ Hoechst-33342 for $15 \mathrm{~min}$ at RT. Sections were cover slipped with Mowiol/DAPCO or ImmuMount (Thermoscientific). We used the following primary antibodies, usually in a double staining protocol in the dilutions indicated in parenthesis: Rabbit anti-GFAP, polyclonal (Sigma G9269; 1/500), rabbit anti-caspase-3/activated (Calbiochem PC679; 1/200), rat anti-MBP, polyclonal (Abcam ab7349; 1/1000), mouse anti-Smi32, monoclonal (Palex 23R-100; $1 / 2000)$, mouse anti- $\beta$ (III) tubulin, monoclonal (Chemicon CBL412; $1 / 100$ ), mouse anti-CD68, monoclonal (Serotec MCA341R; 1/200), mouse anti-NeuN, monoclonal (Millipore MAB377; $1 / 200$ ), guinea pig anti-lba1, polyclonal (Synaptic systems 234,004; 1/500), mouse antihuman mitochondria, monoclonal, fluorescence-labeled with Cy3 (Millipore MAB1273C3; 1/200). Secondary antibodies were labeled with fluorescent dyes: Goat antiguinea pig IgG, Alexa-488 (Invitrogen A11073; 1/500), goat anti-rabbit IgG, TRITC (Sigma T5268; 1/500), goat anti-mouse 
IgG, Alexa-594 (Invitrogen A11005; 1/500), goat anti-mouse IgG, Alexa-488 (Jackson 115$545,003 ; 1 / 500)$, and goat anti-rat IgG, Alexa-488 (1/500).

\section{Microscopy and image analysis}

Sections stained with H\&E were photographed with a stereology microscope (Olympus BX61) using $4 x$ and 10x objectives. For quantitative evaluation we determined the maximal anteriorposterior extension of the tissue lesion and the tissue loss in the lesion center of each rat. The latter was calculated by comparing the remaining tissue area in transverse spinal cord sections to corresponding sections of a rat without $\mathrm{SCl}$. Immunohistochemical staining was evaluated using a Leica epifluorescence microscope. Following visual inspection, objectives and exposure times were selected to account for different signal intensities obtained with different antibodies. Exposure conditions were held constant for quantitative evaluation with GFAP (5x objective), CD68 (10x), Iba1, Smi32, MBP (20x) and activated caspase-3 (40x). Photographs were analyzed using Fuji Image-J, applying the same brightness/contrast adjustments and threshold values for each marker. The intensity of GFAP-immunoreactivity (IR) was measured as integrated density in regions of interest (ROI) in the glial scar around the lesion center; Iba-1: in the white matter in sections anterior and posterior of the lesion and in the lesion center; Smi32 and CD68: in the dorsal columns and in the ventrolateral white matter in sections anterior and posterior of the lesion. Signal intensities were normalized to values found in spinal cord sections from noninjured rats. For evaluation of apoptosis we counted cell nuclei that were IR for activated caspase- 3 and expressed data as percentage of all nuclei in the ROI, which were located in dorsal and ventral grey matter, anterior and posterior of the lesion center (supplementary Fig. S1).

\section{Statistical analysis}

Unless stated otherwise in the figure legends, data are presented as mean values +/- standard error of the mean (SEM). Non-parametric data are represented in a box and whiskers graph. The statistical analysis of weight and behavioral data (changes in time, effect of treatment), performed with GraphPad Prism v5 software, consisted of two-factor ANOVA, followed by posthoc Tukey tests. For histological data, the differences among means were analyzed with unpaired Student's t-test, considering $\mathrm{p}<0.05$ as statistically significant.

\section{Results}

\section{Effect of bmSC implantation on the general health status, body weight and autonomic functions.}

The general health condition of the animals was not compromised. No adverse effects such as sickness behavior or tissue reaction to the bmSC were observed. Unexpectedly, one (bmSCtreated) rat was found dead after $29 \mathrm{dpo}$ and one (MP treated) after $50 \mathrm{dpo}$. Pathological inspection of these animals did not show any significant abnormality. In five cases, biting at hind limbs occurred, but no animal had to be sacrificed due to sickness behavior or urinary infection. Following SCl surgery, body weight in all rats typically fell by $10-15 \%$ during the first 4 days and subsequently recovered with an average weight gain of about $8 \%$ per week during the first 5 weeks of the study and then slowing declining to $2 \%$ per week (Fig. 2a). 
Treatment was found to have a significant effect on relative change in body weight in bmSCtreated rats versus the control groups (interaction effect time $x$ group, repeated measure ANOVA, $F(7,56)=8.83, p<0.001$ ). Post-hoc testing revealed that bmSC-treated rats initially lost significantly more weight than MP and vehicle-treated controls, but that they later on gained significantly more body weight compared to those groups ( 3 weeks after surgery: $p=0.042 ; 4$ weeks: $\mathrm{p}=0.018 ; 5$ weeks: $\mathrm{p}<0.01$ ). After $\mathrm{SCl}$, animals needed assistance with bladder voiding, and all rats recovered autonomic bladder control within 2 weeks. Based on the volume of manually expelled urine, we found that the interventions with bmSC and MP did not significantly affect the return of spontaneous bladder control (Fig. 2b).
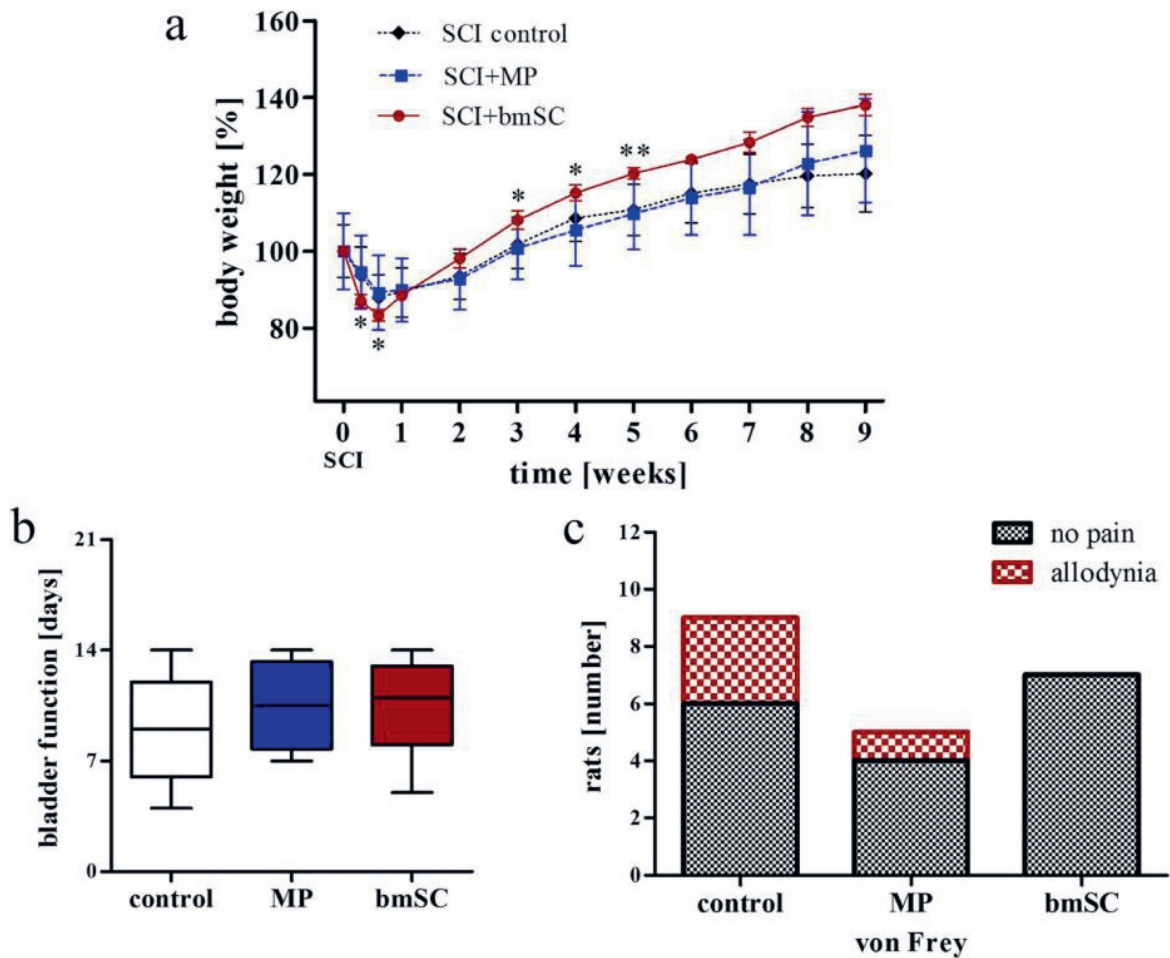

Figure 2 Health status after SCI. No adverse events were attributed to bmSC treatment. a Changes of body weight following SCI: Initially, stem cell treated rats lost more body weight while at a later stage (starting at $14 \mathrm{dpo}$ ) they gained more weight compared to MP-and vehicle-treated animals. Data were normalized to the body weight before surgery (mean +/-SEM; two factor ANOVA, post hoc Tukey test, $\left.{ }^{*} p<0.05,{ }^{* *} p<0.01\right)$. $\boldsymbol{b}$ Recovery of the spontaneous micturition reflex: Displayed is the time after SCI [days] that passed until the animals no longer required manual voiding of the bladder by the experimenter (median, 25\%/95\% and range). There were no significant differences between treatment groups (H-test). c Testing of mechanical nociception (von Frey, reduced threshold of paw withdrawal response) at nine weeks after SCl showed no hyperalgesia/allodynia in bmSC implanted animals, while this occurred in $1 / 5$ rats treated with MP and $3 / 9$ rats that had received $\mathrm{NaCl}$ injections. Treatments following $\mathrm{SCl}$ are designated as: control - injections of $0.8 \%$ saline solution; $\mathrm{MP}$ - of methyl prednisolone; bmSC - of human bone marrow-derived stem cells.

The response to tactile stimulation of the hind paws was tested manually with von Frey hairs before $\mathrm{SCl}$ surgery and after 9 weeks at the end of the study. Confirming the observations on overall health, none of the bmSC treated animals showed mechanical allodynia/hyperalgesia 
(lowered threshold of the paw withdrawal response). This was, however, the case in three animals of the $\mathrm{NaCl}$ control group and one rat of the MP treatment group (Fig. 2c).

\section{Tissue damage caused by the $\mathrm{SCl}$}

At the end of the study, the spinal cords of all animals were investigated with histology. Hematoxylin/eosin staining of transverse sections revealed extensive tissue damage caused by the contusion injury (Fig. 3). At the lesion center, more than half of the tissue was destroyed in all cases. Cavitation occurred, and to a large extent the remaining tissue contained non-neuronal scar, necrotic tissue and infiltration of inflammatory cells (Fig. 3a-f). Ependymal cells, identified morphologically, appeared to have proliferated. There were no quantitative differences between the treatment groups regarding the tissue loss in the center of the lesion (Fig. $3 \mathrm{~g}$ ). The anteriorposterior extension of the damage, which comprised all sections with pathological tissue alterations, was on average $4.7 \mathrm{~mm}$ (SD $=1.5 \mathrm{~mm}$; Fig. $3 \mathrm{~h}$ ) without significant differences between treatment groups (t-tests, $\mathrm{p}>0.05$ ). The lesion centers, characterized by a fluid-filled cavity and scar formation, had an average size of $1.4 \mathrm{~mm}(\mathrm{SD}=1.1 \mathrm{~mm})$ also without significant effect of treatment.
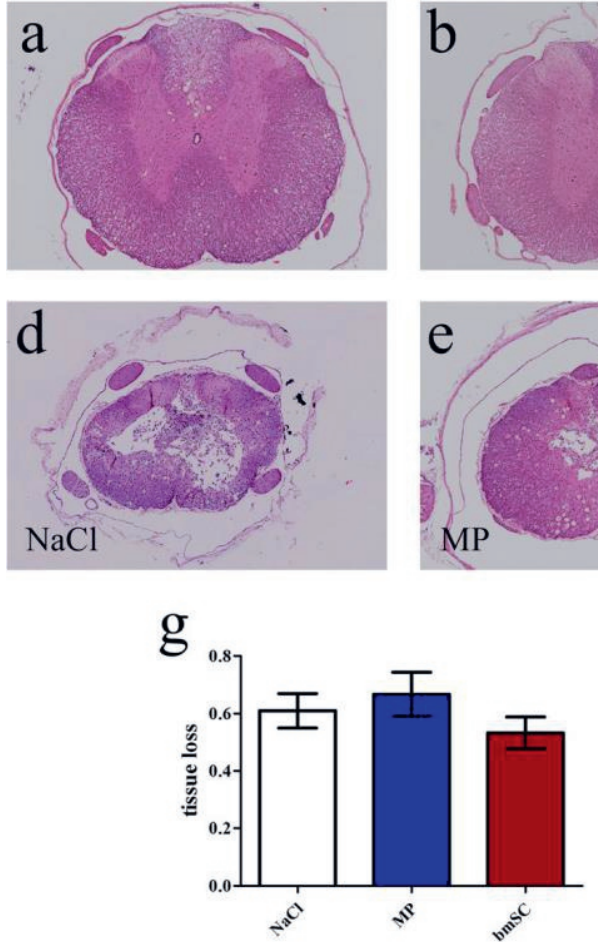
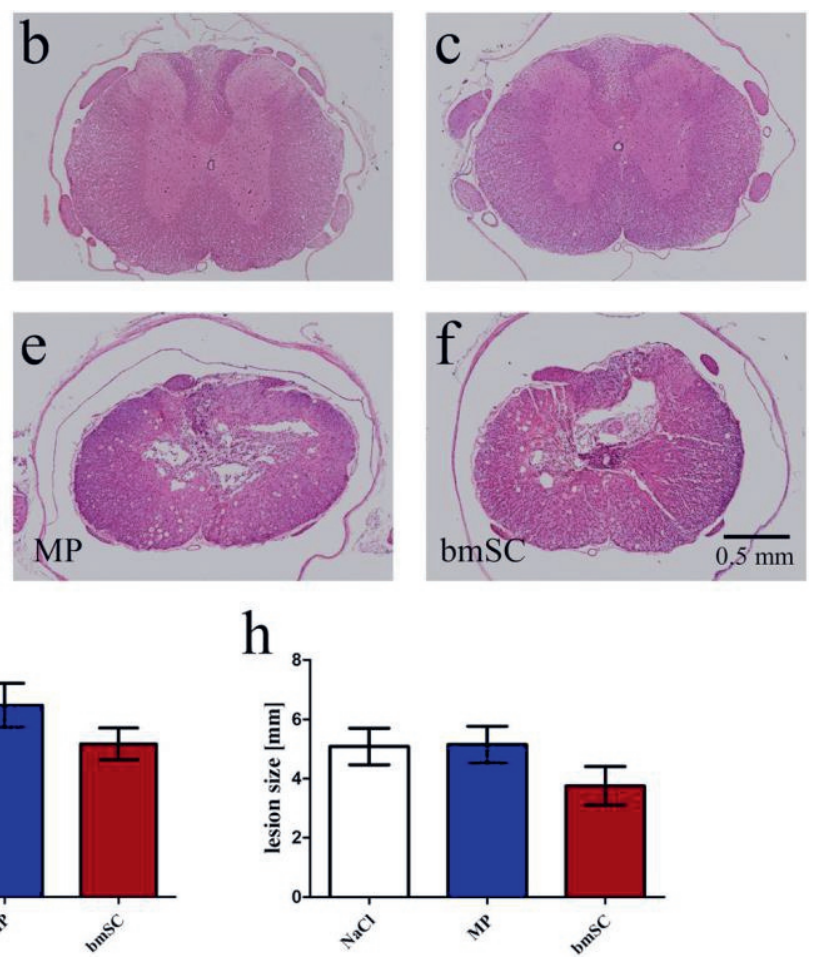

Figure 3 Treatment with bmSC and MP did not affect tissue degeneration. Lesion size and extent of tissue degeneration were evaluated in H\&E-stained spinal cord sections at 10 weeks after SCl. a-f Panels show representative tissue sections $0.9 \mathrm{~cm}$ anterior of the lesion site (ac) and at the lesion center ( $d$-f); treatment groups were: $\boldsymbol{a}, \boldsymbol{d}$ injection of saline; b,e methylprednisolone; and $c, f$ human bmSC; same magnification in all photographs. $\boldsymbol{g}$ Relative tissue loss in the center of the lesion (normalized to spinal cord sections without lesion). $\boldsymbol{h}$ Anterior to posterior extension of lesion size as identified in H\&E-stained spinal cord sections. Bars show means and SEM, $n=5-7$ animals, differences between treatment groups were not significant. 


\section{Recovery of sensory-motor functions}

At 2 dpo, 23 successfully operated animals scored $<2$ in the BBB locomotor function scale (none or only slight movements of one or two joints; mean score of both hind legs), demonstrating a reasonable degree of reliability of the $\mathrm{SCl}$ rat model in our hands. Scoring differences between two blinded independent investigators were low (0-1), and in case of differences, the mean score of the two evaluators was recorded. Due to spontaneous recovery, time significantly affected motor function in all treatment groups (Fig. $4 ; p<0.001$ ), and a significant interaction effect was found between the groups and the treatment over time (repeated measure ANOVA, $F(7,56)=5.75, p<0.001)$. Importantly, rats treated with bmSC had significantly better motor function (BBB scores) compared to MP-treated rats at 4 days $(p=0.015), 7$ days $(p=0.029), 2$ weeks ( $p=0.008), 3$ weeks $(p=0.005), 4$ weeks $(p=0.009)$ and 5 weeks $(p=0.015)$ after surgery (Fig. 4). After this time, mean score differences between bmSC and MP treatment remained in the same order of magnitude ( $\triangle B B B$ was 4.5 at week 5 and 3.9 at week 9 ). These results indicate that the bmSC implantation resulted in better motor improvement than standard MP therapy. The effect was noted already at 4 dpo and reached highly significant levels during 5 weeks of recovery. Differences in recovery between bmSC and $\mathrm{NaCl}$ treatment, however, were smaller ( $\triangle \mathrm{BBB}$ was 0.8 at week 5 and 1.5 at week 9 ) and did not reach significance.

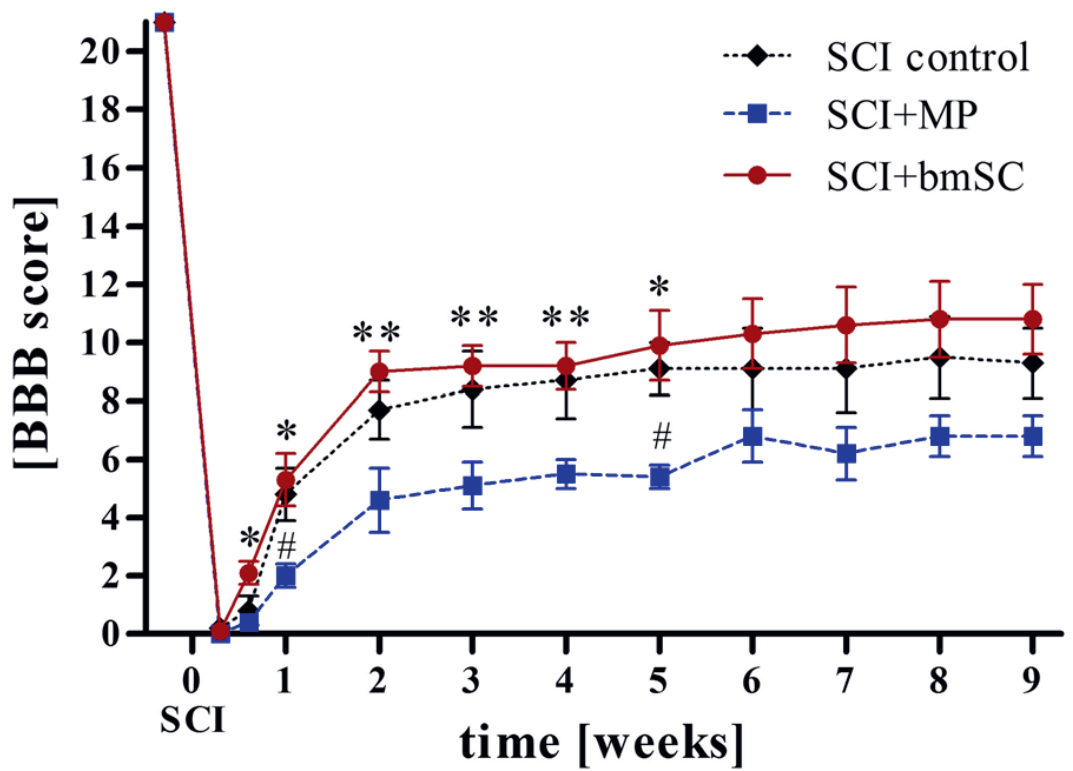

Figure 4 Injection of bmSC caused better recovery of motor function than MP treatment. Mean BBB scores ( \pm SEM) of the three treatment groups. All rats had $\mathrm{BBB}=21$ before $\mathrm{SCl}$, and the first evaluation occurred two days after surgery. As indicated in Fig. 1 , only animals with $\mathrm{BBB}<2$ at $2 \mathrm{dpo}$ ( $\mathrm{SCl}$ considered as complete) were included in the evaluation. Following a two-factor ANOVA that revealed effects of treatment and time after $\mathrm{SCl}$, post hoc Tukey test showed significant differences between bmSC and $\mathrm{MP}$ treatment $(* \mathrm{p}<0.05, * * \mathrm{p}<$ 0.01 ) and between $\mathrm{NaCl}$ and $\mathrm{MP}$ treatment ( $\# \mathrm{p}<0.05$ ).

In addition to evaluation in the open field, rats were subjected to the Rotarod test. At 4 dpo none of the animals that met the inclusion criterion $(\mathrm{BBB}<2$ ) was able use their hindlimbs to maintain balance on the rotating bar. Spontaneous recovery caused a significant increase in Rotarod score 
during the first 4 weeks in all experimental groups (supplementary Fig. S2). After 4 weeks, motor performance in this test did not improve further and in the saline treated animals actually deteriorated thereafter. Several rats refused the task as they did not grasp the bar with their fore paws. Their low score contributed to a very high variability. Thus, although bmSC treated animals had higher mean scores throughout the period of evaluation than both control groups, these differences were not significant.
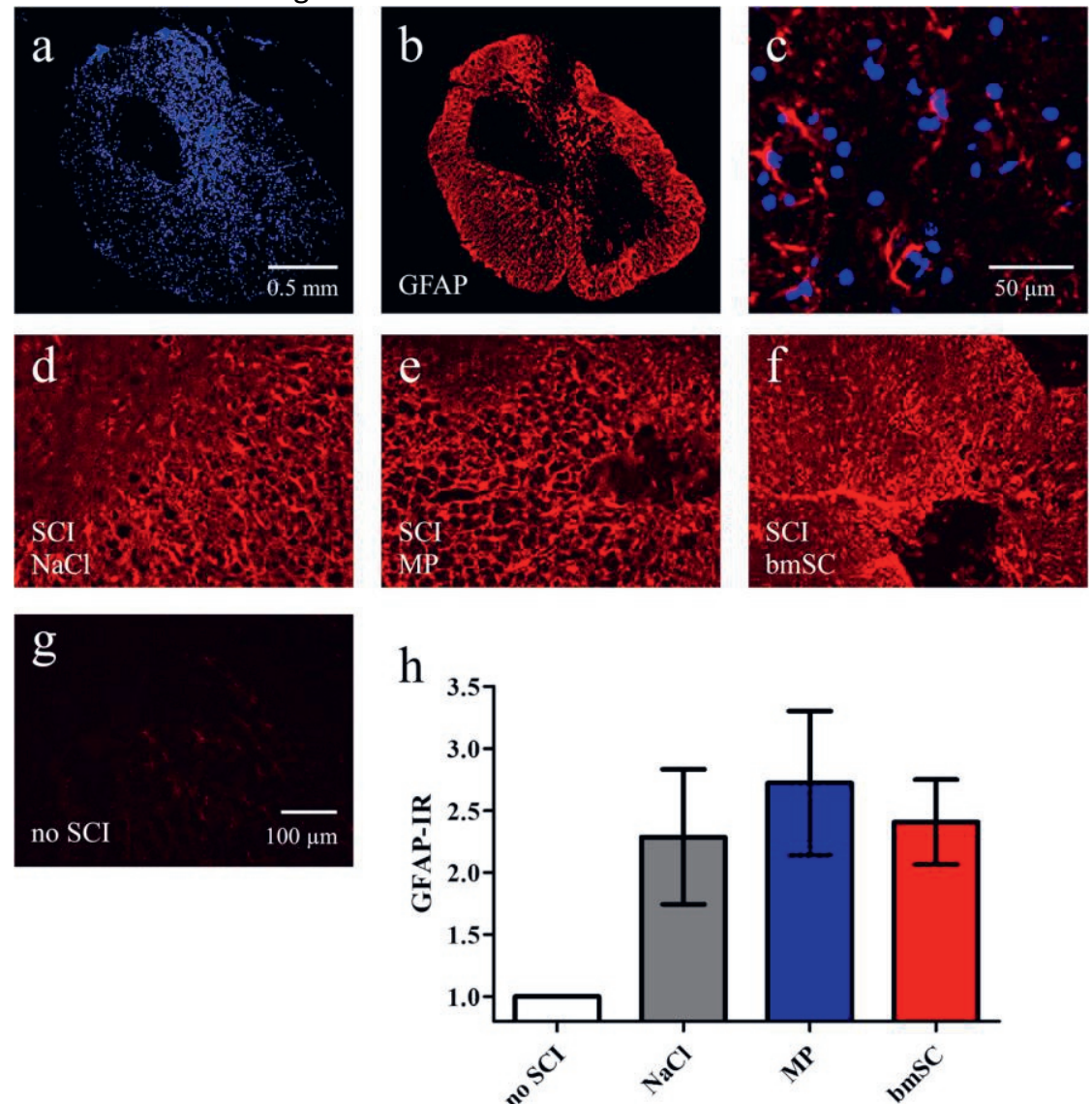

Figure 5 Astrogliosis was not affected by bmSC and MP treatment. Evaluation of GFAP-IR in spinal cord tissue ten weeks after SCl. a-b Overview of scar formation around the lesion center in a typical example; nuclear labeling with Hoechst-33342 (a) was combined with GFAP (b) immunostaining; $5 x$ objective, scale bar $0.5 \mathrm{~mm}$ in a. $c$ Reactive astrocytes in the gey matter outside of the lesion center. $d$-f Higher magnification of GFAP-IR close to the lesion site in SCl rats with control treatment (d), MP injections (e), bmSC implants (f), and $g$ in the white matter of an animal without SCl; 20x objective, images $d$ - $g$ with the same times of exposure, scale bar $100 \mu m$ in g. $\boldsymbol{h}$ Quantification of GFAP-IR (integrated density) near the lesion site revealed no significant differences between $S C I$ treatment groups ( $t$-tests, $p>0.5)$. Data were normalized to GFAP-IR in the white matter of rats without lesion (statistical difference not indicated); bars show means and SEM, $n$ $=5-6$ rats $/$ group .

\section{Effect of bmSC and MP treatment on the astrocytic scar}

Astrocytes were visualized with GFAP-IHC in spinal cord sections containing the lesion site and in anterior and posterior sections without tissue alterations. This showed a dramatic increase of GFAP staining around the lesion center (Fig. 5a-g), indicating a persistent astrocytic scar in the 
chronic stage at 10 weeks after $\mathrm{SCl}$. Treatment conditions had no significant effect on the GFAPIR neither in white matter outside the lesion area nor in the center of $\mathrm{SCl}$ (Fig. 5h).

\section{Effect of bmSC and MP treatment on microglial and macrophages}

Microglia and macrophages were stained with antibodies against Iba1, again using sections including the lesion site, anterior and posterior of this region (Fig. 6a-g). In the white matter of spinal cord sections outside of the area directly affected by the $\mathrm{SCl}$ we found cells with typical microglia morphology. Their Iba1 expression was 2- to 5-fold stronger compared to the white matter of rats without SCI. In the lesion center, Iba1-IR increased about 10-fold in animals treated with saline or MP but only 4-fold in animals that had received bmSC implants (Fig. 6h). Compared to the control treatment ( $\mathrm{NaCl}$ injections) the effect of bmSC was significant (t-test, $p<0.05$ ), indicating that the injected cells might have reduced activation of microglia or macrophages.

\section{Effect of bmSC and MP treatment on axon pathology}

Non-phosphorylated neurofilaments are associated with their disassembled state in neuronal cell somata. In mature axons, in contrast, neurofilaments are heavily phosphorylated. Since this depends on myelin signals, the presence of non-phosphorylated neurofilaments in fiber tracts is indicative of demyelination and axonal damage (Trapp, Peterson et al. 1998, Yuan, Rao et al. 2012).
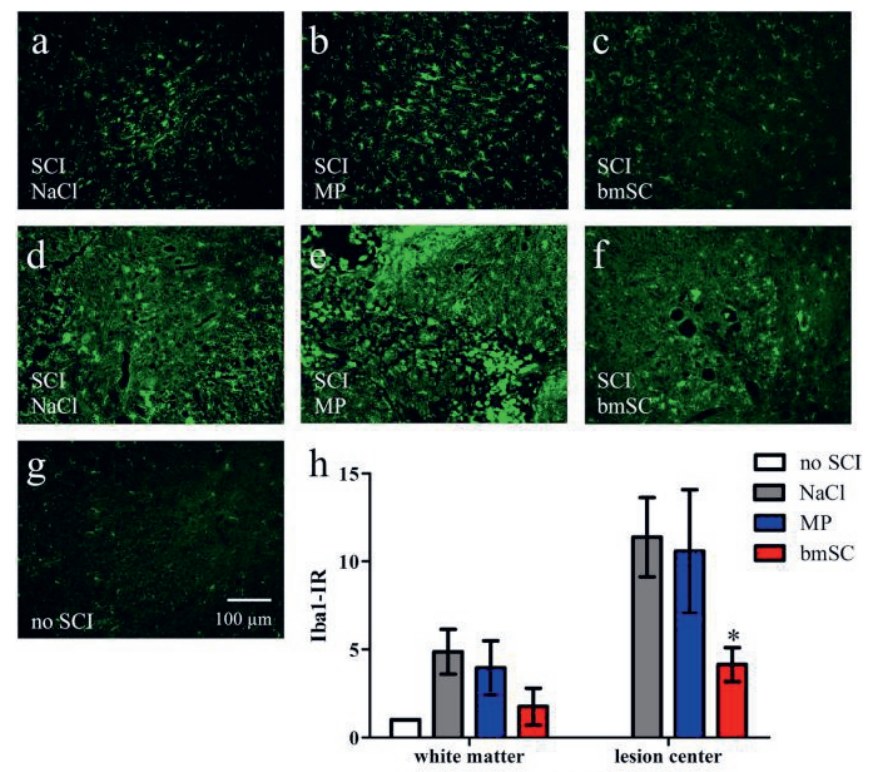

Treatment after $\mathrm{SCI}$

Figure 6 Injection of bmSC reduced activation of microglia/macrophages. Evaluation of Iba1-IR in spinal cord tissue ten weeks after SCI. ac Microglia in spinal cord white matter $0.5-0.7 \mathrm{~cm}$ anterior of the lesion center. $d$-f Microglia and macrophages in sections containing the lesion center; representative examples from rats treated with saline $(a, d), M P(b, e)$ and bmSC $(c, f) . g$ Microglia in the white matter of an animal without SCl; 20 objective, scale bar $100 \mu \mathrm{m}$ valid for all photographs. h Quantification of Iba1-IR in the white matter ca. $0.8 \mathrm{~cm}$ anterior to and within the area close to the lesion center. Here, Iba1 expression was significantly lower after bmSC treatment compared to control treatment (t-test, ${ }^{*} p<0.5$ ). Data were normalized to Iba1-IR in the white matter of rats without lesion (statistical difference not indicated); bars show means and SEM, $n=5-6$ rats/group 
We investigated this using the monoclonal antibody Smi32, which labels non-phosphorylated neurofilament-M and $-\mathrm{H}$ (Lee, Otvos et al. 1988). Immune staining was observed in the white matter tracts of all $\mathrm{SCl}$ animals but not of non-injured rats. In the ascending dorsal colums the local Smi32-IR was particularly prominent in sections above the lesion site.
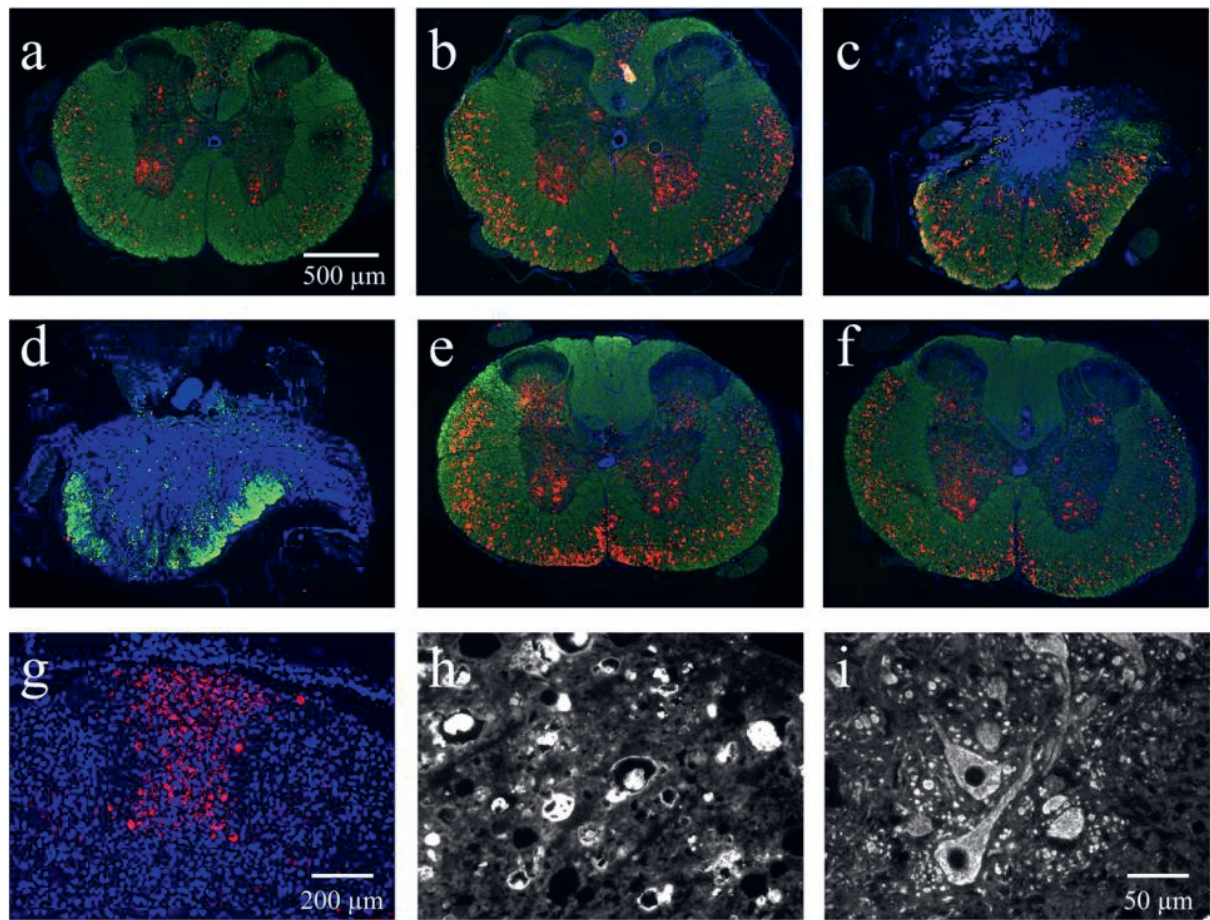

Figure 7 The presence of non-phosphorylated filaments as an indicator of axonal damage. Ten weeks after SCl immune staining with Smi32 antibody (red) was combined with myelin basic protein-IR (green) and Hoechst-33342 nuclear staining (blue). a-f Overview of transverse spinal cord sections at intervals of approximately $3.2 \mathrm{~mm}$ from $8 \mathrm{~mm}$ anterior to $8 \mathrm{~mm}$ posterior of the lesion site; $5 x$ objective, scale bar in a. Note the presence of Smi32-binding in the ascending dorsal columns anterior but not posterior of the lesion site and in white matter tracts in all sections.

g Non-phosphorylated neurofilament in ascending fiber tracts anterior of the site of injury, 20x objective. h-i Higher magnification of Smi32-IR in white matter ( $h$ ) and motor neurons in the ventral horn (i), 40x objective, scale bar in i. No Smi32 staining was observed in the white matter of animals without $\mathrm{SCl}$ (see Fig. 8).

In contrast, it was absent in the dorsal area of sections containing the lesion site, where all fiber tracts had completely degenerated, and also in the dorsal columns below the lesion, where these axons were not affected by the $\mathrm{SCl}$ (Fig. 7a-h). In ventrolateral fiber tracts, non-phosphorylated neurofilament was found in all spinal cord sections of lesioned rats. Smi32-IR was also visible in the somata of nerve cells, most strongly in the ventral horns (Fig. 7i). This could also be observed in tissue of non-injured animals and is not pathological. Quantification of the Smi32-IR revealed a significant effect of bmSC treatment in the dorsal columns anterior of the lesion site, where the ascending somatosensory axons were affected by the $\mathrm{SCl}$ (Fig. 8a-d, i). 
Stem cell treatment reduced the amount of axonal damage compared to saline treatment $(\mathrm{t}$ test, $p<0.05)$. The strong expression of non-phosphorylated neurofilaments in ventral and lateral fiber tracts was not significantly different between treatments (Fig. 8e-h, i).
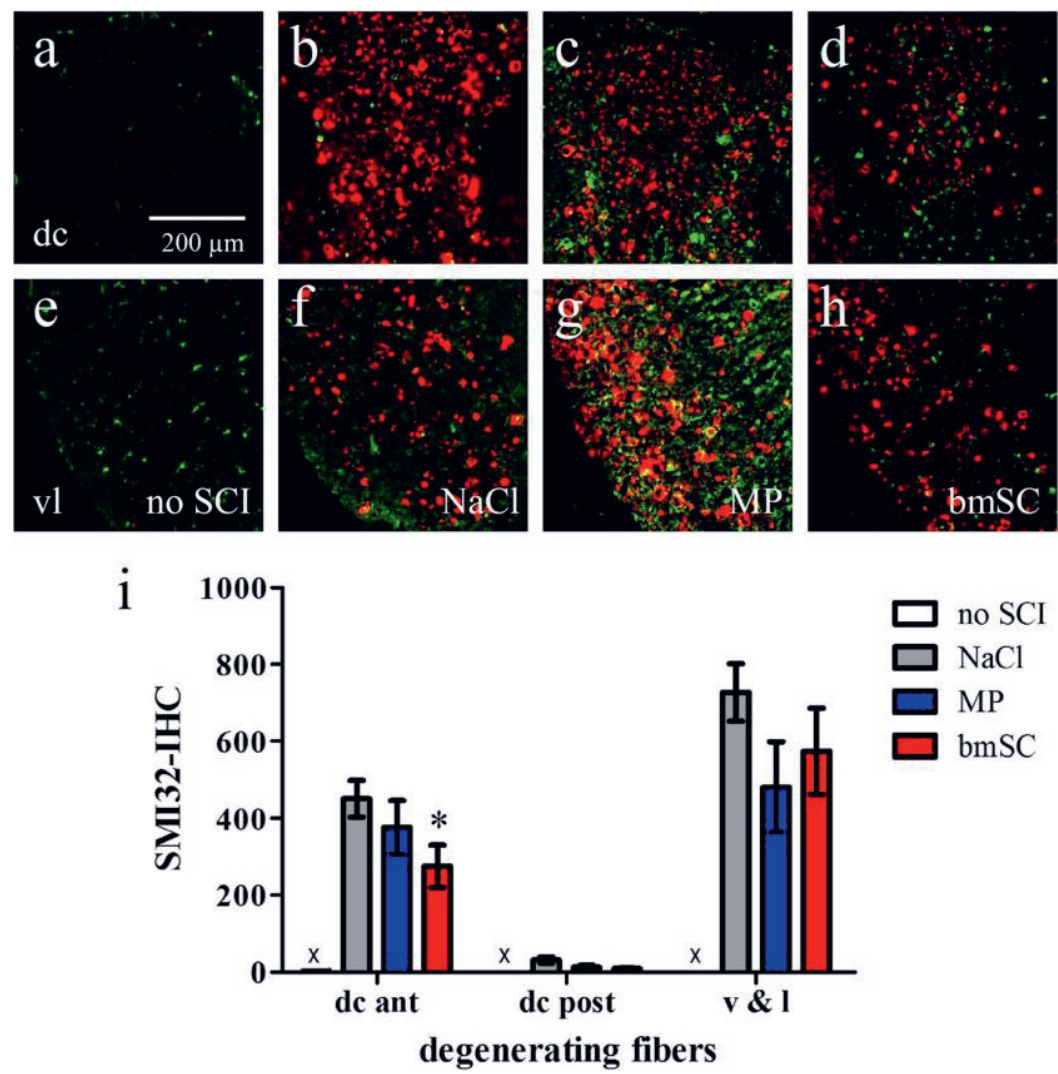

Figure 8 Treatment with bmSC reduced axonal damage in ascending fiber tracts anterior of the lesion site. Staining with Smi32 (red) was combined with Iba1 (green) in spinal cord tissue ten weeks after SCI. a-h Smi32 IR in the dorsal columns (a-d) and ventrolateral white matter (e-h) of a rat without SCI ( $a, e)$, and of SCl animals treated with saline (b, $f), M P(c, g)$ and bmSC injections (d, $h$ ); 20 objective, scale bar in a. Note the absence of non-phosphorylated neurofilament in control samples without SCI in a and e. $i$ Quantification of Smi32-IR in the ascending dorsal columns anterior and posterior of the lesion site (dc ant, dc post), the ventrolateral white matter (v\&l) and corresponding regions without SCI (no Smi32-IR, marked $x$ ). Bars show means and SEM, $n=5-6$ rats/group. Treatment with bmSC was associated with reduced Smi32-IR in the anterior dorsal columns compared to saline treatment ( $t$-test $\left.{ }^{*} p<0.05\right)$, while MP had no effect and differences in dc post and v/ were not significant.

\section{Effect of bmSC and MP treatment on neuroinflammation}

To a large degree the devastating effects of $\mathrm{SCl}$ are due to a persistent neuroinflammatory response, one of its hallmarks being the lysosomal antigen CD68 (ED1), which is present in activated microglia and macrophages (McKay, Brooks et al. 2007). We found that activation of these myeloid cells was still very strong at 10 weeks after $\mathrm{SCl}$ (Fig. 9a, b). The histological distribution of CD68 IR throughout the white matter resembled that of axonal damage. Chronic neuroinflammation was observed in fiber tracts distal of the lesion, such as ascending somatosensory fibers anterior and the descending corticocpinal tract posterior of T9/T10 (Fig. 
9c, d). Activated microglia and macrophages were also present in the lesion center and in ventral and lateral white matter tracts (Fig. 9e, f). Quantification of CD68-IR revealed that it was lower in MP treated animals than after $\mathrm{NaCl}$ treatment, while no significant effects were found after bmSC injection (Fig. 9g-k).

\section{Effect of bmSC and MP treatment on apoptosis}

Apoptosis was evaluated using an antibody against activated caspase-3, which at 10 weeks after $\mathrm{SCl}$ was clearly identified in cell nuclei (supplementary Fig. S1, Fig 10a-h). While some apoptotic cells were also detected in the grey matter of rats without $\mathrm{SCl}$ (up to $7 \%$ of all nuclei), the percentage was much higher $(15 \%-20 \%)$ in the rats with spinal cord contusion. Treatment with bmSC significantly reduced apoptosis in the ventral horn (Fig. 10i).
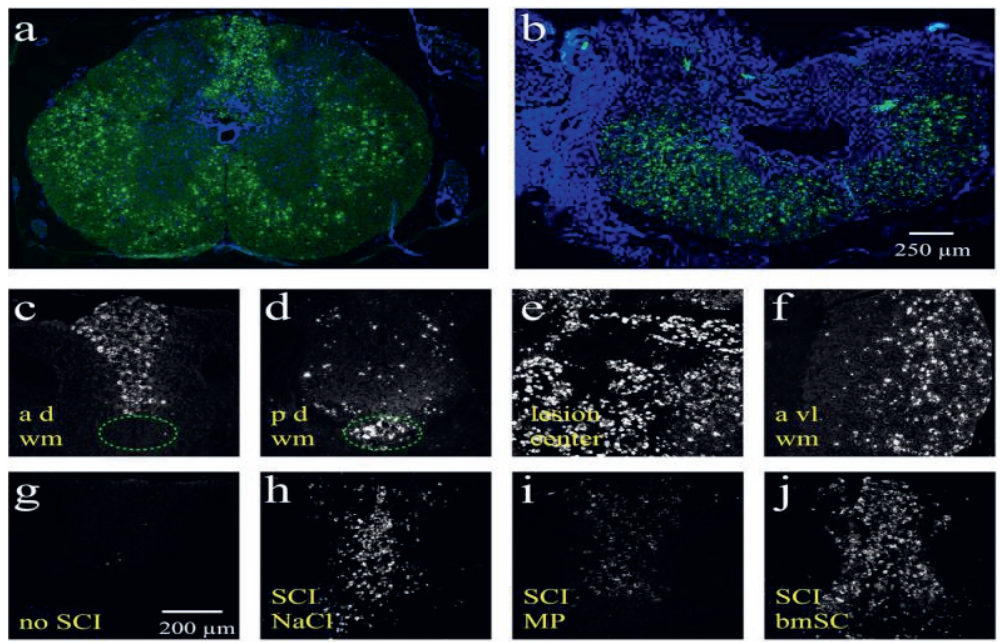

$\mathrm{k}$

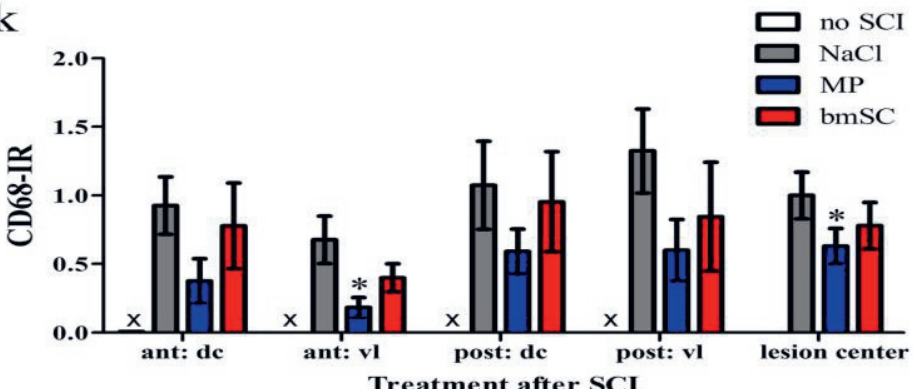

Figure 9 Injections of MP mitigated SCl-induced neuroinflammation. Microglia activation and macrophage infiltration ten weeks after SCI were evaluated with immune staining of CD68 (ED1). $\boldsymbol{a}-\boldsymbol{b}$ Overview of transverse spinal cord sections $0.8 \mathrm{~cm}$ anterior of the lesion site and at its center. CD68 (green) was combined with Hoechst-33342 nuclear staining (blue), 5x objective, scale bar in b. Note very strong CD68$I R$ everywhere in the white matter as well as its absence in the scar tissue (b). c-f Examples of activated microglia/macrophages in ascending fiber tracts in the dorsal columns anterior of the lesion site (c), in corticospinal tract posterior of the lesion center (d; marked with dotted ellipse in $c$ and d), in the lesion center (e), and anterior ventrolateral white matter ( $f$ ). $g$-j Examples of CD68-IR in dorsal columns of rats without SCl and after SCI treatments; 10x objective, scale bar in $\mathrm{g} . \mathbf{k}$ Quantification of CD68-IR in the dorsal columns (dc) and ventrolateral white matter ( $\mathrm{Vl}$ ) anterior and posterior of the lesion site and corresponding regions without SCI (no CD68-IR). Bars show means and SEM, $n=5$ rats/group. As indicated ( $t$-test $* p<0.05$ ) treatment with MP was associated with reduced CD68-IR compared to saline treatment. Injections of bmSC had no significant effect 

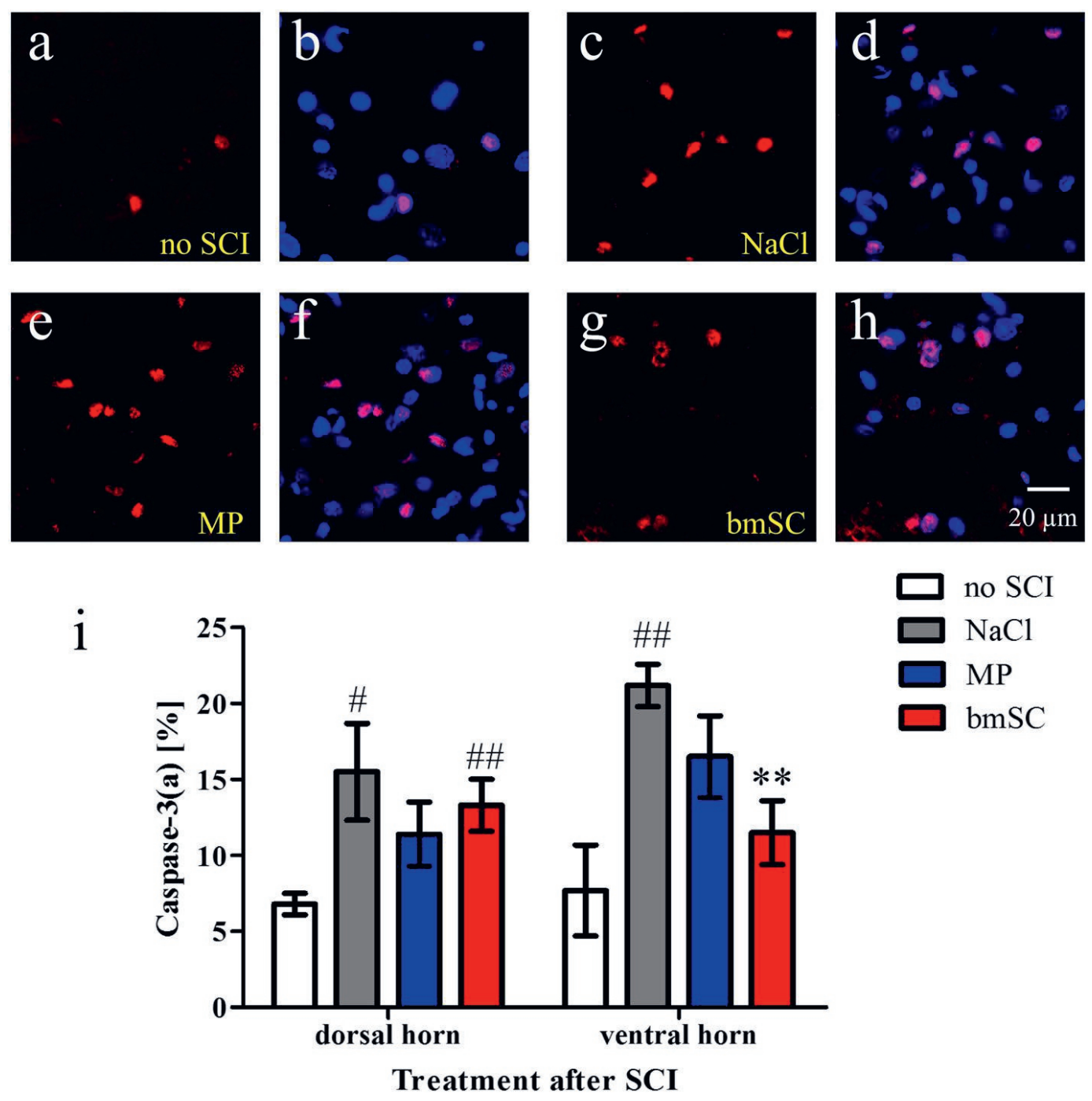

Figure 10 Injection of bmSC reduced apoptosis in the ventral horn. Ten weeks after SCI, cellular apoptosis was evaluated using activated caspase-3 as a marker. a-h Representative ROI containing apoptotic nuclei in the ventral horns of non-injured animals (a, b), after $\mathrm{SCl} /$ treatment with saline $(c, d)$, with MP $(e, f)$ and with $b m S C(g, h)$. Immune staining of activated caspase-3 (red, all panels) was combined with Hoechst-33342 nuclear staining (blue, $b, d, f, h$, double exposure); 40x objective, scale bar in $h$. $i$ Quantification of apoptosis in the grey matter is expressed as the percentage of activated caspase-3 IR nuclei of all nuclei. Bars show means and SEM, $n=5$ rats/group; statistical evaluation with ANOVA, post-hoc Tukey tests. More apoptosis was observed after SCl when rats were treated with saline (\#p< $0.05, \# p<0.01$ ). This increase in number of apoptotic cells failed to be significant after MP treatment and in the ventral horn also after bmSC treatment. Compared to saline, bmSC injections caused a highly significant reduction of apoptosis in the ventral grey matter $(* * p<$ 0.01). 


\section{Discussion}

\section{Summary}

The therapeutic benefit of human bmSC as a treatment of $\mathrm{SCl}$ was compared to high dose MP injections in adult rats. Within two hours after T9/T10 spinal cord contusion one dose of a dedicated human bmSC preparation (Neuroplast BV) was injected into the cisterna magna. These allogeneic implants were not rejected and significantly improved the recovery of motor functions compared to MP treatment. The mean BBB score of bmSC treated rats after nine weeks was 10.8, compared to 6.8 after MP interventions. Differences between bmSC and saline injections (score of 9.3) were smaller and did not reach significance (Figs. 2,4). On the histological level (Figs. 3,5-10), bmSC treatment was beneficial with respect to axonal degeneration and apoptosis, compared to both control groups, while MP only had an anti-inflammatory effect. To date, more than 25 studies have been published using bone marrow-derived stem cells to treat $\mathrm{SCl}$ in rats (Shende and Subedi 2017, Mukhamedshina, Shulman et al. 2019, Romanelli, Bieler et al. 2019, Zhao, Zhou et al. 2019). In the past, the cells were usually expanded before use and their phenotype was not characterized. For the present study, we prepared human bmSC solely by removing immune cells from the bone marrow extract and did not cultivate them before implantation. Based on characterization with flow cytometry the injected cell suspension contained about $8 \%$ stem cells with a roughly equal proportion of hematopoietic and mesenchymal cells. How effective was this treatment in comparison with previous approaches? Even with standardized methods of evaluating motor function (BBB, rotarod) it is difficult to compare the outcomes reported by different laboratories (cf. BBB-scores of SCl control groups in (de Munter, Beugels et al. 2019, Mukhamedshina, Shulman et al. 2019, Maqueda and Rodriguez 2020)). With this caveat we may conclude that the therapeutic benefit of the new human bmSC preparation in rats was similar to what has been achieved using autologous cells. In the rat $\mathrm{SCl}$ model of severe contusion injury, no stem cell treatment has so far succeeded in repairing the tissue loss in the lesion center. Despite this, a benefit on functional recovery is observed justifying clinical trials (Shende and Subedi 2017, Srivastava, Agrahari et al. 2019).

\section{Steroid treatment and limitations of the present study}

Many publications on $\mathrm{SCl}$ treatment with MP report small to moderate improvement of motor recovery in the first weeks compared to placebo treatment. These are attributed to a reduction of inflammation, oxidative stress and neuronal apoptosis (Lu, Niu et al. 2016). However, an absence of therapeutic benefit or even negative effects were also found (Lankhorst, ter Laak et al. 2000). In monkeys, MP inhibited the SCl-induced proliferation of ependymal stem cells in the spinal cord (Ye, Qin et al. 2018). A meta-analysis of animal experiments concluded that "beneficial effects of MP administration were obtained in 34\% of the studies, no effects in 58\%, and mixed results in $8 \%$. The results were inconsistent both among and within species, even when attempts were made to detect any patterns in the results through subgroup analyses" (Akhtar, Pippin et al. 2009). Due to its privileged role as the only FDA-approved pharmacological intervention in human $\mathrm{SCl}$ patients, MP is nonetheless often included in pre-clinical research. Following consultation with the EMA, we treated our rats with five intraperitoneal injections of $30 \mathrm{mg} / \mathrm{kg}$ MP with the first dose immediately after surgery and the following over 24 hours, similar to the NASCIS II trial (Bracken, Shepard et al. 1998). Compared to saline injections, this 
treatment significantly attenuated inflammation as shown with CD68 staining ten weeks after $\mathrm{SCl}$ (Fig. 9). Unexpectedly, it reduced motor recovery of the rats (Fig. 4). Ethical principles in animal experimentation demand the largest possible reduction in the number of animals. Based on expected effect size and variance we planned eight rats for the treatment and six for the three different control groups. While a highly significant benefit of bmSC compared to MP treatment was reached (Fig. 4) and differences with all control groups were significant on the histological level (Figs. 6-10), this design was underpowered to demonstrate a functional benefit of bmSC compared to saline treatment. Additional tests with the Rotarod assay indicated a positive influence of bmSC on motor recovery compared to both control groups, however these data did not reach significance because of their high variability (Supplementary Fig. S2). This was primarily caused by the fact that $1 / 2$ to $1 / 3$ of the rats, irrespective of treatment, did not try to hold on to the rotating bar, although all animals had successfully been trained to do the task prior to $\mathrm{SCl}$. Increasing body weight of the animals appeared to make the task more difficult during the study.

In a future clinical application, the bmSC are intended to be extracted from the same person who suffered the $\mathrm{SCl}$ and will receive the treatment. The time between bmSC preparation and injection shall not exceed $48 \mathrm{hrs}$ (Neuroplast, patent WO2015/059300A1). Deviating from this procedure we tested the human cells in rats. Since it was not possible to implant the cells immediately after their preparation, bmSC were cryopreserved and resuspended for implantation, and this reduced their viability. Of all nucleated cells in the bmSC preparation 3.3 $\%$ were hematopoietic stem cells (CD34), $3.8 \%$ mesenchymal stem cells (CD271, CD90, CD105, CD73) and the rest were non-identified stroma cells also including dead cells.

Despite these limitations, the implants were not rejected, the treated animals showed no sickness behavior and a better recovery of body weight than control groups (Fig. 2). We attribute this success to the properties of the human bmSC as modulators of innate immunity.

\section{The advantages of bmSC implants as a therapy of SCI}

Today, stem cell-based therapies are among the most promising experimental strategies to treat neurodegenerative pathologies including $\mathrm{SCl}$. As an advantage to other sources, such as embryonic and induced pluripotent stem cells (iPCS), adult stem cells are easily isolated from blood, bone marrow or adipose tissue. In contrast to iPSC (Gazdic, Volarevic et al. 2018, Nagoshi, Tsuji et al. 2019) they do not require genetic reprogramming and pose no risk of tumor formation. Several attempts using bmSC in rodents have achieved significant improvements in motor functions, which were in the same order of magnitude as in the present study (Tetzlaff, Okon et al. 2011, Shende and Subedi 2017).

Despite the inherent difficulties to publish negative results, some failures to reach functional improvement have also come to light (Hofstetter, Schwarz et al. 2002, Ankeny, McTigue et al. 2004, Tetzlaff, Okon et al. 2011), and this raises the question as to the best conditions for bmSC treatment of SCl.

Three considerations deserve particular attention: preparation of the bmSC, mode and time of application.

1) Following standard extraction of bone marrow from the ilicac crest of human donors, we are using a novel procedure to prepare bmSC, which is based exclusively on the elimination of 
macrophages and lymphocytes without manipulation or expansion in vitro. This procedure allows implantation within $48 \mathrm{hrs}$ after harvesting of the cells. In most of the previous studies bmSC were expanded to large numbers before use (Tetzlaff, Okon et al. 2011, Shende and Subedi 2017) and this, unfortunately, reduces their growth potential (Hayflick limit (Schellenberg, Lin et al. 2011)) as well as their anti-inflammatory properties (Li, Ding et al. 2012). It also leads to the accumulation of stochastic mutations, such that the risk of malignant transformation cannot be ruled out (Wagner 2012). A major advantage of our approach is to avoid negative changes associated with long term cultivation.

2) Cell implants that are intended for the therapy of CNS pathologies first need to reach their target tissues. While contusion $\mathrm{SCl}$ initially disrupts the blood-spinal cord barrier, this is restored by endogenous repair processes. Therefore, systemic applications of cells, such as by intravenous injection (Cizkova, Rosocha et al. 2006, Vaquero, Zurita et al. 2006), may have only a limited time window, which in rodents lasts about one week for the gray matter (Donnelly and Popovich 2008). Since we intend to explore treatment in the chronic phase in the future, we chose infusion into the cerebrospinal fluid (CSF). Stem cell injections into the CSF were shown to be more effective than into the blood circulation (Vaquero, Zurita et al. 2006, Paul, Samdani et al. 2009, Shin, Kim et al. 2013), and in the majority of clinical studies cells were transplanted via lumbar puncture (Hofstetter, Schwarz et al. 2002, Shende and Subedi 2017). In rats we accessed the subarachnoid space via the cisterna magna (Shin, Kim et al. 2013), implying that the injected cells had to migrate toward the area of injury in the spinal cord. While the mechanisms of this are not well understood, homing to damaged areas has been shown to be a property of bmSC even when injected into the blood stream (Cizkova, Rosocha et al. 2006). We considered the alternative to inject the cells directly below the dura mater of the spinal cord, as was done previously after dorsal column transection (Lu, Jones et al. 2005) and compression injury (de Munter, Beugels et al. 2019). However, in preparatory experiments we found that spinal cord injection per se caused additional damage. This application may be more effective for interventions in the chronic phase, when cells can be implanted into the cavity within the spinal cord that has formed by then (Lu, Wang et al. 2012).

3) Thus, the time of intervention is another crucial parameter when considering stem cell therapy of $\mathrm{SCl}$. By far the most animal experiments have been carried out in the acute phase, and with bmSC this seems to be justified because their main benefit is expected to be neuroprotection by modulating the immediate inflammatory response (Donnelly and Popovich 2008, de Munter, Shafarevich et al. 2019, de Munter, Beugels et al. 2019). Our histological evaluation indicates that the acute intervention, while not reducing gross tissue damage (Fig. 3), did have lasting cytoprotective effects as shown with a reduction in axonal damage (Fig. 8) and apoptosis (Fig. 10) ten weeks later. Since immune suppression on macrophages was larger after MP treatment (Fig. 9), we hypothesize that the bmSC elicited additional neurotrophic effects. These will be explored in future $\mathrm{SCl}$ experiments using intervention in the chronic state. In a delayed treatment protocol with intraspinal administration into the lesion cavity the integration of grafted cells promises to be better because the release of toxic compounds, lytic enzymes and free radicals of the early phase has somewhat subsided (Shende and Subedi 2017). 


\section{The putative mode of action of bmSC after SCl}

This raises the question regarding the mechanisms by which the injected bmSC were effective in our experiments. Increasing evidence suggests that extracellular vehicles (EVs) are important players in mediating the therapeutic effects of therapeutically applied stem cells (Rani, Ryan et al. 2015, Ruppert, Nguyen et al. 2018, Romanelli, Bieler et al. 2019, Zhao, Zhou et al. 2019). Exosomes from mesenchymal stem cells exert immune-suppressive effects by enforcing M2 macrophage polarization, inhibiting complement activation (Zhao, Zhou et al. 2019) and indirectly driving regulatory T cell induction (Zhang, Chopp et al. 2015). In addition, classical mechanisms of paracrine release of cytokines and growth factors are likely to be involved (Neuhuber, Timothy Himes et al. 2005, Gnecchi, Danieli et al. 2016), although attempts at isolating these factors so far have failed to replace stem cells with a pure pharmacological intervention. Stem cell-conditioned media which contain EVs as well as paracrine factors can be effective, although repeated delivery may be required (Rani, Ryan et al. 2015, Romanelli, Bieler et al. 2019).

It is believed that beneficial effects of bmSC are derived rather from the mesenchymal and not the hematopoietic stem cell fraction (Shende and Subedi 2017), and this view is linked to the expectation that the cells integrate and differentiate in the tissue (Gnecchi, Danieli et al. 2016). Our bmSC preparation contained less than $5 \%$ mesenchymal stem cell. We have reason to believe that hematopoietic stem cells and remaining stromal cells (not expressing CD34, CD271, CD90, CD105, CD73) also released modulators that positively influenced recovery after SCI.

Although the injected bmSC reduced Iba1 staining, their effect on CD68 did not reach significance. The fact that cell treatment improved motor recovery much better than MP, while the latter did reduce the number of CD68 positive macrophages, also indicates that bmSC may have acted on other than myeloid cells.

The formation of fibrotic and glial scar is a major impediment to axonal regeneration after spinal cord injury. While reports with bmSC have claimed to reduce this (Shende and Subedi 2017, de Munter, Beugels et al. 2019, Romanelli, Bieler et al. 2019), we did not see differences in scar formation or lesion size between different groups. Either there was a transient effect, not visible ten weeks after $\mathrm{SCl}$, or the damage caused by $200 \mathrm{Kdyn}(2 \mathrm{~N})$ contusion injury was too large to put any scar reducing effects in evidence.

Were there continuing effects in the chronic stage? The behavioral data show that almost all improvement in sensory-motor performance of the rats occurred within the first three weeks and that the therapeutic benefit of bmSC treatment also occurred in this period (Fig. 4). Using a specific antibody against human mitochondrial proteins (Millipore MAB1273C3, validated in vitro) we searched for the presence of human cells in the spinal cords of all rats. At ten weeks after $\mathrm{SCl}$ we were not able to detect the implants. Although the absence of an IR signal is certainly not conclusive, it is more likely that the implanted bmSC were only effective in the acute and subacute phase after $\mathrm{SCl}$.

Differences observed after ten weeks on the histological level, such as lower microglial activation and reduced axonal damage may be the result of better recovery in the subacute phase. This must certainly be the case for the lingering anti-inflammatory effect of acute MP injections. It is intriguing, though, that we observed a high level of apoptosis and a significant effect of bmSC on this phenomenon even at ten weeks after lesion. Double IHC with antibodies against activated caspase-3/Iba1 and activated caspase-3/NeuN indicated that the apoptotic nuclei did not belong 
to microglia or neurons (data not shown). Previous studies found continuing apoptosis of oligodendrocytes in the chronic phase after SCl (Beattie, Farooqui et al. 2000). Other groups (Lu, Jones et al. 2005, Cizkova, Rosocha et al. 2006) were able to locate injected bmSC infiltrating the lesion site. In several cases, cells were found to have differentiated into oligodendrocytes, whereas the expression of neural markers was rare. Following the most thorough analysis of cellular transplantation therapies for $\mathrm{SCl}$, Tetzlaff and colleagues (Tetzlaff, Okon et al. 2011) concluded that remyelination of demyelinated axons may be the most realistic therapeutic objective.

\section{Conclusions for improving SCI therapy based on bmSC implants}

Using acute intervention with bmSC we were able to improve the natural recovery process within the first 10 weeks after lesion compared with corticosteroid treatment without adverse effects due to a possible immunological rejection. By reaching these objectives, the results of this study confirmed the beneficial effects of stem cells that were obtained earlier using immunecompromised rats and balloon compression SCl (de Munter, Beugels et al. 2019). In this and many other studies implanted stem cells could not be identified in the tissue when this was attempted in the chronic stages after SCl. Their failure to survive may be attributed to a hostile microenvironment created by the lesion (Khazaei, Ahuja et al. 2020). It is therefore an objective to modify the tissue response such that implanted cells remain functional. Since the bmSC themselves modulate the innate immune system (Ruppert, Nguyen et al. 2018, de Munter, Shafarevich et al. 2019, Zhao, Zhou et al. 2019), we suggest that a combination of pharmacological/cell-based therapies should complement the signals released from the bmSC by activating different molecular targets.

In the past, even the most promising results of preclinical studies with rodents could not be translated to clinical therapies of $\mathrm{SCl}$ or any other neuro-degenerative disease. Depending on the physiological question and the risk of treatment, additional studies with non-human primates may therefore be necessary before a clinical trial is justified (Tsintou, Dalamagkas et al. 2020). Since large mammals are expensive, sample sizes are usually small. Such experiments are ethically justified only to the extent that the animal models are more predictive for clinical interventions than experiments with rodents.

A recent comparative study with bmSC injections after $\mathrm{SCl}$ in 115 rats and 17 pigs arrived at similar results in both species (Mukhamedshina, Shulman et al. 2019). The present results demonstrate that our bmSC preparation had benefits and no negative side effects even when implanted in a different species and with a considerable percentage of non-viable cells due to one freezing/thawing cycle before implantation. In a clinical trial, bmSC would be prepared from the same patient, implanted without cryopreservation and within $48 \mathrm{hrs}$ after injury.

Since the potential risk for the patient is minimal we do not see the necessity of an intermediate study with large mammals or non-human primates, especially since differences in the motor systems between different primate species are also not negligible (Lemon and Griffiths 2005). Exaggerated promises are a recurrent phenomenon in $\mathrm{SCl}$ research.

Our conclusion, while optimistic, is more modest: The intrathecal transplantation of human bone marrow-derived cells prepared via negative selection and without cultivation will contribute to a combinatorial therapy of $\mathrm{SCl}$. 


\section{Supplementary}
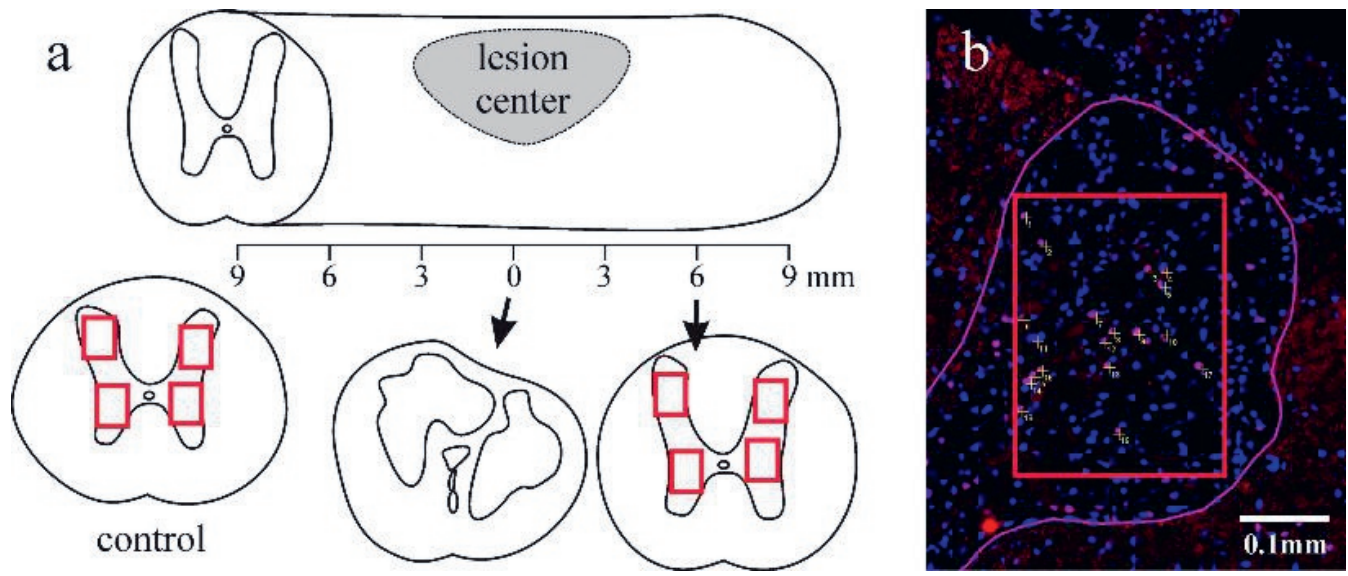

Additional file 1 Fig. S1. Evaluation of cellular apoptosis. Spinal cord sections were processed with double IHC against activated caspase$3 / \mathrm{NeuN}$ (neurons) and activated caspase-3/Iba1 (microglia/macrophages) and combined with DAPI nuclear staining. a Drawing of spinal cord and transverse sections indicating the ROIs for evaluation in the grey matter (40 x objective). $\boldsymbol{b}$ Low power photograph of the dorsal horn of a rat with $\mathrm{SCl}$, demonstrating the distribution of apoptotic nuclei (pin k). Annotation indicates outline of grey matter, ROI,counted cell nuclei and scale bar $=100 \mu \mathrm{m}$.

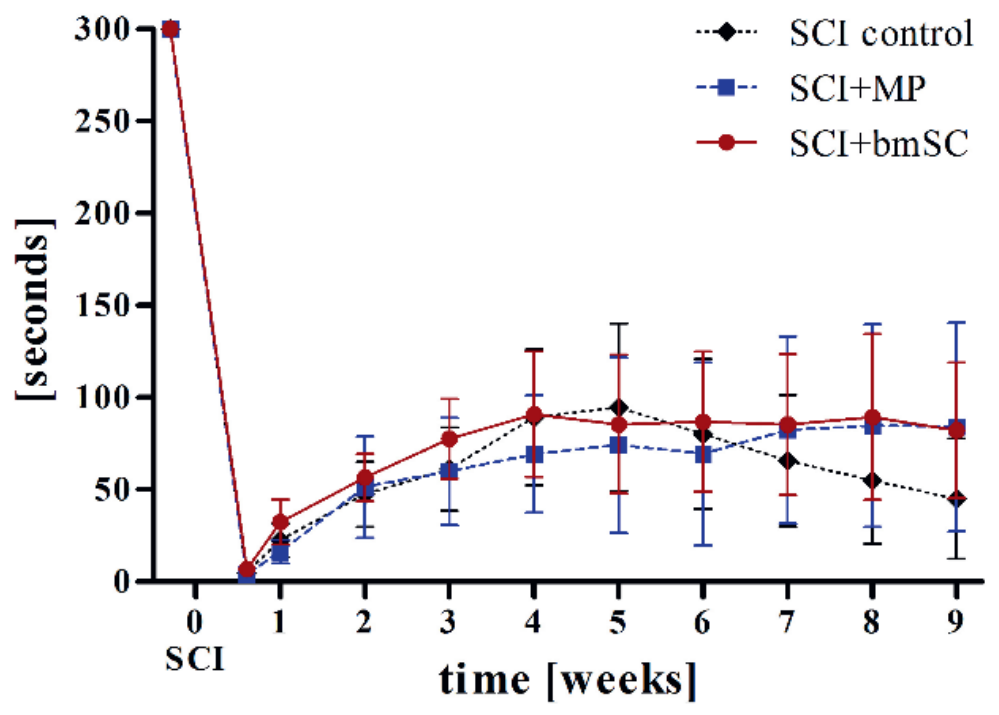

Additional file 2 Fig. S2. Motor recovery as revealed with the Rotarod test. Motor performance in the rotarod stepping test is expressed in the amount of time [sec] that the animals maintained themselves on the rotating bar (mean \pm SEM); SCI + bmSC: treatment with human bone marrow-derived stem cells; $\mathrm{SCl}+\mathrm{MP}$ : injections of methyl prednisolone; $\mathrm{SCl}$ control: injections of $\mathrm{NaCl}$. Before SCl, all animals reached the maximum time of $300 \mathrm{~s}$. The first evaluation was performed at $4 \mathrm{dpo}$. Differences between groups were not significant. Rats that did not attempt to hold on to the bar and therefore received a score of zero sec were not excluded from the statistical evaluation. 


\section{Chapter 5}

\section{Bone marrow-derived stem cells in chronic neuro-degenerative processes}

\section{Introduction chapter $\mathbf{5}$}

Chapter 5 displays the results of the experiments performed with a transplantation of a minimal manipulated stem cell preparation derived from human bone marrow in animal models for chronic neurodegenerative processes. We aimed for testing human stem cells in Parkinson's disease (PD). Although available alpha-synuclein models as well as mutated forms of the LRRK2 gene recapitulate most of the symptoms of PD, undisputable representative animal models able to reproduce this multisystem pathological condition are not available. So, we chose to work with transgenic FUS and SOD mice, representative for the familial form of amyotrophic lateral sclerosis (ALS). The familial form of amyotrophic lateral sclerosis occurs in $10 \%$ of all the ALS cases. The other $90 \%$ are the sporadic forms of ALS in which the causes are unknown.

Figure 1 gives an overview of the mutations in familial forms and the preclinical models in use to test interventions for ALS (Alrafiah 2018).

ALS is traditionally considered a pure motor neuron disease with progressive loss of upper and lower motor neurons. Results of interventions with Neuro-Cells in transgenic FUS and SOD mice are displayed in chapter 5.1 .

As of now, it is more and more recognized to be a multisystem disorder. Many patients suffering ALS also exhibit mild cognitive impairment and a subset have severe impairment with features of frontotemporal dementia (FTLD). FTLD is considered a presenile dementia. The current classification of FTLD is based on the major constituent protein: FTLD-tau, FTLD-TDP-43, and FTLD-FUS. Transgenic FUS mice thus have a genotype with at least two phenotypes: ALS and FTLD.

Frontotemporal lobar degeneration is the result of damage to neurons in parts of the brain called the frontal and temporal regions. Gradually, this damage causes difficulties in thinking and behaviours normally controlled by these parts of the brain. These group of disorders causes unusual behaviours, emotional problems, and severe loss of thinking abilities, and are responsible for the majority of dementia cases under the age of 60 years.

ALS and FTLD are both found to correlate with reductions to endoplasmic reticulum -

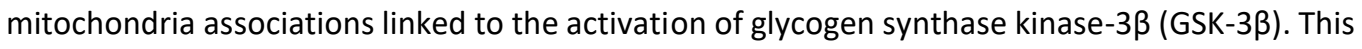
kinase is also strongly associated with ALS/FTD (Stoica, Paillusson et al. 2016).

We were able to also investigate the effect of Neuro-Cells in transgenic FUS mice, which exhibited (subtle) FTLD-like signs and symptoms, as a rule some weeks before the onset of the first ALS-like motor signs. Findings are described in chapter 5.2. 


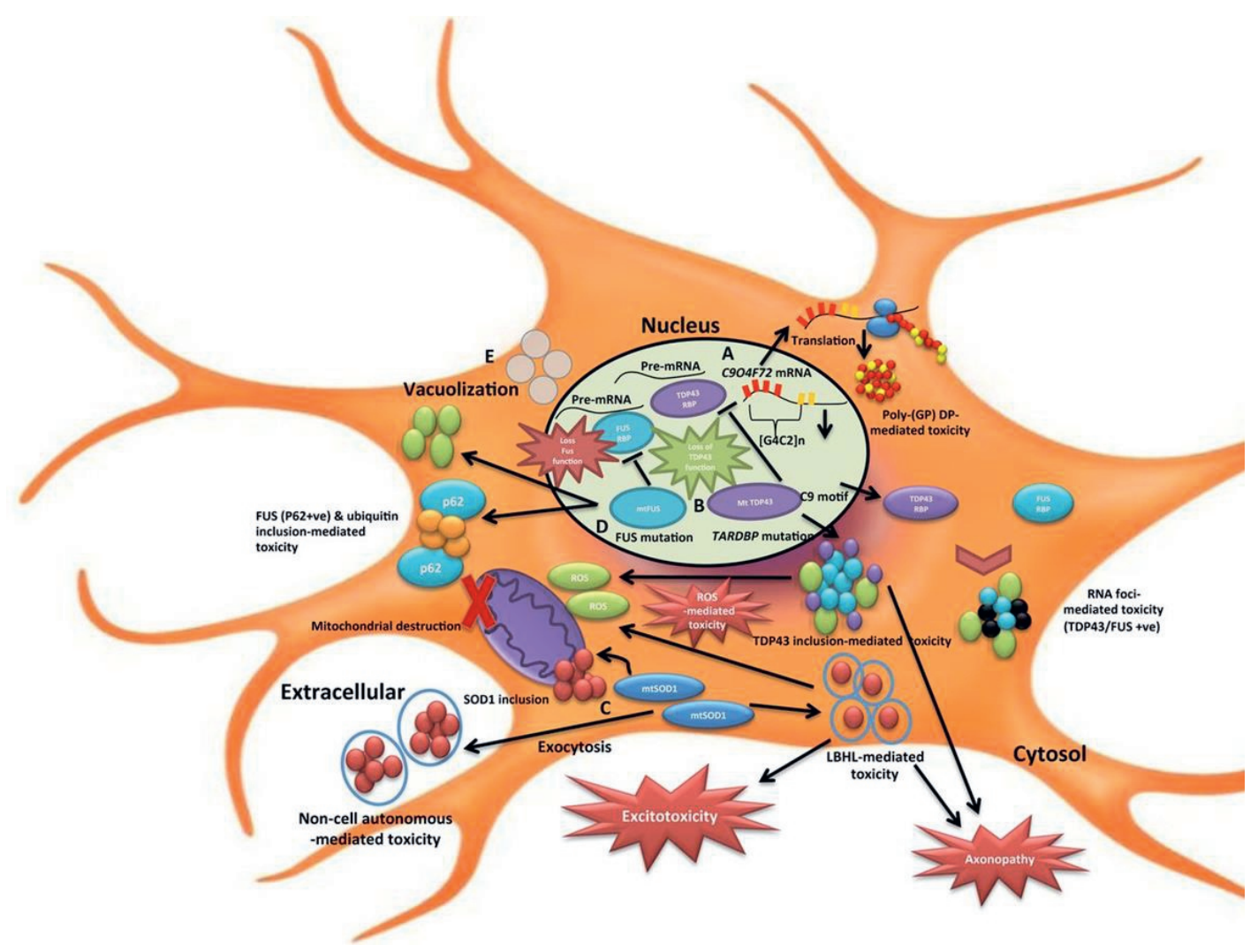

Figure 1. Pathogenesis of C9OR72-, TARDBP-, SOD1-, and FUS-associated ALS. A: Chromosome 9 hexanucleotide repeat72 (C9ORF72) 2 mutation acts through a gain-of-function (GOF) mechanism. GGGGCC[G4C2] is translocated to the cytosol and then either translated to form aggregates of poly-(GP) dipeptide-repeat proteins (DPR) or misfolded to form aggregates of ubiquitinated (U) RNA foci associated with TDP43 or FUS proteins, which both mediate neuronal toxicity. B: transactive response DNA-binding protein (TARDBP) mutation acts through both loss of function (LOF) and GOF mechanisms. Normal TDP43 function is lost due to mutant (mt) TDP43 proteins inhibiting normal TDP43 from binding to pre-mRNA. C: superoxide dismutase 1 (SOD1) mutation acts through a GOF mechanism. Mutant SOD1 dimers in the cytosol accumulate as SOD1 inclusions within mitochondria and Lewy-body-like hyaline (LBLH) inclusions in the cytosol where they can trigger mitochondrial reactive oxygen species (ROS) generation later, causing mitochondrial destruction. D: fused in sarcoma (FUS) mutation acts through both LOF and GOF mechanisms. Mutant FUS proteins cause LOF by inhibiting normal FUS from binding to premRNA. E: Cytosol vacuolization is caused by all the above-mentioned mutations (Alrafiah 2018 (with permission of the author and the Journal). 


\title{
5.1. Neuro-Cells therapy improves motor outcomes and suppresses inflammation during experimental syndrome of amyotrophic lateral sclerosis in mice
}

de Munter JPJM, Shafarevich I, Liundup A, Pavlov D, Wolters ECh, Gorlova A, Veniaminova E, Umriukhin A, Kalueff A, Svistunov A, Kramer BW, Lesch K-P, Strekalova T (2019) CNS Neurosci Ther 00:1-14 doi: 10.1111/cns.13280

\begin{abstract}
Aims: Mutations in DNA/RNA-binding factor (fused-in-sarcoma) FUS and superoxide dismutase1 (SOD-1) cause amyotrophic lateral sclerosis (ALS). They were reproduced in SOD-1-G93A (SOD1) and new FUS[1-359]-transgenic (FUS-tg) mice, where inflammation contributes to disease progression. The effects of standard disease therapy and anti-inflammatory treatments were investigated using these mutants.

Methods: FUS-tg mice or controls received either vehicle, or standard ALS treatment riluzole (8 $\mathrm{mg} / \mathrm{kg} /$ day), or anti-inflammatory drug a selective blocker of cyclooxygenase-2 celecoxib (30 $\mathrm{mg} / \mathrm{kg} /$ day) for six weeks, or a single intracerebroventricular (i.c.v.) infusion of Neuro-Cells (a preparation of $1.39 \times 10^{6}$ mesenchymal and hemopoietic human stem cells, containing $5 \times 10^{5}$ of $\mathrm{CD}_{3} 4^{+}$cells), which showed anti-inflammatory properties. SOD-1 mice received i.c.v.administration of Neuro-Cells or vehicle.

Results: All FUS-tg-treated animals displayed less marked reductions in weight gain, food/water intake, and motor deficits than FUS-tg-vehicle-treated mice. Neuro-Cell treated mutants had reduced muscle atrophy and lumbar motor neuron degeneration. This group but not celecoxibFUS-tg-treated mice had ameliorated motor performance and lumbar expression of microglial activation marker, ionized calcium-binding adapter molecule-1 (Iba-1), and glycogen-synthasekinase-3ß (GSK-3ß). The Neuro-Cells-treated-SOD-1 mice showed better motor functions than vehicle-treated-SOD-1 group.

Conclusion: The neuropathology in FUS-tg mice is sensitive to standard ALS treatments and Neuro-Cells infusion. The latter improves motor outcomes in two ALS models possibly by suppressing microglial activation.
\end{abstract}

\section{Introduction}

Amyotrophic lateral sclerosis (ALS) is a neurodegenerative disease characterized by progressive degeneration of lower motor neurons, as well as neurons in the cortex and brainstem, which leads to paralysis and premature death (Al-Chalabi, Hardiman et al. 2016). The aetiology of ALS remains unclear both in sporadic cases (90\%) and in the familial forms of ALS (Blair, Williams et al. 2010, Al-Chalabi, Hardiman et al. 2016). Among the known genetic causes that give rise to ALS, the mutation of the fused in sarcoma protein (FUS) is the second most frequent among the familial forms of ALS (Blair, Williams et al. 2010, Freischmidt, Muller et al. 2015, Lutz 2018). Mutations of FUS gene were thought to cause synaptic dysfunction and pathological protein aggregation (Sabatelli, Moncada et al. 2013), which were felt to be key events leading to neuronal degeneration (Marrone, Drexler et al. 2019). However, the most recent studies have revealed that the expression of mutant FUS leads to stress-mediated induction of chaperones, 
decreased expression of ion channels and transporters essential for synaptic function, and reduced synaptic activity without the loss of nuclear FUS or its cytoplasmic aggregation (LopezErauskin, Tadokoro et al. 2018).

The nuclear effects of FUS also seem to result in impairment of the function of paraspeckles, granules in the nuclear interchromatin space that are assembled on a scaffold long noncoding RNA (IncRNA) NEAT1 (Fox and Lamond 2010, Shelkovnikova, Peters et al. 2013, Shelkovnikova, Kukharsky et al. 2018). This results in aberrant microRNA biogenesis, apoptotic processes, oxidative stress, and mitochondrial dysfunction contributing to neurodegenerative processes (Shelkovnikova, Peters et al. 2013, Shelkovnikova, Kukharsky et al. 2018). Indeed, the latest studies using human fibroblast cell lines expressing mutant FUS from ALS patients and post mortem tissue have identified the accumulation of dysfunctional paraspeckles associated with abnormal NEAT1 expression as an important feature of FUS-associated ALS pathology (An, Skelt et al. 2019). NEAT1 was recently reported to promote inflammation via stimulating interleukin$1 \beta$ production and pyroptosis and activating macrophages.(Huang-Fu, Cheng et al. 2018, Zhang, Cao et al. 2019). Regardless of whether the disease is associated with FUS gene mutations or related to other factors, its pathological mechanisms are associated with neuroinflammation (Blair, Williams et al. 2010, Al-Chalabi, Hardiman et al. 2016, Morello, Spampinato et al. 2017, Lutz 2018). In particular, the activation of microglia and astrocytes is considered to be a hallmark of the disease and is accompanied by elevated pro-inflammatory cytokine concentrations in the brain, blood, and cerebrospinal fluid (Mishra, Vijayalakshmi et al. 2017, Morello, Spampinato et al. 2017, Crisafulli, Brajkovic et al. 2018). For example, a recent clinical study reported high blood concentrations of pro-inflammatory cytokines and related proteins in ALS patients, including interleukin-1 $\beta$ (IL-1 $\beta$ ), interleukin-6 (IL-6), interleukin-8 (IL-8), tumor necrosis factor (TNF), and TNF receptor-1 ( $\mathrm{Hu}, \mathrm{Cao}$ et al. 2017). It has been suggested that microglial inflammatory processes might be a key early event that contribute to neurodegeneration and play a dynamic role in the pathogenesis of the disease (Morello, Spampinato et al. 2017, Crisafulli, Brajkovic et al. 2018). Cerebrospinal fluid from ALS patients induces marked microglial activation, and upregulation of the pro-inflammatory cytokines and factors including IL-6, TNF, cyclooxygenase2 (COX-2), and prostaglandin E2 (PGE2), accompanied by a downregulation of trophic factors (Mishra, Vijayalakshmi et al. 2017, Shruthi, Sumitha et al. 2017). Despite the evidence that the level of inflammation is critical in ALS, clinical studies with compounds that target inflammatory mechanisms and associated cascades, including the TNF inhibitor thalidomide, non-steroid antiinflammatory drugs (NSAIDs), a selective COX-2 inhibitor celecoxib, corticosteroids, cyclophosphamide, cyclosporine, cytochrome $\mathrm{C}$ inhibitors, and caspase-reducing drugs have all failed to induce significant improvement of the ALS pathology (Gordon, Moore et al. 2007, Calvo, Moglia et al. 2010, Collins and Bowser 2017). ${ }^{19-21}$ Thus, while the therapeutic niche for antiinflammatory treatment of the ALS is strongly implicated by clinical and preclinical studies, current literature lacks any clear examples of positive results. In the present study, we sought to test the effects of a stem cell therapy "Neuro-Cells" with anti-inflammatory actions (de Munter and Wolters 2013, de Munter, Beugels et al. 2019) on experimental models of ALS in mice. Therefore, we have employed a FUS[1-359]-tg mouse model (Shelkovnikova, Peters et al. 2013) according to the guidelines set by Ludolph et al, 2010, for ALS preclinical studies (Ludolph, Bendotti et al. 2010) that have recommended the use of other ALS models apart from the SOD1 mouse "gold standard" (Gurney, Pu et al. 1994). The pattern of pathology in FUS[1-359]-tg line 
recapitulates key features of human ALS, including motor neuron degeneration and microgliosis in the brainstem and spinal cord, muscle atrophy, paralysis, microglial activation, and elevated levels of pro-inflammatory cytokines in the CNS and blood (Shelkovnikova, Peters et al. 2013, Lysikova, Kukharsky et al. 2019). The model permits the impact of therapy on ALS-related changes to be evaluated including basic physiological and motor functions, as well as evaluation of the expression of pro-inflammatory and degeneration markers such as Iba-1, GSK-3ß, IL-1ß, and IL- 6 in the lumbar spinal cord and blood levels of IL-1ß and IL-6. In the FUS model, the effect of the standard therapies has not been studied. We therefore chose to compare them to NeuroCells. In addition, we examined the effects of Neuro-Cells administration on motor function in the SOD-1 mouse line, a well-established model of ALS (G93A line;25). Here, we gave in both models a single intracerebroventricular (i.c.v.) infusion of a preparation of nonmanipulated human stem cells "Neuro-Cells" obtained from bone marrow, which are a combination of both mesenchymal stem cells (MSCs) and hemopoietic stem cells (HSCs). As both MSCs and HSCs have been shown to have the ability to differentiate into a spectrum of adult cell populations, many studies have sought to examine either the combined or individual contributions to repair in vivo in models of injury and potentially capitalize on the relationship between the two cell populations that is known to exist (Fitzsimmons, Mazurek et al. 2018, Andrzejewska, Jablonska et al. 2019). As for instance, MSCs were shown to act as a feeder layer maintaining HSCs in an undifferentiated state. If HSCs are allowed to differentiate during their expansion, it increases the process of cell aging and death (Kim, Yoo et al. 2008). In spinal injury models, the engraftment of $\mathrm{CD}_{3} 4^{+}$human HSCs produces neurons efficiently in the regenerating chicken embryo spinal cord (Sigurjonsson, Perreault et al. 2005) and the use of MSCs to form guiding strands in the injured spinal cord promotes recovery (Hofstetter, Schwarz et al. 2002). A direct comparison has been made between human mononuclear cell preparations (a mixture of HSCS and MSCs) and culture-expanded MSCs transplanted into a spinal cord injury model in rats without differences with regard to graft efficiency, spinal cord tissue sparing, or glial scar reduction (Samdani, Paul et al. 2009). In view of these results, we found that an injection of a mixture of MSC and HSC, to maximize the potential benefit of these populations, had an anti-inflammatory effect (de Munter, Beugels et al. 2019). The intrathecal administration of the MSC/HSC preparation, containing $4 \times 10^{5}$ of $\mathrm{CD} 34^{+}$cells into rats that had been subjected to a spinal cord injury, was shown to improve functional outcomes and decrease peripheral concentrations of proinflammatory cytokines (TNF, IL-1ß, and IL-6) in the cerebrospinal fluid (de Munter, Beugels et al. 2019). Previous studies have reported beneficial effects of stem cell therapy in animal models of ALS (Uccelli, Milanese et al. 2012, Boido, Piras et al. 2014, Agarwala and Tamplin 2018); the majority of these studies employed manipulated MCSs,(Uccelli, Milanese et al. 2012, Oh, Moon et al. 2015, Mazzini, Vescovi et al. 2016, Gorabi, Kiaie et al. 2019), while the use of unmanipulated stem cells and preparations containing HSCs and MSCs has been shown to increase the therapeutic activity of stem cell therapy (Li and Wu 2011, Caplan 2015, Yousefi, Lavi Arab et al. 2019). Thus, we hypothesized that this treatment might also ameliorate ALS-like pathology owing to the anti-inflammatory effects of Neuro-Cells. Here, we sought compare the effects of Neuro-Cells to the current anti-ALS therapy riluzole (Miller, Mitchell et al. 2012) and the classic anti-inflammatory compound celecoxib (Goldenberg 1999, Maciel, Silva et al. 2013) in the new FUS-tg model. 


\section{Material and methods}

Details on animals and all experimental procedures can be found in Data S1.

\section{Animals and human endpoint}

FUS-tg, SOD-1 male mice and their wild-type littermates (WT) were provided by the FDA-certified IPAC RAS facilities and Charles River provider, respectively (http://www.ipac.ac.ru/index.html and http://www.spf-animals.ru/about/ providers /animals). Mice were single housed under standard conditions and reversed lighting. Experimental procedures were set up in accordance with a Directive 2010/63/EU and approved by the local veterinarian Committee for Bioethics of IPAC RAS (N19-16.06.2017) and MSMU (22/10/17-MSMU-35). Bone marrow collection from healthy volunteers was done under GMP license (Neuroplast BV Farmatec The Netherlands) and approved by Ethical Committee of MUMC, Maastricht University (iCell1 METC MUMC and iCell2 METC Zuyderland Zuid). All efforts were undertaken to ensure compliance with abovementioned regulations concerning human endpoint in animal research.

\section{Study design}

Experimental designs were based on reported patterns of pathology in employed models. ALS pathology in 12-week-old FUS-tg mutants is characterized by rapid, progressive motor neuron degeneration within 2 weeks (Shelkovnikova, Peters et al. 2013), while SOD-1 mouse line (G93A mutants) has more gradually developing ALS pathology displaying its first signs by the age of about 16 weeks 25 progressing to the human endpoint within 4-6 weeks (Browne and Abbott 2016, Rodriguez-Cueto, Santos-Garcia et al. 2018). We devoted our efforts to ensure compliance with above-mentioned observations concerning human endpoint in animal research. At the age of 7-8 weeks, FUS-tg animals and wild-type (WT) controls were studied in a cat-walk, grip test, weighed (data not shown), and assigned to groups. At the age of nine weeks, FUS-tg and WT mice received (a) regular tap water, or (b) riluzole (Ril; $8 \mathrm{mg} / \mathrm{kg} /$ day, via drinking water), or (c) or celecoxib (Cel, $30 \mathrm{mg} / \mathrm{kg} / \mathrm{day}$ ) via food pellets, or (d) single i.c.v. administration of Neuro-Cells (NC, 500,000-CD34 ${ }^{+}$in $10 \mu \mathrm{L}$ of Ringer Lactate buffer), or (d) i.c.v. administration of Ringer Lactate buffer (Figure 1A). Doses of pharmaca were selected as described previously (Pompl, Ho et al. 2003, Li, Sung et al. 2013, Costa-Nunes, Cline et al. 2015); see below). Stereotaxic surgery was adapted from previously reported procedure (Strekalova, Wotjak et al. 2001). During the following six weeks, all mice were weekly weighed and studied in the rotarod, pole, and wire tests for motor function, dosing with pharmaca was continued. As post-surgery physiological parameters of wild-type mice that received either tap water or i.c.v. vehicle injection were similar (Figure S1), these two groups were merged into a vehicle-treated (Veh) group for subsequent analysis. On Week 6 , at the age of fifteen weeks, mice were investigated for food and water intake and then sacrificed 24 hours thereafter. Mice were either perfused with $\mathrm{NaCl}$ or 4\%-paraformaldehyde; muscle gastrocnemius, blood, and spinal cord were harvested for weighing, Western blot, ELISA assays, and histology. Since Neuro-Cells-treated animals showed greater functional improvement than other groups, these mice and mutants subjected to the i.c.v. vehicle infusion were studied in all in vitro assays including muscle atrophy and motor neuron counts in the lumbar part of the spinal cord. The concentrations of IL-1ß and IL- 6 in blood serum and protein expression of IL-1ß, IL-6, Iba-1, and GSK-3ß in the lumbar part of the spinal 
cord of mice treated with either vehicle, Neuro-Cells, or celecoxib were measured by ELISA and Western blot assays. Pharmaca outline and genotype were double blind for all experimenters. Numbers of animals used are indicated in Figure legends. In additional experiment, SOD-1 male mice (G93A line) at age 12 weeks were subjected to the i.c.v. infusion of the Neuro-Cells from the batch used in FUS-tg animals (SOD-1-NC group, $n=7$ ) or to the i.c.v. vehicle administration (SOD-1-Veh group, $n=5$; Figure 1B). Mice were weekly weighed and tested for motor functions for nine weeks as in a previous study and sacrificed at age of 21 weeks, at the onset of ALS-like syndrome in this model (Gurney, Pu et al. 1994, Li, Sung et al. 2013, Browne and Abbott 2016, Rodriguez-Cueto, Santos-Garcia et al. 2018)

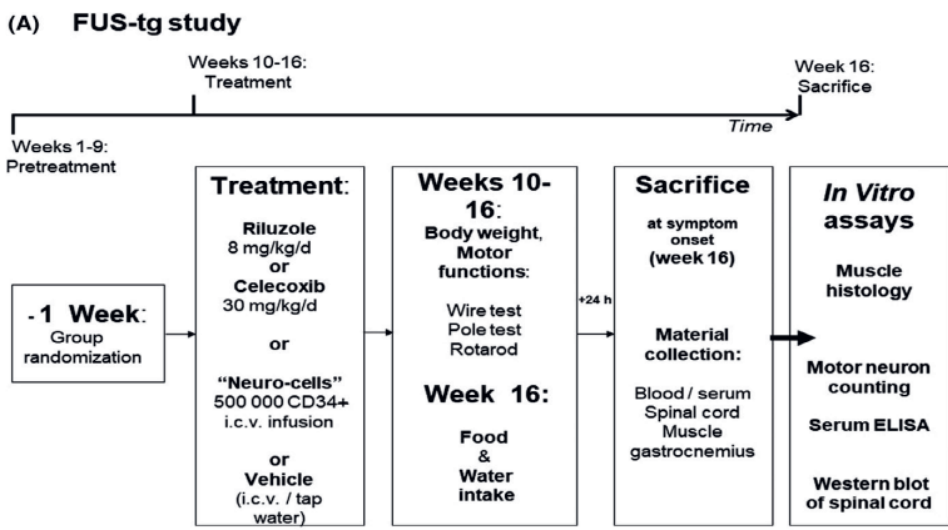

(B) SOD-1 study

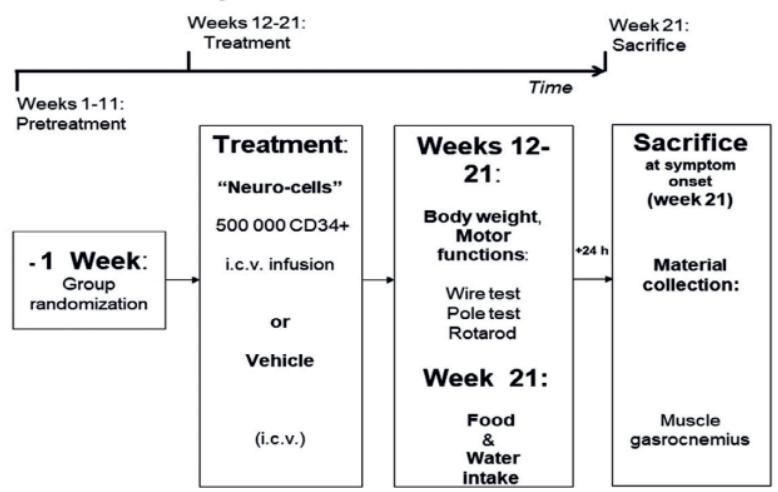

Figure 1. Experiment design of the study on (A) FUS-tg mice and (B) SOD-1 mice

\section{Functional readouts}

Weekly measured body weights of mice were normalized to their baseline values recorded at week 1 (Figure 1). Body weights during weeks 1-6 and weight gain between these weeks were normalized to the mean values of wild-type mice treated with vehicle (WT-Veh). On the 6th week, 24-hour food intake and 12-hour water intake were evaluated as described elsewhere (Costa-Nunes, Cline et al. 2015). 


\section{Wire test}

Mice were allowed to grip a horizontal wire (diameter $0.3 \mathrm{~cm}$, height above the surface $60 \mathrm{~cm}$ ) for 180s. The latency of falling and the number and percent of mice with falling events (latency <20s) were recorded as described elsewhere (Veniaminova, Oplatchikova et al. 2019).

\section{Pole test}

Mice were placed on a top of the vertical bar (diameter $1.1 \mathrm{~cm}$, height $60 \mathrm{~cm}$ ) and allowed to climb down to a horizontal surface. The latency of descending the bar and the number and percent of mice with sliding events (latency to descend < 50s) were scored as described elsewhere (Veniaminova, Oplatchikova et al. 2019).

\section{Rotarod}

Mice were placed on constantly rotting rod of rotarod (Columbus Instruments, Columbus, $\mathrm{OH}$, USA; speed $10 \mathrm{rpm}$ ) for 600s. Latency to fall and the number and percent of mice with falling events (latency < 200s) were registered in three runs as described elsewhere (Veniaminova, Oplatchikova et al. 2019).

\section{Administration of drugs}

In the study with FUS-tg mice, potential effects of Neuro-Cells were compared to effects of celecoxib, NSAID, and a COX-2 inhibitor, that was used as a classic anti-inflammatory compound (Goldenberg 1999, Pompl, Ho et al. 2003, Maciel, Silva et al. 2013), and of riluzole (2-amino-6trifluoromethoxy-benzothiazole), a standard ALS treatment that can slow down the fatal disease progress by 2-3 months (Miller, Mitchell et al. 2012) and frequently serves as a reference drug in translational studies with ALS (Li, Sung et al. 2013, Rodriguez-Cueto, Santos-Garcia et al. 2018). Riluzole tablets (Sandoz, Almere, Netherlands) were crushed and dissolved in tap water, and its concentration was adjusted to the dosage of $8 \mathrm{mg} / \mathrm{kg} /$ day and daily water intake in CD1 mice (Li, Sung et al. 2013, Rodriguez-Cueto, Santos-Garcia et al. 2018). Celecoxib-containing food pellets were produced as described elsewhere (Costa-Nunes, Cline et al. 2015), and drug concentration was adjusted to the dosage of $30 \mathrm{mg} / \mathrm{kg} /$ day and daily diet consumption.

\section{Generation, properties, and intracerebroventricular infusion of Neuro-Cells}

Neuro-Cells, a preparation of human bone marrow-derived HSCs and MSCs, was provided by Neuroplast BV (Maastricht, Netherlands). The Neuro-Cell preparation comprised $1.39 \times 10^{6} \mathrm{MSCs}$ and HSCs, containing $5 \times 10^{5} \mathrm{CD} 34^{+}$cells in $10 \mu \mathrm{L}$. The expression profile of MSC markers was overlapping; in the total cell preparation $85.6 \%$ were $\mathrm{CD}_{105^{+}}, 13 \%$ were $\mathrm{CD} 90^{+}, 7 \%$ were $\mathrm{CD} 271^{+}$, and $4 \%$ were $\mathrm{CD}^{+} 3^{+}$in single FACs staining. Prior to infusion, cells were resuspended and checked for vitality (see Data S1 and Table S2). Animals were anesthetized by halothane (Halothane TM; Willy Rusch, Boblingen, Germany) and immobilized in a stereotaxic frame (World Precision Instruments, Sarasota, TX, USA) for unilateral i.c.v. infusion via a hole made in a scull of mice as described elsewhere (Strekalova, Wotjak et al. 2001). All preparations of Neuro-Cells were from the same stock sample. They were arranged ex temporo; after thawing, cell counting was performed using the "Countess II FL Automated Cell Counter" (Thermo Fisher Scientific AMQAF1000, Toronto, ON, Canada) showing 62\%-68\% cell vitality (see Data S1). 
Subsequent flow cytometry was done, and HSC numbers were adjusted for injection. Pilot studies carried out to determine the distribution of infused Neuro-Cells and optimize the protocols for the i.c.v. administration, suggested their presence in the brain and peripheral organs 12 and 24 hours after injection (100,000 or 250,000 cells were infused to lateral ventricles in 12 mice; see Data S1). Immunohistochemical study of Neuro-Cells-treated mice with human antimitochondrial antibodies was carried out as described elsewhere (Donders, Vanheusden et al. 2015) and revealed a positive signal in their ventricles, brain tissue, lungs, and spleen, suggesting a wide distribution of Neuro-Cells in the cerebrospinal fluid and persistent vitality (see Data S1; Figures S1 and S2). These findings are consistent with the results of the pilot study with i.c.v. infusion of bone marrow-derived mouse stem cells obtained from mutants expressing green fluorescent protein (GFP) (see Data S1; Figure S3,S5). These experiments showed that i.c.v. administration of Neuro-Cells to mice at the concentrations $100,000-500,000$ is well tolerated.

\section{Blood and tissue collection}

Mice were terminally anesthetized by sodium pentobarbitone and from about a half of them, blood, both gastrocnemius muscles and lumbar parts of the spinal cord were collected as described elsewhere (Howland, Liu et al. 2002). Another half was perfused with $4 \%$ paraformaldehyde; the lumbar parts of spinal cords and muscle gastrocnemius were dissected as described elsewhere (Howland, Liu et al. 2002).

\section{Scoring for muscle atrophy}

Muscle gastrocnemius was fixed, sectioned, and stained for hematoxylin and eosin. Scoring for atrophy was performed by three independent pathologists, blinded to sample identity using a light microscope (Axiovision 4.3, Zeiss, Berlin, Germany); ranking histograms were generated ranging samples were from 1 to 11 from "moderate" (1) to "severe" (11) atrophy.

\section{Motor neuron counting}

Briefly, cross sections were carried out at 50- $\mu$ m cuts encompassing L3-L5 with $250 \mu \mathrm{m}$ interval and stained with thionine NISSL. Counts were performed by two observers blinded to sample identity using a Zeiss Axoplan2 system (Zeiss, Berlin, Germany).

\section{ELISA of plasma cytokines}

Mouse enzyme-linked immunosorbent assay (ELISA) was performed using MOUSE IL-1 $\beta$ and IL6 ELISA MAX ${ }^{\mathrm{TM}}$ Deluxe Sets (BioLegend, San Diego, CA, USA) according to the manufacturer's instructions; protein concentrations were measured using the BCA protein assay kit (Pierce, Rockford, IL, USA) as described elsewhere (Couch, Anthony et al. 2013).

\section{Western blot and protein isolation}

Western blot analysis on spinal cord samples and quantification of protein concentration were performed as described elsewhere (58; see Table S3). Relative expression of proteins was calculated in fold changes from levels of $\beta$-tubulin as described elsewhere (Gorlova, Pavlov et al. 
2019). The Western blot images used for quantification are presented in Figure S6 and Appendix S1.

\section{Statistical analysis}

GraphPad Prism 6.00 software (San Diego, CA, USA) was used; dependently on groups, multiple group comparisons were analysed using one-way, two-way, and repeated-measures ANOVA followed by the Tukey's test. Mann-Whitney test was used for two-group comparisons. Qualitative data were analyzed by Fisher's exact test. The level of significance was $P<.05$. The results are presented as bars with standard error of means (SEM).

\section{Results}

Physiological parameters in FUS-tg mice treated with riluzole, celecoxib, or Neuro-Cells

\section{Body weight, food, and liquid intake}

Repeated-measures ANOVA and post hoc Tukey's tests revealed significant increases in body weight normalized to the basal values in WT-Veh, WT-Ril, and WT-Cel mice from week 1 to week $6\left(F_{3,29}=7.86, P=.023\right.$; Figure 2A). FUS-tg-Veh mice displayed a significant decrease in this measure $\left(F_{3,29}=12.76, P=.0147\right)$. No significant changes in this parameter were found in FUS-tg mice that received either treatment $(P>.05)$ indicating partial rescue effects of all applied treatments on FUS-tg mice. Two-way ANOVA and post hoc Tukey's test revealed a significant effect of genotype on body weight, normalized to the means of control mice at each week of study, at third to sixth weeks $(\mathrm{P}<.05$, two-way ANOVA). This parameter was significantly lower in FUS-tg-Veh mice on the third to sixth weeks than in WT-Veh group $(\mathrm{P}=.031, \mathrm{P}=.026, \mathrm{P}=.018$ and $\mathrm{P}=.001$, respectively; Tukey's test, Figure S5). Such decreases were found in FUS-tg-Ril mice on the sixth week $(P=.043)$ and in FUS-tg-Cel group, on the fifth and sixth weeks ( $P=.025$ and $P=.019$, respectively), but not in FUS-tg-NC animals. ANOVA showed significant effects of genotype and treatment for body weight gain $\left(F_{1,10}=27.98, P<.0001\right.$, and $\left.F_{3,10}=3.499, P=.0182\right)$, but not for their interaction $\left(F_{3,10}=0.7239, P=.53499\right)$. There was a significant decrease in body weight gain in FUS-tg- Veh, FUS-tg-Ril, and FUS-tg-Cel groups, but not in FUS-tg-NC animals, in comparison with controls $\left(F_{2,15}=4.6, P=.012 ; F_{2,7}=18.39, P=.0068 ; F_{2,8}=9.27, P<.005 ; F_{2,19}=1.06, P=.599 ;\right.$ respectively, Tukey's test, Figure 2B). FUS-tg-NC did not differ significantly from FUS-tg-Veh animals in this measure $\left(F_{2,11}=2.59, P=.1827\right)$. At Week 6, ANOVA showed significant effects of genotype and treatment for body weight $\left(F_{1,10}=27.98, P<.0001\right.$, and $\left.F_{3,10}=3.499, P=.0182\right)$, but not for their interaction $\left(F_{3,10}=0.7239, P=.53499\right)$. FUS-tg-Veh animals showed a significant decrease in body weight in comparison with WT-Veh group $\left(F_{2,15}=34.72, P=.015\right.$, Figure $\left.2 C\right)$ that was not observed in FUS-tgtreated groups $(P>.05)$. ANOVA revealed significant genotype effect for liquid intake $\left(F_{1,57}=11.78\right.$, $P=.0011)$, but not treatment and a tendency to significance in their interaction $\left(F_{3,57}=0.6534\right.$, $\mathrm{P}=.5841$ and $\mathrm{F}_{3,57}=2.404, \mathrm{P}=.0769$ ). There was significant genotype effect for food intake $\left(F_{1,71}=10.58, P=.0018\right)$, but not treatment effect, nor their interaction $\left(F_{3,71}=1.192, P=.3189\right.$, and $\left.F_{3,71}=1.136, P=.3404\right)$. 
In comparison with WT-Veh group, both parameters were significantly decreased in FUS-tg-Veh mice (food intake: $F_{2,29}=10, P=.0018$, liquid intake: $F_{3,29}=11.78, P=.0011$; Tukey's test; Figure $2 \mathrm{D}, \mathrm{E})$, but not in mutants that received either treatment ( $P>.05)$. Together, in a course of the development of ALS pathology, FUS-tg-Veh mice showed a decline in physiological readouts, which was partially counteracted by all applied treatments, and to the greater extend by NeuroCells infusion.

(A)

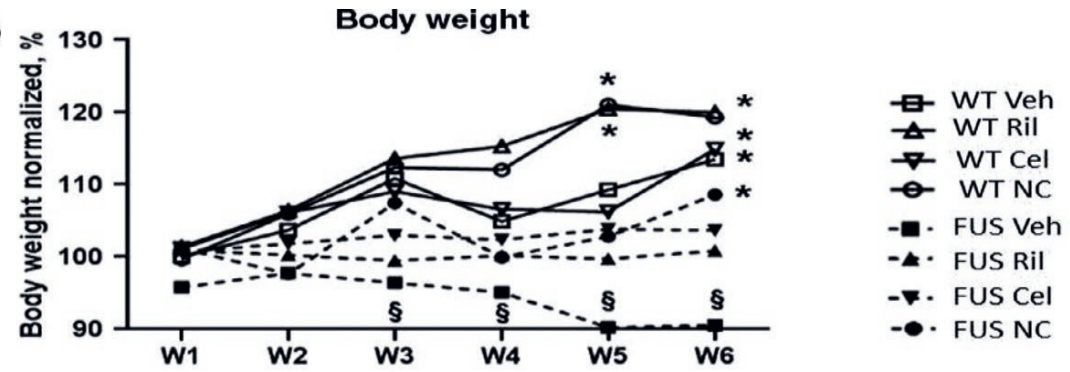

(B)

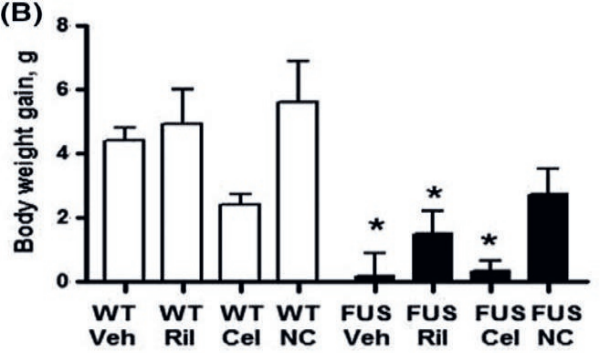

(D)

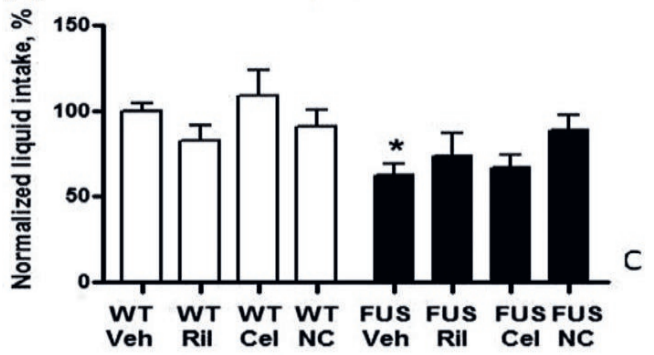

Time
(C)

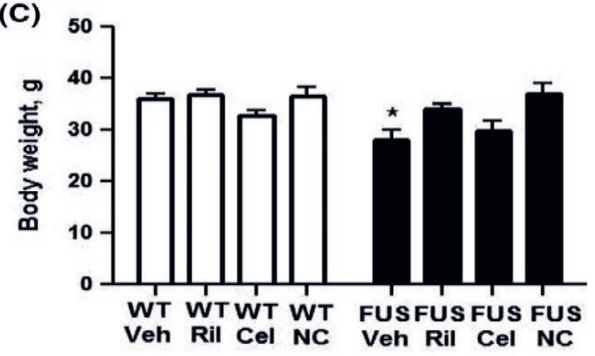

(E)

Food intake

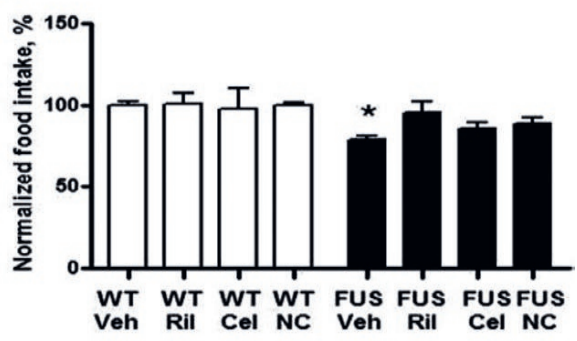

Figure 2. Effects of riluzole, celecoxib, and Neuro-Cells on Physiological parameters of FUS-tg mice. A, There was a significant increase in body weight in the WT groups, but not in the FUS-tg-Veh mice ( ${ }^{*} P<.05$ vs basal values; see the text). FUS-tg mice-NC group showed a significant weight gain. B, In comparison with controls, there was significantly lower weight gain in FUS-tg mice except FUS-tg-NC, $\left({ }^{*} P<\right.$ .05 vs WTVeh group); no such changes were found in the FUS-tg-NC group ( $P>.05)$. C, At Week 6, there was a significant reduction of body weight in FUS-tg-Veh group in comparison with wild-type controls $\left({ }^{*} P<.05\right)$; no such changes were found in mutants that received other treatments $(P>.05)$. In comparison with WT-Veh group, FUS-tg-Veh group displayed a significant decrease in (D) liquid intake and (E) food intake ( $\left.{ }^{*} P<.05\right)$, but not other FUS-tg groups. Each WT-group was comprised of 8 animals; 7-11 mice were used in FUS-tg groups (FUSVeh, $n=11$; FUS-Ril, $n=9$, FUS-Cel, $n=7$, FUS-NC, $n=7$ ) 


\title{
Motor functions
}

No significant group differences were found in motor tests till sixth week of the study, on week 1-5 ( $P>.05$; data not shown). At sixth week, in the wire test, the number of animals that has fallen from the wire was significantly higher in FUS-tg-Veh group than in controls ( $P=.018$, Fisher's test; Figure $3 \mathrm{~A})$, that was not the case for groups of mutants subjected to either treatment $(P>.05)$. In addition, this measure was significantly lower in FUS-tg-NC mice than in FUS-tg-Veh mice $(\mathrm{P}=.0028$, Fisher's test). ANOVA showed significant effects of genotype and treatment for the latency to fall $\left(F_{1,89}=24.52, P<.0001\right.$ and $\left.F_{3,89}=2.867, P=.0410\right)$, but not for their interaction $\left(F_{3,89}=1.126, P=.3431\right)$ and a significant decrease of this parameter in FUS-tg-Veh mice in comparison with WT-Veh mice ( $P=.011$, Tukey's test; Figure $3 B$ ).
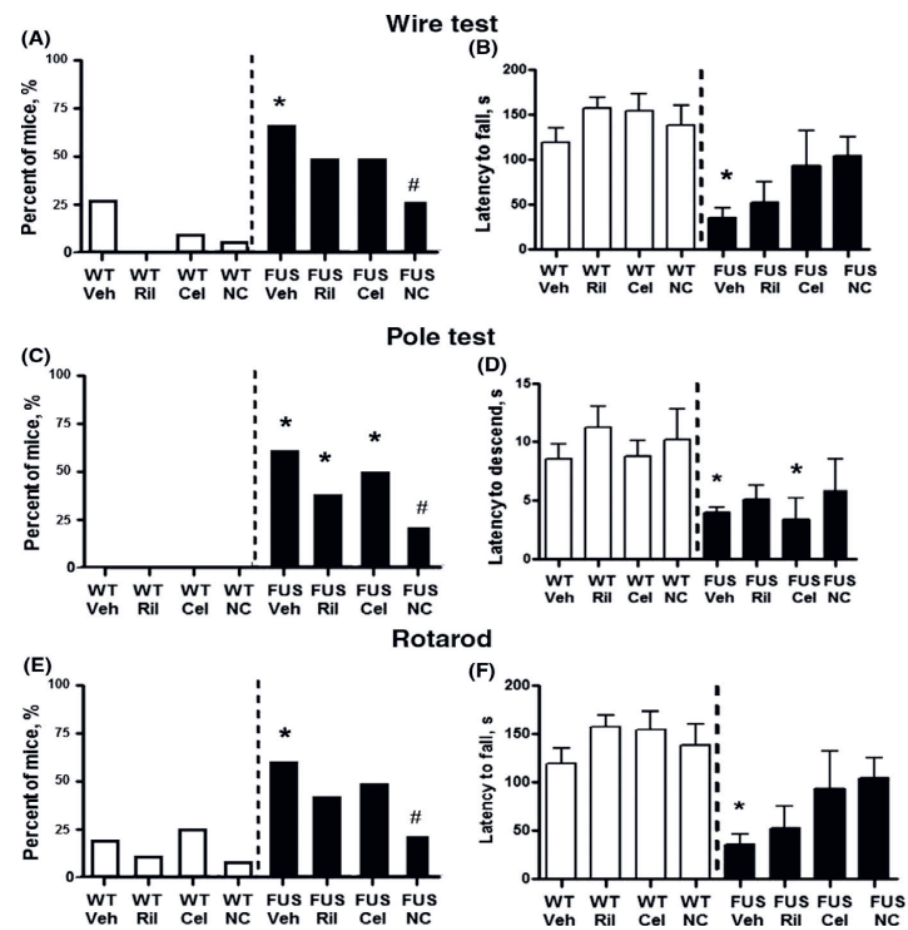

\begin{abstract}
Figure 3. Motor parameters in FUS-tg mice and effects of riluzole, celecoxib, or Neuro-Cells. In comparison with WT-Veh mice, FUS-tg-Veh group showed a significant $(A)$ increase in the number of mice with falling events and (B) decrease in the latency to fall in the wire test, that was not found in FUS-tg animals that received either treatment ( $P>$.05). FUS-tg-NC mice had a significantly lower number of mice with falling events. In the pole test, in comparison with controls, FUS-tg-Veh, FUS-tg-Ril, FUS-tg-Cel, but not in FUS-tg-NC had a significantly (C) higher number of mice with sliding events and $(D)$ decrease in the latency to descend. The latter group had a significantly fewer mice with sliding events than the FUS-tg-Veh group. In the rotarod, in comparison with WT-Veh animals, FUS-tg-Veh mice, but not mutant mice that received either treatment, had (E) higher number of mice with falling events and (F) a significant decrease in the latency to fall. FUS-tg-NC mice had a significantly fewer number of animals displaying falling in comparison with the FUS-tg-Veh group; this group and riluzoletreated FUS-tg mice did not show changes in the latency to fall in comparison with the WT-Veh mice $\left({ }^{*} P<.05\right.$ vs WT-Veh group, \#P<.05 vs FUStg-Veh group; left panels: exact Fisher's test, right panels: two-way ANOVA and Tukey's test). Each WT-group was comprised of 10 animals; 7-15 mice were used in FUS-tg groups (FUS-Veh, $n=15$; FUS-Ril, $n=10$, FUS-Cel, $n=7$, FUS-NC, $n=9$ ).
\end{abstract}


No such differences were observed in FUS-tg mice that received either treatment $(P>.05)$. In the pole test, in comparison with WT-Veh animals, the number of animals with sliding events was significantly higher in FUStg-Veh, FUS-tg-Ril, and FUS-tg-Cel groups $(P=.0023, P=.018$, and $P=.001$, respectively; Fisher's test; Figure $3 C)$, but not in the FUStg-NC group $(P=.38)$. This measure was significantly smaller in the latter group than in FUS-tg-Veh group $(P=.0012$; Figure 3D).

There were significant showed significant effects of genotype for the latency to descend $\left(F_{1,77}=29.03, P<.0001\right.$, two-way ANOVA $)$, but not for treatment and their interaction $\left(F_{3,77}=1.471\right.$, $\mathrm{P}=.2289$, and $\left.\mathrm{F}_{3,77}=0.1812, \mathrm{P}=.9089\right)$. This measure was significantly shorter in FUS-tg-Veh and FUS-tg-Cel animals than in controls ( $\mathrm{P}=.025$ and $\mathrm{P}=.032$, respectively; Tukey's test; Figure 3F) suggesting sliding of these mice and motor deficits. No such changes were shown for FUS-tg-Ril and FUS-tg-NC animals ( $\mathrm{P}=.32$ and $\mathrm{P}=.55$, respectively).

The number of animals falling off the rotarod test was significantly higher in FUS-tg-Veh group than in WT-Veh controls ( $P=.029$, Fisher's test; Figure $3 \mathrm{E})$. No such differences were observed in mutants from the treatment groups $(P>.05)$; this parameter was significantly lower in FUS-tg-NC mice than in FUS-tg-Veh group ( $\mathrm{P}=.0015)$. ANOVA showed significant effects of genotype for the latency to fall in this test $\left(\mathrm{F}_{1,99}=14.36, \mathrm{P}=.0003\right)$, but not for treatment and their interaction $\left(F_{3,99}=1.431, P=.2383\right.$, and $\left.F_{3,99}=1.048, P=.3747\right)$. A significant decrease in this measure was found in FUS-tg Veh group as compared to WT-Veh group ( $F_{3,29}=7.28, P=.023$ Tukey's test; Figure 3F), but not in the groups mutants that received either treatment $(\mathrm{P}>.05)$.

Thus, all treatments prevented the occurrence of significant motor decline in FUS-tg mice in comparison with controls, whereas only the Neuro-Cells infusion resulted in a significant improvement in motor performance in comparison with vehicle-treated mutants. While housing on celecoxib-containing food pellets resulted in a non-significant decrease of body weight in a control group, this factor has unlikely interfered with the evaluation of ALS syndrome in celecoxib-treated mutants, since no differences in behavioural and physiological parameters were found between naïve and celecoxib-treated controls.

\section{Histological hallmarks of ALS syndrome in FUS-tg mice and effects of Neuro-Cells}

There was a significant difference group difference in mass of the left and right muscle gastrocnemius $\left(\mathrm{F}_{3,29}=11.30, \mathrm{P}=.004\right.$, and $\mathrm{F}_{3,29}=12.35, \mathrm{P}<.001$, respectively, one-way ANOVA). In comparison with WT-Veh group, FUS-tg-Veh and FUS-tg-Ril mice, but not FUS-tg-NC animals, showed a significant decrease in these measures $(P=.004$ and $P=.008, P=.002$ and $P=.0016$, $\mathrm{P}=.273$ and $\mathrm{P}=.3165$, respectively, Tukey's test; Figure $4 \mathrm{~A}, \mathrm{~B})$. Because FUS-tg-Ril mice showed a loss of muscle mass similar to that of FUS-tg-Veh animals, further assessment of muscle atrophy using a histological assay was carried out FUS-tg-NC mice that were compared against FUS-tgVeh animals. Histological analysis revealed significant atrophy of muscle gastrocnemius in FUStg-Veh mice (Figure 4C-E). FUS-tg-NC group had significantly lower scores of muscle degeneration than FUS-tg-Veh mice $(U=9.6, P=.037$, Mann-Whitney). Thus, muscle atrophy in mutants was partly rescued by Neuro-Cells infusion. Next, we examined the effects of NeuroCells administration on the motor neuron degeneration at a time corresponding to the onset of the ALS syndrome and the muscle atrophy, as mentioned above. At this time, there was a significant loss (40\%-60\%) of motor neurons in the FUS-tg mutants. FUS-tg-NC group displayed improved motor scores in comparison with other groups as well as higher muscle mass as 
compared to Ril-treated mutants. Thus, motor neuron counts in the lumbar L3-L5 mouse spinal cord were studied in FUS-tg mice treated with either vehicle or Neuro-Cells. We found that the number of motor neurons in the lumbar parts of the spinal cord of FUS-tg-NC animals was significantly higher than that of FUS-tg-Veh animals $(\mathrm{U}=2.62, \mathrm{P}=.039$, Figure $4 \mathrm{~F}-\mathrm{H})$.

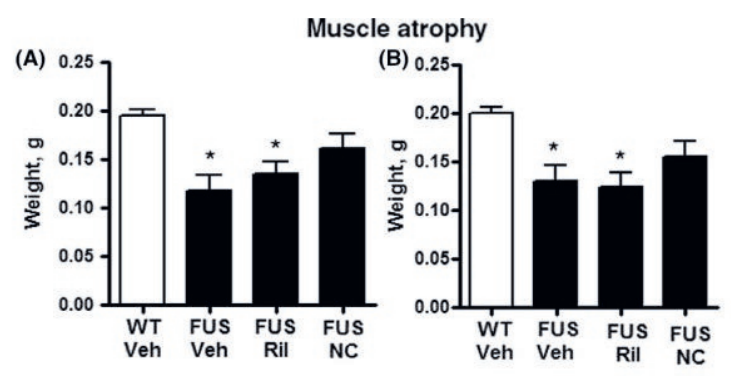

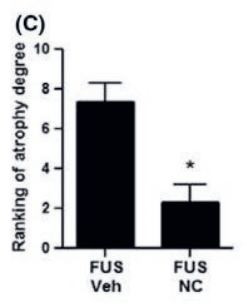

(F)

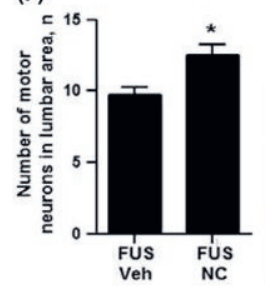

(D) FUS-tg - NC

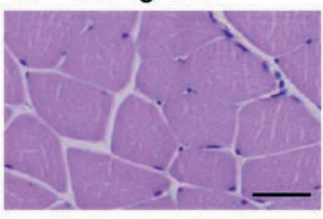

Moderate atrophy
(E) FUS-tg - Veh

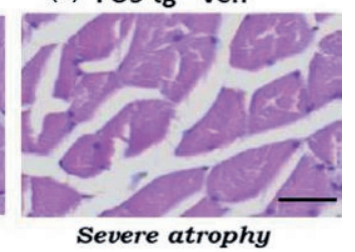

Motor neuron degeneration

(G) FUS-tg - NC

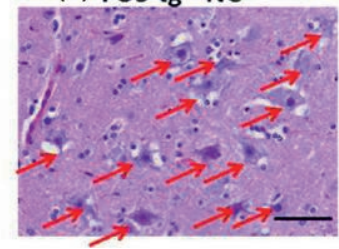

(H) FUS-tg - Veh

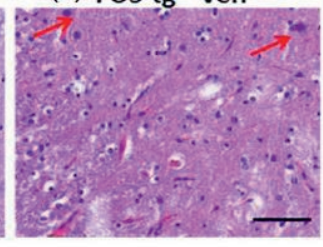

Figure 4. Histological hallmarks of ALS-like syndrome in FUS-tg mice treated with Neuro-Cells. In comparison with WT-Veh, FUS-tg-Veh, FUS-tg-Veh and FUS-tg-Ril showed a significant decrease in the mass of muscles gastrocnemius of $(A)$ left and $(B)$ right limbs $\left({ }^{*} P<.05\right.$ vs WT-Veh group) that was not observed for FUS-tg-NC group ( $P>$.05; 6-10 mice were used: WT-Veh, $n=10$, FUS-Veh, $n=10 ;$ FUS-tg-Ril, $n=8$, FUS-tg-NC, n=6). C, A score of atrophy between (D) moderate and (E) severe cases (extreme histological examples in mice from FUS-tg-NC $(n=5)$ and FUS-tg-Veh ( $n=6)$ groups) revealed significantly lower scores for FUS-tg-NC than FUS-tg-Veh mice $\left(P^{*}<.05\right.$, Mann-Whitney). F, The number of motor neurons was significantly higher in FUS-tg-NC of FUS-tg-Veh mice $\left(P^{*}<.05\right.$, Mann-Whitney, 6 mice per group were used). $H, G$, Photomicrographs exemplifying the range of motor neuron number in the ventral horn of the lumbar cord in FUStg-NC of FUStg-Veh mice in lumbar parts of the spinal cord, respectively. Scale bar $=20 \mu \mathrm{m}$.

\section{Pro-inflammatory changes and altered activities of GSK-3 in FUS-tg mice: effects of celecoxib and Neuro-Cells}

There were significant group differences in serum concentrations of IL-1 $\beta$ and IL-6 ( $F=10.62$ $\mathrm{P}<.001$, and $\mathrm{F}=11.74, \mathrm{P}<.001$, one-way ANOVA, respectively). In comparison with WT-Veh mice, these measures were significantly elevated in FUS-tg-Veh group ( $P=.012$ and $P=.035$, respectively; Tukey's test; Figure 5A,B). No such increases in IL-6 were found for FUS-tg-Cel and FUS-tg-NC groups $(P=.29$ and $P=.22$, respectively). These groups showed a significant decrease 
in this measure in comparison with the FUS-tg-Veh mice ( $\mathrm{P}=.01$ and $\mathrm{P}=.025$, respectively). In comparison with FUS-tg-Veh group, serum levels of IL-1 $\beta$ were significantly lower in FUS-tg-Cel mice and non-significantly lower in FUS-tg-NC mice ( $P=.042$ and $P=.065$, respectively; Figure $5 \mathrm{~A}$ ); no other significant differences were found. Significant group differences in protein levels were found for GSK-3 $\beta$, IL-1 $\beta$, and Iba-1 ( $F=4.992, P=.0035 ; F=6.784, P=.0006$; and $F=5.605, P=.0018)$ but not GSK-3 $\alpha$ ( $F=1.359, P=.272)$. In comparison with WT-Veh mice, expression of GSK-3 $\beta$, IL$1 \beta$, and Iba-1, but not GSK-3 $\alpha$ was significantly elevated in FUS-tg-Veh animals $(P=.026, P=.013$, $\mathrm{P}=.041$, and $\mathrm{P}=.14$, respectively, Tukey's test; Figure $5 \mathrm{C}-\mathrm{F}$; for original Western blot images used for quantification see Figure S6).
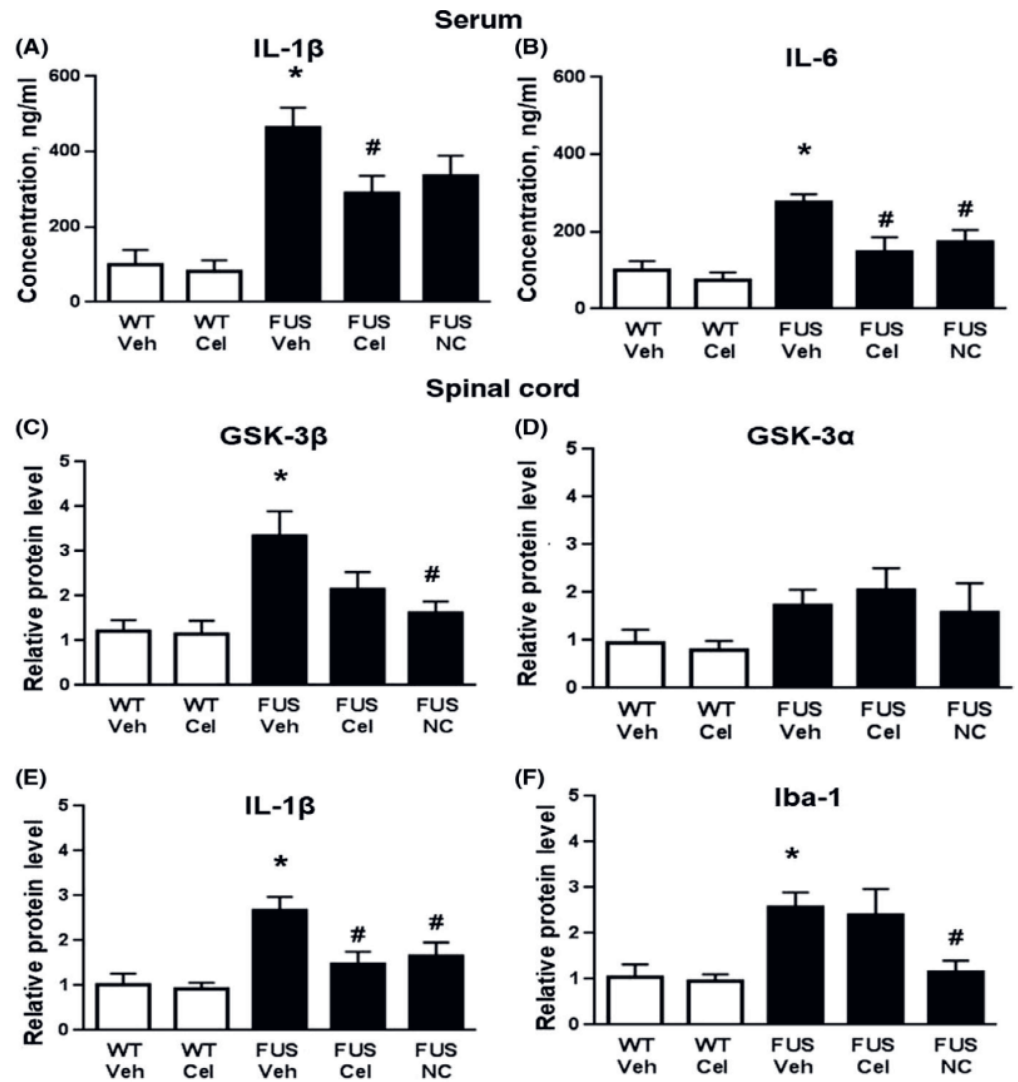

Figure 5. Effects of celecoxib and Neuro-Cells on the expression of molecular markers of inflammation and GSK-3 in FUS-tg mice. A, In comparison with controls, animals from FUS-tg-Veh and FUS-tg-NC groups displayed increased serum concentrations of IL-1B; FUS-tg-Cel group displayed reduced values of this measure in comparison with FUS-tg-Veh mice. B, In comparison with controls, FUS-tg-Veh, but not FUS-tg-Cel and FUS-tg-NC, had elevated serum IL-6. Two later groups had significantly lower serum IL-6 concentrations than FUS-tg-Veh group. In comparison with WT-Veh mice, there were significantly elevated protein levels of (C) GSK-3B, (E) IL-16 and (F) Iba-1 in spinal cords of FUS-tg-Veh animals; but not in FUS-tg-Cel and FUS-tg-NC groups. D, No significant differences were found in the protein levels of GSK-3 $\alpha$ (P>.05). FUS-tg-NC group showed significantly lower values of protein expression of GSK-36, IL-16, and Iba-1 than FUS-tg-Veh mice. FUS-tg-Cel group showed a significant decrease of IL-1B expression in comparison to FUS-Veh group. $\left({ }^{*} P<.05\right.$ vs WT-Veh group, $\# P<.05$ vs FUS-tg-Veh group: one-way ANOVA and Tukey's test). 5-9 mice per group were used: 6 mice in WT-Veh group, 5 mice in WT-Cel and FUS-Cel groups, and 9 mice in FUS-Veh and FUS-NC groups. 
All increased parameters were significantly lower in FUS-tg-NC mice than in the latter group $(\mathrm{P}=.0027, \mathrm{P}=.011$, and $\mathrm{P}=.036$, respectively); similar decreases were found in FUS-tg-Cel group for IL-1 $\beta$, but not for GSK-3 $\beta$ and Iba-1 $(\mathrm{P}=.017, \mathrm{P}=.181$, and $\mathrm{P}=.785$, respectively). Thus, both administration of celecoxib and Neuro-Cells decreased, but only the latter treatment has significantly lowered expression of markers of microglial activation Iba-1 and GSK-3 $\beta$ in the spinal cord.

\section{Effects of administration of Neuro-Cells infusion in SOD-1 mice}

There were no significant differences in body weight between SOD-1-Veh and SOD-1-NC groups during weeks 1-9 ( $P>$.05; Mann-Whitney test). The number of mice fallen from the wire was significantly lower, and the latency to fall was significantly longer in SOD-1-NC than in SOD-1-Veh groups $(P=.028$, Fisher test; and $U=4.5, P=.003$; Figure $6 A, B)$. No other group differences were found (data not shown).
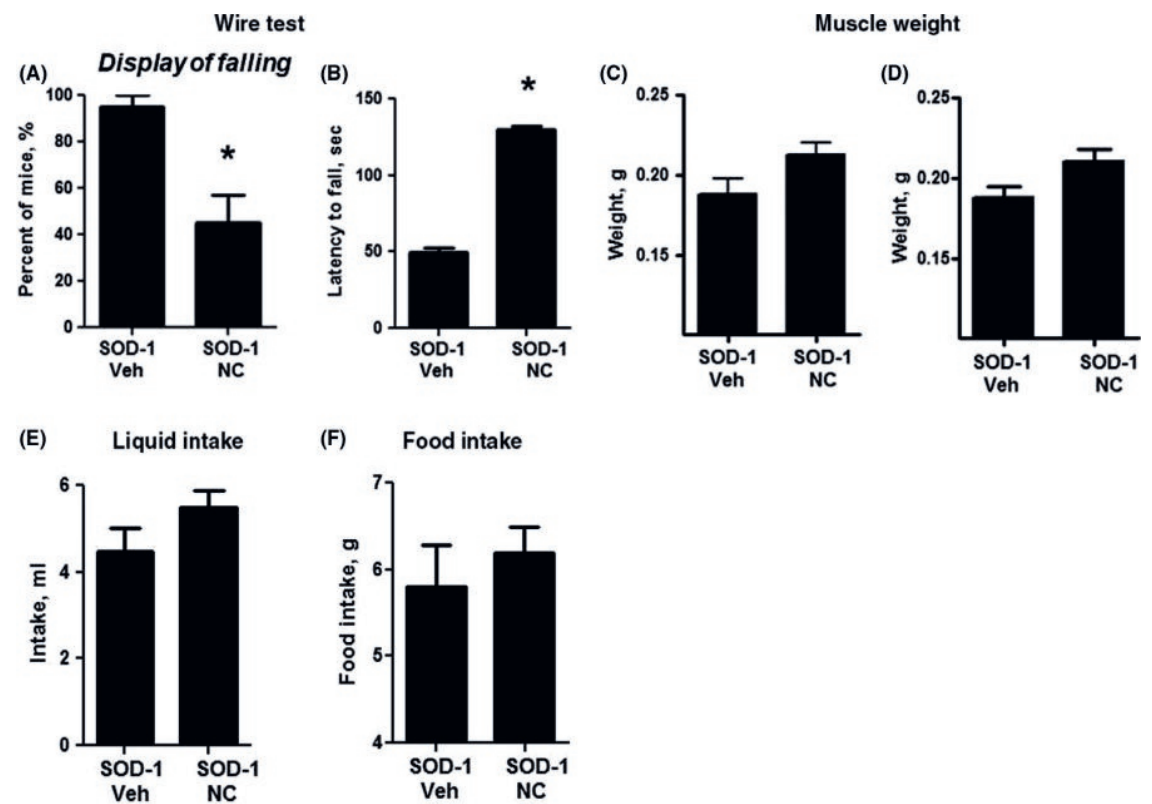

Figure 6. Effects of Neuro-Cells infusion in SOD-1 mice. A, There were significantly fewer numbers of mice displaying the falling in the wire test in SOD-1-NC mice than in SOD-1-Veh mutants. B. The latency to fall in the wire test was significantly longer in SOD-1-NC mice than in $S O D-1-V e h$. C, D, There was nonsignificant trend to higher muscle weight in SOD-1-NC than in SOD-1-Veh group for left and right muscles gastrocnemius, respectively, and for $(E, F)$ higher liquid and food intake in SOD-1-NC mice than in SOD-1-Veh animals ${ }^{*} P<.05$ vs SOD-1-Veh group). 5 mice were used in SOD-1-Veh group, and 7 mice were used in SOD-1-NC group

There was a trend to higher muscle weight in SOD-1-NC animals in comparison with SOD-1-Veh mice for left and right muscles gastrocnemius $(\mathrm{U}=6.5, \mathrm{P}=.081$, and $\mathrm{U}=7, \mathrm{P}=.10$, respectively; Figure $6 C, D)$ and an optical trend to higher liquid and food intake in SOD-1-NC mice $(U=7, P=.10$, $\mathrm{U}=3.6, \mathrm{P}=.16$; Figure $6 \mathrm{E}, \mathrm{F})$. Thus, Neuro-Cells infusion to SOD-1 mutants resulted in overall improved functional readouts in these mice. 


\section{Discussion}

Our study supports the hypothesis that the new stem cell preparation Neuro-Cells ameliorates an experimental ALS syndrome. A single i.c.v. infusion of Neuro-Cells into FUS-tg mutants counteracted the development of neurodegenerative changes, muscle atrophy, motor deficits, and general physical decline and was associated with a decrease in inflammatory markers. These findings are in accordance with recently published results demonstrating beneficial functional and anti-inflammatory action of Neuro-Cells in a rat model of spinal cord injury (de Munter, Beugels et al. 2019). The effects of Neuro-Cells in FUS-tg mice were compared against standard therapies with riluzole and classic anti-inflammatory drug celecoxib. These standard treatments partially ameliorated ALS pathology, but these improvements were less marked than the effects of Neuro-Cells. The administration of Neuro-Cells, but not celecoxib, normalized the expression of Iba-1, a marker of microglial activation and GSK-3ß expression in the spinal cord. While the administration of celecoxib altered cytokine expression in the mutants in a similar manner as Neuro-Cells, it did not alter the expression of Iba-1 and GSK-3ß in the mutants. The findings concerning Iba- 1 and GSK-3ß expression support the view that there is a critical role for microglial activation and inflammation in ALS (Hu, Cao et al. 2017, Mishra, Vijayalakshmi et al. 2017, Morello, Spampinato et al. 2017, Shruthi, Sumitha et al. 2017, Crisafulli, Brajkovic et al. 2018). The upregulation of GSK-3ß cascade is known to be functionally associated with proinflammatory changes and microglial activation, which is a well-established marker of ALS histopathology, and the FUS-ALS forms in particular (Stoica, Paillusson et al. 2016, Duda, Wisniewski et al. 2018). GSK-3ß activities are inversely related to neurotrophin expression, and its downregulation is another recognized molecular feature of human ALS (Mishra, Vijayalakshmi et al. 2017, Shruthi, Sumitha et al. 2017, Sumitha, Manjunatha et al. 2019). GSK-3ß is also implicated in the mechanisms of microglial activation during neurodegeneration (Luca, Calandra et al. 2018). Thus, present study suggests that microglial activation and increased GSK-3ß activities could be targets for ALS therapy, as they were normalized by the administration of the stem cell therapy. It is a generally held view that the anti-inflammatory effects of stem cells are considered to be attributable to the paracrine activity of anti-inflammatory cytokines and growth factors, as well as the release of extracellular vesicles containing anti-inflammatory and antiapoptotic proteins (de Munter and Wolters 2013, Spees, Lee et al. 2016, Dostert, Mesure et al. 2017). These processes are likely to act on RNA-dependent and RNA-independent elements of FUS related pathology (Shelkovnikova, Robinson et al. 2014, An, Skelt et al. 2019, Marrone, Drexler et al. 2019). Transplanted bone marrow derived stem cells were shown to secrete such anti-inflammatory cytokines and growth factors, as IL-10, vascular endothelial growth factor (VEGF), insulin-like growth factor-1 (IGF-1), hepatocyte growth factor (HGF), brain-derived neurotrophic factor (BDNF), neuronal growth factor (NGF), and others (Redondo-Castro, Cunningham et al. 2017, Kshitiz, Ellison et al. 2019). This secretion was shown to be conditiondependent, and in particular, the presence of inflammation was found to stimulate the release of the anti-inflammatory molecules (Redondo-Castro, Cunningham et al. 2017). Given that FUS protein is considered to be functionally related with insulin/IGF-signaling pathway (Therrien, Rouleau et al. 2016), an important element of which is BDNF, a ligand of TrkB receptor (Cline, Steinbusch et al. 2012), which regulates the mechanisms of cellular stress (Hoell, Larsson et al. 2011, Sama, Ward et al. 2013), it can be suggested that paracrine secretion of Neuro-Cells 
cytokines and growth factors may underlie the anti-inflammatory and antidegenerative changes observed in the FUS-tg mice. In addition, FUS protein can regulate the serine-threonine protein kinase (Ak strain transforming, Akt) and forkhead box O1 (FOXO) proteins (Gorlova, Pavlov et al. 2019), further elements of GSK-3 $\beta$ cascade that can explain the reported changes in GSK-3 $\beta$ expression in the FUS-tg model. Moreover, paracrine secretion by stem cells of trophic factors can ameliorate decreased vascular network density in lumbar spinal cords, a recently demonstrated disease mechanism in employed here FUS-tg mice, which is sensitive to a therapy with angiogenetic/growth factors (Crivello, Hogg et al. 2019). Thus, it might be speculated that the effects of the stem cells might be due to paracrine activities and the release of neurotrophins and anti-inflammatory cytokines that classical drug therapy cannot provide (de Munter and Wolters 2013). We found that the physiological parameters and performance of FUS-tg mice treated with Neuro-Cells compared to mutants receiving other therapies were better preserved. In particular, celecoxib-treated mutant mice exhibited limited amelioration of the functional endpoints and no changes in the Iba-1 or GSK-3ß expression. These data may go some way to explain the reported failures of using anti-inflammatory drugs during ALS (Gordon, Moore et al. 2007, Calvo, Moglia et al. 2010, Collins and Bowser 2017). Nevertheless, standard ALS and antiinflammatory treatment induced partial ameliorative effects on the ALS-related abnormalities that validates the FUS-tg line as a model of ALS. To verify results obtained on FUS-tg mice, we performed the i.c.v. infusion of Neuro-Cells in SOD-1 mutants, the classic ALS model. The results indicated that there were improved motor functions under these conditions following NeuroCells administration. Together, our data provide evidence of the disease-counteracting and antiinflammatory effects of Neuro-Cells in two experimental models of ALS and are in line with previously published reports on effectiveness of stem cell therapy during this disease (RuizLopez, Guardiola et al. 2016, Agarwala and Tamplin 2018), as well as with previous findings with this preparation applied in a spinal cord injury model (de Munter, Beugels et al. 2019). They also highlight the importance of compliance in preclinical ALS studies with the internationally accepted guidelines (Ludolph, Bendotti et al. 2010) to more accurately approximate the usefulness of novel therapeutics (see Data S1), including stem cells and thus provide a better basis for clinical trials.

\section{Conclusions}

Our study provides the first evidence for greater efficacy of Neuro-Cells as a therapeutic option capable of counteracting the progression of ALS-like pathology and accompanying inflammatory changes in comparison with the standard pharmacological references. As discussed above, it is very likely that both MSCs and HSCs types of cells contribute to the effect seen in the study. While beneficial effects of HSCs are likely to be due to their well characterized roles in neuropoiesis and production of trophic factors, MSCs, besides their crucial function in the regulation of HSCs functions, might ameliorate angiogenesis and vascular density and exert antiinflammatory effects. Further research is needed to define the mechanisms of anti-inflammatory action and other effects of Neuro-Cells on hallmarks of ALS syndrome. Yet, at this stage, stem cell therapy should be considered as part of therapeutic approach to the treatment of ALS. 


\section{Supplementary}

\section{Animals and housing}

Mouse colony of FUS-tg mice and their wild type littermates (WT) was bred in the FDA-certified SPF facilities of IPAC; generation of FUS-tg mice is described below. SOD-1 mutant mice were obtained from Charles River provider (see main text). Starting from two weeks prior to the experiment, six-weeks-old male mice were single-housed under standard conditions (12 hrs light/dark cycle, lights on at $21: 00$, humidity $50-60 \%$, temperature $22 \pm 1^{\circ} \mathrm{C}$ ) with food and water ad libitum. All efforts were undertaken to minimize the potential discomfort of experimental animals.

\section{Generation of FUS-tg mice}

Generation of FUS-tg mice was performed as described elsewhere (Schelkovnikova et al., 2013). Briefly, a fragment of human FUS [1-359] cDNA including 9 bp of 5'-UTR was cloned into Thy-1 promoter plasmid 323-pTSC21k. A gel-purified fragment obtained by digestion of the resulting plasmid DNA with Notl was used for microinjection of mouse oocytes. Transgenic animals were identified by PCR analysis of DNA from ear biopsies by the presence of 255-bp product (primers 5'-TCTTTGTGCAAGGCCTGGGT-3' and 5'-AGAAGCAAGACCTCT-GCAGAG-3'). The original transgenic line on $\mathrm{C} 57 \mathrm{BI} / \mathrm{CBA}$ genetic background was backcrossed with $\mathrm{CD} 1$ wild type mice for several (>7) generations.

\section{Characteristics of human marrow stem cells}

"Neuro-Cells" is a standardized preparation of fresh, unmanipulated human bone marrowderived stem cells, which is produced under regulations of good manufacturing practices (GMPs) without expansion and/or labeling (de Munter et al., 2019; patent W02015/059300A1). NeuroCells comprise mesenchymal stem cells and their progenitors (MSCs), hematopoietic stem cells and their progenitors (HSCs), and other mononuclear cells (Table 1).

\section{Table 1}

Characterization of cell populations in "Neuro-Cells" preparation

\begin{tabular}{ll}
\hline Cell populations in Neuro-Cells & Absolute number of cells injected per mouse in $10 \mu \mathrm{l}$ \\
\hline Total number of nucleated cells & $1.39 \times 10^{6} / 10 \mu \mathrm{l}$ \\
CD34+ cells & $5.00 \times 10^{5} / 10 \mu \mathrm{l}$ \\
Other mononucleated cells & $8.9 \times 10^{5} / 10 \mu \mathrm{l}$ \\
\hline The proportion of MSCs expressing CD markers in overlapping manner (in total cell preparation, defined by single \\
staining assay): \\
\hline MSC: $\mathrm{CD} 271^{+}$cells (7\%) \\
MSC: CD90 cells (13\%) \\
MSC: CD105+ cells (85.9\%) \\
MSC: CD73+ cells (4\%)
\end{tabular}




\section{Production of human marrow stem cells}

For production of Neuro-Cells, healthy volunteer donors with informed consent were recruited for collection of 50-75 mL of bone marrow from their iliac crest under local anesthesia following standard operating procedures. Briefly, mononuclear cells were isolated by Ficoll density gradient centrifugation ( $1.077 \mathrm{~g} / \mathrm{ml}$; Sigma, Munich, Germany) at $400 \times \mathrm{g}$ for 35 minutes. The mononuclear cells were re-suspended in the culture medium composed of DMEM (GIBCO, Rockville, MD, USA) with low glucose concentration and $10 \%$ fetal bovine serum (FBS; Hyclone, Logan, UT, USA). The mononuclear cells were plated at $1 \times 10^{6} \mathrm{cells} / 25 \mathrm{~cm}^{2}$ in culture flasks and the cultures were incubated at $37^{\circ} \mathrm{C}$ in $5 \% \mathrm{CO}_{2}$ in the air and $95 \%$ humidity. The medium was exchanged after 48 hours and then every 3 to 4 days. When the cultures reached approximately $90 \%$ of confluence, human marrow stem cells ("Neuro-Cells") were passaged with $0.25 \%$ trypsin (GIBCO) and re-plated into passage culture at a density of 5000 to 10,000 cells $/ \mathrm{cm}^{2}$. Cells at passages 3 and 4 were used for transplantation. Upon harvest, the cells were isolated by treatment with $0.25 \%$ trypsin. The cells were then washed four times and re-suspended in PBS at a density of 100,000 cells/ $\mu$ l. Viability of the cells was assessed using a $0.4 \%$ Trypan Blue dye (Sigma, Berlin, Germany) exclusion method prior to and following transplantation. The cells were analyzed for their immunophenotype by flow cytometry (Beckman Coulter, Fullerton, CA, USA). Fluorescein isothiocyanate (FITC)-conjugated or phycoerythrin-conjugated antibodies specific for human CD14, CD19, CD45, CD34, CD73, CD90, CD105, and HLA-DR tested for flow cytometry application. The percentage of positive cells was determined based on fluorescence emission of the nonspecific FITC/phycoerythrin isotypic antibody controls. A preparation of Neuro-Cells was aliquoted, deeply frozen and stored at $-80 \mathrm{C}^{\circ}$ until the use. A standard thawing procedure was applied on the day of the administration of Neuro-Cells (see below). Cells were re-suspended in Ringer Lactate buffer; their vitality was evaluated as described above and concentration in buffer was adjusted to $500,000{\mathrm{CD} 34^{+}}^{+}$in $10 \mu \mathrm{l}$ for i.c.v. injections; vials were kept in $+4 \mathrm{C}^{\circ}$. Table 1 presents an overview of the number of cells injected per a mouse.

\section{Thawing of Neuro-Cells preparations}

For all experiments with i.c.v. administration of Neuro-Cells, preparations from the same stock sample were arranged ex temporo. The standard thawing procedure is described in Table 2.

\section{Vitality assessment of Neuro-Cells preparations after thawing}

After thawing, cell counting was performed using the "Countess II FL Automated Cell Counter" (Thermo Fisher Scientific AMQAF1000, Toronto, ON, Canada) according to the manufacturer's protocol. Three batches of cells (Set 1, Set 2. And Set 3) from the same bone marrow extraction were used in the study.

We checked viability of Neuro-Cells samples used in the study and ensured high vitality percentages in samples, that were ranging from 62 to $68 \%$ Subsequent flow cytometry was done and HSC numbers were adjusted for injection. 


\section{Table 2}

Standard thawing procedure for Neuro-Cells

\section{Step 1}

$150 \mathrm{ml}$ sterile Ringer Lactate solution is used

pre-warm at $37^{\circ} \mathrm{C}$ water bath

\section{Step 2}

1 To thaw frozen Neuro-Cells, cryovials are placed in a water bath at $37^{\circ} \mathrm{C}$ until only a small sliver of ice is present; caution is paid to prevent cryovial cap from submerging in the water.

2 A - Cryovials are transferred to the laminar flow hood

- all vials are wiped with 70\% IPA before opening the cap using a 70\% IPA soaked tissue

B each thawed cell type is transferred into an individual $15 \mathrm{ml}$ tube containing $5 \mathrm{ml}$ pre-warmed thawing buffer

C - cryovials are rinsed twice with fresh pre-warmed thawing buffer

- pooled cells are mixed by gently pipetting up/down twice

D Suspension is centrifuged under $300 \mathrm{~g}$ for $5 \mathrm{~min}$

E - supernatant is completely aspirated

- the cell pellet are handled carefully

- pellet is resuspended into the thawing buffer for washing

$\mathrm{F} \quad$ For washing, pellet is centrifuged under $300 \mathrm{~g}$ for $5 \mathrm{~min}$

G supernatant is completely aspirated

- pellet is resuspended into the thawing buffer for washing

- cells are pooled where applicable

SET 1
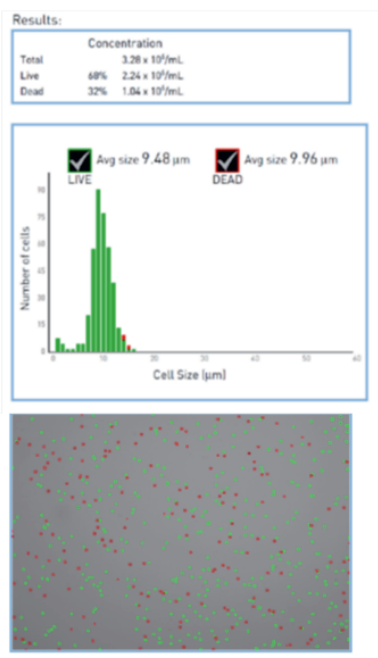

Profile: kkkl•I

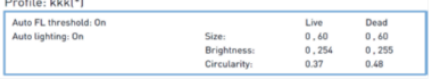

SET 2
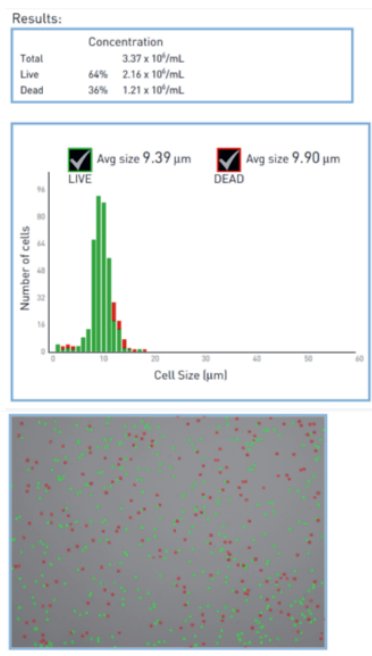

Profle: khkl|•l

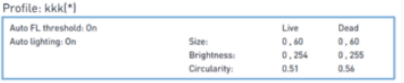

SET 3
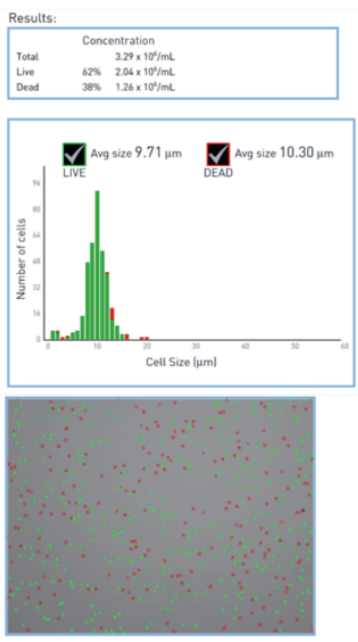

Profile: kkk|*1

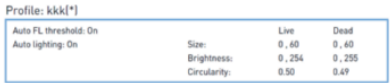


Pilot study to define conditions of i.c.v. infusion of Neuro-Cells with stereotaxic surgery A pilot study was conducted to define optimal conditions of the i.c.v. infusion of Neuro-Cells to mice with stereotaxic surgery. Following conditions of Neuro-Cell administration were tested in a pilot study on 12 CD1 mice: (1) 50, 000 cells for $5 \mathrm{~min}$ in $10 \mathrm{ul}(\mathrm{n}=1)$, (2) 50, 000 cells for $10 \mathrm{~min}$

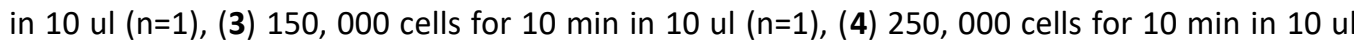
( $n=2)$, (5) 500, 000 cells for $10 \mathrm{~min}$ in $10 \mathrm{ul}(\mathrm{n}=2)$, (6) Ringer Lactate buffer, $10 \mathrm{ul}(\mathrm{n}=2)$, (7) no injection ( $n=1)$. (8) Additionally, the administration of 10,000 stem cells obtained from bone marrow of a mutant mouse expressing green fluorescent protein (GFP) (Kovinva et al., 2019) for $10 \mathrm{~min}$ in $10 \mathrm{ul}(\mathrm{n}=2)$ was carried out in order to compare a diffusion of human stem cell preparation against mouse stem cell preparation. Mice were killed $24 \mathrm{~h}$ after injection using halothane. Brain, liver, lungs, spleen were collected and stained for anti-mitochondrial human antigen from experimental sets 1-7, as previously described (Donders et al., 2015). Briefly, mice were deeply anesthetized by isoflurane inhalation and perfused transcardially with Ringer lactate (pH 7.4) and 4\%-parapharmaldehyde (Sigma-Aldrich) in 30\% PBS-sucrose (Merck Chemicals N.V., Overijse, Belgium). Brains, lungs, lymph nodes, spleen were dissected, positioned into fixative solution for $24 \mathrm{~h}$. Subsequently, tissues were snap frozen in the gas phase of liquid nitrogen and stored at $-80^{\circ} \mathrm{C}$ until further processing. Cryosections $(10 \mu \mathrm{m})$ were cut and stored at $-20^{\circ} \mathrm{C}$ until further processing. Staining for human mitochondria, a marker for cells of human origin in mouse tissue, was performed. Tissue slices were obtained with a Leica CM3050 S cryostat (Leica, GrootBijgaarden, Belgium). The protocol of immunostaining with anti-human mitochondria was previously validated to detect injected cells in a rat study using double staining for C68-positive cells (Donders et al., 2015). Slides were washed with Tris-buffered saline (VWR) containing 0.5\% Tween-20 (Merck Chemicals) (TBS-T), blocked with 10\% normal goat serum (Dako, Heverlee, Belgium) in TBS-T for $45 \mathrm{~min}$ and subsequently incubated overnight with mouse anti-human mitochondria antibody (1:800 in TBS-T; clone 113-1; Millipore, Merck Chemicals, Frankfurt, Germany). Control stainings were performed by omitting the primary antibodies. Brain tissue was counterstained with $0.1 \%$ cresyl violet. Lungs and spleen were counter stained with haematoxylin. Sections were dehydrated and sealed with Entellan mounting medium (Millipore) and imaged and immediately analyzed using a Nikon Eclipse 80i microscope and processed with NIS Elements BR 4.0 software (Nikon Instruments BeLux, Brussels, Belgium). Material from mice treated with GFP-containing stem cells (set 8) was visualized using a fluorescent microscope. Results from these assays are presented below.

\section{Western Blot}

Tissue samples were treated with lysis buffer containing $20 \mathrm{mM}$ of Tris- $\mathrm{HCl}(\mathrm{pH} 7.5), 450 \mathrm{mM}$ of $\mathrm{NaCl}, 1 \%$-solution of Triton X-100, $1 \mathrm{mM}$ of EDTA, $1 \mathrm{mM}$ of NaF, $1 \mathrm{mM}$ of $\mathrm{Na}_{3} \mathrm{VO}_{4}$, and protease inhibitor (Roche Diagnostics, Indianapolis, IN, USA); $50 \mu$ l of buffer per $1 \mathrm{~g}$ of tissue was used. Samples were then centrifuged at $16000 \mathrm{rpm}$ for $20 \mathrm{~min}$ at $4^{\circ} \mathrm{C}$; supernatant was collected and stored until use at $-20^{\circ} \mathrm{C}$. $25 \mu \mathrm{g}$ of protein from each sample was mixed with $35 \mu \mathrm{l}$ of Laemmli buffer. A sample of identical volume, comprising of $26 \mu$ l of Laemmli buffer, $5 \mu$ l of Page Ruler, and $4 \mu \mathrm{l}$ of Magic Mark (Sigma, Munich, Germany) was used as a reference. For electrophoresis, samples were diluted in a solution containing MiliQ $\mathrm{H}_{2} \mathrm{O}, 1.5 \mathrm{M}$ of Tris Buffer (pH 8.8), 30\%solution of Acrylamide, $10 \%$-solution of SDS Temed, and $10 \%$-solution of ammonium persulfate 
(APS). For the next step, a solution containing MiliQ $\mathrm{H}_{2} \mathrm{O}, 0.5 \mathrm{M}$ of Tris Buffer (pH 8.8), 30\%solution of Acrylamide, $10 \%$-solution of SDS Temed, $10 \%$-solution of APS and gel (Sigma, Munich, Germany) was used. The percentage of gel-containing solution was adjusted to the weight of the protein of interest and was $20 \%$ for proteins of the size of $4-40 \mathrm{kDa}, 12.5 \%$ for proteins of the size of $40-70 \mathrm{kDa}, 10 \%$ for proteins of the size of 70-100, and 7.5\% for proteins over $100 \mathrm{kDa}$. A buffer containing $25 \mathrm{mM}$ of Tris Base buffer, $192 \mathrm{mM}$ of Glycine (Sigma, Mannheim, Germany), $10 \%$-solution of SDS and MiliQ $\mathrm{H}_{2} \mathrm{O}(\mathrm{pH}$ 8.3) was used for gel electrophoresis which was carried out under the constant voltages of $80 \mathrm{~V}$ and $130 \mathrm{~V}$.

Polyvinylidene difluoride (PVDF) membrane ( $9 \times 6 \mathrm{~cm}$, EMD Millipore, Billerica, MA, USA) was consequently incubated in a 99\%-methanol solution for $1 \mathrm{~min}$ (Brocacef, Amsterdam, the Netherlands), a MiliQ $\mathrm{H}_{2} \mathrm{O}$ for $5 \mathrm{~min}$, and a transfer buffer for $15 \mathrm{~min}$. The latter contained 25 $\mathrm{mM}$ of Tris Base, $192 \mathrm{mM}$ of glycine, $20 \%$-solution of methanol, and MiliQ $\mathrm{H}_{2} \mathrm{O}(\mathrm{pH} \mathrm{8.3)}$. For the next step, blot "transfer sandwich" was composed of buffer-soaked sponge, consisting of two buffer-soaked Whatman filter papers, gel, activated membrane, and ice-cold transfer buffer; a constant current of $300 \mathrm{~mA}$ was used for $2 \mathrm{~h} 30 \mathrm{~min}$.

The membrane was treated with 5\%-dry milk solution ofTBST, containing $50 \mathrm{mM}$ Tris- $\mathrm{HCl}$ ( $\mathrm{pH}=8.2$ ), $150 \mathrm{mM} \mathrm{NaCl}, 0.05 \%$-solution Tween 20 (Sigma, Munich, Germany) for $1 \mathrm{~h}$ at the room temperature and subsequently incubated with primary antibodies (Table 3) at $4^{\circ} \mathrm{C}$ overnight, followed by incubation with respective horseradish peroxidase-conjugated secondary (HRP) antibodies (Sigma-Aldrich, St. Louis, MO, USA) for $2 \mathrm{~h}$ at the room temperature on a roller. The membrane was washed in TBST three times, 5 min each time, and then placed on the plastic cover. Then, Western Bright ${ }^{\mathrm{TM}}$ ECL kit (Advansta Inc, Menlo Park, CA, USA) was used. Relative optical density of immunoreactive protein bands was examined using ImageJ software (NIH, Bethesda, MD, USA). Results were normalized to the relative intensity of the $\beta$-tubulin band that was selected as a reference protein as described elsewhere (Gorlova et al., 2019). Blots were stripped by incubation with Restore Western Blot Stripping Buffer (Thermo Scientific, Rockford, IL, USA) at the room temperature for $15 \mathrm{~min}$.

\section{Table 3}

Primary antibodies used in the Western blot assay

\begin{tabular}{lc}
\hline Antibody & Dilution \\
\hline Anti- $\beta$-tubulin (Abcam, Cambridge, MA, USA) \#ab8227 & $1: 700$ \\
Anti-GSK-3 $\beta$ (Cell Signaling Technology, Beverly, MA, USA) \#9832 & $1: 800$ \\
Anti-GSK-3 $\alpha$ (Cell Signaling Technology, Beverly, MA, USA) \#4337 & $1: 900$ \\
Anti-IL-1 $\beta$ (Cell Signaling Technology, Beverly, MA, USA) \#12242 & $1: 700$ \\
Anti-Iba1 (Abcam, Cambridge, MA, USA) ab5076 & $1: 500$ \\
\hline
\end{tabular}


To normalize the data, the relative expression value of each protein of interest was expressed as a percent of the concentration of $\beta$-tubulin (the reference protein). The choice of a reference protein was based on the previous observations where its expression was found to vary moderately across various experimental conditions, as well as the linear representation of the intensity of its signal (Gorlova et al., 2019; Pavlov et al., 2019).

\section{Determination of protein concentration}

Protein concentration was quantified using the BCA protein assay kit (Pierce, Rockford, IL, USA) as described elsewhere (Gorlova et al., 2019; Pavlov et al., 2019). The working reagent was prepared in accordance with manufacturer instructions. $25 \mu \mathrm{l}$ of each standard or sample preparations were pipetted into a microplate well; $200 \mu$ l of the working reagent was added to each well and mixed thoroughly on a plate shaker for 30 seconds; assay was run in duplicates. The covered plate was incubated at $37^{\circ} \mathrm{C}$ for 30 minutes and cooled to room temperature for 10 min. The absorbance was measured at $562 \mathrm{~nm}$ in a Biotek Microplate Reader (Biotek Instruments, Winooski, VT, USA). Ascent Software Program (Winooski, VT, USA) coupled to the microplate reader was used to calculate protein values based comparing optical densities with the standard curve. The standard curve was generated by plotting the average blankcorrected $562 \mathrm{~nm}$ measurements for each BSA standard vs. its concentration in $\mu \mathrm{g} / \mathrm{ml}$.

\section{Study compliance with general and proof of concept study requirements specific to ALS}

The presented study is in compliance with the requirements for any proof of concept (you sure?) and preclinical studies (Ludolph et al., 2010) including the statement of a genetic background and key read-outs, breeding protocols, animal livestock and gender, number of animals per group/subgroup, treatment efficacy. Pharmaca outline was double blind for all experimentators. To examine the onset of clinical traits we examined weight loss, grip strength, wire hanging and rotorod test. Histology was applied for positive outcomes and included motor neuron counts in groups of 5-6 mice. Methods and statistics are described elsewhere. Subsequently, we compared our results with previously published literature. A sentence regarding any possible conflict of interests, including the sources of financing and tested treatment is provided. The following prerequisites for the conduct of a preclinical animal study with a therapeutic aim present:

1) Recognition of the validity of the model in terms of the 'genetic validity' of hereditary/familial form of the FUS-tg condition, and the importance of genetic background that is supported by extensive literature on the employed mouse model.

2) The use two different mouse models of ALS, FUS-tg and SOD-1 AG 93 mice.

3) Validity of the characterization of FUS-tg model is supported by compre- hensiveness of undertaken phenotyping. We used classic tests for motor behaviour in mice and classic histological markers of muscular and neuronal degeneration, accompanied by molecular readouts that are well known signs of the disease in a clinic.

4) Our study is a 'proof of concept' study as it investigates the role of pathogenetic mechanisms of neuroinflammation that are therapeutically relevant with the ALS that is clearly different from a 'preclinical drug testing' pre-clinical trial.

5) It is clearly stated that the intervention is meant to be 'disease-modifying'.

6) The outcome was replicated in FUS-tg and SOD-1 mice. 

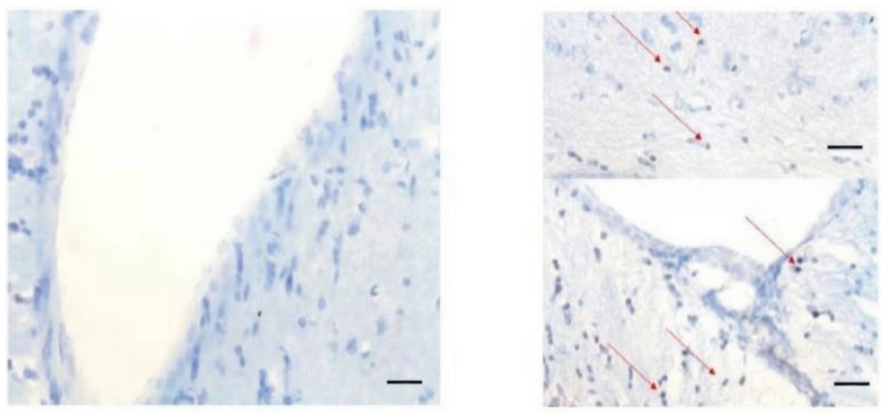

Figure S1. Identification of i.c.v.-infused Neuro-Cells in the parenchyma surrounding lateral ventricles of the mouse brain. After 24 hours, mice treated with 250,000 Neuro-Cells in 10ul of Ringer-lactate buffer could be detected with anti-mitochondrial human antigen within the brain parenchyma of experimental CD1 mice (left: control, vehicle-treated mice, right: Neuro-Cells-injected mice). Anti-human mitochondrial positive staining was observed in regions that were adjacent to the lateral ventricles (red arrows) that were not present in the control. Scale bar $=20$ um and the tissue was counterstained with cresyl violet.

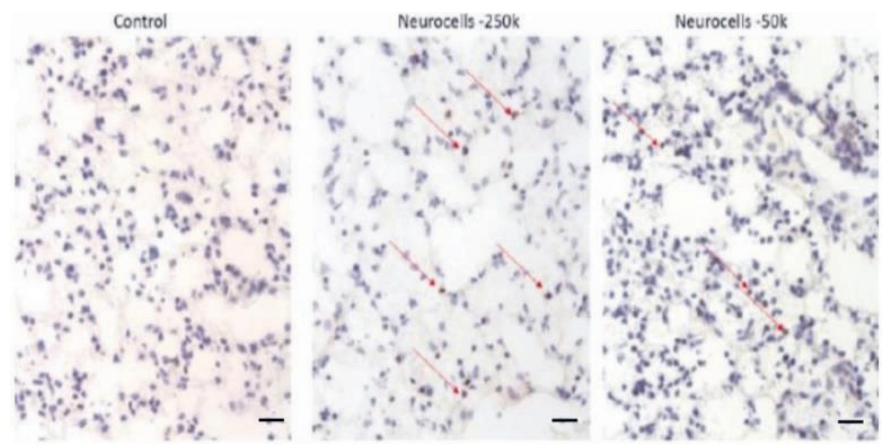

Figure S2. Neuro-Cells were detectable in peripheral organs of experimental CD1 mice after the i.c.v.-infusion: anti-human mitochondria staining in the lung. Mice treated with 50000 or 250000 Neuro-cells in $10 u l$ exhibited positive staining for the antimitochondrial human antigen in the lung (red arrows), spleen and liver (data not shown). Thus, $24 \mathrm{~h}$ post-administration, injected Neurocells had managed to leave the brain and enter peripheral organs. It remains unclear how cells injected into the CSF manage to find there way into peripheral organs so rapidly. Scale bar $=20 u m$ and the tissue was counter stained with haematoxylin.
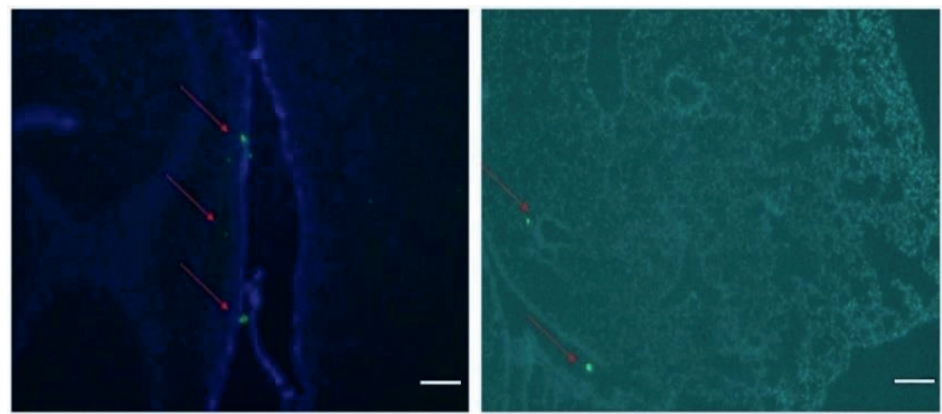

Figure S3. Identification of stem cells derived from GFP mice in the brain parenchyma after their i.c.v. infusion to experimental CD1 mice. To understand how syngeneic stems cells traffic after an i.c.v. injection we injected mouse GFP-expressing bone-marrow-derived stem cells into the CSF. At 24 hours, GFP-positive cells (Kovina et al., 2019) could be detected in the brain parenchyma with a distribution that was similar to that obtained following the administration of Xenogeneic Neuro-Cells. Scale bar $=50$ um and the tissue was counterstained with DAPI. 


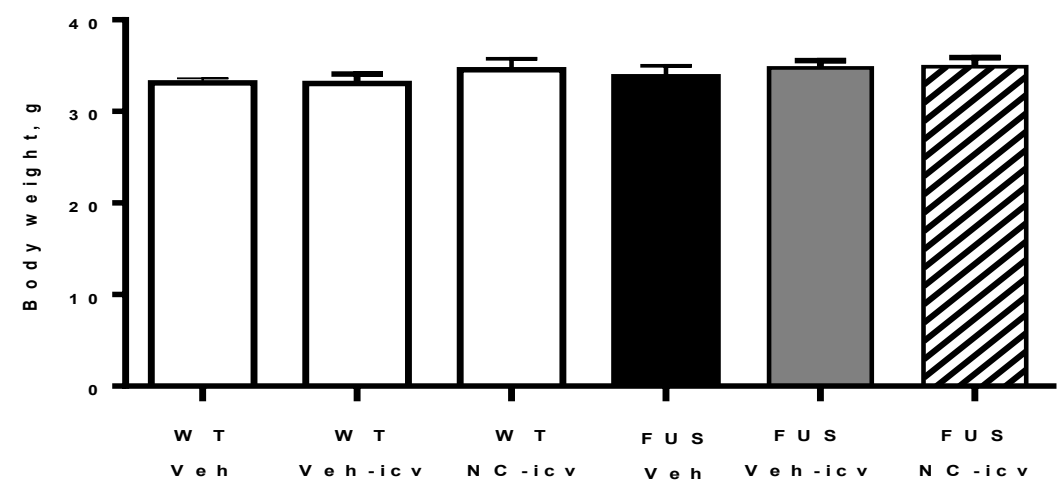

Figure S4. Body weight 1 week after surgery and i.c.v. treatment: lack of effects. Body weights evaluated after one week in wild type controls and FUs-tg mice that received either i.c.v. administration of Neuro-Cells or vehicle did not differ from body weights of non-operated animals that were housed with tap water $\left(F_{2,24}=0.38, p=0.94\right.$, two-way ANOVA, post-hoc Tukey's test). This rules out the possibility of a potential negative impact of surgery on animals' physical state. Based on this finding, control and FUS-tg mice that received either vehicle treatment, were merged according to their genotypes for the subsequent analysis. WT - wild type mice; FUS - FUS-tg mice; Veh - housing on tap water; Veh-icv - infusion of vehicle in i.c.v.; NC-icv - infusion of Neuro-Cells to i.c.v.

\section{Body Weight: group differences}

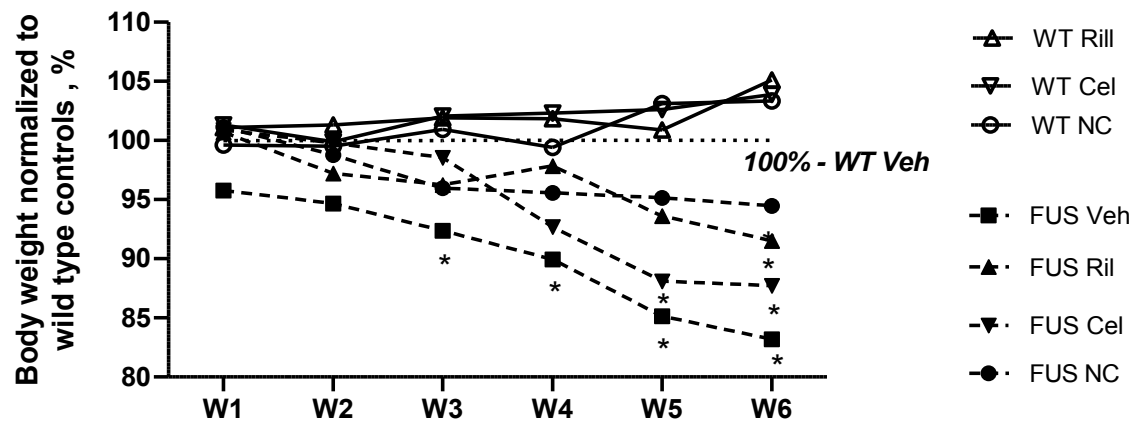

Figure S5. Body weight at Weeks 1-6 of the experiment. Two-way ANOVA and post-hoc Tukey's test revealed a significant effect of genotype on body weight, normalized to the means of control mice, at week $3\left(F_{3,29}=12.94, p=0.012\right.$, two-way ANOVA), week $4\left(F_{3,29}=28.11\right.$, $p=0.002$, two-way ANOVA), week $5\left(F_{3,29}=16.17, p<0.001\right.$, two-way ANOVA) week $6\left(F_{3,29}=19.35, p>0.001\right.$, two-way ANOVA). In addition, there was a significant effect of riluzole treatment at week $6\left(F_{1,12}=14.26, p=0.039\right.$, two-way ANOVA), celecoxib treatment at week 5 $\left(F_{1,14}=8.13, p=0.017\right.$, two-way ANOVA) and week $6\left(F_{1,14}=5.63, p<0.001\right.$, two-way ANOVA), and Neuro-Cells treatment at week 4 $\left(F_{1,13}=12.85, p=0.033\right.$, two-way ANOVA $)$, week $5\left(F_{1,13}=21.88, p=0.024\right.$, two-way ANOVA $)$ and week $6\left(F_{1,13}=11.63, p=0.002\right.$, two-way ANOVA). Post-hoc analysis revealed a significant decrease in body weight in FUS-tg-Veh group at the week 3 ( $p=0.031$, Tukey's test), week 4 ( $p=0.026$, Tukey's test), week 5 ( $p=0.018$, Tukey's test) and week 6 ( $p=0.001$, Tukey's test), in comparison with wild type control mice. FUS-tg mice treated with riluzole showed a significant weight loss at week 6 ( $p=0.043$, Tukey's test), and FUS-tg mice treated with celecoxib had this effect at weeks 5 and 6 ( $p=0.025$ and $p=0.019$, respectively, Tukey's test) in comparison with wild type control mice. ${ }^{*} p<0.05$ vs. WT-Veh group. Thus, all treatments delayed a decrease of body weight in FUS-tg mice in comparison with controls, and infusion of NeuroCells preserved normal body weight longer than administration of celecoxib or riluzole. 


\section{SPINAL CORD}

A

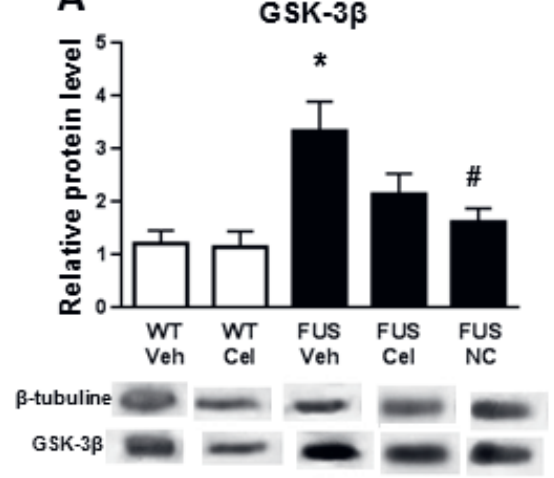

\section{C}

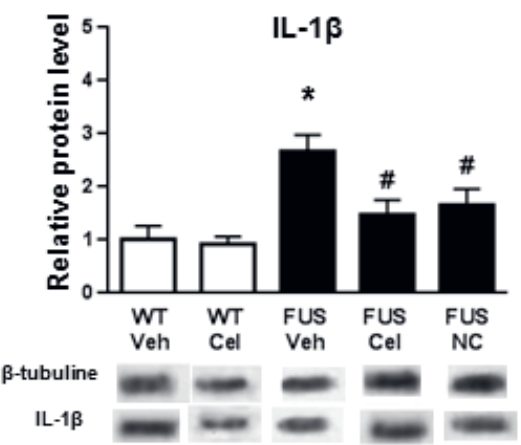

B
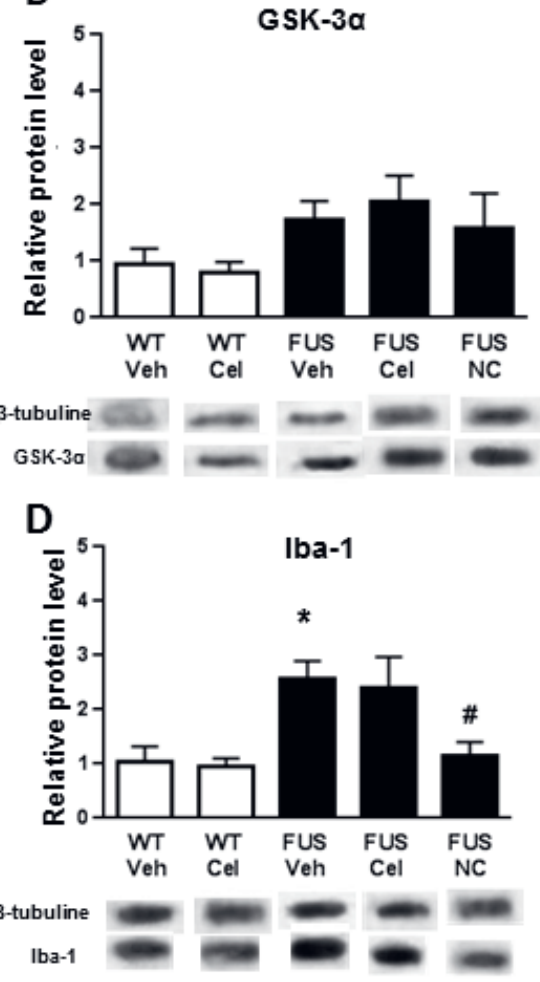

Figure 6. Effects of administration of celecoxib and Neuro-Cells to FUS-tg mice on expression of molecular markers of inflammation and GSK-3. Following examination of Western Blot bands we found significantly elevated protein levels of (A) GSK-3B, (B) IL-1B and (C) IL16 and (D) lba-1 in spinal cords of FUS-tg-Veh animals in comparison with WT-Veh mice that was not found in FUS-tg-Cel and FUS-tg-NC groups ( $p>0.05)$. (D) No significant differences were found in the protein levels of GSK-3 $\alpha(p>0.05)$. Animals from FUS-tg-NC group showed significantly lower values of protein expression of GSK-36, IL-16 and Iba-1 than FUS-tg mice treated with vehicle. Mice from FUS-tg-Cel group showed a significant decrease of protein expression of IL-1B in comparison with FUS-Veh group. B-tubulin was used as a loading control in the Western blot assay, the expression of all proteins is normalized to 8 -tubulin expression $\left({ }^{*} p<0.05, v s\right.$. WT-Veh group, \#p<0.05, vs.FUS-tg-Veh group: one-way ANOVA and Tukey's test), bars are Mean \pm SEM. 


\title{
5.2. Molecular and behavioral abnormalities in the FUS-tg mice mimic frontotemporal lobar degeneration: effects of old and new anti-inflammatory therapies
}

\author{
Johannes de Munter, Diana Babaevskaya, Erik Wolters, Dmitry Pavlov, Ekaterina \\ Lysikova, Allan Kalueff, Anna Gorlova, Margarita Oplatchikova, Igor A. Pomytkin, Andrey \\ Proshin, Aleksei Umriukhin, Klaus-Peter Lesch, Tatyana Strekalova; J Cellular and \\ Molecular Medicine 2020: 00:1-7 (DOI: 10.1111/jcmm.15628).
}

\begin{abstract}
Genetic mutations in FUS, a DNA/RNA-binding protein, are associated with inherited forms of frontotemporal lobar degeneration (FTLD) and amyotrophic lateral sclerosis (ALS). A novel transgenic FUS[1-359]-tg mouse line recapitulates core hallmarks of human ALS in the spinal cord, including neuroinflammation and neurodegeneration, ensuing muscle atrophy and paralysis, as well as brain pathomorphological signs of FTLD. However, a question whether FUS[1-359]-tg mouse displays behavioural and brain pro-inflammatory changes characteristic for the FTLD syndrome was not addressed. Here, we studied emotional, social and cognitive behaviours, brain markers of inflammation and plasticity of pre-symptomatic FUS[1-359]-tg male mice, a potential FTLD model.
\end{abstract}

These animals displayed aberrant behaviours and altered brain expression of inflammatory markers and related pathways that are reminiscent to the FTLD-like syndrome. FTLD-related behavioural and molecular Journal of Cellular and Molecular Medicine features were studied in the pre-symptomatic FUS[1-359]-tg mice that received standard or new ALS treatments, which have been reported to counteract the ALS-like syndrome in the mutants. We used anti-ALS drug riluzole $(8 \mathrm{mg} / \mathrm{kg} / \mathrm{d})$, or anti-inflammatory drug, a selective blocker of cyclooxygenase-2 (celecoxib, $30 \mathrm{mg} / \mathrm{kg} / \mathrm{d}$ ) for 3 weeks, or a single intracerebroventricular (i.c.v.) infusion of human stem cells (Neuro-Cells, $500000-\mathrm{CD}^{4} 4^{+}$), which showed anti-inflammatory properties. Signs of elevated anxiety, depressive-like behaviour, cognitive deficits and abnormal social behaviour were less marked in FUS-tg-treated animals. Applied treatments have normalized protein expression of interleukin-1 $\beta$ (IL-1 $\beta$ ) in the prefrontal cortex and the hippocampus, and of Iba-1 and GSK-3 $\beta$ in the hippocampus. Thus, the pre-symptomatic FUS[1-359]-tg mice demonstrate FTLD-like abnormalities that are attenuated by standard and new ALS treatments, including Neuro-Cell preparation.

\section{Introduction}

Genetic mutations in FUS, which is DNA/RNA-binding protein, can cause frontotemporal lobar degeneration (FTLD) and amyotrophic lateral sclerosis (ALS)(Ito and Suzuki 2011). FTLD is a debilitating disease, often accompanying ALS and involving atrophy of the frontal/temporal 
lobes and affecting emotional, social and cognitive functions (DeLoach, Cozart et al. 2015). Until recently the contribution of FUS to the FTLD/ALS pathology remains poorly understood. The available FTLD models based on the FUS mutation often report somewhat non-specific behavioural deficits and limited brain pathology with a late onset (Shiihashi, Ito et al. 2017), or the very rapid development of physiological and motor ALS-like pathology (Kasey, Hemangini et al. 2016), and, for this reason, it has been argued that further refinement is required (Nolan, Talbot et al. 2016). The construction of the FUS[1-359]-tg mice, expressing truncated human FUS[1-359], has been shown to exhibit many of the hallmark characteristics of ALS (Shelkovnikova, Peters et al. 2013), and FTDL-like changes during the pre-symptomatic stage (Lysikova, Kukharsky et al. 2019). This model provides a promising tool to explore the temporal contribution of FUS mutations on molecular and behavioural outcome. Meanwhile, hitherto the FTDL-like behavioural features and the accompanying molecular changes have not been investigated. Here were addressed this outstanding issue by studying the impact of therapy used in the clinic and new anti-inflammatory therapies on emotional, cognitive and social abnormalities in FUS-tg animals. These therapies have been shown to reduce the ALS-like pathology in these mutants (de Munter, Shafarevich et al. 2019).

\section{Methodology}

Animals, study design, methodology and statistical analysis are described in a Appendix S1 (see also Figure S1). At the age of eight weeks, which is considered to be the beginning of adulthood, the FUS[1-359]-tg (FUS-tg) male mutants display no signs of neurodegeneration in the CNS (Figure S3), nor any motor deficits (Shelkovnikova, Peters et al. 2013, de Munter, Shafarevich et al.2020). For this reasons we selected mice of this age for both Study 1 and Study 2. FUS-tg mice used here showed no deficits in motor tests (not shown).

Over the course of 5 days, wild-type (WT) and FUS-tg mice of average age of 9 weeks were investigated for (a) time spent in the open arms of the O-maze, (b) sucrose preference, (c) the duration of immobility in the tail suspension test, (d) number of rears in the novel cage test, (e) displacement of pellets in the marble test, and ( $f$ ) the duration of attacks and tail rattling in the resident-intruder test (Strekalova and Steinbusch 2010). The FTLD syndrome is well documented to be associated with pathological changes in the limbic system, including the hippocampus and prefrontal cortex and underlie emotional, social and cognitive abnormalities (Nolan, Talbot et al. 2016). These two structures play pivotal roles in the regulation of social, anxiety- and depressivelike behaviours, as well as exploration and cognitive tasks in the mouse models employed here (Strekalova and Steinbusch 2010) and, hence, were studied for potential molecular changes (Figure S1A). Therefore, mice were killed and the hippocampus and the prefrontal cortex collected for RNA isolation/cDNA synthesis and RT-PCR assay of FTDL-related pro-inflammatory markers: tumour necrosis factor (TNF), cyclooxygenase-1 (COX-1), interleukin-1 $\beta$ (IL-1 $\beta$ ) and cytokine expression regulatory molecules implicated in the ALS pathology, matrixmetalloproteinase-9 (MMP-9) and tissue inhibitor of metalloproteinase-1 (TIMP-1)(DeLoach, Cozart et al. 2015). For experimental details, see Appendix S1 and Table S1). 
Then, per os administration of the commonly used ALS treatment riluzole $(8 \mathrm{mg} / \mathrm{kg} / \mathrm{d})$, orantiinflammatorycyclooxygenase-2 blocker celecoxib $(30 \mathrm{mg} / \mathrm{kg} / \mathrm{d})$, or vehicle, to FUS-tg and WT mice of average age of 9 weeks was started; or they received an intracerebroventricular (i.c.v.) infusion of Neuro-Cells $\left(1.39 \times 10^{6}\right.$ mesenchymal and haemopoietic human stem cells containing $5 \times 10^{5}$ of $\mathrm{CD} 4^{+}$cells) or Ringer-solution (de Munter, Shafarevich et al. 2019, de Munter, Beugels et al. 2019), for details on Neuro-Cells preparation, see Appendix S1 and Tables S3 and S4). Two weeks later, over a period of 5 days, mice were behaviourally scored for (a) time spent in lit box in the dark/light test, (b) new object recognition index, (c) the duration of immobility in the tail suspension test, and (d) duration of following, number of attacks and of tail rattling in the resident-intruder test (Couch, Trofimov et al. 2016). A different battery of tests was employed in the second set of animals with the aim of providing an extended behavioural characterization of new FUS-tg line (Figure S1B). To compare molecular changes of mutants in brains to the reported changes in the spinal cord, mice were killed at age of 15 weeks, and the hippocampus and the prefrontal cortex were dissected for Western blots for IL-1 $\beta$, Iba-1, glycogen-synthase-kinase-3 (GSK-3)- $\beta$ and GSK-3 $\alpha$ (de Munter, Shafarevich et al. 2019, de Munter, Beugels et al. 2019). For experimental details, see Appendix S1 and Table S2). Data were treated by unpaired two-tailed $t$ test, or one- or two-way ANOVA followed by Tukey's test, for two or multiple group comparisons, respectively. Repeated measures were analysed by two-way ANOVA for repeated measures followed by Sidak post hoc test.

\section{Results and Discussion}

For full statistical results see Supplementary Tables.

\section{Pre-symptomatic FUS-tg mice display aberrant behaviours and pro-inflammatory changes.}

FUS-tg mice spent less time in open arms of the elevated O-maze and exhibited a reduced latency to immobility in the tail suspension test, decreased sucrose preference, reduced duration of attacks $(P<.05$ vs controls, unpaired t test; Figure $1 A-D)$, and the duration of tail rattling was unchanged ( $P>$.5; Figure 1E; Table $S 5 A$ ). A lack of group differences in general locomotion in the O-maze rules out a possibility of non-specific confounds in behavioural analysis of two genotypes (Figure S3). Two-way ANOVA for repeated measures revealed significant time $x$ genotype interaction and genotype effect in the number of rears in the novel cage test $(P<.05$; Table S5B). Sidak post hoc test for multiple comparisons showed significant increase of this measure in FUStg mice on the 4th min ( $P<.05$ vs WT mice; Figure $1 F)$ and trends to such changes on minutes 2 , 3 and 5 ( $P>.05$, Table S5B). In comparison with controls, mutants exhibited unchanged activity on the 1st min of scoring ( $P>.5$, t test; Table $\mathrm{S} 5 \mathrm{C}$ ) and significantly higher number of rearings averaged over the 2 nd-5th $\mathrm{min}$ of the test $(\mathrm{P}<.05, \mathrm{t}$ test), thus, showing disrupted novelty adaptation (Figure 1F).

There were significant time and genotype effects, as well as significant time $x$ genotype interaction the in number of pellets displaced during the marble test $(P<.05$, t wo-way ANOVA for repeated measures; Table S5D). FUS-tg mice displaced fewer pellets during all time periods of the test, except for 0-15 minutes, suggesting deficient hippocampus-dependent performance ( $P<.05$ vs WT mice, Sidak post hoc test; Figure 1G; Table S5D). 

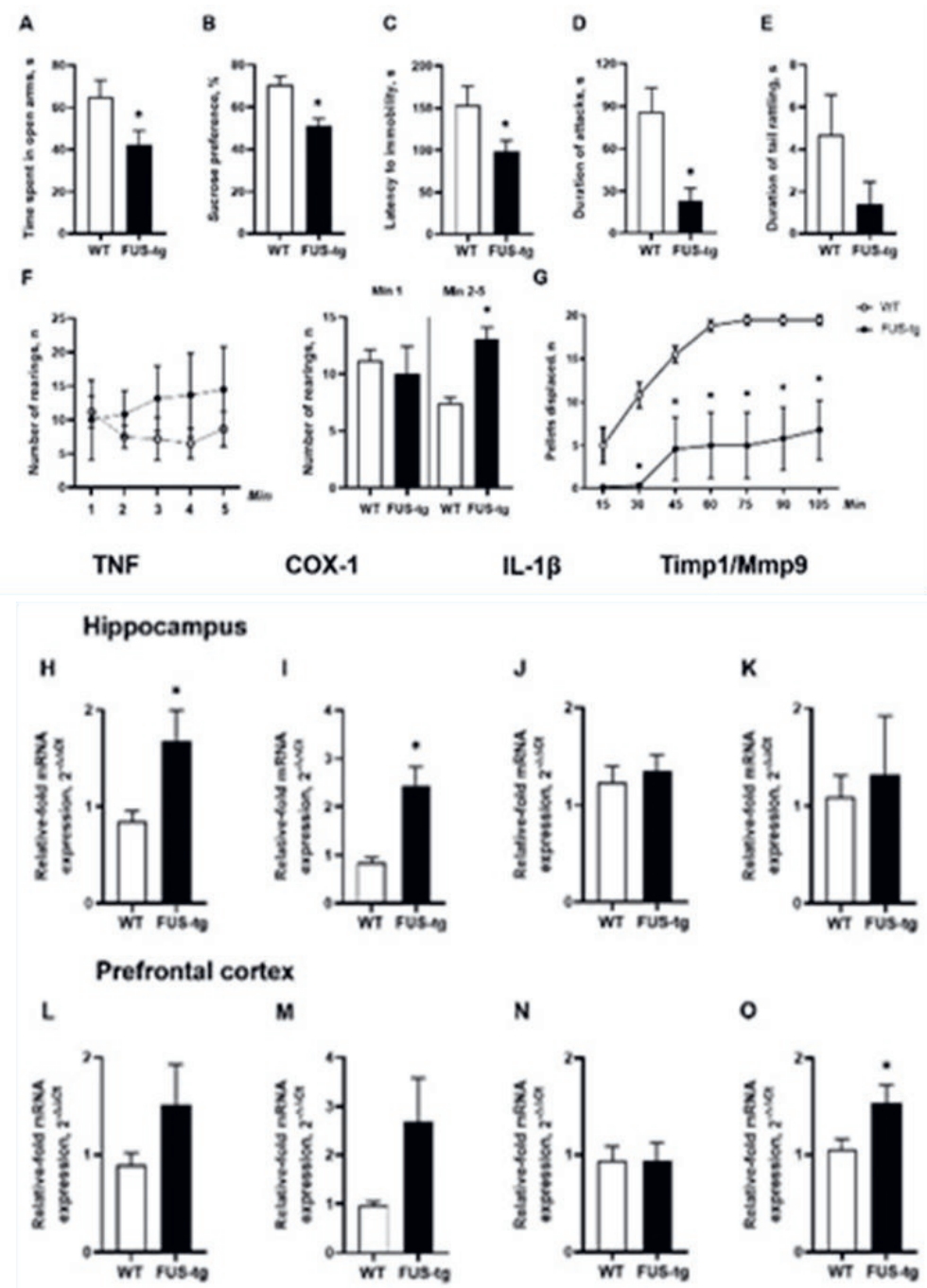

Figure 1. FTLD-like changes in FUS-tg mice in (A-G) behavioural parameters and $(H-O)$ molecular markers; ${ }^{*} P<.05$ : FUS-tg $(n=9-15)$ vs $W T(n=8-14)$ groups, unpaired t test and repeated ANOVA and Tukey's test (see the text).

Signs of helplessness, anhedonia, anxiety-like features, cognitive and social abnormalities in FUStg animals are characteristic of other FTDL paradigms, that is progranulin-deficient mice (Yin, Dumont et al. 2010), $\Delta$ NLS-FUS mice (Shiihashi, Ito et al. 2017), and TDP-43-tg mice (Alfieri, Silva et al. 2016). The current study suggests the most prominent FDTL-related deficits of the FUS-tg mice are the classic tests of emotionality, social and hippocampus-dependent performance. In comparison with other FTLD rodent models based on the FUS mutation, the findings reported here in the FUS-tg mice suggest that no hyperactivity or other non-specific behavioural 
alternations are present, but, typical for this disease, features of anxiety, apathy, cognitive and social deficits are observed (Shiihashi, Ito et al.2017, Nolan, Talbot et al.2016, Lysikova, Kukharsky et al.2019). Hippocampal concentrations of TNF and COX-1 mRNA were elevated in the FUS-tg mice ( $P<.05$ vs controls; unpaired t test; Figure $1 \mathrm{H}-\mathrm{M}$, Table S6). The Timp1/Mmp9 ratio was augmented in the prefrontal cortex $(P<.05$, t test; Figure $1 \mathrm{~J}-\mathrm{K})$, and no other group differences were present $(P>5, t$ test). Together, these data provide evidence of proinflammatory changes within the brain of the FUS-tg mice that a characteristic for FTDLsyndrome (Filiano, Martens et al. 2013) and aberrant Timp1/Mmp9 ratio, a factor of ALS pathology (DeLoach, Cozart et al. 2015), cytokine expression (Schoser and Blottner 1999) and neuronal plasticity (Ethell and Ethell 2007, Trofimov, Strekalova et al. 2017).

\section{Ameliorative effects of standard ALS treatments and "Neuro-cells" on the behavioural and molecular changes in the FUS-tg mice.}

Concerning the duration of immobility, there were no significant effects of genotype, treatment, or their interaction ( $P>5$, two-way ANOVA, Table S7), but FUS-tg-Veh displayed elevated immobility scores $(P<.05$, vs WT-Veh group, Tukey's test; Figure $2 A)$, that were not observed in the treated mutants ( $P>.05$, Tukey's test). In comparison with FUS-tg-Veh mice, this behaviour was decreased in FUS-tg-NC, but not FUS-tg-Ril and FUS-tg-Cel animals $(P<.05$ and $P>.5$, respectively; Tukey's test). For the time spent in the lit box, there were no significant effects of treatment, a genotype $x$ treatment interaction ( $P>.5$, two-way ANOVA), but there was an impact of genotype ( $\mathrm{P}<.05$, two-way ANOVA). In comparison with respective wild-type controls, FUS-tgVeh animals, but not treated mutants exhibited a shortened duration of time spent in the lit box $(\mathrm{P}<.05$ and $\mathrm{P}>\mathrm{.5}$, respectively, Tukey's test; Figure 2B, Table S7), which was increased in FUS-tgNC vs FUS-tg-Veh animals ( $P<.05$, Tukey's test). No other group differences were found. There were no group differences in the object exploration ( $P>.5$, two-way ANOVA and Tukey's test; not shown). A significant genotype $x$ treatment interaction and effects of genotype $(P<.05$, two-way ANOVA), not of treatment ( $P>5$, two-way ANOVA), were found for the preference for the new object. All mutants except FUS-tg-NC animals had decreased scores for this measure $(P<.05$ and $\mathrm{P}>.05$, vs WT groups, respectively, Tukey's test; Figure 2D, Table S7). A significant genotype $x$ treatment interaction was revealed for the duration of 'following' $(\mathrm{P}<.05$ and $\mathrm{P}>.5$, respectively, two-way ANOVA), but not for numbers of attacks and tail rattling ( $P>.5$, Tukey's test; Figure $2 E, F$, Table S7). There was a significant genotype effect on the duration of following and number of attacks, but no significant treatment group differences ( $P>.05$, two-way ANOVA). We found a significant treatment effect on the duration of following $(P<.05$, two-way ANOVA), which was increased in FUS-tg-Veh and FUS-tg-Cel mice $(P<.05$, Tukey's test vs respective control groups; Figure 2D, Table S7), and FUS-tg-Cel group showed its decrease vs FUS-tg-Veh group $(P<.05$, Tukey's test). No other group differences were found. Thus, treatments ameliorated the behavioural end-points in the FUS-tg mice, where their effects on the measures of anxiety and aggression were particularly profound, suggesting their importance in the evaluation of FDTLlike features in this mouse line. Hippocampal concentrations of IL-1 3 , Iba-1, GSK-3 $\beta$ and GSK-3 $\alpha$ were different between the groups ( $P<.05$; one-way ANOVA, Figure 2G-J, Figure S4A; Table S8A). FUS-tg-Veh animals exhibited increased expression of all molecules except GSK-3 $\alpha(P<.05$ and $\mathrm{P}>$.05, vs WT-Veh; respectively; Tukey's test). In FUS-tg-NC mice, concentrations of IL-1 $\beta$ and 
GSK-3 $\beta$ were lower than in the FUS-tg-Veh group ( $P<.05$, Tukey's test). In the prefrontal cortex, levels of IL-1 $\beta$, Iba-1 and GSK-3 $\beta$ were different between the groups $(P<.05)$, but not for GSK-3 $\alpha$ ( $P>05$ and $P>.05$, respectively, Tukey's test). FUS-tg-Veh animals displayed elevated expression of the target molecules ( $P<.05$, vs WT-Veh), except GSK-3 $\alpha$ ( $P>.05$, Tukey's test; Figure 2K-N, Figure S4B, Table S8B). Concentrations of IL-1 $\beta$ were found to be decreased in FUS-tg-NC vs FUStg-Veh mice ( $\mathrm{P}<.05$, Tukey's test). No other group differences were found. In summary, FUS-tg mutants displayed up-regulated protein expression for the inflammatory markers and for GSK3 , which was reminiscent of the changes observed in the spinal cord (Kasey, Hemangini et al. 2016) and were sensitive to the treatments. Thus, behavioural and molecular abnormalities of FUS-tg mice were overly reduced by the use of Riluzole, celecoxib or Neuro-Cells, which often exerted greater effects.

\section{Emotionality and memory scores}
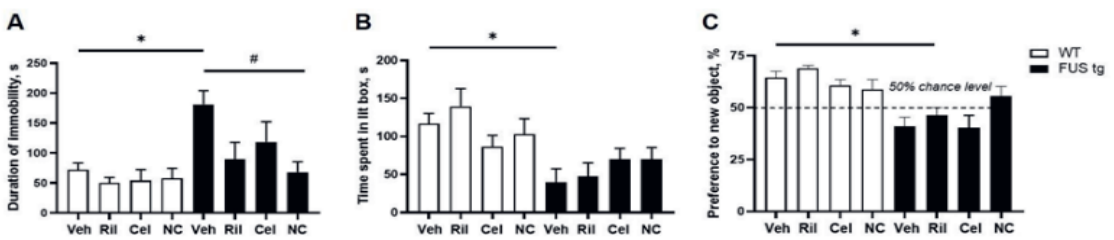

Social behaviour
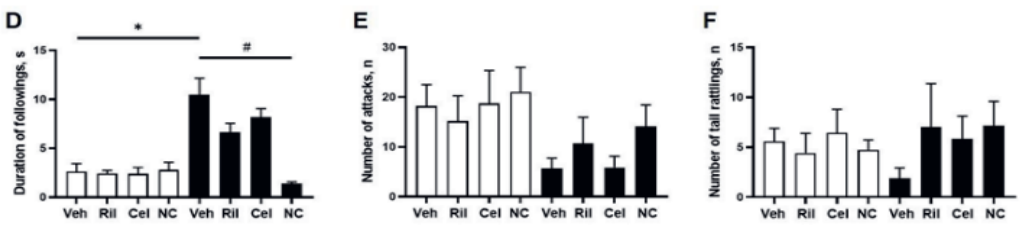

IL-1 $\beta$

lba1

GSK-3 $\beta$

GSK-3a
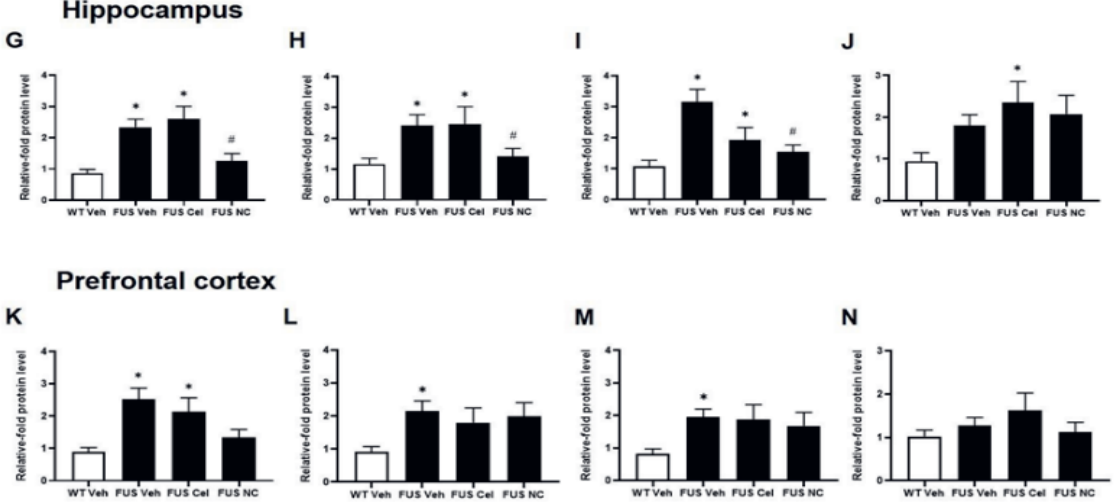

Figure 2. Ameliorative effects of standard ALS treatments and Neuro-Cells in FUS-tg mice on (A-F) behaviours and (G-N) expression of FTLD/ALS-related molecular markers; ${ }^{*} P<.05$, vs respective WT-group $(n=6-12), \# P<.05$, vs FUS-tg-Veh group $(n=7-14) ; A N O V A$ and Tukey's test (see the text). 


\section{Conclusions}

Together, the pre-symptomatic FUS[1-359]-tg mice demonstrate behavioural changes that are reminiscent of the FTLD-syndrome abnormalities, and they are attenuated by all the treatments. Hence, FUS[1-359]-tg mutant mice can be exploited as a new paradigm of the FTLD to address molecular mechanisms underlying this disease and test new treatment options.

\section{Supporting information}

\section{MATERIALS AND METHODS}

\section{Animals and housing conditions}

A colony of FUS-transgenic mice (FUS-tg) and their wild type littermates (WT) was bred and housed in the FDA-certified SPF facilities of the IPAC Center of Pre-clinical Trials. Male mice of both genotypes, 10-weeks-old at the start of the experiment, were single housed in standard plastic cages (27×22x15) and maintained on a 12-hour light/dark cycle (lights on at 21:00), under controllable laboratory conditions $\left(22 \pm 1^{\circ} \mathrm{C}, 55 \%\right.$ humidity, room temperature $\left.22-24 \% \mathrm{C}\right)$, food and water were available ad libitum. Housing conditions and all experimental procedures were set up in accordance with a Directive 2010/63/EU of 22 September 2010 and carried out under approval of the Committee for Bioethics (N19-16.06.2017) of IPAC RAS. Bone marrow collection from healthy volunteers was carried out under GMP license (Neuroplast BV Farmatec The Netherlands) and approved by Ethical Committee of MUMC, Maastricht University (iCell1 METC MUMC and iCell2 METC Zuyderland Zuid). All efforts were undertaken to minimize the potential discomfort of experimental animals.

\section{Production of FUS Transgenic Mice}

A generation of FUS-tg mice was performed as describe elsewhere (Schelkovnikova et al., 2013). Briefly, a fragment of human FUS[1-359] cDNA including 9 bp of 5'-UTR was cloned into Thy-1 promoter plasmid 323-pTSC21k. A gel-purified fragment obtained by digestion of the resulting plasmid DNA with Notl was used for microinjection of mouse oocytes. Transgenic animals were identified by PCR analysis of DNA from ear biopsies by the presence of 255-bp product (primers 5'-TCTTTGTGCAAGGCCTGGGT-3' and 5'-AGAAGCAAGACCTCTGCAGAG-3'). Initially produced transgenic line on C57BI6/CBA genetic background was backcrossed with CD1 wild type mice by seven or more generations.

\section{Study design}

In Study 1, FUS-tg mice at the age of 9 weeks corresponding to a pre-symptomatic stage of the ALS model alone with wild type littermates, were studied for motor functions in the Cat-walk, Wire test, Grip-test, Pole test and Rotarod model with 1-hour inter-test interval as described elsewhere (Veniaminova et al., 2020; de Munter et al., 2020; see below) to verify the absence of any motor deficits during three days prior the experiment (Fig.1A, data now shown). These mice were investigated in the tests for emotionality, social behaviour and hippocampus-dependent performance thereafter. On Day 1, mice were studied in the elevated O-maze test for anxiety- 
like behaviour, on Day 2, they were studied in the sucrose preference test for a sensitivity to reward, on Day 3, mice were scored for novelty exploration in the novel cage test and despair behaviour in the tail suspension test, on Day 4, mice were investigated for hippocampusdependent performance of food pellet displacement behaviour in the marble test and on Day 5 , parameters of social interaction were scored in the resident-intruder test (see below). Seventy two hours after the last test mutant animals were were perfused with $\mathrm{NaCl}$, anaesthetized and killed, alone with respective wild type controls (see below) and brains were harvested and dissected to the hippocampus and the prefrontal cortex for a subsequent molecular analysis with RT PCR (see below). Twelve animals in average were used per group; numbers of animals used is indicated in Figure legends.

In Study 2, FUS-tg mice at the same age as in the Study 1 were tested for motor functions as described above; no motor deficits were found in mutants (data not shown). FUS-tg and WT mice were treated with (1) regular tap water, or (2) riluzole $(8 \mathrm{mg} / \mathrm{kg} /$ day, via drinking water), or (3) or celecoxib $(30 \mathrm{mg} / \mathrm{kg} /$ day) via diet pellets, or (4) single stereotaxic i.c.v. infusion of Neuro-Cells (NC, 500,000-CD34+ in 10 ul of Ringer Lactate buffer), or (5) stereotaxic i.c.v. infusion of Ringer Lactate buffer (Fig.1B; de Munter et al., 2020). Doses of pharmaca and stereotaxic surgery were carried out as described elsewhere (de Munter et al., 2020; see below). Ten animals in average were used per group; numbers of animals used is indicated in Figure legends.

During the following two weeks, all mice were weekly weighed and investigated in the rotarod, pole and wire tests for motor functions, dosing with drugs was continued. As post-surgery physiological parameters of wild type mice that received either tap water or i.c.v. vehicle injection were similar (data not shown), these two groups were merged into a vehicle-treated group for subsequent group comparisons. On the third week, mice were investigated for emotional, social and cognitive behaviors. At this point of study, no signs of motor deficits in were found in FUS-tg groups (data not shown). For the sake of a more complete characterization of this new line of FUS-tg mice, we have chosen to employ a battery of behavioural models similar to Study 1, although with an extended scope of behavioral responses, while providing a sufficient consistency in the analysis of behaviour between the two studies. On Day 1, mice were scored for anxiety-like behavior in the dark/light test, on Days 2 and 3, mice new object recognition index was assessed, on Day 4, mice were studied in the tail suspension test, and on Day 5 , the resident-intruder test was performed (see below). To verify whether brain molecular changes in mutants match those previously reported for spinal cord in symptomatic FUS-tg animals, mice were killed at their symptomatic age of fifteen weeks, given in average age of the onset of the ALS-like syndrome of 14 weeks (Shelkovnikova et al., 2013; de Munter et al., 2020). Dosing of pharmaca was continued for the remaining three weeks and was interrupted $48 \mathrm{~h}$ prior a sacrifice. Mice were anaesthetized, perfused with $\mathrm{NaCl}$ and killed, brains were isolated, the hippocampus and the prefrontal cortex were dissected as described above, for Western blot assay. Brain protein expression of target proteins was measured by Western blot assay in mice treated with either vehicle, Neuro-Cells or celecoxib, since distinct expression changes in the lumbar parts of spinal cord previously showed in these groups for selected markers of inflammation and cellular distress (de Munter et al., 2020). Pharmaca outline and genotype were double blind for all experimenters. 


\section{A}

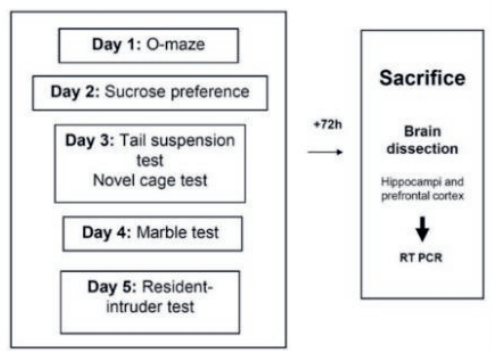

B

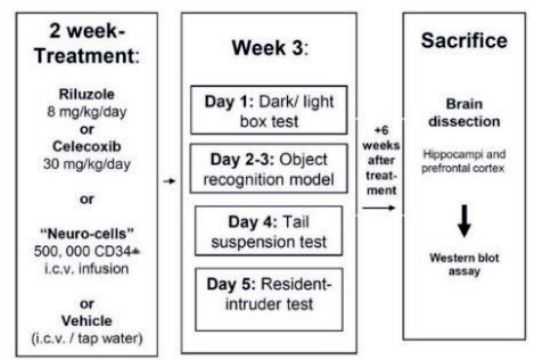

Figure 3 Experiment design of study on (A) naïve FUS-tg mice and (B) FUS-tg mice treated with standard ALS treatment and "Neuro-Cells".

\section{Behavioural testing}

The person performing the experiments was blind for the genotype and treatment until the end of the behavioral tests. Experiments were carried out in the same rooms by the same persons between 09:00 and 17:00 h. Animals were allowed to adapt to experimental room for at least 1 $\mathrm{h}$ before testing. All experiments were recorded on videotape and scored manually and by the means of ViewPoint software (ViewPoint SA, Lissieu, France).

\section{Rotarod}

Mice were placed on constantly rotting rod of rotarod (Columbus Instruments, Columbus, $\mathrm{OH}$, USA; speed $10 \mathrm{rpm}$ ) for $600 \mathrm{~s}$. Latency to fall and the number and percent of mice with falling events (latency<200s) were registered in three runs as described elsewhere (Veniaminova et al., 2020; de Munter et al., 2020).

\section{Wire test}

Mice were allowed to grip a horizontal wire (diameter $0.3 \mathrm{~cm}$, height above the surface $60 \mathrm{~cm}$ ) for 180s. The latency of falling and the number and percent of mice with falling events (latency<20s) were recorded as described elsewhere (Veniaminova et al., 2020; de Munter et al., 2020).

\section{Pole test}

Mice were placed on a top of the vertical bar (diameter $1.1 \mathrm{~cm}$, height $60 \mathrm{~cm}$ ) and allowed to climb down to a horizontal surface. The latency of descending the bar and the number and percent of mice with sliding events (latency to descend $<50$ s) were scored as described elsewhere (Veniaminova et al., 2020; de Munter et al., 2020).

\section{Grip test}

The grip strength meter (Bioseb, Vitrolles, France) was positioned horizontally and mice were held by the tail and lowered towards the apparatus. The mouse was allowed to grab the metal grid bar and are then pulled backwards in the horizontal plane with minimal force sufficient to make it losing a grip. The measurement was accomplished using a sensor and was expressed in units as described elsewhere (de Munter et al., 2020). 


\section{CatWalk test}

CatWalk XT (Noldus, Wageningen, Netherlands) was employed for refined quantitative assessment of motor functions in experimental groups of mice. In the current study, the duration of right and left hindlimb swing was measured in baseline conditions and after the onset of the treatment as described elsewhere (de Munter et al., 2020). These measures were defined as the most sensitive and reliable parameters of motor functions in the FUS-tg mice in pilot experiments (Lysikova and Ninkina, unpublished results).

\section{O-maze test}

The apparatus (Open Science, Moscow, Russia), which consisted of a circular path (runway width $5.5 \mathrm{~cm}$, diameter $46 \mathrm{~cm}$ ), was placed $50 \mathrm{~cm}$ above the floor. Two opposing arms were protected by walls (height $10 \mathrm{~cm}$ ), and the illumination strength was $25 \mathrm{~lx}$. Anxiety-like behavior was assessed using previously validated parameters as described elsewhere (Couch et al., 2016; Costa-Nunes et al., 2020). Mice were placed in one of the closed arm compartments of the maze. Total duration of time spent in the open arms of the maze was scored as the parameter of anxiety-like behavior during 5 min.

\section{Sucrose Preference}

Mice were given 8 hours of free choice between two bottles of either 1\% sucrose or standard drinking water, as described elsewhere (Strekalova et al., 2004, Couch et al., 2013; Pavlov et al., 2019). Bottles were weighed before and after conducting the sucrose preference, and consumption calculated accordingly. The beginning of the test started with the onset of the dark (active) phase of animals' cycle. To prevent the possible effects of side preference in drinking behaviour, the position of the bottles in the cage was switched at 4 hours, halfway through testing. No previous food or water deprivation was applied before the test. Other conditions of the test were applied as described elsewhere (Strekalova and Steinbusch 2010). Percentage preference for sucrose is calculated using the following formula: Sucrose Preference $=$ Volume (Sucrose solution)/(Volume (Sucrose solution) + Volume (Water) x 100.

\section{Novel Cage Test}

The 5-min long novel cage test was carried out to assess exploration of a new environment as described elsewhere (Strekalova et al., 2004, Couch et al., 2016; Veniaminova et al., 2020). Mice were introduced into a standard plastic cage $(21 \mathrm{~cm} \times 21 \mathrm{~cm} \times 15 \mathrm{~cm})$ filled with fresh sawdust. The number of exploratory rears was counted under red light per each minute, and summed up for minutes 2-5 of the test.

\section{Tail suspension test}

Mice were subjected to the tail suspension by being hung by their tails with adhesive tape to a rod $50 \mathrm{~cm}$ above the floor for $6 \mathrm{~min}$. Animals were tested in a dark room where only the area of the modified tail suspension construction was illuminated by a spotlight from the ceiling; the lighting intensity on the height of the mouse position was 25 Lux. The total duration of immobility was scored according to the protocol that was previously validated with Noldus EthoVision XT 8.5 (Noldus Information Technology, Wageningen, Netherlands) as described elsewhere (Malatynska et al., 2012). In accordance with the commonly accepted criteria of immobility, the 
immobility behaviour was defined as the absence of any movements of the animals' head and body.

Pellet displacement marble test

All experimental groups were tested for pellet displacement in a marble test as described elsewhere (Strekalova et al., 2013; Veniaminova et al., 2017, 2020). A tendency to displace small objects, e.g. small stones or food pellets, from a tube inside the cage, is species-specific in mice and has been demonstrated to depend on an intact hippocampal formation. Using a paper tube (internal diameter $4 \mathrm{~cm}$, length $10 \mathrm{~cm}$ ), filled with 20 food pellets and placed in the middle of a home cage $(21 \mathrm{~cm} \times 27 \mathrm{~cm} \times 14 \mathrm{~cm})$, the number of food pellet displaced by each mouse was assessed every $15 \mathrm{~min}$ during $1 \mathrm{~h}$ and $45 \mathrm{~min}$.

\section{Resident-intruder test}

In the resident-intruder test, mice were individually placed in an observation cage $(30 \times 60 \times 30 \mathrm{~cm})$ for $30 \mathrm{~min}$. Then, each mouse was exposed to a previously group-housed naïve C57BL/6N male intruder of similar weight and age for $8 \mathrm{~min}$ in the same cage. The duration and the number of attack and tail rattling, and the duration of following behavior were scored as described elsewhere (Couch et al., 2016; Strekalova et al., 2018; Gorlova et al., 2020; Veniaminova et al., 2020).

\section{Dark/Light Box Test}

Mice were placed into the black compartment $(15 \times 20 \times 25 \mathrm{~cm})$ from where they could visit the lit box (30x20x25 cm, Open Science, Moscow, Russia). Time spent by mice in the lit part of the box, in which illumination intensity was 25 Lux on the surface of the apparatus, was scored during 5min period, as described elsewhere (Costa-Nunes et al., 2013; Strekalova et al., 2018).

\section{Object Recognition Memory test}

Mice were placed in a glass cylinder observation chamber $(\varnothing 25 \mathrm{~cm}$, height $35 \mathrm{~cm})$ that was situated on a stand of $1 \mathrm{~m}$ high placed by two walls of the lab room. The cylinder was $5 \mathrm{~cm}$ from the edge on two opposite sides and $30 \mathrm{~cm}$ from the edge on the other two sides. Using soundproof conditions with subtle illumination ( 5 Lux) animals were allowed to explore two identical objects (taste-free and smell-free plastic toys of $6 \mathrm{~cm} \times 3 \mathrm{~cm} \times 2.5 \mathrm{~cm}$ ) which were located in either part of the cylinder or 15 min. Previous experiments (Strekalova et al., 2013) have shown that object placed by the edge is explored by C57BI6 mice in average $50 \%$ less than the same object at the opposite location that is likely to be owing to their species-specific tegmotaxic traits and fear of height.

On the Day 1, animals were allowed to explore two objects placed either close to the walls "preferable" zone (the area in $30 \mathrm{~cm}$ from edge) or distanced from walls "non-preferable" zone (the area in $5 \mathrm{~cm}$ from edge) in the observation cylinder. On the Day 2, the test was repeated. The object from "non-preferred" zone was replaced with a new object of a similar size $(3 \mathrm{~cm} \times 6$ $\mathrm{cm} \times 3 \mathrm{~cm}$ ) and of exactly the same material. A placement of a new object to "non-preferred" area meant to contrast behavioral manifestation of novelty exploration under competing motivations of animals of staying by the walls and avoid the height. The duration of exploration 
of each object was recorded on each day. Preference for the object exploration was calculated as a percentage of the duration of exploration of a new object from the total duration of exploration of both objects on Day 2: Index of object preference (recognition) = [Object exploration /Total exploration of two objects] $\times 100 \%$. An increased preference in the exploration of a new object that has replaced the former one in the "non-preferred" area from day 1 to day 2, was taken as an index of recognition (memory) of the former object.

\section{Killing and Tissue Collection}

Mice were terminally anaesthetized with an intraperitoneal injection of sodium pentobarbitone. The left ventricle was perfused in situ with $10 \mathrm{~mL}$ ice-cold saline; the brain of each mouse was dissected and the prefrontal cortex and the hippocampi as described elsewhere (Trofimov et al., 2017; de Munter et al., 2020) and stored at $-80^{\circ} \mathrm{C}$ until use.

\section{$\underline{\text { Quantitative RT-PCR (qPCR) }}$}

RNA extraction was performed as previously described from specifically microdissected snapfrozen hippocampus and prefrontal cortex (Couch et al., 2013, 2016). mRNA was extracted by using TRI Reagent (Molecular Research Center, Inc., Cincinnati, OH, USA). First strand cDNA synthesis was performed using random primers and Superscript III transcriptase (Invitrogen, Darmstadt, Germany); $1 \mu \mathrm{g}$ total RNA was converted into cDNA. Standard curves were generated using total cDNA to enable normalization to three housekeeping genes glyceraldehyde-3phosphate (GAPDH), TATA-binding-protein (Tbp), and beta-Actin (ActB) that were selected from four candidates; beta2-microtubulin was excluded to its less stable expression using BioGazelle qBase+ v2.6 software (Biogazelle, Gent, Belgium) and GeNorm algorythm. qPCR was performed using the SYBR Green master mix (Bio-Rad Laboratories, Philadelphia, PA, USA) and the CFX96 Real-time System (Bio-Rad Laboratories, Philadelphia, PA, USA) for IL-1 $\beta$, TNF, COX-1, GSK-3 $\alpha$, GSK-3 $\beta$, as well as Mmp9 and Timp1.

Details of primers and cycling conditions can be found in Table 1 (AlcorBio, St.Petersburg, Russia). Data were calculated as relative-fold changes compared to control mice as described elsewhere (Couch et al., 2016, Trofimov et al., 2017). Results of qRT-PCR measurement were expressed as $C t$ values, where $\mathrm{Ct}$ is defined as the threshold cycle of PCR at which amplified product was $0.05 \%$ of normalized maximal signal. We used the comparative $\mathrm{Ct}$ method and computed the difference between the expression of the gene of interest and the geometric mean of the 3 housekeeping genes in each cDNA sample (2- $\Delta \Delta \mathrm{Ct}$ method). Data are given as expression-folds compared to the mean expression values in control mice. Results are expressed as relative-fold compared to control animals

The qRT-PCR was performed in a $12 \mu \mathrm{l}$ reaction volume containing a 10xPCR Buffer $(1.2 \mu \mathrm{l}), 25$ $\mathrm{mmol} \mathrm{MgCl} 2(2 \mu \mathrm{l}), 10 \mathrm{mmol}$ dNTPs $(1 \mu \mathrm{l})$, specific forward and reverse primers at $20 \mathrm{pmol} / \mu \mathrm{l}$ concentration $(0.5 \mu \mathrm{l}), 10 \mathrm{pmol} / \mu \mathrm{l}$ probe $(0.3$ ? $\mu \mathrm{l})$, cDNA $(1 \mu \mathrm{l}), 5 \mu / \mu \mathrm{l}$ Taq DNA polymerase $(0.5$ $\mu l)$ (Beagle, St. Petersburg, Russia), and ddH2O (5 $\mu \mathrm{l})$. All samples were run in triplicate. Cycling was performed at $95 \mathrm{C}^{\circ}$ for $5 \mathrm{~min}$ followed by a 50 -cycle amplification at $95^{\circ} \mathrm{C}$ for $5 \mathrm{~s}$, then at the annealing temperature $60^{\circ} \mathrm{C}$ defined previously for $10 \mathrm{~s}$ and at the temperature $72^{\circ} \mathrm{C}$ for $15 \mathrm{~s}$. 
Table 1

Sequences of primers used

\begin{tabular}{lll}
\hline Gene & Forward primer $5^{\prime}$-3 $^{\prime}$ & Reverse primer $5^{\prime}$ - $3^{\prime}$ \\
\hline GAPDH & TGCACCACCAACTGCTTAG & GGATGCAGGGATGATGTTC \\
B-actin & CTAAGGCCAACCGTGAAAAG & ACCAGAGGCATACAGGGACA \\
TNF & GCCTGTAGCCCACGTCGTA & GGCACCACTAGTTGGTTGTCTTTG \\
COX-1 & GCCTGAGCCCAGATATAGCA & TTTCCGGCTAGAGGTGGGTA \\
IL-1 $\beta$ & AACCTGCTGGTGTGTGACGTTTC & CAGCACGAGGCTTTTTTGTTGT \\
GSK-3 $\beta$ & TCCATTCCTTTGGAATCTGC & CAATTCAGCCAACACACAGC \\
GSK-3 $\alpha$ & AATCTTGGCCAGTCTGAGCT & TCAGTCCTGGTGAACTGTCC \\
Iba-1 & GGCAATGGAGATATCGATA & AGAATCATTCTCAAGATGGC \\
Mmp9 & CCTCTGCATGAAGACGACAT & GAGGTGCAGTGGGACACATA \\
Timp1 & CTGGCATAATCTGAGCCCTG & GCAAAGTGATCGCTCTGGTAG \\
Tbp & ACCTTCACCAATGACTCCTATG & ATGATGACTGCAATCGC \\
\hline
\end{tabular}

\section{Western Blot}

Tissue samples were treated with lysis buffer containing $20 \mathrm{mM}$ of Tris- $\mathrm{HCl}(\mathrm{pH} 7.5), 450 \mathrm{mM}$ of $\mathrm{NaCl}, 1 \%$-solution of Triton X-100, $1 \mathrm{mM}$ of EDTA, $1 \mathrm{mM}$ of NaF, $1 \mathrm{mM}$ of Na3VO4, and protease inhibitor (Roche Diagnostics, Indianapolis, IN, USA); $50 \mu \mathrm{l}$ of buffer per $1 \mathrm{~g}$ of tissue was used. Samples were then centrifuged at $16000 \mathrm{rpm}$ for $20 \mathrm{~min}$ at $4^{\circ} \mathrm{C}$; supernatant was collected and stored until use at $-20^{\circ} \mathrm{C}$. $25 \mu \mathrm{g}$ of protein from each sample was mixed with $35 \mu \mathrm{l}$ of Laemmli buffer. A sample of identical volume, comprising of $26 \mu \mathrm{l}$ of Laemmli buffer, $5 \mu$ l of Page Ruler, and $4 \mu$ of Magic Mark (Sigma, Munich, Germany) was used as a reference. For electrophoresis, samples were diluted in a solution containing MiliQ H2O, $1.5 \mathrm{M}$ of Tris Buffer (pH 8.8), 30\%solution of Acrylamide, $10 \%$-solution of SDS Temed, and 10\%-solution of ammonium persulfate (APS). For the next step, a solution containing MiliQ H2O, $0.5 \mathrm{M}$ of Tris Buffer (pH 8.8), 30\%solution of Acrylamide, $10 \%$-solution of SDS Temed, $10 \%$-solution of APS and gel (Sigma, Munich, Germany) was used. The percentage of gel-containing solution was adjusted to the weight of the protein of interest and was $20 \%$ for proteins of the size of $4-40 \mathrm{kDa}, 12.5 \%$ for proteins of the size of $40-70 \mathrm{kDa}, 10 \%$ for proteins of the size of $70-100$, and $7.5 \%$ for proteins over $100 \mathrm{kDa}$. A buffer containing $25 \mathrm{mM}$ of Tris Base buffer, $192 \mathrm{mM}$ of Glycine (Sigma, Mannheim, Germany), $10 \%$-solution of SDS and MiliQ H2O (pH 8.3) was used for gel electrophoresis which was carried out under the constant voltages of $80 \mathrm{~V}$ and $130 \mathrm{~V}$. Polyvinylidene difluoride (PVDF) membrane ( $9 \times 6 \mathrm{~cm}$, EMD Millipore, Billerica, MA, USA) was consequently incubated in a 99\%-methanol solution for $1 \mathrm{~min}$ (Brocacef, Amsterdam, the Netherlands), a MiliQ H2O for $5 \mathrm{~min}$, and a transfer buffer for $15 \mathrm{~min}$. The latter contained $25 \mathrm{mM}$ of Tris Base, $192 \mathrm{mM}$ of glycine, $20 \%$-solution of methanol, and MiliQ H2O (pH 8.3). For the next step, blot "transfer sandwich" was composed of buffer-soaked sponge, consisting of two buffer-soaked Whatman filter papers, gel, activated membrane, and ice-cold transfer buffer; a constant current of $300 \mathrm{~mA}$ was used for $2 \mathrm{~h} 30 \mathrm{~min}$. The membrane was treated with $5 \%$-dry milk solution of TBST, containing $50 \mathrm{mM} \mathrm{Tris-HCl}$ ( $\mathrm{pH}=8.2$ ), $150 \mathrm{mM} \mathrm{NaCl}, 0.05 \%$-solution Tween 20 (Sigma, Munich, Germany) for $1 \mathrm{~h}$ at the room 
temperature and subsequently incubated with primary antibodies (Table 2) at $4^{\circ} \mathrm{C}$ overnight, followed by incubation with respective horseradish peroxidase-conjugated secondary (HRP) antibodies (Sigma-Aldrich, St. Louis, MO, USA) for $2 \mathrm{~h}$ at the room temperature on a roller. The membrane was washed in TBST three times, 5 min each time, and then placed on the plastic cover. Then, Western BrightTM ECL kit (Advansta Inc, Menlo Park, CA, USA) was used. Relative optical density of immunoreactive protein bands was examined using ImageJ software (NIH, Bethesda, MD, USA). Results were normalized to the relative intensity of the $\beta$-tubulin band that was selected as a reference protein as described elsewhere (Gorlova et al., 2019).

\section{Table 2}

Primary antibodies used in the Western blot assays

\begin{tabular}{lc}
\hline Antibody & Dilution \\
\hline Anti- $\beta$-tubulin (Abcam, Cambridge, MA, USA) \#ab8227 & $1: 700$ \\
Anti-GSK-3 $\beta$ (Cell Signaling Technology, Beverly, MA, USA) \#9832 & $1: 800$ \\
Anti-GSK-3 $\alpha$ (Cell Signaling Technology, Beverly, MA, USA) \#4337 & $1: 900$ \\
Anti-IL-1 $\beta$ (Cell Signaling Technology, Beverly, MA, USA) \#12242 & $1: 700$ \\
Anti-Iba1 (Abcam, Cambridge, MA, USA) ab5076 & $1: 500$ \\
\hline
\end{tabular}

To normalize the data, the relative expression value of each protein of interest was expressed as a percent of the concentration of $\beta$-tubulin, which was used as the reference protein. The choice of a reference protein was based on the previous observations where its expression was found to vary moderately across various experimental conditions, as well as the linear representation of the intensity of its signal (Gorlova et al., 2019; Pavlov et al., 2019; de Munter et al., 2020).

\section{Determination of protein concentration}

Protein concentration was quantified using the BCA protein assay kit (Pierce, Rockford, IL, USA) as described elsewhere (Gorlova et al., 2019; Pavlov et al., 2019, de Munter et al., 2020). The working reagent was prepared in accordance with manufacturer instructions. $25 \mu \mathrm{l}$ of each standard or sample preparations were pipetted into a microplate well; $200 \mu$ l of the working reagent was added to each well and mixed thoroughly on a plate shaker for 30 seconds; assay was run in duplicates. The covered plate was incubated at $37^{\circ} \mathrm{C}$ for 30 minutes and cooled to room temperature for $10 \mathrm{~min}$. The absorbance was measured at $562 \mathrm{~nm}$ in a Biotek Microplate Reader (Biotek Instruments, Winooski, VT, USA). Ascent Software Program (Winooski, VT, USA) coupled to the microplate reader was used to calculate protein values based comparing optical densities with the standard curve. The standard curve was generated by plotting the average blank-corrected $562 \mathrm{~nm}$ measurements for each BSA standard vs. its concentration in $\mu \mathrm{g} / \mathrm{ml}$.

\section{Administration of drugs}

In the study with FUS-tg mice, potential effects of Neuro-Cells were compared to effects of celecoxib, NSAID and a COX-2 inhibitor, that was used as a classic anti-inflammatory compound 
(Goldenberg et al., 1999; Pompl et al., 2003), and of riluzole (2-amino-6-trifluoromethoxybenzothiazole), a standard ALS treatment that can slow down the fatal disease progress by $2-3$ months (Miller et al., 2012) and frequently serves as a reference drug in translational studies with ALS (Li et al., 2013; Rodríguez-Cueto et al., 2018). Riluzole tablets (Sandoz, Almere, Netherlands) were crushed and dissolved in tap water, its concentration was adjusted to the dosage of $8 \mathrm{mg} / \mathrm{kg} /$ day and daily water intake in CD1 mice (Li et al., 2013; de Munter et al., 2020). Celecoxib-containing food pellets were produced as described elsewhere (Costa-Nunes et al., 2013; Munter et al., 2020), drug concentration was adjusted to the dosage of $30 \mathrm{mg} / \mathrm{kg} / \mathrm{day}$ and daily diet consumption. Intake of solutions and food pellets was measured during the first three days of dosing and then weekly as described elsewhere (de Munter et al., 2020).

\section{Characteristics of human marrow stem cells}

"Neuro-Cells" is a standardized preparation of fresh, unmanipulated human bone marrowderived stem cells, which was produced under regulations of good manufacturing practices (GMPs) without expansion and/or labeling (de Munter et al., 2019; patent WO2015/059300A1) and provided by Neuroplast BV (Maastricht, Netherlands). Neuro-Cells comprise mesenchymal stem cells and their progenitors (MSCs), hematopoietic stem cells and their progenitors (HSCs), and other mononuclear cells (Table 3 ). The Neuro-Cells preparation comprised $1.39 \times 10^{6} \mathrm{MSCs}$ and HSCs, containing $5 \times 10^{5} \mathrm{CD} 34^{+}$cells in $10 \mathrm{ul}$. The expression profile of MSC markers is overlapping; in the total cell preparation used in this study, $85.6 \%$ were $\mathrm{CD}^{2} 105^{+}, 13 \%$ were $\mathrm{CD} 90^{+}$, $7 \%$ were $\mathrm{CD} 271^{+}$, and $4 \%$ were $\mathrm{CD}_{3}{ }^{+}$in single FACs staining.

\section{Table 3}

Characterization of cell populations in "Neuro-Cells" preparation

\begin{tabular}{ll}
\hline Cell populations in Neuro-Cells & $\begin{array}{l}\text { Absolute number of cells injected } \\
\text { per mouse in } 10 \mu \mathrm{l}\end{array}$ \\
\hline Total number of nucleated cells & $1.39 \times 10^{6} / 10 \mu \mathrm{l}$ \\
CD34+ cells & $5.00 \times 10^{5} / 10 \mu \mathrm{l}$ \\
Other mononucleated cells & $8.9 \times 10^{5} / 10 \mu \mathrm{l}$ \\
\hline
\end{tabular}

The proportion of MSCs expressing CD markers in overlapping manner (in total cell preparation, defined by single staining assay):

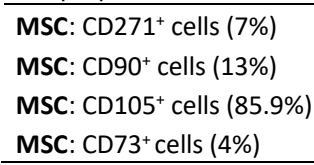

\section{Generation of human marrow stem cells}

For production of Neuro-Cells, healthy volunteer donors with informed consent were recruited for collection of 50-75 mL of bone marrow from their iliac crest under local anesthesia following standard operating procedures. Briefly, mononuclear cells were isolated by Ficoll density gradient centrifugation ( $1.077 \mathrm{~g} / \mathrm{ml}$; Sigma, Munich, Germany) at $400 \times \mathrm{g}$ for 35 minutes. The mononuclear cells were re-suspended in the culture medium composed of DMEM (GIBCO, Rockville, MD, USA) with low glucose concentration and $10 \%$ fetal bovine serum (FBS; Hyclone, 
Logan, UT, USA). The mononuclear cells were plated at $1 \times 10^{6}$ cells $/ 25 \mathrm{~cm}^{2}$ in culture flasks and the cultures were incubated at $37^{\circ} \mathrm{C}$ in $5 \% \mathrm{CO}_{2}$ in the air and $95 \%$ humidity. The medium was exchanged after 48 hours and then every 3 to 4 days. When the cultures reached approximately $90 \%$ of confluence, human marrow stem cells ("Neuro-Cells") were passaged with $0.25 \%$ trypsin (GIBCO) and re-plated into passage culture at a density of 5000 to 10,000 cells $/ \mathrm{cm}^{2}$. Cells at passages 3 and 4 were used for transplantation. Upon harvest, the cells were isolated by treatment with $0.25 \%$ trypsin. The cells were then washed four times and re-suspended in PBS at a density of 100,000 cells/ $\mu$ l. Viability of the cells was assessed using a $0.4 \%$ Trypan Blue dye (Sigma, Berlin, Germany) exclusion method prior to and following transplantation. The cells were analyzed for their immunophenotype by flow cytometry (Beckman Coulter, Fullerton, CA, USA). Fluorescein isothiocyanate (FITC)-conjugated or phycoerythrin-conjugated antibodies specific for human CD14, CD19, CD45, CD34, CD73, CD90, CD105, and HLA-DR tested for flow cytometry application. The percentage of positive cells was determined based on fluorescence emission of the nonspecific FITC/phycoerythrin isotypic antibody controls. A preparation of Neuro-Cells was aliquoted, deeply frozen and stored at $-80 \mathrm{C}^{\circ}$ until the use.

\section{Table 4}

Standard thawing procedure for Neuro-Cells

\begin{tabular}{|c|c|c|}
\hline \multicolumn{3}{|c|}{ Step 1} \\
\hline 1 & & $\begin{array}{l}50 \mathrm{ml} \text { sterile Ringer Lactate solution is used } \\
\text { pre-warm at } 37^{\circ} \mathrm{C} \text { water bath }\end{array}$ \\
\hline \multicolumn{3}{|r|}{ 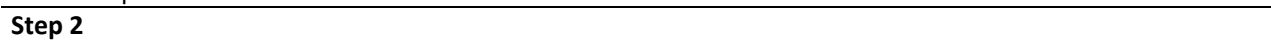 } \\
\hline 1 & & $\begin{array}{l}\text { To thaw frozen Neuro-Cells, cryovials are placed in a water bath at } 37^{\circ} \mathrm{C} \text { until only a small sliver of ice } \\
\text { is present; caution is paid to prevent cryovial cap from submerging in the water. }\end{array}$ \\
\hline \multirow[t]{7}{*}{2} & A & $\begin{array}{l}\text { - Cryovials are transferred to the laminar flow hood } \\
\text { - all vials are wiped with 70\% IPA before opening the cap using a 70\% IPA soaked tissue }\end{array}$ \\
\hline & $B$ & $\begin{array}{l}\text { each thawed cell type is transferred into an individual } 15 \mathrm{ml} \text { tube containing } 5 \mathrm{ml} \text { pre-warmed thawing } \\
\text { buffer }\end{array}$ \\
\hline & $\mathrm{C}$ & $\begin{array}{l}\text { - cryovials are rinsed twice with fresh pre-warmed thawing buffer } \\
\text { - pooled cells are mixed by gently pipetting up/down twice }\end{array}$ \\
\hline & $\mathrm{D}$ & Suspension is centrifuged under $300 \mathrm{~g}$ for $5 \mathrm{~min}$ \\
\hline & $\bar{E}$ & $\begin{array}{l}\text { - supernatant is completely aspirated } \\
\text { - the cell pellet are handled carefully } \\
\text { - pellet is resuspended into the thawing buffer for washing }\end{array}$ \\
\hline & $\mathrm{F}$ & For washing, pellet is centrifuged under $300 \mathrm{~g}$ for $5 \mathrm{~min}$ \\
\hline & $\bar{G}$ & $\begin{array}{l}\text { supernatant is completely aspirated } \\
\text { - pellet is resuspended into the thawing buffer for washing } \\
\text { - cells are pooled where applicable }\end{array}$ \\
\hline
\end{tabular}

Intracerebroventricular infusion of Neuro-Cells

After thawing according to a standard procedure (see Table 4), cells were re-suspended in Ringer Lactate buffer and studied for vitality. A counting was performed using the "Countess II FL Automated Cell Counter" (Thermo Fisher Scientific AMQAF1000, Toronto, ON, Canada) according to the manufacturer's protocol. Three batches of Neuro-Cells from the same bone marrow extraction were used in the study. The viability measurement of Neuro-Cells samples 
used in the experiment has ensured high vitality percentages in samples, that were ranging from 62 to $68 \%$. Subsequent flow cytometry was done and HSC numbers were adjusted in injection suspension prior the infusion of Neuro-Cells to a mouse brain. Therefore, their concentration in buffer was adjusted to $500,000{\mathrm{CD} 34^{+}}^{+}$in $10 \mu$ for i.c.v. injections; vials were kept in $+4 \mathrm{C}^{\circ}$. Separate preliminary studies were carried out to determine the distribution of infused NeuroCells and optimize the protocols for the i.c.v. administration (de Munter et al., 2020). These studies have suggested the presence of Neuro-Cells in the brain and peripheral organs 12 and 24 h after injection of 100, 000 or 250, 000 cells were infused to lateral ventricles. A positive signal in the ventricles, brain tissue, lungs, and spleen was found in Neuro-Cell-treated mice using immunohistochemical assay with human anti-mitochondrial antibodies that was carried out as described elsewhere (Donders et al., 2015). These results suggested a wide distribution of NeuroCells in the cerebrospinal fluid and their persistent vitality and were consistent with the results of the pilot study with i.c.v. infusion of bone marrow-derived mouse stem cells obtained from mutants expressing Green Fluorescent Protein (GFP) (de Munter et al., 2020). These experiments also showed that i.c.v. administration of Neuro-Cells to mice at the concentrations 100,000 500,000 is well tolerated. Animals were anesthetized by halothane (Halothane TM; Willy Rusch, Boblingen, Germany) and immobilized in a stereotaxic frame (World Precision Instruments, Sarasota, TX, USA) for unilateral i.c.v. infusion via a hole made in a scull of mice as described elsewhere (Strekalova et al., 2001, 2002). Specifically, after incision of the skin, the periost of the skull was removed and the hole was drilled above the left lateral ventricle of the brain (0.5 $\mathrm{mm}$ posterior and $1.0 \mathrm{~mm}$ lateral from the midline; coordinates according to Franklin \& Paxinos, 1997). For injection of Neuro-Cells and vehicle, Hamilton syringe (inner diameter: $230.3 \mu \mathrm{m}$ ) was carefully lowered into the hole $1.7 \mathrm{~mm}$ below the surface of the skull. Following conditions of Neuro-Cell administration were employed: 10 ul of Neuro-cells suspension (500, 000 cells) in sterile Ringer lactate buffer or buffer alone were infused unilaterally in $10 \mathrm{~min}$. At the end of the injection, the holes were sealed with bone wax and the skin was closed with tissue glue (Histoacryl, B. Braun Surgical, Melsungen, Germany). After surgery, mice were maintained in a warm environment for 3 to $4 \mathrm{~h}$ before transferring them back to the animal room.

\section{SUPPLEMENTARY FIGURES AND TABLES WITH STATISTICAL RESULTS}

\section{Nissle staining of brains of FUS-tg and wild type control mice}

Nissl staining was performed as described elsewhere (Shelkovnikova et al., 2013). All steps were essentially performed as described previously, five FUS[1-359]-tg 8-weeks-old animals per group were used, paraffin brain blocks were obtained as described elsewhere (Shelkovnikova et al., 2014, 2019). To produce paraffin blocks of dissected brains, PFA-fixed hemispheres were incubated 2 times for $1 \mathrm{~h}$ with 70\%-ethanol solution, for $1.5 \mathrm{~h}$ with $80 \%$-ethanol solution, for $1 \mathrm{~h}$ with 95\%-ethanol solution, 3 times for $1.5 \mathrm{~h}$, in $100 \%$-ethanol solution, 3 times for 1.5 hour in xylene, for $2 \mathrm{~h}$, in paraffin first wax paraplast Xtra (at $58^{\circ} \mathrm{C}$ ), for $2 \mathrm{~h}$ paraffin second wax paraplast Xtra (at $58^{\circ} \mathrm{C}$ ) in cassettes (Sigma-Aldrich, St. Louis, MO, USA). Initially, a small amount of molten paraffin was dispensed in mold from paraffin reservoir. Tissue was transferred into the mold using warm forceps. Subsequently, the mold was placed on a cold plate for paraffin to solidify into a thin layer. Hot paraffin was added to the mold from the paraffin dispenser to cover the front surface of the plastic cassette. Then paraffin blocks were stored until use at the room 
temperature. To remove paraffin, sections were incubated 3 times for 5 min with xylene, 2 times for 10 min with 100\%-ethanol solution, 2 times for $10 \mathrm{~min}$ with 95\%-ethanol solution, 2 times for 10 min with $70 \%$-ethanol solution, 2 min for 10 min with $50 \%$-ethanol solution (Sigma-Aldrich, St. Louis, MO, USA) and 2 times for $5 \mathrm{~min}$ in ice-cold deionized water. 20- $\mu \mathrm{m}$-thick hemisphere sections from paraffin brain blocks were obtained from lateral 3.6 to lateral $0.4 \mathrm{~mm}$ along the medial-lateral axis ahead of bregma (Paxinos and Franklin, 2001) using a Leica CM 1850 cryostat (Leica Microsystems, Wetzlar, Germany) and mounted on gelatin-covered glass with coverslips. For Nissle assay, brain sections were randomly selected, dewaxed with xylene (Sigma-Aldrich, St. Louis, MO, USA), treated with 95\%-ethanol solution (Sigma-Aldrich, St. Louis, MO, USA), stained with $0.1 \%$ cresyl violet for $15 \mathrm{~min}$ (Sigma-Aldrich, St. Louis, MO, USA) and washed with distilled water. Images were acquired on a Leica SP8 microscope (Leica Microsystems, Mannheim, Germany).

A

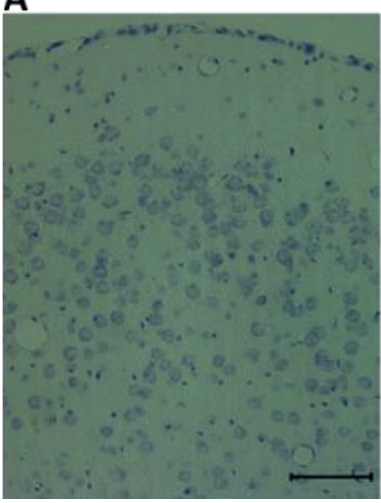

B

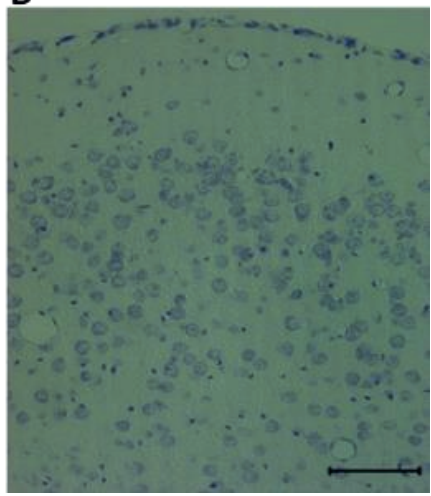

Supplementary Figure 2. Nissle staining of frontal lobes of (A) the WT mouse and (B) FUS[1-359]-tg mouse at age of 8 weeks. No signs of neurodegeneration in FUS[1-359]-tg can be observed; magnification x 200, scale $100 \mathrm{mkm} . \mathrm{gg}$

\section{General locomotor activity in the elevated O-maze}

We scored total numbers of crossed sections $(4 \times 5.5 \mathrm{~cm})$ in both arms of the elevated O-maze during $5 \mathrm{~min}$ to estimate possible changes in locomotion between two genotypes. No significant differences were found ( $d f=18, p=0.6091$; two-tailed t-test; Suppl. Fig.3).

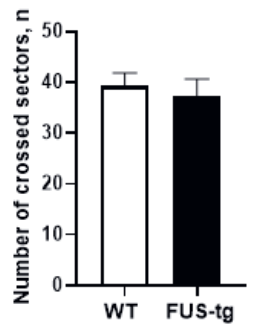

Supplementary Figure 3. A lack of genotype differences in locomotor activity in the O-maze test. There were no significant differences between groups in the number of crossed sections in 0 -maze ( $p>0.05$, $t$-test), ten animals per group were used. WT-wild type mice, FUS-tg - FUS[1-359] mice. Bars are Mean \pm SEM. 
These data show that FUS-tg and wild type control mice had similar response to the testing procedure in the $\mathrm{O}$-maze in terms of locomotion. This lack of changes in general locomotion rules out a possibility of confounds in behavioral analysis of mice in this test.

Western blot study of protein expression of molecular markers of inflammation and GSK-3 FUStg mice treated with old and new anti-inflammatory therapies

Western blot assay was carried out to investigate the expression of molecular markers of inflammation and GSK-3 in the hippocampus and prefrontal cortex of FUS-tg mice that received celecoxib or Neuro-Cells. To normalize the data, the relative expression value of each protein of interest was expressed as a percent of the concentration of $\beta$-tubulin (see above) as described elsewhere (de Munter et al., 2020).

\section{A Hippocampus}
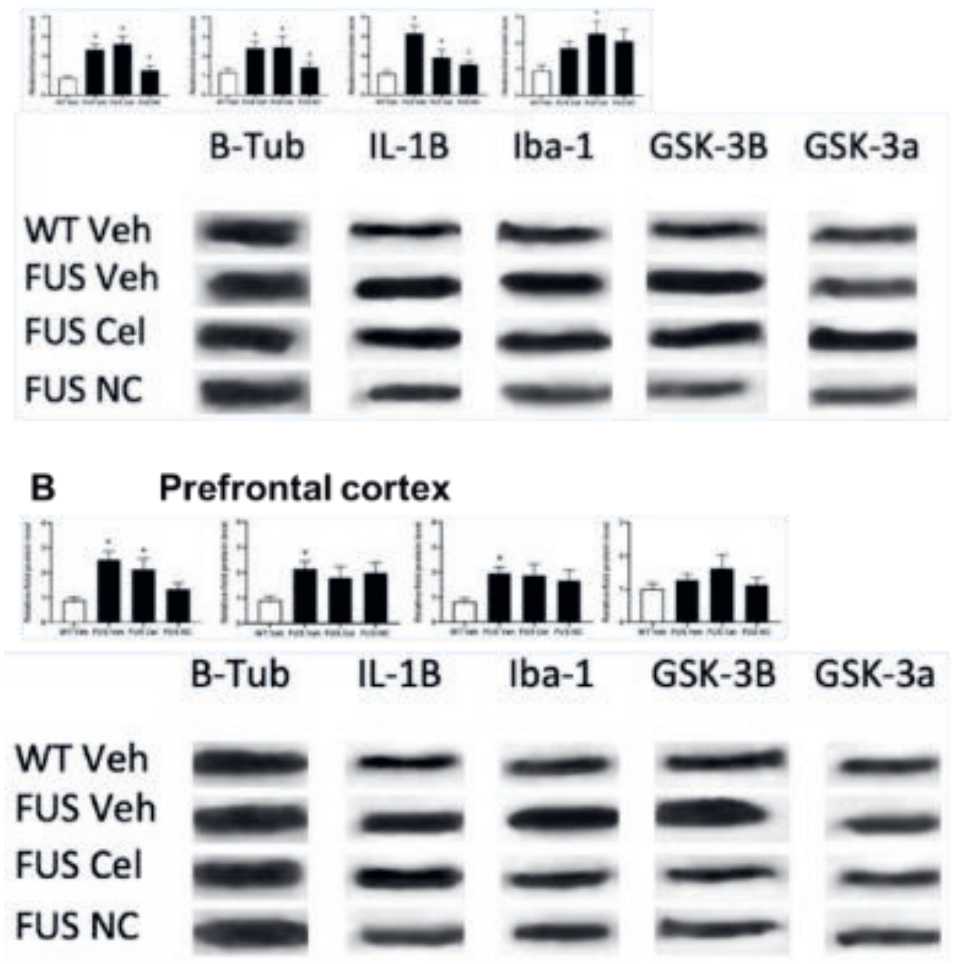

Supplementary Figure 4. Effects of standard ALS treatments and Neuro-Cells on behavioural and brain molecular changes in FUS-tg mice. (A) Following examination of Western Blot bands in the hippocampus, we found significantly elevated protein levels of IL-16, Iba-1 and GSK-3B in FUS Veh and FUS Cel animals in comparison with WT Veh mice $(p<0.05)$ that was not found in FUS-tg-NC group ( $p>0.05)$. FUStg-NC mice had significantly lower expression of these proteins in comparison with other groups of mutants $(p<0.05)$. FUS Cel mice showed significantly higher protein concentration of GSK-3 $\alpha$ than mice $(p<0.05)$. (B) The analysis of Western Blot bands in the prefrontal cortex has revealed a significant increase of protein levels of IL-16 in GSK-36 in FUS Veh and FUS Cel mice and significant increase of protein concentrations of Iba-1 and GSK-3B in FUS Veh animals in comparison with the WT Veh group ( $p<0.05)$. No other group differences were found ( $p>0.05)$. B-tubulin was used as a loading control in the Western blot assay, the expression of all proteins is normalized to B-tubulin expression $\left({ }^{*} p<0.05\right.$, vs. WT Veh group, \#p<0.05, vs. FUS Veh group: one-way ANOVA and Tukey's test), see the main ms text; bars are Mean \pm SEM. 
The choice of a reference protein was based on the previous observations where its expression was found to vary moderately across various experimental conditions, as well as the linear representation of the intensity of its signal (Gorlova et al., 2019; Pavlov et al., 2019; de Munter et al., 2020).

Table 5

Summary of statistics

5A. Summary of comparisons between the FUS-tg and WT groups (unpaired t-test)

\begin{tabular}{|c|c|c|c|c|}
\hline $\begin{array}{l}\text { Elevated O-maze: } \\
\text { time spent in } \\
\text { open arms }\end{array}$ & $\begin{array}{l}\text { Sucrose test: } \\
\text { sucrose } \\
\text { preference }\end{array}$ & $\begin{array}{l}\text { Tail suspension } \\
\text { test: Duration } \\
\text { of immobility }\end{array}$ & $\begin{array}{l}\text { Resident-Intruder test: } \\
\text { Duration of attacks }\end{array}$ & $\begin{array}{l}\text { Resident-Intruder } \\
\text { test: Duration of tail } \\
\text { rattling }\end{array}$ \\
\hline $\begin{array}{l}t=2.09, d f=23 \\
p=0.048 \downarrow\end{array}$ & $\begin{array}{l}t=3.55, d f=19, \\
p=0.002 \downarrow\end{array}$ & $\begin{array}{l}\mathrm{t}=2.15, \mathrm{df}=14, \\
\mathrm{p}=0.049 \downarrow\end{array}$ & $\begin{array}{l}\mathrm{t}=3.18, \mathrm{df}=17 \\
\mathrm{p}=0.005 \uparrow\end{array}$ & $\begin{array}{l}t=1.49, d f=17 \\
p=0.153\end{array}$ \\
\hline
\end{tabular}

5B. Repeated comparisons rearings novel cage test Fus-tg \& WT(2way ANOVA, unpaired t-test)

\begin{tabular}{lllll}
\hline $\operatorname{Min} 1$ & $\operatorname{Min} 2$ & $\operatorname{Min} 3$ & $\operatorname{Min} 4$ & $\operatorname{Min} 5$ \\
\hline $\mathrm{t}=0.48, \mathrm{df}=50$, & $\mathrm{t}=1.38, \mathrm{df}=50$, & $\mathrm{t}=2.48, \mathrm{df}=50$, & $\mathrm{t}=2.96, \mathrm{df}=50$, & $\mathrm{t}=2.41, \mathrm{df}=50$, \\
$\mathrm{p}=0.993$ & $\mathrm{p}=0.618$ & $\mathrm{p}=0.081$ & $\mathrm{p}=\mathbf{0 . 0 2 3} \mathrm{p}$ & $\mathrm{p}=0.095$ \\
\hline
\end{tabular}

5C. Summary comparisons WT vs FUS-tg in displaced food pellets marble test (unpaired t-test)

\begin{tabular}{lllllll}
\hline Min 15 & Min 30 & Min 45 & Min 60 & Min 75 & Min 90 & Min 105 \\
\hline$t=1.57$, & $t=3.42$, & $t=3.57$, & $t=4.54$, & $t=4.75$, & $t=4,49$, & $t=4.16$, \\
$d f=63$, & $d f=63$, & $d f=63$, & $d f=63$, & $d f=63$, & $d f=63$, & $d f=63$, \\
$p=0.593$ & $p=0.008 \downarrow$ & $p=0.005 \downarrow$ & $p=0.0002 \downarrow$ & $p<0.0001 \downarrow$ & $p<0.0002 \downarrow$ & $p=0.0007 \downarrow$ \\
\hline
\end{tabular}

Table 5A: Summary of comparisons between the FUS-tg and WT groups in the measures of emotionality and social behaviour (two-tailed unpaired t-test). Fig. 1A-E. Welsh' correction was used in the analysis of tail suspension test; significant group differences are in bold; $\uparrow$ an increase; $\downarrow$ a decrease of a parameter vs WT group; bold is significant.

Table 5b: Summary of comparisons in the number of exploratory rearings in the novel cage test between the FUS-tg and the WT groups. Two-way ANOVA for repeated measures revealed significant time $x$ genotype interaction $(F=2.62, p<.05)$ and genotype effect $(F=7.17, p<.05)$. Fig 1F. FUS-tg mice showed an increase of this measure on the $4^{\text {th }}$ min in comparison with WT mice (Sidak post-hoc test); $\uparrow$ an increase; $\downarrow$ a decrease of a parameter vs WT group; bold is significant.

Table 5C: Summary of comparisons in numbers of displaced food pellets in the marble test between the FUS-tg and WT groups. There were significant time and genotype effects, as well as significant time $x$ genotype interaction the in number of pellets displaced during the marble test $(F=18.8, p<.05 ; F=21.2, p<.05$ and $F=3.18, p<.05$, respectively, two-way ANOVA for repeated measures). Fig.1G. WT mice had higher than FUS-tg mice number of displaced pellets at nearly all time points of the test (Sidak post-hoc test). $\uparrow$ an increase; $\downarrow$ a decrease of a parameter vs WT group; bold is significant. 
Table 6

Comparisons of the FUS-tg and WT brain mRNA (unpaired t-test)

\begin{tabular}{|c|c|c|}
\hline \multirow{2}{*}{$\begin{array}{l}\text { Molecular } \\
\text { factors }\end{array}$} & \multicolumn{2}{|c|}{ Brain structure } \\
\hline & Hippocampus & Prefrontal cortex \\
\hline TNF & $\mathrm{t}=2.42, \mathrm{df}=26, \mathrm{p}=0.023 \uparrow$ & $t=1.43, d f=26, p=0.166$ \\
\hline IL-1 $\beta$ & $t=0.54, d f=28, p=0.593$ & $t=0.36, d f=23, p=0.718$ \\
\hline COX-1 & $t=3.66, d f=27, p=0.001 \uparrow$ & $\mathrm{t}=1.82, \mathrm{df}=27, \mathrm{p}=0.079$ \\
\hline TIMP1 & $t=0.98, d f=8, p=0.355$ & $t=1.16, d f=16, p=0.264$ \\
\hline Mmp9 & $t=0.34, d f=8, p=0.746$ & $t=0.53, d f=17, p=0.600$ \\
\hline TIMP1/Mmp9 & $t=0.35, d f=8, p=0.736$ & $\mathrm{t}=2.30, \mathrm{df}=17, \mathrm{p}=0.034 \uparrow$ \\
\hline
\end{tabular}

Table 6: Summary of the FUS-tg and WT group comparisons in brain mRNA concentration of molecular factors involved in inflammation, degeneration and plasticity (Fig. $\mathbf{1 H}-\mathbf{N}$ ). There were significant group differences in the expression of target molecules in the hippocampus and the prefrontal cortex (unpaired two-tail t-test); $\uparrow$ an increase; $\downarrow$ a decrease of a parameter vs WT group; bold is significant.

Table 7: Summary of comparisons between the FUS-tg treated with vehicle, celecoxib, riluzole or Neuro-Cells in the measures of emotionality and social behaviour (Fig 2 A-F, two-way ANOVA and Tukey test; data for WT group comparisons are not shown). In the dark/light box, there was no significant genotype $x$ treatment interaction in the time spent in the lit box $(F(3,55)=1.96$, $p=0.130)$. ANOVA revealed significant genotype effect for this measure $(F(1,55)=18.84$, $\mathrm{P}<0.0001)$, indicating increased anxiety-like behavior in the FUS-tg. There was no significant treatment effect on time spent in the lit box $(F(3,55)=0.35, p=0.79)$. In the tail suspension test, a two-way ANOVA did not show a significant genotype $x$ treatment interaction in the duration of immobility $(F(3,62)=2.09, p=0.11)$. There was a significant genotype effect for this parameter $(F(1,62)=13.29, p=0.0005)$, indicating increased despair behavior in the FUS-tg group. There was a significant treatment effect on the duration of immobility $(F(3,62)=4.02, p=0.011)$. In the social interaction test, significant genotype $x$ treatment interaction was revealed by a two-way ANOVA in the duration of 'following' behavior $(F(3,60)=9.70, p<0.0001)$, but not in the number of attacks $(F(3,53)=0.43, p=0.73)$ and number of tail rattling events $(F(3,53)=1.004, p=0.400)$. ANOVA analysis showed significant genotype effects for the number of attacks $(F(1,53)=8.28, p=0.006)$ and duration of following $(F(1,60)=39.45, p<0.0001)$ and significant treatment effects on duration of following $(F(3,60)=8.76, p<0.0001)$. Tukey analysis revealed significant group differences (in bold); $\uparrow$ an increase; $\downarrow$ a decrease of a parameter between groups. 


\section{Table 7}

Summary of statistics FUS-tg mice treated (two-way ANOVA and Tukey-test)

\begin{tabular}{lllllll}
\hline Groups & $\begin{array}{l}\text { Dark/light } \\
\text { box: time } \\
\text { spent in lit } \\
\text { box }\end{array}$ & $\begin{array}{l}\text { Tail } \\
\text { suspension: } \\
\text { Duration of } \\
\text { immobility }\end{array}$ & $\begin{array}{l}\text { Object } \\
\text { recognition: } \\
\text { Preference } \\
\text { new object }\end{array}$ & $\begin{array}{l}\text { Resident } \\
\text { Intruder: } \\
\text { number of } \\
\text { attacks }\end{array}$ & $\begin{array}{l}\text { Resident } \\
\text { Intruder: } \\
\text { number of } \\
\text { tail rattling }\end{array}$ & $\begin{array}{l}\text { Resident } \\
\text { Intruder: } \\
\text { Duration of } \\
\text { following }\end{array}$ \\
\hline $\begin{array}{l}\text { WT-Veh vs } \\
\text { FUS-tg-Veh }\end{array}$ & $\mathbf{p}=\mathbf{0 . 0 3 6 \uparrow}$ & $\mathbf{p}=\mathbf{0 . 0 0 5 \downarrow}$ & $\mathbf{p}<0.01 \uparrow$ & $\mathrm{p}=0.361$ & $\mathrm{p}=0.880$ & $\mathrm{p}<0.0001 \downarrow$ \\
\hline $\begin{array}{l}\text { WT-Ril vs } \\
\text { FUS-tg-Ril }\end{array}$ & $\mathbf{p}=\mathbf{0 . 0 1 7 \uparrow}$ & $\mathrm{p}=0.864$ & $\mathbf{p}<0.01 \uparrow$ & $\mathrm{p}=0.997$ & $\mathrm{p}=0.993$ & $\mathrm{p}=0.058$ \\
\hline $\begin{array}{l}\text { WT-Cel vs } \\
\text { FUS-tg-Cel }\end{array}$ & $\mathrm{p}=0.998$ & $\mathrm{p}=0.575$ & $\mathrm{p}=0.270$ & $\mathrm{p}=0.524$ & $\mathrm{p}=0.999$ & $\mathrm{p}<0.002 \downarrow$ \\
\hline $\begin{array}{l}\text { WT-NC vs } \\
\text { FUS-tg-NC }\end{array}$ & $\mathrm{p}=0.893$ & $\mathrm{p}>0.999$ & $\mathrm{p}>0.999$ & $\mathrm{p}=0.966$ & $\mathrm{p}=0.995$ & $\mathrm{p}=0.958$ \\
\hline $\begin{array}{l}\text { FUS-tg-Veh } \\
\text { vs FUS-tg-Ril }\end{array}$ & $\mathrm{p}>0.999$ & $\mathrm{p}=0.059$ & $\mathrm{p}>0.999$ & $\mathrm{p}=0.992$ & $\mathrm{p}=0.700$ & $\mathrm{p}=0.124$ \\
\hline $\begin{array}{l}\text { FUS-tg-Veh } \\
\text { vs FUS-tg-Cel }\end{array}$ & $\mathrm{p}=0.941$ & $\mathrm{p}=0.428$ & $\mathrm{p}=0.980$ & $\mathrm{p}>0.999$ & $\mathrm{p}=0.894$ & $\mathrm{p}=0.720$ \\
\hline $\begin{array}{l}\text { Fus-tg-Veh vs } \\
\text { Fus-tg-NC }\end{array}$ & $\mathrm{p}=0.936$ & $\mathrm{p}=\mathbf{0 . 0 0 8 \uparrow}$ & $\mathrm{p}=0.160$ & $\mathrm{p}=0.869$ & $\mathrm{p}=0.670$ & $\mathrm{p}<0.0001 \uparrow$ \\
\hline
\end{tabular}

\section{Table 8A}

Summary of statistics FUS-tg mice treated (one-way ANOVA/Tukey-test) Hippocampus

\begin{tabular}{lllll}
\hline Groups & $\mathrm{IL}-1 \beta$ & $\mathrm{Iba}-1$ & $\mathrm{GSK}-3 \beta$ & GSK-3 $\alpha$ \\
\hline WT-Veh vs FUS-tg-Veh & $\mathrm{p}=\mathbf{0 . 0 0 0 1 \downarrow}$ & $\mathrm{p}=\mathbf{0 . 0 2 0 9 \downarrow}$ & $\mathrm{p}=\mathbf{0 . 0 0 0 1 \downarrow}$ & $\mathrm{p}=0.2003$ \\
WT-Veh vs FUS-tg-Cel & $\mathrm{p}=\mathbf{0 . 0 0 0 3} \downarrow$ & $\mathrm{p}=0.077$ & $\mathrm{p}=0.372$ & $\mathrm{p}=\mathbf{0 . 0 3 6 6} \downarrow$ \\
WT-Veh vs FUS-tg-NC & $\mathrm{p}=0.646$ & $\mathrm{p}=0.950$ & $\mathrm{p}=0.748$ & $\mathrm{p}=0.071$ \\
FUS-tg-Veh vs FUS-tg-Cel & $\mathrm{p}=0.889$ & $\mathrm{p}=0.999$ & $\mathrm{p}=0.108$ & $\mathrm{p}=0.670$ \\
Fus-tg-Veh vs Fus-tg-NC & $\mathrm{p}=\mathbf{0 . 0 1 4} \uparrow$ & $\mathrm{p}=0.148$ & $\mathrm{p}=\mathbf{0 . 0 0 9 \uparrow}$ & $\mathrm{p}=0.915$ \\
\hline
\end{tabular}

Table 8A: Summary of group comparisons of brain concentrations of protein factors of inflammation and degeneration in the hippocampus of the WT-Veh group and FUS-tg mice treated with vehicle, celecoxib or Neuro-Cells (Fig.2 G-J). There were significant group differences in protein concentrations of IL-1 $\beta$, Iba-1 GSK-3 $\beta$ and GSK-3 $\alpha \quad(F(3,30)=12.37$, $p<0.0001 ; F(3,30)=4.38, p=0.011 ; F(3,30)=9.15, p=0.0002 ; F(3,28)=3.76, p=0.022 ;$ one-way ANOVA, respectively). Tukey analysis revealed significant group differences in target molecules (in bold); $\uparrow$ an increase; $\downarrow$ a decrease of a parameter between groups.

\section{Table 8B}

Summary of statistics FUS-tg mice treated (one-way ANOVA/Tukey-test) Prefrontal cortex

\begin{tabular}{lllll}
\hline Groups & $\mathrm{IL}-1 \beta$ & $\mathrm{Iba}-1$ & GSK-3 $\beta$ & GSK-3 $\alpha$ \\
\hline WT-Veh vs FUS-tg-Veh & $\mathbf{p}=\mathbf{0 . 0 0 0 5} \downarrow$ & $\mathbf{p}=\mathbf{0 . 0 1 7} \downarrow$ & $\mathrm{p}=\mathbf{0 . 0 1 7} \downarrow$ & $\mathrm{p}=0.799$ \\
WT-Veh vs FUS-tg-Cel & $\mathbf{p}=\mathbf{0 . 0 4 8} \downarrow$ & $\mathrm{p}=0.230$ & $\mathrm{p}=0.113$ & $\mathrm{p}=0.319$ \\
WT-Veh vs FUS-tg-NC & $\mathrm{p}=0.697$ & $\mathrm{p}=0.092$ & $\mathrm{p}=0.164$ & $\mathrm{p}=0.990$ \\
FUS-tg-Veh vs FUS-tg-Cel & $\mathrm{p}=0.823$ & $\mathrm{p}=0.897$ & $\mathrm{p}=0.998$ & $\mathrm{p}=0.736$ \\
Fus-tg-Veh vs Fus-tg-NC & $\mathbf{p}=\mathbf{0 . 0 3 1 \uparrow}$ & $\mathrm{p}=0.984$ & $\mathrm{p}=0.905$ & $\mathrm{p}=0.960$ \\
\hline
\end{tabular}


Table 8B: Summary of group comparisons of brain concentrations of protein factors of inflammation and degeneration in the prefrontal cortex of the WT-Veh group and FUS-tg animals treated with vehicle, celecoxib or Neuro-Cells (Fig.2K-N). Significant group differences were found for protein levels of IL-1 $\beta$, Iba-1 and GSK-3 $\beta(F(3,30)=7.79, p=0.0005 ; F(3,30)=3.84$, $p=0.019$ and $F(3,30)=3.966, p=0.017$; one-way ANOVA, respectively) but not GSK-3 $\alpha$ $(F(3,30)=1.10, p=0.366$, one-way ANOVA). Tukey analysis revealed significant group differences in target molecules (in bold); $\uparrow$ an increase; $\downarrow$ a decrease of a parameter between groups; ns: not significant. 


\section{Chapter 6}

\section{Discussion}

\section{Introduction chapter 6}

Based on literature as well as the outcomes of the preclinical studies as presented before, here we propose a multi-pathway effect of stem cells, explaining their action. Due to their necrotizing effects, inflammatory processes themselves stimulate a cascade of various secondary processes, inducing further inflammation. By their signaling proteins, stem cells play a major role in this multi-facetted cascade. Bm-SCs, therefore, can be seen as multitasking 'drugs' able to simultaneously switch of the various secondary pathways. Classical drugs, though, do not have this ability and therefore their effect on inflammatory processes is minimized by leaving several of these activated secondary pro-inflammatory pathways untouched. In this chapter, the multipathway approach of stem cells is postulated and justified by the results of all the presented preclinical experiments. 


\title{
6.1. Why do anti-inflammatory signals of bone marrow-derived stromal cells improve neuro-degenerative conditions where anti-inflammatory drugs fail?
}

\author{
de Munter JPJM, Mey J, Strekalova T, Kramer BW, Wolters ECh (2020) J \\ Neural Transm https://doi.org/10.1007/s00702-020-02173-3.
}

\begin{abstract}
Neurodegenerative disorders share the final degenerative pathway, the inflammation-induced apoptosis and/or necrosis, irrespective of their aetiology, be it of acute and chronic traumatic, vascular and idiopathic origin. Although disease-modifying strategies are an unmet need in these disorders, lately, (pre)clinical studies suggested favourable effects after an intervention with bone marrow-derived stromal cells $(\mathrm{bm}-\mathrm{SC})$. Recent interventions with intrathecal transplantation of these cells in preclinical rodent models improved the functional outcome and reduced the inflammation, but not anti-inflammatory drugs. The benefit of bm-SCs was demonstrated in rats with an acute (traumatic spinal cord injury, $\mathrm{tSCl}$ ) and in mice with a chronic (amyotrophic lateral sclerosis (ALS)-like FUS 1-358 or SOD1-G93-A mutation) neurodegenerative process. $\mathrm{Bm}-\mathrm{SCs}$, were found to modify underlying disease processes, to reduce final clinical $\mathrm{SCl}-$ related outcome, and to slow down ALS-like clinical progression. After double-blind interventions with bm-SC transplantations, Vehicle (placebo), and (non)steroidal antiinflammatory drugs (Methylprednisolone, Riluzole, Celecoxib), clinical, histological and histochemical findings, serum/spinal cytokines, markers for spinal microglial activation inclusive, evidenced the cell-to-cell action of bm-SCs in both otherwise healthy and immune-deficient tSClrats, as well as wild-type and FUS/SOD1-transgenic ALS-like mice. The multi-pathway hypothesis of the cell-to-cell action of bmSCs, presumably using extracellular vesicles (EVs) as carriers of messages in form of RNAs, DNA, proteins and lipids rather than influencing a single inflammatory pathway, could be justified by the reported differences of cytokines and other chemokines in the serum and spinal tissue. The mode of action of bm-SCs is hypothesized to be associated with its dedicated adjusting of the pro-apoptotic glycogen synthase kinase- $3 \beta$ level towards an antiapoptotic level whereas their multi-pathway hypothesis seems to be confirmed by the decreased levels of the pro-inflammatory interleukin (IL)-1 $\beta$ and tumor necrosing factor (TNF) as well as the level of the marker of activated microglia, ionized calcium binding adapter (Iba)-1 level.
\end{abstract}

\section{Introduction}

Neurodegenerative disorders are becoming increasingly prevalent and are a growing burden on the population worldwide. Acute neurodegenerative disorders are caused by trauma or vascular problems, leading to apoptosis and inflammation. Though many molecular and genetic causes are thought to serve as predisposing or disease-propagating factors, the underlying pathogenesis in chronic neurodegenerative disorders such as amyotrophic lateral sclerosis (ALS) is in most cases still obscure. Recent discoveries in these diseases, though, have demonstrated the presence of inflammation propagating substrates, and trials with several potential immune- 
modulating therapies provided increasing evidence that primary induced apoptosis followed by secondary inflammation are heavily involved in the pathogenesis not only in acute but also in chronic neurodegenerative diseases. Although steroidal and non-steroidal anti-inflammatory drugs (N)SAIDs), with their anti-inflammatory effects, as well as various neurotrophic factors, with their pro-survival signaling mechanisms, in the past had been proven to be effective in attenuating neuronal death in many in vitro and in vivo models of neurodegeneration, all larger phase II/III trials with both N)SAIDs and/or various neurotrophic factors, so far, did bring equivocal and/or worse outcomes (Gilgun-Sherki, Melamed et al. 2006, Hernan, Logroscino et al. 2006, McGeer and McGeer 2007, Schwartz and Ziv 2008, Schwartz and Shechter 2010, Bracken 2012, Ling, Murdoch et al. 2016). Maybe wrong timing of administration, nonselective inhibition of COX-2 or Rho-A, sub-optimal dose in target site, or limited penetration to the brain through the blood-brain barrier here may have played a role. Differences between rodent models and humans aside, perhaps the most confounding factor might be that the point(s) of action might be downstream of the pathophysiological process and retrospective in terms of neuronal death induction. Neuroprotection via pro-survival signaling also might not adequately annihilate the continuing pathological insult or might be too late to reverse the demise of compromised neurons (Tang 2017). Unfortunately, monitoring inflammation by identifying microglia-produced cytokines as biomarkers to help in the diagnosis, to predict the progression, and to target key immune factors in the various neurodegenerative processes is still a challenge. The translation of cytokines as a biomarker in clinical practice is further hampered by intraindividual variation, environmental factors, and genetic background, disease stage, anatomical onset of motor neuron impairment (Hu, Cao et al. 2017, McCauley and Baloh 2019, MorenoMartinez, Calvo et al. 2019, Moreno-Martinez, de la Torre et al. 2019). Even age and gender, play a role, and the different pro- and anti-inflammatory cytokines along the disease progression therefore should be further studied to understand its time point activation and its relation to other molecular and clinical mediators in neurodegeneration to finally provide a better monitoring of disease progression (Moreno-Martinez, Calvo et al. 2019).

Various genetic and environmental factors underly neurodegeneration, the result from activated inflammasomes, responsible for the activation of inflammatory responses removing cell debris, wastes and pathogens via phagocytosis. Inflammasomes are key signalling platforms that detect pathogenic microorganisms and sterile stressors, and that activate highly pro-inflammatory cytokines. In terms of molecular pathogenesis, neurodegenerative disorders share a negative contribution of nonneuronal cells (immune cells, glial cells) expressing and activating inflammasomes as a significant commonality (Lewis, Manning et al. 2012, Orsini, Oliveira et al. 2015).

Microglia, the resident immune cells in the CNS, comprise an entire spectrum of phenotypes that span the range from deleterious to regulatory to remodeling effects. Although microglial activation provides a defense against injury and infection, chronic or excessive activation is considered to be detrimental and has been implicated in many neurodegenerative and psychiatric disorders (Hammond, Dufort et al. 2019). In response to their environment, microglia are able to rapidly change morphology and function (London, Cohen et al. 2013). Gene expression analyses led to the identification of homeostatic (state 1 microglia) as well as "disease-associated" microglial phenotypes (DAMs) (Keren-Shaul, Spinrad et al. 2017). 
As DAMs are not associated with the disease etiology, but rather with a general response program that is involved in clearance of the protease-resistant misfolded and aggregated proteins, one still rather prefers the name "reactive" microglia. Out of the enormous variety of reactive microglia, two main types of reactive microglia have been defined: the classically activated (cytotoxic) (state 2) microglia that affect neuronal survival and that secrete proinflammatory cytokines, tumour necrosis factor TNF), interleukins-1 $\beta$ and 12 (IL-1 $\beta$, IL-12), interferon-gamma (IFN- - ), and nitric oxide inclusive, the so-called interferon response microglia (IRMs]; and the alternatively activated (cytoprotective) microglia that express genes involved in innate immune response, thus supporting an anti-inflammatory response and preventing classical microglial activation, called activated response (state 3) microglia (ARMs).

ARM-response overlaps with the DAM-response described by Keren-Shaul (Keren-Shaul, Spinrad et al. 2017), but these cells are not necessarily disease associated and might be considered part of the normal evolution of microglia in healthy aging. At odds with the original DAM-response description is also the heterogeneity in the ARMs. Alternatively activated microglia secrete interleukin-4 (IL-4), interleukin-13, or transforming growth factor $\beta$ (Hammond, Dufort et al. 2019). Distinct 'reactive' microglia signatures can be used to better understand microglia function and to identify and manipulate specific subpopulations in health and disease. The ionized calcium binding adapter marker (Iba)-1, which is upregulated in reactive microglia (IRM and ARM), is often used to identify these cells in general (Sala Frigerio, Wolfs et al. 2019).

In acute neuro-degenerative disorders, the classical activated microglia response (IRM) is caused by primary insult-induced necrosis, whereas in chronic disorders, ongoing activation is elicited by a genetic and/or environmental-driven abnormal accumulation of misfolded proteins, mitochondrial dysfunction, oxidative stress and/or inflammation, all processes which reinforce each other (Lim, Byeon et al. 2007, Ganguly, Chakrabarti et al. 2017). In ALS, as with other neurodegenerative diseases, the degeneration is a complex interplay between multiple pathogenic cellular mechanisms such as oxidative stress, mitochondrial dysfunction, impaired axonal transport, excitotoxicity, protein aggregation, endoplasmic reticulum stress, neuroinflammation, abnormal RNA processing, non-neuronal cells and target muscle contribution (Mancuso and Navarro 2015).

Activated cells proliferate and form dense clusters around the cell bodies of injured neurons (Ramirez, Poulton et al. 2011). These classically reactive phenotypes of intrinsic microglia and/or monocyte-derived macrophages produce a pro-inflammation signal cascade by the secretion of various cytotoxic factors, pro-inflammatory signaling molecules, and the expression of immune molecules, TNF and other inflammatory cytokines inclusive. They also increase their expression Iba-1. Once classically activated state 2 microglia start to express glycogen synthase kinase-3 $\beta$ (GSK-3 $\beta$ ), what they normally not do (Tang, Han et al. 2015), thus further promoting both innate and adaptive immune responses (Wang, Brown et al. 2011, Beurel, Grieco et al. 2015).

GSK-3 $\beta$, though, has an interesting paradoxical effect: a high dose initiates a pro-apoptotic effect during mitochondrial-mediated intrinsic apoptosis but in a low dose, it induces an anti-apoptotic effect during death receptor-mediated extrinsic apoptosis. Low doses of GSK-3 inhibitors, therefore, provide a feasible means to counteract excessive inflammation and induce neuroprotective actions in chronic neurodegenerative conditions, among them amyotrophic lateral sclerosis (Mazzardo-Martins, Martins et al. 2012). 
Activation of microglia is a hallmark of brain pathology, and reactive microglia are especially thought to be involved in neuroinflammatory responses (Ito, Imai et al. 1998). As a consequence, the environment around the damaged neurons becomes toxic, and thus further enhancing the degeneration (Subramaniam and Federoff 2017). Once the inciting event has been adequately resolved, a lower production of pro-inflammatory cytokines will polarize these cells, switching them from state 2 microglia (IRMs) into state 3 microglia (ARMs) that express genes involved in innate immune response, facilitating phagocytosis of cell debris and misfolded proteins, promoting tissue repair, and supporting neuronal survival by neurotrophic factors (Khalid, Ampie et al. 2017). However, when the pathogenic stimulus cannot be adequately cleared, chronic inflammation develops with a persistent IRM response that can cause unintended injury to local tissues.

Thus, chronic neurodegeneration is facilitated by the lack of neurotrophic growth factors and by the continued production of cytotoxic by-products of a pro-inflammatory response (Hooten, Beers et al. 2015). The type, location and connections of the necrotic cell populations are leading in the (variable) clinical expression of these neurodegenerative processes.

\section{Anti-inflammatory drug-Interventions in neurodegeneration}

As discussed above, neurodegenerative diseases share strong neuro-inflammatory multipathway components, which are at least in part responsible for the continuing cell death. Pharmacological treatments therefore should intend to reduce this inflammatory response. Curiously, so far, interventions with anti-inflammatory drugs in patients suffering these disorders did not result in successful treatments (Gilgun-Sherki, Melamed et al. 2006, Hernan, Logroscino et al. 2006, McGeer and McGeer 2007, Schwartz and Ziv 2008, Schwartz and Shechter 2010, Ling, Murdoch et al. 2016). In patients suffering acute neurodegeneration such as spinal cord injuries, in which secondary inflammatory processes are mainly responsible for final clinical outcome, initially it was suggested that methylprednisolone (MP) did significantly reduce disability, though this could not be confirmed in later studies, and side effects appeared to outweigh any beneficial effects (Hurlbert 2000, Bracken 2012).

Also, in patients suffering chronic neurodegenerative disorders, Alzheimer disease, Parkinson disease and amyotrophic lateral sclerosis (ALS) inclusive, anti-inflammatory drugs were found to be ineffective (Fondell, O'Reilly et al. 2012, Collins and Bowser 2017, Khalid, Ampie et al. 2017, Crisafulli, Brajkovic et al. 2018). Activation of microglia and astrocytes with increased levels of pro-inflammatory serum and CSF cytokines IL-1 $\beta$, IL-6, IL-8, TNF and vascular endothelial growth factor (VEGF) are considered the hallmark in ALS (Ciervo, Ning et al. 2017, Hu, Cao et al. 2017, Morello, Spampinato et al. 2017, Crisafulli, Brajkovic et al. 2018).

Interventions with corticosteroids and/or other anti-inflammatory drugs such as the COX-2 inhibitor celecoxib, which causes reduction of the brain levels of inflammatory cytokines TNF and IL-1 $\beta$ (Osman, Mubasher et al. 2016), however, were found ineffective in experimental ALS-like animals and/or ALS patients (Galbiati, Onesto et al. 2012, Collins and Bowser 2017, Crisafulli, Brajkovic et al. 2018). Apart from an eventual, subtle, inconsistent increase of survival time in ALS which might be seen in some patients after an intervention with riluzole (Miller, Mitchell et al. 2012) and/or edavarone (Yoshino and Kimura 2006), disease-modifying interventions, for instance adequate inflammasome-targeted strategies, are still an unmet need in most 
neurodegenerative disorders (Voet, Srinivasan et al. 2019). Further, growth factors may play a potential role in facilitating functional recovery in degenerative neurons (Shruthi, Sumitha et al. 2017).

\section{BM-Derived Stromal Cell-Interventions in neurodegeneration}

Although interventions with anti-inflammatory drugs in experimental neuro-degenerative animal studies have not resulted in successful clinical trials, a more recent approach to treat such disorders, in both experimental animals and humans, with implanting bone marrow-derived stromal cells (bm-SCs), seems very promising. Such transplants supposedly modulate the immune system in both acute (Deda, Inci et al. 2008, Martinez, Palomo Ruiz et al. 2017, Tsai, Liou et al. 2018, Cofano, Boido et al. 2019, Jin, Medress et al. 2019) and chronic (Mazzini, Vescovi et al. 2016, Ciervo, Ning et al. 2017, Gashmardi, Hosseini et al. 2017, Sykova, Rychmach et al. 2017, Cizkova, Cubinkova et al. 2018, Garbuzova-Davis, Haller et al. 2018, Oh, Noh et al. 2018, Gugliandolo, Bramanti et al. 2019) neurodegenerative disorders in experimental animals as well as in patients. Our own experiments with human bm-SC in experimental animal models of both an acute (traumatic spinal cord injury; tSCI) (de Munter, Beugels et al. 2019, Romero-Ramirez, Wu et al. 2020) and a chronic neurodegenerative disorder (amyotrophic lateral sclerosis; ALS) (de Munter, Shafarevich et al. 2019) were fully in line with these findings. In these studies, fresh bm-SCs specimen were manufactured into standardized preparations for intrathecal application, in order to bring naïve stem cells into the environment where neuroinflammation and degeneration are ongoing. Hereto, these specimens were reduced in volume after positive depletion of erythrocytes, monocytes and lymphocytes and negative selection of untouched stem cells (Neuro-Cells: patent WO2015/ 059300A1). We explored the effect of an intrathecal transplantation with bm-SCs $\left(4 \times 10^{5} \mathrm{CD} 34^{+}\right.$cells) in both T-cell-deficient and immune competent Wistar rats, one day after a traumatic spinal cord injury, resulting in a complete paraplegia (de Munter, Beugels et al. 2019, Romero-Ramirez, Wu et al. 2020) Bm-SCs were found to be free of side-effects, to significantly protect for $\mathrm{SCl}$-related mortality, and to improve natural motor recovery (Basso, Beattie et al. 1995) compared to placebo-treated animals, in the following weeks (de Munter, Beugels et al. 2019). When compared to an acute $48 \mathrm{hr}$ intra-peritoneal highdose methylpred-nisolone (MP) application (Romero-Ramirez, Wu et al. 2020), bm-SC again significantly improved locomotor functions (Basso, Beattie et al. 1995) and restored body weight. $\mathrm{Bm}$-SC-treated rats also never evidenced $\mathrm{SCl}$-associated neuropathic pains during testing of mechanical nociception (von Frey), as sporadically seen in SCl-rats treated with placebo and/or MP. In those experiments, there was no rejection of the transplants, and there were no adverse events. The effects of an intrathecal intervention with bm-SCs ( $5 \times 10^{5} \mathrm{CD} 34^{+}$cells) were also studied in two different experimental ALS-like mice models. As the aetiology of ALS is still unclear, animal models are based on gene mutations which are found in familial cases: $\mathrm{Cu}-\mathrm{Zn}$ superoxide dismutase gene SOD1, C9ORF72, PGRN, TBK1, TARDBP, and FUS genes (Freischmidt, Muller et al. 2015, Al-Chalabi, Hardiman et al. 2016, Lutz 2018). Still asymptomatic 10-weeks old FUS(1-358) (Shelkovnikova, Peters et al. 2013) and 12-weeks-old SOD1(G93A) mutant mice (de Munter, Shafarevich et al. 2019) were treated with bm-SC transplantations before developing a progressive loss of motor functions, muscle atrophy and weights loss due to a fast degeneration of spinal motor neurons with denervation in the following weeks, thereby representing a 
relevant preclinical model for amyotrophic lateral sclerosis (ALS). Conform previous studies (Uccelli, Milanese et al. 2012, Boido, Piras et al. 2014, Ciervo, Ning et al. 2017), intrathecal bmSC transplantations in FUS(1-358) and SOD1(G93A) mutant ALS-like mice were found to significantly induce disease-modifying effects; they significantly delayed cachexia, weight loss and motor dysfunction, as well as muscle atrophy and the loss of spinal lumbar motor neuron as seen in placebo-treated transgenic mice. Interventions with riluzole and/or celecoxib at the same (pre-symptomatic) age in these animals, however, failed to slow down the development of these ALS-like symptoms in the mutant mice.

\section{Mode-of-action of BM-Derived Stromal Cells}

The mode of action of bone marrow-derived stromal cells was originally postulated to be related to cellular integration by leveraging the plasticity of the stromal/stem and progenitor cells for the replacement of lost neural tissue. In addition, the mechanism was also considered to relate indirectly via cellular interactions which stimulate secretion of neurotrophic factors as well as factors affecting the immune response by modulating $\mathrm{T}$ - and B-cell activity thereby decreasing apoptosis of neural cells and inflammatory responses (Ruppert, Nguyen et al. 2018). Mesenchymal stem cells (MSCs) and hematopoietic stem cells (HSCs) are the main stem cells sourced by bone marrow (Kucia, Reca et al. 2005). Both stem cell types are capable of differentiation into spindle neuron-like cells (Koshizuka, Okada et al. 2004, Sigurjonsson, Perreault et al. 2005, Ye, Zeng et al. 2011). Further, after harvesting, HSCs differentiate easily in pro-inflammatory cells increasing inflammation. These cells, though, can be kept in their naïve status when at the same time MSCs were present (Le Blanc and Ringden 2005). As stem cells only sparsely pass intact blood-brain-barriers (BBB) and/or CSF-brain barriers, it is most probably that eventual effects of bm-SCs are not reached by cell replacement but might rather be effectuated by communicators, signaling proteins that freely pass those barriers, though. If given intrathecally, the bm-SCs are trapped in the cerebrospinal fluid and disappear within a couple of weeks completely (Engelhardt and Sorokin 2009, Redzic 2011, Abramowski, Krasemann et al. 2016). The bm-SCs are decision making-cells that coordinate their operations with their immediate environment (Fischbach, Bluestone et al. 2013, Caplan 2017). They act cell-to-cell using all kind of communicators, such as extracellular vesicles (EVs) and soluble factors such as cytokines (including chemokines, interferons, interleukins, lymphokines, and tumour necrosis factor), growth factors and mitochondria transfer. EVs are small, membrane-bound nanoparticles that can be released from most, if not all cells, and that can carry functionally active cargo (proteins, nucleic acids) that has been shown to modify the recipient cells physiology to react in a paracrine and endocrine manner (Yanez-Mo, Siljander et al. 2015, Zhang, Yeo et al. 2016, Harting, Srivastava et al. 2018, Ruppert, Nguyen et al. 2018). The EVs-cargo which comprises DNA, RNA, protein and lipids reflects the physiological as well as the pathophysiological state of a cell (Abels and Breakefield 2016). EVs are emerging as a promising tool for therapeutic delivery owing to its favorable intrinsic features of biocompatibility, stability, stealth capacity, and the ability to overcome natural barriers (Dostert, Mesure et al. 2017, Shahjin, Chand et al. 2019). In other studies, bm-SC-EVs were found to exert immune-suppressive effects by enforcing ARM macrophage polarization and stimulating T-cell induction as well as producing neurotrophic factors and anti-inflammatory cytokines, as a dedicated reaction of 
environmental vesicles or cytokines from degenerating, malfunctioning cells (Dostert, Mesure et al. 2017, Cizkova, Cubinkova et al. 2018, Harting, Srivastava et al. 2018, Kim, Oh et al. 2018, Wang, Pei et al. 2018, Beers and Appel 2019, Shahjin, Chand et al. 2019). This hypothesis, though, is still a hypothesis, and recently, the possibility that bm-SCs one way or the other might donate healthy mitochondria to neurons that harbour dysfunctional mitochondria has also been raised to explain their positive effects (Babenko, Silachev et al. 2015). In order to further address the question why immune-modulating bm-SCs strategies are more successful than antiinflammatory drugs in human neurodegenerative disorders, we want to summarize the different cytokines and proteins with the relevant pathway and want to discuss a compilation of all findings from three preclinical studies, looking after the effects of an intervention with bm-SC in in SCl and ALS-like animal models (de Munter, Shafarevich et al. 2019, de Munter, Beugels et al. 2019, Romero-Ramirez, Wu et al. 2020). The following cytokines and proteins were studied in the mentioned preclinical experiments:

\section{TNF:}

Tumour necrosis factor (TNF) is important to maintain immunity and cellular homeostasis and creating a balance between cell survival, apoptosis and necroptosis. TNF regulates the generation of reactive oxygen species (ROS) and reactive nitrogen species (RNS), and this ROS/RNS signaling plays an important role in activating and controling inflammatory conditions (Blaser, Dostert et al. 2016). Further TNF initiates the MAPK signaling pathway and the NF-kappa B signaling pathway, both involved in apoptosis and necroptosis (Wrzodek, Buchel et al. 2013).

\section{$\underline{\text { IL-1B: }}$}

Interleukin-1 $\beta$ is a pro-inflammatory cytokine and a mediator of neuronal injury. Experiments with Interleukin-1 cause an impaired cerebral blood flow (Murray, Parry-Jones et al. 2015). Mechanistically it seems that Interleukin-1 $\beta$ is also correlated with the caspase pathways, thus initiating apoptosis (Spinello, Vecile et al. 2019).

$\underline{\text { IL-6: }}$

Interleukin- 6 is a cytokine that is released by proteolytic cleavage and is involved in the regulation of the immune system and inflammation within the central nervous system. IL- 6 binds to an IL-6 receptor, and then associates with a dimer of the ubiquitously expressed gp130 receptor subunit, which initiates intra-cellular signaling. Interleukin- 6 can bind to the membrane of cells (liver and leucocytes) and initiate a classical signaling, which is regenerative and antiinflammatory, though the soluble form can bind with a co-protein to nearly all cell types and initiate trans signaling, which is inflammatory and pro-apoptotic (Rose-John 2012). IL-6 signaling activates downstream signaling pathways such as Janus kinases/signal transducers and activators of transcription (Jak/STAT), the phosphatidylinositol 3-kinase cascade and the mitogen-activated protein kinase cascade through gp130 homodimer formation (Garbers, Hermanns et al. 2012).

$\underline{\text { Iba-1: }}$

Iba-1 is a marker of reactive microglia (Imai and Kohsaka 2002). Microglial activation presumably involves the FGF2/FGFR1 (fibroblast growth factor and receptor) pathway as can be seen when 
this pathway is blocked (Zou, Shi et al. 2019). Microglia play an important role in modulating inflammation, and especially the polarized (ARM) microglia contribute to a more regenerative environment. This was confirmed, as a matter of fact, by the microglia expression of arg1, CD206 and CCR2 (Roszer 2015) in our experiment (Figure 2). However, activation of microglia might also be reached by the modulating effects of II-6 and TNF (Chu 2013, Schaper and Rose-John 2015).

\section{GSK-3ß:}

Glycogen synthase kinase-3 is responsible for maintaining selective intracellular phosphorylation of many substrates. This enzyme is involved in all kind of different roles in multiple signaling pathways. The upregulation of GSK-3 $\beta$ expression in T-Cells is seen as pathogenic in autoimmune diseases (Beurel, Kaidanovich-Beilin et al. 2013). Blocking GSK-3 may bring down disease-progression in neurodegenerative diseases by decreasing inflammation and apoptosis and providing a cell protective environment (Morales-Garcia, Susin et al. 2013).

Figure 1 presents an overview of the time axis of these three studies in which we compared the histological effects of bm-SC with the effects reached after matched interventions with placebo (vehicle), methyl-prednisolone, Riluzole and/or Celecoxib in SCl-lesioned and ALS-like experimental animals, at different timepoints after intrathecal application (1, 2 and 3).The findings will be put into perspective of the hypothesis that stem cells are decision-making cells and that they adapt to their environment. At the time point marked with the number 1 in the red circle (Figure 1), 3 days after the administration of the intrathecal intervention with bm-SCs or Vehicle and 4 days after the initial lesioning, histology was performed of the spinal tissue in both balloon compression-induced $\mathrm{SCl}$-lesioned and sham-lesioned immune-deficient rats (caudal, central and rostral of the eventual lesion). Findings are displayed in Figure 2.

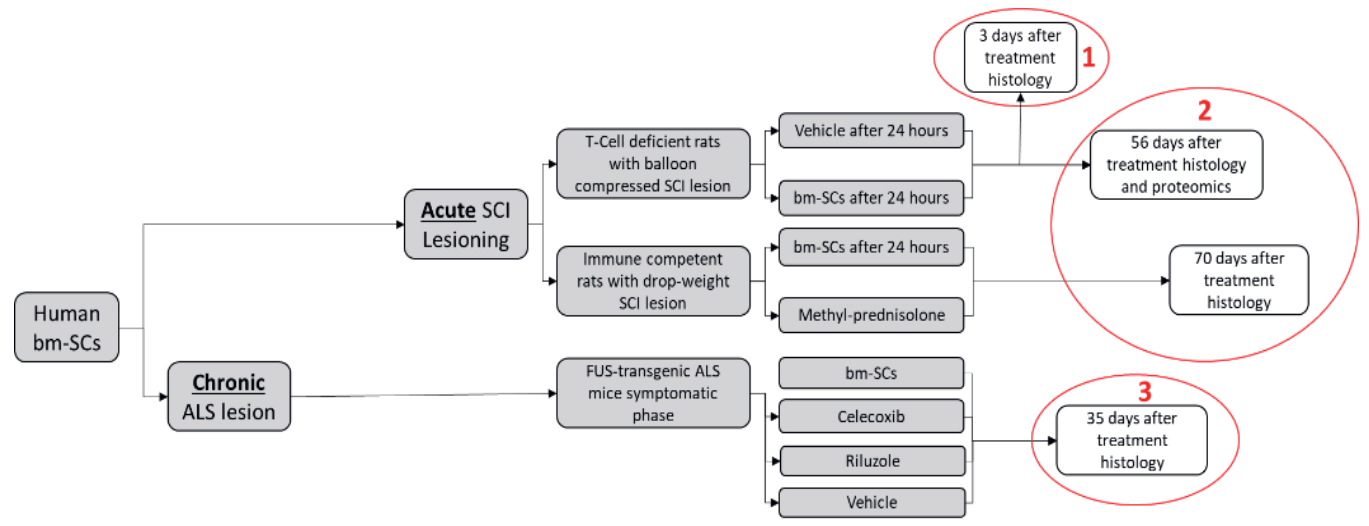

Figure 1: overview of the three preclinical studies, looking after the effects of an intervention with the same bm-SCs in acute and chronic degenerative diseases, providing the different time points of tissue sampling for histology

Naïve bm-SCs applied 24 hours after the lesioning straight into the cerebrospinal fluid of a SCl injured rat were able to polarize IRMs into ARMs, to decrease astrocytes in the lesion, to protect neurons for apoptosis in the lesion and to decrease serum pro-inflammatory interleukins (IL-1 $\beta$. 
II-6 and TNF) when compared to the vehicle treated animals. The focus of the bm-SCs cells was to "detox" the cerebrospinal fluid and save precious neurons in an acute neurodegenerative condition (de Munter, Beugels et al. 2019). At the time point marked with the number 2 in the red circle (Figure 1), 56 days after the administration of the intrathecal intervention with bm-SCs or Vehicle and 57 days after the initial balloon compression-induced lesioning in immunedeficient rats, histology was performed of the spinal tissue (caudal, central and rostral of the lesion) and lesion tissue was prepared for proteomics to investigate the up and downregulation of different regulons. Findings at this timepoint are displayed in Figure 3. At the time point also marked with the number 2 in the red circle (Figure 1), 70 days after the administration of the intervention with bm-SCs, Methyl-prednisolone or Vehicle, and 71 days after the initial dropweight lesioning of otherwise healthy rats, lesion site, expression of astroglia and western Blot Iba-1 in the spinal lesion site were investigated. Findings are displayed in Figure 4. Finally, at the time point marked with the number 3 in the red circle (Figure 1), 35 days after the application of Vehicle, bm-SCs, Riluzole or Celecoxib in still asymptomatic ALS-like FUS-mutated mice, ELISA serum and spinal Western Blot histology were performed (de Munter, Shafarevich et al. 2019). Findings are displayed in Figure 5. As shown in figure 2, three days after the intervention with the Vehicle, the devastating effects of the $\mathrm{SCl}$ lesioning In the Vehicle-treated rats were mainly found due to a persistent neuroinflammatory response, as reflected by the increased expression of microglia in IRM mode, as well as the increased astrogliosis and apoptosis, when compared to the animals treated with bm-SC (de Munter, Beugels et al. 2019). The results reached at the various timepoints after the interventions with bm-SCs are summarized in Table 1.
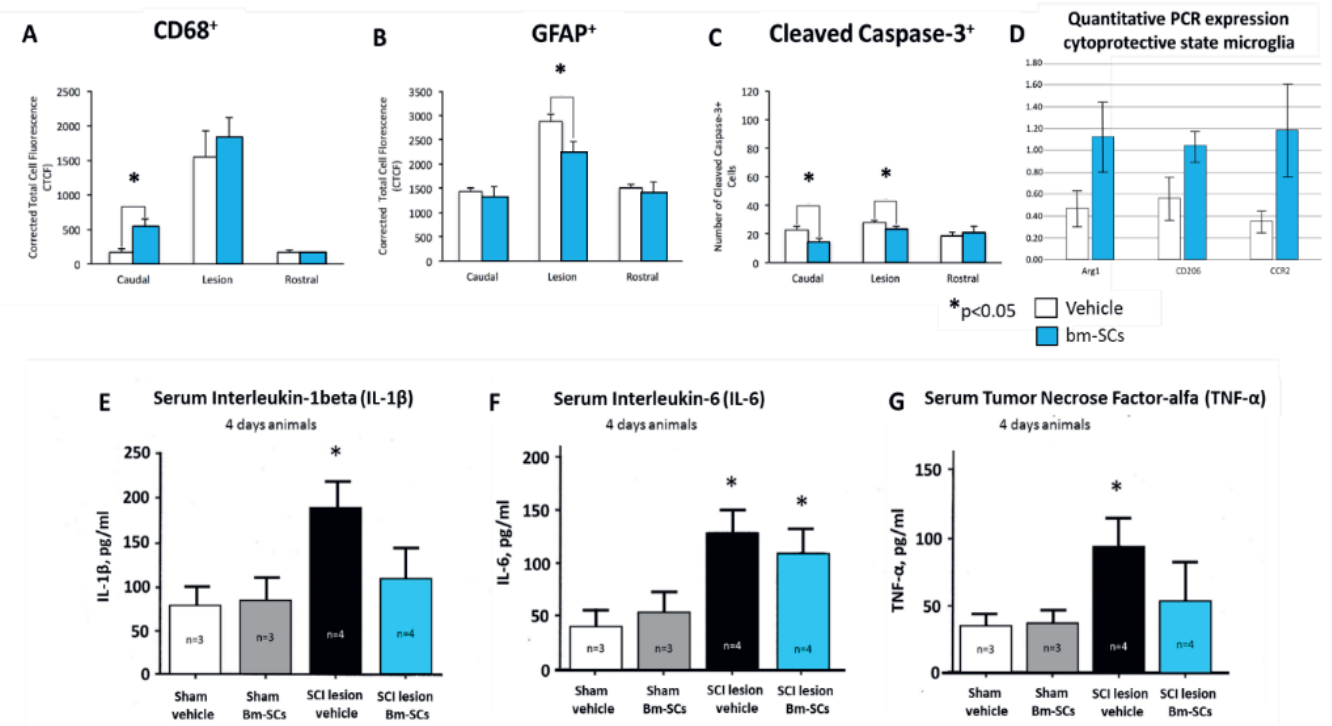

Figure 2: Expression of microglia (2A), astroglia (2B), and apoptosis (2C) caudal, central and rostral of the SCl lesion, and the quantified polarization from IRM to ARM microglia (2D) 3 days after the interventions with bm-SCs or Vehicle in T-cell deficient balloon compressioninduced spinal cord injured rats. (2E) Displays the serum concentration of Interleukin-16, (2F) the serum Interleukin-6, and (2G) the serum TNF levels) in the sham and SCI-lesioned rats treated with Vehicle or bm-SC (de Munter, Beugels et al. 2019). 
56 Days after the interventions, histological studies of the lesioned tissues in the bm-SC and Vehicle-treated SCl-lesioned animals did not establish any significant difference in the expression of microglia, astrocytes and apoptosis anymore (see figure 3). A comprehensive proteomic profile of the lesioned spinal tissue showed various changes in the up- and down-regulation of the protein expression when compared with the findings at baseline (vehicle treated animals), which were set to $100 \%$. The most important findings were the downregulation of proinflammatory proteins and the upregulation of the proteins involved in axonal and cellular regeneration.

A

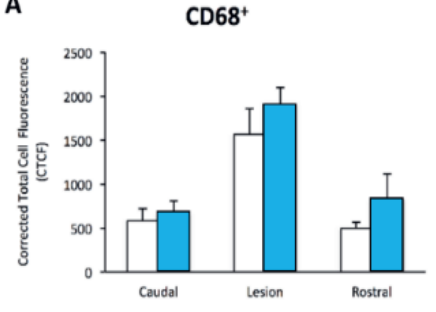

B

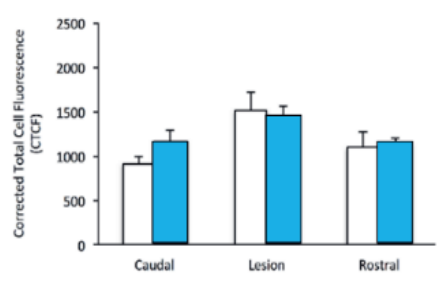

C

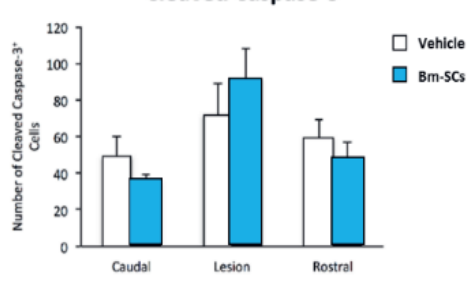

D Up-regulation Lesion Down-regulation Lesion
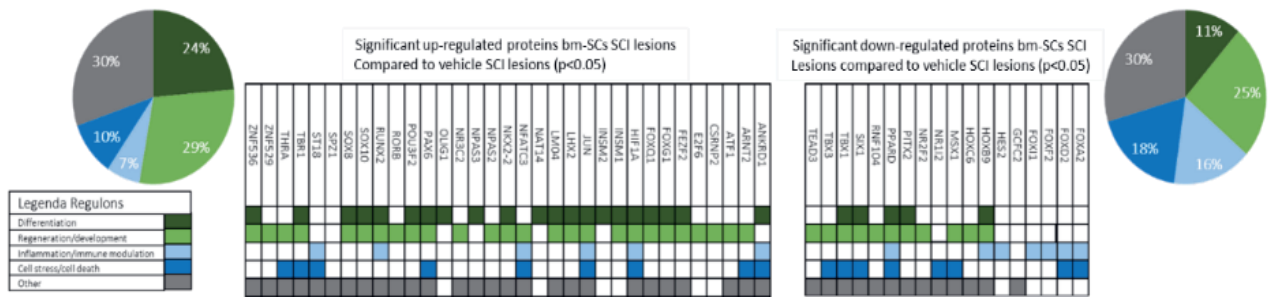

Figure 3: Expression of microglia (3A), astroglia (3B) and apoptosis (3C) caudal, central, and rostral of the SCl lesion in the spinal cord of animals sacrificed 56 days after the intervention with bm-SCs or Vehicle, in T-cell deficient balloon compression-induced spinal cord injured rats. In $3 D$ the significant $(p<0.05)$ up-and down-regulated proteins of the analysed lesioned spinal tissue are presented. Protein expression in the injured tissues of the Vehicle-treated animals are displayed in the baseline (de Munter, Beugels et al. 2019).

As might be appreciated in Figure 4, 70 days after the intervention with Vehicle, Methylprednisolone or bm-SC in drop weight-induced SCl-injured, otherwise healthy rats, the absence of any significant difference in histological findings as established 56 days after the intervention with bm-SC and Vehicle treated - SCl-lesioned immune-deficient rats, as displayed in Figure 3 could be confirmed in immune competent rats. The lesion size in the animals treated with bm-SCs was somewhat smaller than in the rats treated with Vehicle and Methylprednisolone, but not significantly.

An interesting finding, though, was the significant lower expression of Iba-1 in the lesion site of the animals treated with bm-SCs, but not in the animals treated with Methylprednisolone and/or 
Vehicle (Romero-Ramirez, Wu et al. 2020) confirming the hypothesis that bm-SCs reach antiinflammatory effects by different means than pharmacological interventions.

A

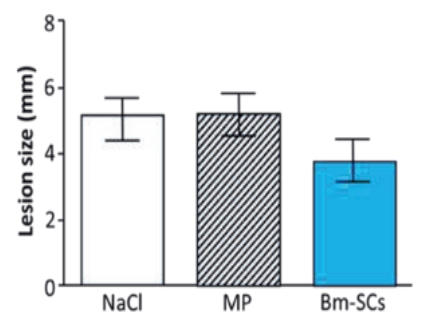

B

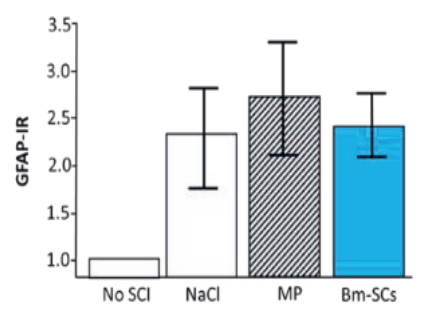

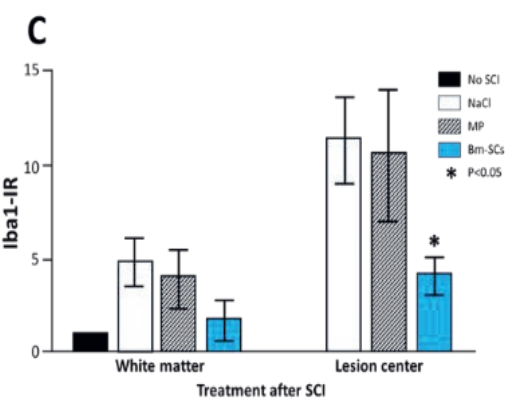

Figure 4: Lesion size as evaluated with cleaved Caspase-3 (4A), expression of astroglia (4B) and Western blot Iba-1 (4C) in the spinal cord tissue (data were normalized to Iba1-IR in the white matter of the not-lesioned (No SCI) rats) in immune competent rats after a drop weight-induced $\mathrm{SCl}$ lesion, 70 days after an intervention with Methylprednisolone (MP), Vehicle (NaCl) or human stem cells (bm-SCs) (Romero-Ramirez, Wu et al. 2020).

In these animals, apoptosis, as evaluated with activated caspase-3, was found significantly reduced in the ventral horns as well as axonal pathology in the ascending dorsal columns when compared to Vehicle and/or MP-treated rats (Romero-Ramirez, Wu et al. 2020).

Most straight forward answer to the initial question about the mode-of-action of bm-SCs seems to be the multi-pathway approach of bm-SCs in contrast to the single pathway approach of (N)SAIDS. An alternative explanation could be the activation of a still not clear pathway more upstream of the inflammatory cascades. Bm-SCs might be seen as decision making cells, that coordinate their operations with their immediate environment (Fischbach, Bluestone et al. 2013, Caplan 2017). Their cell-to-cell communication here may play a major role and future research must elucidate the content of stem cells secreted EVs in modulating inflammatory environments.

In summary, bm-SC's immune-modulating properties, including their paracrine cytokines with their polarizing effect on IRMs, attack more and different mechanisms than the individual antiinflammatory drugs, as also suggested by our proteomic findings in the $\mathrm{SCl}$-rats (de Munter, Beugels et al. 2019). Despite the evidence that inflammation is critical in both $\mathrm{SCl}$ and $\mathrm{ALS}$, treatment with various anti-inflammatory drugs (including Rho-A, COX-2 and TNF inhibitors, steroids, cyclophosphamide, cyclosporine, cytochrome-C inhibitors, and caspase-reducing drugs) seems to fail to clinically-significant modify SCI and/or ALS symptomatology and/or pathology in humans (Hurlbert 2000, Bracken 2012, Collins and Bowser 2017, Crisafulli, Brajkovic et al. 2018), unless the result of insufficient dosage or bioavailability, delayed time points of delivery, and/or or the taking-over of the eventually inhibited pathway by other single or down-stream pathways. By the way, the bm-SC-induced immunomodulatory and regenerative effects might also be mediated when the stem cells quickly pass on their effects to resident cells (Eggenhofer, Luk et al. 2014). Figure 6 illustrates the multi-pathway approach of bm-SCs.

As for the application route of stem cells in patients suffering neurodegenerative disorders, in our opinion, bm-SC might be best implanted intrathecally. 

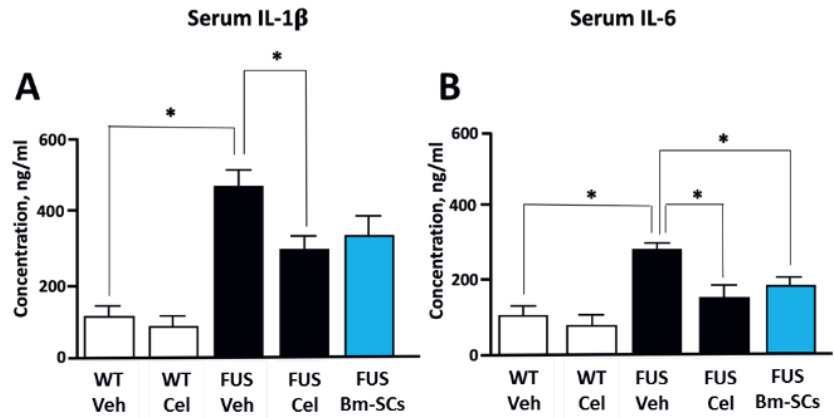

C

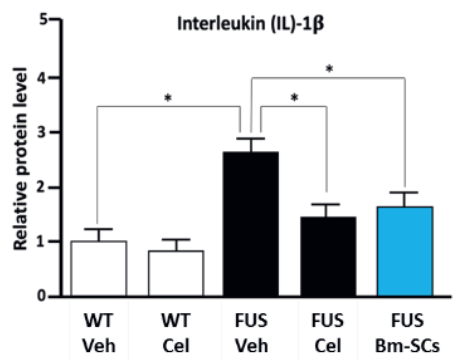

D

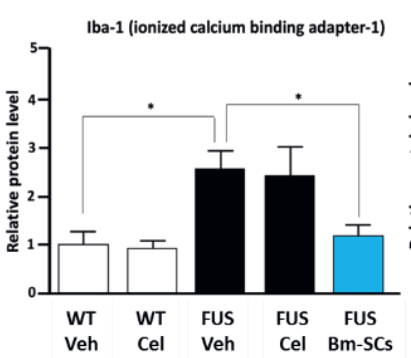

$\mathbf{E}$

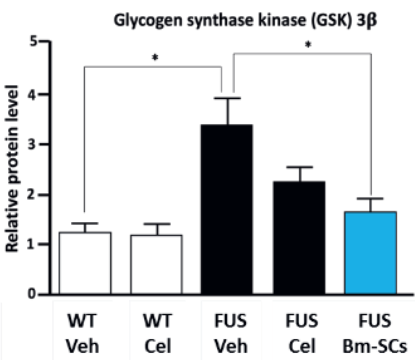

Figure 5 Overview of the ELISA serum IL-1B (5A) and IL-6 (5B) levels, and the western blot staining of spinal IL-1B (5C), Iba-1 (5D) and GSK$3 B(5 E)$ levels in wild type (WT) and FUS-tg mice treated with Vehicle, Riluzole, Celecoxib and bm-SCs as established 35 days after these interventions in the at that time asymptomatic animals (de Munter, Shafarevich et al. 2019).

\section{Table 1:}

Summary of the effects of interventions with intrathecal applied bm-SC in experimental animal models for both acute (SCI) and chronic (ALS-like) neurodegenerative disorders.

Intrathecal application $24 \mathrm{hr}$ after SCl lesioning

\begin{abstract}
cytokine TNF $\downarrow(p<0.05)$ in serum and spinal tissue
\end{abstract}
cytokines IL-1 $\downarrow \downarrow(p<0.05)$ and $\downarrow$ IL-6 (trending)

Iba-1 $\downarrow(\mathrm{p}<0.05)$ in serum and spinal tissue

polarize cytotoxic macrophages 2 (IRMs) into cytoprotective macrophages 3 (ARMs) apoptotic/pro-

inflammatory proteins $\downarrow(p<0.05)$

regenerative/differentiating proteins $\uparrow(p<0.05)$
Intrathecal application in still aymptomatic ALS-like FUS-tg mice (see Fig. 5) cytokine IL-1ß $\downarrow$ and IL- 6 levels $\downarrow$ in serum and spinal tissue $(p<0.05)$

Iba- $1 \downarrow(p<0.05)$ in serum and spinal tissue

GSK-3 $\downarrow \downarrow(p<0.05)$ in spinal tissue

Intravenous application ends up with most bm-SCs stuck in lung and liver (Fischer, Harting et al. 2009), and the number of engrafted bm-SCs in the central nervous system will be minimal due to the lack of ability to easily cross the blood-brain barrier by these cells (Cerri, Greco et al. 2015). On top of this, repeated intrathecal bm-SC transplantations proved to be safe and feasible, and are found most promising for the treatment of patients with neurological diseases (Pan, Deng et al. 2019) 


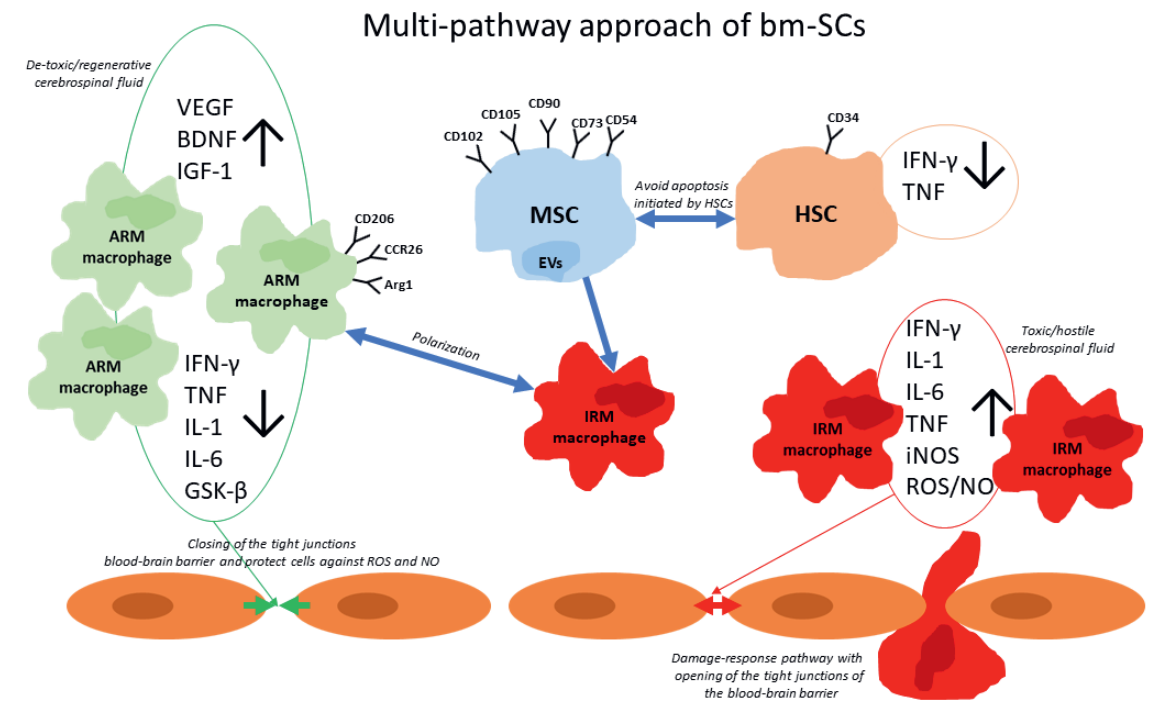

Figure 6 An overview of the interaction of stem cells in the maintenance of a regenerative non-toxic cerebrospinal fluid. The MSCs by cellto-cell communication polarize the IRM macrophages into ARM macrophages. The ARM macrophages decrease the pro-inflammatory cytokines and enhance the growth factors. ARM macrophages gen-expression for CD206, CCR26 and Arg1. (Abbreviations: ARM: activated response microglia, BDNF:Brain-derived neurotrophic factor; EVs: Extracellular vesicles, GSK-B: glycogen synthase kinase-3 beta,HSC: hematopoietic stem cell,IGF-1: insulin-like growth factor-1, IFN- : Interferon-gamma, IL-1: Interleukin-1, IL-6: Interleukin-6, iNOS: inducible nitric oxide synthase, IRM: Interferon Response Microglia, MSC: mesenchymal stem cell, NO: nitric oxide, ROS: reactive oxygen species, TNF: tumor necrose factor, VEGF: vascular endothelial growth factor).

\section{Conclusion}

Evidence is provided for bm-SCs to:

1. significantly improve survival and accelerate natural motor recovery in rats suffering balloon compression and/or weight-induced spinal cord injuries with a complete paraplegia in combination with reduced apoptosis, whereas methylprednisolone failed to do so;

2. significantly delay the onset of ALS-like symptoms in pre-symptomatic FUS- and SOD1transgenic mice, whereas riluzole and celecoxib failed to do so.

These effects may be initially reached by bm-SC's preventing for the neurodegeneration-induced inflammatory reaction with sharply increased serum/spinal II-1 $\beta$ and TNF levels, later on, having passed their effects to resident cells, in combination with bringing down the pro-inflammatory and pro-apoptotic degeneration-induced effects, as evidenced by their reduction of raised GSK$3 \beta$ and the conversion of IRM microglia into ARM microglia. As (N)SAIDs are clinically ineffective in these acute and chronic neurodegenerative conditions, bm-SCs here might reach their effects by reducing specifically the increased GSK-3 $\beta$ and Iba-1 protein levels in the affected central nervous system. It is possible that bm-SCs might reach these effects by acting on other than myeloid cells. Finally, the fact that bm-SCs can adapt their activity depending the environment where they are in, justifies the manufacturing/processing approach to keep these cells in a naïve condition before entering the disease arena. 


\section{Chapter 7}

\section{Conclusions and Summary}

\section{Introduction chapter 7}

After displaying the preclinical results and proposing the hypothesis of the decision-making stem cells, which detox the hostile cerebrospinal fluid, chapter 7.1 elaborates on this concept. The whole process from the first laboratory tests to the proof of concept in the animal experiments allowing to test our hypothesis in a clinical trial in patients suffering neurodegenerative disorders, will be addressed. The creation of an innovative new clinical bm-SC preparation (named Neuro-Cells) for the treatment of neurodegenerative disorders will be explained in this chapter. Due to the effect of this new preparation on the final patho-physiological pathway to neurodegeneration, necrosis, as shared by both acute and chronic neurodegenerative diseases, this new preparation is expected to induce a e disease-modifying rather than symptomatic effect. In the end, the questions as defined in chapter 1 , will be addressed in detail.

Finally, chapter 7.2, offers a summary of the preclinical findings as realised in the experimental treatment of preclinical acute and chronic neurodegenerative conditions with fresh human stem cell transplantations, as well as the proposed multi-pathway action of these stem cells in the treatment of neurodegenerative processes in Dutch and in English. 


\subsection{Bone marrow-derived stem cells: from bench to bedside}

Increasing evidence indicates that inflammation is particularly involved in the pathogenesis of neurodegenerative diseases, and even if inflammation is not a primary causative process, its presence may contribute to the continued neuronal loss. Accordingly, both neurotrophic factors as well as anti-inflammatory agents, steroidal and non-steroidal anti-inflammatory drugs inclusive, were hypothesized to prevent and treat neurodegenerative conditions such as Alzheimer's disease, Parkinson's disease, amyotrophic lateral sclerosis and traumatic brain/spinal cord injuries. However, there is always a confounding factor with hypothesized therapeutic interventions: the interventions might engage downstream of the underlying cause and retrospective in terms of final outcomes of the aimed disorder (Tang 2017). Unfortunately, clinical trials with anti-inflammatory drugs in neurodegenerative disorders, so far, did bring equivocal outcomes (Schwartz and Shechter 2010, Bracken 2012), and some clinical trials even resulted in detrimental effects (Ling et al 2016). Although pro-survival signaling mechanisms from the brain-derived neurotrophic factor (BDNF), ciliary neurotrophic factor (CNTF), and granulocyte-colony stimulating factor (G-CSF), have all been shown to attenuate motor neuron death and prolong survival in ALS-like vitro (Kamei, Tanaka et al. 2007) and in vivo models (Lu, Jones et al. 2005, Bouhy, Malgrange et al. 2006, Blurton-Jones, Kitazawa et al. 2009), all the larger clinical phase II/III trials failed to show any benefits (Cedarbaum, Stambler et al. 1999, Meininger, Bensimon et al. 2004, Gordon, Moore et al. 2007, Fondell, O'Reilly et al. 2012).

Neurodegeneration as many faces and many causes. The causes are still not known for the majority of the diseases. The burden of neurodegenerative diseases for the individual patient and for the community is high. The number of patients will increase as due to a direct result of the improved health care, mean age will increase in the next two decades (Arthur, Calvo et al. 2016, Longinetti and Fang 2019), and many neurodegenerative diseases, especially parkinsonism, ischemic stroke, amyotrophic lateral sclerosis and Alzheimer's disease are strongly related to aging (Wirdefeldt, Adami et al. 2011). Although spinal cord injury and traumatic brain injury were mostly seen in younger people, , over the last twenty years the mean age of these patients changed from 35 years of age to over 50 years of age (Furlan, Sakakibara et al. 2013). As 20 years ago, spinal cord injury was mainly caused by traffic accidents, today we see a shift towards falling accidents in and around the residencies of the patients (van den Berg, Castellote et al. 2010).

The causes of neurodegenerative diseases may differ, but they share a final common pathway by inducing cell death and necrosis. In typical neurodegenerative diseases, this final pathway is initiated by activated glycogen synthase kinase $3 \beta$ (GSK3) signaling damages ER-mitochondria associations (Stoica, Paillusson et al. 2016), and targetting this activation, therefore, might be regarded a potential therapy of neurodegenerative diseases (Duda, Wisniewski et al. 2018). These reduced ER-mitochondria associations are evidenced in FUS (fused-in-sarcoma) and TDP43 (transactive response DNA binding protein $43 \mathrm{kDa}$ ) transgenic ALS/FTD-like mice. Pathological TDP-43 aggregates are also the major component of ubiquitin-positive cytoplasmic inclusions found in the brains of patients with frontotemporal lobar degeneration (FTLD) and amyotrophic 
lateral sclerosis (ALS), and are also found in patients suffering Alzheimer's disease, Parkinson's disease and other synucleinopathies (Stoica, Paillusson et al. 2016). In these disorders, the resulting mitochondriopathy results in reduced ATP levels with cell death and necrosis. As a matter of fact, cell death and necrosis in itself are inflammatory stimuli and lead to the activation of pro-inflammatory cytokines and microglia with the maintenance of a toxic environment, and, as a consequence, ongoing damage of cells and tissue. This secondary inflammation is shared by all neurodegenerative disorders. These pro-inflammatory cytokines, nitric oxide species, TNF- $\alpha$, and the interleukins IL-1 $\beta$ and IL- 6 inclusive, increase the production of cytotoxic reactive oxygen species (ROS) and may lead to abnormal accumulation of misfolded proteins, mitochondrial dysfunction, oxidative stress and/or persistent inflammation. These processes not only progressively worsen the toxic environment surrounding neural cells but also reinforce each other (Lim and Beal 2006; Ganguly et al 2017). Activated microglia, astrocytes and infiltrated Thelper cells thus regulate cell death and eliminate associated waste materials within the central nervous system. The type, location and connections of the necrotic cell populations are leading in the variable clinical presentation of these neurodegenerative processes. In acute insults this secondary inflammatory process starts within hours after the initial cause and can last up to one year, whereas in more chronic insults this process is less severe but persists continuously. Here, the cerebrospinal fluid which nourishes the spinal cord and the brain is turned into a toxic environment in which inflammatory components actively enhance the death of neural tissue. It is not possible to stop, cure or effectively slow down the progress of these acute and chronic neurodegenerative diseases up to date. The majority of the actual interventions is focused to the intervention of only one inflammatory pathway instead of the multi-pathways leading to secondary inflammation. For example, Celecoxib, which fails to bring down ongoing secondary inflammatory processes, only interferes with the cyclooxygenase-2 signaling pathway. To stop or slow down the secondary inflammation, we need an intervention, which can simultaneously act at different inflammatory pathways involved. Only such intervention can stop or slow down the secondary inflammation and thereby effectively stop, bring down or delay the progress of the neurodegenerative process. An effective treatment to prevent, stop, resolve or to slow-down the secondary inflammatory cascades in acute, but not in chronic, neurodegenerative processes needs to be available within 24 hours after the CNS insult (Silva, Sousa et al. 2014, Chitnis and Weiner 2017).

Stem cells, as mentioned before, can be seen as decision making cells. For example, a high concentration of for example interferon- $\gamma$ can activate the naïve stem cells to inhibit the innate immune responses, whereas a low concentration of interferon- $\gamma$ will activate the same naïve stem cells to do the opposite and enhance the innate immune responses (Chan, Tang et al. 2006, Corcione, Benvenuto et al. 2006). To assure that the stem cells can adapt to local circumstances, we believe that it is crucial not to change in any way the characteristics of these cells before the cells are re-implanted in the patient. Stem cells have all kind of receptors, which can be activated by specific antibodies. Such a antibody-receptor binding on the surface of the stem cell can change the expression of the stem cell (change in polarization of the cell membrane) and by changing the expression the same stem cell loses its naïve status (Andrzejewska, Jablonska et al. 2019). To avoid changing the expression of the stem cells, therefore, a negative selection is used to isolate the stem cells. Negative selection means that magnetic beads bound on specific 
antibodies are used to remove the lymphocytes and other unwanted cells from the bone marrow (Schuler, Harasymczuk et al. 2011). The antibody-free stem cells can freely pass through, while the other cells are trapped by a magnet and taken out of the sample.

As both, HSCs and MSCs are pluripotent cells, it was originally postulated that these cells could replace destroyed neural tissue. However, two decades later, we know:

- that both HSCs and MSCs can differentiate into spindle formed cells, which phenotypically are neurons alike;

- $\quad$ that both HSCs and MSCs can modulate T- and B-Cells and react depending the environment in an inflammatory-stimulating respectively inflammatory-inhibiting manner;

- that both HSCs and MSCs can directly or indirectly secrete paracrine factors, which can stimulate repair/regeneration/revascularization;

- In vitro, isolated HSCs will act pro-inflammatory and initiate aging and cell death. Together with MSCs, HSCs stay undifferentiated and inactive;

- The naïve status of stem cells seems to be important as these cells can make their own decision based on the input of the environment;

- There is no consensus regarding the number of stem cells, needed to initiate an effect, as stem cells can activate neighborhood cells to support. The classical pharmacokinetics and pharmacodynamics of drugs do not apply to stem cells;

Stem cells can be expanded in the laboratory, but not indefinitely. Besides the fact that culturing of the stem cells takes easily 3 to 4 weeks, it is also reported that culturing per se will lead to telomere shortening and other chromosomal alterations (Mayshar, Ben-David et al. 2010, Ferreira, Irioda et al. 2012). Finally, in case of an acute CNS insult, the expanded cells will first become available when the secondary inflammatory cascades are already fully deployed. Looking again to the effects of stem cells in preclinical settings (tables presented in Chapter 2) time to implant stem cells after an acute lesion is crucial. Indeed, best outcomes were reported when the stem cells were applied in the acute stage of the insult.

Evaluation of the preclinical and clinical studies with fresh bone marrow-derived mononuclear cells (a mixture of MSCs, HSCs and stomal cells), similar results were reported as in the studies with only expanded MSCs and/or HSCs. Another important conclusion in the in chapter 2 presented reviews was the fact that intrathecal and intraparenchymal cell transplants were superior to intra-arterial and intravenously applied cells. In conclusion, expanded allogenic MSCs and HSCs applied intrathecally within 24 hours after the onset of an acute neuro-degenerative process (a SCl lesion) seemed to be the best choice, based on the literature review presented in Chapter 2. Of note, in these studies, cyclosporine was needed to suppress the rejection of the cells. Looking back to these (pre)clinical studies, there are still remarks and short comings, which might have influenced the outcomes of the reported studies: 
- Cyclosporine is a cell protecting drug itself (Palladini, Caronti et al. 1996) and has a negative effect on stem cells (Guo, Zeng et al. 2007).

- In the presented studies the MSCs and HSCs were no longer naïve. The cells were exposed to specific antibodies for their selection and programmed to expand to reach sufficient numbers of cells.

- Performing a Ficoll-gradient centrifugation of bone marrow (Hernandez, Cortina et al. 2007) is a method by which the white layer of cells containing stem cells can be selected without using specific magnetic antibodies, but this preparation contains high numbers of pro-inflammatory immune cells, T- and B-Lymphocytes, monocytes and natural-killer cells inclusive. Erythrocytes, though, are at least depleted. Looking at literature, applying stem cells intrathecally (into the immune privileged cerebrospinal fluid) is safe but the presence of erythrocytes and lymphocytes have to be avoided (Assmus, Tonn et al. 2010, Jones 2014).

The stem cell preparations (bm-SCs) used in the preclinical studies in SCl and ALS-like animal models as described in chapters 4 and 5 , are based on the removal of lymphocytes out of the harvested human bone marrow preparation. by labeling with specific magnetic antibodies against respectively T-Cells, B-Cells, NK (natural killer)-Cells and monocytes. These cells are unwanted and as much as possible removed by positive selection. The remaining stem cells were not labeled (negative selection). From a valorization point, 2 patents for using the waste product with negative selected cells (Neuro-Cells (C) has been filed and granted.

The in chapter 3 presented preclinical experiment to test the eventual stem cell-induced angiogenesis in an acute ischemic lesion was performed with a gradient centrifuged mixture of bone marrow derived HSCs and MSCs, still containing erythrocytes and lymphocytes. This preparation was administered directly in the blood vessels and the muscles, where the presence of erythrocytes and lymphocytes in the preparation did not matter. HSCs and MSCs were found able to stimulate angiogenesis and to decrease ischemia. Before developing clinical experiments, of course, the following step is to develop a robust and professional manufacturing under good manufacturing practices (GMP) of a stem cells-containing product, as a GMP compliant product is mandatory when going into clinical trials to treat patients.

Literature summarized in chapter 2 suggested positive preclinical and clinical outcomes in neurodegenerative processes after an intervention with human bone marrow-derived mononucleated cells, containing both HSCs and MSCs.

The mechanism of action was not completely understood but there was enough evidence to assume that the secretion of paracrine factors and or immune regulating proteins were crucial in modulating neuro-inflammation. To elaborate on this hypothesis, the first need was to reconfirm the improvement of the neurologic outcome in animal models of acute ischemia (chapter 3), of spinal cord injury (Chapter 4), of amyotrophic lateral sclerosis and frontotemporal lobe degeneration (Chapter 5) after an intervention with a combination of HSCs and MSCs .

Interpretation of the results of the interventions with bone marrow-derived stem cells provided further evidence indeed for an improvement of the clinical outcome in rats with an acute 
occlusion of the hindlimb artery, by enhancing the angiogenesis. This effect was evaluated by measuring the density of micro-vessels in the affected limb and to compare the results with those found in vehicle treated animals.

We also tested bm-SCs (Neuro-Cells) in two animal models for spinal cord injury and performed a head-to-head comparison between rats treated with bm-SCs (Neuro-Cells), placebo, and a high dose of methylprednisolone. Interventions with bm-SCs were found effective in increasing the recovery in both acute spinal cord injury animal models, whereas interventions with methylprednisolone and placebo failed to do so.

Finally, in a new FUS-tg model for ALS, we also established a significant bm-SCs-induced improvement of clinical and neuropathological hallmarks of ALS, when comparing the effects with final outcomes in those animals when treated with placebo, riluzole and the COX-2 inhibitor celecoxib. These findings could also be confirmed in another model for ALS, the SOD-1 mutant mouse. In the FUS-tg FTLD-like mice, interventions with bm-SCs did significantly prevent for increased concentrations of IL-1 $\beta$ and GSK-3 $\beta$ as evidenced in the FUS-tg-Veh group $(p<0.05)$. In these animals, behavioral and molecular abnormalities of FUS-tg mice were also found reduced after these interventions, to a greater extent as compared to the interventions with riluzole and/or celecoxib.

So, the combination of HSCs and MSCs in human bm-SCs and/or Neuro-Cells was found to improve the neurological/vascular condition in various (neuro)degenerative animal models, notably without the presence of cyclosporine. In an acute ischemic degenerative environment stem cells promoted the formation of micro-vessels, and in both an acute traumatic spinal cord and a chronic ALS-like and FTLD-like neurodegenerative environment, Neuro-Cells decreased the secondary inflammation process and rescued neural tissue. These experiments arrested the case that bm-SCs indeed affect the final common pathway of secondary inflammation in (neuro)degenerative processes, most probably by preventing the activation of GSK-3 $\beta$ and the damage of ER-mitochondrial associations.

Conclusion: based on the results of the preclinical studies in spinal cord injured rats and ALS-like and FTLD-like mice, an intrathecal intervention with Neuro-Cells might be seen as a potential intervention for neurodegenerative disorders in which cell death initiates the activation of secondary inflammatory cascades.

In the immune privileged environment of the spinal cord and the brain, bm-SCs simultaneously act on several pathways of inflammation, whereas (N)SAIDs and/or riluzole fail to do so. In neurodegenerative processes, bm-SCs, the decision makers, were found to bring down or prevent for increased GSK-3 $\beta$ levels, IBA-1 (a microglia activator) levels as well as the levels of pro-inflammatory cytokines IL-1 $\beta$ and TNF- $\alpha$. In the typical neurodegenerative processes such as $A D, P D, A L S$, and FTLD, key is the progressive damage of ER-mitochondria associations. By affecting ER-mitochondria associations, and thus ATP production, GSK-3 $\beta$ acts as a downstream regulatory switch for numerous signaling pathways involved in glycogen metabolism, cell development, gene transcription, and protein translation to cytoskeletal organization, cell cycle regulation, proliferation, and apoptosis. Based on the outcomes of our preclinical studies, an intervention with bm-SCs (Neuro-Cells) in typical neurodegenerative conditions can 'detox' the cerebrospinal fluid and create a more regenerative climate. Concerning the original questions 
regarding interventions with stem cell preparations as formulated in chapter 1 , the following conclusions might be made:

\section{Which cells?}

Not-manipulated negatively selected bone marrow-derived HSCs and MSCs, intrathecally applied, seems to be a safe and effective treatment in preclinical models of neurodegeneration. Generally speaking, clinical interventions with fresh autologous bm-SCs are preferred as the patient's owns stem cells will not activate a host-versus graft or graft-versus-host reaction. However, they also have their limitations, which justify the use of allogenic bm-SCs. Based on literature these limitations are diabetes, renal failure, aging, and severe ALS, as plasticity is decreasing. Also, the number of fresh bm-SCs $(50 \mathrm{ml}$ bone marrow contains about 50-60 × 106 CD34 ${ }^{+}$cells) is limited, and their half-life is about 72 hours. PM, during aging, the number of bm$\mathrm{SCs}$ is also declining.

\section{Which dose?}

The question which dose of stem cells to apply seems to be irrelevant. After all, the effect of cells, with their ability to migrate, replicate, differentiate, and to respond to the microenvironment is not strictly dose dependent. In the performed studies the dose was titrated on the total number of $\mathrm{CD} 34^{+}$cells. The dose injected intrathecally contained between 400,000 and $500,000 \mathrm{CD} 34^{+}$cells and an equal number of MSC positive stained cells.

\section{When to apply?}

Timing is key and taking literature and the outcome of the preclinical studies into account, an effective treatment window in acute neurodegenerative processes lies between 24 to 72 hours after the initial CNS insult. As for the more chronic neurodegenerative disorders, the best strategy also appears to start as early as possible, as the disease itself results in an ongoing necrosis of neural cells, assuming that what is dead cannot be replaced with this therapy. Key is to slow-down the ongoing and self-reinforcing disease process by applying bm-SCs as early as possible.

\section{Indications to apply}

Compiling the anti-inflammatory characteristics of bm-SCs as confirmed in an acute traumatic and a chronic degenerative model of neurodegeneration suggests that the bm-SCs are rather not-specific disease-modifying drugs. Neurodegeneration in general results in cell death with the activation of IRM activated microglia and macrophages in in the central nervous system. Bm-SCs provide protection to neural cells, polarize the activated microglia and macrophages and detox the cerebrospinal fluid. Therefore, bm-SCs might offer a disease-modifying effect in both acute and chronic neurodegenerative disorders, as displayed in figure 1 . This figure provides an overview of potential indications for therapeutic interventions with bm-SCs of which 3 are preclinically proven. 
Therapeutic window for disease modifying Neuro-Cells in neurodegenerative disorders

\section{Neuro-Cells}

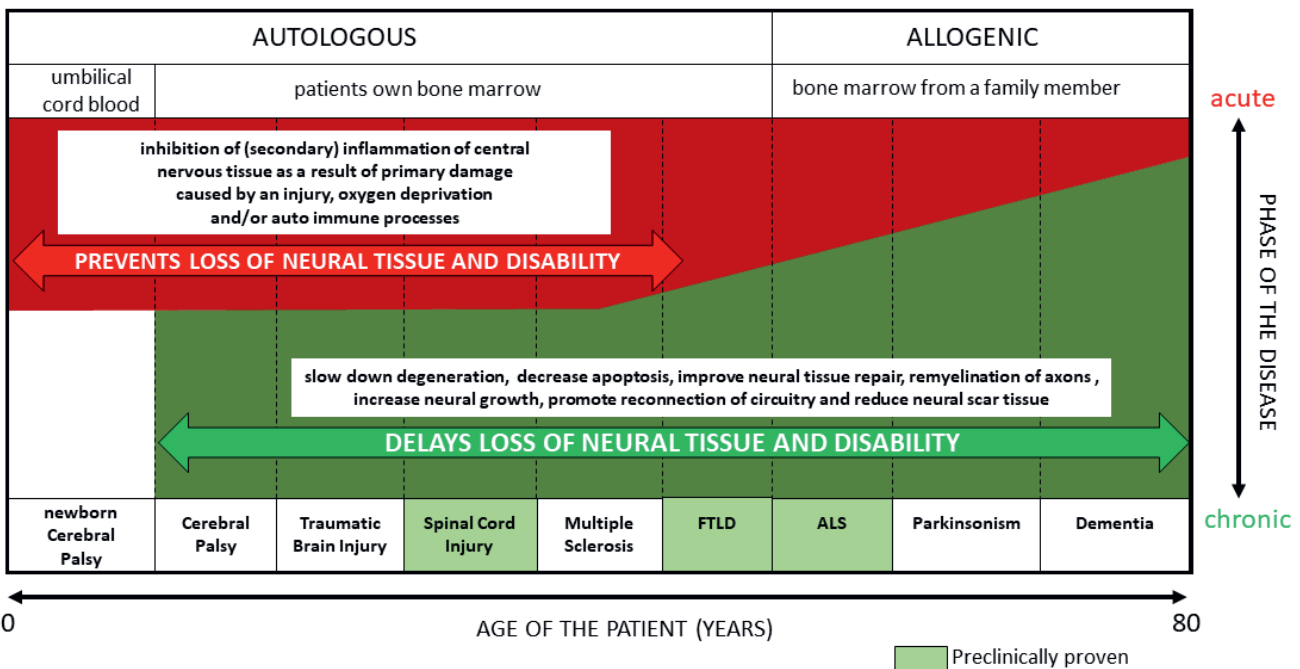

Figure 1 presents in an overview the disease modifying effect of bm-SCs in an acute CNS insult Spinal Cord Injury and two chronic degenerative CNS insults Amyotrophic Lateral Sclerosis and Frontotemporal Lobar Degeneration. 


\subsection{Summary: the patient's own bone marrow-derived stromal cells as disease modifier in (neuro)degenerative disorders}

Neurodegenerative disorders share the final degenerative pathway, the cell death-induced secondary inflammation with progressive apoptosis and/or necrosis, irrespective of their aetiology. In two preclinical models for acute neurodegeneration (balloon-compressed and drop weight impact $\mathrm{SCl}$ models) and in two preclinical models for chronic neurodegeneration (ALS-like FUS 1-358 and SOD1-G93-A mutation), a GMP produced negative selected human bone marrow derived stem cell preparation (bm-SCs; Neuro-Cells) was tested for safety and efficacy.

After double-blind interventions with this preparation, with placebo, or with (non)steroidal antiinflammatory drugs (methylprednisolone, riluzole, celecoxib), clinical, histological and histochemical findings (serum/spinal cytokines and markers for spinal microglial activation inclusive) evidenced the cell-to-cell action of bm-SCs in both otherwise healthy and immunedeficient tSCl-rats, as well as in wild-type and FUS/SOD1-transgenic ALS-like and FUS-transgenic FTLD-like mice. All studies yielded significantly better results in bm-SC-treated animals as compared to the animals treated with placebo and/or NSAIDs. In SCl-lesioned rats, bm-SCs led to faster motor recovery, less apoptotic cells and less astrocytes in the lesion as compared to vehicle and methylprednisolone. In ALS-like mice, bm-SCs led to less motor impairment, less muscle atrophy and a decreased loss of motor neurons in the spinal cord as compared to vehicle, riluzole and celecoxib treated animals. In the FUS-tg FTLD-like mice, after interventions with bmSCs (Neuro-Cells), behavioural and molecular abnormalities of FUS-tg mice were also found reduced to a greater extent as compared to the interventions with riluzole and/or celecoxib.

The multi-pathway hypothesis of the action of bmSCs, presumably through extracellular vesicles (EVs) as messaging carriers of RNA, DNA, proteins and lipids, rather than influencing a single inflammatory pathway, could be justified by the established differences of serum and spinal tissue levels of cytokines and other chemokines. The mode of action of bm-SCs is hypothesized to be associated with its dedicated adjusting of the pro-apoptotic glycogen synthase kinase-3 $\beta$ level towards an anti-apoptotic level whereas their multi-pathway hypothesis seems to be confirmed by the decreased levels of the pro-inflammatory interleukin (IL)-1 $\beta$ and tumor necrosing factor (TNF) as well as the level of the marker of activated microglia, ionized calcium binding adapter (Iba)-1 level. With the results presented, the next phase, translating the results into humans seems justified. 


\subsection{Samenvatting: patiënt's eigen beenmerg stamcellen om (neuro)degeneratieve aandoeningen aan te pakken}

Hoewel de oorzaken van de diverse neurodegeneratieve aandoeningen niet altijd bekend zijn, delen deze aandoeningen wel dezelfde pathofysiologie. De initiële celdood en necrose in het centrale zenuwstelsel zijn verantwoordelijk voor het activeren van de secondaire ontstekingscascades.

In preklinische diermodellen voor acute (balloncompressie en slaggewicht-geïnduceerde ruggenmergletsels) en chronische (FUS-1-358 en SOD1-G93-A mutatie) neurodegeneratieve processen, is een uit menselijk beenmerg afkomstig stamcel preparaat (bm-SCs, Neuro-Cells) getest op veiligheid en werkzaamheid.

Dit stamcel product is onder GMP-condities en met negatieve selectie tot stand gekomen. In een dubbelblinde studieopzet is het stamcel preparaat vergeleken met een niet-werkzame placebo, danwel ontstekingsremmers: (N)SAIDS zoals methyl-prednisolon, riluzole en celecoxib.

In vergelijking tot placebo- en methylprednisolon-behandelde dieren, verbeterde de achterpoot functie van de met stamcellen behandelde dwarslaesie dieren significant sneller, en was er sprake van minder celdood en een lagere concentratie aan ontstekingscellen (astrocyten) in het beschadigde weefsel.

Van de ALS-achtige dieren vertoonden de dieren behandeld met stamcellen significant minder uitval van de spierfuncties, hadden deze dieren minder spieratrofie en was er sprake van een significant hoger aantal intacte motorneuronen in het spinale weefsel in vergelijking tot de dieren behandeld met placebo, riluzole of celecoxib. Tenslotte bleken de met stamcellenbehandelde FTLD-achtige muizen significant beschermd voor de normaal in deze dieren optredende verhoging van de IL-1 $\beta$ en GSK-3 $\beta$ concentraties. Ook bleken de hier optredende gedragsafwijkingen duidelijk afgenomen, veel meer dan na interventies met riluzole en/of celecoxib.

De resultaten van de serum cytokinen en de western-blot weefsel preparaten in de bm-SCbehandelde proefdieren maken het aannemelijk dat de stamcellen multi-taskers waren, die meerdere processen tegelijkertijd beïnvloeden, hierbij gebruik makend van extracellulaire vesicles als communicatoren voor de interactie. Op basis van ons onderzoek mag ervan uitgegaan worden dat bm-SCs (Neuro-Cells) in preklinische neurodegeneratieve ziekteprocessen vooral werkzaam is door het onderdrukken respectievelijk voorkomen van de in deze ziekten aanwezige progressieve activatie van het GSK-3 $\beta$, die gepaard gaat met de aantasting van de verbindingen tussen het endoplasmatisch reticulum en de mitochondria, waardoor een tekort aan ATP met necrose optreedt.

Op grond van de door ons verkregen preklinische resultaten lijkt het gerechtvaardigd de vastgestelde gunstige effecten van bm-SCs te vertalen naar een mogelijk ziekte-modificerende behandeling voor humane (neuro)degeneratieve aandoeningen. 


\section{Literature}

Abdul Wahid, S. F., N. A. Ismail, W. F. Wan Jamaludin, N. A. Muhamad, M. K. A. Abdul Hamid, H. Harunarashid and N. M. Lai (2018). "Autologous cells derived from different sources and administered using different regimens for 'no-option' critical lower limb ischaemia patients." Cochrane Database Syst Rev 8: CD010747.

Abels, E. R. and X. O. Breakefield (2016). "Introduction to Extracellular Vesicles: Biogenesis, RNA Cargo Selection, Content, Release, and Uptake." Cell Mol Neurobiol 36(3): 301-312.

Abramowski, P., S. Krasemann, T. Ernst, C. Lange, H. Ittrich, M. Schweizer, A. R. Zander, R. Martin and B. Fehse (2016). "Mesenchymal Stromal/Stem Cells Do Not Ameliorate Experimental Autoimmune Encephalomyelitis and Are Not Detectable in the Central Nervous System of Transplanted Mice." Stem Cells Dev 25(15): 1134-1148.

Adams, H. P., Jr., P. H. Davis, E. C. Leira, K. C. Chang, B. H. Bendixen, W. R. Clarke, R. F. Woolson and M. D. Hansen (1999). "Baseline NIH Stroke Scale score strongly predicts outcome after stroke: A report of the Trial of Org 10172 in Acute Stroke Treatment (TOAST)." Neurology 53(1): 126-131.

Agarwala, S. and O. J. Tamplin (2018). "Neural Crossroads in the Hematopoietic Stem Cell Niche." Trends Cell Biol 28(12): 987-998.

Aggarwal, S. and M. F. Pittenger (2005). "Human mesenchymal stem cells modulate allogeneic immune cell responses." Blood 105(4): 1815-1822.

Akhtar, A. Z., J. J. Pippin and C. B. Sandusky (2009). "Animal studies in spinal cord injury: a systematic review of methylprednisolone." Altern Lab Anim 37(1): 43-62.

Akyurekli, C., Y. Le, R. B. Richardson, D. Fergusson, J. Tay and D. S. Allan (2015). "A systematic review of preclinical studies on the therapeutic potential of mesenchymal stromal cell-derived microvesicles." Stem Cell Rev 11(1): 150-160.

Al-Chalabi, A., O. Hardiman, M. C. Kiernan, A. Chio, B. Rix-Brooks and L. H. van den Berg (2016). "Amyotrophic lateral sclerosis: moving towards a new classification system." Lancet Neurol 15(11): 1182-1194.

Alexander, J. K. and P. G. Popovich (2009). "Neuroinflammation in spinal cord injury: therapeutic targets for neuroprotection and regeneration." Progress in brain research 175: 125-137.

Alfieri, J. A., P. R. Silva and L. M. Igaz (2016). "Early Cognitive/Social Deficits and Late Motor Phenotype in Conditional Wild-Type TDP-43 Transgenic Mice." Front Aging Neurosci 8: 310.

Alrafiah, A. R. (2018). "From Mouse Models to Human Disease: An Approach for Amyotrophic Lateral Sclerosis." In Vivo 32(5): 983-998.

Amann, B., C. Luedemann, R. Ratei and J. A. Schmidt-Lucke (2009). "Autologous bone marrow cell transplantation increases leg perfusion and reduces amputations in patients with advanced critical limb ischemia due to peripheral artery disease." Cell Transplant 18(3): 371-380.

An, H., L. Skelt, A. Notaro, J. R. Highley, A. H. Fox, V. La Bella, V. L. Buchman and T. A. Shelkovnikova (2019). "ALSlinked FUS mutations confer loss and gain of function in the nucleus by promoting excessive formation of dysfunctional paraspeckles." Acta Neuropathol Commun 7(1): 7.

Andersson, A. K. (2011). "Embryonic stem cells and property rights." The Journal of medicine and philosophy 36(3): 221-242.

Andres, R. H., R. Choi, G. K. Steinberg and R. Guzman (2008). "Potential of adult neural stem cells in stroke therapy." Regenerative medicine 3(6): 893-905.

Andrzejewska, A., A. Jablonska, M. Seta, S. Dabrowska, P. Walczak, M. Janowski and B. Lukomska (2019). "Labeling of human mesenchymal stem cells with different classes of vital stains: robustness and toxicity." Stem Cell Res Ther 10(1): 187.

Ankeny, D. P., D. M. McTigue and L. B. Jakeman (2004). "Bone marrow transplants provide tissue protection and directional guidance for axons after contusive spinal cord injury in rats." Exp Neurol 190(1): 17-31.

Antonic, A., E. S. Sena, J. S. Lees, T. E. Wills, P. Skeers, P. E. Batchelor, M. R. Macleod and D. W. Howells (2013) "Stem cell transplantation in traumatic spinal cord injury: a systematic review and meta-analysis of animal studies." PLoS Biol 11(12): e1001738. 
Aronowski, J., R. Strong and J. C. Grotta (1997). "Reperfusion injury: demonstration of brain damage produced by reperfusion after transient focal ischemia in rats." Journal of cerebral blood flow and metabolism : official journal of the International Society of Cerebral Blood Flow and Metabolism 17(10): 1048-1056.

Arthur, K. C., A. Calvo, T. R. Price, J. T. Geiger, A. Chio and B. J. Traynor (2016). "Projected increase in amyotrophic lateral sclerosis from 2015 to 2040." Nat Commun 7: 12408.

Asahara, T., H. Masuda, T. Takahashi, C. Kalka, C. Pastore, M. Silver, M. Kearne, M. Magner and J. M. Isner (1999). "Bone marrow origin of endothelial progenitor cells responsible for postnatal vasculogenesis in physiological and pathological neovascularization." Circ Res 85(3): 221-228.

Assinck, P., G. J. Duncan, B. J. Hilton, J. R. Plemel and W. Tetzlaff (2017). "Cell transplantation therapy for spinal cord injury." Nat Neurosci 20(5): 637-647.

Assmus, B., A. Rolf, S. Erbs, A. Elsasser, W. Haberbosch, R. Hambrecht, H. Tillmanns, J. Yu, R. Corti, D. G. Mathey, C. W. Hamm, T. Suselbeck, T. Tonn, S. Dimmeler, T. Dill, A. M. Zeiher and V. Schachinger (2010). "Clinical outcome 2 years after intracoronary administration of bone marrow-derived progenitor cells in acute myocardial infarction." Circulation. Heart failure 3(1): 89-96.

Assmus, B., T. Tonn, F. H. Seeger, C. H. Yoon, D. Leistner, J. Klotsche, V. Schachinger, E. Seifried, A. M. Zeiher and S. Dimmeler (2010). "Red blood cell contamination of the final cell product impairs the efficacy of autologous bone marrow mononuclear cell therapy." J Am Coll Cardiol 55(13): 1385-1394.

Astori, G., S. Soncin, V. Lo Cicero, F. Siclari, D. Surder, L. Turchetto, G. Soldati and T. Moccetti (2010). "Bone marrow derived stem cells in regenerative medicine as advanced therapy medicinal products." American journal of translational research 2(3): 285-295.

Asumda, F. Z. and P. B. Chase (2011). "Age-related changes in rat bone-marrow mesenchymal stem cell plasticity." BMC cell biology 12: 44.

Aurora, A. B. and E. N. Olson (2014). "Immune modulation of stem cells and regeneration." Cell Stem Cell 15(1): 14-25.

Babenko, V. A., D. N. Silachev, L. D. Zorova, I. B. Pevzner, A. A. Khutornenko, E. Y. Plotnikov, G. T. Sukhikh and D. B. Zorov (2015). "Improving the Post-Stroke Therapeutic Potency of Mesenchymal Multipotent Stromal Cells by Cocultivation With Cortical Neurons: The Role of Crosstalk Between Cells." Stem Cells Transl Med 4(9): 1011-1020.

Bakshi, A., A. L. Barshinger, S. A. Swanger, V. Madhavani, J. S. Shumsky, B. Neuhuber and I. Fischer (2006). "Lumbar puncture delivery of bone marrow stromal cells in spinal cord contusion: a novel method for minimally invasive cell transplantation." J Neurotrauma 23(1): 55-65.

Bakshi, A., C. Hunter, S. Swanger, A. Lepore and I. Fischer (2004). "Minimally invasive delivery of stem cells for spinal cord injury: advantages of the lumbar puncture technique." J Neurosurg Spine 1(3): 330-337.

Barbosa da Fonseca, L. M., B. Gutfilen, P. H. Rosado de Castro, V. Battistella, R. C. Goldenberg, T. Kasai-Brunswick, C. L. Chagas, E. Wajnberg, A. Maiolino, S. Salles Xavier, C. Andre, R. Mendez-Otero and G. R. de Freitas (2010). "Migration and homing of bone-marrow mononuclear cells in chronic ischemic stroke after intraarterial injection." Experimental neurology 221(1): 122-128.

Bareyre, F. M. (2008). "Neuronal repair and replacement in spinal cord injury." J Neurol Sci 265(1-2): 63-72.

Barry, J., Y. Gu and C. Gu (2010). "Polarized targeting of L1-CAM regulates axonal and dendritic bundling in vitro." Eur J Neurosci 32(10): 1618-1631.

Barzilay, R., I. Kan, T. Ben-Zur, S. Bulvik, E. Melamed and D. Offen (2008). "Induction of human mesenchymal stem cells into dopamine-producing cells with different differentiation protocols." Stem Cells Dev 17(3): 547554.

Barzilay, R., Y. S. Levy, E. Melamed and D. Offen (2006). "Adult stem cells for neuronal repair." The Israel Medical Association journal : IMAJ 8(1): 61-66.

Basso, D. M., M. S. Beattie and J. C. Bresnahan (1995). "A sensitive and reliable locomotor rating scale for open field testing in rats." Journal of neurotrauma 12(1): 1-21.

Basso, D. M., M. S. Beattie and J. C. Bresnahan (1996). "Graded histological and locomotor outcomes after spinal cord contusion using the NYU weight-drop device versus transection." Experimental neurology 139(2): 244-256. 
Battistella, V., G. R. de Freitas, L. M. da Fonseca, D. Mercante, B. Gutfilen, R. C. Goldenberg, J. V. Dias, T. H. KasaiBrunswick, E. Wajnberg, P. H. Rosado-de-Castro, S. V. Alves-Leon, R. Mendez-Otero and C. Andre (2011). "Safety of autologous bone marrow mononuclear cell transplantation in patients with nonacute ischemic stroke." Regenerative medicine 6(1): 45-52.

Bavisotti, C. C., F. Scalia, A. M. Gammazza and e. al. (2019). "Review: extracellular vesicle-mediated cell-cell communication in the nervous system: focus on neurological diseases." Int. J. Mol. Sci 20: 434-457.

Beattie, M. S., A. A. Farooqui and J. C. Bresnahan (2000). "Review of current evidence for apoptosis after spinal cord injury." J Neurotrauma 17(10): 915-925.

Beers, D. R. and S. H. Appel (2019). "Immune dysregulation in amyotrophic lateral sclerosis: mechanisms and emerging therapies." Lancet Neurol 18(2): 211-220.

Bejot, Y., H. Bailly, J. Durier and M. Giroud (2016). "Epidemiology of stroke in Europe and trends for the 21st century." Presse Med 45(12 Pt 2): e391-e398.

Ben-David, U., N. Benvenisty and Y. Mayshar (2010). "Genetic instability in human induced pluripotent stem cells: classification of causes and possible safeguards." Cell Cycle 9(23): 4603-4604.

Benet, L. Z., C. M. Bowman, M. L. Koleske, C. L. Rinaldi and J. K. Sodhi (2019). "Understanding drug-drug interaction and pharmacogenomic changes in pharmacokinetics for metabolized drugs." J Pharmacokinet Pharmacodyn 46(2): 155-163.

Beugels J, de Munter JP, Van der Hulst R, Kramer BW, Wolters ECh (2019). Efficacy of different doses of human autologous adult bone marrow stem cell transplantation on angiogenesis in an immune deficient rat model with hind limb ischemia. J Stem Cell Res Dev DOI:10.24966/SRDT-2060/S1002

Beurel, E., S. F. Grieco and R. S. Jope (2015). "Glycogen synthase kinase-3 (GSK3): regulation, actions, and diseases." Pharmacol Ther 148: 114-131.

Beurel, E., O. Kaidanovich-Beilin, W. I. Yeh, L. Song, V. Palomo, S. M. Michalek, J. R. Woodgett, L. E. Harrington, H. Eldar-Finkelman, A. Martinez and R. S. Jope (2013). "Regulation of Th1 cells and experimental autoimmune encephalomyelitis by glycogen synthase kinase-3." J Immunol 190(10): 5000-5011.

Bjorklund, A., D. Kirik, C. Rosenblad, B. Georgievska, C. Lundberg and R. J. Mandel (2000). "Towards a neuroprotective gene therapy for Parkinson's disease: use of adenovirus, AAV and lentivirus vectors for gene transfer of GDNF to the nigrostriatal system in the rat Parkinson model." Brain research 886(1-2): 82-98.

Bjugstad, K. B., Y. D. Teng, D. E. Redmond, Jr., J. D. Elsworth, R. H. Roth, S. K. Cornelius, E. Y. Snyder and J. R. Sladek, Jr. (2008). "Human neural stem cells migrate along the nigrostriatal pathway in a primate model of Parkinson's disease." Experimental neurology 211(2): 362-369.

Blair, I. P., K. L. Williams, S. T. Warraich, J. C. Durnall, A. D. Thoeng, J. Manavis, P. C. Blumbergs, S. Vucic, M. C. Kiernan and G. A. Nicholson (2010). "FUS mutations in amyotrophic lateral sclerosis: clinical, pathological, neurophysiological and genetic analysis." J Neurol Neurosurg Psychiatry 81(6): 639-645.

Blandini, F., L. Cova, M. T. Armentero, E. Zennaro, G. Levandis, P. Bossolasco, C. Calzarossa, M. Mellone, B. Giuseppe, G. L. Deliliers, E. Polli, G. Nappi and V. Silani (2010). "Transplantation of undifferentiated human mesenchymal stem cells protects against 6-hydroxydopamine neurotoxicity in the rat." Cell Transplant 19(2): 203-217.

Blaser, H., C. Dostert, T. W. Mak and D. Brenner (2016). "TNF and ROS Crosstalk in Inflammation." Trends Cell Biol 26(4): 249-261.

Blight, A. R. (1983). "Cellular morphology of chronic spinal cord injury in the cat: analysis of myelinated axons by line-sampling." Neuroscience 10(2): 521-543.

Blits, B., B. M. Kitay, A. Farahvar, C. V. Caperton, W. D. Dietrich and M. B. Bunge (2005). "Lentiviral vectormediated transduction of neural progenitor cells before implantation into injured spinal cord and brain to detect their migration, deliver neurotrophic factors and repair tissue." Restorative neurology and neuroscience 23(5-6): 313-324.

Blurton-Jones, M., M. Kitazawa, H. Martinez-Coria, N. A. Castello, F. J. Muller, J. F. Loring, T. R. Yamasaki, W. W. Poon, K. N. Green and F. M. LaFerla (2009). "Neural stem cells improve cognition via BDNF in a transgenic model of Alzheimer disease." Proceedings of the National Academy of Sciences of the United States of America 106(32): 13594-13599. 
Boido, M., A. Piras, V. Valsecchi, G. Spigolon, K. Mareschi, I. Ferrero, A. Vizzini, S. Temi, L. Mazzini, F. Fagioli and A. Vercelli (2014). "Human mesenchymal stromal cell transplantation modulates neuroinflammatory milieu in a mouse model of amyotrophic lateral sclerosis." Cytotherapy 16(8): 1059-1072.

Bonin, R. P., C. Bories and Y. De Koninck (2014). "A simplified up-down method (SUDO) for measuring mechanical nociception in rodents using von Frey filaments." Mol Pain 10: 26.

Botelho, R. V., J. W. Daniel, J. L. Boulosa, B. O. Colli, L. Farias Rde, O. J. Moraes, W. E. Pimenta, Jr., C. H. Ribeiro, F. R. Ribeiro, M. A. Taricco, M. V. Carvalho and W. M. Bernardo (2009). "[Effectiveness of methylprednisolone in the acute phase of spinal cord injuries--a systematic review of randomized controlled trials]." Revista da Associacao Medica Brasileira 55(6): 729-737.

Bouchez, G., L. Sensebe, P. Vourc'h, L. Garreau, S. Bodard, A. Rico, D. Guilloteau, P. Charbord, J. C. Besnard and S. Chalon (2008). "Partial recovery of dopaminergic pathway after graft of adult mesenchymal stem cells in a rat model of Parkinson's disease." Neurochemistry international 52(7): 1332-1342.

Bouhy, D., B. Malgrange, S. Multon, A. L. Poirrier, F. Scholtes, J. Schoenen and R. Franzen (2006). "Delayed GMCSF treatment stimulates axonal regeneration and functional recovery in paraplegic rats via an increased BDNF expression by endogenous macrophages." FASEB journal : official publication of the Federation of American Societies for Experimental Biology 20(8): 1239-1241.

Bovolenta, L. A., M. L. Acencio and N. Lemke (2012). "HTRIdb: an open-access database for experimentally verified human transcriptional regulation interactions." BMC Genomics 13: 405.

Bracken, M. B. (2002). "Steroids for acute spinal cord injury." Cochrane database of systematic reviews(3): CD001046.

Bracken, M. B. (2012). "Steroids for acute spinal cord injury." Cochrane Database Syst Rev 1: CD001046.

Bracken, M. B., M. J. Shepard, T. R. Holford, L. Leo-Summers, E. F. Aldrich, M. Fazl, M. G. Fehlings, D. L. Herr, P. W. Hitchon, L. F. Marshall, R. P. Nockels, V. Pascale, P. L. Perot, Jr., J. Piepmeier, V. K. Sonntag, F. Wagner, J. E. Wilberger, H. R. Winn and W. Young (1998). "Methylprednisolone or tirilazad mesylate administration after acute spinal cord injury: 1-year follow up. Results of the third National Acute Spinal Cord Injury randomized controlled trial." Journal of neurosurgery 89(5): 699-706.

Brochard, V., B. Combadiere, A. Prigent, Y. Laouar, A. Perrin, V. Beray-Berthat, O. Bonduelle, D. Alvarez-Fischer, J. Callebert, J. M. Launay, C. Duyckaerts, R. A. Flavell, E. C. Hirsch and S. Hunot (2009). "Infiltration of CD4+ lymphocytes into the brain contributes to neurodegeneration in a mouse model of Parkinson disease." J Clin Invest 119(1): 182-192.

Broussalis, E., M. Killer, M. McCoy, A. Harrer, E. Trinka and J. Kraus (2011). "Current therapies in ischemic stroke. Part A. Recent developments in acute stroke treatment and in stroke prevention." Drug discovery today.

Browne, E. C. and B. M. Abbott (2016). "Recent progress towards an effective treatment of amyotrophic lateral sclerosis using the SOD1 mouse model in a preclinical setting." Eur J Med Chem 121: 918-925.

Bruderer, R., O. M. Bernhardt, T. Gandhi, S. M. Miladinovic, L. Y. Cheng, S. Messner, T. Ehrenberger, V. Zanotelli, Y. Butscheid, C. Escher, O. Vitek, O. Rinner and L. Reiter (2015). "Extending the limits of quantitative proteome profiling with data-independent acquisition and application to acetaminophen-treated threedimensional liver microtissues." Mol Cell Proteomics 14(5): 1400-1410.

Bruno, A., C. Saha and L. S. Williams (2006). "Using change in the National Institutes of Health Stroke Scale to measure treatment effect in acute stroke trials." Stroke; a journal of cerebral circulation 37(3): 920-921.

Bunge, R. P., W. R. Puckett, J. L. Becerra, A. Marcillo and R. M. Quencer (1993). "Observations on the pathology of human spinal cord injury. A review and classification of 22 new cases with details from a case of chronic cord compression with extensive focal demyelination." Adv Neurol 59: 75-89.

Cabanes, C., S. Bonilla, L. Tabares and S. Martinez (2007). "Neuroprotective effect of adult hematopoietic stem cells in a mouse model of motoneuron degeneration." Neurobiol Dis 26(2): 408-418.

Cahan, P., H. Li, S. A. Morris, E. Lummertz da Rocha, G. Q. Daley and J. J. Collins (2014). "CellNet: network biology applied to stem cell engineering." Cell 158(4): 903-915.

Calvo, A., C. Moglia, M. Balma and A. Chio (2010). "Involvement of immune response in the pathogenesis of amyotrophic lateral sclerosis: a therapeutic opportunity?" CNS Neurol Disord Drug Targets 9(3): 325-330.

Caplan, A. I. (2015). "Adult Mesenchymal Stem Cells: When, Where, and How." Stem Cells Int 2015: 628767. 
Caplan, A. I. (2017). "Mesenchymal Stem Cells: Time to Change the Name!" Stem Cells Transl Med 6(6): 14451451.

Caplan, A. I. and J. E. Dennis (2006). "Mesenchymal stem cells as trophic mediators." J Cell Biochem 98(5): 10761084.

Carvalho, K. A., E. N. Vialle, G. H. Moreira, R. C. Cunha, R. B. Simeoni, J. C. Francisco, L. C. Guarita-Souza, L. Oliveira, L. Zocche and M. Olandoski (2008). "Functional outcome of bone marrow stem cells (CD45(+)/CD34(-)) after cell therapy in chronic spinal cord injury in Wistar rats." Transplantation proceedings 40(3): 845846.

Cedarbaum, J. M., N. Stambler, E. Malta, C. Fuller, D. Hilt, B. Thurmond and A. Nakanishi (1999). "The ALSFRS-R: a revised ALS functional rating scale that incorporates assessments of respiratory function. BDNF ALS Study Group (Phase III)." J Neurol Sci 169(1-2): 13-21.

Cerri, S., R. Greco, G. Levandis, C. Ghezzi, A. S. Mangione, M. T. Fuzzati-Armentero, A. Bonizzi, M. A. Avanzini, R. Maccario and F. Blandini (2015). "Intracarotid Infusion of Mesenchymal Stem Cells in an Animal Model of Parkinson's Disease, Focusing on Cell Distribution and Neuroprotective and Behavioral Effects." Stem Cells Transl Med 4(9): 1073-1085.

Chamberlain, J. D., S. Meier, L. Mader, P. M. von Groote and M. W. Brinkhof (2015). "Mortality and longevity after a spinal cord injury: systematic review and meta-analysis." Neuroepidemiology 44(3): 182-198.

Chan, J. L., K. C. Tang, A. P. Patel, L. M. Bonilla, N. Pierobon, N. M. Ponzio and P. Rameshwar (2006). "Antigenpresenting property of mesenchymal stem cells occurs during a narrow window at low levels of interferon-gamma." Blood 107(12): 4817-4824.

Chao, Y. X., B. P. He and S. S. Tay (2009). "Mesenchymal stem cell transplantation attenuates blood brain barrier damage and neuroinflammation and protects dopaminergic neurons against MPTP toxicity in the substantia nigra in a model of Parkinson's disease." Journal of neuroimmunology 216(1-2): 39-50.

Chen, H. H., S. C. Schock, J. Xu, F. Safarpour, C. S. Thompson and A. F. Stewart (2007). "Extracellular ATP-dependent upregulation of the transcription cofactor LMO4 promotes neuron survival from hypoxia." Exp Cell Res 313(14): 3106-3116.

Chen, L., D. M. He and Y. Zhang (2009). "The differentiation of human placenta-derived mesenchymal stem cells into dopaminergic cells in vitro." Cell Mol Biol Lett 14(3): 528-536.

Chen, X., W. Liu, Y. Guoyuan, Z. Liu, S. Smith, D. B. Calne and S. Chen (2003). "Protective effects of intracerebral adenoviral-mediated GDNF gene transfer in a rat model of Parkinson's disease." Parkinsonism \& related disorders 10(1): 1-7.

Chen, Y. B., Q. Z. Jia, D. J. Li, J. H. Sun, S. Xi, L. P. Liu, D. X. Gao and D. W. Jiang (2015). "Spinal cord injury in rats treated using bone marrow mesenchymal stem-cell transplantation." Int J Clin Exp Med 8(6): 9348-9354.

Cheng, X., Y. Wang, Q. He, M. Qiu, S. R. Whittemore and Q. Cao (2007). "Bone morphogenetic protein signaling and olig1/2 interact to regulate the differentiation and maturation of adult oligodendrocyte precursor cells." Stem Cells 25(12): 3204-3214.

Chernykh, E. R., V. V. Stupak, G. M. Muradov, M. Y. Sizikov, E. Y. Shevela, O. Y. Leplina, M. A. Tikhonova, A. D. Kulagin, I. A. Lisukov, A. A. Ostanin and V. A. Kozlov (2007). "Application of autologous bone marrow stem cells in the therapy of spinal cord injury patients." Bull Exp Biol Med 143(4): 543-547.

Chia, R., A. Chio and B. J. Traynor (2018). "Novel genes associated with amyotrophic lateral sclerosis: diagnostic and clinical implications." Lancet Neurol 17(1): 94-102.

Chitnis, T. and H. L. Weiner (2017). "CNS inflammation and neurodegeneration." J Clin Invest 127(10): 3577-3587.

Cho, G. W., M. Y. Noh, H. Y. Kim, S. H. Koh, K. S. Kim and S. H. Kim (2010). "Bone marrow-derived stromal cells from amyotrophic lateral sclerosis patients have diminished stem cell capacity." Stem Cells Dev 19(7): 1035-1042.

Chu, W. M. (2013). "Tumor necrosis factor." Cancer Lett 328(2): 222-225.

Ciervo, Y., K. Ning, X. Jun, P. J. Shaw and R. J. Mead (2017). "Advances, challenges and future directions for stem cell therapy in amyotrophic lateral sclerosis." Mol Neurodegener 12(1): 85.

Cizkova, D., V. Cubinkova, T. Smolek, A. N. Murgoci, J. Danko, K. Vdoviakova, F. Humenik, M. Cizek, J. Quanico, I. Fournier and M. Salzet (2018). "Localized Intrathecal Delivery of Mesenchymal Stromal Cells Conditioned Medium Improves Functional Recovery in a Rat Model of Spinal Cord Injury." Int J Mol Sci 19(3). 
Cizkova, D., F. Le Marrec-Croq, J. Franck, L. Slovinska, I. Grulova, S. Devaux, C. Lefebvre, I. Fournier and M. Salzet (2014). "Alterations of protein composition along the rostro-caudal axis after spinal cord injury: proteomic, in vitro and in vivo analyses." Front Cell Neurosci 8: 105.

Cizkova, D., J. Rosocha, I. Vanicky, S. Jergova and M. Cizek (2006). "Transplants of human mesenchymal stem cells improve functional recovery after spinal cord injury in the rat." Cell Mol Neurobiol 26(7-8): 1167-1180.

Cline, B. H., H. W. Steinbusch, D. Malin, A. V. Revishchin, G. V. Pavlova, R. Cespuglio and T. Strekalova (2012). "The neuronal insulin sensitizer dicholine succinate reduces stress-induced depressive traits and memory deficit: possible role of insulin-like growth factor 2." BMC Neurosci 13: 110.

Cobellis, G., C. Maione, C. Botti, A. Coppola, A. Silvestroni, S. Lillo, V. Schiavone, A. M. Molinari and V. Sica (2010). "Beneficial effects of VEGF secreted from stromal cells in supporting endothelial cell functions: therapeutic implications for critical limb ischemia." Cell Transplant.

Cofano, F., M. Boido, M. Monticelli, F. Zenga, A. Ducati, A. Vercelli and D. Garbossa (2019). "Mesenchymal Stem Cells for Spinal Cord Injury: Current Options, Limitations, and Future of Cell Therapy." Int J Mol Sci 20(11).

Collins, M. and R. Bowser (2017). "Molecular and cellular therapies for motor neuron diseases." Amsterdam Academic Press: 61-99.

Corcione, A., F. Benvenuto, E. Ferretti, D. Giunti, V. Cappiello, F. Cazzanti, M. Risso, F. Gualandi, G. L. Mancardi, V. Pistoia and A. Uccelli (2006). "Human mesenchymal stem cells modulate B-cell functions." Blood 107(1): 367-372.

Costa-Nunes, J. P., B. H. Cline, M. Araujo-Correia, A. Valenca, N. Markova, O. Dolgov, A. Kubatiev, N. Yeritsyan, H. W. Steinbusch and T. Strekalova (2015). "Animal Models of Depression and Drug Delivery with Food as an Effective Dosing Method: Evidences from Studies with Celecoxib and Dicholine Succinate." Biomed Res Int 2015: 596126.

Couch, Y., D. C. Anthony, O. Dolgov, A. Revischin, B. Festoff, A. I. Santos, H. W. Steinbusch and T. Strekalova (2013). "Microglial activation, increased TNF and SERT expression in the prefrontal cortex define stress-altered behaviour in mice susceptible to anhedonia." Brain Behav Immun 29: 136-146.

Couch, Y., A. Trofimov, N. Markova, V. Nikolenko, H. W. Steinbusch, V. Chekhonin, C. Schroeter, K. P. Lesch, D. C. Anthony and T. Strekalova (2016). "Low-dose lipopolysaccharide (LPS) inhibits aggressive and augments depressive behaviours in a chronic mild stress model in mice." J Neuroinflammation 13(1): 108.

Courtine, G., M. B. Bunge, J. W. Fawcett, R. G. Grossman, J. H. Kaas, R. Lemon, I. Maier, J. Martin, R. J. Nudo, A. Ramon-Cueto, E. M. Rouiller, L. Schnell, T. Wannier, M. E. Schwab and V. R. Edgerton (2007). "Can experiments in nonhuman primates expedite the translation of treatments for spinal cord injury in humans?" Nature medicine 13(5): 561-566.

Cova, L., M. T. Armentero, E. Zennaro, C. Calzarossa, P. Bossolasco, G. Busca, G. Lambertenghi Deliliers, E. Polli, G. Nappi, V. Silani and F. Blandini (2010). "Multiple neurogenic and neurorescue effects of human mesenchymal stem cell after transplantation in an experimental model of Parkinson's disease." Brain research 1311: 12-27.

Cox, C. S., Jr., J. E. Baumgartner, M. T. Harting, L. L. Worth, P. A. Walker, S. K. Shah, L. Ewing-Cobbs, K. M. Hasan, M. C. Day, D. Lee, F. Jimenez and A. Gee (2011). "Autologous bone marrow mononuclear cell therapy for severe traumatic brain injury in children." Neurosurgery 68(3): 588-600.

Crigler, L., R. C. Robey, A. Asawachaicharn, D. Gaupp and D. G. Phinney (2006). "Human mesenchymal stem cell subpopulations express a variety of neuro-regulatory molecules and promote neuronal cell survival and neuritogenesis." Exp Neurol 198(1): 54-64.

Crisafulli, S. G., S. Brajkovic, M. S. Cipolat Mis, V. Parente and S. Corti (2018). "Therapeutic Strategies Under Development Targeting Inflammatory Mechanisms in Amyotrophic Lateral Sclerosis." Mol Neurobiol 55(4): 2789-2813.

Crivello, M., M. C. Hogg, E. Jirstrom, L. Halang, I. Woods, M. Rayner, K. S. Coughlan, S. A. Lewandowski and J. H. M. Prehn (2019). "Vascular regression precedes motor neuron loss in the FUS (1-359) ALS mouse model." Dis Model Mech 12(8).

Croft, A. P. and S. A. Przyborski (2009). "Mesenchymal stem cells expressing neural antigens instruct a neurogenic cell fate on neural stem cells." Experimental neurology 216(2): 329-341. 
Dalous, J., J. Larghero and O. Baud (2012). "Transplantation of umbilical cord-derived mesenchymal stem cells as a novel strategy to protect the central nervous system: technical aspects, preclinical studies, and clinical perspectives." Pediatric research 71(4 Pt 2): 482-490.

Danielyan, L., R. Schafer, A. von Ameln-Mayerhofer, F. Bernhard, S. Verleysdonk, M. Buadze, A. Lourhmati, T. Klopfer, F. Schaumann, B. Schmid, C. Koehle, B. Proksch, R. Weissert, H. M. Reichardt, J. van den Brandt, G. H. Buniatian, M. Schwab, C. H. Gleiter and W. H. Frey, 2nd (2011). "Therapeutic efficacy of intranasally delivered mesenchymal stem cells in a rat model of Parkinson disease." Rejuvenation research 14(1): 316.

Dass, B., C. W. Olanow and J. H. Kordower (2006). "Gene transfer of trophic factors and stem cell grafting as treatments for Parkinson's disease." Neurology 66(10 Suppl 4): S89-103.

de Lau, L. M. and M. M. Breteler (2006). "Epidemiology of Parkinson's disease." Lancet Neurol 5(6): 525-535.

de Munter J, Babaevskaya D, Wolters E, et al (2020). "Molecular and behavioural abnormalities in the FUS-tg mice mimic frontotemporal lobar degeneration: Effects of old and new anti-inflammatory therapies". J Cell Mol Med 00:1-7 DOI: 10.1111/jcmm.15628.

de Munter JP, Mey J, Strekalova T, Kramer BW, Wolters ECh (2020) Why do anti-inflammatory signals of bone marrow-derived stromal cells improve neuro-degenerative conditions where anti-inflammatory drugs fail? J Neural Transm DOI: 10.1007/s00702-020-02173-3

de Munter J, I. Shafarevich, A. Liundup, D. Pavlov, E. C. Wolters, A. Gorlova, E. Veniaminova, A. Umriukhin, A. Kalueff, A. Svistunov, B. W. Kramer, K. P. Lesch and T. Strekalova (2019). "Neuro-Cells therapy improves motor outcomes and suppresses inflammation during experimental syndrome of amyotrophic lateral sclerosis in mice." CNS Neurosci Therapeutics, 5: 504-517.

de Munter, J. P., J. Beugels, S. De Munter, L. Janssen, B. Cillero-Pastor, O. Moskvin, G. Brook, D. Pavlov, T. Strekalova, B. W. Kramer and E. C. Wolters (2019). "Standardized human bone marrow-derived stem cells infusion improves survival and recovery in a rat model of spinal cord injury." J Neurol Sci 402: 16-29.

de Munter, J. P., C. Lee and E. C. Wolters (2013). "Cell based therapy in Parkinsonism." TransI Neurodegener 2(1): 13.

de Munter, J.P., Melamed, E., Wolters, E.Ch (2013). "Stem cell grafting in parkinsonism - Why, how and when." Parkinsonism \& related disorders 20 Suppl 1: S67-70.

de Munter, J. P. and E. Wolters (2013). Autologous adult stem cells in ischemic and traumatic CNS disorders." J Neural Transm 120(1): 91-102.

de Munter, J. P. and E. C. Wolters (2013). "Autologous stem cells in neurology: is there a future?" J Neural Transm 120(1): 65-73.

Deda, H., M. C. Inci, A. E. Kurekci, K. Kayihan, E. Ozgun, G. E. Ustunsoy and S. Kocabay (2008). "Treatment of chronic spinal cord injured patients with autologous bone marrow-derived hematopoietic stem cell transplantation: 1-year follow-up." Cytotherapy 10(6): 565-574.

Deda, H., M. C. Inci, A. E. Kurekci, A. Sav, K. Kayihan, E. Ozgun, G. E. Ustunsoy and S. Kocabay (2009). "Treatment of amyotrophic lateral sclerosis patients by autologous bone marrow-derived hematopoietic stem cell transplantation: a 1-year follow-up." Cytotherapy 11(1): 18-25.

Delcroix, G. J., K. M. Curtis, P. C. Schiller and C. N. Montero-Menei (2010). "EGF and bFGF pre-treatment enhances neural specification and the response to neuronal commitment of MIAMI cells." Differentiation 80(4-5): 213-227.

Delcroix, G. J., E. Garbayo, L. Sindji, O. Thomas, C. Vanpouille-Box, P. C. Schiller and C. N. Montero-Menei (2011). "The therapeutic potential of human multipotent mesenchymal stromal cells combined with pharmacologically active microcarriers transplanted in hemi-parkinsonian rats." Biomaterials 32(6): 15601573.

DeLoach, A., M. Cozart, A. Kiaei and M. Kiaei (2015). "A retrospective review of the progress in amyotrophic lateral sclerosis drug discovery over the last decade and a look at the latest strategies." Expert Opin Drug Discov 10(10): 1099-1118.

Deuis, J. R., L. S. Dvorakova and I. Vetter (2017). "Methods Used to Evaluate Pain Behaviors in Rodents." Front Mol Neurosci 10: 284. 
Devaux, S., D. Cizkova, J. Quanico, J. Franck, S. Nataf, L. Pays, L. Hauberg-Lotte, P. Maass, J. H. Kobarg, F. Kobeissy, C. Meriaux, M. Wisztorski, L. Slovinska, J. Blasko, V. Cigankova, I. Fournier and M. Salzet (2016). "Proteomic Analysis of the Spatio-temporal Based Molecular Kinetics of Acute Spinal Cord Injury Identifies a Time- and Segment-specific Window for Effective Tissue Repair." Mol Cell Proteomics 15(8): 2641-2670.

DeVivo, M. J. (1997). "Causes and costs of spinal cord injury in the United States." Spinal Cord 35(12): 809-813.

Dezawa, M., H. Kanno, M. Hoshino, H. Cho, N. Matsumoto, Y. Itokazu, N. Tajima, H. Yamada, H. Sawada, H. Ishikawa, T. Mimura, M. Kitada, Y. Suzuki and C. Ide (2004). "Specific induction of neuronal cells from bone marrow stromal cells and application for autologous transplantation." The Journal of clinical investigation 113(12): 1701-1710.

Diaz-Ruiz, A., P. Vergara, F. Perez-Severiano, J. Segovia, G. Guizar-Sahagun, A. Ibarra and C. Rios (2004). "Cyclosporin-A inhibits inducible nitric oxide synthase activity and expression after spinal cord injury in rats." Neurosci Lett 357(1): 49-52.

Diem-Zangerl, A., K. Seppi, W. Oberaigner and W. Poewe (2010). "Mortality in Parkinson's disease, a 20-year follow-up study." Mov Disord 25(5): 661-662.

Dignat-George, F. and C. M. Boulanger (2011). "The many faces of endothelial microparticles." Arterioscler Thromb Vasc Biol 31(1): 27-33.

Dimmeler, S. and A. Leri (2008). "Aging and disease as modifiers of efficacy of cell therapy." Circulation research 102(11): 1319-1330.

Dominici, M., K. Le Blanc, I. Mueller, I. Slaper-Cortenbach, F. Marini, D. Krause, R. Deans, A. Keating, D. Prockop and E. Horwitz (2006). "Minimal criteria for defining multipotent mesenchymal stromal cells. The International Society for Cellular Therapy position statement." Cytotherapy 8(4): 315-317.

Donders, R., M. Vanheusden, J. F. Bogie, S. Ravanidis, K. Thewissen, P. Stinissen, W. Gyselaers, J. J. Hendriks and N. Hellings (2015). "Human Wharton's Jelly-Derived Stem Cells Display Immunomodulatory Properties and Transiently Improve Rat Experimental Autoimmune Encephalomyelitis." Cell Transplant 24(10): $2077-$ 2098.

Donnelly, D. J. and P. G. Popovich (2008). "Inflammation and its role in neuroprotection, axonal regeneration and functional recovery after spinal cord injury." Experimental neurology 209(2): 378-388.

Dorsey, E. R., R. Constantinescu, J. P. Thompson, K. M. Biglan, R. G. Holloway, K. Kieburtz, F. J. Marshall, B. M. Ravina, G. Schifitto, A. Siderowf and C. M. Tanner (2007). "Projected number of people with Parkinson disease in the most populous nations, 2005 through 2030." Neurology 68(5): 384-386.

Dostert, G., B. Mesure, P. Menu and E. Velot (2017). "How Do Mesenchymal Stem Cells Influence or Are Influenced by Microenvironment through Extracellular Vesicles Communication?" Front Cell Dev Biol 5: 6.

Driver, J. A., T. Kurth, J. E. Buring, J. M. Gaziano and G. Logroscino (2008). "Parkinson disease and risk of mortality: a prospective comorbidity-matched cohort study." Neurology 70(16 Pt 2): 1423-1430.

Du, Y., X. Li, D. Yang, X. Zhang, S. Chen, K. Huang and W. Le (2008). "Multiple molecular pathways are involved in the neuroprotection of GDNF against proteasome inhibitor induced dopamine neuron degeneration in vivo." Experimental biology and medicine 233(7): 881-890.

Duda, P., J. Wisniewski, T. Wojtowicz, O. Wojcicka, M. Jaskiewicz, D. Drulis-Fajdasz, D. Rakus, J. A. McCubrey and A. Gizak (2018). "Targeting GSK3 signaling as a potential therapy of neurodegenerative diseases and aging." Expert Opin Ther Targets 22(10): 833-848.

Dunac, A., C. Frelin, M. Popolo-Blondeau, M. Chatel, M. H. Mahagne and P. J. Philip (2007). "Neurological and functional recovery in human stroke are associated with peripheral blood CD34+ cell mobilization." Journal of neurology 254(3): 327-332.

Durinck, S., P. T. Spellman, E. Birney and W. Huber (2009). "Mapping identifiers for the integration of genomic datasets with the R/Bioconductor package biomaRt." Nat Protoc 4(8): 1184-1191.

Duty, S. and P. Jenner (2011). "Animal models of Parkinson's disease: a source of novel treatments and clues to the cause of the disease." Br J Pharmacol 164(4): 1357-1391.

Eggen, B. J., D. Raj, U. K. Hanisch and H. W. Boddeke (2013). "Microglial phenotype and adaptation." J Neuroimmune Pharmacol 8(4): 807-823.

Eggenhofer, E., F. Luk, M. H. Dahlke and M. J. Hoogduijn (2014). "The life and fate of mesenchymal stem cells." Front Immunol 5: 148. 
Engelhardt, B. and L. Sorokin (2009). "The blood-brain and the blood-cerebrospinal fluid barriers: function and dysfunction." Seminars in immunopathology 31(4): 497-511.

Erkkinen, M. G., M. O. Kim and M. D. Geschwind (2018). "Clinical Neurology and Epidemiology of the Major Neurodegenerative Diseases." Cold Spring Harb Perspect Biol 10(4).

Ethell, I. M. and D. W. Ethell (2007). "Matrix metalloproteinases in brain development and remodeling: synaptic functions and targets." J Neurosci Res 85(13): 2813-2823.

Fabregat, A., K. Sidiropoulos, P. Garapati, M. Gillespie, K. Hausmann, R. Haw, B. Jassal, S. Jupe, F. Korninger, S. McKay, L. Matthews, B. May, M. Milacic, K. Rothfels, V. Shamovsky, M. Webber, J. Weiser, M. Williams, G. Wu, L. Stein, H. Hermjakob and P. D'Eustachio (2016). "The Reactome pathway Knowledgebase." Nucleic Acids Res 44(D1): D481-487.

Fadini, G. P., C. Agostini and A. Avogaro (2010). "Autologous stem cell therapy for peripheral arterial disease metaanalysis and systematic review of the literature." Atherosclerosis 209(1): 10-17.

Falavigna, A., F. W. Quadros, A. R. Teles, C. C. Wong, G. Barbagallo, D. Brodke, A. Al-Mutair and K. D. Riew (2018). "Worldwide Steroid Prescription for Acute Spinal Cord Injury." Global Spine J 8(3): 303-310.

Fancy, S. P., C. Zhao and R. J. Franklin (2004). "Increased expression of Nkx2.2 and Olig2 identifies reactive oligodendrocyte progenitor cells responding to demyelination in the adult CNS." Mol Cell Neurosci 27(3): 247-254.

Farkouh, A., T. Riedl, R. Gottardi, M. Czejka and A. Kautzky-Willer (2019). "Sex-Related Differences in Pharmacokinetics and Pharmacodynamics of Frequently Prescribed Drugs: A Review of the Literature." Adv Ther.

Fehlings, M. G., J. R. Wilson, J. S. Harrop, B. K. Kwon, L. A. Tetreault, P. M. Arnold, J. M. Singh, G. Hawryluk and J. R. Dettori (2017). "Efficacy and Safety of Methylprednisolone Sodium Succinate in Acute Spinal Cord Injury: A Systematic Review." Global Spine J 7(3 Suppl): 116S-137S.

Feigin, V. L., C. M. Lawes, D. A. Bennett and C. S. Anderson (2003). "Stroke epidemiology: a review of populationbased studies of incidence, prevalence, and case-fatality in the late 20th century." Lancet neurology 2(1): 43-53.

Ferreira, R. J., A. C. Irioda, R. C. Cunha, J. C. Francisco, L. C. Guarita-Souza, G. V. Srikanth, S. Nityanand, R. Rosati, J. C. Chachques and K. A. de Carvalho (2012). "Controversies about the chromosomal stability of cultivated mesenchymal stem cells: their clinical use is it safe?" Curr Stem Cell Res Ther 7(5): 356-363.

Filiano, A. J., L. H. Martens, A. H. Young, B. A. Warmus, P. Zhou, G. Diaz-Ramirez, J. Jiao, Z. Zhang, E. J. Huang, F. B. Gao, R. V. Farese, Jr. and E. D. Roberson (2013). "Dissociation of frontotemporal dementia-related deficits and neuroinflammation in progranulin haploinsufficient mice." J Neurosci 33(12): 5352-5361.

Fillmore, H. L., K. L. Holloway and G. T. Gillies (2005). "Cell replacement efforts to repair neuronal injury: a potential paradigm for the treatment of Parkinson's disease." NeuroRehabilitation 20(3): 233-242.

Fischbach, M. A., J. A. Bluestone and W. A. Lim (2013). "Cell-based therapeutics: the next pillar of medicine." Sci Transl Med 5(179): 179ps177.

Fischer, U. M., M. T. Harting, F. Jimenez, W. O. Monzon-Posadas, H. Xue, S. I. Savitz, G. A. Laine and C. S. Cox, Jr. (2009). "Pulmonary passage is a major obstacle for intravenous stem cell delivery: the pulmonary firstpass effect." Stem Cells Dev 18(5): 683-692.

Fitzsimmons, R. E. B., M. S. Mazurek, A. Soos and C. A. Simmons (2018). "Mesenchymal Stromal/Stem Cells in Regenerative Medicine and Tissue Engineering." Stem Cells Int 2018: 8031718.

Fondell, E., E. J. O'Reilly, K. C. Fitzgerald, G. J. Falcone, M. L. McCullough, M. J. Thun, Y. Park, L. N. Kolonel and A. Ascherio (2012). "Non-steroidal anti-inflammatory drugs and amyotrophic lateral sclerosis: results from five prospective cohort studies." Amyotroph Lateral Scler 13(6): 573-579.

Forostyak, S., P. Jendelova, M. Kapcalova, D. Arboleda and E. Sykova (2011). "Mesenchymal stromal cells prolong the lifespan in a rat model of amyotrophic lateral sclerosis." Cytotherapy 13(9): 1036-1046.

Fox, A. H. and A. I. Lamond (2010). "Paraspeckles." Cold Spring Harb Perspect Biol 2(7): a000687.

Fox, S. H., R. Katzenschlager, S. Y. Lim, B. Ravina, K. Seppi, M. Coelho, W. Poewe, O. Rascol, C. G. Goetz and C. Sampaio (2011). "The Movement Disorder Society Evidence-Based Medicine Review Update: Treatments for the motor symptoms of Parkinson's disease." Mov Disord 26 Suppl 3: S2-41. 
Frankola, K. A., N. H. Greig, W. Luo and D. Tweedie (2011). "Targeting TNF-alpha to elucidate and ameliorate neuroinflammation in neurodegenerative diseases." CNS Neurol Disord Drug Targets 10(3): 391-403.

Freischmidt, A., K. Muller, L. Zondler, P. Weydt, B. Mayer, C. A. von Arnim, A. Hubers, J. Dorst, M. Otto, K. Holzmann, A. C. Ludolph, K. M. Danzer and J. H. Weishaupt (2015). "Serum microRNAs in sporadic amyotrophic lateral sclerosis." Neurobiol Aging 36(9): 2660 e2615-2620.

Friedrich, E. B., K. Walenta, J. Scharlau, G. Nickenig and N. Werner (2006). "CD34-/CD133+/VEGFR-2+ endothelial progenitor cell subpopulation with potent vasoregenerative capacities." Circ Res 98(3): e20-25.

Friedrich, M. A., M. P. Martins, M. D. Araujo, C. Klamt, L. Vedolin, B. Garicochea, E. F. Raupp, J. S. Ammar, D. C. Machado, J. C. Costa, R. G. Nogueira, P. H. Rosado-de-Castro, R. Mendez-Otero and G. R. de Freitas (2011). "Intra-Arterial Infusion of Autologous Bone-Marrow Mononuclear Cells in Patients with Moderate to Severe Middle-Cerebral-Artery Acute Ischemic Stroke." Cell transplantation.

Fujikawa, T., S. H. Oh, L. Pi, H. M. Hatch, T. Shupe and B. E. Petersen (2005). "Teratoma formation leads to failure of treatment for type I diabetes using embryonic stem cell-derived insulin-producing cells." Am J Pathol 166(6): 1781-1791.

Fujita, J., A. M. Crane, M. K. Souza, M. Dejosez, M. Kyba, R. A. Flavell, J. A. Thomson and T. P. Zwaka (2008). "Caspase activity mediates the differentiation of embryonic stem cells." Cell Stem Cell 2(6): 595-601.

Furlan, J. C., B. M. Sakakibara, W. C. Miller and A. V. Krassioukov (2013). "Global incidence and prevalence of traumatic spinal cord injury." Can J Neurol Sci 40(4): 456-464.

Gabathuler, R. (2010). "Approaches to transport therapeutic drugs across the blood-brain barrier to treat brain diseases." Neurobiol Dis 37(1): 48-57.

Galbiati, M., E. Onesto, A. Zito, V. Crippa, P. Rusmini, R. Mariotti, M. Bentivoglio, C. Bendotti and A. Poletti (2012). "The anabolic/androgenic steroid nandrolone exacerbates gene expression modifications induced by mutant SOD1 in muscles of mice models of amyotrophic lateral sclerosis." Pharmacol Res 65(2): 221-230.

Ganguly, G., S. Chakrabarti, U. Chatterjee and L. Saso (2017). "Proteinopathy, oxidative stress and mitochondrial dysfunction: cross talk in Alzheimer's disease and Parkinson's disease." Drug Des Devel Ther 11: 797-810.

Gao, X., G. Enikolopov and J. Chen (2008). "Direct isolation of neural stem cells in the adult hippocampus after traumatic brain injury." Journal of neurotrauma 25(8): 985-995.

Garbers, C., H. M. Hermanns, F. Schaper, G. Muller-Newen, J. Grotzinger, S. Rose-John and J. Scheller (2012). "Plasticity and cross-talk of interleukin 6-type cytokines." Cytokine Growth Factor Rev 23(3): 85-97.

Garbuzova-Davis, S., E. Haller, S. Navarro, T. E. Besong, K. J. Boccio, S. Hailu, M. Khatib, P. R. Sanberg, S. H. Appel and C. V. Borlongan (2018). "Transplantation of human bone marrow stem cells into symptomatic ALS mice enhances structural and functional blood-spinal cord barrier repair." Exp Neurol 310: 33-47.

Garea-Rodriguez, E., C. Schlumbohm, B. Czeh, J. Konig, G. Helms, C. Heckmann, B. Meller, J. Meller and E. Fuchs (2012). "Visualizing dopamine transporter integrity with iodine-123-FP-CIT SPECT in combination with high resolution MRI in the brain of the common marmoset monkey." Journal of neuroscience methods 210(2): 195-201.

Gashmardi, N., S. E. Hosseini, D. Mehrabani, M. A. Edalatmanesh and Z. Khodabandeh (2017). "Impacts of Bone Marrow Stem Cells on Caspase-3 Levels after Spinal Cord Injury in Mice." Iran J Med Sci 42(6): 593-598.

Gazdic, M., V. Volarevic, C. R. Harrell, C. Fellabaum, N. Jovicic, N. Arsenijevic and M. Stojkovic (2018). "Stem Cells Therapy for Spinal Cord Injury." Int J Mol Sci 19(4).

Geeraerts, T., K. Deiva, I. M'Sika, H. Salim, C. Hery and M. Tardieu (2006). "Effects of SDF-1alpha and gp120IIIB on apoptotic pathways in SK-N-SH neuroblastoma cells." Neuroscience letters 399(1-2): 115-120.

Geffner, L. F., P. Santacruz, M. Izurieta, L. Flor, B. Maldonado, A. H. Auad, X. Montenegro, R. Gonzalez and F. Silva (2008). "Administration of autologous bone marrow stem cells into spinal cord injury patients via multiple routes is safe and improves their quality of life: comprehensive case studies." Cell transplantation 17(12): 1277-1293.

Gerdoni, E., B. Gallo, S. Casazza, S. Musio, I. Bonanni, E. Pedemonte, R. Mantegazza, F. Frassoni, G. Mancardi, R. Pedotti and A. Uccelli (2007). "Mesenchymal stem cells effectively modulate pathogenic immune response in experimental autoimmune encephalomyelitis." Annals of neurology 61(3): 219-227. 
Giang, K. W., Z. Mandalenakis, S. Nielsen, L. Bjorck, G. Lappas, M. Adiels, C. Jern and A. Rosengren (2017). "Longterm trends in the prevalence of patients hospitalized with ischemic stroke from 1995 to 2010 in Sweden." PLoS One 12(6): e0179658.

Gilgun-Sherki, Y., E. Melamed and D. Offen (2006). "Anti-inflammatory drugs in the treatment of neurodegenerative diseases: current state." Curr Pharm Des 12(27): 3509-3519.

Giraldi-Guimaraes, A., M. Rezende-Lima, F. P. Bruno and R. Mendez-Otero (2009). "Treatment with bone marrow mononuclear cells induces functional recovery and decreases neurodegeneration after sensorimotor cortical ischemia in rats." Brain research.

Gnecchi, M., P. Danieli, G. Malpasso and M. C. Ciuffreda (2016). "Paracrine Mechanisms of Mesenchymal Stem Cells in Tissue Repair." Methods Mol Biol 1416: 123-146.

Gnecchi, M., Z. Zhang, A. Ni and V. J. Dzau (2008). "Paracrine mechanisms in adult stem cell signaling and therapy." Circ Res 103(11): 1204-1219.

Goldenberg, M. M. (1999). "Celecoxib, a selective cyclooxygenase-2 inhibitor for the treatment of rheumatoid arthritis and osteoarthritis." Clin Ther 21(9): 1497-1513; discussion 1427-1498.

Gorabi, A. M., N. Kiaie, G. E. Barreto, M. I. Read, H. A. Tafti and A. Sahebkar (2019). "The Therapeutic Potential of Mesenchymal Stem Cell-Derived Exosomes in Treatment of Neurodegenerative Diseases." Mol Neurobiol 56(12): 8157-8167.

Gordon, P. H., D. H. Moore, R. G. Miller, J. M. Florence, J. L. Verheijde, C. Doorish, J. F. Hilton, G. M. Spitalny, R. B. MacArthur, H. Mitsumoto, H. E. Neville, K. Boylan, T. Mozaffar, J. M. Belsh, J. Ravits, R. S. Bedlack, M. C. Graves, L. F. McCluskey, R. J. Barohn, R. Tandan and A. L. S. S. G. Western (2007). "Efficacy of minocycline in patients with amyotrophic lateral sclerosis: a phase III randomised trial." Lancet Neurol 6(12): 10451053.

Gorlova, A., D. Pavlov, D. C. Anthony, E. D. Ponomarev, M. Sambon, A. Proshin, I. Shafarevich, D. Babaevskaya, C. K. P. Lessmall es, L. Bettendorff and T. Strekalova (2019). "Thiamine and benfotiamine counteract ultrasound-induced aggression, normalize AMPA receptor expression and plasticity markers, and reduce oxidative stress in mice." Neuropharmacology 156: 107543.

Gowland, A., S. Opie-Martin, K. M. Scott, A. R. Jones, P. R. Mehta, C. J. Batts, C. M. Ellis, P. N. Leigh, C. E. Shaw, J. Sreedharan and A. Al-Chalabi (2019). "Predicting the future of ALS: the impact of demographic change and potential new treatments on the prevalence of ALS in the United Kingdom, 2020-2116." Amyotroph Lateral Scler Frontotemporal Degener 20(3-4): 264-274.

Gu, Y., M. He, X. Zhou, J. Liu, N. Hou, T. Bin, Y. Zhang, T. Li and J. Chen (2016). "Endogenous IL-6 of mesenchymal stem cell improves behavioral outcome of hypoxic-ischemic brain damage neonatal rats by supressing apoptosis in astrocyte." Sci Rep 6: 18587.

Gugliandolo, A., P. Bramanti and E. Mazzon (2019). "Mesenchymal Stem Cells: A Potential Therapeutic Approach for Amyotrophic Lateral Sclerosis?" Stem Cells Int 2019: 3675627.

Guo, J., Y. Zeng, Y. Liang, L. Wang, H. Su and W. Wu (2007). "Cyclosporine affects the proliferation and differentiation of neural stem cells in culture." Neuroreport 18(9): 863-868.

Gupta, R., M. E. Bathen, J. S. Smith, A. D. Levi, N. N. Bhatia and O. Steward (2010). "Advances in the management of spinal cord injury." The Journal of the American Academy of Orthopaedic Surgeons 18(4): 210-222.

Gurney, M. E., H. Pu, A. Y. Chiu, M. C. Dal Canto, C. Y. Polchow, D. D. Alexander, J. Caliendo, A. Hentati, Y. W. Kwon, H. X. Deng and et al. (1994). "Motor neuron degeneration in mice that express a human $\mathrm{Cu}, \mathrm{Zn}$ superoxide dismutase mutation." Science 264(5166): 1772-1775.

Hagar, J. A., D. A. Powell, Y. Aachoui, R. K. Ernst and E. A. Miao (2013). "Cytoplasmic LPS activates caspase-11: implications in TLR4-independent endotoxic shock." Science 341(6151): 1250-1253.

Hagen, E. M., G. E. Eide, T. Rekand, N. E. Gilhus and M. Gronning (2010). "A 50-year follow-up of the incidence of traumatic spinal cord injuries in Western Norway." Spinal Cord 48(4): 313-318.

Hagen, E. M., S. A. Lie, T. Rekand, N. E. Gilhus and M. Gronning (2010). "Mortality after traumatic spinal cord injury: 50 years of follow-up." Journal of neurology, neurosurgery, and psychiatry 81(4): 368-373.

Hall, V. J., J. Y. Li and P. Brundin (2007). "Restorative cell therapy for Parkinson's disease: a quest for the perfect cell." Seminars in cell \& developmental biology 18(6): 859-869. 
Hammond, T. R., C. Dufort, L. Dissing-Olesen, S. Giera, A. Young, A. Wysoker, A. J. Walker, F. Gergits, M. Segel, J. Nemesh, S. E. Marsh, A. Saunders, E. Macosko, F. Ginhoux, J. Chen, R. J. M. Franklin, X. Piao, S. A. McCarroll and B. Stevens (2019). "Single-Cell RNA Sequencing of Microglia throughout the Mouse Lifespan and in the Injured Brain Reveals Complex Cell-State Changes." Immunity 50(1): 253-271 e256.

Hardiman, O., A. Al-Chalabi, A. Chio, E. M. Corr, G. Logroscino, W. Robberecht, P. J. Shaw, Z. Simmons and L. H. van den Berg (2017). "Amyotrophic lateral sclerosis." Nat Rev Dis Primers 3: 17085.

Harting, M. T., A. K. Srivastava, S. Zhaorigetu, H. Bair, K. S. Prabhakara, N. E. Toledano Furman, J. V. Vykoukal, K. A. Ruppert, C. S. Cox, Jr. and S. D. Olson (2018). "Inflammation-Stimulated Mesenchymal Stromal CellDerived Extracellular Vesicles Attenuate Inflammation." Stem Cells 36(1): 79-90.

Hayashi, K., S. Ohta, Y. Kawakami and M. Toda (2009). "Activation of dendritic-like cells and neural stem/progenitor cells in injured spinal cord by GM-CSF." Neurosci Res 64(1): 96-103.

Hemmat, S., D. M. Lieberman and S. P. Most (2010). "An introduction to stem cell biology." Facial plastic surgery :FPS 26(5): 343-349.

Hentze, H., R. Graichen and A. Colman (2007). "Cell therapy and the safety of embryonic stem cell-derived grafts." Trends Biotechnol 25(1): 24-32.

Hernan, M. A., G. Logroscino and L. A. Garcia Rodriguez (2006). "Nonsteroidal anti-inflammatory drugs and the incidence of Parkinson disease." Neurology 66(7): 1097-1099.

Hernandez, P., L. Cortina, H. Artaza, N. Pol, R. M. Lam, E. Dorticos, C. Macias, C. Hernandez, L. del Valle, A. Blanco, A. Martinez and F. Diaz (2007). "Autologous bone-marrow mononuclear cell implantation in patients with severe lower limb ischaemia: a comparison of using blood cell separator and Ficoll density gradient centrifugation." Atherosclerosis 194(2): e52-56.

Hirata, K., T. S. Li, M. Nishida, H. Ito, M. Matsuzaki, S. Kasaoka and K. Hamano (2003). "Autologous bone marrow cell implantation as therapeutic angiogenesis for ischemic hindlimb in diabetic rat model." Am J Physiol Heart Circ Physiol 284(1): H66-70.

Hoell, J. I., E. Larsson, S. Runge, J. D. Nusbaum, S. Duggimpudi, T. A. Farazi, M. Hafner, A. Borkhardt, C. Sander and T. Tuschl (2011). "RNA targets of wild-type and mutant FET family proteins." Nat Struct Mol Biol 18(12): 1428-1431.

Hofstetter, C. P., E. J. Schwarz, D. Hess, J. Widenfalk, A. El Manira, D. J. Prockop and L. Olson (2002). "Marrow stromal cells form guiding strands in the injured spinal cord and promote recovery." Proc Natl Acad Sci U S A 99(4): 2199-2204.

Holowiecki, J. (2008). "Indications for hematopoietic stem cell transplantation." Pol Arch Med Wewn 118(11): 658-663.

Hooten, K. G., D. R. Beers, W. Zhao and S. H. Appel (2015). "Protective and Toxic Neuroinflammation in Amyotrophic Lateral Sclerosis." Neurotherapeutics 12(2): 364-375.

Howland, D. S., J. Liu, Y. She, B. Goad, N. J. Maragakis, B. Kim, J. Erickson, J. Kulik, L. DeVito, G. Psaltis, L. J. DeGennaro, D. W. Cleveland and J. D. Rothstein (2002). "Focal loss of the glutamate transporter EAAT2 in a transgenic rat model of SOD1 mutant-mediated amyotrophic lateral sclerosis (ALS)." Proc Natl Acad Sci U S A 99(3): 1604-1609.

Hsiao, S. T., A. Asgari, Z. Lokmic, R. Sinclair, G. J. Dusting, S. Y. Lim and R. J. Dilley (2012). "Comparative analysis of paracrine factor expression in human adult mesenchymal stem cells derived from bone marrow, adipose, and dermal tissue." Stem Cells Dev 21(12): 2189-2203.

Hu, Y., C. Cao, X. Y. Qin, Y. Yu, J. Yuan, Y. Zhao and Y. Cheng (2017). "Increased peripheral blood inflammatory cytokine levels in amyotrophic lateral sclerosis: a meta-analysis study." Sci Rep 7(1): 9094.

Huang-Fu, N., J. S. Cheng, Y. Wang, Z. W. Li and S. H. Wang (2018). "Neat1 regulates oxidized low-density lipoprotein-induced inflammation and lipid uptake in macrophages via paraspeckle formation." Mol Med Rep 17(2): 3092-3098.

Huang, X., J. M. Kim, T. H. Kong, S. R. Park, Y. Ha, M. H. Kim, H. Park, S. H. Yoon, H. C. Park, J. O. Park, B. H. Min and B. H. Choi (2009). "GM-CSF inhibits glial scar formation and shows long-term protective effect after spinal cord injury." Journal of the neurological sciences 277(1-2): 87-97. 
Hugenholtz, H., D. E. Cass, M. F. Dvorak, D. H. Fewer, R. J. Fox, D. M. Izukawa, J. Lexchin, S. Tuli, N. Bharatwal and C. Short (2002). "High-dose methylprednisolone for acute closed spinal cord injury--only a treatment option." Can J Neurol Sci 29(3): 227-235.

Hurlbert, R. J. (2000). "Methylprednisolone for acute spinal cord injury: an inappropriate standard of care." J Neurosurg 93(1 Suppl): 1-7.

Ibarra, A., D. Correa, K. Willms, M. T. Merchant, G. Guizar-Sahagun, I. Grijalva and I. Madrazo (2003). "Effects of cyclosporin-A on immune response, tissue protection and motor function of rats subjected to spinal cord injury." Brain research 979(1-2): 165-178.

lihoshi, S., O. Honmou, K. Houkin, K. Hashi and J. D. Kocsis (2004). "A therapeutic window for intravenous administration of autologous bone marrow after cerebral ischemia in adult rats." Brain research 1007(12): 1-9.

Imai, Y. and S. Kohsaka (2002). "Intracellular signaling in M-CSF-induced microglia activation: role of Iba1." Glia 40(2): 164-174.

Inoue, M., O. Honmou, S. Oka, K. Houkin, K. Hashi and J. D. Kocsis (2003). "Comparative analysis of remyelinating potential of focal and intravenous administration of autologous bone marrow cells into the rat demyelinated spinal cord." Glia 44(2): 111-118.

Ito, D., Y. Imai, K. Ohsawa, K. Nakajima, Y. Fukuuchi and S. Kohsaka (1998). "Microglia-specific localisation of a novel calcium binding protein, Iba1." Brain Res Mol Brain Res 57(1): 1-9.

Ito, D. and N. Suzuki (2011). "Conjoint pathologic cascades mediated by ALS/FTLD-U linked RNA-binding proteins TDP-43 and FUS." Neurology 77(17): 1636-1643.

Jackson, J. S., J. P. Golding, C. Chapon, W. A. Jones and K. K. Bhakoo (2010). "Homing of stem cells to sites of inflammatory brain injury after intracerebral and intravenous administration: a longitudinal imaging study." Stem Cell Res Ther 1(2): 17.

Jager, M., P. Hernigou, C. Zilkens, M. Herten, X. Li, J. Fischer and R. Krauspe (2010). "Cell therapy in bone healing disorders." Orthop Rev (Pavia) 2(2): e20.

Janzen, V., H. E. Fleming, T. Riedt, G. Karlsson, M. J. Riese, C. Lo Celso, G. Reynolds, C. D. Milne, C. J. Paige, S. Karlsson, M. Woo and D. T. Scadden (2008). "Hematopoietic stem cell responsiveness to exogenous signals is limited by caspase-3." Cell Stem Cell 2(6): 584-594.

Jin, M. C., Z. A. Medress, T. D. Azad, V. M. Doulames and A. Veeravagu (2019). "Stem cell therapies for acute spinal cord injury in humans: a review." Neurosurg Focus 46(3): E10.

Jones, T. B. (2014). "Lymphocytes and autoimmunity after spinal cord injury." Exp Neurol 258: 78-90.

Jung, D. I., J. Ha, B. T. Kang, J. W. Kim, F. S. Quan, J. H. Lee, E. J. Woo and H. M. Park (2009). "A comparison of autologous and allogenic bone marrow-derived mesenchymal stem cell transplantation in canine spinal cord injury." Journal of the neurological sciences 285(1-2): 67-77.

Junker, J. P., P. Sommar, M. Skog, H. Johnson and G. Kratz (2010). "Adipogenic, chondrogenic and osteogenic differentiation of clonally derived human dermal fibroblasts." Cells, tissues, organs 191(2): 105-118.

Kamei, N., N. Tanaka, Y. Oishi, T. Hamasaki, K. Nakanishi, N. Sakai and M. Ochi (2007). "BDNF, NT-3, and NGF released from transplanted neural progenitor cells promote corticospinal axon growth in organotypic cocultures." Spine 32(12): 1272-1278.

Kamiya, N., M. Ueda, H. Igarashi, Y. Nishiyama, S. Suda, T. Inaba and Y. Katayama (2008). "Intra-arterial transplantation of bone marrow mononuclear cells immediately after reperfusion decreases brain injury after focal ischemia in rats." Life Sci 83(11-12): 433-437.

Kang, Y., H. Ding, H. Zhou, Z. Wei, L. Liu, D. Pan, S. Feng and E. al. (2018). "Epidemiology of worldwide spinal cord injury: a literature review." J Neurorestoratil(6): 1-9.

Kasner, S. E. (2006). "Clinical interpretation and use of stroke scales." Lancet neurology 5(7): 603-612.

Kassis, I., N. Grigoriadis, B. Gowda-Kurkalli, R. Mizrachi-Kol, T. Ben-Hur, S. Slavin, O. Abramsky and D. Karussis (2008). "Neuroprotection and immunomodulation with mesenchymal stem cells in chronic experimental autoimmune encephalomyelitis." Archives of neurology 65(6): 753-761.

Ke, X., Q. Li, L. Xu, Y. Zhang, D. Li, J. Ma and X. Mao (2015). "Netrin-1 overexpression in bone marrow mesenchymal stem cells promotes functional recovery in a rat model of peripheral nerve injury." J Biomed Res 29(5): 380-389. 
Keeney, M., I. Chin-Yee, K. Weir, J. Popma, R. Nayar and D. R. Sutherland (1998). "Single platform flow cytometric absolute CD34+ cell counts based on the ISHAGE guidelines. International Society of Hematotherapy and Graft Engineering." Cytometry 34(2): 61-70.

Keren-Shaul, H., A. Spinrad, A. Weiner, O. Matcovitch-Natan, R. Dvir-Szternfeld, T. K. Ulland, E. David, K. Baruch, D. Lara-Astaiso, B. Toth, S. Itzkovitz, M. Colonna, M. Schwartz and I. Amit (2017). "A Unique Microglia Type Associated with Restricting Development of Alzheimer's Disease." Cell 169(7): 1276-1290 e1217.

Khalid, S. I., L. Ampie, R. Kelly, S. S. Ladha and C. Dardis (2017). "Immune Modulation in the Treatment of Amyotrophic Lateral Sclerosis: A Review of Clinical Trials." Front Neurol 8: 486.

Khazaei, M., C. S. Ahuja, H. Nakashima, N. Nagoshi, L. Li, J. Wang, J. Chio, A. Badner, D. Seligman, A. Ichise, S. Shibata and M. G. Fehlings (2020). "GDNF rescues the fate of neural progenitor grafts by attenuating Notch signals in the injured spinal cord in rodents." Sci Transl Med 12(525).

Kim, J. and P. Hematti (2009). "Mesenchymal stem cell-educated macrophages: a novel type of alternatively activated macrophages." Experimental hematology 37(12): 1445-1453.

Kim, S. H., K. W. Oh, H. K. Jin and J. S. Bae (2018). "Immune inflammatory modulation as a potential therapeutic strategy of stem cell therapy for ALS and neurodegenerative diseases." BMB Rep 51(11): 545-546.

Kim, S. S., S. W. Yoo, T. S. Park, S. C. Ahn, H. S. Jeong, J. W. Kim, D. Y. Chang, K. G. Cho, S. U. Kim, Y. Huh, J. E. Lee, S. Y. Lee, Y. D. Lee and H. Suh-Kim (2008). "Neural induction with neurogenin1 increases the therapeutic effects of mesenchymal stem cells in the ischemic brain." Stem Cells 26(9): 2217-2228.

Kim, Y. J., H. J. Park, G. Lee, O. Y. Bang, Y. H. Ahn, E. Joe, H. O. Kim and P. H. Lee (2009). "Neuroprotective effects of human mesenchymal stem cells on dopaminergic neurons through anti-inflammatory action." Glia 57(1): 13-23.

Kinnaird, T., E. Stabile, M. S. Burnett and S. E. Epstein (2004). "Bone-marrow-derived cells for enhancing collateral development: mechanisms, animal data, and initial clinical experiences." Circ Res 95(4): 354-363.

Kinnaird, T., E. Stabile, M. S. Burnett, C. W. Lee, S. Barr, S. Fuchs and S. E. Epstein (2004). "Marrow-derived stromal cells express genes encoding a broad spectrum of arteriogenic cytokines and promote in vitro and in vivo arteriogenesis through paracrine mechanisms." Circ Res 94(5): 678-685.

Kinnaird, T., E. Stabile, M. S. Burnett, M. Shou, C. W. Lee, S. Barr, S. Fuchs and S. E. Epstein (2004). "Local delivery of marrow-derived stromal cells augments collateral perfusion through paracrine mechanisms." Circulation 109(12): 1543-1549.

Kirshblum, S., S. Millis, W. McKinley and D. Tulsky (2004). "Late neurologic recovery after traumatic spinal cord injury." Arch Phys Med Rehabil 85(11): 1811-1817.

Kishk, N. A., H. Gabr, S. Hamdy, L. Afifi, N. Abokresha, H. Mahmoud, A. Wafaie and D. Bilal (2010). "Case control series of intrathecal autologous bone marrow mesenchymal stem cell therapy for chronic spinal cord injury." Neurorehabil Neural Repair 24(8): 702-708.

Klapka, N. and H. W. Muller (2006). "Collagen matrix in spinal cord injury." J Neurotrauma 23(3-4): 422-435.

Klepanec, A., M. Mistrik, C. Altaner, M. Valachovicova, I. Olejarova, R. Slysko, T. Balazs, T. Urlandova, D. Hladikova, B. Liska, J. Tomka, I. Vulev and J. Madaric (2012). "No difference in intra-arterial and intramuscular delivery of autologous bone marrow cells in patients with advanced critical limb ischemia." Cell Transplant 21(9): 1909-1918.

Knutsdottir, S. (1993). "Spinal cord injuries in Iceland 1973-1989. A follow up study." Paraplegia 31(1): 68-72.

Koh, S. H., W. Baik, M. Y. Noh, G. W. Cho, H. Y. Kim, K. S. Kim and S. H. Kim (2012). "The functional deficiency of bone marrow mesenchymal stromal cells in ALS patients is proportional to disease progression rate." Experimental neurology 233(1): 472-480.

Koshizuka, S., S. Okada, A. Okawa, M. Koda, M. Murasawa, M. Hashimoto, T. Kamada, K. Yoshinaga, M. Murakami, H. Moriya and M. Yamazaki (2004). "Transplanted hematopoietic stem cells from bone marrow differentiate into neural lineage cells and promote functional recovery after spinal cord injury in mice." J Neuropathol Exp Neurol 63(1): 64-72.

Krause, J. S., L. L. Saunders and J. Acuna (2012). "Gainful employment and risk of mortality after spinal cord injury: effects beyond that of demographic, injury and socioeconomic factors." Spinal Cord 50(10): 784-788. 
Kshitiz, D. D. Ellison, Y. Suhail, J. Afzal, L. Woo, O. Kilic, J. Spees and A. Levchenko (2019). "Dynamic secretome of bone marrow-derived stromal cells reveals a cardioprotective biochemical cocktail." Proc Natl Acad Sci U S A 116(28): 14374-14383.

Kucia, M., R. Reca, V. R. Jala, B. Dawn, J. Ratajczak and M. Z. Ratajczak (2005). "Bone marrow as a home of heterogenous populations of nonhematopoietic stem cells." Leukemia : official journal of the Leukemia Society of America, Leukemia Research Fund, U.K 19(7): 1118-1127.

Kumar, A. A., S. R. Kumar, R. Narayanan, K. Arul and M. Baskaran (2009). "Autologous bone marrow derived mononuclear cell therapy for spinal cord injury: A phase I/II clinical safety and primary efficacy data." Experimental and clinical transplantation : official journal of the Middle East Society for Organ Transplantation 7(4): 241-248.

Kumar, R., J. Lim, R. A. Mekary, A. Rattani, M. C. Dewan, S. Y. Sharif, E. Osorio-Fonseca and K. B. Park (2018). "Traumatic Spinal Injury: Global Epidemiology and Worldwide Volume." World Neurosurg 113: e345e363.

Laguna Goya, R., P. Tyers and R. A. Barker (2008). "The search for a curative cell therapy in Parkinson's disease." Journal of the neurological sciences 265(1-2): 32-42.

Lankhorst, A. J., M. P. ter Laak, F. P. Hamers and W. H. Gispen (2000). "Combined treatment with alphaMSH and methylprednisolone fails to improve functional recovery after spinal injury in the rat." Brain Res 859(2): 334-340.

Lawall, H., P. Bramlage and B. Amann (2011). "Treatment of peripheral arterial disease using stem and progenitor cell therapy." Journal of vascular surgery : official publication, the Society for Vascular Surgery [and] International Society for Cardiovascular Surgery, North American Chapter 53(2): 445-453.

Lawrence, S. (2018). "Spinal cord injuries treatment and management." Medscape, news and perspective drugs and diseases(CME \& Education ): emedicine.medscape.com/article/793582-treatment.

Le Blanc, K. and O. Ringden (2005). "Use of mesenchymal stem cells for the prevention of immune complications of hematopoietic stem cell transplantation." Haematologica 90(4): 438.

Lee, A. S., C. Tang, F. Cao, X. Xie, K. van der Bogt, A. Hwang, A. J. Connolly, R. C. Robbins and J. C. Wu (2009). "Effects of cell number on teratoma formation by human embryonic stem cells." Cell Cycle 8(16): 26082612.

Lee, P. H., J. W. Kim, O. Y. Bang, Y. H. Ahn, I. S. Joo and K. Huh (2008). "Autologous mesenchymal stem cell therapy delays the progression of neurological deficits in patients with multiple system atrophy." Clin Pharmacol Ther 83(5): 723-730.

Lee, P. H., J. E. Lee, H. S. Kim, S. K. Song, H. S. Lee, H. S. Nam, J. W. Cheong, Y. Jeong, H. J. Park, D. J. Kim, C. M. Nam, J. D. Lee, H. O. Kim and Y. H. Sohn (2012). "A randomized trial of mesenchymal stem cells in multiple system atrophy." Annals of neurology 72(1): 32-40.

Lee, V. M., L. Otvos, Jr., M. J. Carden, M. Hollosi, B. Dietzschold and R. A. Lazzarini (1988). "Identification of the major multiphosphorylation site in mammalian neurofilaments." Proc Natl Acad Sci U S A 85(6): 19982002.

Leistner, D. M., U. Fischer-Rasokat, J. Honold, F. H. Seeger, V. Schachinger, R. Lehmann, H. Martin, I. Burck, C. Urbich, S. Dimmeler, A. M. Zeiher and B. Assmus (2011). "Transplantation of progenitor cells and regeneration enhancement in acute myocardial infarction (TOPCARE-AMI): final 5-year results suggest long-term safety and efficacy." Clinical research in cardiology : official journal of the German Cardiac Society 100(10): 925-934.

Lemon, R. N. and J. Griffiths (2005). "Comparing the function of the corticospinal system in different species: organizational differences for motor specialization?" Muscle Nerve 32(3): 261-279.

Levy, Y. S., M. Bahat-Stroomza, R. Barzilay, A. Burshtein, S. Bulvik, Y. Barhum, H. Panet, E. Melamed and D. Offen (2008). "Regenerative effect of neural-induced human mesenchymal stromal cells in rat models of Parkinson's disease." Cytotherapy 10(4): 340-352.

Lewis, C. A., J. Manning, F. Rossi and C. Krieger (2012). "The Neuroinflammatory Response in ALS: The Roles of Microglia and T Cells." Neurol Res Int 2012: 803701.

Li, J., M. Sung and S. B. Rutkove (2013). "Electrophysiologic biomarkers for assessing disease progression and the effect of riluzole in SOD1 G93A ALS mice." PLoS One 8(6): e65976. 
Li, J., H. Zhu, Y. Liu, Q. Li, S. Lu, M. Feng, Y. Xu, L. Huang, C. Ma, Y. An, R. C. Zhao, R. Wang and C. Qin (2010). "Human mesenchymal stem cell transplantation protects against cerebral ischemic injury and upregulates interleukin-10 expression in Macacafascicularis." Brain research 1334: 65-72.

Li, K., Y. H. Tan, A. R. Light and K. Y. Fu (2013). "Different peripheral tissue injury induces differential phenotypic changes of spinal activated microglia." Clin Dev Immunol 2013: 901420.

$\mathrm{Li}, \mathrm{T}$. and Y. Wu (2011). "Paracrine molecules of mesenchymal stem cells for hematopoietic stem cell niche." Bone Marrow Res 2011: 353878.

Li, T. S., M. Kubo, K. Ueda, M. Murakami, A. Mikamo and K. Hamano (2010). "Impaired angiogenic potency of bone marrow cells from patients with advanced age, anemia, and renal failure." J Thorac Cardiovasc Surg 139(2): 459-465.

Li, X. Y., J. Ding, Z. H. Zheng, X. Y. Li, Z. B. Wu and P. Zhu (2012). "Long-term culture in vitro impairs the immunosuppressive activity of mesenchymal stem cells on T cells." Mol Med Rep 6(5): 1183-1189.

Li, Y. L., G. Z. Wu, G. S. Dawe, L. Zeng, S. S. Cui, G. Loers, T. Tilling, L. Sun, M. Schachner and Z. C. Xiao (2008). "Cell surface sialylation and fucosylation are regulated by L1 via phospholipase Cgamma and cooperate to modulate neurite outgrowth, cell survival and migration." PLoS One 3(12): e3841.

Lian, Q., Y. Zhang, J. Zhang, H. K. Zhang, X. Wu, F. F. Lam, S. Kang, J. C. Xia, W. H. Lai, K. W. Au, Y. Y. Chow, C. W. Siu, C. N. Lee and H. F. Tse (2010). "Functional mesenchymal stem cells derived from human induced pluripotent stem cells attenuate limb ischemia in mice." Circulation 121(9): 1113-1123.

Lim, J. H., Y. E. Byeon, H. H. Ryu, Y. H. Jeong, Y. W. Lee, W. H. Kim, K. S. Kang and O. K. Kweon (2007) "Transplantation of canine umbilical cord blood-derived mesenchymal stem cells in experimentally induced spinal cord injured dogs." Journal of veterinary science 8(3): 275-282.

Lin, M. T. and M. F. Beal (2006). "Mitochondrial dysfunction and oxidative stress in neurodegenerative diseases." Nature 443(7113): 787-795.

Ling, Q. L., E. Murdoch and K. H. Ruan (2016). "How can we address the controversies surrounding the use of NSAIDS in neurodegeneration?" Future Med Chem 8(11): 1153-1155.

Logroscino, G., B. J. Traynor, O. Hardiman, A. Chio, D. Mitchell, R. J. Swingler, A. Millul, E. Benn, E. Beghi and Eurals (2010). "Incidence of amyotrophic lateral sclerosis in Europe." J Neurol Neurosurg Psychiatry 81(4): $385-$ 390.

London, A., M. Cohen and M. Schwartz (2013). "Microglia and monocyte-derived macrophages: functionally distinct populations that act in concert in CNS plasticity and repair." Front Cell Neurosci 7: 34.

Longinetti, E. and F. Fang (2019). "Epidemiology of amyotrophic lateral sclerosis: an update of recent literature." Curr Opin Neurol 32(5): 771-776.

Lopez-Erauskin, J., T. Tadokoro, M. W. Baughn, B. Myers, M. McAlonis-Downes, C. Chillon-Marinas, J. N. Asiaban, J. Artates, A. T. Bui, A. P. Vetto, S. K. Lee, A. V. Le, Y. Sun, M. Jambeau, J. Boubaker, D. Swing, J. Qiu, G. G. Hicks, Z. Ouyang, X. D. Fu, L. Tessarollo, S. C. Ling, P. A. Parone, C. E. Shaw, M. Marsala, C. Lagier-Tourenne, D. W. Cleveland and S. Da Cruz (2018). "ALS/FTD-Linked Mutation in FUS Suppresses Intra-axonal Protein Synthesis and Drives Disease Without Nuclear Loss-of-Function of FUS." Neuron 100(4): 816-830 e817.

Lossinsky, A. S. and R. R. Shivers (2004). "Structural pathways for macromolecular and cellular transport across the blood-brain barrier during inflammatory conditions. Review." Histol Histopathol 19(2): 535-564.

Lu, G. B., F. W. Niu, Y. C. Zhang, L. Du, Z. Y. Liang, Y. Gao, T. Z. Yan, Z. K. Nie and K. Gao (2016). "Methylprednisolone promotes recovery of neurological function after spinal cord injury: association with Wnt/beta-catenin signaling pathway activation." Neural Regen Res 11(11): 1816-1823.

Lu, P., L. L. Jones and M. H. Tuszynski (2005). "BDNF-expressing marrow stromal cells support extensive axonal growth at sites of spinal cord injury." Exp Neurol 191(2): 344-360.

Lu, P., Y. Wang, L. Graham, K. McHale, M. Gao, D. Wu, J. Brock, A. Blesch, E. S. Rosenzweig, L. A. Havton, B. Zheng, J. M. Conner, M. Marsala and M. H. Tuszynski (2012). "Long-distance growth and connectivity of neural stem cells after severe spinal cord injury." Cell 150(6): 1264-1273.

Lu, Q. R., T. Sun, Z. Zhu, N. Ma, M. Garcia, C. D. Stiles and D. H. Rowitch (2002). "Common developmental requirement for Olig function indicates a motor neuron/oligodendrocyte connection." Cell 109(1): 75-86.

Luca, A., C. Calandra and M. Luca (2018). "Molecular Bases of Alzheimer's Disease and Neurodegeneration: The Role of Neuroglia." Aging Dis 9(6): 1134-1152. 
Ludolph, A. C., C. Bendotti, E. Blaugrund, A. Chio, L. Greensmith, J. P. Loeffler, R. Mead, H. G. Niessen, S. Petri, P. F. Pradat, W. Robberecht, M. Ruegg, B. Schwalenstocker, D. Stiller, L. van den Berg, F. Vieira and S. von Horsten (2010). "Guidelines for preclinical animal research in ALS/MND: A consensus meeting." Amyotroph Lateral Scler 11(1-2): 38-45.

Lutz, C. (2018). "Mouse models of ALS: Past, present and future." Brain Res 1693(Pt A): 1-10.

Lysikova, E. A., M. S. Kukharsky, K. D. Chaprov, N. A. Vasilieva, A. Y. Roman, R. K. Ovchinnikov, A. V. Deykin, N. Ninkina and V. L. Buchman (2019). "Behavioural impairments in mice of a novel FUS transgenic line recapitulate features of frontotemporal lobar degeneration." Genes Brain Behav 18(8): e12607.

Maciel, I. S., R. B. Silva, F. B. Morrone, J. B. Calixto and M. M. Campos (2013). "Synergistic effects of celecoxib and bupropion in a model of chronic inflammation-related depression in mice." PLoS One 8(9): e77227.

Malatynska E, Steinbusch H, Redkozubova O, Bolkunov A. Kubatiev A, Yeritsyan NB, Vignisse J, Bachurin S, Strekalova T (2012). "Anhedonic-like traits and lack of affective deficits in 18-month-old C57BL/6 mice: Implications for modeling elderly depression". Exp. Gerontol 47: 552-564.

Mancuso, R. and X. Navarro (2015). "Amyotrophic lateral sclerosis: Current perspectives from basic research to the clinic." Prog Neurobiol 133: 1-26.

Maness, P. F. and M. Schachner (2007). "Neural recognition molecules of the immunoglobulin superfamily: signaling transducers of axon guidance and neuronal migration." Nat Neurosci 10(1): 19-26.

Mann, A. and M. F. Chesselet (2015). "Techniques in motor assessment in rodents." Movement disorders genetics and models London, San Diego, Waltham Oxford.

Maqueda, A. and F. J. Rodriguez (2020). "Efficacy of human HC016 cell transplants on neuroprotection and functional recovery in a rat model of acute spinal cord injury." J Tissue Eng Regen Med 14(2): 319-333.

Marrone, L., H. C. A. Drexler, J. Wang, P. Tripathi, T. Distler, P. Heisterkamp, E. N. Anderson, S. Kour, A. Moraiti, S. Maharana, R. Bhatnagar, T. G. Belgard, V. Tripathy, N. Kalmbach, Z. Hosseinzadeh, V. Crippa, M. AboRady, F. Wegner, A. Poletti, D. Troost, E. Aronica, V. Busskamp, J. Weis, U. B. Pandey, A. A. Hyman, S. Alberti, A. Goswami and J. Sterneckert (2019). "FUS pathology in ALS is linked to alterations in multiple ALS-associated proteins and rescued by drugs stimulating autophagy." Acta Neuropathol 138(1): 67-84.

Marsden, C. D. (1996). "Movement Disorders." Oxford Textbook of Medicine Vol 3: 3998-4022.

Martinez, A., M. D. Palomo Ruiz, D. I. Perez and C. Gil (2017). "Drugs in clinical development for the treatment of amyotrophic lateral sclerosis." Expert Opin Investig Drugs 26(4): 403-414.

Mayshar, Y., U. Ben-David, N. Lavon, J. C. Biancotti, B. Yakir, A. T. Clark, K. Plath, W. E. Lowry and N. Benvenisty (2010). "Identification and classification of chromosomal aberrations in human induced pluripotent stem cells." Cell stem cell 7(4): 521-531.

Mazzardo-Martins, L., D. F. Martins, J. Stramosk, F. J. Cidral-Filho and A. R. Santos (2012). "Glycogen synthase kinase 3-specific inhibitor AR-A014418 decreases neuropathic pain in mice: evidence for the mechanisms of action." Neuroscience 226: 411-420.

Mazzini, L., A. Vescovi, R. Cantello, M. Gelati and A. Vercelli (2016). "Stem cells therapy for ALS." Expert Opin Biol Ther 16(2): 187-199.

McCauley, M. E. and R. H. Baloh (2019). "Inflammation in ALS/FTD pathogenesis." Acta Neuropathol 137(5): 715730.

McCluskey, L., S. Campbell, D. Anthony and S. M. Allan (2008). "Inflammatory responses in the rat brain in response to different methods of intra-cerebral administration." Journal of neuroimmunology 194(1-2): 27-33.

McDonald, J. W. and C. Sadowsky (2002). "Spinal-cord injury." Lancet 359(9304): 417-425.

McGeer, P. L. and E. G. McGeer (2007). "NSAIDs and Alzheimer disease: epidemiological, animal model and clinical studies." Neurobiol Aging 28(5): 639-647.

McKay, S. M., D. J. Brooks, P. Hu and E. M. McLachlan (2007). "Distinct types of microglial activation in white and grey matter of rat lumbosacral cord after mid-thoracic spinal transection." J Neuropathol Exp Neurol 66(8): 698-710.

McKinley, W., M. A. Meade, S. Kirshblum and B. Barnard (2004). "Outcomes of early surgical management versus late or no surgical intervention after acute spinal cord injury." Arch Phys Med Rehabil 85(11): 1818-1825. 
Mehta, P., W. Kaye, J. Raymond, R. Punjani, T. Larson, J. Cohen, O. Muravov and K. Horton (2018). "Prevalence of Amyotrophic Lateral Sclerosis - United States, 2015." MMWR Morb Mortal Wkly Rep 67(46): 1285-1289.

Meininger, V., G. Bensimon, W. R. Bradley, B. Brooks, P. Douillet, A. A. Eisen, L. Lacomblez, P. N. Leigh and W. Robberecht (2004). "Efficacy and safety of xaliproden in amyotrophic lateral sclerosis: results of two phase III trials." Amyotroph Lateral Scler Other Motor Neuron Disord 5(2): 107-117.

Meyer, A. K., M. Maisel, A. Hermann, K. Stirl and A. Storch (2010). "Restorative approaches in Parkinson's Disease: which cell type wins the race?" Journal of the neurological sciences 289(1-2): 93-103.

Milber, J. M., J. V. Noorigian, J. F. Morley, H. Petrovitch, L. White, G. W. Ross and J. E. Duda (2012). "Lewy pathology is not the first sign of degeneration in vulnerable neurons in Parkinson disease." Neurology 79(24): 2307 2314.

Miller, R. G., J. D. Mitchell and D. H. Moore (2012). "Riluzole for amyotrophic lateral sclerosis (ALS)/motor neuron disease (MND)." Cochrane Database Syst Rev(3): CD001447.

Mishra, P. S., K. Vijayalakshmi, A. Nalini, T. N. Sathyaprabha, B. W. Kramer, P. A. Alladi and T. R. Raju (2017). "Etiogenic factors present in the cerebrospinal fluid from amyotrophic lateral sclerosis patients induce predominantly pro-inflammatory responses in microglia." J Neuroinflammation 14(1): 251.

Morales-Garcia, J. A., C. Susin, S. Alonso-Gil, D. I. Perez, V. Palomo, C. Perez, S. Conde, A. Santos, C. Gil, A. Martinez and A. Perez-Castillo (2013). "Glycogen synthase kinase-3 inhibitors as potent therapeutic agents for the treatment of Parkinson disease." ACS Chem Neurosci 4(2): 350-360.

Morello, G., A. G. Spampinato and S. Cavallaro (2017). "Neuroinflammation and ALS: Transcriptomic Insights into Molecular Disease Mechanisms and Therapeutic Targets." Mediators Inflamm 2017: 7070469.

Moreno-Martinez, L., A. C. Calvo, M. J. Munoz and R. Osta (2019). "Are Circulating Cytokines Reliable Biomarkers for Amyotrophic Lateral Sclerosis?" Int J Mol Sci 20(11).

Moreno-Martinez, L., M. de la Torre, J. M. Toivonen, P. Zaragoza, A. Garcia-Redondo, A. C. Calvo and R. Osta (2019). "Circulating Cytokines Could Not Be Good Prognostic Biomarkers in a Mouse Model of Amyotrophic Lateral Sclerosis." Front Immunol 10: 801.

Mukhamedshina, Y., I. Shulman, S. Ogurcov, A. Kostennikov, E. Zakirova, E. Akhmetzyanova, A. Rogozhin, G. Masgutova, V. James, R. Masgutov, I. Lavrov and A. Rizvanov (2019). "Mesenchymal Stem Cell Therapy for Spinal Cord Contusion: A Comparative Study on Small and Large Animal Models." Biomolecules 9(12).

Murray, K. N., A. R. Parry-Jones and S. M. Allan (2015). "Interleukin-1 and acute brain injury." Front Cell Neurosci 9: 18.

Murrell, W., A. Wetzig, M. Donnellan, F. Feron, T. Burne, A. Meedeniya, J. Kesby, J. Bianco, C. Perry, P. Silburn and A. Mackay-Sim (2008). "Olfactory mucosa is a potential source for autologous stem cell therapy for Parkinson's disease." Stem cells 26(8): 2183-2192.

Nagoshi, N., O. Tsuji, M. Nakamura and H. Okano (2019). "Cell therapy for spinal cord injury using induced pluripotent stem cells." Regen Ther 11: 75-80.

Neirinckx, V., G. Agirman, C. Coste, A. Marquet, V. Dion, B. Rogister, R. Franzen and S. Wislet (2015). "Adult bone marrow mesenchymal and neural crest stem cells are chemoattractive and accelerate motor recovery in a mouse model of spinal cord injury." Stem Cell Res Ther 6: 211.

Nejati-Koshki, K., Y. Mortazavi, Y. Pilehvar-Soltanahmadi, S. Sheoran and N. Zarghami (2017). "An update on application of nanotechnology and stem cells in spinal cord injury regeneration." Biomed Pharmacother 90: 85-92.

Nelson, L. M., B. Topol, W. Kaye, D. Williamson, D. K. Horton, P. Mehta and T. Wagner (2018). "Estimation of the Prevalence of Amyotrophic Lateral Sclerosis in the United States Using National Administrative Healthcare Data from 2002 to 2004 and Capture-Recapture Methodology." Neuroepidemiology 51(3-4): 149-157.

Neuhuber, B., B. Timothy Himes, J. S. Shumsky, G. Gallo and I. Fischer (2005). "Axon growth and recovery of function supported by human bone marrow stromal cells in the injured spinal cord exhibit donor variations." Brain research 1035(1): 73-85.

Norenberg, M. D., J. Smith and A. Marcillo (2004). "The pathology of human spinal cord injury: defining the problems." J Neurotrauma 21(4): 429-440. 
Nourse, J. L., J. L. Prieto, A. R. Dickson, J. Lu, M. M. Pathak, F. Tombola, M. Demetriou, A. P. Lee and L. A. Flanagan (2014). "Membrane biophysics define neuron and astrocyte progenitors in the neural lineage." Stem Cells 32(3): 706-716.

Novakovic, R., G. Toth and P. D. Purdy (2009). "Review of current and emerging therapies in acute ischemic stroke." Journal of neurointerventional surgery 1(1): 13-26.

Oh, K. W., C. Moon, H. Y. Kim, S. I. Oh, J. Park, J. H. Lee, I. Y. Chang, K. S. Kim and S. H. Kim (2015). "Phase I trial of repeated intrathecal autologous bone marrow-derived mesenchymal stromal cells in amyotrophic lateral sclerosis." Stem Cells Transl Med 4(6): 590-597.

Oh, K. W., M. Y. Noh, M. S. Kwon, H. Y. Kim, S. I. Oh, J. Park, H. J. Kim, C. S. Ki and S. H. Kim (2018). "Repeated Intrathecal Mesenchymal Stem Cells for Amyotrophic Lateral Sclerosis." Ann Neurol 84(3): 361-373.

Olanow, C. W. and P. Brundin (2013). "Parkinson's disease and alpha synuclein: is Parkinson's disease a prion-like disorder?" Mov Disord 28(1): 31-40.

Orito, K., H. Harada, M. Hara, S. Yamashita, K. Kikuchi and M. Shigemori (2010). "Cerebrospinal fluid following cerebral ischemia accelerates the proliferation of bone marrow stromal cells in vitro." The Kurume medical journal 57(1-2): 21-28.

Orsini, M., A. B. Oliveira, O. J. Nascimento, C. H. Reis, M. A. Leite, J. A. de Souza, C. Pupe, O. G. de Souza, V. H. Bastos, M. R. de Freitas, S. Teixeira, C. Bruno, E. Davidovich and B. Smidt (2015). "Amyotrophic Lateral Sclerosis: New Perpectives and Update." Neurol Int 7(2): 5885.

Osman, A. E., M. Mubasher, N. E. ElSheikh, H. AlHarthi, M. S. AlZahrani, N. Ahmed, G. ElGhazali, B. A. Bradley and A. S. Fadil (2016). "Association of single nucleotide polymorphisms in pro-inflammatory cytokine and tolllike receptor genes with pediatric hematogenous osteomyelitis." Genet Mol Res 15(2).

Ourednik, J., V. Ourednik, W. P. Lynch, M. Schachner and E. Y. Snyder (2002). "Neural stem cells display an inherent mechanism for rescuing dysfunctional neurons." Nat Biotechnol 20(11): 1103-1110.

Palladini, G., B. Caronti, G. Pozzessere, A. Teichner, F. R. Buttarelli, E. Morselli, E. Valle, G. Venturini, A. Fortuna and F. E. Pontieri (1996). "Treatment with cyclosporine A promotes axonal regeneration in rats submitted to transverse section of the spinal cord--II--Recovery of function." J Hirnforsch 37(1): 145-153.

Pan, K., L. Deng, P. Chen, Q. Peng, J. Pan, Y. Wu and Y. Wang (2019). "Safety and Feasibility of Repeated Intrathecal Allogeneic Bone Marrow-Derived Mesenchymal Stromal Cells in Patients with Neurological Diseases." Stem Cells Int 2019: 8421281.

Parish, C. L. and E. Arenas (2007). "Stem-cell-based strategies for the treatment of Parkinson's disease." Neurodegenerative diseases 4(4): 339-347.

Park, D. H., D. J. Eve, Y. G. Chung and P. R. Sanberg (2010). "Regenerative medicine for neurological disorders." ScientificWorldJournal 10: 470-489.

Park, H. C., Y. S. Shim, Y. Ha, S. H. Yoon, S. R. Park, B. H. Choi and H. S. Park (2005). "Treatment of complete spinal cord injury patients by autologous bone marrow cell transplantation and administration of granulocytemacrophage colony stimulating factor." Tissue engineering 11(5-6): 913-922.

Park, H. J., G. Bang, B. R. Lee, H. O. Kim and P. H. Lee (2011). "Neuroprotective effect of human mesenchymal stem cells in an animal model of double toxin-induced multiple system atrophy parkinsonism." Cell Transplant 20(6): 827-835.

Park, H. J., P. H. Lee, O. Y. Bang, G. Lee and Y. H. Ahn (2008). "Mesenchymal stem cells therapy exerts neuroprotection in a progressive animal model of Parkinson's disease." Journal of neurochemistry 107(1): 141-151.

Park, J.-H., D.-H. Kim, D.-Y. Kwon and e. al. (2019). "Trends in the incidence and prevalence of Parkinson's disease in Korea: a nationwide, population-based study." BMC Geriatrics(19): 320-330.

Paspala, S. A., A. B. Balaji, P. Nyamath, K. S. Ahmed, A. A. Khan, M. N. Khaja, M. L. Narsu, Y. P. Devi, T. V. Murthy and C. M. Habibullah (2009). "Neural stem cells \& supporting cells--the new therapeutic tools for the treatment of spinal cord injury." The Indian journal of medical research 130(4): 379-391.

Pasterkamp, R. J. and R. J. Giger (2009). "Semaphorin function in neural plasticity and disease." Curr Opin Neurobiol 19(3): 263-274.

Paul, C., A. F. Samdani, R. R. Betz, I. Fischer and B. Neuhuber (2009). "Grafting of human bone marrow stromal cells into spinal cord injury: a comparison of delivery methods." Spine 34(4): 328-334. 
Pavlov D, Bettendorff L, Gorlova A, Olkhovik A, Kalueff AV, Ponomarev ED, Inozemtsev A, Chekhonin V, Lesch KP, Anthony DC, Strekalova T (2019). "Neuroinflammation and aberrant hippocampal plasticity in a mouse model of emotional stress evoked by exposure to ultrasound of alternating frequencies". Prog Neuropsychopharmacol Biol Psychiatry 90:104-116.

Perry, V. H., M. D. Bell, H. C. Brown and M. K. Matyszak (1995). "Inflammation in the nervous system." Curr Opin Neurobiol 5(5): 636-641.

Pesce, M., A. Orlandi, M. G. lachininoto, S. Straino, A. R. Torella, V. Rizzuti, G. Pompilio, G. Bonanno, G. Scambia and M. C. Capogrossi (2003). "Myoendothelial differentiation of human umbilical cord blood-derived stem cells in ischemic limb tissues." Circulation research 93(5): e51-62.

Pittenger, M. F., A. M. Mackay, S. C. Beck, R. K. Jaiswal, R. Douglas, J. D. Mosca, M. A. Moorman, D. W. Simonetti, S. Craig and D. R. Marshak (1999). "Multilineage potential of adult human mesenchymal stem cells." Science 284(5411): 143-147.

Pittenger, M. F. and B. J. Martin (2004). "Mesenchymal stem cells and their potential as cardiac therapeutics." Circ Res 95(1): 9-20.

Pitzer, C., S. Klussmann, C. Kruger, E. Letellier, C. Plaas, T. Dittgen, F. Kirsch, B. Stieltjes, D. Weber, R. Laage, A. Martin-Villalba and A. Schneider (2010). "The hematopoietic factor granulocyte-colony stimulating factor improves outcome in experimental spinal cord injury." Journal of neurochemistry 113(4): 930-942.

Podjaski, C., J. I. Alvarez, L. Bourbonniere, S. Larouche, S. Terouz, J. M. Bin, M. A. Lecuyer, O. Saint-Laurent, C. Larochelle, P. J. Darlington, N. Arbour, J. P. Antel, T. E. Kennedy and A. Prat (2015). "Netrin 1 regulates blood-brain barrier function and neuroinflammation." Brain 138(Pt 6): 1598-1612.

Pompl, P. N., L. Ho, M. Bianchi, T. McManus, W. Qin and G. M. Pasinetti (2003). "A therapeutic role for cyclooxygenase-2 inhibitors in a transgenic mouse model of amyotrophic lateral sclerosis." FASEB J 17(6): 725-727.

Ponemone, V., S. Gupta, D. Sethi, M. Suthar, M. Sharma, R. J. Powell, K. L. Harris, N. Jungla, P. Arambam, U. Kaul, A. Seth and S. Bukhari (2017). "Safety and Effectiveness of Bone Marrow Cell Concentrate in the Treatment of Chronic Critical Limb Ischemia Utilizing a Rapid Point-of-Care System." Stem Cells Int 2017: 4137626.

Popovich, P. G. and W. F. Hickey (2001). "Bone marrow chimeric rats reveal the unique distribution of resident and recruited macrophages in the contused rat spinal cord." J Neuropathol Exp Neurol 60(7): 676-685.

Potas, J. R., Y. Zheng, C. Moussa, M. Venn, C. A. Gorrie, C. Deng and P. M. Waite (2006). "Augmented locomotor recovery after spinal cord injury in the athymic nude rat." J Neurotrauma 23(5): 660-673.

Ramirez, A. I., R. de Hoz, E. Salobrar-Garcia, J. J. Salazar, B. Rojas, D. Ajoy, I. Lopez-Cuenca, P. Rojas, A. Trivino and J. M. Ramirez (2017). "The Role of Microglia in Retinal Neurodegeneration: Alzheimer's Disease, Parkinson, and Glaucoma." Front Aging Neurosci 9: 214.

Ramirez, J. J., W. E. Poulton, E. Knelson, C. Barton, M. A. King and R. L. Klein (2011). "Focal expression of mutated tau in entorhinal cortex neurons of rats impairs spatial working memory." Behav Brain Res 216(1): 332340.

Ramos-Moreno, T., C. G. Castillo and A. Martinez-Serrano (2012). "Long term behavioral effects of functional dopaminergic neurons generated from human neural stem cells in the rat 6-OH-DA Parkinson's disease model. Effects of the forced expression of BCL-X(L)." Behavioural brain research 232(1): 225-232.

Rani, S., A. E. Ryan, M. D. Griffin and T. Ritter (2015). "Mesenchymal Stem Cell-derived Extracellular Vesicles: Toward Cell-free Therapeutic Applications." Mol Ther 23(5): 812-823.

Raposo, G. and W. Stoorvogel (2013). "Extracellular vesicles: exosomes, microvesicles, and friends." J Cell Biol 200(4): 373-383.

Redondo-Castro, E., C. Cunningham, J. Miller, L. Martuscelli, S. Aoulad-Ali, N. J. Rothwell, C. M. Kielty, S. M. Allan and E. Pinteaux (2017). "Interleukin-1 primes human mesenchymal stem cells towards an antiinflammatory and pro-trophic phenotype in vitro." Stem Cell Res Ther 8(1): 79.

Redzic, Z. (2011). "Molecular biology of the blood-brain and the blood-cerebrospinal fluid barriers: similarities and differences." Fluids Barriers CNS 8(1): 3. 
Ren, H., M. Han, J. Zhou, Z. F. Zheng, P. Lu, J. J. Wang, J. Q. Wang, Q. J. Mao, J. Q. Gao and H. W. Ouyang (2014). "Repair of spinal cord injury by inhibition of astrocyte growth and inflammatory factor synthesis through local delivery of flavopiridol in PLGA nanoparticles." Biomaterials 35(24): 6585-6594.

Riordan, N. H., K. Chan, A. M. Marleau and T. E. Ichim (2007). "Cord blood in regenerative medicine: do we need immune suppression?" J Transl Med 5: 8.

Rodriguez-Cueto, C., I. Santos-Garcia, L. Garcia-Toscano, F. Espejo-Porras, M. Bellido, J. Fernandez-Ruiz, E. Munoz and E. de Lago (2018). "Neuroprotective effects of the cannabigerol quinone derivative VCE-003.2 in SOD1(G93A) transgenic mice, an experimental model of amyotrophic lateral sclerosis." Biochem Pharmacol 157: 217-226.

Romanelli, P., L. Bieler, C. Scharler, K. Pachler, C. Kreutzer, P. Zaunmair, D. Jakubecova, H. Mrowetz, B. Benedetti, F. J. Rivera, L. Aigner, E. Rohde, M. Gimona, D. Strunk and S. Couillard-Despres (2019). "Extracellular Vesicles Can Deliver Anti-inflammatory and Anti-scarring Activities of Mesenchymal Stromal Cells After Spinal Cord Injury." Front Neurol 10: 1225.

Romero-Ramirez, L., S. Wu, J. de Munter, E. C. Wolters, B. W. Kramer and J. Mey (2020). "Treatment of rats with spinal cord injury using human bone marrow-derived stromal cells prepared by negative selection." J Biomed Sci 27(1): 35 .

Rooney, J., S. Byrne, M. Heverin, B. Corr, M. Elamin, A. Staines, B. Goldacre and O. Hardiman (2013). "Survival analysis of irish amyotrophic lateral sclerosis patients diagnosed from 1995-2010." PLoS One 8(9): e74733.

Rosado, I. R., M. S. Lavor, E. G. Alves, F. B. Fukushima, K. M. Oliveira, C. M. Silva, F. M. Caldeira, P. M. Costa and E. G. Melo (2014). "Effects of methylprednisolone, dantrolene, and their combination on experimental spinal cord injury." Int J Clin Exp Pathol 7(8): 4617-4626.

Rose-John, S. (2012). "IL-6 trans-signaling via the soluble IL-6 receptor: importance for the pro-inflammatory activities of IL-6." Int J Biol Sci 8(9): 1237-1247.

Roszer, T. (2015). "Understanding the Mysterious M2 Macrophage through Activation Markers and Effector Mechanisms." Mediators Inflamm 2015: 816460.

Ruiz-Lopez, F. J., J. Guardiola, V. Izura, J. Gomez-Espuch, F. Iniesta, M. Blanquer, J. Lopez-San Roman, V. Saez, P. De Mingo, S. Martinez and J. M. Moraleda (2016). "Breathing pattern in a phase I clinical trial of intraspinal injection of autologous bone marrow mononuclear cells in patients with amyotrophic lateral sclerosis." Respir Physiol Neurobiol 221: 54-58.

Ruppert, K. A., T. T. Nguyen, K. S. Prabhakara, N. E. Toledano Furman, A. K. Srivastava, M. T. Harting, C. S. Cox, Jr. and S. D. Olson (2018). "Human Mesenchymal Stromal Cell-Derived Extracellular Vesicles Modify Microglial Response and Improve Clinical Outcomes in Experimental Spinal Cord Injury." Sci Rep 8(1): 480.

Sabatelli, M., A. Moncada, A. Conte, S. Lattante, G. Marangi, M. Luigetti, M. Lucchini, M. Mirabella, A. Romano, A. Del Grande, G. Bisogni, P. N. Doronzio, P. M. Rossini and M. Zollino (2013). "Mutations in the 3' untranslated region of FUS causing FUS overexpression are associated with amyotrophic lateral sclerosis." Hum Mol Genet 22(23): 4748-4755.

Sadan, O., M. Bahat-Stromza, Y. Barhum, Y. S. Levy, A. Pisnevsky, H. Peretz, A. B. Ilan, S. Bulvik, N. Shemesh, D. Krepel, Y. Cohen, E. Melamed and D. Offen (2009). "Protective effects of neurotrophic factor-secreting cells in a 6-OHDA rat model of Parkinson disease." Stem Cells Dev 18(8): 1179-1190.

Sahoo, S., E. Klychko, T. Thorne, S. Misener, K. M. Schultz, M. Millay, A. Ito, T. Liu, C. Kamide, H. Agrawal, H. Perlman, G. Qin, R. Kishore and D. W. Losordo (2011). "Exosomes from human CD34(+) stem cells mediate their proangiogenic paracrine activity." Circ Res 109(7): 724-728.

Sala Frigerio, C., L. Wolfs, N. Fattorelli, N. Thrupp, I. Voytyuk, I. Schmidt, R. Mancuso, W. T. Chen, M. E. Woodbury, G. Srivastava, T. Moller, E. Hudry, S. Das, T. Saido, E. Karran, B. Hyman, V. H. Perry, M. Fiers and B. De Strooper (2019). "The Major Risk Factors for Alzheimer's Disease: Age, Sex, and Genes Modulate the Microglia Response to Abeta Plaques." Cell Rep 27(4): 1293-1306 e1296.

Sama, R. R., C. L. Ward, L. J. Kaushansky, N. Lemay, S. Ishigaki, F. Urano and D. A. Bosco (2013). "FUS/TLS assembles into stress granules and is a prosurvival factor during hyperosmolar stress." J Cell Physiol 228(11): 2222 2231. 
Samdani, A. F., C. Paul, R. R. Betz, I. Fischer and B. Neuhuber (2009). "Transplantation of human marrow stromal cells and mono-nuclear bone marrow cells into the injured spinal cord: a comparative study." Spine 34(24): 2605-2612.

Sato, K., K. Ozaki, I. Oh, A. Meguro, K. Hatanaka, T. Nagai, K. Muroi and K. Ozawa (2007). "Nitric oxide plays a critical role in suppression of T-cell proliferation by mesenchymal stem cells." Blood 109(1): 228-234.

Savic, G., M. J. DeVivo, H. L. Frankel, M. A. Jamous, B. M. Soni and S. Charlifue (2017). "Long-term survival after traumatic spinal cord injury: a 70-year British study." Spinal Cord 55(7): 651-658.

Savitz, S. I., V. Misra, M. Kasam, H. Juneja, C. S. Cox, Jr., S. Alderman, I. Aisiku, S. Kar, A. Gee and J. C. Grotta (2011). "Intravenous autologous bone marrow mononuclear cells for ischemic stroke." Annals of neurology 70(1): 59-69.

Scerpa, M. C., N. Daniele, F. Landi, M. Caniglia, A. M. Cometa, C. Ciammetti, C. Rossi, F. Locatelli, G. Isacchi and F. Zinno (2011). "Automated washing of human progenitor cells: evaluation of apoptosis and cell necrosis." Transfusion medicine 21(6): 402-407.

Schallert, T., S. M. Fleming, J. L. Leasure, J. L. Tillerson and S. T. Bland (2000). "CNS plasticity and assessment of forelimb sensorimotor outcome in unilateral rat models of stroke, cortical ablation, parkinsonism and spinal cord injury." Neuropharmacology 39(5): 777-787.

Schaper, F. and S. Rose-John (2015). "Interleukin-6: Biology, signaling and strategies of blockade." Cytokine Growth Factor Rev 26(5): 475-487.

Schatteman, G. C., H. D. Hanlon, C. Jiao, S. G. Dodds and B. A. Christy (2000). "Blood-derived angioblasts accelerate blood-flow restoration in diabetic mice." J Clin Invest 106(4): 571-578.

Schellenberg, A., Q. Lin, H. Schuler, C. M. Koch, S. Joussen, B. Denecke, G. Walenda, N. Pallua, C. V. Suschek, M. Zenke and W. Wagner (2011). "Replicative senescence of mesenchymal stem cells causes DNAmethylation changes which correlate with repressive histone marks."Aging (Albany) 3(9):873-888.

Scheubel, R. J., J. Holtz, I. Friedrich, J. Borgermann, S. Kahrstedt, A. Navarrete Santos, R. E. Silber and A. Simm (2010). "Paracrine effects of CD34 progenitor cells on angiogenic endothelial sprouting." Int J Cardiol 139(2): 134-141.

Schiattarella, G. G., C. Perrino, F. Magliulo, A. Carbone, A. G. Bruno, M. De Paulis, A. Sorropago, R. V. Corrado R. Bottino, G. Menafra, R. Abete, E. Toscano, G. Giugliano, B. Trimarco and G. Esposito (2014). "Physical activity in the prevention of peripheral artery disease in the elderly." Front Physiol 5: 12.

Schoenfeld, A. J., M. D. Laughlin, B. J. McCriskin, J. O. Bader, B. R. Waterman and P. J. Belmont, Jr. (2013). "Spinal injuries in United States military personnel deployed to Iraq and Afghanistan: an epidemiological investigation involving 7877 combat casualties from 2005 to 2009." Spine (Phila Pa 1976) 38(20): 17701778.

Schofield, R. (1983). "The stem cell system." Biomedicine \& pharmacotherapy = Biomedecine \& pharmacotherapie 37(8): 375-380.

Schoser, B. G. and D. Blottner (1999). "Matrix metalloproteinases MMP-2, MMP-7 and MMP-9 in denervated human muscle." Neuroreport 10(13): 2795-2797.

Schroeder, G. D., C. K. Kepler and A. R. Vaccaro (2016). "The Use of Cell Transplantation in Spinal Cord Injuries." J Am Acad Orthop Surg 24(4): 266-275.

Schuler, P. J., M. Harasymczuk, B. Schilling, S. Lang and T. L. Whiteside (2011). "Separation of human CD4+CD39+ $T$ cells by magnetic beads reveals two phenotypically and functionally different subsets." J Immunol Methods 369(1-2): 59-68.

Schwarting, S., S. Litwak, W. Hao, M. Bahr, J. Weise and H. Neumann (2008). "Hematopoietic stem cells reduce postischemic inflammation and ameliorate ischemic brain injury." Stroke 39(10): 2867-2875.

Schwartz, M. and R. Shechter (2010). "Systemic inflammatory cells fight off neurodegenerative disease." Nat Rev Neurol 6(7): 405-410.

Schwartz, M. and Y. Ziv (2008). "Immunity to self and self-maintenance: what can tumor immunology teach us about ALS and Alzheimer's disease?" Trends Pharmacol Sci 29(6): 287-293.

Sekhon, L. H. and M. G. Fehlings (2001). "Epidemiology, demographics, and pathophysiology of acute spinal cord injury." Spine (Phila Pa 1976) 26(24 Suppl): S2-12. 
Shahjin, F., S. Chand and S. V. Yelamanchili (2019). "Extracellular Vesicles as Drug Delivery Vehicles to the Central Nervous System." J Neuroimmune Pharmacol.

Shan, L. Y., J. Z. Li, L. Y. Zu, C. G. Niu, A. Ferro, Y. D. Zhang, L. M. Zheng and Y. Ji (2013). "Platelet-derived microparticles are implicated in remote ischemia conditioning in a rat model of cerebral infarction." CNS Neurosci Ther 19(12): 917-925.

Shannon, P., A. Markiel, O. Ozier and E. al. (2003). "Cytoscape: a software environment for integrated models of biomolecular interaction networks." Genome Res 13(11): 2498-2504.

Shao, A., S. Tu, J. Lu and J. Zhang (2019). "Crosstalk between stem cell and spinal cord injury: pathophysiology and treatment strategies." Stem Cell Res Ther 10(1): 238.

Shechter, R., A. London, C. Varol, C. Raposo, M. Cusimano, G. Yovel, A. Rolls, M. Mack, S. Pluchino, G. Martino, S. Jung and M. Schwartz (2009). "Infiltrating blood-derived macrophages are vital cells playing an antiinflammatory role in recovery from spinal cord injury in mice." PLoS medicine 6(7): e1000113.

Shechter, R., O. Miller, G. Yovel, N. Rosenzweig, A. London, J. Ruckh, K. W. Kim, E. Klein, V. Kalchenko, P. Bendel, S. A. Lira, S. Jung and M. Schwartz (2013). "Recruitment of beneficial M2 macrophages to injured spinal cord is orchestrated by remote brain choroid plexus." Immunity 38(3): 555-569.

Shelkovnikova, T. A., M. S. Kukharsky, H. An, P. Dimasi, S. Alexeeva, O. Shabir, P. R. Heath and V. L. Buchman (2018). "Protective paraspeckle hyper-assembly downstream of TDP-43 loss of function in amyotrophic lateral sclerosis." Mol Neurodegener 13(1): 30.

Shelkovnikova, T. A., O. M. Peters, A. V. Deykin, N. Connor-Robson, H. Robinson, A. A. Ustyugov, S. O. Bachurin, T. G. Ermolkevich, I. L. Goldman, E. R. Sadchikova, E. A. Kovrazhkina, V. I. Skvortsova, S. C. Ling, S. Da Cruz, P. A. Parone, V. L. Buchman and N. N. Ninkina (2013). "Fused in sarcoma (FUS) protein lacking nuclear localization signal (NLS) and major RNA binding motifs triggers proteinopathy and severe motor phenotype in transgenic mice." J Biol Chem 288(35): 25266-25274.

Shelkovnikova, T. A., H. K. Robinson, J. A. Southcombe, N. Ninkina and V. L. Buchman (2014). "Multistep process of FUS aggregation in the cell cytoplasm involves RNA-dependent and RNA-independent mechanisms." Hum Mol Genet 23(19): 5211-5226.

Shende, P. and M. Subedi (2017). "Pathophysiology, mechanisms and applications of mesenchymal stem cells for the treatment of spinal cord injury." Biomed Pharmacother 91: 693-706.

Shi, E., T. Kazui, X. Jiang, N. Washiyama, K. Yamashita, H. Terada and A. H. Bashar (2007). "Therapeutic benefit of intrathecal injection of marrow stromal cells on ischemia-injured spinal cord." Ann Thorac Surg 83(4): 1484-1490.

Shiihashi, G., D. Ito, I. Arai, Y. Kobayashi, K. Hayashi, S. Otsuka, K. Nakajima, M. Yuzaki, S. Itohara and N. Suzuki (2017). "Dendritic Homeostasis Disruption in a Novel Frontotemporal Dementia Mouse Model Expressing Cytoplasmic Fused in Sarcoma." EBioMedicine 24: 102-115.

Shin, D. A., J. M. Kim, H. I. Kim, S. Yi, Y. Ha, D. H. Yoon and K. N. Kim (2013). "Comparison of functional and histological outcomes after intralesional, intracisternal, and intravenous transplantation of human bone marrow-derived mesenchymal stromal cells in a rat model of spinal cord injury." Acta Neurochir (Wien) 155(10): 1943-1950.

Shintani, S., T. Murohara, H. Ikeda, T. Ueno, T. Honma, A. Katoh, K. Sasaki, T. Shimada, Y. Oike and T. Imaizumi (2001). "Mobilization of endothelial progenitor cells in patients with acute myocardial infarction." Circulation 103(23): 2776-2779.

Shruthi, S., R. Sumitha, A. M. Varghese, S. Ashok, B. K. Chandrasekhar Sagar, T. N. Sathyaprabha, A. Nalini, B. W. Kramer, T. R. Raju, K. Vijayalakshmi and P. A. Alladi (2017). "Brain-Derived Neurotrophic Factor Facilitates Functional Recovery from ALS-Cerebral Spinal Fluid-Induced Neurodegenerative Changes in the NSC-34 Motor Neuron Cell Line." Neurodegener Dis 17(1): 44-58.

Shyu, W. C., S. Z. Lin, M. F. Chiang, C. Y. Su and H. Li (2006). "Intracerebral peripheral blood stem cell (CD34+) implantation induces neuroplasticity by enhancing beta1 integrin-mediated angiogenesis in chronic stroke rats." The Journal of neuroscience : the official journal of the Society for Neuroscience 26(13): 3444-3453. 
Shyu, W. C., S. Z. Lin, P. S. Yen, C. Y. Su, D. C. Chen, H. J. Wang and H. Li (2008). "Stromal cell-derived factor-1 alpha promotes neuroprotection, angiogenesis, and mobilization/homing of bone marrow-derived cells in stroke rats." J Pharmacol Exp Ther 324(2): 834-849.

Siddiq, S., D. Pamphilon, S. Brunskill, C. Doree, C. Hyde and S. Stanworth (2009). "Bone marrow harvest versus peripheral stem cell collection for haemopoietic stem cell donation in healthy donors." Cochrane database of systematic reviews(1): CD006406.

Sigurjonsson, O. E., M. C. Perreault, T. Egeland and J. C. Glover (2005). "Adult human hematopoietic stem cells produce neurons efficiently in the regenerating chicken embryo spinal cord." Proc Natl Acad Sci U S A 102(14): 5227-5232.

Silva, N. A., N. Sousa, R. L. Reis and A. J. Salgado (2014). "From basics to clinical: a comprehensive review on spinal cord injury." Prog Neurobiol 114: 25-57.

Singh, A., L. Tetreault, S. Kalsi-Ryan, A. Nouri and M. G. Fehlings (2014). "Global prevalence and incidence of traumatic spinal cord injury." Clin Epidemiol 6: 309-331.

Soini, Y., K. Kahlos, R. Sormunen, M. Saily, P. Mantymaa, P. Koistinen, P. Paakko and V. Kinnula (2005). "Activation and relocalization of caspase 3 during the apoptotic cascade of human mesothelioma cells." APMIS 113(6): 426-435.

Somoza, R., C. Juri, M. Baes, U. Wyneken and F. J. Rubio (2010). "Intranigral transplantation of epigenetically induced BDNF-secreting human mesenchymal stem cells: implications for cell-based therapies in Parkinson's disease." Biol Blood Marrow Transplant 16(11): 1530-1540.

Spees, J. L., R. H. Lee and C. A. Gregory (2016). "Mechanisms of mesenchymal stem/stromal cell function." Stem Cell Res Ther 7(1): 125.

Spinello, A., E. Vecile, A. Abbate, A. Dobrina and A. Magistrato (2019). "How Can Interleukin-1 Receptor Antagonist Modulate Distinct Cell Death Pathways?" J Chem Inf Model 59(1): 351-359.

Springer, J. E., R. D. Azbill and P. E. Knapp (1999). "Activation of the caspase-3 apoptotic cascade in traumatic spinal cord injury." Nat Med 5(8): 943-946.

Srivastava, R. N., A. K. Agrahari, A. Singh, T. Chandra and S. Raj (2019). "Effectiveness of bone marrow-derived mononuclear stem cells for neurological recovery in participants with spinal cord injury: A randomized controlled trial." Asian J Transfus Sci 13(2): 120-128.

Stadtfeld, M. and K. Hochedlinger (2010). "Induced pluripotency: history, mechanisms, and applications." Genes \& development 24(20): 2239-2263.

Stamatovic, S. M., R. F. Keep and A. V. Andjelkovic (2008). "Brain endothelial cell-cell junctions: how to "open" the blood brain barrier." Current neuropharmacology 6(3): 179-192.

Stenderup, K., J. Justesen, C. Clausen and M. Kassem (2003). "Aging is associated with decreased maximal life span and accelerated senescence of bone marrow stromal cells." Bone 33(6): 919-926.

Stoica, R., S. Paillusson, P. Gomez-Suaga, J. C. Mitchell, D. H. Lau, E. H. Gray, R. M. Sancho, G. Vizcay-Barrena, K. J. De Vos, C. E. Shaw, D. P. Hanger, W. Noble and C. C. Miller (2016). "ALS/FTD-associated FUS activates GSK-3beta to disrupt the VAPB-PTPIP51 interaction and ER-mitochondria associations." EMBO Rep 17(9): 1326-1342.

Strauss, D. J., M. J. Devivo, D. R. Paculdo and R. M. Shavelle (2006). "Trends in life expectancy after spinal cord injury." Arch Phys Med Rehabil 87(8): 1079-1085.

Strekalova T, Bahzenova N. Trofimov A. Schmitt-Böhrer AG, Markova N, Grigoriev V, Zamoyski V, Serkova T, Redkozubova O, Vinogradova D, Umriukhin A, Fisenko V, Lillesaar C, Shevtsova E, Sokolov V, Aksinenko A, Lesch K.-P, Bachurin S (2018). "Pro-neurogenic, Memory-Enhancing and Anti-stress Effects of DF302, a Novel Fluorine Gamma-Carboline Derivative with Multi-target Mechanism of Action". Mol Neurobiol. 55: 335-349.

Strekalova T, Anthony DC, Dolgov O, Anokhin K, Kubatiev A, Steinbusch HM, Schroeter C (2013)."The differential effects of chronic imipramine or citalopram administration on physiological and behavioral outcomes in naïve mice". Behav Brain Res. 245:101-106.

Strekalova, T. and H. W. Steinbusch (2010). "Measuring behavior in mice with chronic stress depression paradigm." Prog Neuropsychopharmacol Biol Psychiatry 34(2): 348-361. 
Strekalova T, Spanagel R, Bartsch D, Henn FA, Gass P (2004). "Stress-induced anhedonia in mice is associated with deficits in forced swimming and exploration". Neuropsychopharmacology 29: 2007-2017.

Strekalova, T., C. T. Wotjak and M. Schachner (2001). "Intrahippocampal administration of an antibody against the HNK-1 carbohydrate impairs memory consolidation in an inhibitory learning task in mice." Mol Cell Neurosci 17(6): 1102-1113.

Suberviola, B., A. Gonzalez-Castro, J. Llorca, F. Ortiz-Melon and E. Minambres (2008). "Early complications of highdose methylprednisolone in acute spinal cord injury patients." Injury 39(7): 748-752.

Subramaniam, S. R. and H. J. Federoff (2017). "Targeting Microglial Activation States as a Therapeutic Avenue in Parkinson's Disease." Front Aging Neurosci 9: 176.

Subramanian, A., P. Tamayo, V. K. Mootha, S. Mukherjee, B. L. Ebert, M. A. Gillette, A. Paulovich, S. L. Pomeroy, T. R. Golub, E. S. Lander and J. P. Mesirov (2005). "Gene set enrichment analysis: a knowledge-based approach for interpreting genome-wide expression profiles." Proc Natl Acad Sci U S A 102(43): 1554515550.

Sumitha, R., V. M. Manjunatha, R. K. Sabitha, P. A. Alladi, A. Nalini, L. T. Rao, B. K. Chandrasekhar Sagar, H. W. M. Steinbusch, B. W. Kramer, T. N. Sathyaprabha and T. R. Raju (2019). "Cerebrospinal Fluid from Patients with Sporadic Amyotrophic Lateral Sclerosis Induces Degeneration of Motor Neurons Derived from Human Embryonic Stem Cells." Mol Neurobiol 56(2): 1014-1034.

Sykova, E., A. Homola, R. Mazanec, H. Lachmann, S. L. Konradova, P. Kobylka, R. Padr, J. Neuwirth, V. Komrska, V. Vavra, J. Stulik and M. Bojar (2006). "Autologous bone marrow transplantation in patients with subacute and chronic spinal cord injury." Cell Transplant 15(8-9): 675-687.

Sykova, E., P. Rychmach, I. Drahoradova, S. Konradova, K. Ruzickova, I. Vorisek, S. Forostyak, A. Homola and M. Bojar (2017). "Transplantation of Mesenchymal Stromal Cells in Patients With Amyotrophic Lateral Sclerosis: Results of Phase I/Ila Clinical Trial." Cell Transplant 26(4): 647-658.

Tagliaferri, F., C. Compagnone, M. Korsic, F. Servadei and J. Kraus (2006). "A systematic review of brain injury epidemiology in Europe." Acta Neurochir (Wien) 148(3): 255-268; discussion 268.

Taguchi, A., T. Soma, H. Tanaka, T. Kanda, H. Nishimura, H. Yoshikawa, Y. Tsukamoto, H. Iso, Y. Fujimori, D. M. Stern, H. Naritomi and T. Matsuyama (2004). "Administration of CD34+ cells after stroke enhances neurogenesis via angiogenesis in a mouse model." J Clin Invest 114(3): 330-338.

Takahashi, T., C. Kalka, H. Masuda, D. Chen, M. Silver, M. Kearney, M. Magner, J. M. Isner and T. Asahara (1999). "Ischemia- and cytokine-induced mobilization of bone marrow-derived endothelial progenitor cells for neovascularization." Nat Med 5(4): 434-438.

Tang, B. L. (2017). "Amyotrophic lateral sclerosis disease modifying therapeutics: a cell biological perspective." Neural Regen Res 12(3): 407-408.

Tang, B. L. (2017). "The use of mesenchymal stem cells (MSCs) for amyotrophic lateral sclerosis (ALS) therapy - a perspective on cell biological mechanisms." Rev Neurosci 28(7): 725-738.

Tang, W., N. Han, Y. Liu, Z. Li and Y. Wei (2015). "GSK3beta expression and phosphorylation during neuronal maturation in the rat dorsal root ganglion." Int J Clin Exp Med 8(4): 5897-5903.

Tatard, V. M., G. D'Ippolito, S. Diabira, A. Valeyev, J. Hackman, M. McCarthy, T. Bouckenooghe, P. Menei, C. N. Montero-Menei and P. C. Schiller (2007). "Neurotrophin-directed differentiation of human adult marrow stromal cells to dopaminergic-like neurons." Bone 40(2): 360-373.

Tateishi-Yuyama, E., H. Matsubara, T. Murohara, U. Ikeda, S. Shintani, H. Masaki, K. Amano, Y. Kishimoto, K. Yoshimoto, H. Akashi, K. Shimada, T. Iwasaka and T. Imaizumi (2002). "Therapeutic angiogenesis for patients with limb ischaemia by autologous transplantation of bone-marrow cells: a pilot study and a randomised controlled trial." Lancet 360(9331): 427-435.

Tetzlaff, W., E. B. Okon, S. Karimi-Abdolrezaee, C. E. Hill, J. S. Sparling, J. R. Plemel, W. T. Plunet, E. C. Tsai, D. Baptiste, L. J. Smithson, M. D. Kawaja, M. G. Fehlings and B. K. Kwon (2011). "A systematic review of cellular transplantation therapies for spinal cord injury." Journal of neurotrauma 28(8): 1611-1682.

Therrien, M., G. A. Rouleau, P. A. Dion and J. A. Parker (2016). "FET proteins regulate lifespan and neuronal integrity." Sci Rep 6: 25159.

Thery, C. (2011). "Exosomes: secreted vesicles and intercellular communications." F1000 Biol Rep 3: 15. 
Thomas, J., F. Liu and D. C. Link (2002). "Mechanisms of mobilization of hematopoietic progenitors with granulocyte colony-stimulating factor." Current opinion in hematology 9(3): 183-189.

Tondreau, T., L. Lagneaux, M. Dejeneffe, M. Massy, C. Mortier, A. Delforge and D. Bron (2004). "Bone marrowderived mesenchymal stem cells already express specific neural proteins before any differentiation." Differentiation 72(7): 319-326.

Tran, T. S., A. L. Kolodkin and R. Bharadwaj (2007). "Semaphorin regulation of cellular morphology." Annu Rev Cell Dev Biol 23: 263-292.

Trapp, B. D., J. Peterson, R. M. Ransohoff, R. Rudick, S. Mork and L. Bo (1998). "Axonal transection in the lesions of multiple sclerosis." N Engl J Med 338(5): 278-285.

Trofimov, A., T. Strekalova, N. Mortimer, O. Zubareva, A. Schwarz, E. Svirin, A. Umriukhin, A. Svistunov, K. P. Lesch and V. Klimenko (2017). "Postnatal LPS Challenge Impacts Escape Learning and Expression of Plasticity Factors Mmp9 and Timp1 in Rats: Effects of Repeated Training." Neurotox Res 32(2): 175-186.

Tropel, P., N. Platet, J. C. Platel, D. Noel, M. Albrieux, A. L. Benabid and F. Berger (2006). "Functional neuronal differentiation of bone marrow-derived mesenchymal stem cells." Stem Cells 24(12): 2868-2876.

Tsai, M. J., D. Y. Liou, Y. R. Lin, C. F. Weng, M. C. Huang, W. C. Huang, F. W. Tseng and H. Cheng (2018). "Attenuating Spinal Cord Injury by Conditioned Medium from Bone Marrow Mesenchymal Stem Cells." J Clin Med 8(1).

Tsintou, M., K. Dalamagkas and N. Makris (2020). "Taking central nervous system regenerative therapies to the clinic: curing rodents versus nonhuman primates versus humans." Neural Regen Res 15(3): 425-437.

Uccelli, A., M. Milanese, M. C. Principato, S. Morando, T. Bonifacino, L. Vergani, D. Giunti, A. Voci, E. Carminati, F. Giribaldi, C. Caponnetto and G. Bonanno (2012). "Intravenous mesenchymal stem cells improve survival and motor function in experimental amyotrophic lateral sclerosis." Mol Med 18: 794-804.

Ulndreaj, A., A. Badner and M. G. Fehlings (2017). "Promising neuroprotective strategies for traumatic spinal cord injury with a focus on the differential effects among anatomical levels of injury." F1000Res 6: 1907.

Urbich, C. and S. Dimmeler (2004). "Endothelial progenitor cells: characterization and role in vascular biology." Circ Res 95(4): 343-353.

Urdzikova, L., P. Jendelova, K. Glogarova, M. Burian, M. Hajek and E. Sykova (2006). "Transplantation of bone marrow stem cells as well as mobilization by granulocyte-colony stimulating factor promotes recovery after spinal cord injury in rats." J Neurotrauma 23(9): 1379-1391.

Urdzikova, L. M., J. Ruzicka, M. LaBagnara, K. Karova, S. Kubinova, K. Jirakova, R. Murali, E. Sykova, M. JhanwarUniyal and P. Jendelova (2014). "Human mesenchymal stem cells modulate inflammatory cytokines after spinal cord injury in rat." Int J Mol Sci 15(7): 11275-11293.

van den Berg, M. E., J. M. Castellote, I. Mahillo-Fernandez and J. de Pedro-Cuesta (2010). "Incidence of spinal cord injury worldwide: a systematic review." Neuroepidemiology 34(3): 184-192; discussion 192.

Van Tongeren, R. B., J. F. Hamming, W. E. Fibbe, V. Van Weel, S. J. Frerichs, A. M. Stiggelbout, J. H. Van Bockel and J. H. Lindeman (2008). "Intramuscular or combined intramuscular/intra-arterial administration of bone marrow mononuclear cells: a clinical trial in patients with advanced limb ischemia." J Cardiovasc Surg (Torino) 49(1): 51-58.

Vanicky, I., L. Urdzikova, K. Saganova, D. Cizkova and J. Galik (2001). "A simple and reproducible model of spinal cord injury induced by epidural balloon inflation in the rat." Journal of neurotrauma 18(12): 1399-1407.

Vaquero, J., M. Zurita, S. Oya and M. Santos (2006). "Cell therapy using bone marrow stromal cells in chronic paraplegic rats: systemic or local administration?" Neuroscience letters 398(1-2): 129-134.

Veeraputhiran, M., J. W. Theus, G. Pesek, B. Barlogie and M. Cottler-Fox (2010). "Viability and engraftment of hematopoietic progenitor cells after long-term cryopreservation: effect of diagnosis and percentage dimethyl sulfoxide concentration." Cytotherapy 12(6): 764-766.

Veniaminova E, Cespuglio R, Chernukha I, Schmitt-Boehrer AG, Morozov S, Kalueff AV, Kuznetsova O, Anthony DC, Lesch KP, Strekalova T (2020). "Metabolic, Molecular, and Behavioral Effects of Western Diet in Serotonin Transporter-Deficient Mice: Rescue by Heterozygosity?" Front Neurosci.14:24.

Veniaminova, E., M. Oplatchikova, L. Bettendorff, E. Kotenkova, A. Lysko, E. Vasilevskaya, A. V. Kalueff, L. Fedulova, A. Umriukhin, K. P. Lesch, D. C. Anthony and T. Strekalova (2019). "Prefrontal cortex inflammation and liver pathologies accompany cognitive and motor deficits following Western diet consumption in non-obese female mice." Life Sci 241: 117163. 
Venkataramana, N. K., S. K. Kumar, S. Balaraju, R. C. Radhakrishnan, A. Bansal, A. Dixit, D. K. Rao, M. Das, M. Jan, P. K. Gupta and S. M. Totey (2010). "Open-labeled study of unilateral autologous bone-marrow-derived mesenchymal stem cell transplantation in Parkinson's disease." Translational research : the journal of laboratory and clinical medicine 155(2): 62-70.

Venkataramana, N. K., R. Pal, S. A. Rao, A. L. Naik, M. Jan, R. Nair, C. C. Sanjeev, R. B. Kamble, D. P. Murthy and K. Chaitanya (2012). "Bilateral transplantation of allogenic adult human bone marrow-derived mesenchymal stem cells into the subventricular zone of Parkinson's disease: a pilot clinical study." Stem cells international 2012: 931902.

Vilalta, M., I. R. Degano, J. Bago, D. Gould, M. Santos, M. Garcia-Arranz, R. Ayats, C. Fuster, Y. Chernajovsky, D. Garcia-Olmo, N. Rubio and J. Blanco (2008). "Biodistribution, long-term survival, and safety of human adipose tissue-derived mesenchymal stem cells transplanted in nude mice by high sensitivity non-invasive bioluminescence imaging." Stem Cells Dev 17(5): 993-1003.

Voet, S., S. Srinivasan, M. Lamkanfi and G. van Loo (2019). "Inflammasomes in neuroinflammatory and neurodegenerative diseases." EMBO Mol Med 11(6).

Wagenaar, N., C. H. Nijboer and F. van Bel (2017). "Repair of neonatal brain injury: bringing stem cell-based therapy into clinical practice." Dev Med Child Neurol 59(10): 997-1003.

Wagey, R. S., B. (2014). "Mesenchymal stem and progenitor cells: problems, potential and promise." Journal of stem cells res, rev \& rep. 1(3): 9.

Wagner, W. (2012). "Implications of long-term culture for mesenchymal stem cells: genetic defects or epigenetic regulation?" Stem Cell Res Ther 3(6): 54.

Wang, F., T. Yasuhara, T. Shingo, M. Kameda, N. Tajiri, W. J. Yuan, A. Kondo, T. Kadota, T. Baba, J. T. Tayra, Y. Kikuchi, Y. Miyoshi and I. Date (2010). "Intravenous administration of mesenchymal stem cells exerts therapeutic effects on parkinsonian model of rats: focusing on neuroprotective effects of stromal cellderived factor-1alpha." BMC neuroscience 11: 52.

Wang, H., J. Brown and M. Martin (2011). "Glycogen synthase kinase 3: a point of convergence for the host inflammatory response." Cytokine 53(2): 130-140.

Wang, L., S. Pei, L. Han, B. Guo, Y. Li, R. Duan, Y. Yao, B. Xue, X. Chen and Y. Jia (2018). "Mesenchymal Stem CellDerived Exosomes Reduce A1 Astrocytes via Downregulation of Phosphorylated NFkappaB P65 Subunit in Spinal Cord Injury." Cell Physiol Biochem 50(4): 1535-1559.

Wang, Z. X., D. Li, J. X. Cao, Y. S. Liu, M. Wang, X. Y. Zhang, J. L. Li, H. B. Wang, J. L. Liu and B. L. Xu (2014). "Efficacy of autologous bone marrow mononuclear cell therapy in patients with peripheral arterial disease." J Atheroscler Thromb 21(11): 1183-1196.

Whittemore, S. R. (1999). "Neuronal replacement strategies for spinal cord injury." J Neurotrauma 16(8): 667673.

Wilkins, A., K. Kemp, M. Ginty, K. Hares, E. Mallam and N. Scolding (2009). "Human bone marrow-derived mesenchymal stem cells secrete brain-derived neurotrophic factor which promotes neuronal survival in vitro." Stem cell research.

Wirdefeldt, K., H. O. Adami, P. Cole, D. Trichopoulos and J. Mandel (2011). "Epidemiology and etiology of Parkinson's disease: a review of the evidence." Eur J Epidemiol 26 Suppl 1: S1-58.

Wolters, E. C., T. Van Laar and H. W. Berendse (2010). "Parkinsonism and related disorders." VU University Press Third Edition: 143-158.

Wood, M. J., A. J. O'Loughlin and L. Samira (2011). "Exosomes and the blood-brain barrier: implications for neurological diseases." Ther Deliv 2(9): 1095-1099.

Wragg, A., J. A. Mellad, L. E. Beltran, M. Konoplyannikov, H. San, S. Boozer, R. J. Deans, A. Mathur, R. J. Lederman, J. C. Kovacic and M. Boehm (2008). "VEGFR1/CXCR4-positive progenitor cells modulate local inflammation and augment tissue perfusion by a SDF-1-dependent mechanism." J Mol Med 86(11): 1221-1232.

Wright, K. T., W. El Masri, A. Osman, J. Chowdhury and W. E. Johnson (2010). "Bone Marrow for the Treatment of Spinal Cord Injury: Mechanisms and Clinical Application." Stem cells.

Wrzodek, C., F. Buchel, M. Ruff, A. Drager and A. Zell (2013). "Precise generation of systems biology models from KEGG pathways." BMC Syst Biol 7: 15. 
Wyndaele, M. and J. J. Wyndaele (2006). "Incidence, prevalence and epidemiology of spinal cord injury: what learns a worldwide literature survey?" Spinal Cord 44(9): 523-529.

Xu, H., K. Miki, S. Ishibashi, J. Inoue, L. Sun, S. Endo, I. Sekiya, T. Muneta, J. Inazawa, M. Dezawa and H. Mizusawa (2010). "Transplantation of neuronal cells induced from human mesenchymal stem cells improves neurological functions after stroke without cell fusion." Journal of neuroscience research 88(16): 35983609.

Xu, Y. X., L. Chen, R. Wang, W. K. Hou, P. Lin, L. Sun, Y. Sun and Q. Y. Dong (2008). "Mesenchymal stem cell therapy for diabetes through paracrine mechanisms." Medical hypotheses 71(3): 390-393.

Yanez-Mo, M., P. R. Siljander, Z. Andreu, A. B. Zavec, F. E. Borras, E. I. Buzas, K. Buzas, E. Casal, F. Cappello, J. Carvalho, E. Colas, A. Cordeiro-da Silva, S. Fais, J. M. Falcon-Perez, I. M. Ghobrial, B. Giebel, M. Gimona, M. Graner, I. Gursel, M. Gursel, N. H. Heegaard, A. Hendrix, P. Kierulf, K. Kokubun, M. Kosanovic, V. KraljIglic, E. M. Kramer-Albers, S. Laitinen, C. Lasser, T. Lener, E. Ligeti, A. Line, G. Lipps, A. Llorente, J. Lotvall, M. Mancek-Keber, A. Marcilla, M. Mittelbrunn, I. Nazarenko, E. N. Nolte-'t Hoen, T. A. Nyman, L. O'Driscoll, M. Olivan, C. Oliveira, E. Pallinger, H. A. Del Portillo, J. Reventos, M. Rigau, E. Rohde, M. Sammar, F. Sanchez-Madrid, N. Santarem, K. Schallmoser, M. S. Ostenfeld, W. Stoorvogel, R. Stukelj, S. G. Van der Grein, M. H. Vasconcelos, M. H. Wauben and O. De Wever (2015). "Biological properties of extracellular vesicles and their physiological functions." J Extracell Vesicles 4: 27066.

Yang, B., R. Strong, S. Sharma, M. Brenneman, K. Mallikarjunarao, X. Xi, J. C. Grotta, J. Aronowski and S. I. Savitz (2011). "Therapeutic time window and dose response of autologous bone marrow mononuclear cells for ischemic stroke." Journal of neuroscience research 89(6): 833-839.

Ye, J., Y. Qin, Y. Tang, M. Ma, P. Wang, L. Huang, R. Yang, K. Chen, C. Chai, Y. Wu and H. Shen (2018) "Methylprednisolone inhibits the proliferation of endogenous neural stem cells in nonhuman primates with spinal cord injury." J Neurosurg Spine 29(2): 199-207.

Ye, Y., Y. M. Zeng, M. R. Wan and X. F. Lu (2011). "Induction of human bone marrow mesenchymal stem cells differentiation into neural-like cells using cerebrospinal fluid." Cell biochemistry and biophysics 59(3): 179-184.

Yin, F., M. Dumont, R. Banerjee, Y. Ma, H. Li, M. T. Lin, M. F. Beal, C. Nathan, B. Thomas and A. Ding (2010). "Behavioral deficits and progressive neuropathology in progranulin-deficient mice: a mouse model of frontotemporal dementia." FASEB J 24(12): 4639-4647.

Yonemori, F., H. Yamada, T. Yamaguchi, A. Uemura and A. Tamura (1996). "Spatial memory disturbance after focal cerebral ischemia in rats." Journal of cerebral blood flow and metabolism : official journal of the International Society of Cerebral Blood Flow and Metabolism 16(5): 973-980.

Yoon, S. H., Y. S. Shim, Y. H. Park, J. K. Chung, J. H. Nam, M. O. Kim, H. C. Park, S. R. Park, B. H. Min, E. Y. Kim, B. H. Choi, H. Park and Y. Ha (2007). "Complete spinal cord injury treatment using autologous bone marrow cell transplantation and bone marrow stimulation with granulocyte macrophage-colony stimulating factor: Phase I/II clinical trial." Stem cells 25(8): 2066-2073.

Yoshida, Y. (2012). "Semaphorin signaling in vertebrate neural circuit assembly." Front Mol Neurosci 5: 71.

Yoshihara, T., M. Ohta, Y. Itokazu, N. Matsumoto, M. Dezawa, Y. Suzuki, A. Taguchi, Y. Watanabe, Y. Adachi, S. Ikehara, H. Sugimoto and C. Ide (2007). "Neuroprotective effect of bone marrow-derived mononuclear cells promoting functional recovery from spinal cord injury." Journal of neurotrauma 24(6): 1026-1036.

Yoshino, H. and A. Kimura (2006). "Investigation of the therapeutic effects of edaravone, a free radical scavenger, on amyotrophic lateral sclerosis (Phase II study)." Amyotroph Lateral Scler 7(4): 241-245.

Young, M. D., M. J. Wakefield, G. K. Smyth and A. Oshlack (2010). "Gene ontology analysis for RNA-seq: accounting for selection bias." Genome Biol 11(2): R14.

Yousefi, F., F. Lavi Arab, K. Saeidi, H. Amiri and M. Mahmoudi (2019). "Various strategies to improve efficacy of stem cell transplantation in multiple sclerosis: Focus on mesenchymal stem cells and neuroprotection." J Neuroimmunol 328: 20-34.

Yuan, A., M. V. Rao, Veeranna and R. A. Nixon (2012). "Neurofilaments at a glance." J Cell Sci 125(Pt 14): $3257-$ 3263. 
Zappia, E., S. Casazza, E. Pedemonte, F. Benvenuto, I. Bonanni, E. Gerdoni, D. Giunti, A. Ceravolo, F. Cazzanti, F. Frassoni, G. Mancardi and A. Uccelli (2005). "Mesenchymal stem cells ameliorate experimental autoimmune encephalomyelitis inducing T-cell anergy." Blood 106(5): 1755-1761.

Zeng, R., L. W. Wang, Z. B. Hu, W. T. Guo, J. S. Wei, H. Lin, X. Sun, L. X. Chen and L. J. Yang (2011). "Differentiation of Human Bone Marrow Mesenchymal Stem Cells into Neuron-like Cells in Vitro." Spine (Phila Pa 1976).

Zhang, B., R. W. Yeo, K. H. Tan and S. K. Lim (2016). "Focus on Extracellular Vesicles: Therapeutic Potential of Stem Cell-Derived Extracellular Vesicles." Int J Mol Sci 17(2): 174.

Zhang, C., C. Zhou, J. J. Teng, R. L. Zhao and Y. Q. Song (2009). "Multiple administrations of human marrow stromal cells through cerebrospinal fluid prolong survival in a transgenic mouse model of amyotrophic lateral sclerosis." Cytotherapy 11(3): 299-306.

Zhang, H., N. Zhang, M. Li, H. Feng, W. Jin, H. Zhao, X. Chen and L. Tian (2008). "Therapeutic angiogenesis of bone marrow mononuclear cells (MNCs) and peripheral blood MNCs: transplantation for ischemic hindlimb." Ann Vasc Surg 22(2): 238-247.

Zhang, J., Y. Li, J. Chen, Y. Cui, M. Lu, S. B. Elias, J. B. Mitchell, L. Hammill, P. Vanguri and M. Chopp (2005). "Human bone marrow stromal cell treatment improves neurological functional recovery in EAE mice." Experimental neurology 195(1): 16-26.

Zhang, P., L. Cao, R. Zhou, X. Yang and M. Wu (2019). "The IncRNA Neat1 promotes activation of inflammasomes in macrophages." Nat Commun 10(1): 1495.

Zhang, Y., M. Chopp, Y. Meng, M. Katakowski, H. Xin, A. Mahmood and Y. Xiong (2015). "Effect of exosomes derived from multipluripotent mesenchymal stromal cells on functional recovery and neurovascular plasticity in rats after traumatic brain injury." J Neurosurg 122(4): 856-867.

Zhang, Y., L. Li, J. Yu, D. Zhu, Y. Zhang, X. Li, H. Gu, C. Y. Zhang and K. Zen (2014). "Microvesicle-mediated delivery of transforming growth factor beta1 siRNA for the suppression of tumor growth in mice." Biomaterials 35(14): 4390-4400.

Zhang, Y., I. Strehin, K. Bedelbaeva, D. Gourevitch, L. Clark, J. Leferovich, P. B. Messersmith and E. Heber-Katz (2015). "Drug-induced regeneration in adult mice." Sci Transl Med 7(290): 290ra292.

Zhang, Z., X. Wang and S. Wang (2008). "Isolation and characterization of mesenchymal stem cells derived from bone marrow of patients with Parkinson's disease." In vitro cellular \& developmental biology. Animal 44(5-6): 169-177.

Zhao, C., X. Zhou, J. Qiu, D. Xin, T. Li, X. Chu, H. Yuan, H. Wang, Z. Wang and D. Wang (2019). "Exosomes Derived From Bone Marrow Mesenchymal Stem Cells Inhibit Complement Activation In Rats With Spinal Cord Injury." Drug Des Devel Ther 13: 3693-3704.

Zhao, W., D. R. Beers and S. H. Appel (2013). "Immune-mediated mechanisms in the pathoprogression of amyotrophic lateral sclerosis." J Neuroimmune Pharmacol 8(4): 888-899.

Zhou, L. and H. D. Shine (2003). "Neurotrophic factors expressed in both cortex and spinal cord induce axonal plasticity after spinal cord injury." Journal of neuroscience research 74(2): 221-226.

Zhu, B., D. Xu, X. Deng, Q. Chen, Y. Huang, H. Peng, Y. Li, B. Jia, W. B. Thoreson, W. Ding, J. Ding, L. Zhao, Y. Wang, K. L. Wavrin, S. Duan and J. Zheng (2012). "CXCL12 enhances human neural progenitor cell survival through a CXCR7- and CXCR4-mediated endocytotic signaling pathway." Stem cells 30(11): 2571-2583.

Zhu, Q., J. Ma, L. Yu and C. Yuan (2009). "Grafted neural stem cells migrate to substantia nigra and improve behavior in Parkinsonian rats." Neuroscience letters 462(3): 213-218.

Zietlow, R., E. L. Lane, S. B. Dunnett and A. E. Rosser (2008). "Human stem cells for CNS repair." Cell Tissue Res 331(1): 301-322.

Zisa, D., A. Shabbir, G. Suzuki and T. Lee (2009). "Vascular endothelial growth factor (VEGF) as a key therapeutic trophic factor in bone marrow mesenchymal stem cell-mediated cardiac repair." Biochemical and biophysical research communications 390(3): 834-838.

Zou, L. H., Y. J. Shi, H. He, S. M. Jiang, F. F. Huo, X. M. Wang, F. Wu and L. Ma (2019). "Effects of FGF2/FGFR1 Pathway on Expression of A1 Astrocytes After Infrasound Exposure." Front Neurosci 13: 429. 


\section{Acknowledgment}

At last after a long journey of 30 years I can defend my thesis and finish my PhD. This journey started in 1991 with Prof.dr. Hein Wellens en dr.Ton Gorgels. They were able to start my personal scientific fire and a PhD was added to my bucket list of things I would like to accomplish in my life. Finally it was my dear friend and college Prof.dr.Erik Wolters, who invested time, patience and knowledge to bring me to this defense. Off course, a PhD candidate has to do the work and without sweat no glory so to say. Start and build a company at one hand and invest in parallel time to do research, write publications and present your interests at congresses at the other hand, is only possible when the scientific goals and the company perspectives are the same. In my case I was lucky that after this long journey I finally found the combination, the passion in science combining with a company to translate the science in treatments for patients. I'm grateful for having this unique opportunity.

However, besides this combination I was also very blessed to receive help from a superb team of international scientists. My friend and promotor Erik Wolters, who was always there to support me, rephrase my sentences when needed, discuss the conclusion and convinced me to go further when the energy was temporary gone. My promotor Boris Kramer, who forced me to come out of my comfort zone and who challenged me to the edge to formulate my conclusions and to stick closely to my ideas. I also want to thank Tatyana Strekalova, who not only was my co-promotor but also made it possible to perform preclinical research with the University of Oxford, Würzburg and Moscow. My appreciation goes also to Jörg Mey, my second co-promotor for the scientific way of continuously challenging my results. I thank the members of the jury chaired by Prof.dr.Luc Zimmermann who carefully judged my work and granted me the opportunity to defend my thesis.

I want to express my gratitude for the help of Sasja Verhoog with this booklet and for designing the cover page and the employees and former employees of Neuroplast who assisted me in all the work presented today.

I want to acknowledge my family for the support they have given me all these years. My wife Lidy who not only enriched my life but was always standing next to me when I had to face disappointments or had to start all over again. Don't give up and we will work it out in the one or the other way was always her advice. My daughter Michelle and my son Alexander who accepted always what I was doing and when we could not go somewhere because I had to work again. Today, a special remembrance to my deceived father and mother. Their love and trust made me the person I am today. The same love and trust Lidy and I pass to our children and grandchildren.

Finally, I want to thank God for being able to reach this personal milestone. My whole life I experienced a kind of force, trust and confidence, which helped me to start all over again and again and not to give up. As a young physician, I lost a patient with a spinal cord injury because he was not able to find a way to live further with his disability. Today, 35 years later, I hope that I can contribute with my thesis to help patients with a disability not to give up and keep fate in the future of regenerative medicine.

Johannes de Munter 


\section{Curriculum Vitae}

\section{Johannes Petrus Jozef Maria de Munter}

Date and place of birth: 6 November 1959, Heerlen, The Netherlands

Marital state:

Married, two children (born 1986 and 1987)

Nationality:

Dutch

E.mail:

h.demunter@neuroplast.com

\section{Current work position}

Founder, CEO and Chief Regulatory Officer of Neuroplast BV, a stem cell development company founded in 2014 and situated in Brightlands Chemelot Campus, Geleen, The Netherlands.

\section{Work Experiences}

Trained physician and started his carrier as Emergency Health Care Physician and General Practitioner. During this work he was confronted with the tremendous impact Spinal Cord Injury had on young people involved in traffic accidents. It was an unexpected suicide of a young spinal cord injured patient, who triggered and motivated Johannes in his personal quest to search for new therapies to improve the quality of life of patients with a spinal cord injury. Finally, it took 20 years to find new opportunities to help these patients. In between, Johannes worked for nearly 18 years as public health physician and was responsible for infection disease control and epidemiology of the municipal public health department in Maastricht, The Netherlands. Cofounded two private companies (AED Solutions bv and Emergency Health Care Consultancy). Joined Medtronic Vitatron BV as Manager research and clinical and started to work with stem cells in a German stem cell clinic in 2008. Founded in 2014 together with Erik Wolters Amarna Stem Cells BV, which was renamed Neuroplast BV in 2016. From 2008 on he could work to fulfill his dreams and work with excellent people to develop a therapy for neurodegenerative diseases, spinal cord injury inclusive.

\section{Training and education}

Master in Epidemiology 1990-1992

Master in Public Health (environmental Health \& infectious disease) 1990-1991

Research General Practitioner 1987

General Practitioner 1986, Emergency Response Physician 1984-1986

Medical school Maastricht University 1978-1984

High School (VWO) Eijkhagen college, Landgraaf The Netherlands 1972-1978

\section{International experience}

Navy Military healthcare abroad, Tropical Medicine Tanzania, John Hopkins Baltimore, Public Access Defibrillation projects and Lay Rescue Dispatching, Contribution to international congresses, Round table discussions EMA/FDA regarding ATMPs, ATMP regulation Russia, member International Consortium Neurosciences (Oxford, Wurzburg, Maastricht and Moscow) and participant US global Scale-up program. 


\section{Publications}

Wolters ECh, de Hoo K, Kramer BW, de Munter JPJM (2021)." Anti-inflammatory effects of naive stem cells dampen systemic/compartmental overreactive Immune responses". Journal of Immunological Sciences in press;

de Munter J, Babaevskaya D, Wolters E, et al (2020). "Molecular and behavioural abnormalities in the FUS-tg mice mimic frontotemporal lobar degeneration: Effects of old and new antiinflammatory therapies". J Cell Mol Med 00:1-7 DOI: 10.1111/jcmm.15628.

de Munter JPJM, Mey J, Strekalova T, Kramer BW, Wolters ECh (2020) Why do anti-inflammatory signals of bone marrow-derived stromal cells improve neuro-degenerative conditions where anti-inflammatory drugs fail? J Neural Transm DOI: 10.1007/s00702-020-02173-3

Romero-Ramirez L, Wu S, de Munter JP, Wolters E, Kramer, BW, Mey J (2020). Treatment of rats with spinal cord injury using human bone marrow-derived stromal cells prepared by negative selection. J BiomediSci 27:35

de Munter J, Shafarevich I, Liundup A, Pavlov D, Wolters EC, Gorlova A, Veniaminova E, Umriukhin A, Kalueff A, Svistunov A, Kramer BW, Lesch KP, Strekalova T (2019). Neuro-Cells therapy improves motor outcomes and suppresses inflammation during experimental syndrome of amyotrophic lateral sclerosis in mice. CNS Neurosci Ther doi:.org/10.1111/CNS.13280.

de Munter JP, Beugels J, Demunter S, Jansen L, Cillero-Pastor B, Moskvin O, Brook G, Pavlov D, Strekalova T, Kramer BW, Wolters EC (2019). Standardized human bone marrow-derived stem cells infusion improves survival and recovery in a rat model of spinal cord injury. J Neurol Sci 402: 16-29.

Beugels J, de Munter JP, Van der Hulst R, Kramer BW, Wolters ECh (2019). Efficacy of different doses of human autologous adult bone marrow stem cell transplantation on angiogenesis in an immune deficient rat model with hind limb ischemia. J Stem Cell Res Dev DOI:10.24966/SRDT-2060/S1002

de Munter, J.P., Melamed, E., Wolters, E.Ch (2013). "Stem cell grafting in parkinsonism - Why, how and when." Parkinsonism \& related disorders 20 Suppl 1: S67-70.

de Munter JP, Lee, C, Wolters EC (2013). Cell based therapy in Parkinsonism. Transl Neurodegener13; 2. doi: 10.1186/2047-9158-2-13..

de Munter JP, Wolters ECh (2013). Autologous adult stem cells in ischemic and traumatic CNS disorders. J Neural Transm 120(1): 91-102.

de Munter JP, Wolters ECh (2013). Autologous stem cells in neurology: is there a future? J Neural Transm 120(1): 65-73.

Wellens HJ Gorgels AP, de Munter H (2003). Cardiac arrest outside of a hospital: how can we improve results of resuscitation?" Circulation 107(15): 1948-1950.

Wellens HJ, Gorgels AP, de Munter H (2003). Sudden Death in the Community; J.Cardiovasc.Electrophysiol. 2003 sep; 14(9 Suppl): 104-7.

Hoebe C, de Munter J, Thijs C (1997). Adverse effects and compliance with mefloquine or proguanil antimalarial chemoprophylaxis. European journal of clinical pharmacology 52(4): 269-275. 


\section{THE PATIENT'S OWN BONE}

MARROW-DERIVED STROMAL CELLS: DISEASE MODIFIERS IN (NEURO)DEGENERATIVE DISORDERS 